FERNANDO PESSOTO HIRATA

ANÁLISE COMPARATIVA ENTRE MODELOS DE PREDIÇÃO DE NORMA E DADOS DE ENSAIOS NA DETERMINAÇÃO DA RESISTÊNCIA AO CISALHAMENTO 
FERNANDO PESSOTO HIRATA

ANÁLISE COMPARATIVA ENTRE MODELOS DE PREDIÇÃO DE NORMA E DADOS DE ENSAIOS NA DETERMINAÇÃO DA RESISTÊNCIA AO CISALHAMENTO

Dissertação apresentada à Escola

Politécnica da Universidade de São

Paulo para obtenção do título de Mestre em Engenharia

São Paulo 
FERNANDO PESSOTO HIRATA

\section{ANÁLISE COMPARATIVA ENTRE MODELOS DE PREDIÇÃO DE NORMA E DADOS DE ENSAIOS NA DETERMINAÇÃO DA RESISTÊNCIA AO CISALHAMENTO}

Dissertação apresentada à Escola Politécnica da Universidade de São Paulo para obtenção do título de Mestre em Engenharia

Área de Concentração:

Engenharia de Estruturas

Orientador: Prof. Dr.

João Carlos Della Bella

São Paulo 
Este exemplar foi revisado e alterado em relação à versão original, sob responsabilidade única do autor e com a anuência de seu orientador.

São Paulo, 30 de julho de 2013.

Assinatura do autor

Assinatura do orientador

FICHA CATALOGRÁFICA

Hirata, Fernando Pessoto

Análise comparativa entre modelos de predição de norma e dados de ensaios na determinação da resistência ao cisalhamento / F.P. Hirata. -- versão corr. -- São Paulo, 2013.

$232 \mathrm{p}$.

Dissertação (Mestrado) - Escola Politécnica da Universidade de São Paulo. Departamento de Engenharia de Estruturas e Geotécnica.

1. Cisalhamento (Dimensionamento; Resistência) 2. Aplicabilidade das normas I. Universidade de São Paulo. Escola Politécnica. Departamento de Engenharia de Estruturas e Geotécnica II. t. 
À minha esposa. 


\section{AGRADECIMENTOS}

Ao meu orientador Prof. Dr. João Carlos Della Bella, pelas longas conversas e orientações.

Aos meus pais, Edméia Marlene e Luiz Makoto, pelo incentivo e apoio ao longo de toda minha vida. Sem eles nada disso seria possível.

À minha esposa, Dina Lúcia, pela paciência, por me acalmar nos momentos difíceis, pelo incentivo e ajuda neste trabalho.

Ao meu irmão, Rogério, por ser meu exemplo, no qual sempre me espelhei.

À minha sogra, Prof. Dra. Maria Elena, por me socorrer nos momentos difíceis e por me guiar nas análises.

Ao meu avô, Sr. Carlos (in memoriam), por ser um dos motivos pelos quais me tornei engenheiro.

À minha família Taqueda, pelas contribuições, ajudas e momentos de descontração.

Aos meus queridos amigos e padrinhos, Vivian e Renato Gasperino, pelos sábios conselhos e amizade.

Ao meu grande amigo, Rodolfo, por todas as orientações e auxílios prestados.

Aos meus amigos da Bureau de Projetos, Consórcio Bureau - Geribello, EGT Engenharia e Metrô-SP, pela solidariedade e torcida.

Aos professores da graduação e mestrado, pelos ensinamentos e orientações. 


\section{RESUMO}

Desde o início do século XX, com as publicações de Ritter e Mörsch, o fenômeno da resistência ao cisalhamento de elementos em concreto armado começou a ser intensamente estudado. Diversos modelos de cálculo foram criados, tentando predizer o valor da resistência ultima de elementos de concreto armado, quando solicitados por esforços cisalhantes.

O fenômeno da resistência ao cisalhamento é extremamente complexo, sendo influenciado por diversos fatores. A elaboração de ensaios e modelos de predição se torna complexa, pois, determinar quais são os parâmetros que influenciam significativamente o fenômeno do cisalhamento, não é simples. Outras dificuldades são: relacionar a resistência ao cisalhamento com o grau de solicitação por esforços fletores e compreender em quais intervalos de parâmetros os principais fatores influenciam o fenômeno. Sendo assim, é essencial verificar a aplicabilidade das normas técnicas em diversos intervalos destes fatores ou parâmetros.

A partir da coleta de cerca de 1.200 resultados de ensaios de laboratório de vigas de concreto armado, solicitadas por esforços de cisalhamento, elaborou-se um banco de dados com os resultados de ensaios da força última resistente, juntamente com diversos parâmetros de cada ensaio.

Para analisar os valores de predição das normas e os valores dos resultados de ensaios, foi necessário definir critérios de análise comparativa, e com ajuda de uma análise paramétrica, foi possível analisar a aplicabilidade de diversas normas em diversos intervalos de parâmetros, classificando assim, cada norma quanto à segurança e prudência ao uso.

Baseado nos resultados das análises efetuadas foi possível verificar que as normas cujas formulações são derivadas da teoria do "Modified Compression Field Theory" apresentaram um comportamento uniforme e adequado na maioria dos intervalos de parâmetros.

Verificou-se, que a norma brasileira NBR 6118 (2007) apresentou resultados satisfatórios nos intervalos usuais dos parâmetros. No entanto, a utilização da norma não se mostrou favorável nos seguintes casos: de média e baixa armadura de cisalhamento, para elementos com estribo; baixa quantidade de armadura longitudinal de flexão ou altura do elemento maior que $25 \mathrm{~cm}$, para elementos sem estribo.

Palavras-chave: Dimensionamento ao cisalhamento; Resistência ao cisalhamento; Comparação entre normas; Aplicabilidade das normas. 


\begin{abstract}
Since the beginning of twentieth century, along with academic publications of Ritter and Mörsch, several studies have been done in order to understand shear strength in reinforced concrete elements. Many mathematical models were created, so the ultimate shear strength in reinforced concrete element could be known when under shear stress.
\end{abstract}

Shear strength phenomenon is extremely complex and influenced by several parameters. Developing laboratory tests and mathematical models become difficult steps when determining all the parameters that will contribute to the ultimate shear strength. Other difficulties are: the relationship between shear strength and different levels of bending stresses and understanding which interval of values the main parameters can interfere the phenomenon.

Therefore, it is essential to check the feasibility of technical standards in various ranges of the mentioned parameters.

From approximately 1,200 laboratory tests results of reinforced concrete beams under shear stresses, a database has been created with the results from the ultimate shear strength results, along with the parameters of each test.

In order compare the values between technical standards and tests results, a criteria has been defined. Throughout a parametric analysis it was possible to check the standards feasibility under different parameters intervals. After, each standard was sorted to a safety level.

Based on the results, the standards which formulations are derived from the Modified Compression Field Theory showed an uniform and adequate behavior in most intervals of each parameters.

It was found that although the Brazilian Standard NBR 6118 (2007) showed good results in usual ranges of parameters, the standard presented unsatisfactory results on the following cases: low and medium shear reinforcement rate when with stirrups; low bending reinforcement rate when without stirrups and elements with depth over $25 \mathrm{~cm}$ without stirrups.

Keywords: Shear design; Shear strength; Standards comparison; Standards feasibility. 


\section{LISTA DE ILUSTRAÇÕES}

Figura 1.1: Fotografia do colapso parcial da cobertura do armazém da força aérea Americana (Cladera, 2002) ............................................................. 3

Figura 4.1: Esquema do Modelo da Treliça Clássica, com $\alpha=90^{\circ} . \ldots \ldots \ldots \ldots \ldots \ldots \ldots . \ldots \ldots$

Figura 4.2: Esquema do modelo da Treliça Generalizada. M é o momento fletor, $V$ é a Força cortante; s é o espaçamento entre estribos, z é Distância entre o centro do banzo comprimido e o centro do banzo tracionado, $\theta$ é o Ângulo da biela de compressão do concreto, menor ou igual a $45^{\circ}$; a é ângulo de inclinação dos estribos, entre $45^{\circ}$ e $90^{\circ}$. (adaptado de Fusco, 2008)

Figura 4.3: Modos de ruptura por solicitação de momento fletor e força cortante. a) Ruptura por força cortante-compressão, b) Ruptura por força cortantetração c) Ruptura por força cortante-flexão, d) Ruptura por flexão da armadura longitudinal (Fusco, 1998) ............................................10

Figura 4.4: Exemplo de regiões B (Bernoulli) e D (Disturbed) para elementos de concreto armado

Figura 4.5: Carregamentos aplicados e deformações medidas (Vecchio, 1986).....12

Figura 4.6: Esquema do mecanismo de ensaio dos painéis (Vecchio, 1986).........13

Figura 4.7: Deformações médias no elemento fissurado (Vecchio, 1986).............13

Figura 4.8: Circulo de Mohr para as deformações médias (Vecchio, 1986) ............14

Figura 4.9: Diagrama de corpo livre do elemento analisado (Vecchio, 1986).........15

Figura 4.10: Tensões no elemento (Vecchio, 1986) .......................................16

Figura 4.11: Relação tensão x deformação para a armação (Vecchio, 1986) ..........17

Figura 4.12: Círculos de tensão e deformação obtidos experimentalmente (Vecchio, 1986)

Figura 4.13: Relação tensão x deformação para concreto fissurado a compressão (Vecchio, 1986).

Figura 4.14: Relação proposta para o amolecimento do concreto (Vecchio, 1986)...19

Figura 4.15: Correlação obtida nos diversos estágios de carregamento entre tensão e deformação para o concreto fissurado (Vecchio, 1986)

Figura 4.16: Relação entre a tensão média de tração e a deformação média de tração do concreto fissurado (Vecchio, 1986) 
Figura 4.17: Comparação entre as tensões locais na fissura e as tensões médias calculadas (Vecchio, 1986).

Figura 4.18: Transferindo tensão de cisalhamento ao longo da fissura por imbrica mento dos agregados (Vecchio, 1986) .....................................23

Figura 4.19: Esforços ao longo da fissura (adaptado de Bhide, 1989) ...................25

Figura 4.20: Esforços na seção da fissura em elementos ser armação transversal de cisalhamento (Vecchio, 1986).....................................................27

Figura 4.21: Correlação entre $\theta, \varepsilon_{1}, \varepsilon_{\mathrm{x}}$, para alguns valores de sxe (Bentz, 2006) .....28

Figura 4.22: Circulo de Mohr para as deformações médias (Vecchio, 1986) ...........29

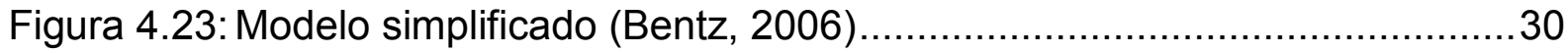

Figura 4.24: Comparação entre o método simplificado e o MCFT, para valores de $\beta$ (Bentz, 2006) 32

Figura 4.25: Comparação entre o método simplificado e o MCFT, para valores de $\theta$ (Bentz, 2006) 33

Figura 4.26: Comparação entre o método simplificado e o MCFT, para elementos com armação transversal de cisalhamento (Bentz, 2006) ....................34

Figura 4.27: Ilustração dos termos bv e dv (AASHTO LRFD, 2007)........................36

Figura 4.28: Ilustração dos parâmetros de cisalhamento para seções que contenham pelo menos a quantidade de armação mínima, $\mathrm{Vp}=0$ (AASHTO LRFD, 2007) 38

Figura 4.29: Deformação longitudinal, ex, para seções com menos armação transversal de cisalhamento que a quantia mínima (AASHTO LRFD, 2007)

Figura 4.30: Determinação do parâmetro de fissuração sxe (AASHTO LRFD, 2007)

Figura 4.31: Regiões para dimensionamento (AASHTO LRFD, 2007) ..................42

Figura 4.32: Modelo considerado para vigas (FIB, 2010) ..............................48

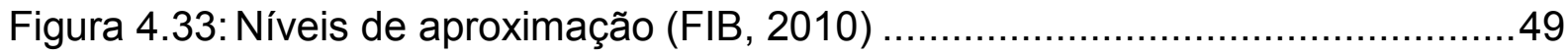

Figura 4.34: Estado de tensão considerado (FIB, 2010) ….................................50

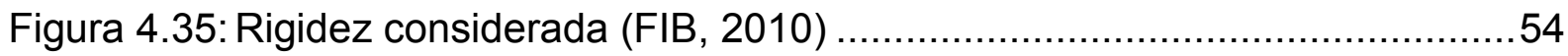

Figura 4.36: Definição de Asl (Eurocode, 2004) ...........................................56

Figura 4.37: Modelo de treliça (Eurocode, 2004) .........................................57 
Figura 4.38: Definição da largura bw (Eurocode, 2004)

Figura 5.1: Fluxograma das etapas do trabalho

Figura 6.1: Influência da altura ,h, em Vrk (força cisalhante resistente) para peças com estribos, calculado para CSA, EURO, ACI, NBR I e NBR II.

Figura 6.2: Influência da altura ,h, em $\tau$ rk (tensão cisalhante resistente) para peças sem estribos, calculado para CSA, EURO, ACI, NBR.

Figura 6.3: Influência da resistência do concreto,fck, em Vrk (força cisalhante resistente) em peças com estribos, calculada para as normas CSA, EURO, ACI, NBR I e NBR II.

Figura 6.4: Influência da resistência do concreto,fck, em trk (tensão cisalhante resistente) em peças sem estribo, calculada para as normas CSA, EURO, ACl, NBR.

Figura 6.5: Influência da taxa geométrica de armação transversal, psw, em Vrk (força cisalhante resistente) em peças com estribos, calculada para as normas CSA, EURO, ACI, NBR I e NBR II.

Figura 6.6: Influência da taxa de armadura longitudinal de peças com estribos, pl, em Vrk (força cisalhante resistente) em peças com estribos, calculada para as normas CSA, EURO, ACI, NBR I e NBR II.

Figura 6.7: Influência da taxa de armadura longitudinal, $\rho l$, em $\tau$ rk (tensão cisalhante resistente) em peças sem estribos, calculada para as normas CSA, EURO, ACI, NBR. .85

Figura 6.8: Influência da tensão axial normal solicitante, on, em Vrk (força cisalhante resistente) em peças com estribos, calculada para as normas CSA, EURO, ACI, NBR I e NBR II. .86

Figura 6.9: Influência da tensão normal solicitante, on, em $\tau$ rk (tensão cisalhante resistente) em peças sem estribos, calculada para as normas CSA, EURO, ACI, NBR.

Figura 6.10: Influência do índice de esbeltez, a/d, em Vrk (força cisalhante resistente) em peças com estribos, calculada para as normas CSA, EURO, ACl, NBR I e NBR II. .88

Figura 6.11: Influência do índice de esbeltez, a/d, em trk (tensão cisalhante resistente) em peças sem estribos, calculada para as normas CSA, EURO, ACI, NBR. .88

Figura 6.12: Elementos com estribos e fatores de segurança unitários .90

Figura 6.13: Elementos com estribos e fatores de segurança de norma 
Figura 6.14: Elementos sem estribos e fatores de segurança unitários

Figura 6.15: Elementos sem estribos e fatores de segurança de norma

.92

Figura 6.16: Resultados de uma viga com estribos reprovada pelo critério definido 97

Figura 6.17: Resultados de uma viga sem estribos aprovada pelo critério definido ..97

Figura 6.18: Definição das faixas de análise da força cisalhante resistente experimental ,Vexp. Sendo Vd - Valor de cálculo, Vseg - Valor limite seguro, Vu - Valor teórico ultimo e Vone - Valor limite oneroso..... 105

Figura 6.19: Distribuição dos parâmetros do banco de dados em categorias definidas na Tabela 6.7, para elementos com estribos 110

Figura 6.20: Correlação entre parâmetros de ensaios e tensão cisalhante resistente experimental, $\tau \exp$, para elementos com estribos, para cada autor, sendo: $d$ - Altura do elemento; fc - Resistência do concreto; $\rho$ l - Taxa geométrica de armadura de flexão; a/d - Índice de esbeltez; psw.fyk Taxa mecânica de estribos e psw - Taxa geométrica de estribos ......111

Figura 6.21: Correlação entre parâmetros de ensaios e tensão cisalhante resistente experimental, $\tau \exp$, para elementos com estribos, conforme o grupo $\mathrm{G}$ fc, sendo: d - Altura do elemento; fc - Resistência do concreto; $\rho l$ Taxa geométrica de armadura de flexão; a/d - Índice de esbeltez; psw.fyk - Taxa mecânica de estribos e psw - Taxa geométrica de estribos

Figura 6.22: Correlação entre parâmetros de ensaios e tensão cisalhante resistente experimental, $\tau$ exp, para elementos com estribos, segundo o grupo $G$ psw.fyk, sendo: $d$ - Altura do elemento; fc - Resistência do concreto; $\rho$ l - Taxa geométrica de armadura de flexão; a/d - Índice de esbeltez; psw.fyk - Taxa mecânica de estribos e psw - Taxa geométrica de estribos

Figura 6.23: Correlação entre as razões Vexp/Vu e os valores do parâmetro psw.fyk, para as normas CSA, EURO, ACl, modelo I na NBR e modelo II da $\mathrm{NBR}$, para elementos com estribos

Figura 6.24: Correlação entre as razões Vexp/Vu e os valores do parâmetro psw.fyk, para as normas CSA, EURO, ACl, modelo I na NBR e modelo II da NBR, conforme a variação da resistência do concreto, para elementos com estribos 115

Figura 6.25: Análise dos valores médios e desvio padrão entre as razões $V \exp / \mathrm{Vu}$ para as normas CSA, EURO, ACl, modelo I na NBR e modelo II da NBR, para elementos com estribos e dados válidos 116

Figura 6.26: Análise dos valores médios e desvio padrão entre as razões $V \exp / \mathrm{Vu}$ para as normas CSA, EURO, ACl, modelo I na NBR e modelo II da 
NBR, para elementos com estribos e dados válidos, separados em três intervalos de psw.fyk

Figura 6.27: Análise dos modelos de predição de norma na determinação da parcela resistente devido ao concreto, $\tau \mathrm{c}$, baseados em resultados de ensaios de elementos armados com estribos, sendo EXP - reta de média dos ensaios; CSA - reta média dos valores de predição da norma CSA e analogamente para ACI, EURO, NBR I e NBR II.

Figura 6.28: Distribuição das normas, segundo o critério de comparação, dados válidos e elementos com estribos, definido neste trabalho.

Figura 6.29: Distribuição das normas, segundo o critério de comparação, dados válidos ( $\rho s w . f y k>\rho s w . f y k$, min e fc < fc,máx), definidos neste trabalho 121

Figura 6.30: Aplicação do critério de comparação para psw.fyk <1 MPa, definido neste trabalho 122

Figura 6.31: Aplicação do critério de comparação para psw.fyk entre 1 e $2 \mathrm{MPa}$, definido neste trabalho

Figura 6.32: Aplicação do critério de comparação para psw.fyk $>2 \mathrm{MPa}$, definido neste trabalho

Figura 6.33: Correlação entre as razões Vexp/Vu e os valores do parâmetro psw.fyk, para as normas CSA, EURO, ACl, modelo I na NBR e modelo II da NBR, para elementos com estribos e dados fora do intervalo válido...127

Figura 6.34: Correlação entre as razões $V \exp / \mathrm{Vu}$ e os valores da resistência do concreto, fc, para as normas CSA, EURO, ACl, modelo I na NBR e modelo II da NBR, para elementos com estribos e dados fora do intervalo válido, para as três categorias do grupo $\mathrm{G} \rho$ sw.fyk.

Figura 6.35: Análise dos valores médios e desvio padrão entre as razões $V \exp / \mathrm{Vu}$ para as normas CSA, EURO, ACl, modelo I na NBR e modelo II da NBR, para elementos com estribos e dados não válidos 128

Figura 6.36: Distribuição das normas, segundo o critério de comparação (com estribos)

Figura 6.37: Distribuição dos parâmetros do banco de dados em categorias definidas na Tabela 6.7, para elementos sem estribos

Figura 6.38: Correlação entre parâmetros de ensaios e tensão cisalhante resistente experimental, $\tau \exp$, para elementos sem estribos, para cada autor, sendo: $d$ - Altura do elemento; fc - Resistência do concreto; $\rho$ l - Taxa geométrica de armadura de flexão e a/d - Índice de esbeltez 133

Figura 6.39: Influência da taxa geométrica de armadura de flexão, pl, para diversas resistências de concreto, fc, na tensão cisalhante resistente dos resultados experimentais de elementos sem estribos 
Figura 6.40: Curvas de aproximação da correlação entre a taxa geométrica de armadura de flexão, pl, para diversas resistências de concreto, fc, na tensão cisalhante resistente e os resultados experimentais de elementos sem estribos

Figura 6.41: Curvas de contorno de $\tau \exp (\mathrm{MPa})$, em função da taxa de armadura longitudinal, $\rho$ l, e altura efetiva do elemento, d, para 449 ensaios. .....136

Figura 6.42: Correlação entre as razões $V \exp / \mathrm{Vu}$ e os valores da resistência do concreto, fc, para as normas CSA, EURO, ACl e NBR, para elementos sem estribos e dados dentro do intervalo válido, para as três categorias do grupo $\mathrm{G}$ rol.

Figura 6.43: Análise dos valores médios e desvio padrão entre as razões $V e x p / V u$ para as normas CSA, EURO, ACI e NBR, para elementos sem estribos e dados válidos

Figura 6.44: Análise dos valores médios e desvio padrão entre as razões Vexp/Vu para as normas CSA, EURO, ACI e NBR, para elementos sem estribos e dados válidos, separados em três intervalos de $\rho l$. 139

Figura 6.45: Análise dos valores médios e desvio padrão entre as razões $V \exp / \mathrm{Vu}$ para as normas CSA, EURO, ACl e NBR, para elementos sem estribos e dados válidos, separados em três intervalos de d 141

Figura 6.46: Análise da segurança para $\rho \mathrm{l}<1,5 \%$, para dados válidos e elementos sem estribos

Figura 6.47: Análise da segurança para $1,5<\rho l<3 \%$, para dados válidos e elementos sem estribos

Figura 6.48: Análise da segurança para $\rho l>3 \%$, para dados válidos e elementos sem estribos.

Figura 6.49: Análise da segurança para $\mathrm{d}<25 \mathrm{~cm}$, para dados válidos e elementos sem estribos.

Figura 6.50: Análise da segurança para $25<\mathrm{d}<60 \mathrm{~cm}$, para dados válidos e elementos sem estribos

Figura 6.51: Análise da segurança para $d>60 \mathrm{~cm}$, para dados válidos e elementos sem estribos.

Figura 6.52: Curvas de contorno de $\underline{\tau_{\exp } / \sqrt{f c}}$, em função da taxa de armadura longitudinal, $\rho$, e altura efetiva do elemento, d, para 131 ensaios de vigas sem estribos. 150

Figura 6.53: Correlação entre as razões $V \exp / \mathrm{Vu}$ e os valores da resistência do concreto, fc, para as normas CSA, EURO, ACl e NBR, para elementos sem estribos e dados fora do intervalo válido, para as três categorias do grupo $\mathrm{G}$ rol 
Figura 6.54: Análise dos valores médios e desvio padrão entre as razões $V \exp / \mathrm{Vu}$ para as normas CSA, EURO, ACI e NBR, para elementos sem estribos e dados não válidos, sendo $\mathrm{N}$ - quantidade de ensaios.

Figura 6.55: Análise dos valores médios e desvio padrão entre as razões $V \exp / \mathrm{Vu}$ para as normas CSA, EURO, ACl e NBR, para elementos sem estribos e dados não válidos, separados em três intervalos de $\rho$ l 153

Figura 6.56: Análise dos valores médios e desvio padrão entre as razões Vexp/Vu para as normas CSA, EURO, ACI e NBR, para elementos sem estribos e dados não válidos, separados em três intervalos de $d$ 154

Figura 6.57: Análise dos dados considerados não validos, para valores de resistência do concreto acima da máxima permitida, para elementos sem estribos

Figura 6.58: Análise da segurança para $\rho \mathrm{l}<1,5 \%$, dados não válidos e elementos sem estribos

Figura 6.59: Análise da segurança para $1,5<\rho l<3 \%$, dados não válidos e elementos sem estribos

Figura 6.60: Análise da segurança para $\rho \mathrm{l}>3 \%$, dados não válidos e elementos sem estribos

Figura 6.61: Análise da segurança para $\mathrm{d}<25 \mathrm{~cm}$, dados não válidos e elementos sem estribos

Figura 6.62: Análise da segurança para $25<\mathrm{d}<60 \mathrm{~cm}$, dados não válidos e elementos sem estribos

Figura 6.63: Análise da segurança para $d>60 \mathrm{~cm}$, dados não válidos e elementos sem estribos 160

Figura 6.64: Correlação entre parâmetros de ensaios e tensão cisalhante resistente experimental, para elementos com estribos e ruptura por esmagamento, segundo os autores, sendo: d - Altura do elemento; fc - Resistência do concreto; $\rho$ l - Taxa geométrica de armadura de flexão; a/d - Índice de esbeltez e psw.fyk - Taxa mecânica de estribos 164

Figura 6.65: Correlação entre as razões Vexp/Vu, para as normas CSA, EURO, ACI, modelo I na NBR e modelo II da NBR, conforme a variação da resistência do concreto, para elementos com estribos e com ruptura por esmagamento do concreto 164

Figura 6.66: Análise da segurança para casos de ruptura por esmagamento do concreto 166

Figura 6.67: Correlação entre parâmetros de ensaios e tensão cisalhante resistente experimental, para elementos sem estribos e carregados axialmente, segundo os autores, sendo: fc - Resistência do concreto; pl - Taxa 
geométrica de armadura de flexão; a/d - Índice de esbeltez e on Tensão axial .

Figura 6.68: Correlação entre as razões $V \exp / \mathrm{Vu}$, para as normas CSA, EURO, ACI e NBR, conforme a variação da resistência do concreto, fc, para elementos sem estribos e solicitados por esforços axiais 170

Figura 6.69: Correlação entre as razões Vexp/Vu, para as normas CSA, EURO, ACI e NBR, conforme a variação da tensão axial, on, para elementos sem estribos e solicitados por esforços axiais

Figura 6.70: Análise da segurança para casos de ruptura elementos sem estribos solicitados por esforços axiais de compressão. 172

Figura 6.71: Análise da segurança para casos de ruptura elementos sem estribos solicitados por esforços axiais de tração. 173

Figura 6.72: Correlação entre parâmetros de ensaios e tensão cisalhante resistente experimental, para elementos com estribos solicitados por esforços axiais, segundo os autores, sendo: d - Altura do elemento; fc Resistência do concreto; $\rho$ - Taxa geométrica de armadura de flexão; a/d - Índice de esbeltez; on - Tensão axial solicitante e psw.fyk - Taxa mecânica de estribos.

Figura 6.73: Correlação entre as razões Vexp/Vu, para as normas CSA, EURO, ACI e NBR, conforme a variação da tensão axial, on, para elementos com estribos e solicitados por esforços axiais

Figura 6.74: Correlação entre as razões Vexp/Vu, para as normas CSA, EURO, ACI e NBR, conforme a variação da tensão axial, on, para elementos com estribos e solicitados por esforços axiais, separados conforme o tipo de solicitação axial.

Figura 6.75: Análise da segurança para casos com compressão, para elementos com estribos

Figura 6.76: Análise da segurança para casos com esforços tração, para elementos com estribos 


\section{LISTA DE TABELAS}

Tabela 4.1: Valores de $\theta$ e $\beta$ para seções com armação transversal de cisalhamento

Tabela 4.2: Valores de $\theta$ e $\beta$ para seções com menos armação transversal de cisalhamento do que o valor mínimo

Tabela 4.3: Critério de avaliação da confiabilidade e desempenho de normas, através da atribuição de pontos de demérito*

Tabela 5.1: Resumo dos parâmetros considerados e suas variações .76

Tabela 6.1: Banco de dados compilado a partir de resultados experimentais de literatura, para elementos com estribos.

Tabela 6.2: Banco de dados compilado a partir de resultados experimentais de literatura, para elementos sem estribos.

Tabela 6.3: Intervalos preliminares para a avaliação das normas quanto à segurança ao dimensionamento.

Tabela 6.4: Critério elaborado para avaliar a segurança dos resultados de predição das normas, situações e números dos grupos correspondentes. 106

Tabela 6.5: Coeficientes de redução das resistências, $\Phi$, para as normas utilizadas 107

Tabela 6.6: Critério elaborado para avaliar a confiabilidade e desempenho de normas, através da atribuição de pontos de demérito 107

Tabela 6.7: Grupos de parâmetros para elementos com estribos 109

Tabela 6.8: Medidas estatísticas dos valores de predição de norma, agrupados e não agrupados (com estribos).

Tabela 6.9: Resumo da análise de exatidão e precisão (com estribos) 118

Tabela 6.10:Quadro resumo das porcentagens de previsões não seguras e onerosas (vigas com estribos).

Tabela 6.11:Resultados do método dos pontos de deméritos 125

Tabela 6.12:Quadro resumo para elementos com estribos 125

Tabela 6.13:Medidas estatísticas dos valores de predição de norma (dados não válidos) 
Tabela 6.14:Quadro resumo das porcentagens de previsões não seguras e onerosas (vigas com estribos).

Tabela 6.15:Resultados do método dos pontos de deméritos 130

Tabela 6.16:Grupos de parâmetros para elementos sem estribos 131

Tabela 6.17:Medidas estatísticas dos valores de predição de norma, agrupados e não agrupados por $\mathrm{pl}$, dados válidos e elementos sem estribos 140

Tabela 6.18:Resumo da análise de exatidão e precisão por intervalo de $\mathrm{\rho l}$, dados válidos e elementos sem estribos.

Tabela 6.19:Medidas estatísticas dos valores de predição de norma, agrupados por d, dados válidos e elementos sem estribos

Tabela 6.20:Resumo da análise de exatidão e precisão por intervalo de $d$, dados válidos e elementos sem estribos

Tabela 6.21:Resumo da análise de exatidão e precisão, intervalo válido e dados sem estribos

Tabela 6.22:Resumo das porcentagens de resultados perigosos e onerosos, dados válidos e elementos sem estribos

Tabela 6.23:Classificação pelo critério de pontos de deméritos (sem estribos)

Tabela 6.24:Tabela resumo da análise de segurança, dados válidos e elementos sem estribos

Tabela 6.25:Medidas estatísticas dos valores de predição de norma, agrupados e não agrupados por $\rho l$, para dados de ensaios não válidos e elementos sem estribos

Tabela 6.26:Resumo da análise de exatidão e precisão por intervalo de $\mathrm{\rho l}$, para dados de ensaios não válidos e elementos sem estribos

Tabela 6.27:Medidas estatísticas dos valores de predição de norma, agrupados por d, dados não válidos e elementos sem estribos 155

Tabela 6.28:Resumo da análise de exatidão e precisão por intervalo de d, agrupados por d, dados não válidos e elementos sem estribos 155

Tabela 6.29:Resumo da análise de exatidão e precisão, dados não válidos e elementos sem estribos

Tabela 6.30:Classificação pelo critério de pontos de deméritos (sem estribos e dados não válidos) 
Tabela 6.31:Resumo da análise de segurança, dados não válidos e elementos sem estribos.....

Tabela 6.32:Banco de dados para ruptura por esmagamento do concreto 163

Tabela 6.33:Medidas estatísticas dos valores de predição de norma, para elementos com ruptura por esmagamento do concreto

Tabela 6.34:Resumo das porcentagens de resultados perigosos e onerosos, para casos de ruptura por esmagamento do concreto.

Tabela 6.35:Classificação pelo critério de pontos de deméritos, para casos de ruptura por esmagamento do concreto

Tabela 6.36:Banco de dados elementos sem estribos solicitados por forças axiais 168

Tabela 6.37:Medidas estatísticas dos valores de predição de norma, para elementos sem estribos, quanto a solicitação axial

Tabela 6.38:Resumo da análise de exatidão e precisão, para elementos sem estribos, quanto a solicitação axial

Tabela 6.39:Resumo das porcentagens de resultados perigosos e onerosos (sem estribos)

Tabela 6.40:Classificação pelo critério de pontos de deméritos (sem estribos) 173

Tabela 6.41:Banco de dados elementos com estribos solicitados por forças axiais 174

Tabela 6.42:Medidas estatísticas dos valores de predição de norma para, elementos com estribos e solicitados por esforços axiais, separados conforme o tipo de solicitação axial 178

Tabela 6.43:Resumo das porcentagens de resultados perigosos e onerosos (com estribos)

Tabela 6.44:Classificação pelo critério de pontos de deméritos (com estribos)

Tabela 7.1: Siglas utilizadas para classificar os modelos de predição das normas quanto à exatidão e precisão.

Tabela 7.2: Siglas utilizadas para qualificar os modelos de predição das normas quanto ao uso 183

Tabela 7.3: Qualificação dos modelos de predição das normas, quanto à exatidão, precisão e segurança ao uso, para elementos com estribos. 
Tabela 7.4: Qualificação dos modelos de predição das normas, quanto à exatidão, precisão e segurança ao uso, para elementos sem armadura ao cisalhamento.

Tabela 8.1: Modelos de predição de norma recomendados e menos recomendados para análise de elementos com estribos, sendo: CSA - CSA (2004), EURO - Eurocode (2004), ACI - ACl (2008), NBR I - modelo I da NBR 6118 (2007) e NBR II - modelo II da NBR 6118 (2007) 198

Tabela 8.2: Modelos de predição norma recomendados e menos recomendados para análise de elementos sem estribos, sendo: CSA - CSA (2004), EURO - Eurocode (2004), ACl - ACl (2008) e NBR - NBR 6118 (2007) 


\section{SUMÁRIO}

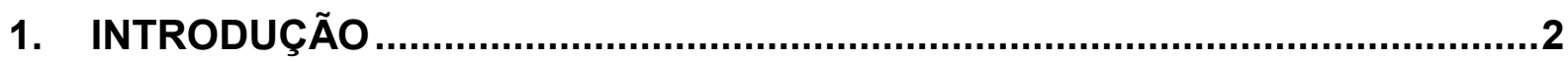

2. MOTIVAÇÃO E JUSTIFICATIVA ……..........................................................

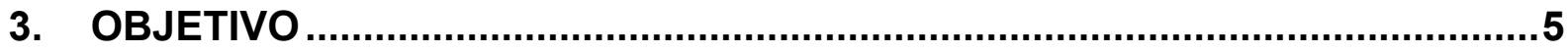

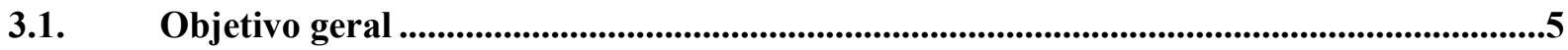

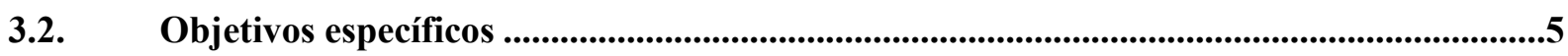

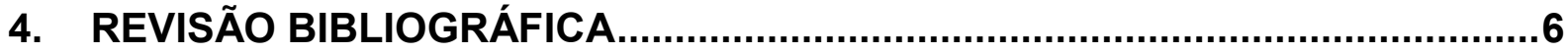

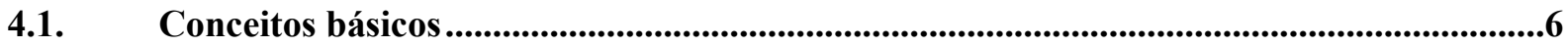

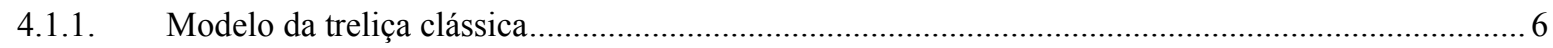

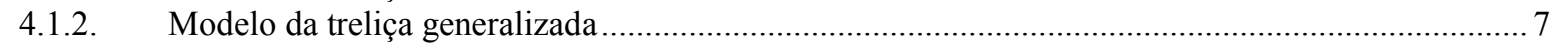

4.1.3. Modelo da treliça com contribuição do concreto..................................................................... 9

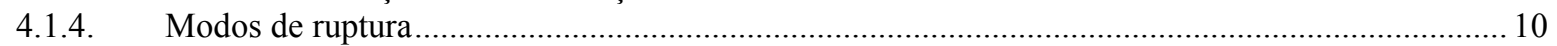

4.1.5. Regiões B (Bernoulli) e D (Disturbed) de elementos de concreto armado.................................. 11

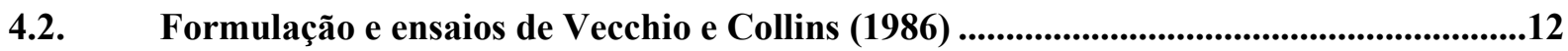

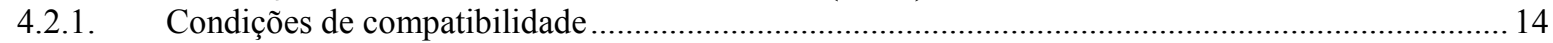

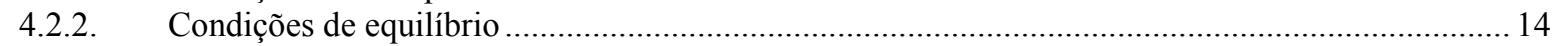

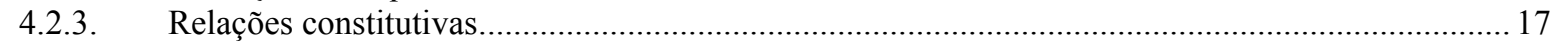

4.2.4. Transferência de esforços através das fissuras.......................................................................2 21

4.2.5. Aplicação do MCFT para análise de elementos de concreto armado ..........................................2 24

4.3. Formulação da AASHTO-LRFD - Bridge design specifications (2007) ......................35

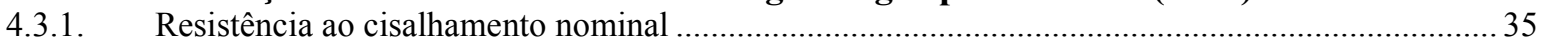

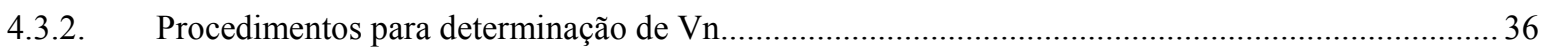

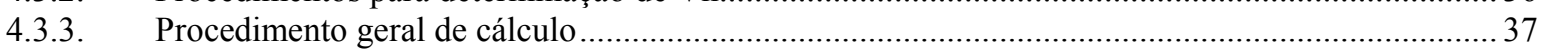

4.4. Formulação da CSA A23.3-04 - Canadian Standard Association - CSA (2004)............42

4.4.1. Definição das parcelas da resistência ao cisalhamento........................................................ 42

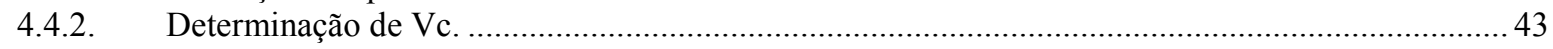

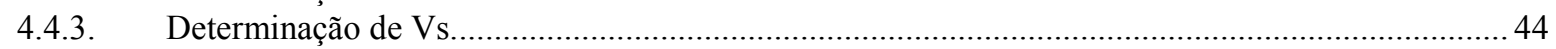

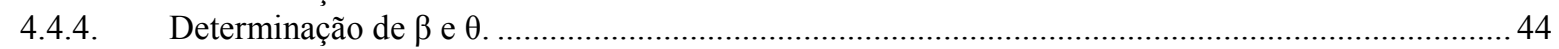

4.4.5. Critérios de detalhamento e verificações. ......................................................................... 47

4.5. Formulação do Código Modelo - FIB (2010)................................................................48

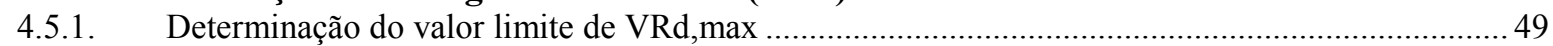

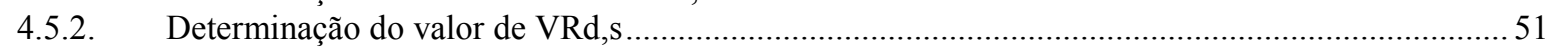

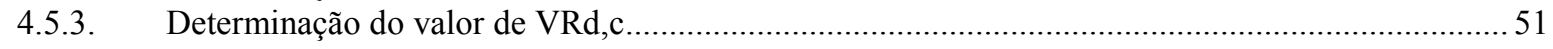

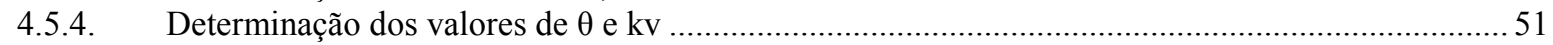

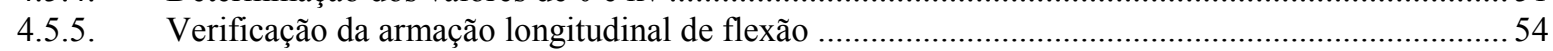

4.6. Formulação do EN 1992-1-1:2004 - Eurocode 2 (2004) ...................................................55

4.6.1. Elementos sem armação transversal de cisalhamento............................................................55

4.6.2. Elementos com armação transversal de cisalhamento. ..........................................................5 57

4.7. Formulação da norma Brasileira ABNT NBR 6118 (2007)..........................................61

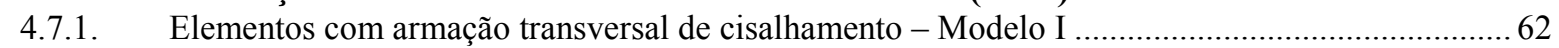


4.7.2. Elementos com armação transversal de cisalhamento - Modelo II ...........................................65

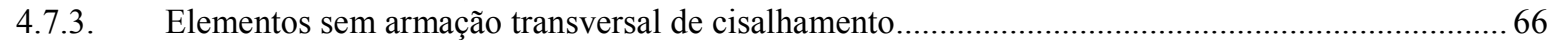

4.8. Formulação da Norma ACI 318M-08 (2008) ....................................................68

4.8.1. Determinação de $V_{\mathrm{Rd}, \mathrm{c}}$, para elementos não protendidos solicitados por momento fletor e força

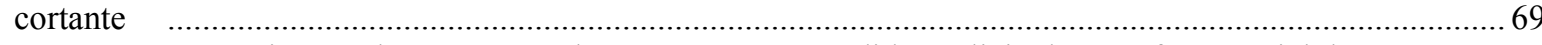

4.8.2. Determinação de $V_{\mathrm{Rd}, c}$, para elementos não protendidos solicitados por forças axial de compressão

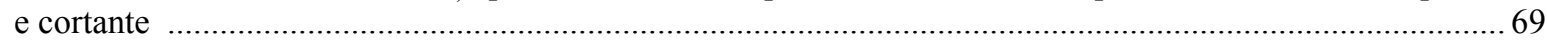

4.8.3. Determinação de $V_{\mathrm{Rd}, c}$, para elementos não protendidos solicitados por forças axial de tração e

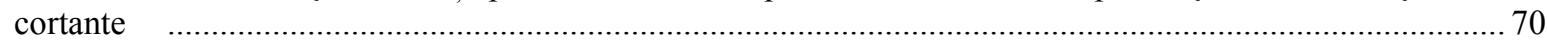

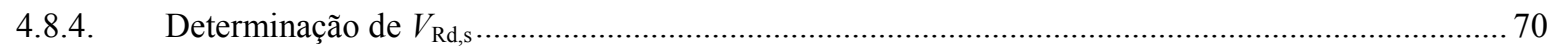

4.9. Escala de demérito de Collins apud Cladera (2002).......................................................72

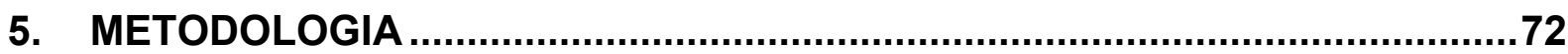

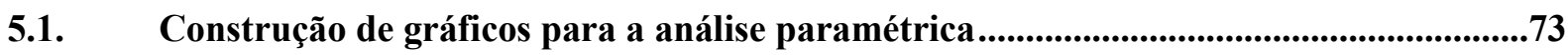

5.1.1. Definição dos valores limítrofes dos parâmetros considerados na análise paramétrica................. 74

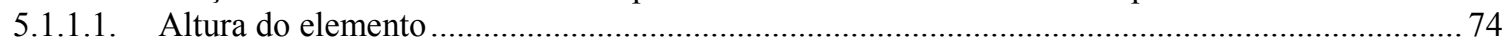

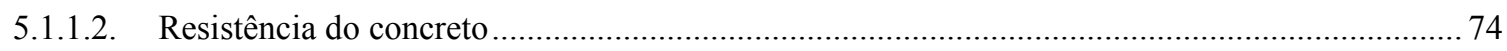

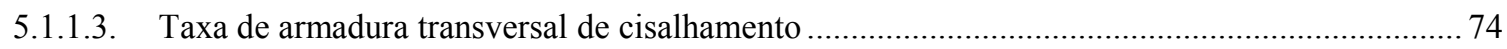

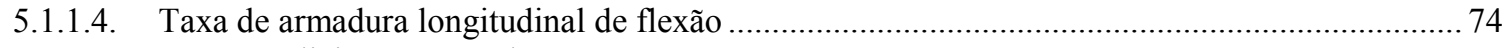

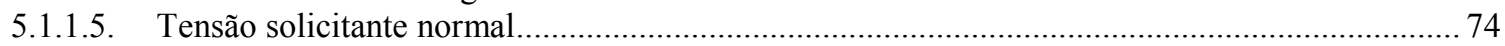

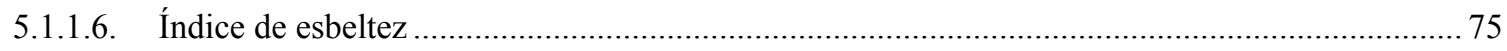

5.2. Construção do banco de dados para análise de predição das normas...........................76

5.2.1. Bancos de dados de elementos de concreto armado, com e sem estribos, e ruptura por força

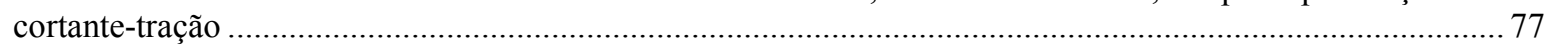

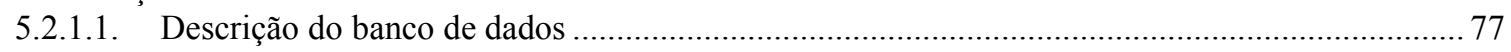

5.2.2. Banco de dados de elementos de concreto armado com estribos e ruptura por força cortante-

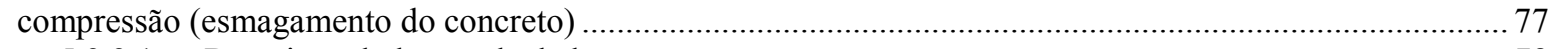

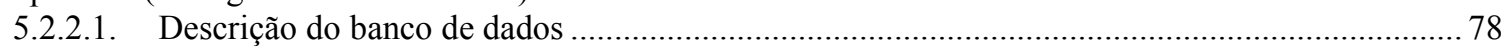

5.2.3. Bancos de dados de elementos de concreto armado, com e sem estribos, e ruptura por força

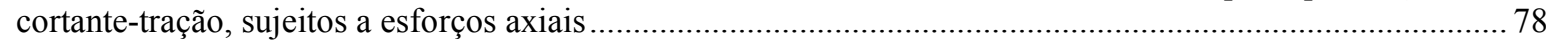

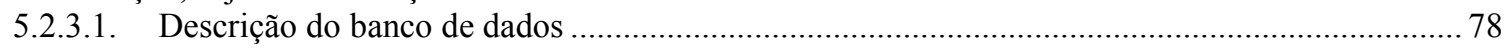

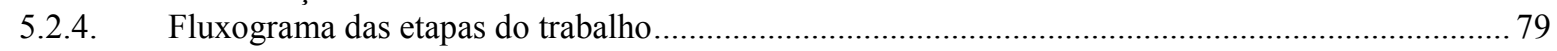

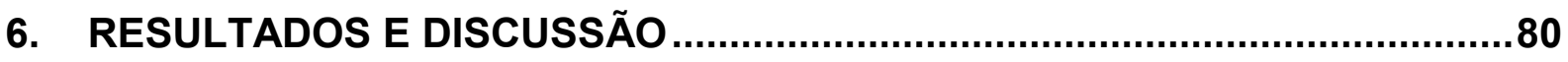

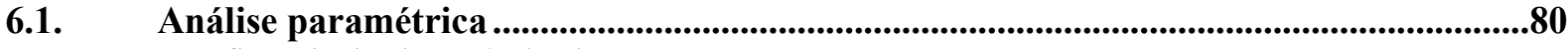

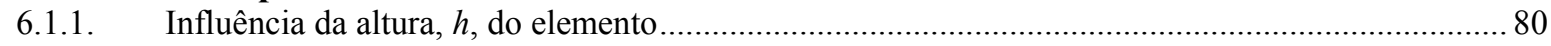

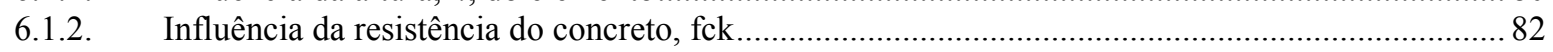

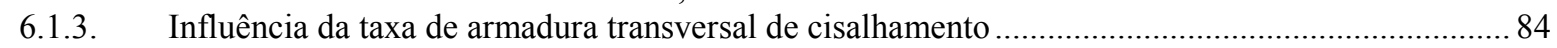

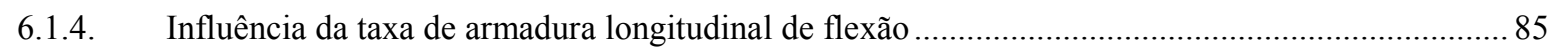

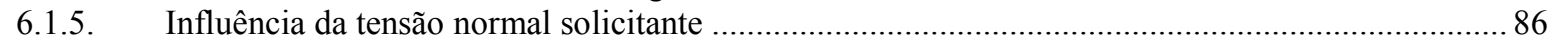

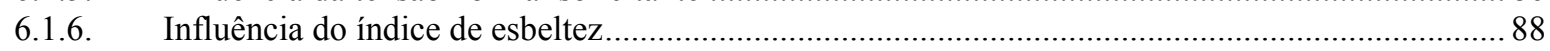

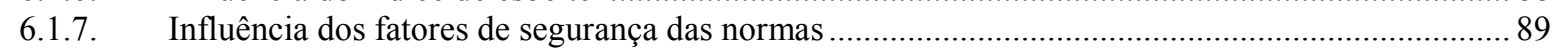

6.2. Análise dos Valores de Previsão das Normas .....................................................................92

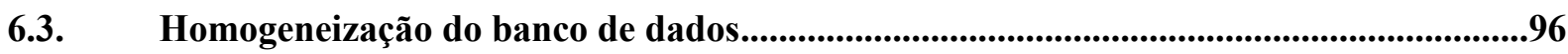

6.3.1. Definição do critério de seleção desenvolvido ................................................................................. 96

6.4. Critérios de análise desenvolvidos ..................................................................................98

6.4.1. Critério de análise da exatidão e precisão para intervalos válidos............................................99

6.4.2. Critério de análise da segurança dos modelos das normas, para intervalos válidos. .................... 102

6.4.3. Critério de análise da exatidão e precisão para intervalos não válidos. ..................................... 107

6.4.4. Critério de análise da segurança dos modelos das normas, para intervalos não válidos............... 108 
6.5. Análise de vigas armadas ao cisalhamento com estribos e ruptura por força cortante-

tração

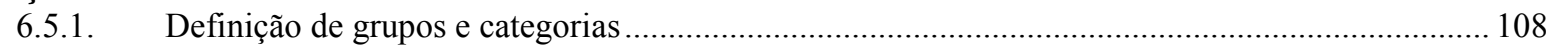

6.5.2. Análise dos resultados de ensaios do banco de dados homogeneizado ........................................ 110

6.5.3. Vigas com resistência do concreto e taxa de armadura transversal dentro dos intervalos válidos da

norma

6.5.3.1. Análise da exatidão e precisão dos modelos das normas com o uso dos resultados de ensaios do

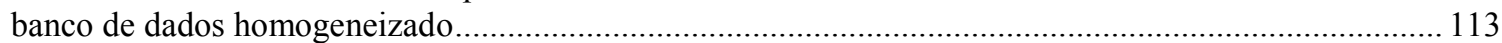

6.5.3.2. Análise da parcela resistente devido ao concreto ............................................................................ 118

6.5.3.3. Análise da segurança dos modelos das normas com o uso dos resultados de ensaios do banco de

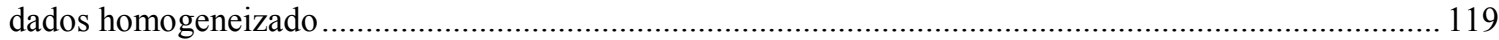

6.5.4. Vigas com resistência do concreto e taxa de armadura transversal fora dos intervalos válidos da

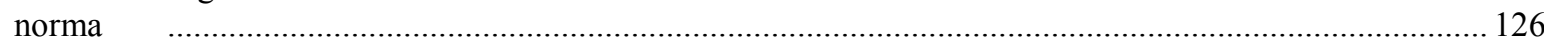

6.5.4.1. Análise da exatidão e precisão dos modelos das normas com o uso dos resultados de ensaios 126

6.5.4.2. Análise da segurança dos modelos das normas com o uso dos resultados de ensaios................ 129

6.6. Análise de vigas não armadas ao cisalhamento e ruptura por força cortante-tração..130

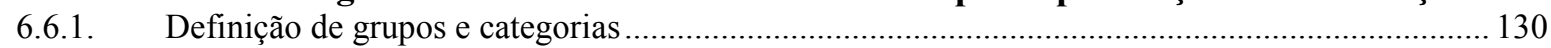

6.6.2. Análise dos resultados de ensaios do banco de dados homogeneizado ......................................... 132

6.6.3. Vigas com resistência do concreto dentro do intervalo válido da norma........................................ 135

6.6.3.1. Análise da exatidão e precisão dos modelos das normas com o uso dos resultados de ensaios do

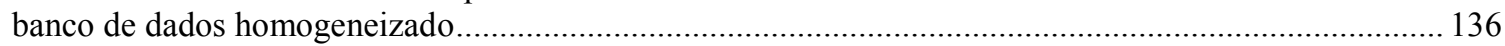

6.6.3.2. Análise da segurança dos modelos das normas com o uso dos resultados de ensaios do banco de

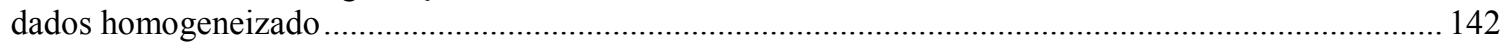

6.6.4. Vigas com resistência do concreto fora dos intervalos válidos da norma...................................... 149

6.6.4.1. Análise da exatidão e precisão dos modelos das normas com o uso dos resultados de ensaios do

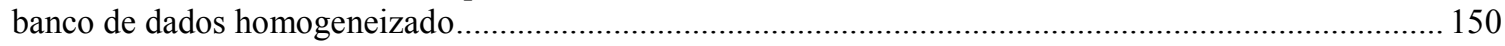

6.6.4.2. Análise da segurança das previsões dos modelos das normas com o uso dos resultados de

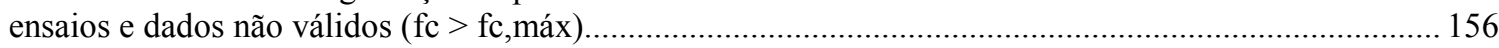

6.7. Análise de vigas armadas ao cisalhamento com estribos e ruptura por esmagamento do

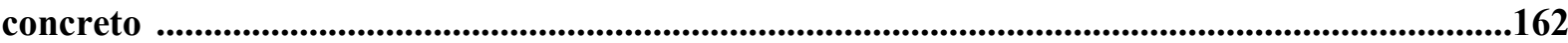

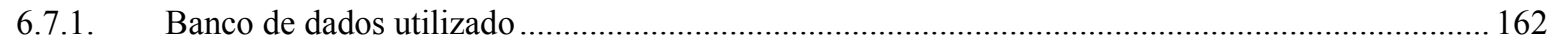

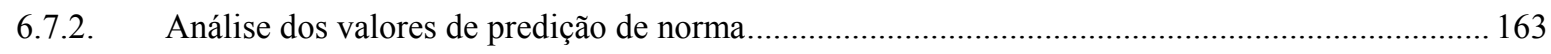

6.8. Análise de vigas solicitadas por esforços axiais ..............................................................167

6.8.1. Análise de vigas sem estribos solicitadas por esforços axiais....................................................... 167

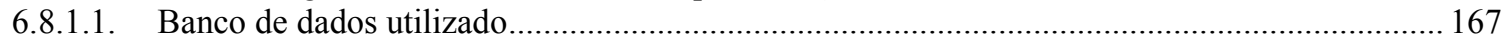

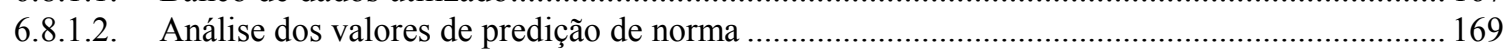

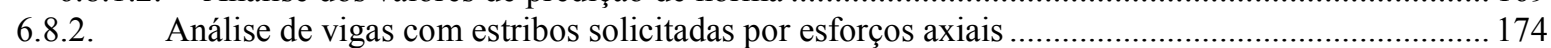

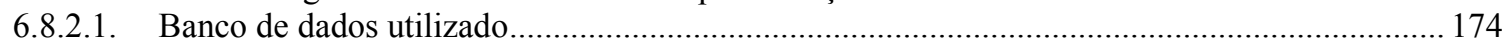

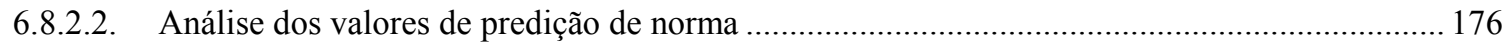

\section{RESUMO DOS RESULTADOS E DISCUSSÕES ........................................181}

7.1. Resumo das análises dos elementos armados ao cisalhamento com estribos.................183

7.1.1. Elementos com estribos, parâmetros dentro dos intervalos válidos e ruptura por força cortante-

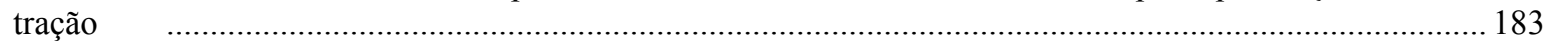

Taxa mecânica de armadura transversal, $\rho$ sw.fyk, menor que $1 \mathrm{MPa}$....................................................... 183

Taxa mecânica de armadura transversal, $\rho$ sw.fyk, maior que $1 \mathrm{MPa}$ e menor ou igual a $2 \mathrm{MPa}$................ 184

Taxa mecânica de armadura transversal, $\rho$ sw.fyk, maior que 2 MPa ....................................................... 185

7.1.2. Elementos com estribos, parâmetros fora dos intervalos válidos e ruptura por força cortante-

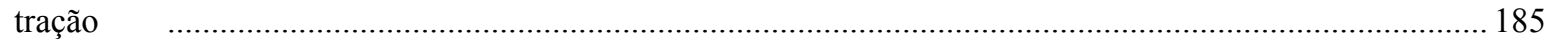

Taxa mecânica de armadura transversal, $\rho s w . f y k$, menor que a taxa mínima recomendada por norma,

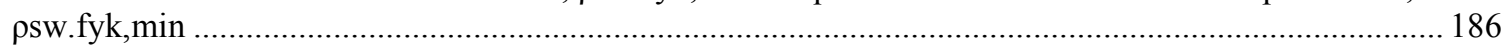

7.1.3. Elementos com estribos, solicitados por esforços axiais e ruptura por força cortante-tração ......... 186

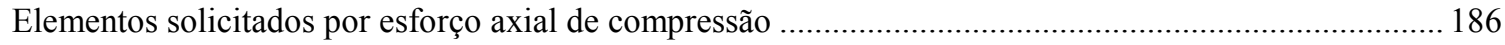

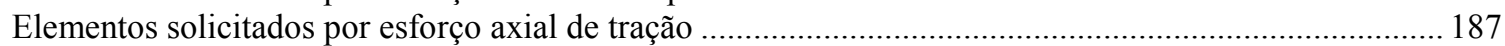

7.1.4. Elementos com estribos e ruptura por esmagamento do concreto …………….............................. 187 
7.2. Resumo das análises dos elementos não armados ao cisalhamento

7.2.1. Elementos sem estribos, parâmetros dentro dos intervalos válidos e ruptura por força cortante-

tração

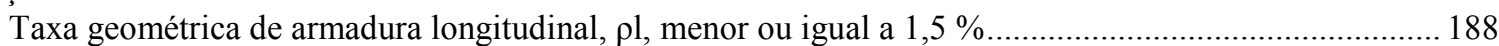

Taxa geométrica de armadura longitudinal, $\rho l$, maior do que $1,5 \%$ e menor ou igual a 3,0 \% ................. 189

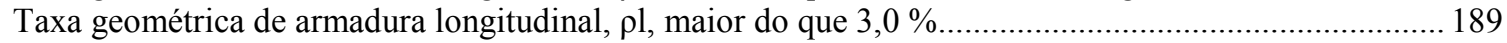

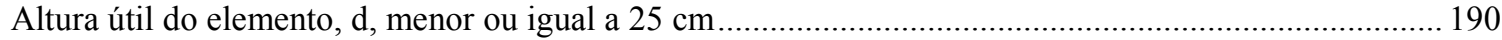

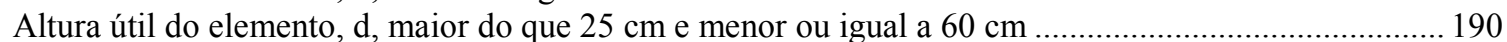

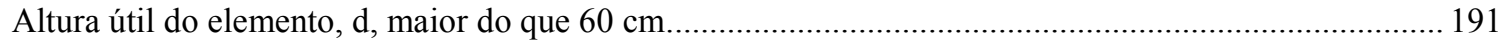

7.2.2. Elementos sem estribos, parâmetros fora dos intervalos válidos e ruptura por força cortantetração

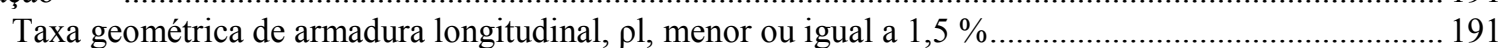

Taxa geométrica de armadura longitudinal, $\rho 1$, maior do que 1,5\% e menor ou igual a 3,0 \%................. 192

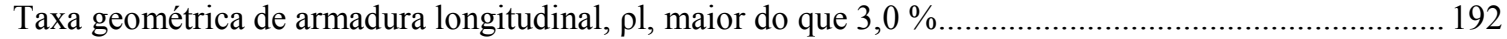

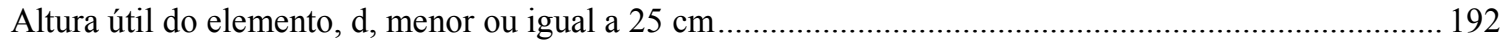

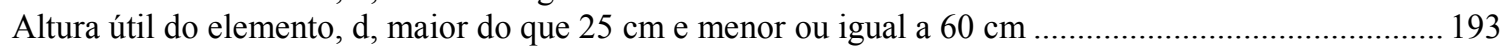

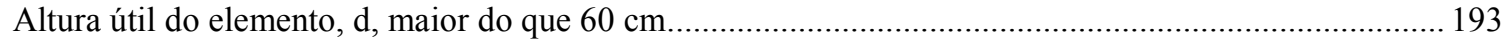

7.2.3. Elementos com estribos, solicitados por esforços axiais e ruptura por força cortante-tração ......... 193

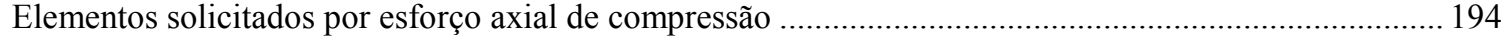

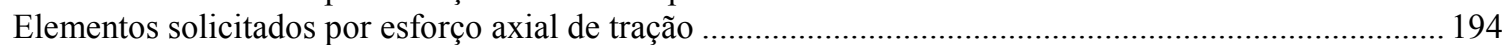

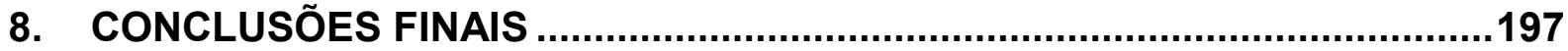

9. PROPOSTAS PARA PESQUISAS FUTURAS .........................................200

10. REFERÊNCIAS BIBLIOGRÁFICAS:................................................201 


\section{Introdução}

A determinação do valor da resistência ao cisalhamento de elementos de concreto armado tem apresentado em vários estudos, desvios quando comparada com valores de resistência obtidos em ensaios de laboratório. A dificuldade em estimar valores fiéis aos ensaios de laboratórios decorre principalmente do fato de existir diversos fenômenos que compõem o comportamento dos elementos em concreto armado, quando solicitados por esforços tangenciais e normais.

Leonhardt (1977) apresenta uma relação de 21 fatores que influenciam a resistência ao cisalhamento de elementos em concreto armado, alguns com importância primária e outros, secundária. Portanto, elaborar uma formulação que considere pelo menos os fatores mais significativos torna-se uma atividade complexa, visto o número de fatores que podem influenciar a determinação da resistência ao cisalhamento. Depois da elaboração do modelo da treliça clássica, de autoria do Ritter e Mörsch, em 1902, tem-se utilizado a treliça isostática com banzos paralelos e bielas comprimidas para a modelagem do fenômeno da resistência ao cisalhamento, incorporando-se ao modelo diversas modificações. Por exemplo, podem ser citados os modelos de treliça com contribuição do concreto, p. ex. NBR 6118 (2007), combinações teóricas envolvendo compressão e cisalhamento, p. ex. CUI Q., e NIE H. (2011), modelos de treliça generalizada, p. ex. Eurocode (2004), e teoria do campo de compressão (compression field theory), p ex. CSA A23.3-04 (2004). Lobo Carneiro, apud Santos Neto (1977) afirma que: "A chamada treliça clássica de Ritter-Mörsch foi uma das concepções mais fecundas na história do concreto armado. Há mais de meio século tem sido a base do dimensionamento das armaduras transversais - estribos e barras inclinadas - das vigas de concreto armado, e está muito longe de ser abandonada ou considerada superada. As pesquisas sugerem apenas modificações ou complementações na teoria, mantendo, no entanto, o seu aspecto fundamental: a analogia entre a viga de concreto armado, depois de fissurada, e a treliça". Esta observação é valida até o presente momento, pois o modelo da treliça clássica apresenta, para a maioria dos casos, valores de resistência seguros do ponto de vista estrutural. Porém, para cenários diferentes de solicitação tangencial dos elementos de concreto armado (como por exemplo, vigas de grande altura ou sujeitos a esforços normais concomitantes de tração), o modelo de treliça clássica não apresenta resultados fiéis aos resultados de ensaios reais, como notado, por exemplo, por Shrinivas e Collins (1989) e National cooperative highway reserch program (2005). Com isso, ultimamente, tem-se pesquisado novos métodos de predição de esforços cisalhantes últimos, combinados com outros esforços solicitantes, por exemplo Zararis e Zararis (2009). Para llustrar a importância de se estudar a resistência ao cisalhamento, será apresentado um caso de ruptura de estrutura devido ao esgotamento da resistência ao cisalhamento. Adotou-se o enfoque da concomitância de esforços normais de tração.

Bhide e Collins (1989) analisaram um colapso parcial do armazém da força aérea de Wilkins em Shelby, Ohio, 1955. O colapso ocorreu devido a falhas no 
modelo estrutural adotado para o dimensionamento de vigas do armazém, que causou uma solicitação de esforço tangencial e esforços normais de tração maiores do que a resistência estrutural da peça.

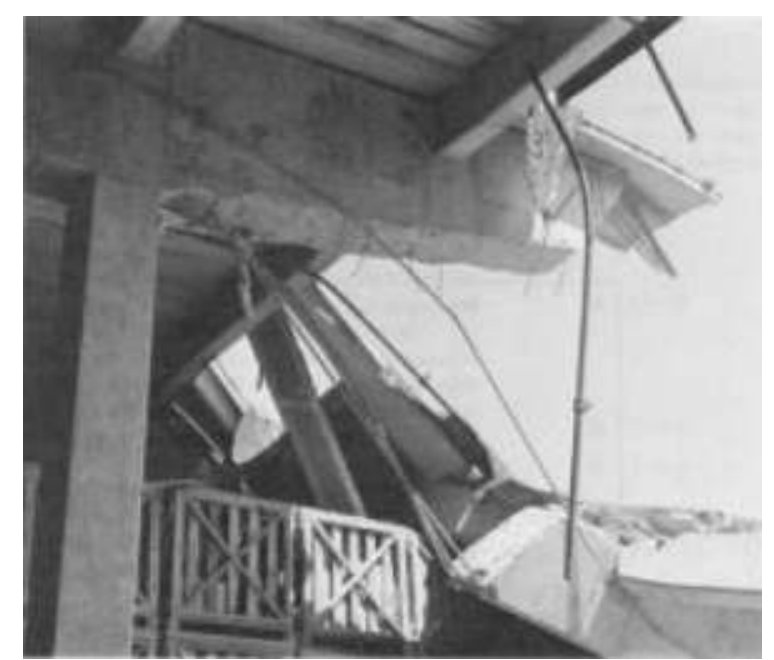

Figura 1.1: Fotografia do colapso parcial da cobertura do armazém da força aérea Americana (Cladera, 2002)

Verificou-se que o trecho de ruptura da viga era uma região que não necessitava de armadura transversal de cisalhamento, pois estava submetida a tensões de cisalhamento, da ordem de 0,5 MPa. Estas tensões eram menores do que o limite superior de 0,62 $\mathrm{MPa}$, indicando assim que, o modelo e a prática adotados estavam não seguros para esse caso. Com isso, questionouse sobre o efeito da força normal na resistência ao cisalhamento do código de construção do $\mathrm{ACl}$ ("ACl Building Code"), o qual permitiu por muitos anos uma tensão admissível de serviço máxima para que se pudesse dispensar a armadura ao cisalhamento. Após o acidente, ensaios feitos pela Associação de Cimento Portland ("Portland Cement Association") mostraram que, ao se aplicar uma tensão de tração em peças com pequena taxa armadura longitudinal (como a usada no armazém de Wilkins), a capacidade de resistência ao cisalhamento pode reduzir 50 \%. A solicitação normal de tração ocorreu devido à retração e efeitos de temperatura, principalmente pelos pilares. Com isso modificaram-se os critérios de projeto da $\mathrm{ACl}$ que anteriormente ignoravam a influencia da força normal.

\section{Motivação e Justificativa}

Torna-se eminente atualizar o conhecimento sobre os modelos de predição da resistência ao cisalhamento de elementos em concreto armado. Além disso, é significativo avaliar a validade das formulações utilizadas, principalmente para cenários de esforços solicitantes e geometrias particulares, que indicam um comportamento do elemento de concreto diferente do usualmente contemplado nas normas técnicas.

Atualmente os métodos de dimensionamento de elementos de concreto, quando submetidos a solicitações normais e tangenciais presentes 
principalmente em normas técnicas, estão em desenvolvimento e aperfeiçoamento. Por isso, estão sendo realizadas pesquisas que influenciam conceitos e critérios usados no cálculo estrutural. A modificação constante dos conceitos sobre os modelos de predição da resistência ao cisalhamento, com a consequente alteração dos critérios de norma técnica, merece estudo cuidadoso para a compreensão dos diversos métodos propostos.

Existem formulações propostas por vários autores para se estimar a resistência ao cisalhamento, publicadas na literatura, por exemplo, Daejoong K. et al (1999), Khuntia e Stojadinovic (2001), Tureyen e Frosch (2003) entre outros. Cada autor destaca que sua formulação apresenta resultados fiéis aos resultados de ensaios, mostrando assim, que o assunto ainda não atingiu um consenso, e que cada método deve representar melhor certa faixa de parâmetros de ensaios, ou seja, um cenário específico.

A resistência ao cisalhamento sofre influência de diversos fatores primários e secundários, e cada modelo de predição trata os principais fatores de maneira distinta. Atualmente existem modelos de predição consolidados na literatura técnica que permitem o dimensionamento de estruturas, por exemplo, vigas, para resistirem a esforços de cisalhamento. Modelos de predição de comportamento baseiam-se em um número grande de ensaios, dos quais a maior porção corresponde a vigas submetidas à flexão simples. Em segundo lugar estão aqueles dedicados aos problemas de flexo-compressão, e em último os relativos aos problemas de flexo-tração, especialmente escassos em peças de grandes dimensões, com baixa taxas de armadura longitudinal.

Principalmente nos casos de elementos submetidos à flexo-tração e cisalhamento, as propostas baseadas no modelo de treliça não são efetivos, pois não consideram de forma direta a interação entre os diversos fatores que compreendem o mecanismo de resistência ao cisalhamento.

Outro fator importante que influência o fenômeno de resistência ao cisalhamento é o chamado efeito de escala, em que peças de grandes dimensões apresentam tensões cisalhantes ultimas menores do que peças de menores dimensões. Kani, Collins e Kuchma, Shioya apud Khuntia e Stojadinovic (2001) estudaram este fenômeno e concluem que, para elementos de grandes dimensões ocorre redução considerável da tensão resistente. Para estruturas simples e convencionais esta situação não apresenta grande influência. No entanto, para obras de grande porte, tais como hidrelétricas, silos, estações de metrô, viadutos e outros, esta redução pode ser significativa.

A motivação em desenvolver uma metodologia de investigação da influência dos principais fatores na resistência ao cisalhamento, e, também, sobre como as normas técnicas abordam essas questões, se dá, principalmente por se tratar de um assunto de extrema importância para engenheiros projetistas. Estes profissionais se deparam com cenários de dimensionamento não convencionais, principalmente de estruturas que requerem maiores cuidados e metodologias mais requintadas para a sua concepção. Daí a necessidade de gerar subsídios para alterações nas recomendações de normas técnicas, por meio de estudos desta natureza. 
Um fato importante, segundo a opinião do autor desta dissertação, e que comprova a necessidade de aprofundar o assunto, é que o modelo de predição elaborado principalmente por Michael Collins da Universidade de Toronto no Canadá, denominado Teoria do Campo Modificado de Compressão ("Modified Compression Field Theory"), está sendo adotado como modelo de predição de algumas normas, após confirmação de boa adequação aos resultados de ensaios em laboratório. A associação americana AASTHO "American Association of State Highway and Transportation Officials", a associação canadense CSA "Canadian Standards Association e o comitê europeu FIB "International Federation for Structural Concrete" adotaram oficialmente o MCFT (Modified Compression Field Theory) como modelo de cálculo da resistência ao cisalhamento de elementos em concreto armado.

\section{Objetivo}

\subsection{Objetivo geral}

A Dissertação tem como objetivo o levantamento bibliográfico dos principais modelos de predição de força cortante resistente de vigas de concreto armado e seus relativos tipos de ruptura. Além disso, qualificar as diversas normas, quanto sua aplicabilidade em diversos intervalos de parâmetros de uso, através da análise comparativa entre os valores de predição, das principais normas utilizadas no meio técnico, e os resultados de ensaios de laboratório,

Destaca-se o interesse em melhor compreender o modelo de predição do método "Modified Compression Field Theory" (MCFT) e suas adaptações, quando incorporadas a algumas normas, como AASHTO-LRFD (2007), CSA (2004) e Código Modelo FIB (2010).

\subsection{Objetivos especificos}

Obter uma conclusão objetiva sobre os comportamentos das normas, quanto ao fenômeno da resistência ao cisalhamento, baseando-se nas ações a seguir:

1. Pesquisa bibliográfica dos principais modelos de cálculo da resistência ao cisalhamento de elementos em concreto armado;

2. Análise paramétrica de diversos casos didáticos para compreensão dos comportamentos dos modelos das normas nos diversos intervalos de parâmetros;

3. Verificação da exatidão, precisão e segurança dos principais modelos de norma, frente à comparação com resultados de ensaios de laboratório, identificando faixas de maior ou menor validade dos modelos de predição;

4. Análise dos resultados de predição de norma para casos de ruptura por esmagamento do concreto, quando comparados com resultados de ensaios; 
5. Análise dos resultados de predição de norma para casos de elementos, solicitados por esforços axiais, quando comparados com resultados de ensaios.

O desenvolvimento do trabalho está relatado nos capítulos apresentados a seguir.

\section{Revisão Bibliográfica}

Inicialmente serão apresentados os conceitos básicos do esforço tangencial (cisalhante), indicando brevemente os conceitos de modelos de predição de comportamento e as formas de ruptura possíveis para elementos de concreto quando submetidos a esforços tangenciais.

Visando a análise de alguns métodos e formulações para estimar a resistência ao cisalhamento de peças em concreto armado e compará-las com resultados de ensaios de laboratório, serão apresentadas as formulações das normas consideradas importantes, bem como os principais mecanismos de ruptura. A formulação elaborada por Vecchio e Collins terá uma abordagem mais detalhada, pois se pretende compreender as diversas considerações do método proposto, que foi desenvolvido ao longo de aproximadamente 30 anos de pesquisa. Como este modelo foi incorporado a algumas normas utilizadas atualmente em todo mundo, sua importância fica evidente, bem como o esforço em melhor compreender o trabalho desenvolvido por esses autores em particular.

Os subitens seguintes contêm os modelos de predição das normas utilizados pelo meio técnico, cujos resultados, quando comparados e analisados, embasarão as conclusões.

\subsection{Conceitos básicos}

Os modelos conceituais que representam elementos de vigas e lajes indicam que quando estes estão sujeitos a ação de um carregamento transversal faz surgir esforços solicitantes, como, por exemplo, momento fletor, força normal, força cortante e momento torçor. Para dimensionar os elementos solicitados por forças cortantes, existem modelos que procuram representar a realidade e fornecer um critério seguro para a construção do elemento em concreto armado. Para melhor compreender os modelos de predição das principais normas, é necessário apresentar os modelos básicos que motivaram a elaboração dos modelos mais complexos.

\subsubsection{Modelo da treliça clássica}

O modelo criado por W. Ritter e modificado por $E$. Mörsch foi pioneiro na determinação da resistência ao cisalhamento de elementos em concreto armado, conhecido atualmente como o modelo da treliça clássica. Segundo Silva e Giongo (2000), a "Analogia da Treliça" foi publicada em 1902 e se tornou uma das concepções mais duradouras da história do concreto armado. 
Ritter afirmou que após uma viga de concreto armado fissurar devido as tensões de tração no concreto, o modelo de comportamento do elemento fissurado podia ser caracterizado por:

1) Banzo superior comprimido, ou cordão de concreto comprimido;

2) Banzo inferior tracionado, armadura longitudinal de tração;

3) Diagonais comprimidas, bielas de concreto entre fissuras, com uma inclinação, $\theta$, igual a $45^{\circ}$ em relação ao eixo longitudinal da viga.

4) Diagonais tracionadas, armadura transversal de cisalhamento (estribos) com uma inclinação, $\alpha$, entre $45^{\circ}$ e $90^{\circ}$ em relação ao eixo longitudinal da viga.

Um esquema desta configuração está apresentado na Figura 4.1

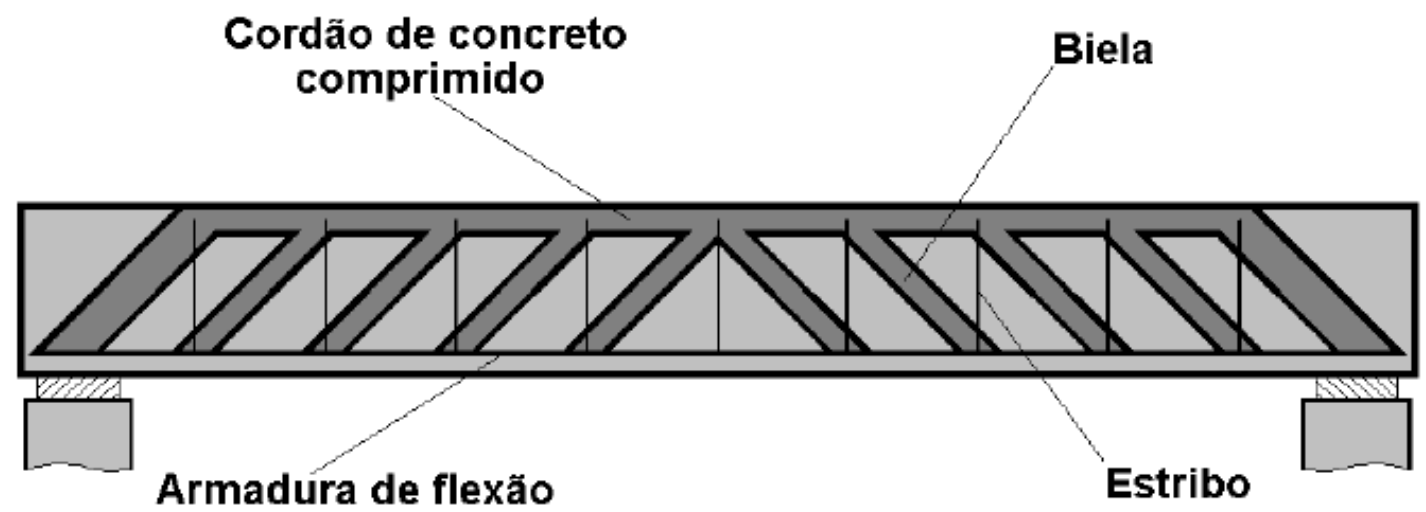

Figura 4.1: Esquema do Modelo da Treliça Clássica, $\operatorname{com} \alpha=90^{\circ}$.

Uma hipótese simplificadora do modelo é considerar a treliça isostática, portanto, não há engastamento nos nós, ou seja, na ligação entre os banzos e as diagonais. $E$ também, o paralelismo entre os banzos superior e inferior.

\subsubsection{Modelo da treliça generalizada}

Segundo Silva e Giongo (2000), na década de 80, Schlaich e Schäfer, baseados em resultados de ensaios, modificaram o modelo da treliça clássica, sugerindo uma inclinação da biela de compressão, $\theta$, menor ou igual a $45^{\circ}$, aproximando, assim, os resultados previstos pelos modelos de treliça e os resultados de ensaios. Visando a economia no dimensionamento dos estribos, segundo $\mathrm{ACl}$ 445R (1999), utilizou-se o procedimento de considerar um ângulo variável da inclinação da biela de compressão diagonal, resguardado pela existência de mecanismos resistentes complementares do imbrica mento entre agregados e o efeito pino, mecanismo resistente que se dá devido à resistência ao cisalhamento da armadura longitudinal nas fissuras. 

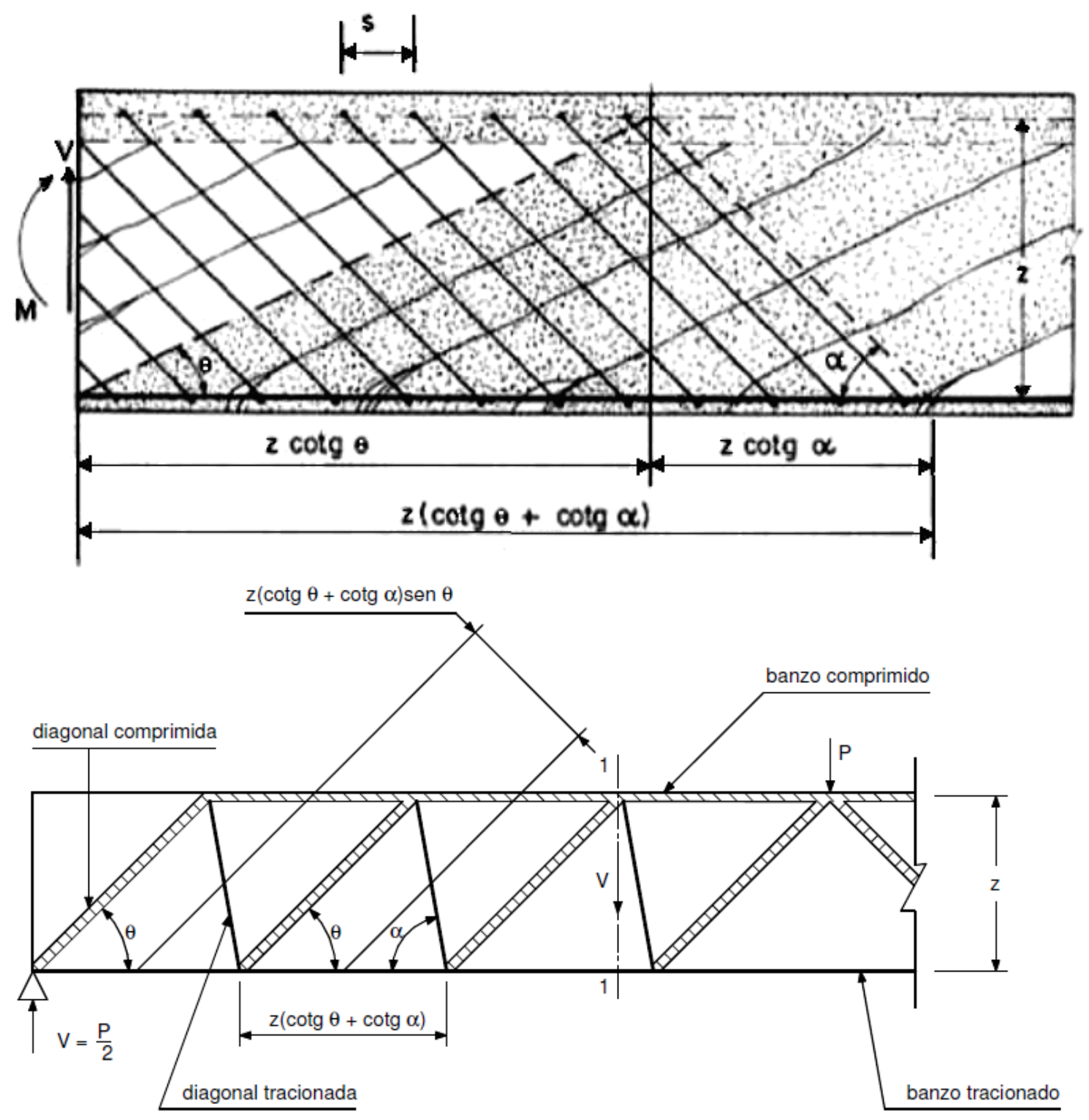

Figura 4.2: $\quad$ Esquema do modelo da Treliça Generalizada. $M$ é o momento fletor, $V$ é a Força cortante; $s$ é o espaçamento entre estribos, $z$ é Distância entre $o$ centro do banzo comprimido e o centro do banzo tracionado, $\theta$ é o Ângulo da biela de compressão do concreto, menor ou igual a $45^{\circ}$; $\alpha$ é ângulo de inclinação dos estribos, entre $45^{\circ}$ e $90^{\circ}$. (adaptado de Fusco, 2008)

Na Figura 4.2 tem-se:

M-Momento fletor;

V - Força cortante;

$s$ - Espaçamento entre estribos;

z - Distância entre o centro do banzo comprimido e o centro do banzo tracionado; 
$\theta$ - Ângulo da biela de compressão do concreto, menor ou igual a $45^{\circ}$;

$\alpha$ - ângulo de inclinação dos estribos, entre $45^{\circ}$ e $90^{\circ}$.

Com auxilio da Figura 4.2, obtém-se os esforços internos solicitantes, conforme descrito a seguir.

Para a determinação da tensão na biela de compressão, $\sigma_{c}$, sabendo que a distância perpendicular entre as diagonais comprimidas é igual a z. $(\cot \theta+\cot \alpha) \cdot \operatorname{sen} \theta$ e impondo o equilíbrio de forças verticais, tem-se a equação 4.1.

$$
\sigma_{c}=\frac{V}{b_{w} z(\cot \theta+\cot \alpha) \operatorname{sen} \theta}
$$

Sendo $b_{\mathrm{w}}$ a largura da viga.

Para determinação da tensão de tração nos estribos, $\sigma_{s}$, adotando-se um comprimento de influência z.( $(\cot \theta+\cot \alpha)$, medida na direção do eixo longitudinal da viga, cuja densidade de estribos é igual a $A_{\text {sw }} / s$,tem-se a equação 4.2 .

$$
\sigma_{s}=\frac{V}{z(\cot \theta+\cot \alpha) \operatorname{sen} \theta} \frac{s}{A_{s w}}
$$

Ressalte-se que o modelo de treliça é isostático, e na verdade a estrutura real é hiperestática, e apresenta outros mecanismos resistentes como o efeito arco, o imbrica mento dos agregados e efeito de pino das armaduras, o que resulta na dificuldade de estimar o ângulo de inclinação da biela, e por consequência, a tensão solicitante de compressão no concreto da biela e a tensão nos estribos. Estas são algumas limitações do modelo da treliça.

\subsubsection{Modelo da treliça com contribuição do concreto.}

Os modelos de treliça tradicionais assumem que a biela de compressão do concreto é paralela à direção das fissuras e que não se transfere esforços ao longo das fissuras, resultando em aproximações conservadoras quando comparadas com resultados de ensaios, conforme Talbot (1909). Desta forma, alguns modelos de predição apresentam um dos dois mecanismos resistente complementar a seguir, ou ambos. Um mecanismo ocorreu devido a 
contribuição da resistência à tração do concreto e o outro, devido a tensão cisalhante que é transmitida através das fissuras inclinadas, seja por imbrica mento do agregado, como pelo atrito cisalhante ("Shear Friction"). As teorias utilizadas na formulação destes modelos consideram a parcela resistente, $V_{c}$, de maneiras distintas. As principais formulações de normas estão apresentadas nos itens a seguir, evidenciando a contribuição do concreto na resistência ao cisalhamento de peças de concreto armado.

Os modelos de treliça com contribuição do concreto utilizam as hipóteses e conclusões da treliça generalizada para a determinação da parcela resistente ao cisalhamento devido ao acréscimo dos estribos, conforme indicado na equação (4.2).

\subsubsection{Modos de ruptura}

Os modos de ruptura por solicitação de momento fletor e força cortante, segundo Fusco (1998), podem ser classificados de acordo com os esquemas a), b), c) e d) da Figura 4.3.

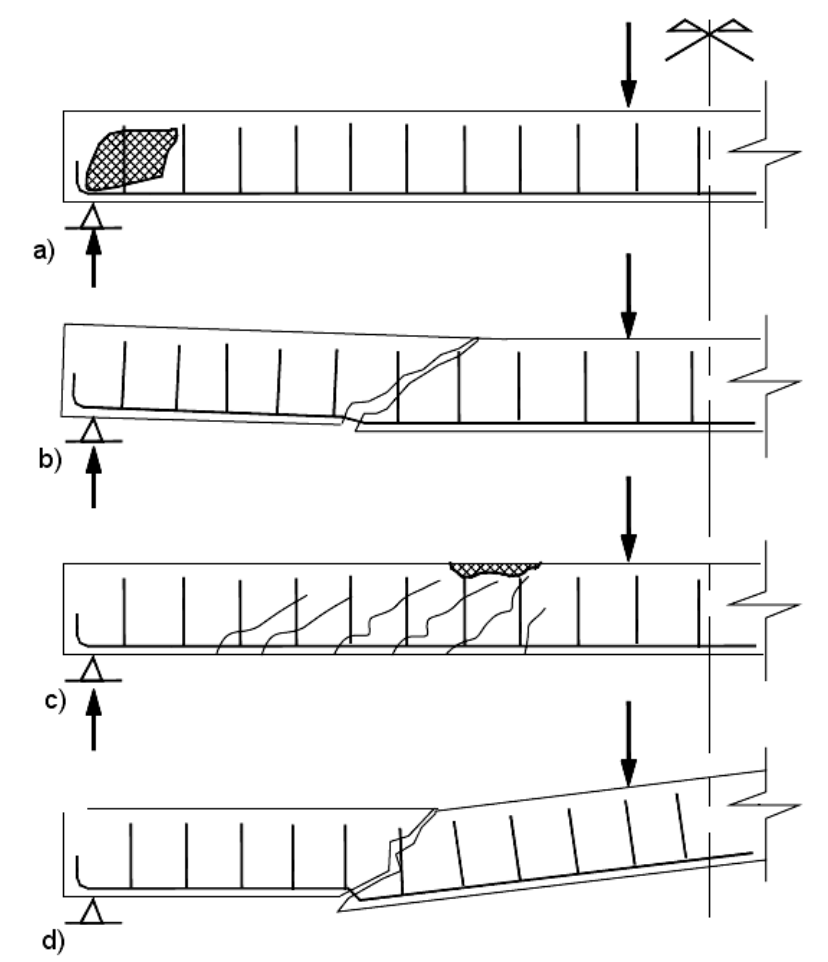

Figura 4.3: $\quad$ Modos de ruptura por solicitação de momento fletor e força cortante. a) Ruptura por força cortante-compressão, b) Ruptura por força cortantetração c) Ruptura por força cortante-flexão, d) Ruptura por flexão da armadura longitudinal (Fusco, 1998)

a) Ruptura por força cortante-compressão: corresponde à ruptura por compressão das bielas diagonais do concreto. A ruína é frágil e sem aviso prévio. A segurança deste estado limite último é garantida definindo que a tensão da força cortante solicitante seja menor que a tensão resistente da diagonal comprimida do concreto. 
b) Ruptura por força cortante-tração: ocorre quando o elemento está subarmado transversalmente, possibilitando o escoamento dos estribos, indicando grandes deformações e fissuras até sua ruína.

c) Ruptura por força cortante-flexão: decorre da interação entre a força cortante e o momento fletor, nas proximidades de cargas concentradas elevadas. A ruptura ocorre quando as fissuras diagonais de cisalhamento cortam uma parte da região que formaria o banzo comprimido da peça fletida. O estado limite último é assegurado pelo dimensionamento e detalhamento adequado da peça à flexão.

d) Ruptura por flexão da armadura longitudinal: acontece quando as bielas de compressão do concreto, que se apoiam no banzo tracionado sobre as barras de armadura longitudinal, provocam tensões de flexão muito elevadas. Neste caso deve-se assegurar um correto detalhamento das armaduras, principalmente o espaçamento e ancoragem dos estribos no banzo tracionado.

Existe a ruptura por falta de ancoragem correta das barras longitudinais de tração nos apoios. Nesta região a armadura longitudinal é bastante solicitada pelo efeito arco e este problema pode ser evitado utilizando grampos nos pontos de ancoragem.

\subsubsection{Regiões B (Bernoulli) e D (Disturbed) de elementos de concreto armado}

Elementos de concreto armado apresentam comportamentos distintos em regiões diferentes, que de forma geral, existe um consenso em discretizar estas regiões.

Na maioria das vezes, os elementos de concreto armado são constituídas por regiões denominadas $B$ e $D$.

As regiões $B$ se referem às regiões onde as distribuições transversais das tensões são lineares, também chamadas de regiões de Bernoulli ou "beam regions", pois nestas regiões valem as hipóteses e formulações de Bernoulli para vigas. Por outro lado, as regiões $D$, também chamadas de regiões de descontinuidades ou "disturbed regions", são caracterizadas por apresentarem distribuições transversais das tensões de forma não lineares, e que se dão por descontinuidades estáticas (cargas ou ações concentradas) e/ou geométricas (aberturas em vigas e nós de pórticos). Silva e Giongo (2000) relata que as regiões $B$ fissuradas podem ser projetadas utilizando modelos de treliça usuais. Para as regiões $D$ é possível utilizar modelos de bielas e tirantes. Além disso, o autor enfatiza que como o modelo de treliça é um caso particular do modelo de bielas e tirantes, ambas as regiões, B e D, podem ser dimensionadas com a utilização de modelos de bielas e tirantes. 


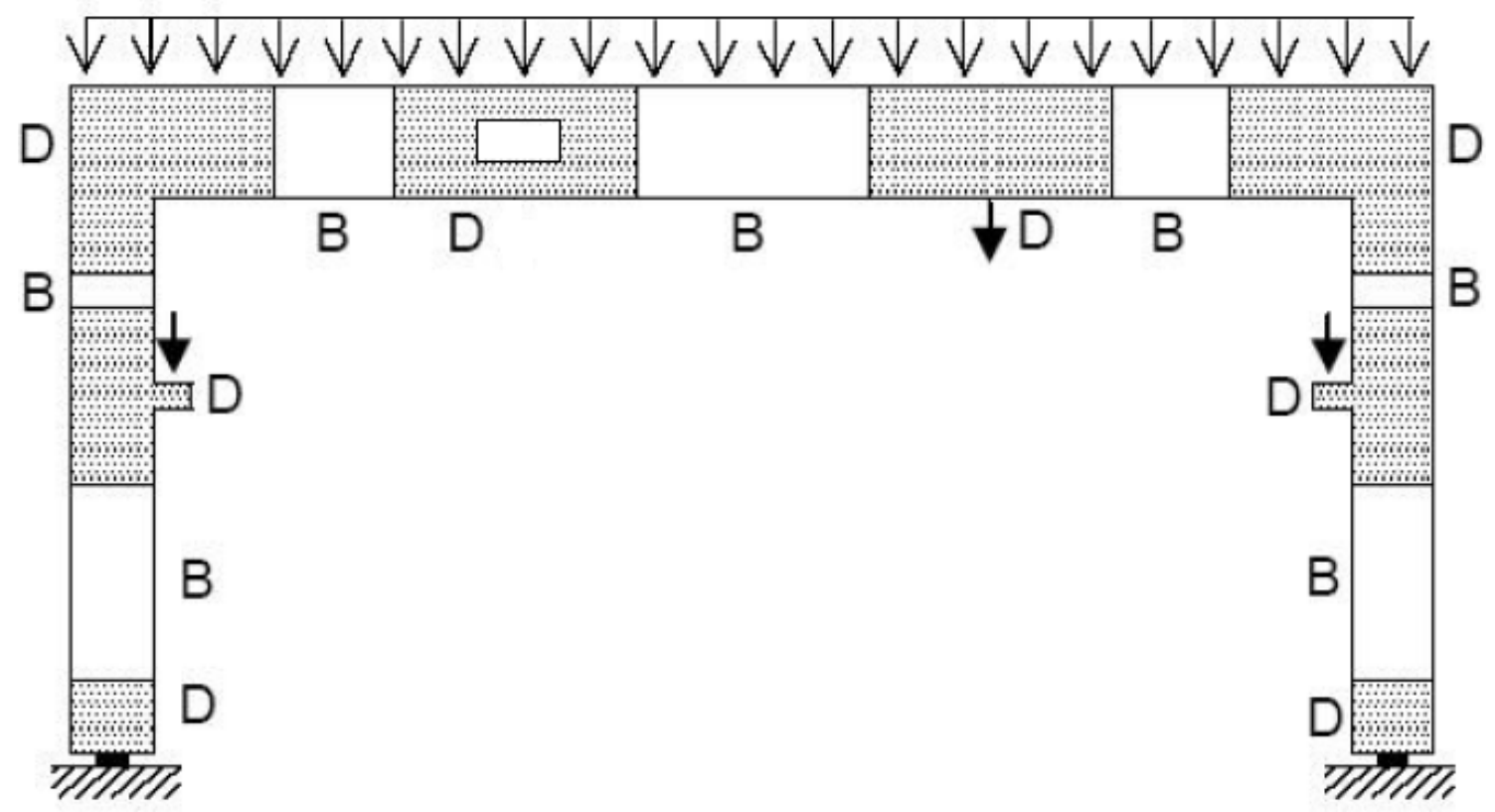

Figura 4.4: Exemplo de regiões B (Bernoulli) e D (Disturbed) para elementos de concreto armado

\subsection{Formulação e ensaios de Vecchio e Collins (1986)}

Vecchio e Collins (1986) desenvolveram um modelo analítico capaz de prever o comportamento de elementos em concreto armado submetidos a esforços de cisalhamento contidos no plano do elemento e tensões axiais. Este modelo foi elaborado com base nos resultados dos ensaios de 30 painéis armados sujeitos a esforços normais e de cisalhamento atuando no plano do elemento, caracterizando assim esforços de membrana, como ilustrado na Figura 4.5. Os painéis foram solicitados através da ação de macacos hidráulicos combinando esforços de cisalhamento puro, compressão ou tração uniaxial, compressão ou tração biaxial. Seu mecanismo pode ser observado na Figura 4.6.

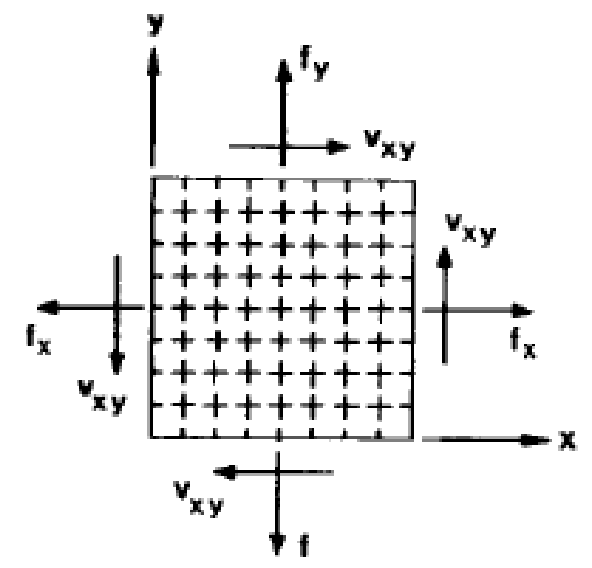

Loading

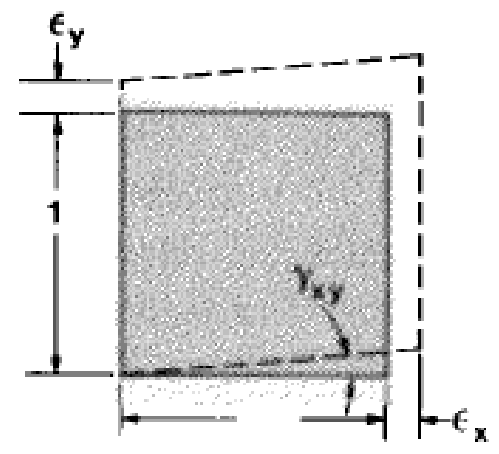

Deformation

Figura 4.5: Carregamentos aplicados e deformações medidas (Vecchio, 1986) 


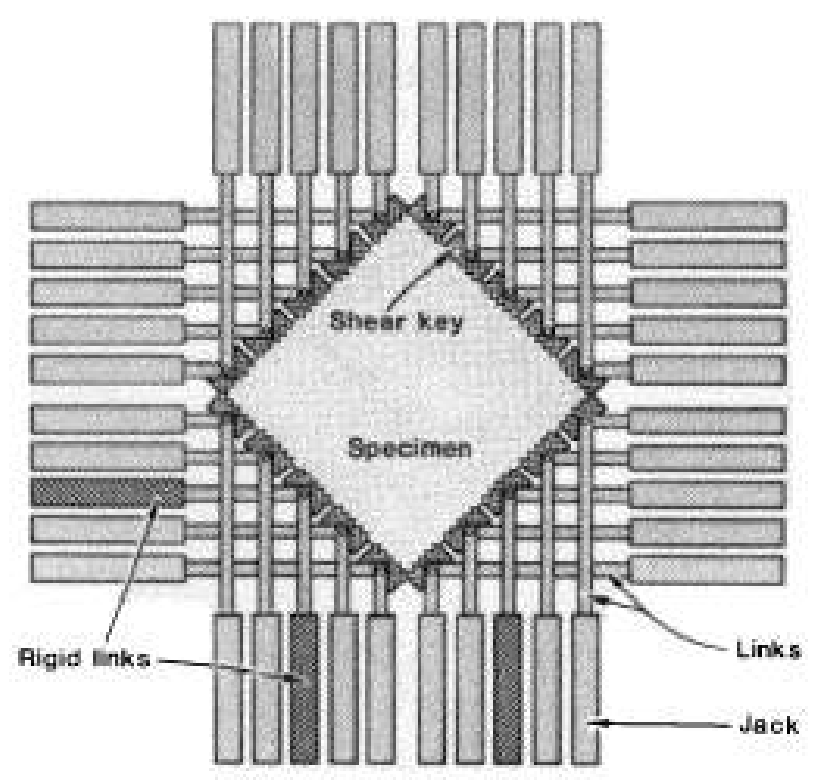

Figura 4.6: Esquema do mecanismo de ensaio dos painéis (Vecchio, 1986)

Os elementos ensaiados possuíam dimensões de $890 \times 890 \times 70 \mathrm{~mm}$, armados com duas camadas de telas soldadas. $O$ carregamento autante no plano das bordas do elemento consiste em tensões axiais $f x$, fy e tensão cisalhante uniforme de $v_{x y}$. Para as deformações normais indica-se $\varepsilon_{x}$ e $\varepsilon_{y}$ e distorção $\gamma_{x y}$ ilustrados na Figura 4.5. A tensão principal de tração é $f_{\mathrm{c} 1}$, a de compressão é $f_{\mathrm{c} 2}$, estando inclinada em relação ao eixo horizontal de $\theta_{\mathrm{c}}$, e a deformação máxima de tração é $\varepsilon_{1}$, a de compressão $\varepsilon_{2}$ conforme Figura 4.7 .

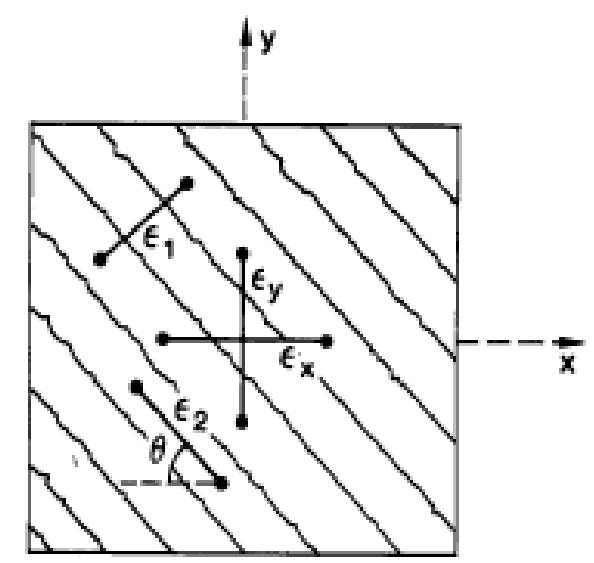

Figura 4.7: Deformações médias no elemento fissurado (Vecchio, 1986) 


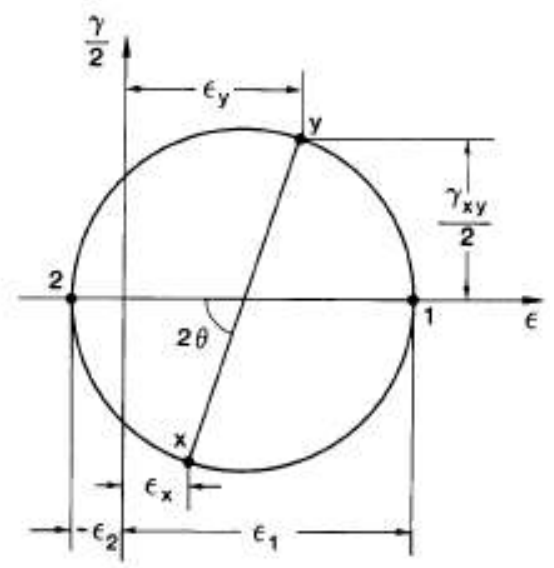

Figura 4.8: Circulo de Mohr para as deformações médias (Vecchio, 1986)

\subsubsection{Condições de compatibilidade}

O método considera as barras solidárias ao concreto e que ambos possuem a mesma deformação, sendo que a armação pode estar pré-tracionada, sendo assim:

$$
\begin{gathered}
\varepsilon_{s x}=\varepsilon_{c x}=\varepsilon_{x} \\
\varepsilon_{s y}=\varepsilon_{c y}=\varepsilon_{y}
\end{gathered}
$$

Com o auxílio do circulo de Mohr para as deformações, Figura 4.8,conhecendo as 3 componentes de deformação $\varepsilon_{x}, \varepsilon_{y}$ e $\gamma_{x y}$, pode se obter a deformação em qualquer direção.

\subsubsection{Condições de equilíbrio}

O carregamento aplicado ao elemento de concreto armado é resistido pelo concreto e pela armação. Conforme o diagrama de corpo livre da Figura 4.9, é possível equacionar equações de equilíbrio para o problema. 


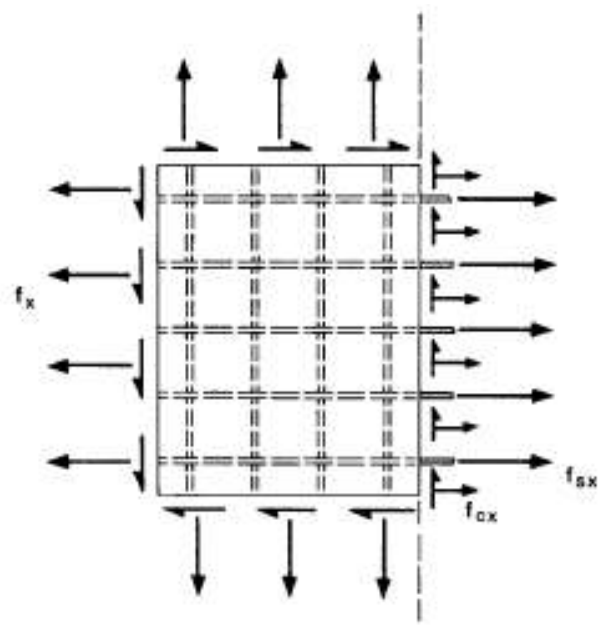

Figura 4.9: Diagrama de corpo livre do elemento analisado (Vecchio, 1986)

Direção x:

$$
\int_{A} f_{x} \cdot d A=\int_{A c} f_{c x} \cdot d A_{c}+\int_{A s x} f_{s x} \cdot d A_{s x}
$$

Na qual:

A - Área da seção transversal;

$A_{c}$ - Área de concreto na seção transversal;

$A_{s x}$ - Área de armação na seção transversal paralela ao eixo x;

$f x$ - Tensão axial na direção x;

fcx - Tensão cisalhante;

fsx - Tensão na armação.

Sendo:

$$
\begin{aligned}
& A \approx A c \\
& A s x=\rho_{s x} \cdot A
\end{aligned}
$$

Temos:

$$
f_{x}=f_{c x}+\rho_{s x} \cdot f_{s x}
$$

De forma equivalente para a direção y temos: 


$$
f_{y}=f_{c y}+\rho_{s y} \cdot f_{s y}
$$

E para a tensão de cisalhamento

$$
\begin{gathered}
v_{s x}=v_{s y}=0 \\
v_{x y}=v_{c x y}
\end{gathered}
$$

Assumindo que

$$
v_{c x}=v_{c y}=v_{c x y}
$$

$O$ estado de tensão do elemento é totalmente definido quando conhecido $f_{c x}, f_{c y}$ e $v_{\text {cxy, }}$, Figura 4.10a.

O circulo de Mohr da Figura 4.10c fornece algumas relações importantes

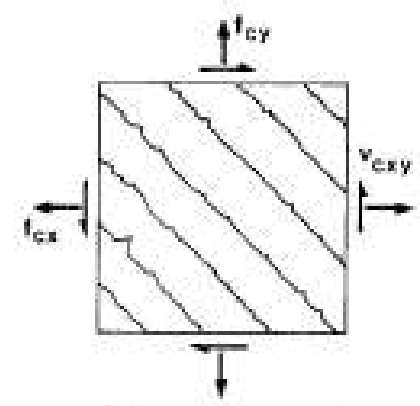

(a) Average Concrato Stresses

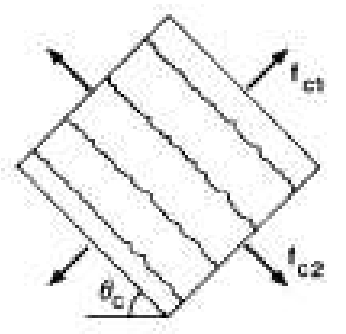

(b) Principal strossos in Concrete

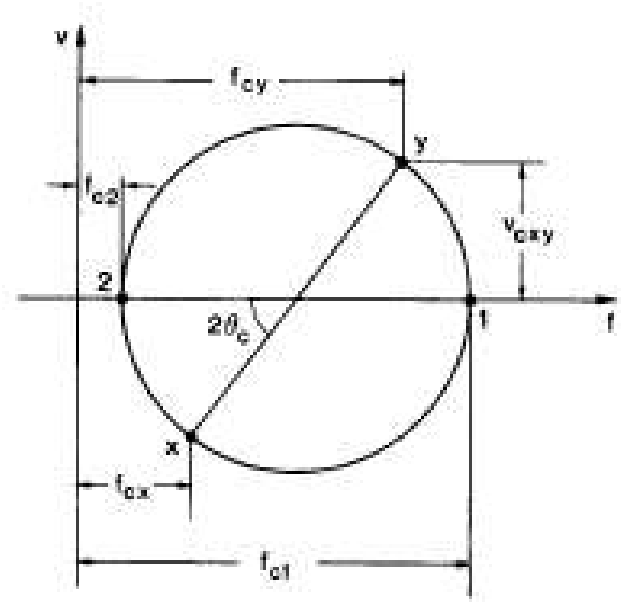

(c) Mohr's Circle for Average Concrete Stresses

Figura 4.10: Tensões no elemento (Vecchio, 1986) 
De acordo com o circulo de Mohr (Figura 4.10), obtêm-se as seguintes relações úteis:

$$
\begin{gathered}
f_{c x}=f_{c 1}=\frac{v_{c x y}}{\operatorname{tg} \theta_{c}} \\
f_{c y}=f_{c 1}-v_{c x y} \cdot \operatorname{tg} \theta_{c}
\end{gathered}
$$

e

$$
f_{c 2}=f_{c 1}-\left(\operatorname{tg} \theta_{c+} \frac{1}{\operatorname{tg} \theta_{c}}\right)
$$

\subsubsection{Relações constitutivas}

As relações constitutivas que relacionam as tensões com as deformações medidas pelos valores médios foram determinadas a partir de ensaios específicos de materiais. Considera-se que as tensões axiais na armação dependem apenas da deforção axial, e adota-se o diagrama billinear com as tensões máximas de escoamento: $f_{y x}$ e $f_{y y}$ para as armações nas direções $x$ e y respectivamente, e desprezando o efeito de pino, ou seja, $v_{s x}$ e $v_{s y}$ nulos.
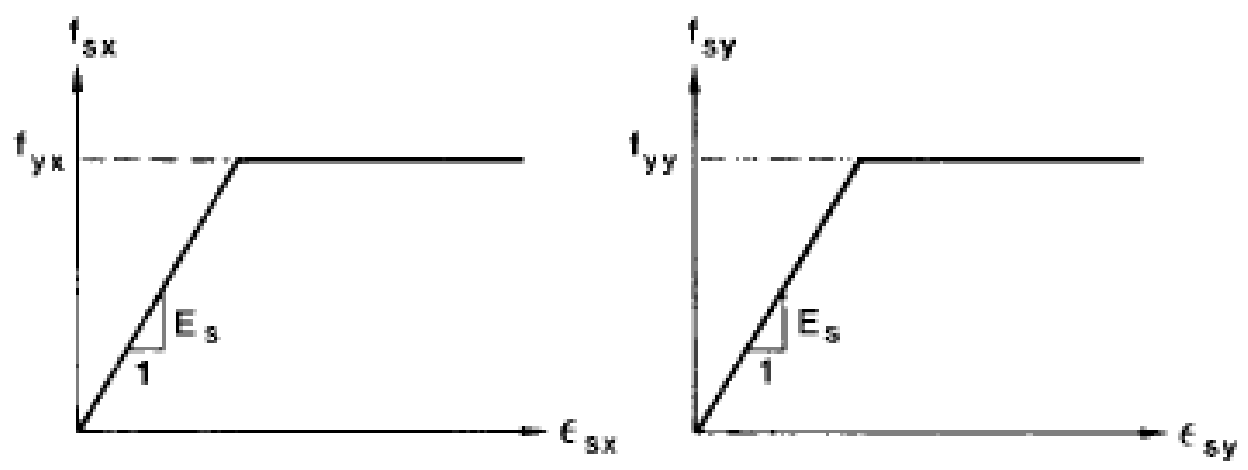

Figura 4.11: Relação tensão $x$ deformação para a armação (Vecchio, 1986)

$$
\begin{aligned}
& f_{s x}=E_{s} \cdot \varepsilon_{x} \leq f_{y x} \\
& f_{s y}=E_{s} \cdot \varepsilon_{y} \leq f_{y y}
\end{aligned}
$$

e

$$
v_{s x}=v_{s y}=0
$$


Em relação ao concreto, assume-se que a direção das tensões principais coincide com a direção das deformações principais.

$$
\theta_{c}=\theta
$$

Os resultados dos ensaios dos painéis possibilitaram a relacionar o campo de tensões no concreto com o campo de deformações, compondo assim as relações de compatibilidade. Para isto, nos ensaios os valores das tensões aplicadas são conhecidos ( $\mathrm{fx}$, fy $\mathrm{e} \mathrm{xy}$ ) e são medidos os valores das deformações $\left(\varepsilon_{x}, \varepsilon_{y}\right.$ e $\left.\gamma_{x y}\right)$. As tensões médias na armação são obtidas a partir da leitura das deformações nas direções longitudinais e transversais e pelas relações constitutivas entre tensão e deformação do material utilizado na armação. Conhecendo as tensões atuantes nas armações e os carregamentos externos impostos é possível calcular as tensões transversais e longitudinais no concreto através das expressões de equilíbrio (4.6) e (4.7). Para a determinação das tensões no concreto que atuam no elemento carregado, além de se saber a priori os carregamentos aplicados, é necessário obter as relações entre as tensões e as deformações. Para isso, cada um dos 30 painéis ensaiados por Collins, e para cada estágio de carregamento, determinou-se o circulo das tensões e o circulo das deformações, conforme ilustrado na Figura 4.12.

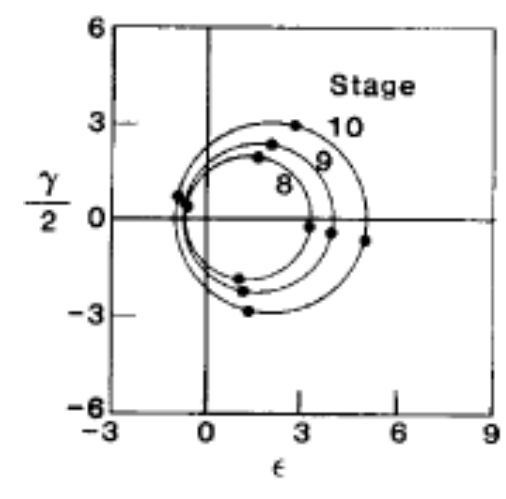

Concrete Strain Circles (millistrains)

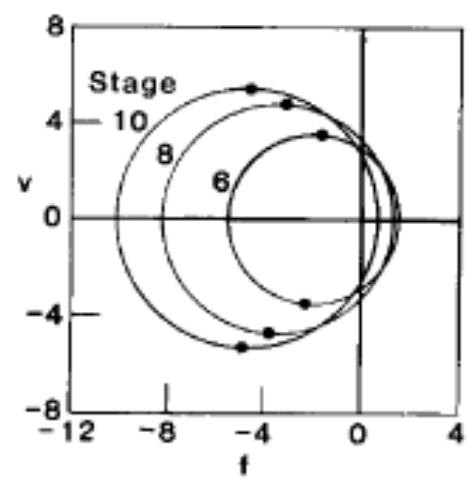

Concrete Stress Circles (MPa)

Figura 4.12: Círculos de tensão e deformação obtidos experimentalmente (Vecchio, 1986)

As relações sugeridas para o comportamento do concreto em termos dos valores médios de tensão e deformação são apresentadas a seguir.

A tensão de compressão principal no concreto $f_{c 2}$ é função não apenas da deformação principal de compressão $\varepsilon_{2}$, mas também da coexistência da tensão principal de tração $\varepsilon_{1}$, ou seja, o concreto fissurado, quando sujeito a altas deformações de tração na direção ortogonal a direção da compressão, torna-se fraco e "amolecido" em comparação ao concreto ensaio em corpos de prova para determinação da resistência à compressão simples. Vide Figura 4.13. 


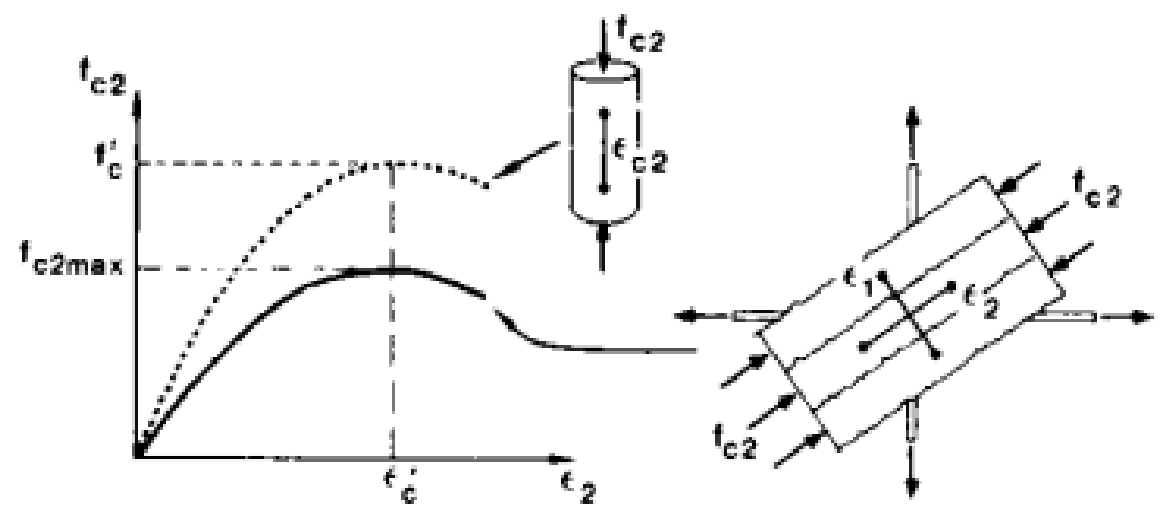

Figura 4.13: Relação tensão $x$ deformação para concreto fissurado a compressão (Vecchio, 1986)

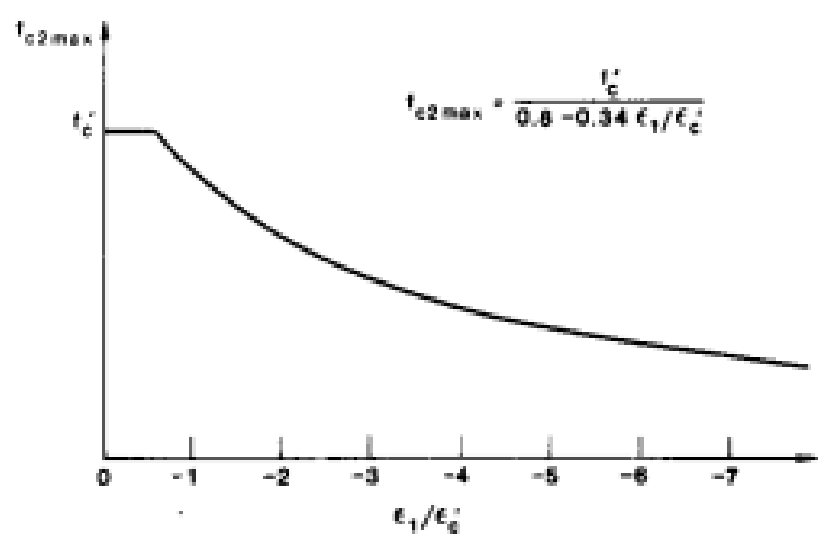

Figura 4.14: Relação proposta para o amolecimento do concreto (Vecchio, 1986)

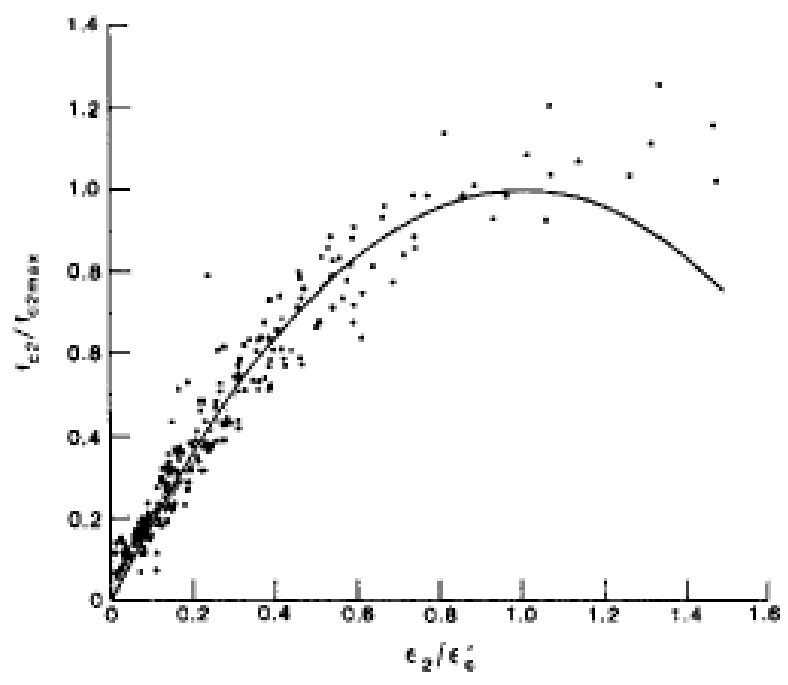

Figura 4.15: Correlação obtida nos diversos estágios de carregamento entre tensão e deformação para o concreto fissurado (Vecchio, 1986) 


$$
f_{c 2}=f_{c 2 \max } \cdot\left[2\left(\frac{\varepsilon_{2}}{\varepsilon_{c}^{\prime}}\right)-\left(\frac{\varepsilon_{2}}{\varepsilon_{c}^{\prime}}\right)^{2}\right]
$$

Na qual:

$$
\frac{f_{c 2 \max }}{f_{c}^{\prime}}=\frac{1}{0,8-0,34 \cdot \frac{\varepsilon_{1}}{\varepsilon_{c}^{\prime}}} \leq 1,0
$$

As relações sugeridas entre a tensão principal média de tração no concreto e a deformação principal média de tração são aproximadamente lineares até a fissuração. Depois disso, a tensão de tração principal média decresce com o aumento dos valores de $\varepsilon_{1}$, conforme ilustrado pela Figura 4.16.
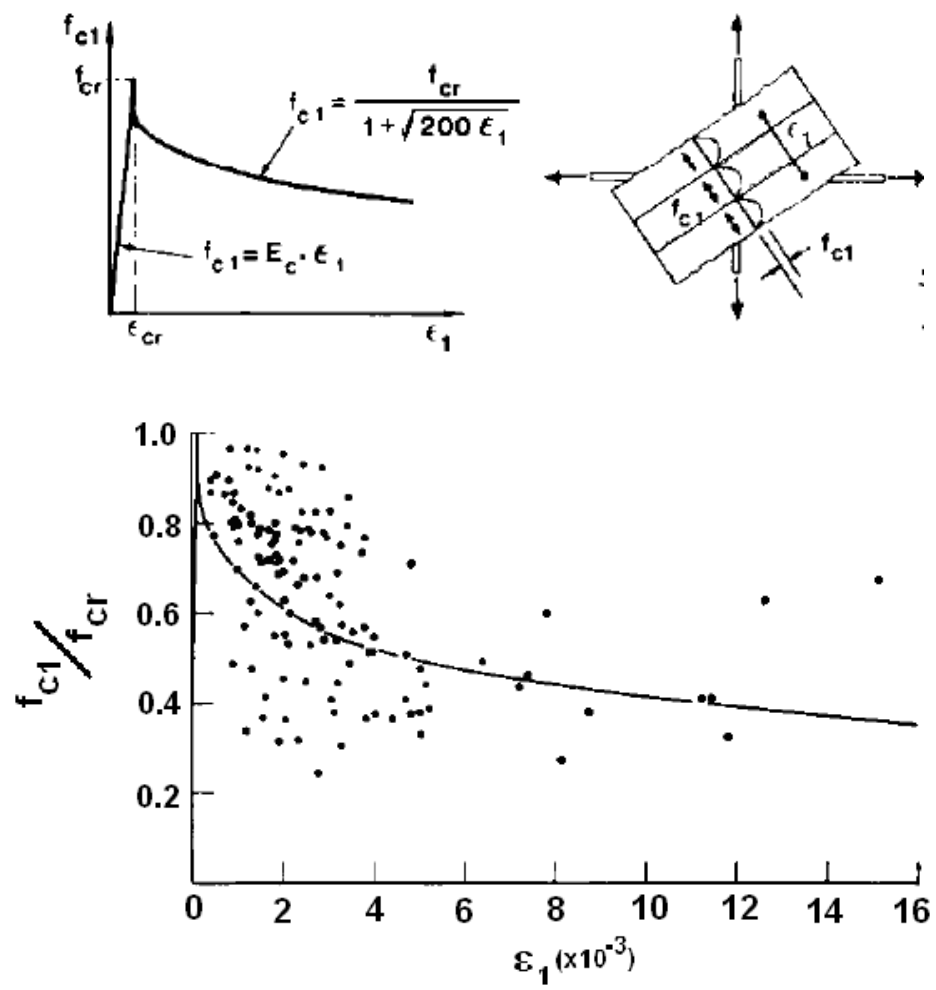

Figura 4.16: Relação entre a tensão média de tração e a deformação média de tração do concreto fissurado (Vecchio, 1986)

Antes da fissuração

$$
f_{c 1}=E_{c} \cdot \varepsilon_{1}
$$


e depois da fissuração

$$
\begin{gathered}
f_{c 1}=\frac{f_{c r}}{1+\sqrt{200 \varepsilon_{1}}} \text { (pequenos elementos) } \\
f_{c 1}=\frac{f_{c r}}{1+\sqrt{500 \varepsilon_{1}}} \text { (grandes elementos) }
\end{gathered}
$$

O autor sugere para a tensão de tração máxima de fissuração

$$
f_{c r}=0,33 \cdot \sqrt{f_{c}^{\prime}} \text { e } \varepsilon_{c r}=\frac{f_{c r}}{E_{c}}
$$

\subsubsection{Transferência de esforços através das fissuras}

O concreto armado fissurado transmite carga através das fissuras de uma maneira complexa, com a abertura e fechamento de fissuras, formação de novas fissuras, transferência de esforço na interface da fissura e variações das tensões nas armações longitudinais e transversais. O método MCFT considera os principais aspectos do comportamento do concreto armado fissurado sem considerar todos esses aspectos. Os complexos estados de tensões e deformações são analisados como valores médios, e as tensões e deformações médias não fornecem informações a respeito das variações locais. Na fissura, a tensão de tração na armação é maior que o valor médio, e entre as fissuras, será menor que o valor médio. As tensões de tração no concreto na região da fissura será zero e será máxima entre fissuras. Essas variações locais são importantes, pois a capacidade última do elemento submetido a tensões biaxiais pode ser determinada pela competência da armação em transferir tração através da fissura.

Definindo-se duas seções, sendo uma na fissura inclinada e a outra no trecho sem fissuras, estas deverão ser estaticamente equivalente, pois 0 carregamento externo é idêntico, conforme mostrado na Figura 4.17. A perda da capacidade resistiva à tração do concreto deverá ser compensada pelo acréscimo da tensão nas armações, ou se as armações já estiverem escoando, pelo aumento da tensão cisalhamento na fissura através do mecanismo do imbrica mento dos agregados. 


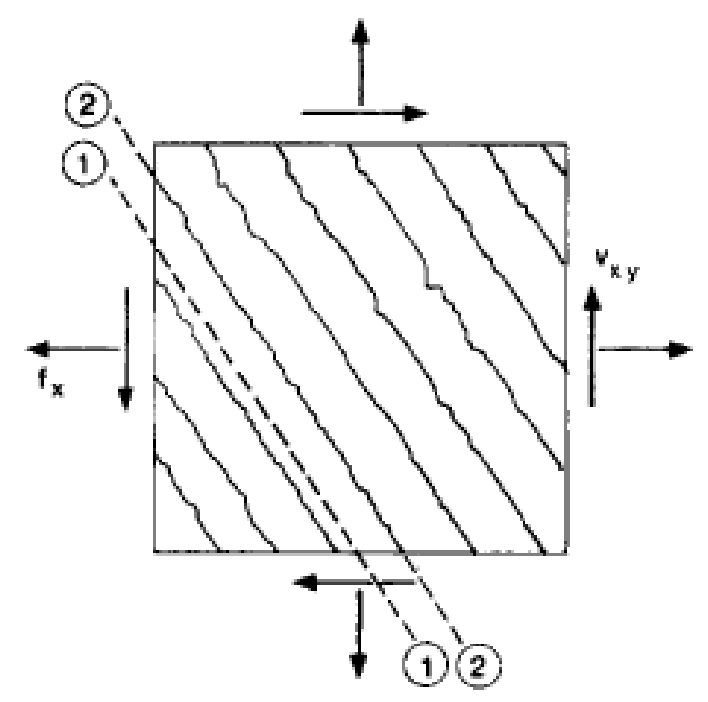

(a) Stresses Applied to Cracked Element

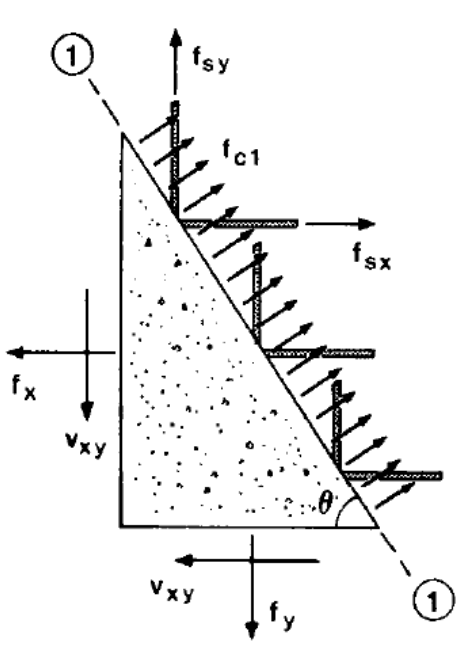

(b) Calculated Average

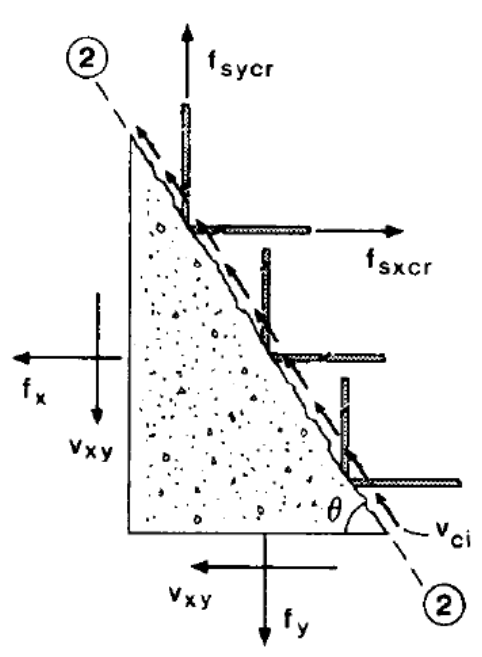

(c) Local Stresses

Figura 4.17: Comparação entre as tensões locais na fissura e as tensões médias calculadas (Vecchio, 1986)

Definindo a equivalência entre os esforços nos planos 1 e 2 , e equacionando o equilíbrio de forças na direção do eixo-y, obtém-se a equação (4.22) que limita a tensão de tração máxima média no concreto para que seja possível transferir os esforços cisalhantes na seção da fissura.

$$
f_{c 1} \leq v_{c i} \cdot \operatorname{tg} \theta+\rho_{s y} \cdot\left(f_{s y c r}-f_{s y}\right)
$$

Supondo a armação transversal de cisalhamento escoando

$$
f_{c 1} \leq v_{c i} \cdot \operatorname{tg} \theta
$$

Estabelecendo o equilíbrio de forças na direção de eixo-x, obtém-se a equação (4.24) que verifica a tensão máxima na armação longitudinal na seção da 
fissura para que seja possível a transferência de esforços cisalhantes na seção da fissura.

$$
f_{s x c r}=f_{s x}+\left(f_{c 1}+\frac{v_{c i}}{\operatorname{tg} \theta}\right) \cdot \frac{1}{\rho_{s x}} \leq f_{y x}
$$

Como para a maioria dos concretos de resistência normal, a fissura irá ocorrer na interface entre argamassa e agregado, a superfície fissurada será rugosa e poderá transferir esforços cisalhantes através do imbrica mento do agregado, conforme ilustrado na Figura 4.18.

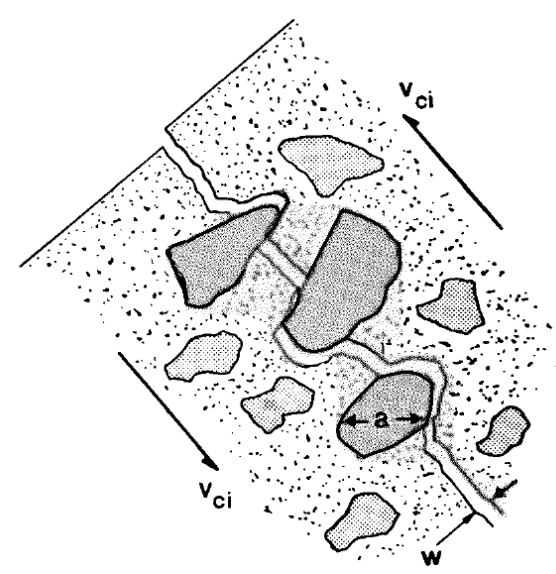

Figura 4.18: Transferindo tensão de cisalhamento ao longo da fissura por imbrica mento dos agregados (Vecchio, 1986)

A relação entre a tensão de cisalhamento na fissura $v_{\mathrm{ci}}$ e a largura da fissura $w$, foi estudada por Walraven, J. C. (1982) apud Vecchio e Collins (1986) e, baseada nos estudos de Walraven, Vecchio e Collins (1989), propõe a seguinte equação para a determinação da tensão cisalhante na fissura:

$$
v_{c i}=\frac{0,18 \sqrt{f_{c}^{\prime}}}{0,31+\frac{24 w}{a+16}}
$$

Na qual:

a - Máximo diâmetro do agregado, em mm; 
$f_{\mathrm{C}}-$ Resistência do concreto, em MPa

$w$ - Largura da fissura, em $\mathrm{mm}$.

A largura da fissura $w$ pode ser estimada como sendo:

$$
w=\varepsilon_{1} \cdot S_{m \theta}
$$

Na qual:

$s_{m \theta}$ - Espaçamento médio entre fissuras numa inclinação $\theta$ da armação longitudinal;

$\varepsilon_{1}$ - Deformação principal de tração.

O espaçamento $s_{\mathrm{m} \theta}$ depende da capacidade da armação longitudinal e transversal de controlar a abertura da fissura, para isso é sugerido que:

$$
s_{m \theta}=\frac{1}{\frac{\sin \theta}{s_{m l}}+\frac{\cos \theta}{s_{m v}}}
$$

Sendo que $s_{\mathrm{ml}}$ e $s_{\mathrm{mv}}$ são os espaçamentos entre fissuras controladas pelas características da armação longitudinal e vertical, respectivamente. Portanto, $s_{\mathrm{ml}}$ é o espaçamento médio entre fissuras que resulta de uma solicitação longitudinal de tração, enquanto que $s_{\mathrm{mv}}$ é o espaçamento médio entre fissuras que resulta de uma solicitação transversal de tração

\subsubsection{Aplicação do MCFT para análise de elementos de concreto armado}

O modelo desenvolvido por Vecchio e Collins (1986) considera o concreto fissurado um novo material com suas próprias relações entre tensão e deformação. As equações de equilíbrio e compatibilidade são formuladas em termos de tensões e deformações médias. Este modelo foi chamado de "Modified compression field theory" (MCFT). O MCFT repercutiu na sociedade acadêmica de forma positiva, sendo que este método, posteriormente, influenciou as formulações das normas AASTHO LRFB bridge design specifications (2007) e a Canadian Standards Association (CSA A23 - 2004), além de métodos de predição de outros autores. 

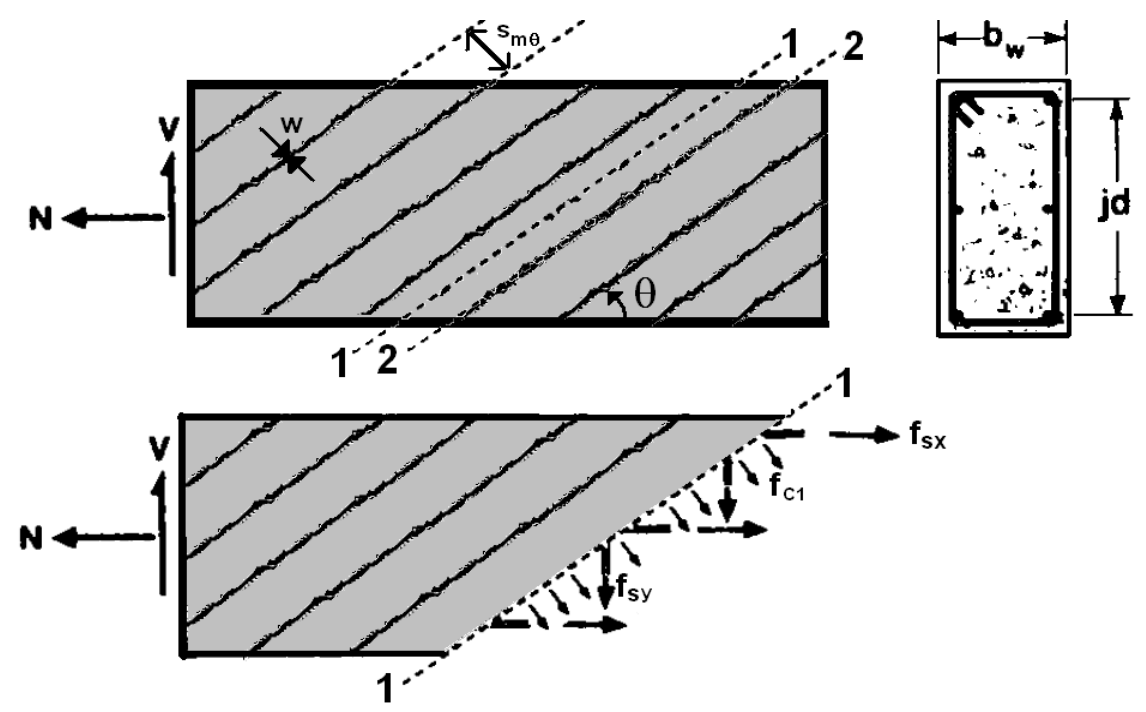

Figura 4.19: Esforços ao longo da fissura (adaptado de Bhide, 1989)

Assumindo que a força de cisalhamento $V$ distribui-se uniformemente na área entre $b_{\mathrm{w}}$ e $j_{\mathrm{d}}$ e baseado no equilíbrio de forças verticais do elemento da Figura 4.19 obtém-se a seguinte equação de equilíbrio:

$$
V=\frac{f_{c 1} \cdot b w \cdot j d}{\operatorname{tg} \theta}+\frac{A s y \cdot f s y}{s} \cdot \frac{j d}{\operatorname{tg} \theta}=V_{c}+V_{s y}
$$

Sendo:

$b_{w}$ - Largura do elemento;

$j_{\mathrm{d}}-$ Altura útil de cisalhamento;

$A_{y}$ - Área de armação transversal de cisalhamento para espaçamento entre estribos de s;

$s$ - Espaçamento entre estribos;

$f_{y}$ - Tensão de tração na armação transversal de cisalhamento;

$f_{c 1}$ - Tensão principal de tração no concreto.

Pode-se observar na que a resistência ao cisalhamento do elemento em concreto armado é a soma de uma parcela de contribuição do concreto que depende da tensão de tração principal do concreto e outra de outra parcela que é a contribuição da armação transversal de cisalhamento e sua tensão de tração. 
Utilizando as equações (4.19), (4.20) e (4.28), pode-se descrever que:

$$
v=\frac{0,33 \sqrt{f_{c}^{\prime}}}{1+\sqrt{500 \varepsilon_{1}}} \cdot \frac{1}{\operatorname{tg} \theta}+\rho_{s y} \cdot f_{s y} \cdot \frac{1}{\operatorname{tg} \theta}
$$

Na qual:

$$
\rho_{s y}=\frac{A_{s y}}{b w . s}
$$

A equação (4.29) pode ser rescrita na seguinte forma:

$$
v=\underbrace{\beta \cdot \sqrt{f_{c}^{\prime}}}_{v_{c}}+\underbrace{\rho_{s y} \cdot f_{s y} \cdot \cot \theta}_{v_{s}}
$$

Na qual:

$$
\beta=\frac{0,33 \cdot \cot \theta}{1+\sqrt{500 \varepsilon_{1}}}
$$

Existe a limitação da tensão de tração máxima média no concreto para que seja possível transferir os esforços cisalhantes na seção da fissura, que pode ser expressa através das equações (4.23) e (4.25), resultando em:

$$
\beta \leq \frac{0,18}{0,31+\frac{24 w}{(a+16)}}
$$

$\mathrm{Na}$ qual a largura da fissura $w$ é calculada pelo produto do espaçamento entre fissuras e a deformação de tração $\varepsilon_{1}$, conforme equação (4.26) $\bigcirc$ termo a representa o diâmetro máximo do agregado grosseiro em $\mathrm{mm}$. Por simplificação, o cálculo do espaçamento entre fissuras, conforme na equação (4.27), considerar-se-á $S_{\mathrm{ml}}$ como sendo a distância vertical entre as barras horizontais alinhadas na direção $\times$ (axial) e $s_{\text {mv }}$ pode ser adotado com sendo a distância horizontal entre as barras verticais alinhadas na direção y. 
Para elementos sem armação transversal de cisalhamento $s_{\mathrm{m} \theta}$ será igual a $s_{x} / \sin \theta$ e a equação (4.33) pode ser expressa da seguinte forma:

$$
\beta \leq \frac{0,18}{0,31+0,686 . s_{x e} \cdot \frac{\varepsilon_{1}}{\sin \theta}}
$$

Na qual

$$
s_{x e}=\frac{35 . s_{m l}}{a+16}
$$

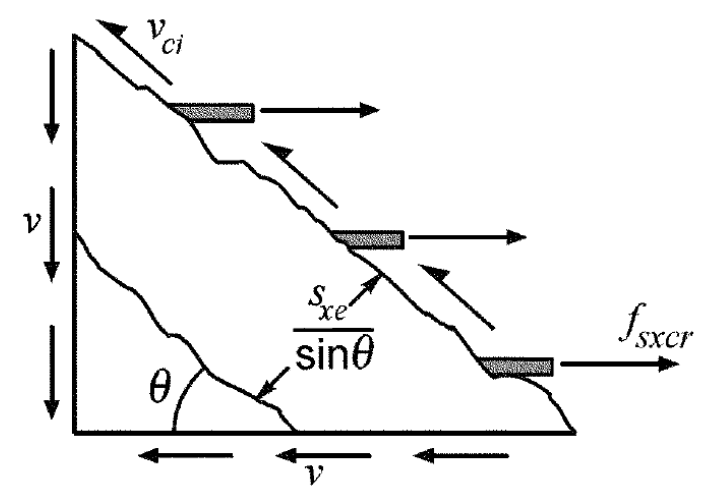

Figura 4.20: Esforços na seção da fissura em elementos ser armação transversal de cisalhamento (Vecchio, 1986)

Ressalta-se que para elementos feitos com concreto de alta resistência $\left(f_{c k}>70\right.$ $\mathrm{MPa}$ ) a fissura tende a passar pelos agregados, e não mais os contornando, e, nesses casos, deve-se considerar o diâmetro máximo do agregado a igual a zero.

Para elementos sem armação transversal de cisalhamento, o valor limite para $\beta$, que resulta na máxima capacidade resistente aos esforços de cisalhamento, irá ocorrer quando as equações (4.32) e (4.34) resultarem no mesmo valor para $\beta$.

Com isso obtém-se a seguinte equação: 


$$
\tan \theta=\frac{0,568+1,258 \cdot s_{x e} \cdot \varepsilon_{1} / \sin \theta}{1+\sqrt{500 \varepsilon_{1}}}
$$

Fixando-se alguns valores para $S_{x e}$, é possível correlacionar $\theta$ e $\varepsilon_{1}$, resultando no seguinte gráfico:
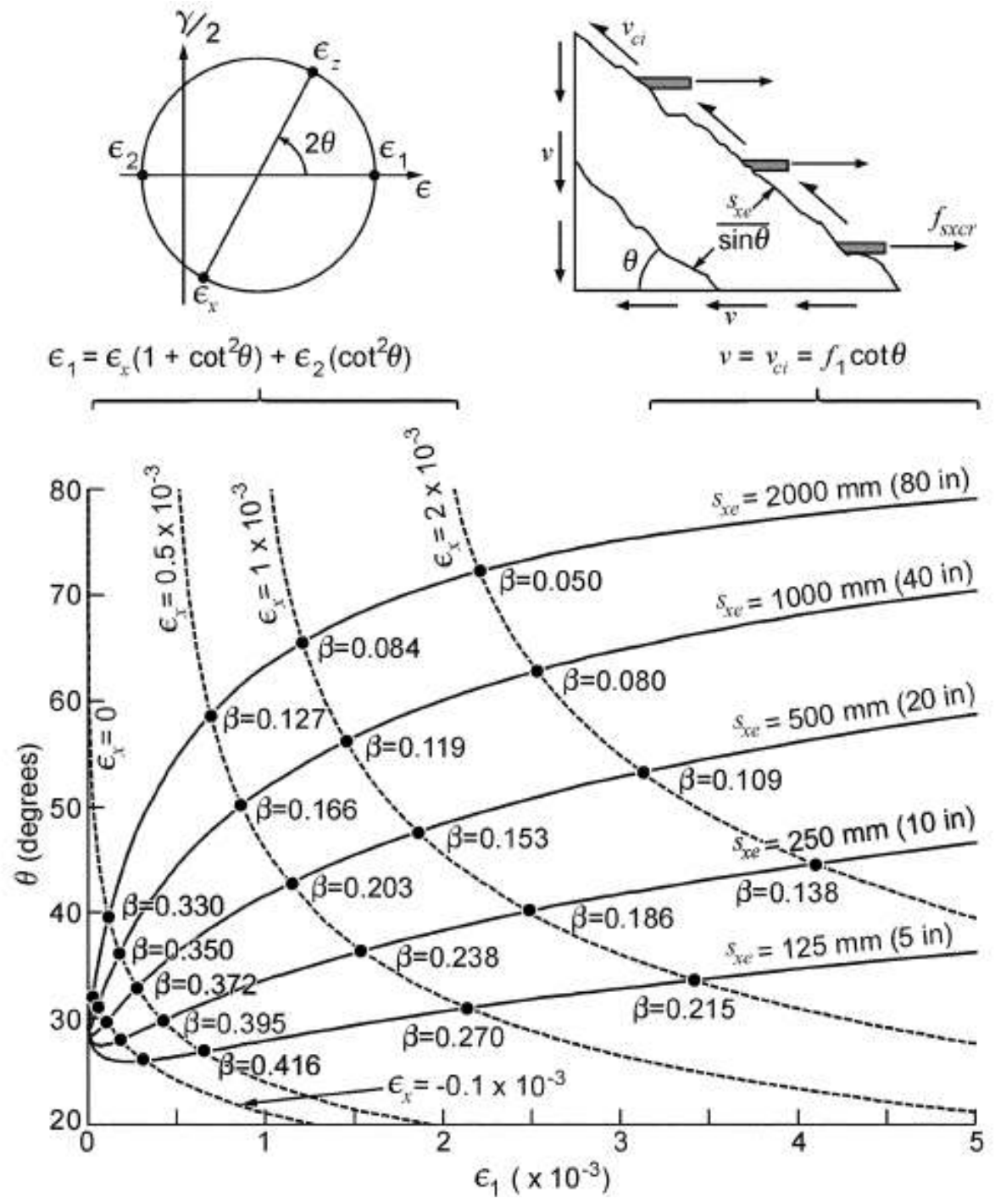

Figura 4.21: Correlação entre $\theta, \varepsilon_{1}, \varepsilon_{x}$, para alguns valores de $s_{x e}(B e n t z, 2006)$

Como o valor de $\varepsilon_{1}$ não está determinado, para relacionar as deformações $\varepsilon_{\mathrm{x}} \mathrm{e}$ $\varepsilon_{1}$, utilizam-se algumas equações obtidas através da análise do circulo de Mohr (Figura 4.22) para as deformações, considerando que a inclinação das tensões principais é a mesma das deformações principais no concreto. 


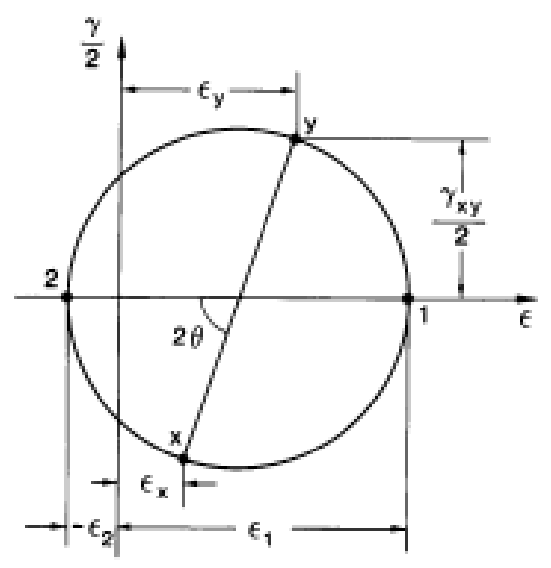

Figura 4.22: Circulo de Mohr para as deformações médias (Vecchio, 1986)

Se a deformação principal de tração, a deformação principal de compressão e o ângulo de inclinação são conhecidos, é possível obter as deformações em qualquer direção, valendo-se das equações seguintes, (onde, porém nenhumas das tensões principais são conhecidas):

$$
\begin{aligned}
& \varepsilon_{x}=\frac{\varepsilon_{1} \cdot \tan ^{2} \theta+\varepsilon_{2}}{1+\tan ^{2} \theta} \\
& \varepsilon_{y}=\frac{\varepsilon_{1}+\varepsilon_{2} \cdot \tan ^{2} \theta}{1+\tan ^{2} \theta}
\end{aligned}
$$

A equação (4.37)pode ser reescrita isolando a deformação principal de tração $\varepsilon_{1}$ :

$$
\varepsilon_{1}=\varepsilon_{x}\left(1+\cot ^{2} \theta\right)+\varepsilon_{2} \cdot \cot ^{2} \theta
$$

Bentz et al (2006) apresentaram algumas aproximações e considerações que relacionam $\varepsilon_{1}, \varepsilon_{\mathrm{x}}$ e $\theta$, compondo a versão simplificada do MCFT, que possibilita estimar a resistência ao cisalhamento de um elemento de maneira simples e não necessita de métodos iterativos, como no MCFT original.

A primeira simplificação proposta é desprezar a tensão de compressão vertical do concreto, $f_{c y}$, pois o elemento utilizado para modelar uma seção transversal inteira da viga não é afetado significativamente por uma compressão ou tração aplicados na superfície inferior ou superior da viga. Essa tensão é 
extremamente importante de regiões conhecidas como regiões de descontinuidade ("D-regions").
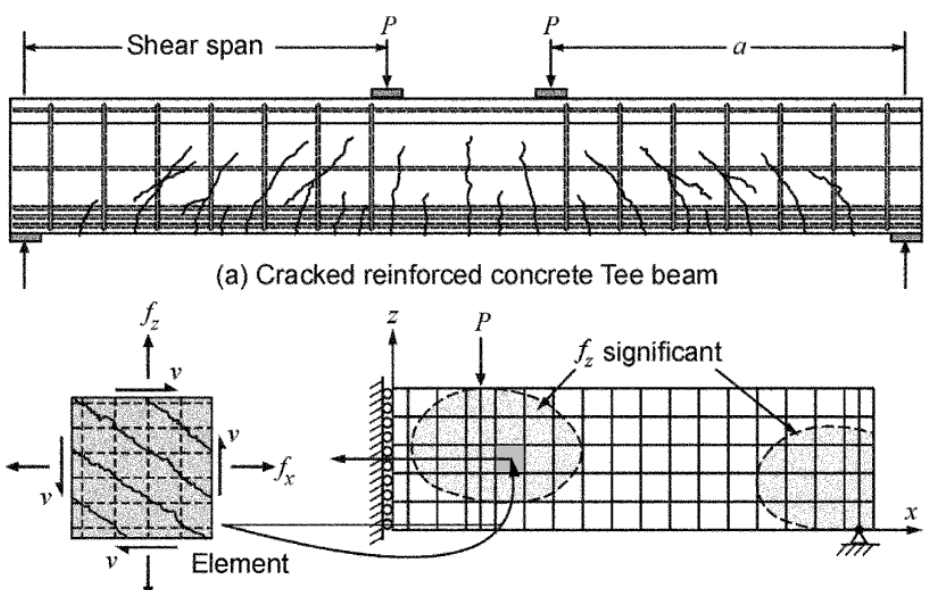

(b) finite element model of beam

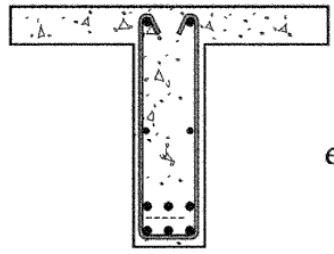

Cross-section

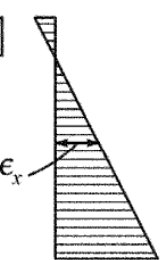

Longitudinal strain $V=V_{n}$

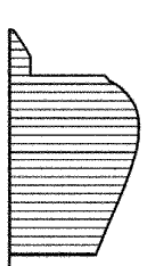

Shear

stress

$V=V_{n}$

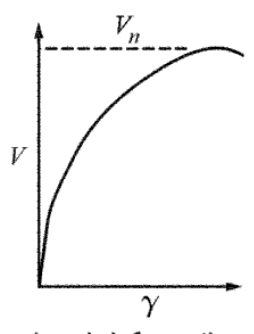

Load-deformation

plot

(c) model of beam section

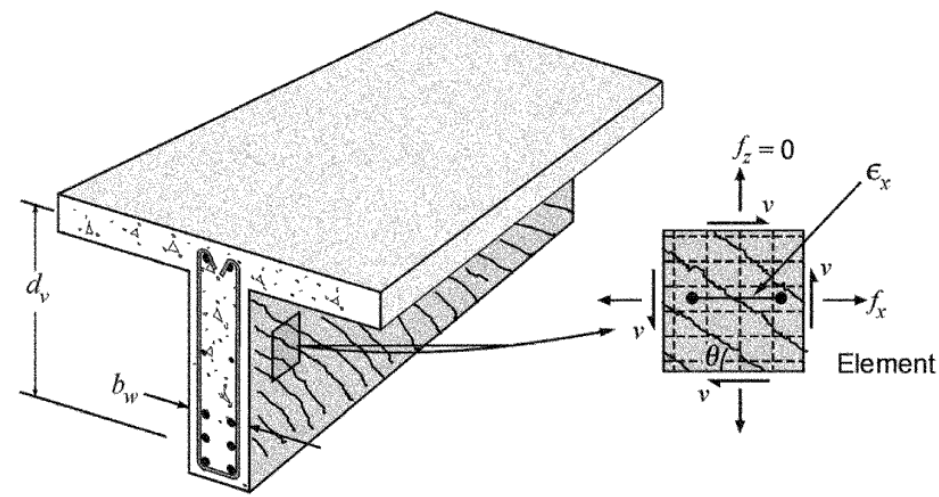

Figura 4.23: Modelo simplificado (Bentz, 2006)

Conforme mostrado na Figura 4.23, as regiões D são extremamente afetadas pelas forças aplicadas, enquanto as regiões conhecidas como regiões de viga de Bernoulli ("B-regions") são menos afetadas. Sendo assim, as equações (4.12) e (4.13) se reduzem a:

$$
f_{c 2}=f_{c 1} \cdot \cot ^{2} \theta
$$


A segunda simplificação é considerar que a tensão de compressão dos elementos será pequena e possível de estimar pela relação:

$$
f_{c 2}=E_{c} \cdot \varepsilon_{2}
$$

Bentz et al (2006) sugerem que:

$$
E_{c}=4950 \sqrt{f_{c}^{\prime}}
$$

A partir das equações(4.39) à (4.42) pode-se obter as seguintes equações:

$$
\begin{gathered}
\varepsilon_{2}=\frac{f_{c 2}}{E_{c}}=\frac{f_{c 1} \cdot \cot ^{2} \theta}{E_{c}}=\frac{0,33 \sqrt{f_{c}^{\prime}}}{4950 \sqrt{f_{c}^{\prime}}} \cdot \cot ^{2} \theta \\
\varepsilon_{1}=\varepsilon_{x}\left(1+\cot ^{2} \theta\right)+\frac{\cot ^{4} \theta}{1500\left(1+\sqrt{500 \varepsilon_{1}}\right)}
\end{gathered}
$$

A maneira pela qual a equação geométrica relaciona $\varepsilon_{1}$ e $\theta$ para diferentes valores de $\varepsilon_{x}$ é mostrada na Figura 4.21. Os pontos de intersecção das linhas que representam valores dados de $\varepsilon_{\mathrm{x}}$ e $s_{\mathrm{xe}}$ definem os valores de $\theta$ e $\varepsilon_{1}$, que simultaneamente obedecem a ambas as equações (4.36) e (4.44). Esses pontos de intersecção podem ter o valor de $\beta$ expresso utilizando a equação (4.32), vide Figura 4.21. Pode se observar que, com o aumento do espaçamento das fissuras $s_{x e}$, os valores de $\beta$, e por consequência a resistência ao cisalhamento, diminuem. Um fator observado é que para vigas grandes armadas que não contém armação transversal de cisalhamento a tensão cisalhamento na ruptura é menor do que em vigas menores com geometria semelhante. Este fenômeno é conhecido como efeito de escala no cisalhamento ("Size effect in shear").

$O$ valor de $\beta$ no MCFT para elementos sem armação transversal de cisalhamento depende de $\varepsilon_{\mathrm{x}}$ e do parâmetro do espaçamento das fissuras $\mathrm{s}_{\mathrm{xe}}$. Bentz et al (2006) definem que o primeiro efeito é o chamado de fator do efeito de deformação ("Strain effect factor") e o segundo de efeito de escala ("Size effect"). Os dois efeitos não são independentes, mas no método simplificado 
do MCFT, a interdependência é ignorada e assume-se que $\beta$ é obtido pelo simples produto do fator do efeito de deformação e fator do efeito de escala. Os valores de $\beta$ obtidos pela equação (4.45) são comparados com os valores obtidos pelo método completo do MCFT e seus valores estão expressos na Figura 4.24. Pode-se observar que para valores de $e_{x} e s_{x e} 0$ método simplificado fornece valores conservativos.

$$
\beta=\underbrace{\frac{0,4}{1+1500 \varepsilon_{x}}}_{\begin{array}{c}
\text { Efeito de } \\
\text { Deformação }
\end{array}} \cdot \underbrace{\frac{1300}{1000+s_{x e}}}_{\begin{array}{c}
\text { Efeito de } \\
\text { Escala }
\end{array}}
$$

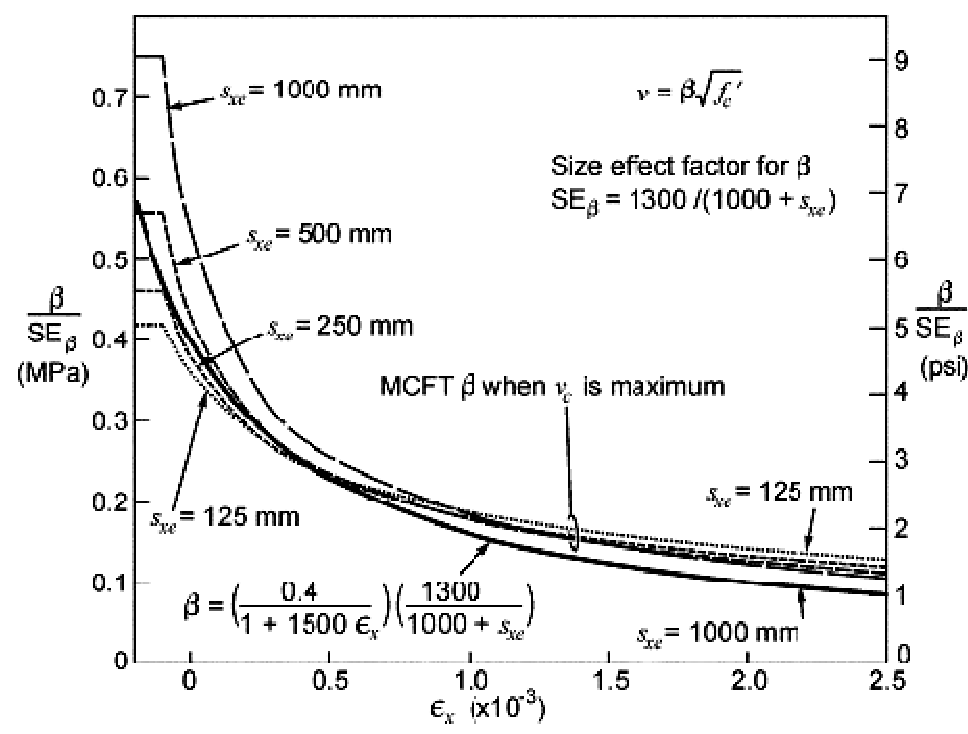

Figura 4.24: Comparação entre o método simplificado e o MCFT, para valores de $\beta$ (Bentz, 2006)

O método simplificado propõe a seguinte expressão para se estimar o ângulo de inclinação da fissura $\theta$.

$$
\theta=\underbrace{\left(29^{\circ}+7000 \varepsilon_{x}\right)}_{\begin{array}{c}
\text { fator de } \\
\text { deformação }
\end{array}} \cdot \underbrace{\left(0,88+\frac{s_{x e}}{2500}\right)}_{\text {efeito de escala }} \leq 75^{\circ}
$$

A equação (4.46) novamente apresenta o produto de dois fatores 0 de deformação e de efeito de escala. Os ângulos fornecidos por essa equação são comparados aos valores obtidos pelo MCFT e ilustrados na Figura 4.25. Percebe-se que para membros sem armação transversal de cisalhamento é 
conservador subestimar o ângulo, pois isto irá aumentar a tensão na armação longitudinal. Isso pode ser observado na Figura 4.25, pois os valores de $\theta$ são conservadores para aproximadamente todas as combinações de $s_{\mathrm{xe}} \mathrm{e} \varepsilon_{\mathrm{x}}$.

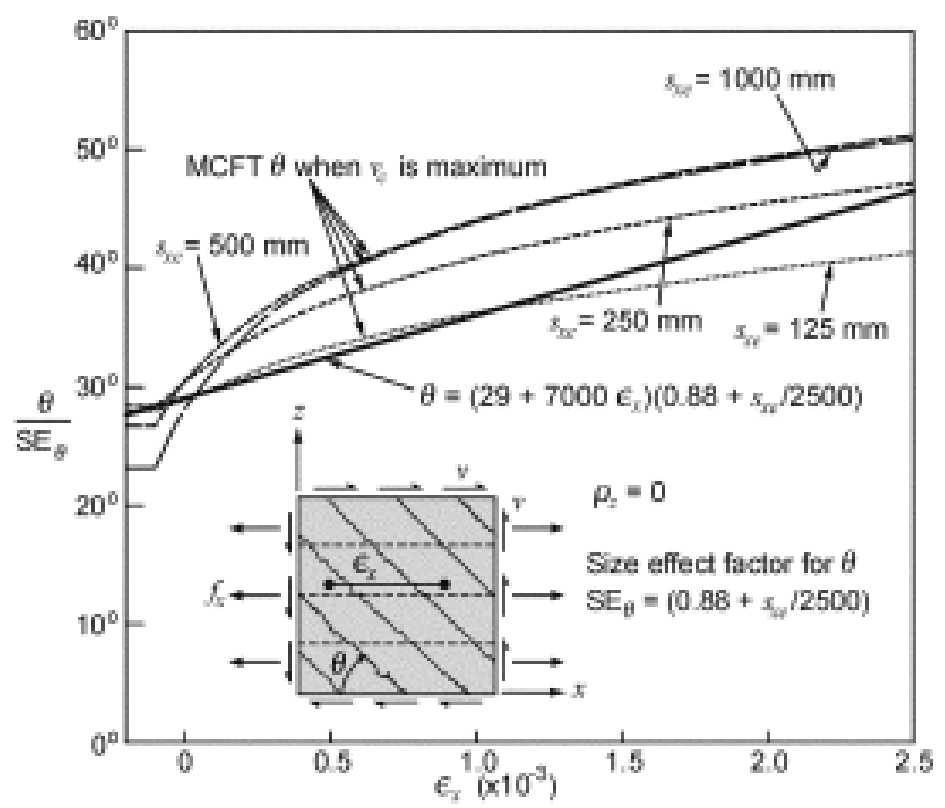

Figura 4.25: Comparação entre o método simplificado e o MCFT, para valores de $\theta$ (Bentz, 2006)

Para os elementos com armação longitudinal e transversal o método completo do MCFT prevê uma variação grande em relação à magnitude das tensões $v_{\mathrm{c}} \mathrm{e}$ $v_{s}$. Bentz et al (2006) ressalta que após o escoamento do aço dos estribos, o ângulo da fissura torna-se menor, aumentando $v_{s}$. Porém, ao mesmo tempo, o aumento de $\varepsilon_{1}$ irá diminuir $\circ V_{c}$, ou seja, com o abatimento do ângulo da biela ou ângulo da fissura, aumenta-se a solicitação do concreto à compressão e a solicitação da armação longitudinal e, com isso, $\varepsilon_{\mathrm{x}}$ aumentará. Por conseguinte, $\varepsilon_{1}$ aumentará, diminuindo assim as parcelas de contribuição ao cisalhamento do concreto e aumentado a parcela de contribuição da armação.

A aproximação efetuada para a determinação dos parâmetros $\theta$ e $\beta$, equivale a obter uma aproximação para $\theta$ que seja maior que as prevista pelo método completo do MCFT, minorando a parcela de contribuição da armação ao cisalhamento, pois esta é diretamente proporcional a cotangente de $\theta$. Para $o$ parâmetro $\beta$ a aproximação equivale a estimar valores inferiores aos obtidos pelo método MCFT, resultando na minoração da parcela de contribuição do concreto ao cisalhamento, pois este é diretamente proporcional a $\beta$.

A manipulação algébrica efetuada na determinação das equações (4.45) e (4.46) possibilitaram utilizá-las também para o caso de elemento armado com armação transversal de cisalhamento, considerando que o espaçamento entre fissuras inclinadas será sempre menor que $300 \mathrm{~mm}$, e portanto adotar $\mathrm{S}_{\mathrm{xe}}$ igual a $300 \mathrm{~mm}$ nas equações (4.45) e (4.46) será conservador. A Figura 4.26 compara os valores obtidos para $\beta$ obtidos pelo MCFT e pela equação (4.45). 
Nota-se aí que os valores são conservadores para a maior parte do intervalo de $\varepsilon_{\mathrm{x}}$, porém, para valores menores de $\varepsilon_{\mathrm{x}}$, os valores estimados não são conservadores, o que segundo Bentz et al (2006) é parcialmente compensado pelos valores conservadores de $\theta$ para pequenos $\varepsilon_{\mathrm{x}}$.
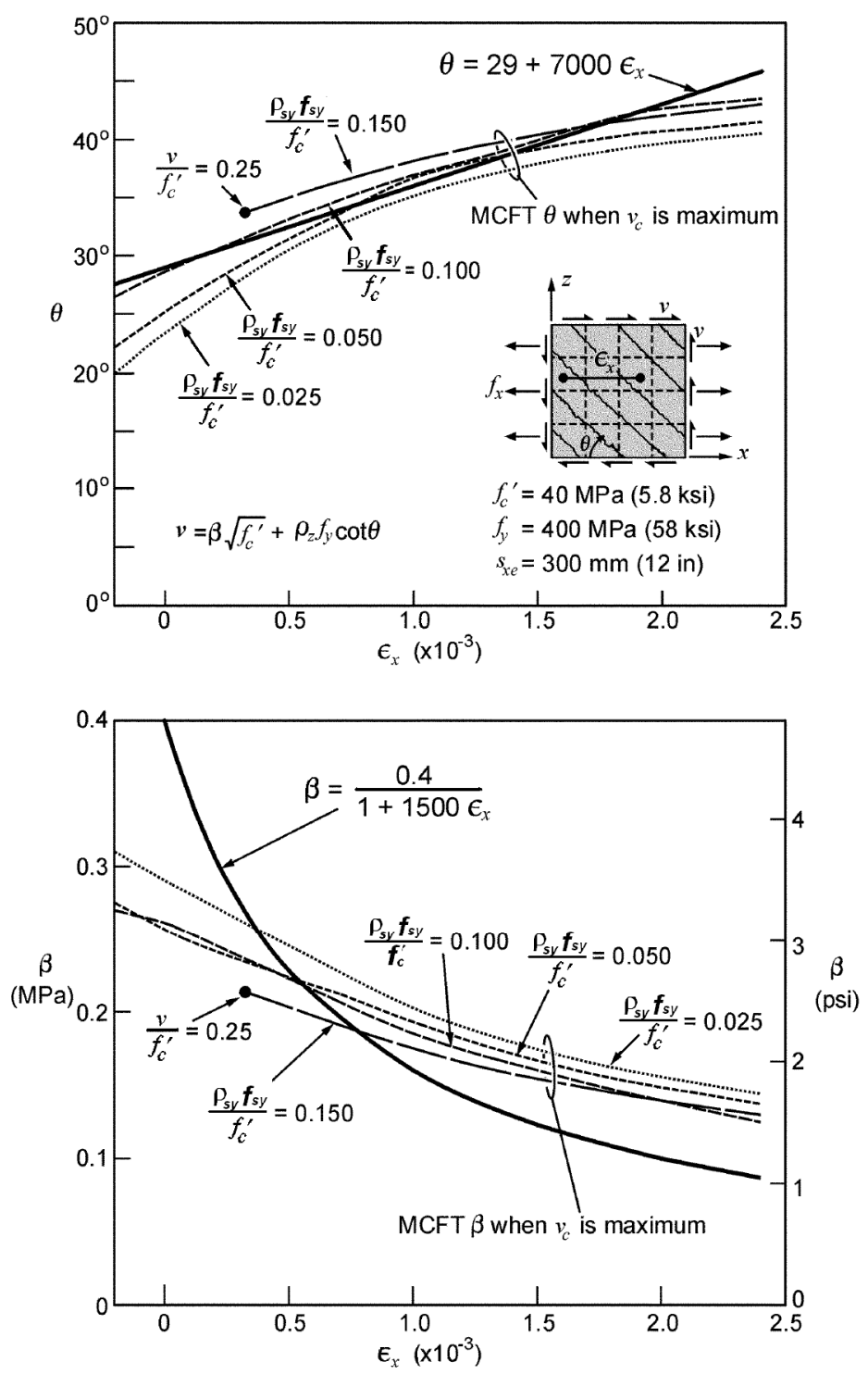

Figura 4.26: Comparação entre o método simplificado e o MCFT, para elementos com armação transversal de cisalhamento (Bentz, 2006) 


\subsection{Formulação da AASHTO-LRFD - Bridge design specifications (2007)}

A norma americana AASHTO LRFD (2007) divide o item sobre a resistência ao cisalhamento e torção em 4 subitens:

1. Regiões de flexão;

2. Regiões próximas as descontinuidades;

3. Regiões de interface;

4. Lajes e sapatas.

O subitem das regiões de flexão, que aborda as regiões de vigas e lajes, permite assumir que o comportamento da estrutura nestes casos segue a teoria de vigas de Bernoulli. Segundo tal teoria, as seções transversais permanecem planas após os carregamentos, e os esforços numa certa seção dependem apenas dos valores calculados dos esforços solicitantes (i.e., momentos, força cortante, forças axial, torção e não se considera os detalhes específicos de como ocorre a introdução das forças no elemento). Para estes casos, a norma AASHTO LRFD permite a análise dos esforços através de modelos de biela-tirante, porém estes últimos não serão abordados.

\subsubsection{Resistência ao cisalhamento nominal}

A Resistência ao cisalhamento nominal é determinada como o menor valor entre:

$$
\begin{gathered}
V_{n}=V_{c}+V_{s}+V_{p} \\
V_{n}=0,25 \cdot f_{c}^{\prime} \cdot b_{v} \cdot d_{v}+V_{p}
\end{gathered}
$$

Na qual:

$$
V_{c}=0,083 \beta \sqrt{f_{c}^{\prime}} b_{v} d_{v}
$$

e

$$
V_{s}=\frac{A_{s y} \cdot f_{y y} \cdot d_{v}(\cot \theta+\cot \alpha) \cdot \sin \alpha}{s}
$$

Sendo: 
f'c - resistência a compressão do concreto (MPa);

$b_{v}$ - largura efetiva da alma $(\mathrm{mm})$;

$d_{v}$ - profundidade de cisalhamento efetiva $(\mathrm{mm})$;

$\mathrm{S}$ - espaçamento dos estribos $(\mathrm{mm})$;

$\beta$ - fator que indica a capacidade das fissuras inclinada em transmitir tração;

$\theta$ - ângulo de inclinação entre a biela de compressão e o eixo longitudinal ( $\left.{ }^{\circ}\right)$;

$\alpha$ - ângulo de inclinação entre os estribos e o eixo longitudinal $\left({ }^{\circ}\right)$;

$A_{\mathrm{sy}}$ - área dos estribos no espaçamento $\mathrm{s}\left(\mathrm{mm}^{2}\right)$;

$f_{y y}$ - tensão de escoamento da armação transversal de cisalhamento (MPa);

$V_{p}$ - Componente na direção da força cortante devido à protensão $(\mathrm{N})$;

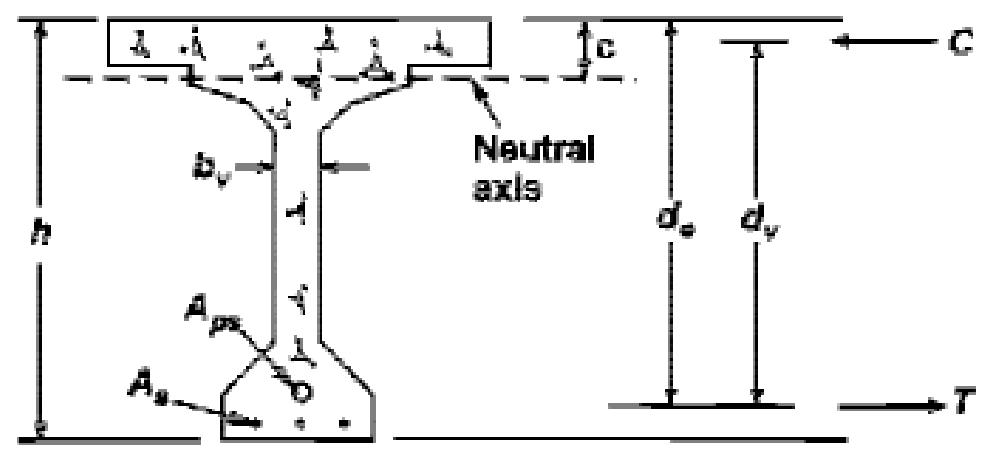

Figura 4.27: Ilustração dos termos bv e dv (AASHTO LRFD, 2007)

Além disso, para elementos submetidos a momentos fletores, a distância entre a força de compressão e de tração, $d_{v}$, pode ser determinada estimando-a pelo maior valor entre $0,9 d$ ou $0,72 h$ ou pela fórmula seguinte:

$$
d_{v}=\frac{M}{A_{s} f_{y}+A_{p s} f_{p s}}
$$

\subsubsection{Procedimentos para determinação de $\mathrm{Vn}$}

Baseado no método do MCFT, a norma AASTHO LRFD apresenta um modelo de comportamento que pode ser usado para prever a relação da tensão de cisalhamento versus a deformação para um elemento submetido a forças de cisalhamento no plano do elemento e forças de membrana. 
AASTHO LRFD sugere três métodos de análise para a determinação da resistência ao cisalhamento. O método 1 é aplicado apenas em elementos não protendidos; o método 2 é aplicado em todos os elementos protendidos e não protendidos, com ou sem armação de cisalhamento e com ou sem forças axiais. Por fim o último método é aplicado para elementos protendidos e não protendidos, sem força axial e com armados apresentando pelo menos a armação mínima de cisalhamento. Nesta dissertação será detalhado o método 2 , por ser o procedimento geral válido para quase todas as situações de carregamentos.

\subsubsection{Procedimento geral de cálculo}

O Método do MCFT apresenta duas possibilidades para a determinação da resistência ao cisalhamento, considerando as condições de quando o elemento é ou não armado com armação transversal de cisalhamento, conforme já descrito no item 4.2.5. Baseado nisto a Norma AASHTO LRFD apresenta duas tabelas para a determinação de $\theta$ e $\beta$, diferenciando os casos de elementos armados com pelo menos a quantidade de armação transversal de cisalhamento mínima, e os elementos com menos armação transversal de cisalhamento do que a armação mínima. A resistência de cisalhamento é, então, determinada pela seguinte expressão:

$$
A_{s y} \geq 0,083 \sqrt{f_{c}^{\prime}} \frac{b_{w} s}{f_{y y}}
$$

Na qual:

$A_{s y}$ - área da seção transversal da armação de cisalhamento compreendida entre a distância s $(\mathrm{mm})$;

$b_{w}$ - largura efetiva da alma, sendo a mínima largura da alma medida paralelamente a linha neutra e entre as resultantes de compressão e de tração devido à flexão $(\mathrm{mm})$;

$s$ - espaçamento entre estribos $(\mathrm{mm})$

$f_{y y}$ - tensão de escoamento da armação transversal de cisalhamento (MPa)

Para seções de elementos que contenham pelo menos a quantidade mínima de armação transversal de cisalhamento, especificada na expressão (4.52), os valores de $\theta$ e $\beta$ são obtidos na Tabela 4.1. O valor $\varepsilon x$ é estimado como sendo a deformação longitudinal calculada à meia altura da seção do elemento, quando este está submetido ao momento fletor, força normal e de cisalhamento, conforme ilustrado na Figura 4.28.Para seções de elementos que contenham menor quantidade de armação do que o mínimo especificado na expressão (4.52), os valores de $\theta$ e $\beta$ são obtidos na Tabela 4.2. O valor de $\varepsilon_{\mathrm{x}}$ refere-se à deformação longitudinal que ocorre dentro da alma do elemento quando este está submetido a momento fletor, força normal e de cisalhamento, conforme ilustrado na Figura 4.29. 


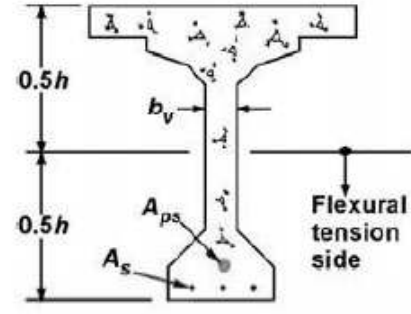

Section
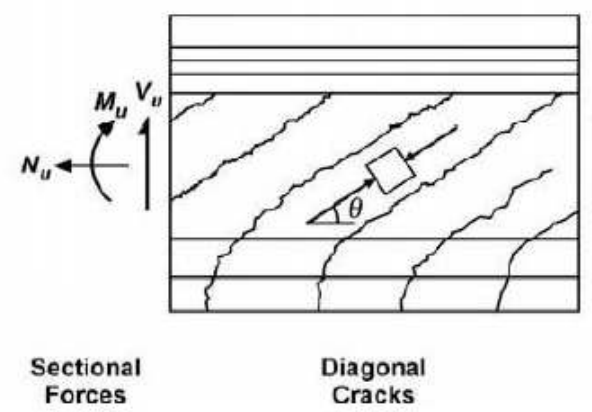

Diagonal Cracks

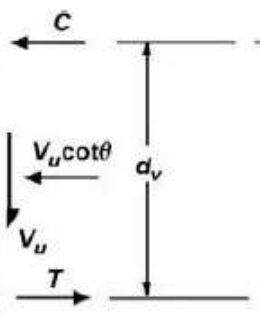

Equivalent Forces

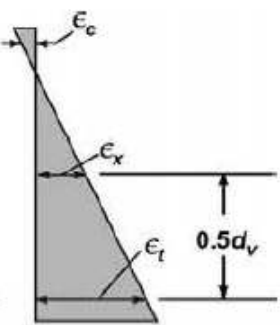

Longitudinal Strains

Figura 4.28: Ilustração dos parâmetros de cisalhamento para seções que contenham pelo menos a quantidade de armação mínima, $V p=0$ (AASHTO LRFD, 2007)

Tabela 4.1: $\quad$ Valores de $\theta$ e $\beta$ para seções com armação transversal de cisalhamento

\begin{tabular}{|c|c|c|c|c|c|c|c|c|c|}
\hline \multirow{2}{*}{$\frac{v_{s}}{f_{e}^{\prime}}$} & \multicolumn{9}{|c|}{$\mathrm{E} \times 1,000$} \\
\hline & $\leq-0.20$ & $\leq 0.10$ & $\leq-0.05$ & $\triangle 0$ & 90.125 & 90.25 & $\approx 0.50$ & 40.75 & c1.00 \\
\hline 40.075 & $\begin{array}{c}22.3 \\
6.32\end{array}$ & $\begin{array}{c}20.4 \\
4.75\end{array}$ & $\begin{array}{c}21.0 \\
4.10\end{array}$ & $\begin{array}{c}21.8 \\
3.75\end{array}$ & $\begin{array}{c}24.3 \\
3.24\end{array}$ & $\begin{array}{c}26.6 \\
2.94\end{array}$ & $\begin{array}{c}30.5 \\
2.59\end{array}$ & $\begin{array}{c}33.7 \\
2.38\end{array}$ & $\begin{array}{c}36.4 \\
2.23 \\
\end{array}$ \\
\hline$\leq 0.100$ & $\begin{array}{c}18.1 \\
3.79\end{array}$ & $\begin{array}{c}20.4 \\
3.38\end{array}$ & $\begin{array}{c}21.4 \\
3.24\end{array}$ & $\begin{array}{c}22.5 \\
3.14\end{array}$ & $\begin{array}{c}24.9 \\
2.91\end{array}$ & $\begin{array}{c}27.1 \\
2.75\end{array}$ & $\begin{array}{c}30.8 \\
2.50\end{array}$ & $\begin{array}{c}34.0 \\
2.32\end{array}$ & $\begin{array}{c}36.7 \\
2.18\end{array}$ \\
\hline$\leq 0.125$ & $\begin{array}{c}19.9 \\
3.18\end{array}$ & $\begin{array}{c}21.9 \\
2.99\end{array}$ & $\begin{array}{c}22.8 \\
2.94\end{array}$ & $\begin{array}{c}23.7 \\
2.87\end{array}$ & $\begin{array}{c}25.9 \\
2.74\end{array}$ & $\begin{array}{c}27.9 \\
2.62\end{array}$ & $\begin{array}{c}31.4 \\
2.42\end{array}$ & $\begin{array}{c}34.4 \\
2.26\end{array}$ & $\begin{array}{c}37.0 \\
2.13\end{array}$ \\
\hline$\leq 0.150$ & $\begin{array}{c}21.6 \\
2.88\end{array}$ & $\begin{array}{c}23.3 \\
2.79\end{array}$ & $\begin{array}{c}24.2 \\
2.78\end{array}$ & $\begin{array}{c}25.0 \\
2.72\end{array}$ & $\begin{array}{c}26.9 \\
2.60\end{array}$ & $\begin{array}{c}28.8 \\
2.52\end{array}$ & $\begin{array}{c}32.1 \\
2.36\end{array}$ & $\begin{array}{c}34.9 \\
2.21\end{array}$ & $\begin{array}{c}37.3 \\
2.08\end{array}$ \\
\hline 90.175 & $\begin{array}{c}23.2 \\
2.73\end{array}$ & $\begin{array}{c}24.7 \\
2.66\end{array}$ & $\begin{array}{c}25.5 \\
2.65\end{array}$ & $\begin{array}{c}26.2 \\
2.60\end{array}$ & $\begin{array}{c}28.0 \\
2.52\end{array}$ & $\begin{array}{c}29.7 \\
2.44\end{array}$ & $\begin{array}{c}32.7 \\
2.28\end{array}$ & $\begin{array}{c}35.2 \\
2.14\end{array}$ & $\begin{array}{c}36.8 \\
1.96\end{array}$ \\
\hline$\leq 0.200$ & $\begin{array}{c}24.7 \\
2.63 \\
\end{array}$ & $\begin{array}{c}26.1 \\
2.59\end{array}$ & $\begin{array}{c}26.7 \\
2.52\end{array}$ & $\begin{array}{c}27.4 \\
2.51\end{array}$ & $\begin{array}{c}29.0 \\
2.43\end{array}$ & $\begin{array}{c}30.6 \\
2.37\end{array}$ & $\begin{array}{c}32.8 \\
2.14\end{array}$ & $\begin{array}{c}34.5 \\
1.94\end{array}$ & $\begin{array}{c}36.1 \\
1.79\end{array}$ \\
\hline 90.225 & $\begin{array}{c}26.1 \\
2.53\end{array}$ & $\begin{array}{c}27.3 \\
2.45\end{array}$ & $\begin{array}{c}27.9 \\
2.42\end{array}$ & $\begin{array}{c}28.5 \\
2.40\end{array}$ & $\begin{array}{c}30.0 \\
2.34\end{array}$ & $\begin{array}{c}30.8 \\
2.14\end{array}$ & $\begin{array}{c}32.3 \\
1.86\end{array}$ & $\begin{array}{c}34.0 \\
1.73\end{array}$ & $\begin{array}{c}35.7 \\
1.64\end{array}$ \\
\hline-0.250 & $\begin{array}{c}27.5 \\
2.39\end{array}$ & $\begin{array}{c}28.6 \\
2.39\end{array}$ & $\begin{array}{c}29.1 \\
2.33\end{array}$ & $\begin{array}{c}29.7 \\
2.33\end{array}$ & $\begin{array}{c}30.6 \\
2.12\end{array}$ & $\begin{array}{c}31.3 \\
1.93\end{array}$ & $\begin{array}{c}32.8 \\
1.70\end{array}$ & $\begin{array}{c}34.3 \\
1.58\end{array}$ & $\begin{array}{c}35.8 \\
1.50\end{array}$ \\
\hline
\end{tabular}

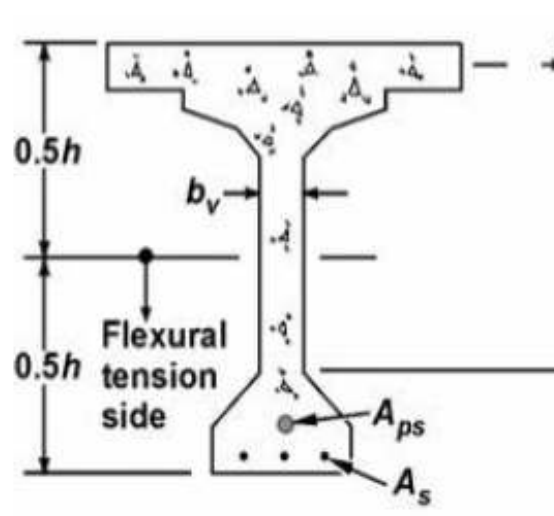

Section

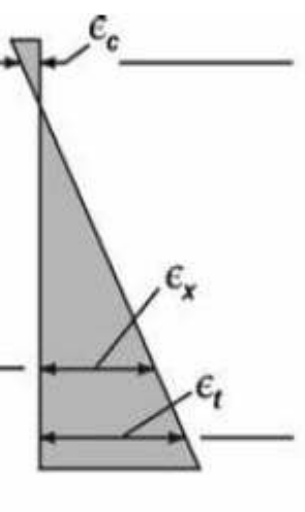

$\begin{array}{ll}\text { Longitudinal } & \text { Longitudinal } \\ \text { Strains } & \text { Forces }\end{array}$

Figura 4.29: Deformação longitudinal, ex, para seções com menos armação transversal de cisalhamento que a quantia mínima (AASHTO LRFD, 2007) 
Tabela 4.2: Valores de $\theta$ e $\beta$ para seções com menos armação transversal de cisalhamento do que o valor mínimo

\begin{tabular}{|c|c|c|c|c|c|c|c|c|c|c|c|}
\hline \multirow{2}{*}{$\begin{array}{c}s_{s e} \\
(\operatorname{mm})\end{array}$} & \multicolumn{11}{|c|}{$P_{8} \times 1000$} \\
\hline & $\leq-0.20$ & $\leq-0.10$ & $\leq-0.05$ & $\leq 0$ & 30.125 & $\leq 0.25$ & $\leq 0.50$ & $\leq 0.75$ & $\leq 1.00$ & $\leq 1.50$ & 2.00 \\
\hline$\leq 130$ & $\begin{array}{c}25.4 \\
6.36\end{array}$ & $\begin{array}{c}25.5 \\
6.06\end{array}$ & $\begin{array}{c}25.9 \\
5.56\end{array}$ & $\begin{array}{r}26.4 \\
5.15\end{array}$ & $\begin{array}{c}27.7 \\
4.41\end{array}$ & $\begin{array}{c}28.9 \\
3.91\end{array}$ & $\begin{array}{c}30.9 \\
3.26\end{array}$ & $\begin{array}{c}32.4 \\
2.86\end{array}$ & $\begin{array}{c}33.7 \\
2.58\end{array}$ & $\begin{array}{c}35.6 \\
2.21\end{array}$ & $\begin{array}{c}37.2 \\
1.96\end{array}$ \\
\hline$\leq 250$ & $\begin{array}{c}27.6 \\
5.78\end{array}$ & $\begin{array}{c}27.6 \\
5.78\end{array}$ & $\begin{array}{c}28.3 \\
5.38\end{array}$ & $\begin{array}{c}29.3 \\
4.89\end{array}$ & $\begin{array}{l}31.6 \\
4.05\end{array}$ & $\begin{array}{c}33.5 \\
3.52\end{array}$ & $\begin{array}{c}36.3 \\
2.88\end{array}$ & $\begin{array}{c}38.4 \\
2.50\end{array}$ & $\begin{array}{c}40.1 \\
2.23\end{array}$ & $\begin{array}{c}42.7 \\
1.88\end{array}$ & $\begin{array}{l}44.7 \\
1.65\end{array}$ \\
\hline$\leq 380$ & $\begin{array}{c}29.5 \\
5.34\end{array}$ & $\begin{array}{c}29.5 \\
5.34\end{array}$ & $\begin{array}{c}29.7 \\
5.27\end{array}$ & $\begin{array}{c}31.1 \\
4.73\end{array}$ & $\begin{array}{l}34.1 \\
3.82\end{array}$ & $\begin{array}{c}36.5 \\
3.28\end{array}$ & $\begin{array}{c}39.9 \\
2.64\end{array}$ & $\begin{array}{c}42.4 \\
22.26\end{array}$ & $\begin{array}{c}44.4 \\
2.01\end{array}$ & $\begin{array}{c}47.4 \\
1.68\end{array}$ & $\begin{array}{c}49.7 \\
1.46\end{array}$ \\
\hline$\$ 900$ & $\begin{array}{c}31.2 \\
4.99\end{array}$ & $\begin{array}{c}31.2 \\
4.99 \\
\end{array}$ & $\begin{array}{c}31.2 \\
4.99 \\
\end{array}$ & $\begin{array}{c}32.3 \\
4.61 \\
\end{array}$ & $\begin{array}{c}36.0 \\
3.65\end{array}$ & $\begin{array}{c}38.8 \\
3.09 \\
\end{array}$ & $\begin{array}{c}42.7 \\
2.46\end{array}$ & $\begin{array}{c}45.5 \\
2.09\end{array}$ & $\begin{array}{c}47.6 \\
1.85 \\
\end{array}$ & $\begin{array}{c}50.9 \\
1.52\end{array}$ & $\begin{array}{c}53.4 \\
1.31 \\
\end{array}$ \\
\hline$\leq 750$ & $\begin{array}{c}34.1 \\
4.46\end{array}$ & $\begin{array}{c}34.1 \\
4.46\end{array}$ & $\begin{array}{c}34.1 \\
4.46\end{array}$ & $\begin{array}{c}34.2 \\
4.43\end{array}$ & $\begin{array}{c}38.9 \\
3.39\end{array}$ & $\begin{array}{c}42.3 \\
2.82\end{array}$ & $\begin{array}{c}46.9 \\
2.19\end{array}$ & $\begin{array}{c}50.1 \\
1.84\end{array}$ & $\begin{array}{c}52.6 \\
1.60\end{array}$ & $\begin{array}{c}56.3 \\
1.30\end{array}$ & $\begin{array}{c}59.0 \\
1.10\end{array}$ \\
\hline$\leq 1000$ & $\begin{array}{c}36.6 \\
4.06\end{array}$ & $\begin{array}{c}36.6 \\
4.06\end{array}$ & $\begin{array}{c}36.6 \\
4.06\end{array}$ & $\begin{array}{c}36.6 \\
4.06\end{array}$ & $\begin{array}{c}41.2 \\
3.20\end{array}$ & $\begin{array}{c}45.0 \\
2.62\end{array}$ & $\begin{array}{c}50.2 \\
2.00 \\
\end{array}$ & $\begin{array}{c}53.7 \\
1.66\end{array}$ & $\begin{array}{c}56.3 \\
1.43\end{array}$ & $\begin{array}{c}60.2 \\
1.14\end{array}$ & $\begin{array}{c}63.0 \\
0.95\end{array}$ \\
\hline$\leq 1500$ & $\begin{array}{c}40.8 \\
3.50 \\
\end{array}$ & $\begin{array}{c}40.8 \\
3.50 \\
\end{array}$ & $\begin{array}{c}40.8 \\
3.50 \\
\end{array}$ & $\begin{array}{c}40.8 \\
3.50 \\
\end{array}$ & $\begin{array}{c}44.5 \\
2.92 \\
\end{array}$ & $\begin{array}{c}49.2 \\
2.32 \\
\end{array}$ & $\begin{array}{c}55.1 \\
1.72 \\
\end{array}$ & $\begin{array}{c}58.9 \\
1.40 \\
\end{array}$ & $\begin{array}{c}61.8 \\
1.18 \\
\end{array}$ & $\begin{array}{c}65.8 \\
0.92 \\
\end{array}$ & $\begin{array}{c}68.6 \\
0.75 \\
\end{array}$ \\
\hline$\leq 2000$ & $\begin{array}{c}44.3 \\
3.10\end{array}$ & $\begin{array}{c}44.3 \\
3.10\end{array}$ & $\begin{array}{c}44.3 \\
3.10\end{array}$ & $\begin{array}{r}44.33 \\
3.10\end{array}$ & $\begin{array}{c}47.1 \\
2.71\end{array}$ & $\begin{array}{c}52.3 \\
2.11\end{array}$ & $\begin{array}{c}58.7 \\
1.52\end{array}$ & $\begin{array}{c}62.8 \\
1.21\end{array}$ & $\begin{array}{c}65.7 \\
1.01\end{array}$ & $\begin{array}{c}69.7 \\
0.76\end{array}$ & $\begin{array}{c}72.4 \\
0.62\end{array}$ \\
\hline
\end{tabular}

A menos que sejam necessários cálculos mais precisos, $\varepsilon_{\mathrm{x}}$ pode ser estimado por uma das 3 equações seguinte:

1. Se a seção contém pelo menos a quantidade mínima de armação transversal de cisalhamento:

$\varepsilon_{x} \cong \frac{\varepsilon_{t}}{2}=\frac{\left(\frac{\left|M_{d}\right|}{d_{v}}+0,5 N_{d}+0,5\left(V_{d}-V_{p}\right) \cot \theta-A_{p s} f_{p 0}\right)}{2\left(E_{s} A_{s}+E_{p} A_{p s}\right)}$

A deformação $\varepsilon_{x}$ não pode ser maior que 0,001 .

Elementos que contêm pelo menos a quantidade mínima de armação transversal de cisalhamento possuem uma considerável capacidade de redistribuição da força cortante, que parte das regiões com elevadas tensões da seção transversal para as regiões com menores tensões. Devido a essa capacidade de redistribuição é apropriado estimar $\varepsilon_{\mathrm{x}}$ pelo valor da meia altura da seção transversal. 
2. Se a seção contém menos armação transversal de cisalhamento do que a quantidade mínima:

$$
\varepsilon_{x} \cong \varepsilon_{t}=\frac{\left(\frac{\left|M_{d}\right|}{d_{v}}+0,5 N_{d}+0,5\left(V_{d}-V_{p}\right) \cot \theta-A_{p s} f_{p 0}\right)}{\left(E_{s} A_{s}+E_{p} A_{p s}\right)}
$$

Neste caso a deformação $\varepsilon_{x}$ não pode ser maior que 0,002 .

Elementos que não contém armação transversal de cisalhamento ou contém menos armação que o valor mínimo, equação (4.52), possuir uma menor capacidade de redistribuição para força de cisalhamento. Por isto, é conveniente efetuar o cálculo das tensões no local sujeito ao máximo valor de deformação longitudinal, ou seja, na interface entre o flange de tração e a alma do elemento, conforme ilustrado na Figura 4.29.

3. Para qualquer caso que se obtenha um valor de $\varepsilon_{x}$ negativo, a deformação longitudinal poderá ser obtida considerando a rigidez do concreto, a compressão e a área de contribuição do lado de tração devido à flexão.

$$
\varepsilon_{x} \cong \frac{\varepsilon_{t}}{2}=\frac{\left(\frac{\left|M_{d}\right|}{d_{v}}+0,5 N_{d}+0,5\left(V_{d}-V_{p}\right) \cot \theta-A_{p s} f_{p 0}\right)}{2\left(E_{s} A_{s}+E_{p} A_{p s}+E_{c} A_{c}\right)}
$$

Sendo para as três equações:

$A_{c}$ - área de concreto na região de tração devido à flexão $\left(\mathrm{mm}^{2}\right)$;

$A_{p s}$ - área de armação protendida na região de tração devido à flexão $\left(\mathrm{mm}^{2}\right)$;

$A_{s}$ - área de armação passiva na região de tração devido à flexão, vide Figura 4.29. Para o cálculo de As nestas equações, barras que possuem um comprimento menor que o comprimento de ancoragem após a seção devem ser ignoradas $\left(\mathrm{mm}^{2}\right)$;

$f_{p o}$ - tensão da tensão inicial no aço de protensão (MPa); 
$N_{d}$ - força axial solicitante de cálculo. Sinal positivo para tração e negativo para compressão $(\mathrm{N})$;

$M_{d}$ - momento solicitante de cálculo, nunca menor que Vu.dv (N.mm);

$V_{u}$ - força de cisalhamento solicitante de cálculo $(\mathrm{N})$.

A região de tração devido à flexão pode ser considerada como a meia altura que contém a zona de tração à flexão, conforme Figura 4.29.

O espaçamento entre fissuras sxe, utilizado na

Tabela 4.2, deve ser determinado pela equação (4.35) do MCFT, considerando o espaçamento $s_{x}$ ou $s_{\mathrm{ml}}$ o menor valor entre $d_{v}$ ou a maior distância entre camadas de armação longitudinal para controle de fissuras (isso apenas para camadas em que a área de aço é maior ou igual a $0,003 . b_{v} \cdot s_{x}$ conforme indicado na FG).

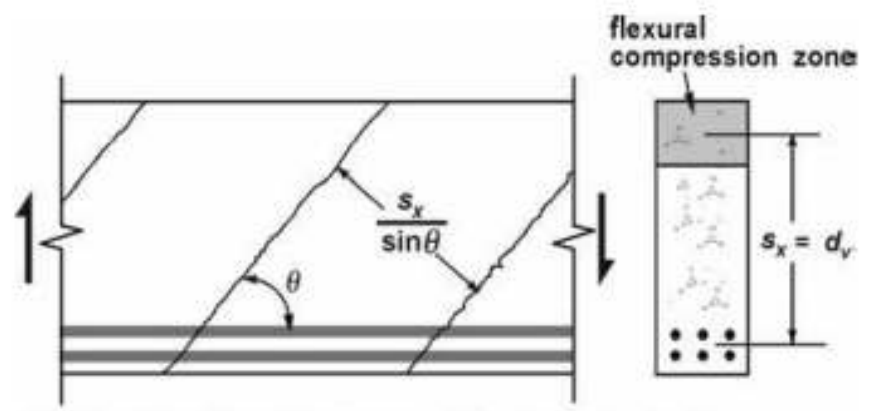

(a) Member without transverse reinforcement and with concentrated longitudinal reinforcement

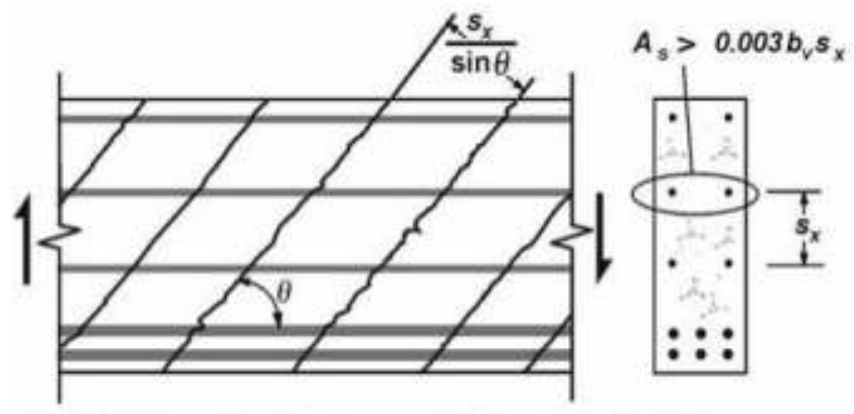

(b) Member without transverse reinforcement but with well distributed longitudinal reinforcement

Figura 4.30: Determinação do parâmetro de fissuração $s_{x e}$ (AASHTO LRFD, 2007)

Para elementos armados transversalmente utiliza-se a mesma premissa do MCFT, considerando $s_{x e}$ igual a $300 \mathrm{~mm}$. 
A formulação apresentada anteriormente é aplicada para regiões de Bernoulli. Entretanto, a norma LRFD permite que regiões de extremidade dos elementos, que estão sujeitos a estados complexos de tensões, sejam projetados utilizando-se a força de cisalhamento a uma distância $0,5 \cdot d_{v} \cdot \cot (\theta)$ a partir do apoio. De forma geral, os trecho de dimensionamento, ou chamados vãos de dimensionamento, serão resultado da divisão dos elementos em vãos de dimensão $d_{v} \cdot \cot (\theta)$, conforme mostrado na Figura 4.31 , e cada um dimensionado pela força cortante no trecho médio do vão de cisalhamento.
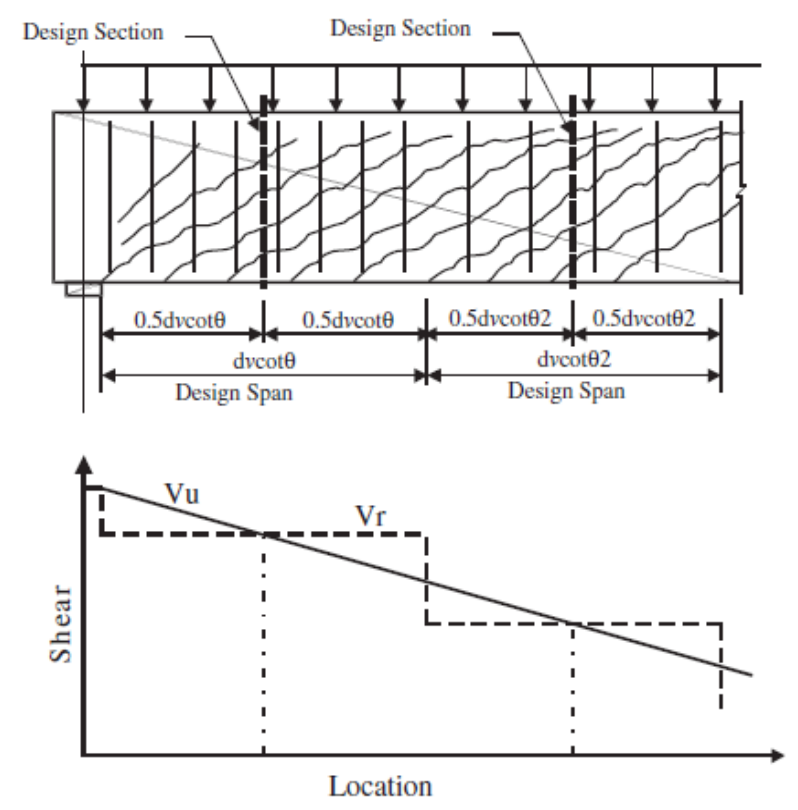

Figura 4.31: Regiões para dimensionamento (AASHTO LRFD, 2007)

\subsection{Formulação da CSA A23.3-04 - Canadian Standard Association - CSA (2004)}

A norma canadense CSA (2004) apresenta em sua seção 11.3 as verificações para esforços de cisalhamento e torção em regiões de flexão. A versão da norma canadense de 1994 incorporou em sua formulação os princípios do MCFT e apresentava, de forma bastante similar à AASHTO-LRFD (2008), tabelas com os valores de $\beta$ e $\theta$ para os casos de existir ou não armação transversal de cisalhamento. Na última versão da norma CSA de 2004, algumas mudanças foram incorporadas simplificando bastante as formulações da MCFT e substituindo as tabelas com os valores de $\beta$ e $\theta$ por expressões algébricas simplificadas.

Devido ao fato de que toda a teoria do "Modified Compression Field Theory", e suas simplificações, já foi detalhadamente explicadas nos itens 4.2 e 4.3, serão expostos apenas os passos a seguir, incorporados pela norma CSA (2004).

\subsubsection{Definição das parcelas da resistência ao cisalhamento.}

A resistência ao cisalhamento de cálculo, ou seja, minorada pelos seus fatores de segurança, é obtida pela seguinte equação: 


$$
V_{r}=V_{c}+V_{s}+V_{p}
$$

Entretanto, $V_{r}$ não pode exceder:

$$
V_{r, \max }=0,25 \phi_{c} f_{c}^{\prime} b_{w} d_{v}+V_{p}
$$

Nas quais:

$V_{\mathrm{r}}$ - força de cisalhamento resistente $(\mathrm{N})$;

$V_{c}$ - força de cisalhamento resistida pelo concreto $(\mathrm{N})$;

$V_{s}$ - força de cisalhamento resistida pelos estribos $(\mathrm{N})$;

$V_{p}$ - componente da força efetiva de protensão na direção do cisalhamento minorada pelo fator $\phi_{p}$. Para elementos com altura variável seria a soma das componentes da força efetiva de protensão e as componentes de compressão e tração à flexão na direção da força de cisalhamento aplicada, sendo positivo se resistir ao esforço aplicado, minorado pelo fator $\phi_{p}(\mathrm{~N})$;

$V_{\mathrm{r}, \mathrm{Max}}-$ força de cisalhamento resistente máxima $(\mathrm{N})$;

$\phi_{\mathrm{c}}-$ fator de resistência para o concreto;

$f_{\mathrm{c}}$ - resistência do concreto $(\mathrm{MPa})$;

$b_{\mathrm{w}}$ - largura da alma da viga $(\mathrm{mm})$;

$d_{\mathrm{v}}$ - altura efetiva de cisalhamento, considerado o maior valor entre $0,9 d$ e $0,72 h(\mathrm{~mm})$;

\subsubsection{Determinação de Vc.}

$\mathrm{O}$ valor de $\mathrm{V}_{\mathrm{c}}$ deve ser calculado como:

$$
V_{c}=\phi_{c} \lambda \beta \sqrt{f_{c}^{\prime}} b_{w} d_{v}
$$

Na qual:

$\phi_{\mathrm{C}}-$ fator de resistência para o concreto;

$\lambda$ - fator de influência para concretos de baixa densidade; 
$\beta$ - fator que representa a resistência ao cisalhamento de concreto fissurado;

$f_{c}^{\prime}$ - resistência do concreto que não pode ser superior a $64 \mathrm{MPa}(\mathrm{MPa})$;

$\mathrm{b}_{\mathrm{w}}$ - largura da alma da viga $(\mathrm{mm})$;

$d_{v}$ - altura efetiva de cisalhamento, considerado o maior valor entre $0,9 d$ e $0,72 \mathrm{~h}(\mathrm{~mm})$.

\subsubsection{Determinação de Vs.}

$\mathrm{O}$ valor de $\mathrm{V}_{\mathrm{s}}$ deve ser calculado como:

$$
V_{s}=\frac{\phi_{s} A_{v} f_{y} d_{v}(\cot \theta+\cot \alpha)}{s} \sin \alpha
$$

Na qual:

$\phi_{\mathrm{s}}$ - fator de resistência para o aço;

$A v$ - área da armação transversal de cisalhamento compreendida entre uma distância s $\left(\mathrm{mm}^{2}\right)$;

fy - tensão de escoamento da armação transversal de cisalhamento (MPa);

$d_{v}$ - altura efetiva de cisalhamento, considerado o maior valor entre $0,9 d$ e $0,72 \mathrm{~h}(\mathrm{~mm})$;

$\theta$ - ângulo de inclinação da biela de compressão em relação ao eixo longitudinal $\left({ }^{\circ}\right)$;

$\mathrm{s}$ - espaçamento entre estribos $(\mathrm{mm})$;

$\alpha$ - ângulo de inclinação do estribo em relação ao eixo longitudinal $\left({ }^{\circ}\right)$.

\subsubsection{Determinação de $\beta$ e $\theta$.}

Assim como a norma AASTHO-LRFD, a norma CSA também apresenta alguns métodos simplificados para casos específicos de solicitação. Há também um método geral que pode ser aplicado em casos mais genéricos. Por apresentar maior aplicabilidade, será apresentada apenas a formulação geral. 
$O$ valor de $\beta$ é idêntico ao sugerido por Bentz et al (2006), conforme equação (4.45):

$$
\beta=\frac{0,4}{1+1500 \varepsilon_{X}} \frac{1300}{1000+s_{x e}}
$$

E para elementos armados com pelo menos a quantidade mínima de armação transversal de cisalhamento, adota-se $s_{x e}$ igual a $300 \mathrm{~mm}$.A quantidade mínima de armação transversal de cisalhamento é dada pela equação:

$$
A_{s y} \geq 0,06 \sqrt{f_{c}^{\prime}} \frac{b_{w} s}{f_{y y}}
$$

Para elemento sem armação transversal de cisalhamento, ou em quantia menor que a mínima, $s_{x e}$ deve ser a mesma proposta na equação (4.35):

$$
s_{x e}=\frac{35 . s_{m l}}{a+16}
$$

Sendo a o diâmetro máximo do agregado em $\mathrm{mm}$.

$\mathrm{O}$ valor de $s_{\mathrm{xe}}$ não poder ser menor que $0,85 . \mathrm{s}_{\mathrm{ml}}$. Além disso, o espaçamento $s_{\mathrm{ml}}$ deve ser igual a $d_{\mathrm{v}}$, ou a máxima distância entre camadas da armação longitudinal, prevalecendo o menor valor entre os dois, e desde que as camadas possuam uma área no mínimo igual a $0,003 \cdot b_{\mathrm{w}} \cdot s_{\mathrm{ml}}$. Esta situação está ilustrada na Figura 4.30.

Para f'c maior do que 70MPa, deve-se zerar o diâmetro máximo do agregado a. Para o intervalo entre 60 e $70 \mathrm{MPa}$, deve-se interpolar linearmente o diâmetro máximo do agregado, de forma que esse passe a valer zero para $70 \mathrm{MPa}$.

O valor de $\theta$ é obtido pela modificação da equação (4.46), ao considerar $s_{x e}$ igual a $300 \mathrm{~mm}$.

$$
\theta=\left(29^{\circ}+7000 \varepsilon_{X}\right)
$$

Para determinação de $\theta$, o valor da deformação longitudinal $\varepsilon_{x}$, na meia altura da seção transversal deve ser obtida pela equação 


$$
\varepsilon_{x}=\frac{\left(\frac{\left|M_{d}\right|}{d_{v}}+0,5 N_{d}+\left(V_{d}-V_{p}\right)-A_{p} f_{p 0}\right)}{2\left(E_{s} A_{s}+E_{p} A_{p}\right)}
$$

Caso o valor da deformação longitudinal $\varepsilon_{\mathrm{x}}$ seja negativo, a contribuição do concreto a compressão deve ser considerada obtendo-se assim a seguinte equação:

$$
\varepsilon_{x}=\frac{\left(\frac{\left|M_{d}\right|}{d_{v}}+0,5 N_{d}+\left(V_{d}-V_{p}\right)-A_{p} f_{p 0}\right)}{2\left(E_{s} A_{s}+E_{p} A_{p}+E_{c} A_{c}\right)}
$$

Sendo:

$A_{c}$ - área de concreto na região de tração devido à flexão $\left(\mathrm{mm}^{2}\right)$;

$A_{p}$ - área de armação protendida na região de tração devido à flexão $\left(\mathrm{mm}^{2}\right)$;

$A_{s}$ - área de armação passiva na região de tração devido à flexão, vide Figura 4.29. Para o cálculo de As nestas equações, barras que possuem um comprimento menor que o comprimento de ancoragem após a seção devem ser ignoradas $\left(\mathrm{mm}^{2}\right)$;

$f_{p o}$ - tensão da tensão inicial no aço de protensão (MPa);

$N_{d}$ - força axial solicitante de cálculo. Sinal positivo para tração e negativo para compressão $(\mathrm{N})$;

$M_{d}$ - momento solicitante de cálculo, nunca menor que Vu.dv (N.mm);

$V_{u}$ - força de cisalhamento solicitante de cálculo $(\mathrm{N})$.

Observações para as equações (4.62) e (4.63):

a) $V_{f}$ e $M_{f}$ devem ser valores positivos e $M_{f}$ não deve ser menor que $\left(V_{f^{-}}\right.$ $\left.V_{\mathrm{p}}\right) \cdot d_{\mathrm{v}}$

b) O valor de As, área da barra que termina menos que seu comprimento de ancoragem a partir da seção considerada deve ser reduzido na proporção do seu comprimento em relação ao comprimento de ancoragem; 
c) A deformação longitudinal $\varepsilon_{x}$ não deve ser menor que $-0,20 \times 10^{-3}$ e nem maior que $3 \times 10^{-3}$

d) Para seções a uma distância menor que $d_{v}$ do apoio, utiliza-se o esforço a uma distância $d_{\mathrm{v}}$ do apoio;

e) Se a tensão de tração for grande suficiente para fissurar a face de compressão devido à flexão da seção, o valor de $\varepsilon_{\mathrm{x}}$ deve ser duplicado por 2;

\subsubsection{Critérios de detalhamento e verificações.}

O Máximo espaçamento entre estribos deverá ser o menor valor entre $0,7 . d_{v} \mathrm{e}$ $600 \mathrm{~mm}$. Porém, se o valor da força cortante solicitante exceder $0,125 . \lambda \phi_{c} f_{c}^{\prime} b_{w} \cdot d_{v}+V_{p}$, os espaçamento máximos serão os valores descritos acima reduzidos pela metade.

Em todas as seções, a armação longitudinal deverá resistir a um valor adicional de forças causadas pelo cisalhamento. Para elementos sujeitos a baixos valores de tração e torção, este critério pode ser substituído pela alternativa de estender o comprimento da armação longitudinal a uma distância de $d_{v} \cot \theta$, além da seção requerida desta armação longitudinal.

Para o lado com tração devido à flexão, a armação longitudinal de flexão deverá ser designada para resistir a uma força maior ou igual a $F_{\mathrm{lt}}$ sendo:

$$
F_{l t}=\frac{M_{f}}{d_{v}}+0,5 N_{f}+\left(V_{f}-0,5 V_{s}-V_{p}\right) \cot \theta
$$

Sendo $M_{f}$ e $V_{f}$ tomados pelos valores positivos, e $N_{f}$ é positivo para a forças de tração e negativo para compressão. Além disso, $d_{v}$ deve ser o braço de alavanca correspondente ao momento solicitante.

Nas seções onde o termo $M_{f} / d_{v}$ é menor que a soma dos outros termos devidos a força axial e de cisalhamento, a armação longitudinal de flexão na borda comprimida deve ser designada para resistir a uma força maior ou igual a força $F_{\mathrm{lc}}$, sendo:

$$
F_{l c}=-\frac{M_{f}}{d_{v}}+0,5 N_{f}+\left(V_{f}-0,5 V_{s}-V_{p}\right) \cot \theta
$$


Sendo $M_{\mathrm{f}}$ e $V_{\mathrm{f}}$ tomados pelos valores positivos e $N_{\mathrm{f}}$ é positivo para a forças de tração e negativo para compressão.

\subsection{Formulação do Código Modelo - FIB (2010)}

O Código Modelo FIB 2010 é a continuação do modelo de códigos que têm sido desenvolvidos e publicados pela "International Federation for Structural Concrete" (FIB) e seus antecessores CEB e FIP, ao longo das últimas três décadas. O código modelo FIB 2010 encontra-se na sua primeira versão preliminar completa. Com isso, as informações apresentadas nessa dissertação irão contemplar as formulações apresentadas na versão premiliar, que poderão, portanto, ser revisadas, pelo comitê da FIB, futuramente na publicação da versão final do código modelo.

A formulação do código modelo (2010) para a resistência ao cisalhamento se aplica para elementos como a alma de vigas e lajes, e não consideram a contribuição dos flanges. A Figura 4.32 apresenta o modelo considerado para a determinação da resistência ao cisalhamento em vigas.

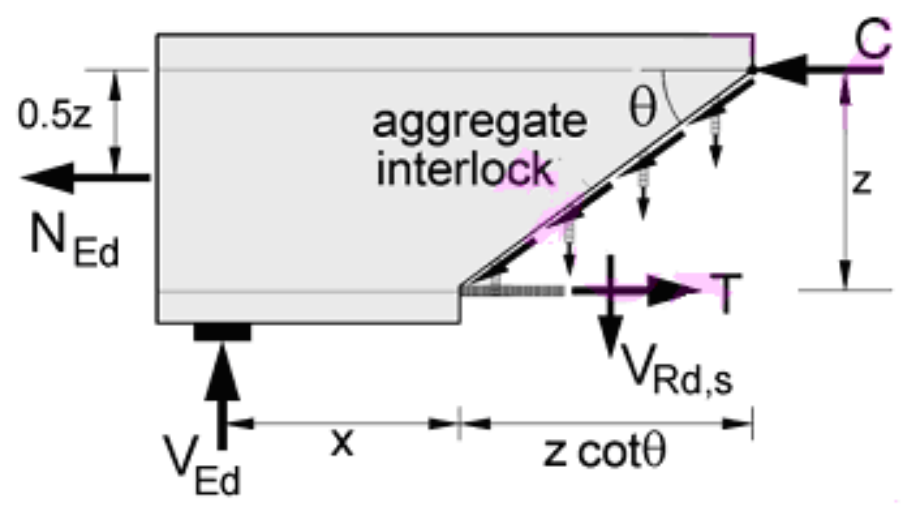

Figura 4.32: Modelo considerado para vigas (FIB, 2010)

O código modelo define a força de resistência ao cisalhamento composta por duas parcelas: uma definida pela resistência do concreto, e a outra pela resistência da armação transversal de cisalhamento. Essa situação está representada na expressão seguinte:

$$
V_{R d}=V_{R d, c}+V_{R d, s} \geq V_{E d}
$$

Na qual:

$V_{\mathrm{Rd}}$ - força cisalhante resistente de cálculo $(\mathrm{N})$;

$V_{\mathrm{Rd}, \mathrm{c}}$ - força cisalhante resistente de cálculo devido ao concreto $(\mathrm{N})$; 
$V_{\mathrm{Rd}, \mathrm{s}}$ - força cisalhante resistente de cálculo devido à armação transversal de cisalhamento $(\mathrm{N})$;

$V_{E d}-$ força cisalhante solicitante de cálculo $(\mathrm{N})$.

O código modelo (2010) propõe três níveis de aproximação para a determinação da resistência ao cisalhamento. Os níveis diferem na complexidade de aplicação dos métodos e na precisão dos resultados, conforme é apresentado na Figura 4.33:

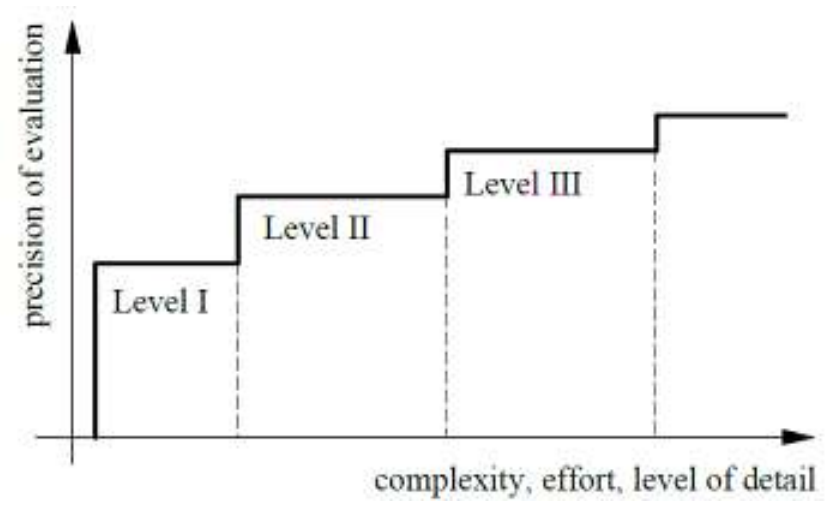

Figura 4.33: Níveis de aproximação (FIB, 2010)

Da mesma forma que as normas AASTHO-LRFD (2007) e a CSA A23 (2004) apresentam a possibilidade de análises simplificadas para determinada situação de carregamento de um elemento, o código modelo (2010) também permite a utilização de parâmetros conservadores para determinados casos. Essa medida facilita, desse modo algumas etapas de dimensionamento. Porém, a formulação apresentada neste trabalho será a referente ao nível de aproximação III, que possibilita o dimensionamento e verificação de elementos sobre condições complexas de carregamento e estruturas mais elaboradas. As equações deste nível são derivadas do "Modified compression Field theory" (MCFT), considerando que o elemento possui uma armação bem definida pelo menos na direção longitudinal.

\subsubsection{Determinação do valor limite de VRd,max}

O valor máximo permitido para a força cisalhante resistente de cálculo é:

$$
V_{R d, \max }=k_{c} \frac{f_{c k}}{\gamma_{c}} b_{w} z \frac{\cot \theta+\cot \alpha}{1+\cot ^{2} \theta}
$$


Na qual:

$k_{\mathrm{c}}$ - fator de redução da resistência do concreto;

$f_{\mathrm{ck}}-$ resistência característica do concreto $(\mathrm{MPa})$;

$Y_{C}$ - coeficiente de ponderação da resistência do concreto;

$b_{\mathrm{w}}$ - menor largura da seção, compreendida ao longo da altura útil d. Entretanto, no caso de elementos estruturais protendidos, quando existirem bainhas injetadas com diâmetro $\Phi>b_{\mathrm{w}} / 8$, a largura resistente a considerar deve ser $\left(b_{w}-1 / 2 \Sigma \Phi\right)$, na posição da alma em que essa diferença seja mais desfavorável. Isto à exceção do nível que define o banzo tracionado da viga $(\mathrm{mm})$;

$z$ - braço de alavanca para elementos com altura constante, correspondente ao momento fletor. Ao analisar esforços de cisalhamento sem força axial, pode-se utilizar a aproximação $z=0,9 d(\mathrm{~mm})$.

$\theta$ - ângulo de inclinação da tensão de compressão da biela $\left(^{\circ}\right)$;

$\alpha$ - ângulo de inclinação do estribo em relação ao eixo longitudinal da viga $\left({ }^{\circ}\right)$.

O coeficiente que reduz a resistência à compressão do concreto fissurado é determinado pelo estado de tensão de compressão com armação tracionada numa direção obliqua à direção de compressão. Essa situação é ilustrada na Figura 4.34, e a expressão para fator de redução da resistência do concreto, $k_{\mathrm{c}}$, neste caso é:

$$
k_{c}=0,55\left(\frac{30}{f_{c k}}\right)^{1 / 3} \leq 0,55
$$

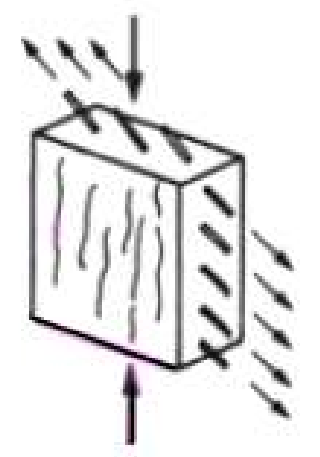

Figura 4.34: Estado de tensão considerado (FIB, 2010) 


\subsubsection{Determinação do valor de VRd,s}

A parcela da força de cisalhamento resistente de cálculo, provida pela armação transversal de cisalhamento, pode ser definida pela seguinte expressão:

$$
V_{R d, s}=\frac{A_{s w}}{s} \cdot z \cdot f_{y w d}(\cot \theta+\cot \alpha) \operatorname{sen} \alpha
$$

Sendo:

$A_{\mathrm{sw}}$ - área de armação transversal de cisalhamento compreendida em um espaçamento $s\left(\mathrm{~mm}^{2}\right)$;

$s$ - espaçamento entre estribos $(\mathrm{mm})$;

$z$ - braço de alavanca interno para momento fletor $(\mathrm{mm})$;

$f_{\text {ywd }}$ - tensão de escoamento de cálculo da armação transversal de cisalhamento (MPa);

\subsubsection{Determinação do valor de VRd,c}

A parcela da força de cisalhamento resistente de cálculo provida pelo concreto pode ser definida pela seguinte expressão:

$$
V_{R d, c}=k_{v} \frac{\sqrt{f_{c k}}}{\gamma_{c}} \cdot z \cdot b_{w}
$$

Sendo:

$k_{v}$ - fator que indica a capacidade das fissuras inclinada em transmitir tração;

O valor de $\sqrt{ } f_{c k}$ deve ser limitado à 8 , portanto equivale a limitar o $f_{c k}$ a $64 \mathrm{MPa}$.

$O$ fator $k_{\mathrm{v}}$ tem o mesmo significado do fator determinado como $\beta$ na formulação do MCFT, ou seja, reproduz a capacidade do concreto em transmitir esforços de tração nas fissuras.

\subsubsection{Determinação dos valores de $\theta$ e kv}

O valor de $k_{v}$ é semelhante ao sugerido para o $\beta$ pelo Bentz et al (2006), conforme equação (4.45). Porém são convenientes algumas alterações e considerações, que resultam na seguinte expressão: 


$$
k_{v}=\frac{0,4}{1+1500 \varepsilon_{x}} \frac{1300}{1000+0,7 k_{d g} z}
$$

Para elementos armados com pelo menos a quantidade mínima de armação transversal de cisalhamento adota-se $0,7 k_{\mathrm{dg}} z=300 \mathrm{~mm}$. Nesse caso, a equação fica reduzida apenas ao seu primeiro termo fracinário.

A quantidade mínima de armação transversal de cisalhamento será:

$$
A_{s y} \geq 0,08 \sqrt{f_{c k}} \frac{b_{w} s}{f_{y k}}
$$

Para elemento sem armação transversal de cisalhamento ou em quantia menor que a mínima, $k_{\mathrm{dg}}$ deve ser:

$$
k_{d g}=\frac{48}{d g+16}
$$

Sendo dg o diâmetro máximo do agregado em $\mathrm{mm}$.

O valor de $k_{\mathrm{dg}}$ não poder ser menor que 1,15.

Para $f_{\mathrm{ck}}$ maior que 70MPa deve-se zerar o diâmetro máximo do agregado $d g$. Para o intervalo entre 64 e $70 \mathrm{MPa}$ deve-se interpolar linearmente o diâmetro máximo do agregado de forma a valer zero para $70 \mathrm{MPa}$.

O valor de $\theta$ também é obtido pela modificação da equação (4.46), ao considerar $s_{x e}$ igual a $300 \mathrm{~mm}$, resultando na mesma equação.

$$
\theta=\left(29^{\circ}+7000 \varepsilon_{X}\right)^{\circ}
$$


Para determinação de $\theta$, o valor da deformação longitudinal $\varepsilon_{x}$, na meia altura da seção transversal, pode ser superestimada (considerando a mesma aproximadamente metade do valor da deformação na armação longitudinal). Ela é representada pela seguinte equação:

$$
\varepsilon_{x}=\frac{\left(\frac{\left|M_{E d}\right|}{z}+0,5 N_{E d}+V_{E d}-A_{p} f_{p 0}\right)}{2\left(E_{s} A_{s}+E_{p} A_{p}\right)}
$$

Caso o valor da deformação longitudinal $\varepsilon_{\mathrm{x}}$ seja negativo, a contribuição do concreto a compressão deve ser considerada. Obtêm-se, assim, a seguinte equação:

$$
\varepsilon_{X}=\frac{\left(\frac{\left|M_{E d}\right|}{z}+0,5 N_{E d}+V_{E d}-A_{p} f_{p 0}\right)}{2\left(E_{s} A_{s}+E_{p} A_{p}+E_{c} A_{c}\right)}
$$

Sendo:

$A_{c}$ - área de concreto na região de tração devido à flexão $\left(\mathrm{mm}^{2}\right)$;

$A_{p}$ - área de armação protendida na região de tração devido à flexão $\left(\mathrm{mm}^{2}\right)$;

$A_{s}$ - área de armação passiva na região de tração devido à flexão $\left(\mathrm{mm}^{2}\right)$;

$f_{p o}$ - tensão da tensão inicial no aço de protensão (MPa);

$N_{E d}$ - força axial solicitante de cálculo. Sinal positivo para tração e negativo para compressão $(\mathrm{N})$;

$M_{E d}$ - momento solicitante de cálculo, nunca menor que $\mathrm{V}_{\mathrm{Ed} . \mathrm{z}}$ (N.mm);

$V_{E d}-$ força de cisalhamento solicitante de cálculo $(\mathrm{N})$.

A Figura 4.35 apresenta o produto de rigidez à esforço axial, considerado para o intervalo onde a deformação axial na armação, $\varepsilon_{t}$, resulta em tração (maior que zero) ou em compressão (menor que zero). 


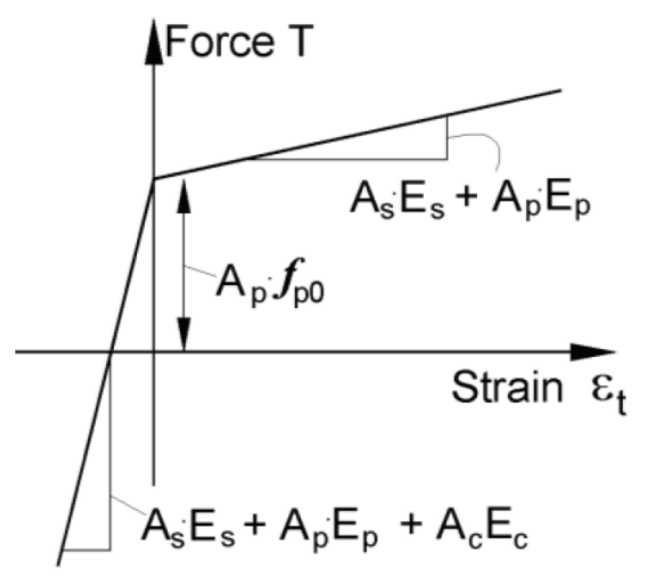

Figura 4.35: Rigidez considerada (FIB, 2010)

Observações:

a) $V_{E d}$ e $M_{E d}$ devem ser valores positivos e $M_{E d}$ não deve ser menor que $V_{\mathrm{Ed}} \cdot Z$;

b) O valor de As (área da barra que termina menos que seu comprimento de ancoragem a partir da seção considerada) deve ser reduzido na proporção do seu comprimento em relação ao comprimento de ancoragem;

c) A deformação longitudinal $\varepsilon_{x}$ não deve ser menor que $-0,20 \times 10^{-3}$; e nem maior que $3 \times 10^{-3}$;

d) Para seções a uma distância menor que $z$ do apoio, calcula-se a deformação axial a uma distância $z$ do apoio;

\subsubsection{Verificação da armação longitudinal de flexão}

Deve-se ainda verificar a força adicional, $\Delta F_{\mathrm{td}}$, na armação longitudinal de flexão devido à força de cisalhamento, através da equação:

$$
\begin{aligned}
& \Delta F_{t d}=0,5 V_{E d}(\cot \theta-\cot \alpha)+0,5 V_{R d, c}(\cot \theta+\cot \alpha) \\
& \operatorname{com} \Delta F_{t d} \leq \frac{M_{d, \max }-M_{d}}{z}
\end{aligned}
$$

Sendo

$M_{\mathrm{d}, \max }$ - momento máximo ao longo da viga ( $\left.\mathrm{kN} . \mathrm{mm}\right)$;

$M_{\mathrm{d}}$ - momento na seção analisada (kN.mm); 


\subsection{Formulação do EN 1992-1-1:2004 - Eurocode 2 (2004)}

Cladera e Marí (2007) fazem uma análise da nova formulação do Eurocode (2004), e citam que este modelo é baseado no modelo de treliça com o ângulo de inclinação da biela variável. Baseado no teorema estático ou do limite inferior, a norma propõe uma solução simples e com segurança garantida pelo teorema estático, desde que os mecanismos de plastificação sejam possíveis.

É importante ressaltar que, nesse teorema, é definido que qualquer campo de tensões estaticamente admissível fornecerá um limite inferior da verdadeira carga de colapso. Um campo de tensões é dito estaticamente admissível quando satisfaz às condições de contorno em tensões, ao equilíbrio e à condição de compatibilidade.

O Eurocode (2004) apresenta uma formulação para elementos sem armação transversal de cisalhamento, e outra para elementos que necessitam de armação transversal de cisalhamento.

Os critérios para se dispensar ou não a armação transversal de cisalhamento são:

a) Se $V_{d} \leq V_{r d, c}$, sendo $V_{d}$ a força de cisalhamento solicitante de cálculo e $V_{\text {rd,c }}$ força de cisalhamento resistente para elementos sem armação transversal de cisalhamento. Pode-se dispensar o uso de armação transversal de cisalhamento.

b) Se caso $V_{d} \geq V_{r d, c}$ deve-se verificar se $V_{d} \leq V_{r d}$. Sendo $V_{r d}$ a força de cisalhamento resistente para elementos com armação transversal de cisalhamento. Além disso, $V_{\text {rd }}$ está limitado ao valor de $V_{r d \text {,max }}$, sendo $V_{r d, m a x}$ a força de cisalhamento máxima a qual o elemento pode resistir, determinada pelo esmagamento da biela comprimida do concreto.

\subsubsection{Elementos sem armação transversal de cisalhamento.}

O valor de cálculo para a resistência ao cisalhamento, para elemento não armados transversalmente $V_{\mathrm{rd}, \mathrm{c}}$, é obtido pelo maior valor entre:

$$
V_{R d, c}=\left[\frac{0,18}{\gamma_{c}} \cdot k\left(100 \rho_{l} f_{c k}\right)^{1 / 3}+0,15 \sigma_{c p}\right] b_{w} d
$$

e

$$
V_{R d, c}=\left(v_{\min }+0,15 \sigma_{c p}\right) b_{w} d
$$


Nas quais:

$\gamma_{c}$ - coeficiente de segurança para a resistência do concreto;

$k$ - fator de escala;

$\rho_{l}-$ densidade de armação longitudinal;

$f_{\text {ck }}$ - valor da resistência a compressão do concreto ( $\left.\mathrm{MPa}\right)$, que deve ser menor que 50MPa;

$\sigma_{\mathrm{cp}}$ - tensão axial devido a carregamento ou protensão, tendo sinal positivo para compressão $(\mathrm{N})$;

bw - menor largura da seção transversal na região de tração $(\mathrm{mm})$;

d - distância entre o limite da borda comprimida e o eixo da armação longitudinal $(\mathrm{mm})$;

Sendo :

$$
\begin{gathered}
k=1+\sqrt{\frac{200}{d}} \leq 2,0 \\
v_{\text {min }}=0,035 k^{3 / 2} \cdot f_{c k}^{1 / 2} \\
\rho_{l}=\frac{A_{s l}}{b_{w} d} \leq 0,02
\end{gathered}
$$

Na qual:

AsI - é a área da armação de tração, cuja a extremidade ultrapassa, no mínimo, o comprimento de ancoragem $I_{b d}$ mais a altura efetiva $d$ além da seção considerada, conforme Figura $4.36\left(\mathrm{~mm}^{2}\right)$.

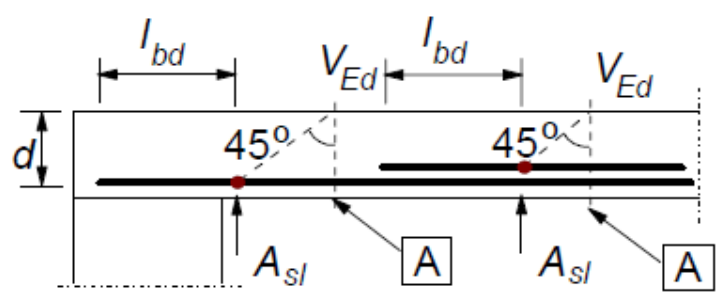

Figura 4.36: Definição de Asl (Eurocode, 2004)

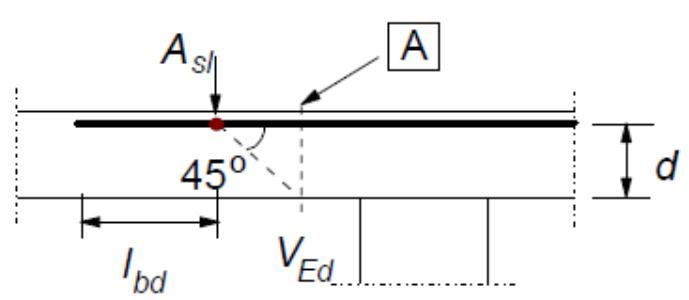

A - section considered 
Para elementos que não necessitam de armação transversal de cisalhamento, a força de cisalhamento $\mathrm{Vd}$ calculada deve de qualquer maneira satisfazer a seguinte condição:

$$
V_{d} \leq 0,5 \cdot b_{w} \cdot d \cdot v \cdot f c d
$$

Sendo:

$v$ - fator de redução da resistência do concreto fissurado por cisalhamento

$$
v=0,6\left[1-\frac{f c k}{250}\right]
$$

\subsubsection{Elementos com armação transversal de cisalhamento.}

O detalhamento de elementos armados com armação de cisalhamento é baseado no modelo de treliça, no qual não se considera a contribuição do concreto na resistência ao cisalhamento, conforme apresentado na Figura 4.37.

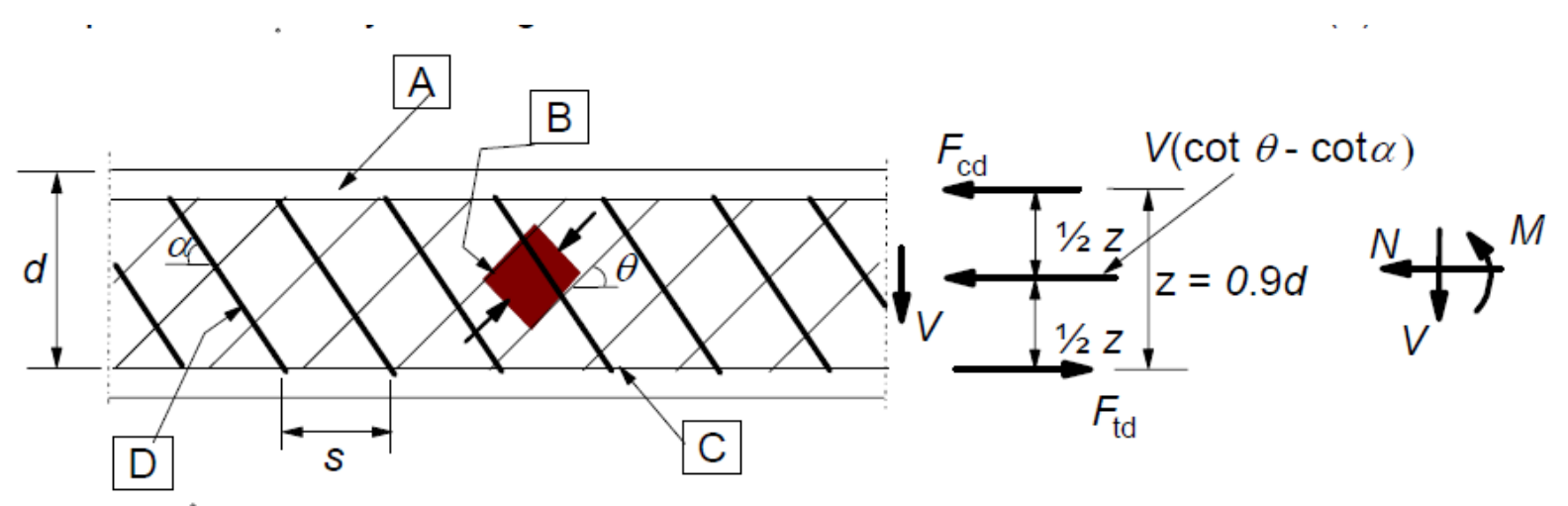

A - compression chord, B - struts, $\mathrm{C}$ - tensile chord, D- shear reinforcement

Figura 4.37: Modelo de treliça (Eurocode, 2004)

Na Figura 4.37 a notação utilizada é:

$\alpha$ - ângulo entre a armação transversal de cisalhamento e o eixo da viga perpendicular à direção da força de cisalhamento $\left({ }^{\circ}\right)$;

$\theta$ - ângulo entre a biela de compressão do concreto e o eixo da barra perpendicular à direção da força de cisalhamento $\left({ }^{\circ}\right)$;

$F_{\mathrm{td}}-$ valor de cálculo da força de tração na armação longitudinal $(\mathrm{N})$; 
$F_{c d}$ - valor de cálculo da força de compressão no concreto perpendicular $\grave{A}$ direção da força de cisalhamento $(\mathrm{N})$;

$b_{\mathrm{w}}$ - menor largura da do elemento entre o flange de compressão e o de tração, conforme Figura $4.38(\mathrm{~mm})$.

$z$ - braço de alavanca para elementos com altura constante, correspondente ao momento fletor. Ao analisar esforços de cisalhamento sem força axial, pode-se utilizar a aproximação $z=0,9 d(\mathrm{~mm})$.
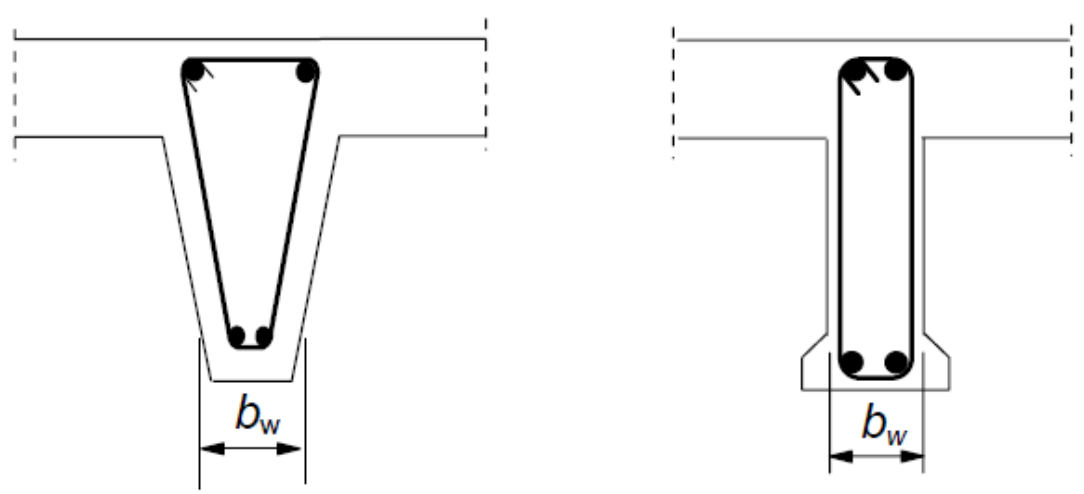

Figura 4.38: Definição da largura bw (Eurocode, 2004)

Os valores limites para $\theta$ são:

$$
1 \leq \cot \theta \leq 2,5
$$

Apesar do Eurocode (2004) não considerar a contribuição do concreto no cálculo da resistência ao cisalhamento, ele permite que $\theta$ assuma valores menores, limitando-se a $21,8^{\circ}$.

O valor da resistência ao cisalhamento devido à armação transversal de cisalhamento perpendicular a armação longitudinal é:

$$
V_{R d, s}=\frac{A_{s w}}{s} \cdot z \cdot f_{y w d} \cdot \cot \theta
$$

Na qual:

$$
f_{y w d}=0,8 f_{y w k}
$$


A força solicitante de cálculo deve ser menor que $V_{R d, \max }$, que é a força de cisalhamento máxima que o elemento pode resistir, limitada pelo esmagamento da biela comprimida do concreto

$$
V_{R d, \max }=\frac{\alpha_{c w} \cdot b_{w} \cdot z \cdot v \cdot f_{c d}}{\cot \theta+\tan \theta}
$$

Na qual:

$A_{\mathrm{SW}}$ - área da seção da armação transversal de cisalhamento $\left(\mathrm{mm}^{2}\right)$;

$s$ - espaçamento entre estribos $(\mathrm{mm})$;

$f_{\text {ywd }}$ - tensão de escoamento de cálculo da armação transversal de cisalhamento (MPa);

$v$ - fator redutor da resistência ao cisalhamento do concreto fissurado;

$\alpha_{\mathrm{cw}}-$ coeficiente que leva em conta o estado de tensão do flange comprimido;

$O$ valor de $v$ pode ser definido através da equação (4.82). Para elementos em que a tensão na armação transversal de cisalhamento é menor que $80 \%$ da resistência característica de escoamento da armação, $v$ pode ser obtido pelas seguintes equações:

$$
\begin{array}{cc}
v=0,6 & \text { para } f_{c k} \leq 60 \mathrm{MPa} \\
v=0,9-\frac{f_{c k}}{200}>0,5 & \text { para } f_{c k}>60 \mathrm{MPa}
\end{array}
$$

O valor recomendado para $\alpha_{\mathrm{cw}}$ é:

$$
\begin{array}{cc}
1,0 & \text { para elementos não comprimidos } \\
\left(1+\sigma_{c p} / f_{c d}\right. & \text { para } 0 \leq \sigma_{c p} \leq 0,25 f_{c d}
\end{array}
$$




$$
\begin{array}{rr}
1,25 & \text { para } 0,25 f_{c d}<\sigma_{c p} \leq 0,5 f_{c d} \\
2,5\left(1-\sigma_{c p} / f_{c d}\right) & \text { para } 0,5 f_{c d}<\sigma_{c p} \leq 1,0 f_{c d}
\end{array}
$$

Na qual:

$\sigma_{c d}$ - tensão média de compressão, sinal positivo, no concreto devido à força axial. Deve ser obtido pelo valor médio na seção transversal de concreto considerando a armação. $O$ valor de $\sigma_{c d}$ não precisa ser calculado a uma distância menor que 0,5.d. $\cot \theta$ a partir da borda do elemento (MPa).

A área máxima da armação transversal de cisalhamento, $A_{\mathrm{sw}, \mathrm{Max}}$ para $\cot \theta=1$ é dada pela equação:

$$
\frac{A_{s w, \max } f_{y w d}}{b_{w} s} \leq 0,5 . \alpha_{c w} \cdot v \cdot f_{c d}
$$

O Eurocode apresenta um valor mínimo de armação transversal de cisalhamento, $A_{\mathrm{sw}, \mathrm{Min}}$ para $\cot \theta=1$,é dada pela seguinte equação:

$$
\frac{A_{s w, \min } f_{y w d}}{b_{w} s} \leq 0,08 \sqrt{f_{c d}}
$$

Deve-se ainda verificar a força adicional, $\Delta F_{\mathrm{td}}$, na armação longitudinal de flexão devido à força de cisalhamento $V_{d}$, através da equação:

$$
\Delta F_{t d}=0,5 V_{d}(\cot \theta-\cot \alpha) \leq \frac{M_{d, \max }-M_{d}}{z}
$$

Sendo:

$M_{\mathrm{d}, \max }$ - momento máximo ao longo da viga ( $\left.\mathrm{kN} . \mathrm{mm}\right)$;

$M_{\mathrm{d}}-$ momento na seção analisada ( $\left.\mathrm{kN} . \mathrm{mm}\right)$; 


\subsection{Formulação da norma Brasileira ABNT NBR 6118 (2007)}

A norma brasileira para projetos de estruturas de concreto da Associação Brasileira de Normas Técnicas - NBR 6118 (2007) apresenta uma formulação para a determinação da resistência ao cisalhamento de peças em concreto baseada na publicação do Walraven (1987). Os itens referentes à resistência ao cisalhamento são baseados no modelo de treliça com banzos paralelos, podendo variar os parâmetros referentes ao ângulo das bielas comprimidas e da inclinação dos estribos, (cenário semelhante ao descrito no item 4.5).

A formulação aplica-se a elementos lineares armados ou protendidos submetidos a forças cortantes, não podendo ser atribuído a elementos de volume, vigas paredes e consolos curtos. A NBR 6118 (2007) apresenta dois modelos de cálculo: o modelo I considera o ângulo da biela de compressão, $\theta$, constante e igual a $45^{\circ}$; o modelo II considera uma variação de $\theta$ entre $30^{\circ} \mathrm{e}$ $45^{\circ}$.

Além disso, existe uma verificação para a dispensa da armação transversal de cisalhamento para elementos que obedeçam a certa restrição, conforme será detalhado mais adiante.

A NBR 6118 (2007) define que a resistência do elemento estrutural, numa determinada seção transversal, deve ser considerada satisfatória quando verificadas simultaneamente as seguintes condições:

$$
\begin{gathered}
V_{S d} \leq V_{R d 2} \\
V_{S d} \leq V_{R d 3}=V_{c}+V_{s w}
\end{gathered}
$$

Onde:

$V_{\mathrm{Sd}}$ - força cortante solicitante de cálculo, na seção $(\mathrm{N})$;

$V_{\mathrm{Rd} 2}$ - força cortante resistente de cálculo, relativa à ruína das diagonais comprimidas de concreto $(\mathrm{N})$;

$V_{\mathrm{Rd} 3}=V_{\mathrm{c}}+V_{\mathrm{sw}}$ - força cortante resistente de cálculo, relativa à ruína por tração diagonal, onde $V_{c}$ é a parcela de força cortante absorvida por mecanismos complementares ao de treliça, e $V_{\text {sw }}$ a parcela resistida pela armação transversal de cisalhamento $(\mathrm{N})$; 
$\mathrm{Na}$ região dos apoios, os cálculos devem considerar as forças cortantes agentes nas respectivas faces, levando em conta as reduções para cargas próximas ao apoio.

\subsubsection{Elementos com armação transversal de cisalhamento - Modelo I}

O critério do modelo I admite diagonais de compressão inclinadas de $\theta=45^{\circ}$ em relação ao eixo longitudinal do elemento estrutural, e admite ainda que a parcela complementar $V_{\mathrm{c}}$ tenha valor constante, independente de $V_{\mathrm{Sd}}$.

a) Verificação da compressão diagonal do concreto:

Neste subitem verifica-se a máxima tensão de compressão no concreto devido a força de cisalhamento, condicionando ao valor limite de tensão igual à $f_{\mathrm{cd} 2}$, que equivale a tensão máxima de compressão no concreto após a perda da resistência a compressão, do elemento que possui armações tracionadas, cuja expressão é:

$$
\mathrm{f}_{\mathrm{cd} 2}=0,6\left(1-\frac{\mathrm{f}_{\mathrm{ck}}}{250}\right) f_{c d}, \quad(\text { MPa })
$$

Portanto, a máxima força de compressão resistente do concreto, devido a solicitação por esforços de cisalhamento, é:

$$
\mathrm{V}_{\mathrm{Rd} 2}=0,27 \alpha_{\mathrm{v} 2} \mathrm{f}_{\mathrm{cd}} \mathrm{b}_{\mathrm{w}} \mathrm{d}
$$

Na qual:

$$
\begin{gathered}
\alpha_{\mathrm{v} 2}=(1-\mathrm{fck} / 250) \\
f_{c d}=\frac{f_{c k}}{\gamma_{c}}
\end{gathered}
$$

A norma estabelece o limite máximo para $f_{\mathrm{ck}}$ igual a $50 \mathrm{MPa}$.

b) Cálculo da armação transversal de cisalhamento 


$$
\mathrm{V}_{\mathrm{Rd} 3}=V_{c}+V_{s w}
$$

Na qual:

$$
\mathrm{V}_{\mathrm{sw}}=\left(\mathrm{A}_{\mathrm{sw}} / \mathrm{s}\right) 0,9 \mathrm{df} \mathrm{f}_{\mathrm{ywd}}(\operatorname{sen} \alpha+\cos \alpha)
$$

Sendo:

$V_{\mathrm{c}}=0$ nos elementos estruturais tracionados quando a linha neutra se situa fora da seção $(\mathrm{N})$;

$V_{c}=V_{c} 0$ na flexão simples e na flexo-tração com a linha neutra cortando a seção $(\mathrm{N})$;

$V_{\mathrm{c}}=V_{\mathrm{c} 0}\left(1+M_{\mathrm{o}} / M_{\mathrm{Sd}, \text { máx }}\right) \leq 2 V_{\mathrm{c} 0}$ na flexo-compressão $(\mathrm{N})$;

$V_{\mathrm{c} 0}=0,6 f_{\mathrm{ctd}} b_{\mathrm{w}} \mathrm{d}(\mathrm{N})$

$f_{\mathrm{ctd}}=\left(0,21 \cdot f_{c k}^{2 / 3)} / \gamma_{\mathrm{c}}(\mathrm{MPa})\right.$;

YC - coeficiente de ponderação da resistência do concreto.

Onde:

$b_{\mathrm{w}}$ - menor largura da seção, compreendida ao longo da altura útil d. Entretanto, no caso de elementos estruturais protendidos, quando existirem bainhas injetadas com diâmetro $\Phi>b_{\mathrm{w}} / 8$, a largura resistente a ser considerada é $\left(b_{w}-1 / 2 \Sigma \Phi\right)$, na posição da alma em que essa diferença seja mais desfavorável. Isso à exceção do nível que define o banzo tracionado da viga $(\mathrm{mm})$;

$d$ - altura útil da seção, igual à distância da borda comprimida ao centro de gravidade da armação de tração. Entretanto no caso de elementos estruturais protendidos com cabos distribuídos ao longo da altura, $d$ não precisa ser tomado com valor menor que $0,8 \mathrm{~h}(\mathrm{~mm})$;

$A_{\mathrm{sw}}$ - área de armação transversal de cisalhamento compreendida no espaçamento longitudinal $\mathrm{s}\left(\mathrm{mm}^{2}\right)$;

$s$ - espaçamento entre elementos da armação transversal de cisalhamento $A_{\text {sw, }}$, medido segundo o eixo longitudinal do elemento estrutural $(\mathrm{mm})$; 
$f_{\text {ywd }}$ - tensão na armação transversal passiva, limitada ao valor $f_{\mathrm{yd}}$ no caso de estribos e a $70 \%$ desse valor no caso de barras dobradas, não se tomando, para ambos os casos, valores superiores a $435 \mathrm{MPa}(\mathrm{MPa})$;

$\alpha \square$ - ângulo de inclinação da armação transversal de cisalhamento em relação ao eixo longitudinal do elemento estrutural, podendo-se tomar $45^{\circ} \leq \alpha \leq \square 90^{\circ}$ $\left({ }^{\circ}\right)$;

$M_{0}$ é o valor do momento fletor que anula a tensão normal de compressão na borda da seção (tracionada por $M_{\mathrm{d} \text {,max }}$ ), provocada pelas forças normais de diversas origens concomitantes com $V_{\mathrm{Sd}}$. Essa tensão é calculada com valores de $\gamma_{f}$ e $\gamma_{p}$ iguais a 1,0 e 0,9 respectivamente. Os momentos correspondentes a essas forças normais não devem ser considerados no cálculo dessa tensão, pois são considerados em $M_{\text {Sd. }}$. Devem ser considerados apenas os momentos isostáticos de protensão (kN.mm);

$M_{\text {Sd,max }}$ é o momento fletor de cálculo, máximo no trecho em análise, que pode ser tomado como o de maior valor no semitramo considerado. Para esse cálculo, não se consideram os momentos isostáticos de protensão, apenas os hiperestáticos (kN.mm);

c) Decalagem do diagrama de força no banzo tracionado:

Quando a armação longitudinal de tração for determinada através do equilíbrio de esforços na seção normal ao eixo do elemento estrutural, os efeitos provocados pela fissuração oblíqua podem ser substituídos pela decalagem do diagrama de força no banzo tracionado, $\alpha_{\lambda}$. Esta é dada pela seguinte expressão:

$$
a_{\lambda}=d\left[\frac{V_{S d, \text { máx }}}{2\left(V_{s d, \text { máx }}-V_{c}\right)}(1+\cot \alpha)(-\cot \alpha)\right]
$$

Na qual:

$\alpha_{\lambda} \geq 0,5 d$, no caso geral $(\mathrm{mm})$;

$\alpha_{\lambda} \geq 0,2 d$, para estribos inclinados a $45^{\circ}(\mathrm{mm})$. 
Essa decalagem pode ser substituída, aproximadamente, pela correspondente decalagem do diagrama de momentos fletores.

A decalagem do diagrama de força no banzo tracionado pode também ser obtida simplesmente aumentando-se a força de tração, em cada seção, por meio da expressão:

$$
\mathrm{R}_{\text {Sd,cor }}=\frac{\mathrm{M}_{\mathrm{Sd}}}{\mathrm{z}}+\left|\mathrm{V}_{\mathrm{Sd}}\right|(\cot \theta-\cot \alpha) \frac{1}{2}
$$

Sendo:

$M_{\mathrm{sd}}$ - momento solicitante na seção de análise (kN.mm);

$V_{\text {sd }}$ - força cortante na seção de análise $(\mathrm{kN})$;

$z$ - braço de alavanca entre a força de compressão e a de tração na armação, podendo ser considerada igual $0,9 d(\mathrm{~mm})$;

\subsubsection{Elementos com armação transversal de cisalhamento - Modelo II}

O modelo II admite diagonais de compressão inclinadas de $\theta$ em relação ao eixo longitudinal do elemento estrutural, $\operatorname{com} \theta$ variando livremente entre $30^{\circ} \mathrm{e}$ $45^{\circ}$. Admite ainda que a parcela complementar $V_{c}$ sofra redução com 0 aumento de $V_{\text {Sd. }}$.

a) Verificação da compressão diagonal do concreto:

Neste subitem verifica-se a máxima tensão de compressão no concreto, devido a força de cisalhamento, condicionando o valor limite de tensão igual a $f_{\mathrm{cd} 2}$, conforme equação (4.98). Isso resulta em:

$$
\mathrm{V}_{\mathrm{Rd} 2}=0,54 \alpha_{\mathrm{v} 2} \mathrm{f}_{\mathrm{cd}} \mathrm{b}_{\mathrm{w}} \mathrm{d} \operatorname{sen}^{2} \theta(\cot \alpha+\cot \theta)
$$

Com $\alpha_{\mathrm{v} 2}$ calculado pela equação (4.100).

b) Cálculo da armação transversal de cisalhamento 
Verifica-se a mesma inequação discutida em (4.102), sendo que, neste modelo, a força resistente ao cisalhamento devido à parcela de contribuição da armação transversal de cisalhamento é igual a:

$$
\mathrm{V}_{\mathrm{sw}}=\left(\mathrm{A}_{\mathrm{sw}} / \mathrm{s}\right) 0,9 \mathrm{df} \mathrm{f}_{\mathrm{ywd}}(\cot \alpha+\cot \theta) \operatorname{sen} \alpha
$$

A parcela resistente do concreto é definida pela força $V_{c}$, que deverá ser:

$V_{\mathrm{c}}=0$, em elementos estruturais tracionados quando a linha neutra se situa fora da seção $(\mathrm{N})$;

$V_{c}=V_{c 1}$, na flexão simples e na flexotração com a linha neutra cortando a seção $(\mathrm{N})$;

$V_{\mathrm{c}}=V_{\mathrm{c} 1}\left(1+M_{0} / M_{\mathrm{Sd}, \mathrm{máx}}\right)<2 V_{\mathrm{c} 1}$ na flexo-compressão $(\mathrm{N})$, com:

$V_{\mathrm{c} 1}=V_{\mathrm{c} 0}$ quando $V_{\mathrm{Sd}} \leq V_{\mathrm{c} 0}(\mathrm{~N})$

$V_{\mathrm{c} 1}=0$ quando $V_{\mathrm{Sd}}=V_{\mathrm{Rd} 2}(\mathrm{~N})$, interpolando-se linearmente para valores intermediários entre $V_{\mathrm{c} 0 \mathrm{e}} V_{\mathrm{Rd} 2}$.

Para a determinação do comprimento de decalagem e da verificação ao acréscimo de força nas armações de tração, utiliza-se a mesma metodologia já descrita para o modelo I.

\subsubsection{Elementos sem armação transversal de cisalhamento}

A NBR 6118 (2007) define que, para elementos planos como lajes e elementos que possuem um largura da alma maior que $5 d$ (sendo $d$ a altura útil da seção), existe a possibilidade de dispensa da armação transversal de cisalhamento. Isto mediante as duas verificações, explicitadas a seguir.

a) Verificação da resistência do concreto ao cisalhamento:

$$
\begin{gathered}
\text { Vsd } \leq \text { VRd1 } \\
V R d 1=\left[\tau_{r d 1} \kappa\left(1,2+40 \rho_{l}\right)+0,15 \sigma_{c p}\right] b_{w} d
\end{gathered}
$$

Na qual:

$$
\tau_{\mathrm{Rd} 1}=0,25 \cdot\left(0,21 \cdot f_{c k}^{2 / 3)} / \gamma_{\mathrm{c}}(\mathrm{MPa})\right.
$$

Yc - coeficiente de ponderação da resistência do concreto;

$\mathrm{K}$ - coeficiente que reduz a resistência com o aumento da altura da peça; 
$\rho_{l}$ - taxa de armação transversal de cisalhamento;

$\sigma_{\mathrm{cp}}-$ tensão axial devido a esforços axiais ou de protensão (MPa).

Sendo assim:

$$
\begin{gathered}
\rho_{\mathrm{l}}=\frac{A_{s l}}{b_{w} d} \leq 0,02 \\
\sigma_{c p}=\frac{N_{S d}}{b_{w} d}
\end{gathered}
$$

Sendo $A_{\mathrm{sl}}$ a área de armação longitudinal na seção tracionada, e $N_{\mathrm{sd}}$ é a força longitudinal na seção devido à protensão ou carregamento (compressão positiva).

Os valores recomendados para k são:

$$
\begin{array}{ll}
\kappa=1 & \begin{array}{l}
\text { para elementos em que mais de } 50 \\
\% \text { da armação inferior não for chegar } \\
\text { até o apoio; }
\end{array} \\
\kappa=|1,6-d| \geq 1 & \begin{array}{l}
\text { para os demais casos, sendo d em } \\
\text { metros. }
\end{array}
\end{array}
$$

b) A verificação do concreto à compressão diagonal

Para elementos sem a armação transversal de cisalhamento, a resistência máxima de cálculo para tensão de compressão nas bielas é:

$$
\mathrm{V}_{\mathrm{Rd} 2}=0,5 \alpha_{\mathrm{v} 1} \mathrm{f}_{\mathrm{cd}} \mathrm{b}_{\mathrm{w}} 0,9 \mathrm{~d}
$$

Sendo:

$$
\alpha_{\mathrm{v} 1}=\left(0,7-\frac{f_{c k}}{200}\right) \leq 0,5
$$


A NBR 6118 (2007) apresenta um valor mínimo para a taxa de armação transversal de cisalhamento, conforme expressão a seguir:

$$
\rho_{s w}=\frac{A_{s w}}{b_{w} \cdot \operatorname{sen} \alpha} \geq 0,2 \frac{\overbrace{0,3 \cdot f c k^{2 / 3}}^{f_{c t m}}}{f y w k}
$$

\subsection{Formulação da Norma ACl 318M-08 (2008)}

Na norma americana ACl 318M-08 (2008) a resistência ao cisalhamento é baseada na tensão média na seção transversal efetiva, $b_{\mathrm{w}} \cdot d$. A resistência ao cisalhamento devido ao concreto, $V_{\mathrm{Rd}, \mathrm{c}}$, é considerada a mesma para elementos armados ao cisalhamento e não armados. No caso de elementos não armado ao cisalhamento o mecanismo resistente é oriundo apenas da resistência do concreto, enquanto para elementos armados ao cisalhamento, uma parcela da resistência ao cisalhamento, $V_{\mathrm{Rd}}$, é devido ao concreto, $V_{\mathrm{Rd,c}}$, e o esforço solicitante que permanecer deve ser resistido pelos estribos. Sendo assim, temos:

$$
V_{R d}=V_{R d, c}+V_{R d, s}
$$

Na qual:

$V_{\mathrm{Rd}}$ - força de cisalhamento resistente do elemento $(\mathrm{N})$;

$V_{\mathrm{Rd}, \mathrm{c}}$ - parcela da força de cisalhamento resistente devido ao concreto $(\mathrm{N})$;

$V_{\mathrm{Rd}, \mathrm{s}}$ - parcela da força de cisalhamento resistente devido aos estribos (N).

Conforme as características dos esforços solicitantes, o modelo de predição da norma ACl 318-08 (2008) prevê 3 formulações para a determinação da força de cisalhamento resistente de cálculo provida pelo concreto, para elementos não protendidos, sendo os três casos de solicitações:

1. Elemento não protendido solicitado por momento fletor e força de cisalhamento;

2. Elemento não protendido solicitado por força axial de compressão e de cisalhamento;

3. Elemento não protendido solicitado por força axial de tração e de cisalhamento. 
4.8.1. Determinação de $V_{\mathrm{Rd}, \mathrm{c}}$, para elementos não protendidos solicitados por momento fletor e força cortante

O primeiro caso ocorre em elementos não protendidos solicitados por momento fletor e força cortante, cuja formulação sugeria é:

$$
V_{R d, c}=\left(0,16 \cdot \lambda \cdot \sqrt{f_{c k}}+17 \rho_{s l} \cdot \frac{V \cdot d}{M}\right) \cdot b_{w} \cdot d
$$

Sendo:

$\lambda$ - fator de redução para concretos leves, cujo valor é unitário para concretos normais;

$f_{\mathrm{ck}}$ - resistência característica do concreto (MPa), limitada a $69 \mathrm{MPa}$;

$b_{\mathrm{w}}$ - largura da seção transversal do elemento $(\mathrm{mm})$;

$d$ - altura útil do elemento, sendo a distância entre a fibra extrema comprimida da seção e o centro de gravidade da armadura de flexão, e com valor maior que $80 \%$ da altura da peça;

$\rho_{\mathrm{sl}}$ - taxa geométrica de armadura longitudinal de flexão;

$V$ - força cisalhante solicitante $(\mathrm{N})$;

$M$ - momento solicitante (N.mm).

Para este caso limita-se a força de cisalhamento resistente máxima resistida apenas pelo concreto em:

$$
V_{R d, c} \leq 0,29 \cdot \lambda \cdot \sqrt{f_{c k}} \cdot b_{w} \cdot d
$$

4.8.2. Determinação de $V_{\mathrm{Rd}, \mathrm{c}}$, para elementos não protendidos solicitados por forças axial de compressão e cortante

Para elementos solicitados a força normal de compressão, pode-se determinar $V_{\mathrm{Rd}, \mathrm{c}}$ da seguinte forma: 


$$
V_{R d, c}=0,17 \cdot\left(1+\frac{N}{14 \cdot A c}\right) \cdot \lambda \cdot \sqrt{f_{c k}} \cdot b_{w} \cdot d
$$

Tendo:

$\mathrm{N}$ - força axial solicitante de compressão $(\mathrm{N})$;

$A_{c}$ - área da seção transversal $\left(\mathrm{mm}^{2}\right)$;

Limitando a máxima força cortante resistente devido ao concreto em:

$$
V_{R d, c} \leq 0,29 \cdot \lambda \cdot \sqrt{f_{c k}} \cdot b_{w} \cdot d \cdot \sqrt{1+\frac{0,29 \cdot N}{A c}}
$$

\subsubsection{Determinação de $V_{\mathrm{Rd}, \mathrm{c}}$, para elementos não protendidos solicitados por forças axial de tração e cortante}

Para elementos solicitados a força normal de tração, a norma permite, de forma conservadora, desprezar a resistência devido ao concreto, mas também permite considerar uma redução devido a força normal de tração, sendo neste caso, $V_{\mathrm{Rd}, \mathrm{c}}$ determinado da seguinte forma:

$$
V_{R d, c}=0,17 \cdot\left(1+\frac{0,29 \cdot N}{A c}\right) \cdot \lambda \cdot \sqrt{f_{c k}} \cdot b_{w} \cdot d
$$

Tendo:

$\mathrm{N}$ - força axial solicitante, tendo sinal negativo para tração $(\mathrm{N})$;

$A_{\mathrm{c}}$ - área da seção transversal $\left(\mathrm{mm}^{2}\right)$;

\subsubsection{Determinação de $V_{\mathrm{Rd}, \mathrm{s}}$}

O modelo da treliça clássica é utilizado para determinar a parcela resistente devido ao uso da armação transversal de cisalhamento (estribos). A norma ACl permite: dispensar a armação de cisalhamento; utilizar a quantia mínima ou utilizar a quantidade necessária de armação de cisalhamento para resistir ao esforço solicitante, conforme mostrado a seguir: 


$$
\begin{array}{cl}
V_{S d} \leq 0,5 . \phi \cdot V_{R d, c} & \text { Podem-se dispensar os estribos } \\
0,5 . \phi . V_{R d, c} \leq V_{S d} \leq \phi \cdot V_{R d, c} & \frac{A_{S w, \min } f_{y w}}{b_{w} s} \leq 0,062 \sqrt{f_{c k}} \\
V_{S d} \geq \phi \cdot V_{R d, c} & \text { Utilizar } \phi V_{R d, s}=V_{S d}-\phi V_{R d, c}
\end{array}
$$

Sendo:

$V_{S d}$ - força de cisalhamento solicitante $(\mathrm{N})$;

$\phi$ - fator de redução da resistência;

$V_{\mathrm{Rd}, \mathrm{c}}$ - parcela da força de cisalhamento resistente devido ao concreto $(\mathrm{N})$;

$V_{\mathrm{Rd}, \mathrm{s}}$ - parcela da força de cisalhamento resistente devido aos estribos $(\mathrm{N})$.

$A_{\text {sw,min }}$ área de armação transversal de cisalhamento mínima compreendida em um espaçamento $s\left(\mathrm{~mm}^{2}\right)$;

$b_{\mathrm{w}}$ - largura da seção transversal do elemento $(\mathrm{mm})$;

$d$ - altura útil do elemento, sendo a distância entre a fibra extrema comprimida da seção e o centro de gravidade da armadura de flexão, e com valor maior que $80 \%$ da altura da peça;

$s$ - espaçamento entre estribos $(\mathrm{mm})$;

$f_{\mathrm{yw}}$ - tensão de escoamento característica da armação transversal de cisalhamento, limitada em $420 \mathrm{MPa}(\mathrm{MPa})$.

A tensão na armação transversal é restrita a $420 \mathrm{MPa}$ para controle da abertura das fissuras diagonais.

Por fim, defini-se a parcela da força de cisalhamento resistente devido aos estribos, $V_{\mathrm{Rd}, \mathrm{s}}$, como:

$$
V_{R d, s}=\frac{A_{s w}}{s} \cdot d \cdot f_{y w d}(\cot \theta+\cot \alpha) \operatorname{sen} \alpha
$$

Define-se, também, um valor máximo permitido para a força cisalhante resistente devido aos estribos, na forma indicada a seguir: 


$$
V_{R d, s} \leq 0,66 \cdot \sqrt{f c k} \cdot b_{w} \cdot d
$$

\subsection{Escala de demérito de Collins apud Cladera (2002)}

O método de análise desenvolvido por Collins apud Cladera (2002), tem como objetivo, avaliar a confiabilidade e de comparar o desempenho de diferentes equações normativas para o dimensionamento ao cisalhamento em peças de concreto armado, através do desenvolvimento de uma metodologia em termos de uma escala de demérito.

A escala de demérito desenvolvida por Collins está expressa na

Tabela 4.3. A metodologia consiste em atribuir pontos de demérito para cada caso de análise de $V_{\text {exp }} / V_{\mathrm{k}}$, de forma que no final processo somam-se todos os pontos de demérito da norma, possibilitando compará-las. A norma que obteve a maior soma de pontos de demérito era classificada como a norma menos apropriada para utilização e a norma com menor soma de pontos de demérito era classificada como a norma mais apropriada.

Tabela 4.3: Critério de avaliação da confiabilidade e desempenho de normas, através da atribuição de pontos de demérito*

\begin{tabular}{|c|cc|}
\hline Classificação & $\boldsymbol{V}_{\text {exp }} / \boldsymbol{V}_{\mathbf{k}}$ & Ponto de Demérito \\
\hline Extremamente Perigosa & $<0,50$ & 10 \\
\hline Perigosa & $0,50 \vdash 0,65$ & 5 \\
\hline Baixa Segurança & $0,65 \vdash 0,85$ & 2 \\
\hline Segurança Apropriada & $0,85 \vdash 1,30$ & 0 \\
\hline Conservadora & $1,30 \vdash 2,0$ & 1 \\
\hline Extremamente Conservadora & $\geq 2,0$ & $\underline{2}$ \\
\hline
\end{tabular}

- Collins apud Cladera (2002)

\section{Metodologia}

Neste capítulo estão descritas as metodologias de como serão gerados os dados a partir das normas, tão bem como, a construção de bancos de dados a partir de ensaios experimentais existentes na literatura. 
A obtenção dos resultados de predição das normas será feita a partir da elaboração de planilhas eletrônicas que permitam gerar gráficos e resultados para uma quantidade grande de elementos de forma automatizada. Os dados assim expostos permitirão a verificação de influência dos diversos fatores em repostas de interesse, comparações entre os modelos de norma e discussão dos modelos em questão, frente aos ensaios experimentais.

\subsection{Construção de gráficos para a análise paramétrica}

Para análise paramétrica em questão, definiu-se 6 parâmetros principais que potencialmente influenciam o modelo de cálculo. Em cada estudo fixam-se 5 dos parâmetros e varia-se apenas um parâmetro, com o intuito de se analisar a influência deste parâmetro na força resistente.

Inicialmente definiram-se 6 parâmetros principais. Foram eles:

1. Efeito de escala, representado pela altura do elemento, $h$; quando comparada com as outras dimensões do elemento;

2. Resistência do concreto, representada pelo resultado dos corpos de prova e obtenção da resistência característica do concreto à compressão, fck;

3. Taxa de armadura transversal de cisalhamento, $\rho_{s w}$;

$$
\rho_{s w}=A_{s w} / b_{w} s
$$

4. Taxa de armadura longitudinal de flexão, $\rho_{i}$;

$$
\rho_{l}=A_{s l} / b_{w} d
$$

5. Tensão axial, $\sigma_{n}$;

$$
\sigma_{n}=N / b_{w} d
$$

6. Índice de esbeltez, que é a razão entre o vão de cisalhamento e a altura útil do elemento, considerando carregamento pontual, $a / d$;

Sendo:

$\mathrm{N}$ - Força axial de compressão ou tração.

Para a análise de elementos não armados ao cisalhamento com estribos, fica claro o fato de que foram analisados apenas 5 parâmetros, não contemplando a variação da taxa de armadura transversal. 
As formulações das normas ASHTO-LRFD (2007) e FIB (2010) não foram utilizadas, pois se verificou que os resultados apresentados, por ambas, eram semelhantes aos resultados de predição da norma CSA (2004).

\subsubsection{Definição dos valores limítrofes dos parâmetros considerados na análise paramétrica}

\subsubsection{Altura do elemento}

A seção transversal das vigas analisadas é definida por dois parâmetros, largura e altura da seção, sendo definidos para cada um deles os símbolos, $b_{w}$ e $h$, respectivamente.

A largura da seção será considerada constante em todos os casos e igual a 50 $\mathrm{cm}$. A altura da seção teve uma variação entre os valores extremos de $50 \mathrm{~cm}$ e $250 \mathrm{~cm}$. Em casos em que outro parâmetro foram o foco das comparações, foi definida uma altura padrão de $100 \mathrm{~cm}$.

\subsubsection{Resistência do concreto}

Para se avaliar a influência da resistência do concreto na força resistente ao cisalhamento, variou-se os parâmetros de resistência do concreto entre os valores de $20 \mathrm{MPa}$ e $80 \mathrm{MPa}$, abrangendo uma grande faixa de resistência utilizada atualmente. Para os casos em que o parâmetro de resistência não variou, fixou-se o valor da resistência em $40 \mathrm{MPa}$.

\subsubsection{Taxa de armadura transversal de cisalhamento}

Frente ao fato que a armadura transversal de cisalhamento influencia a resistência ao cisalhamento, utilizou-se um intervalo de taxa de armadura transversal entre $0,12 \%$ e $0,48 \%$. O limite inferior se refere à armadura mínima exigida pela norma brasileira NBR 6118 (2007) e o valor máximo se refere a quatro vezes o valor mínimo. O valor padrão fixado foi de 0,24 \%.

\subsubsection{Taxa de armadura longitudinal de flexão}

Um fator que influência a resistência ao cisalhamento de peça em concreto armado é a armadura longitudinal de flexão, principalmente nas formulações em que não se utiliza armadura transversal de cisalhamento. Para a determinação do limite de variação deste parâmetro, utilizou-se como limite inferior a taxa de armadura mínima proposta pela norma NBR 6118 (2007) para o concreto de resistência de $40 \mathrm{MPa}$. Para o limite superior utilizou-se metade da máxima taxa de armadura permitida pela norma brasileira, ou seja, variouse a taxa de armadura longitudinal entre $0,230 \%$ e 2,0 \%, e o valor fixado para as demais análises foi 1,6\%.

\subsubsection{Tensão solicitante normal}

A tensão axial de compressão ou de tração atuante em um elemento pode influenciar consideravelmente a resistência ao cisalhamento. Porém, para as formulações baseadas no modelo da treliça clássica, ou a treliça generalizada, 
este fenômeno é pouco considerado, principalmente quando comparado, por exemplo, com o método da teoria do MCFT.

O intervalo para variação do parâmetro considera a máxima tensão de compressão de $50 \%$ da tensão de resistência do concreto (fck), e máxima tensão de tração igual a tensão média resistente à tração do concreto (fctm) conforme a norma NBR 6118 (2007). A tração do concreto é dada por:

$$
\mathrm{f}_{\mathrm{ctm}}=0,3 \cdot f c k^{2 / 3}
$$

Para o valor padrão, considerou-se o valor nulo, não ocorrendo tração ou compressão.

\subsubsection{6. Índice de esbeltez}

Um dos índices possíveis de se relacionar a esbeltez do elemento está na relação entre o vão de cisalhamento e a altura efetiva. Para as vigas biapoiadas solicitadas por duas cargas pontuais de igual valor e em posições simétricas, o vão de cisalhamento é a distância entre o apoio e a carga mais próxima. Este índice, além de indicar a esbeltez do elemento, representa, para este caso específico, uma relação entre a solicitação por flexão em razão da solicitação por cisalhamento.

Neste caso, o intervalo considerado é de 1,5 a 4,0. Com isso, pretende-se futuramente investigar qual a influência da solicitação normal devido à flexão, na resistência ao cisalhamento. O valor padrão adotado foi o de 2,0.

A Tabela 5.1 apresenta um resumo dos parâmetros estudados, bem como os intervalos de variação considerados no estudo. 
Tabela 5.1: Resumo dos parâmetros considerados e suas variações

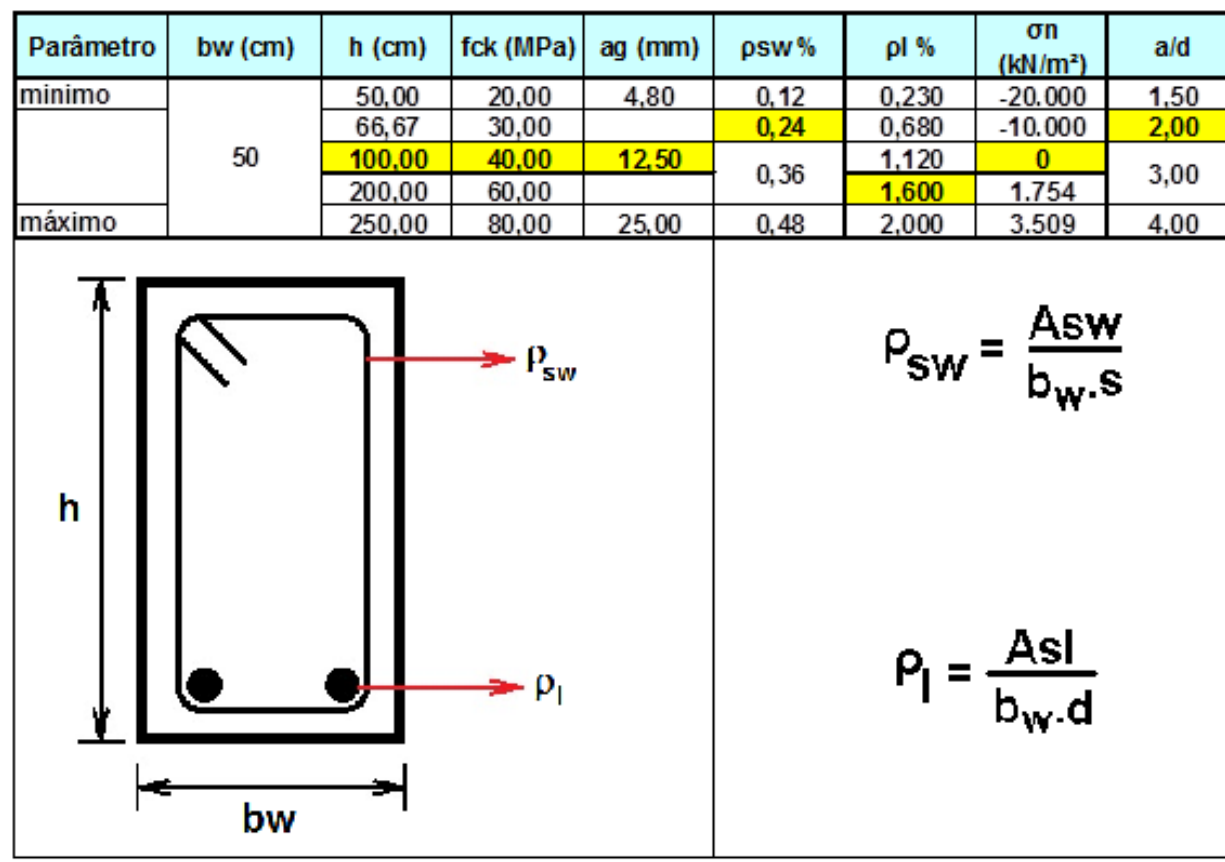

Parâmetro Padrão

Obs 1: Valores negativos para solicitação normal de compressão.

Obs 2: Para os casos de elementos não armados ao cisalhamento a taxa de armadura transversal de cisalhamento é nula.

\subsection{Construção do banco de dados para análise de predição das normas}

Para analisar os comportamentos dos modelos de predição de norma frente aos resultados de ensaios de laboratório, foram elaborados bancos de dados. Os bancos de dados foram concebidos a partir de resultados de ensaios de vigas publicados na literatura. Os bancos de dados reúnem os principais parâmetros que condicionam a determinação da resistência ao cisalhamento, assim como os valores últimos dos ensaios.

Basicamente foram elaborados 5 bancos de dados sendo eles:

1. Banco de dados de elementos de concreto armado com estribos e ruptura por força cortante-tração;

2. Banco de dados de elementos de concreto armado sem estribos e ruptura por força cortante-tração;

3. Banco de dados de elementos de concreto armado com estribos e ruptura por força cortante-compressão (esmagamento do concreto);

4. Banco de dados de elementos de concreto armado com estribos e ruptura por força cortante-tração, sujeitos a esforços axiais; e, 
5. Banco de dados de elementos de concreto armado sem estribos e ruptura por força cortante-tração, sujeitos a esforços axiais.

\subsubsection{Bancos de dados de elementos de concreto armado, com e sem estribos, e ruptura por força cortante-tração}

As normas utilizadas para o dimensionamento de elementos de concreto armado foram baseadas em modelos e ensaios distintos, com isso os resultados de esforços resistentes obtidos na utilização das normas são diferentes. Existe assim, a necessidade de se analisar o desempenho das normas utilizadas, e em quais faixas de intervalos são seguras ou pouco seguras. Visando esta análise, compilaram-se num banco de dados, extremamente extenso, exatamente 1.235 resultados de ensaios de laboratório de vigas de concreto armado, que após homogeneização e tratamento estatístico, foi utilizado nas comparações com os resultados das normas.

\subsubsection{Descrição do banco de dados}

O banco de dados compilado contém 1.235 resultados de ensaios de laboratório de vigas de concreto armado, sendo 547 resultados de ensaios de vigas armadas ao cisalhamento com estribos e 688 de vigas não armadas ao cisalhamento. Todas as vigas ensaiadas possuíam armadura longitudinal de flexão e foram carregadas perpendicularmente ao eixo longitudinal da peça, por carga concentrada no meio do vão, ou por duas cargas equidistantes do apoio ou por cargas uniformemente distribuídas.

Baseado nos artigos de literatura, apresentados nas referências bibliográficas deste trabalho, foram separados os diversos modos de ruptura, tentando assim, definir os estados limites últimos corretos para cada análise, visto o fato que a maioria das normas apresenta equações diferentes para representar cada estado limite último.

Os resumos dos dados de ensaios utilizados estão ilustrados na Tabela $6.1 \mathrm{e}$ na Tabela 6.2 do capítulo 6.2, que contêm resultados de elementos armados e não armados ao cisalhamento, respectivamente. Estes dados referem-se aos ensaios de laboratório que indicaram ruptura forças cortantes, discriminados pelos próprios autores ou pelos autores que replicaram os resultados em sua publicação.

\subsubsection{Banco de dados de elementos de concreto armado com estribos e ruptura por força cortante-compressão (esmagamento do concreto)}

Neste item, separaram-se todos os ensaios que apresentaram ruptura por força cortante-compressão, ou seja, ruptura por esmagamento do concreto. Desta forma, permite-se analisar o comportamento dos modelos de predição de norma, quando comparados com resultados de ensaios de elementos armados com estribos e que tiveram sua ruína caracterizada pelo esgotamento da capacidade resistente do concreto. Torna-se importante separar esta analise das demais, pois a maioria das normas apresenta formulações especificas para a predição dos valores de resistência ao cisalhamento. 


\subsubsection{Descrição do banco de dados}

O banco de dados utilizado foi concebido por dados de ensaios de três autores, pois estes apresentaram resultados claros de ruptura do concreto a compressão. Este é composto por 20 ensaios e sua utilização terá um caráter mais qualitativo, visto o número reduzido de ensaios.

O banco de dados utilizado está apresentado na Tabela 6.32. Pode-se notar que as peças tiveram altas taxas mecânicas de estribos, de forma a proporcionar a ruptura por esmagamento do concreto. Os ensaios foram executados em elementos com estribos, carregados perpendicularmente ao eixo principal, armados a flexão e apresentaram ruptura por esmagamento do concreto.

\subsubsection{Bancos de dados de elementos de concreto armado, com e sem estribos, e ruptura por força cortante-tração, sujeitos a esforços axiais}

Para a elaboração destes dois bancos de dados, utilizaram-se os ensaios que apresentaram variação das tensões axiais solicitantes, de forma a permitir a análise da influência das tensões axiais nos resultados de predição dos modelos de predição de norma.

O motivo principal desta análise, é avaliar a influência da força normal de tração na resistência ao cisalhamento, e para isto também é necessário analisar os dados de ensaios de elementos submetidos à compressão ou livres de solicitações normais, moldados em condições de parâmetros semelhantes. Exclui-se deste banco de dados os ensaios que apresentaram ruptura por esmagamento do concreto ou por deficiência da armadura de flexão, conforme apontado pelos próprios autores.

\subsubsection{Descrição do banco de dados}

O Banco de dados utilizado para a análise de ensaios de vigas sem estribos, sujeitas a esforços axiais, apresenta-se na Tabela 6.36, cujos resultados apresentados referem-se apenas aos casos que ocorreram rupturas por cisalhamento e não por outras razões como, por exemplo, flexão. O banco de dados é composto por 41 resultados de ensaios de vigas de concreto armado sem estribos e submetidos a esforços axiais solicitantes. As publicações utilizadas referem-se aos autores Mattock (1969), Cossio e Siess (1960) e Haddadin et al. (1971)

O banco de dados utilizado para a análise de elementos com estribos e solicitados por esforços axiais, baseia-se nas publicações de Mattock e Wang (1984) e Haddadin et al. (1971), e é composto por 32 resultados de ensaios de vigas de concreto armadas ao cisalhamento, e está expresso na Tabela 6.41. 
5.2.4. Fluxograma das etapas do trabalho

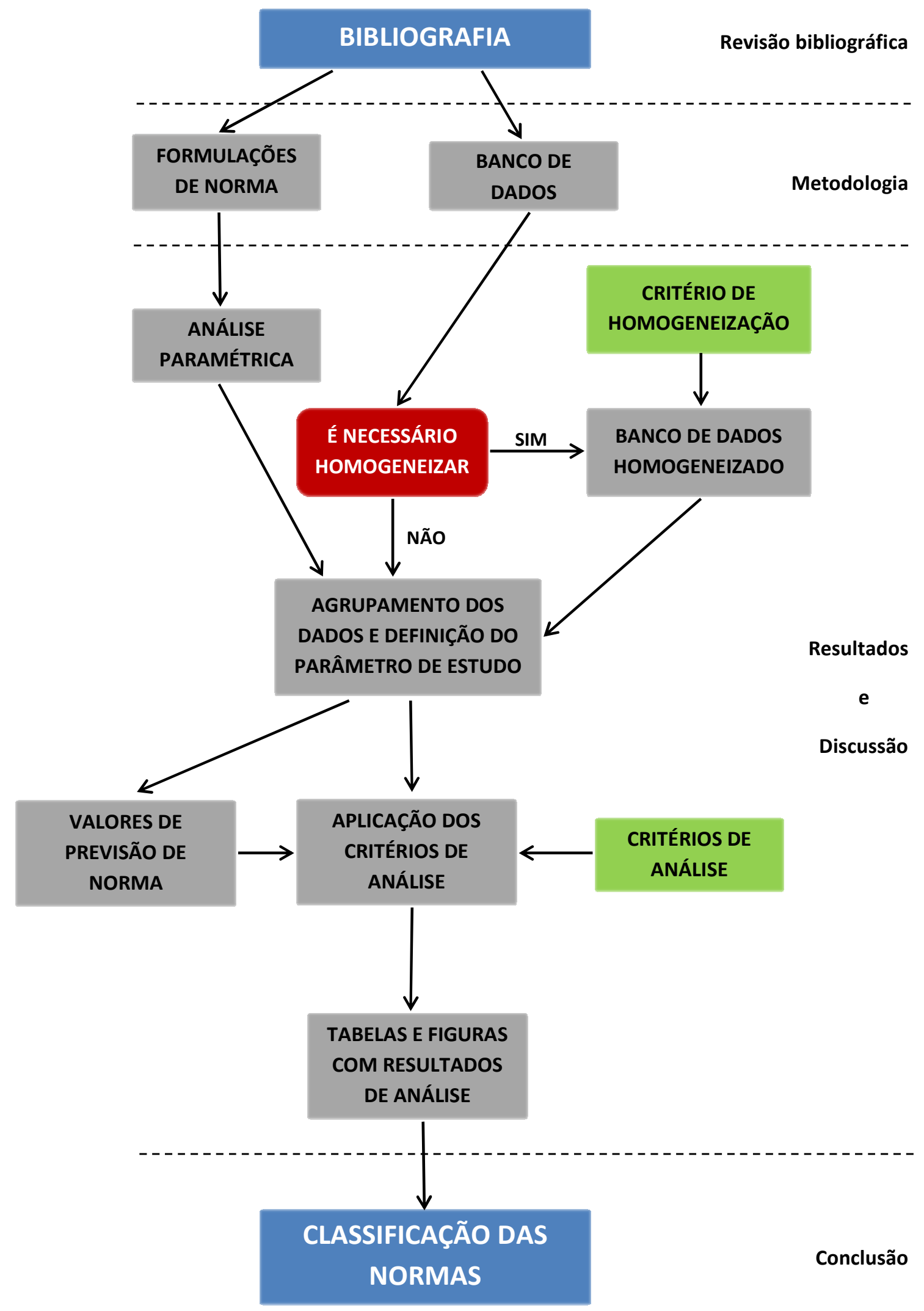

Figura 5.1: Fluxograma das etapas do trabalho 


\section{Resultados e discussão}

A primeira parte do estudo compreende a comparação dos valores das forças resistentes ao cisalhamento para elementos de viga de concreto armado, armado e não armado ao cisalhamento, obtidas a partir das normas descritas no item Revisão Bibliográfica. Para isso, criaram-se diversos casos de análise, que serão mais descridos em seguida.

\subsection{Análise paramétrica}

O processo de análise paramétrica permite verificar a sensibilidade do modelo de cálculo às variações dos parâmetros. Este estudo é extremamente importante, pois indica os intervalos de variação dos parâmetros em que há discrepância entre os resultados dos modelos de predição das normas. Além disso, no estudo paramétrico é simples variar apenas o parâmetro de estudo e fixar os demais, já na análise dos resultados de ensaios de diversos autores, agrupar os dados não é simples, devido a grande variabilidade de parâmetros ensaiados.

Os resultados apresentados encontram-se na forma de gráficos cartesianos, sendo que para o estudo dos elementos de concreto armado com armadura de cisalhamento (estribos) indicou-se no eixo das ordenadas o valor da força cisalhante resistente teórica ultima, $V_{\mathrm{rk}}$, e para os elementos não armados com estribos, a tensão cisalhante resistente característica, $\tau_{\mathrm{rk}}$, ou seja, a força cisalhante resistente de cálculo dividido pela área resistente efetiva $\left(b_{\mathrm{w}} \cdot d\right)$. Os valores característicos, que contemplam a utilização dos fatores de segurança de norma unitários permitem comparar as formulações dos modelos de predição da força cortante das diversas normas, separando a segurança imposta pelos fatores de segurança. Ao fim deste capítulo, no item 6.1.7, será explanado melhor o assunto sobre a consideração ou não dos fatores de segurança.

Para a variação dos parâmetros indicados na Tabela 4.1 e considerando os fatores de segurança de norma, obtiveram-se: os resultados aqui expressos como figuras, em que apenas um dos fatores varia enquanto os demais são mantidos constantes de acordo com os valores indicados na metodologia e nas respectivas figuras.

\subsubsection{Influência da altura, $h$, do elemento}

Foram construídas duas figuras uma para peça com estribos e a outra para peças sem estribos. A Figura 6.1 apresenta a influência da altura do elemento em $V_{r k}$, mantendo-se os demais parâmetros constantes, como preconizado na metodologia e indicado na própria figura. Já a Figura 6.2 mostra a influência da altura do elemento sem estribo em $\tau_{\mathrm{rk}}$, mantendo os demais parâmetros constantes de acordo com a metodologia. 


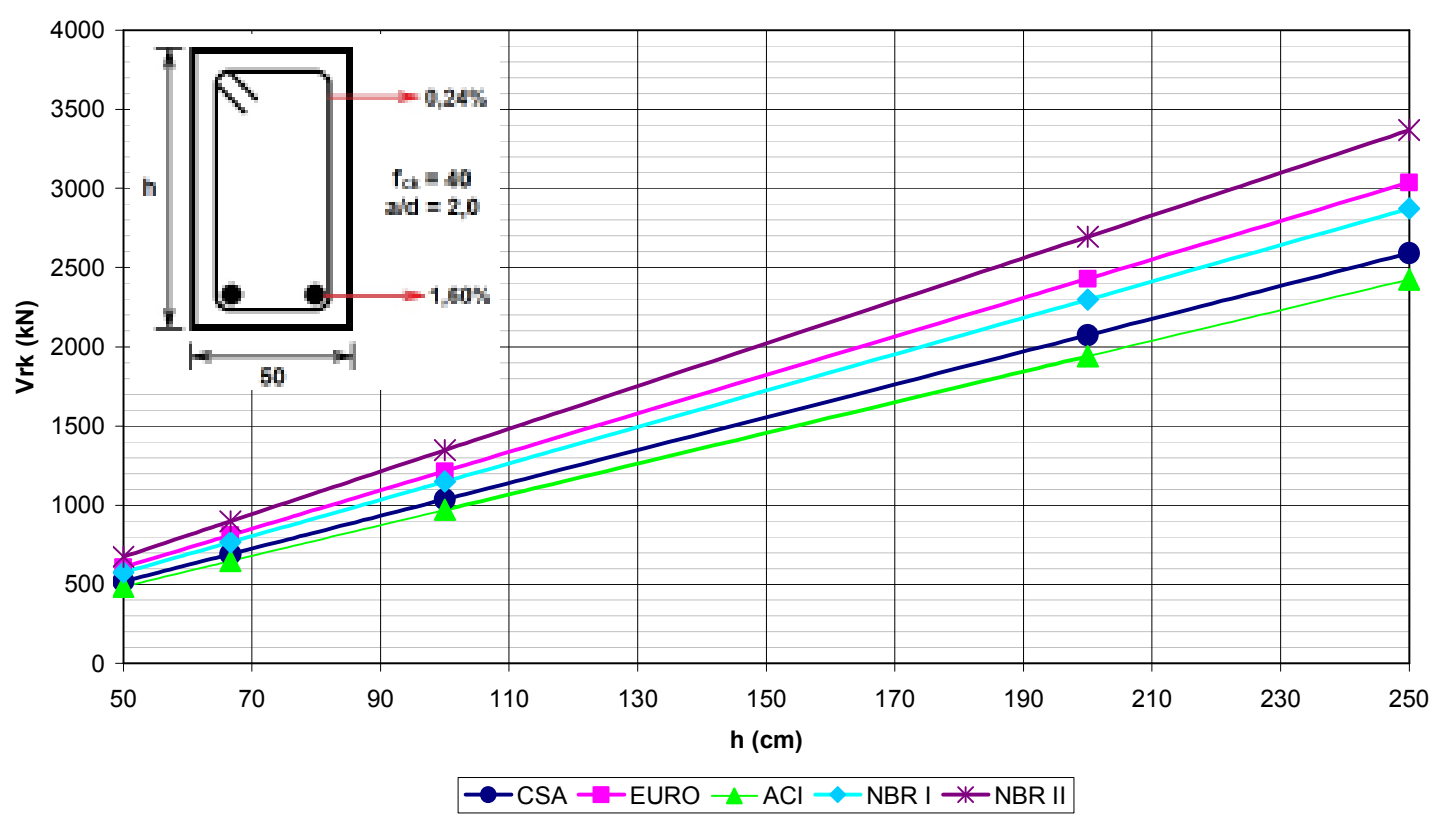

Figura 6.1: Influência da altura ,h, em Vrk (força cisalhante resistente) para peças com estribos, calculado para CSA, EURO, ACI, NBR I e NBR II.

O termo CSA se refere aos valores calculados utilizando a norma CSA (2004), EURO à norma Eurocode (2004), ACl à norma ACI 318M-08 (2008), NBR I ao modelo de cálculo I da norma NBR 6118 (2007), NBR II ao modelo de cálculo II, e o termo NBR indica o modelo de cálculo da NBR 6118 (2007) para elementos sem armadura de cisalhamento.

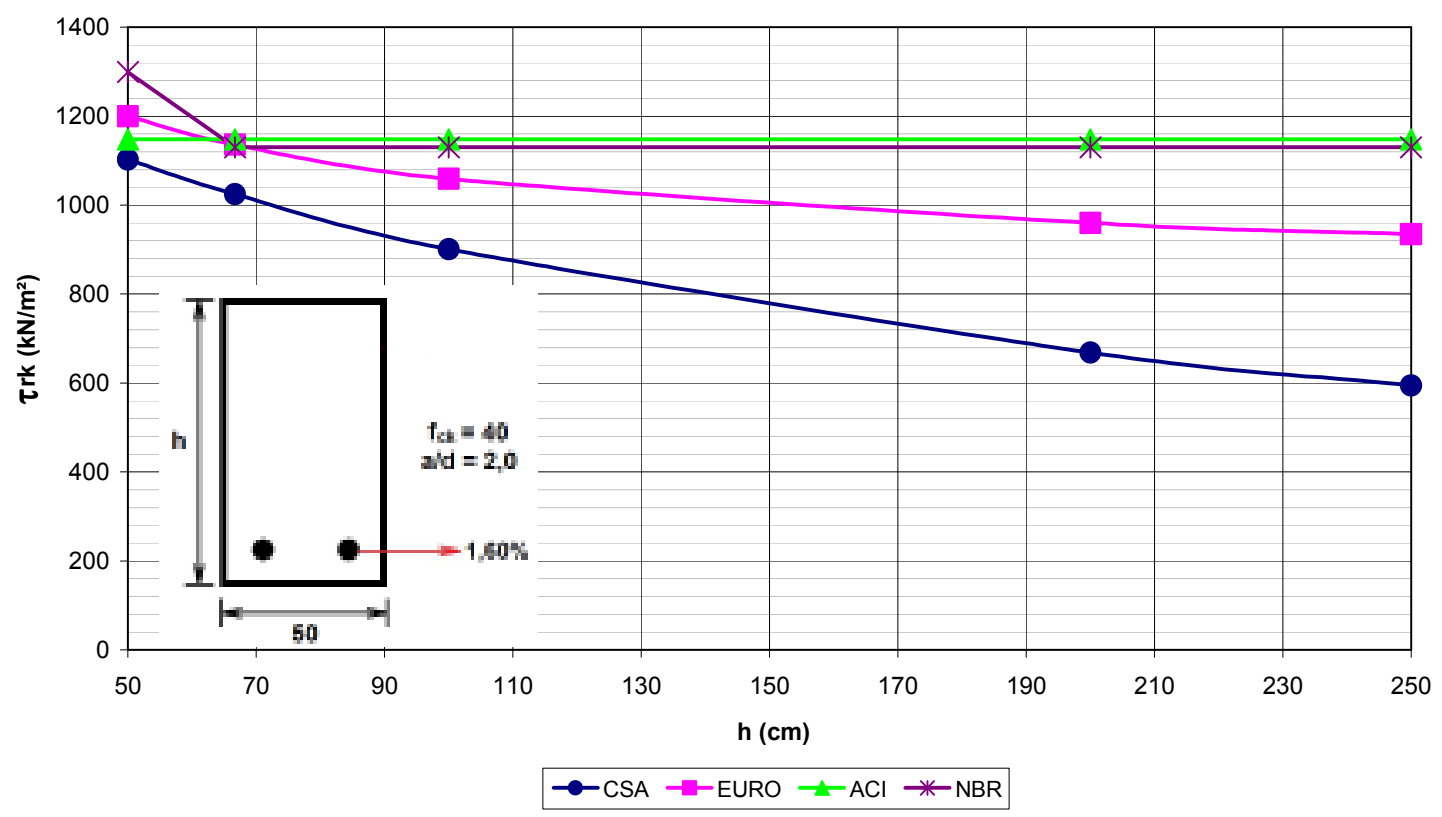

Figura 6.2: Influência da altura ,h, em $\tau$ rk (tensão cisalhante resistente) para peças sem estribos, calculado para CSA, EURO, ACI, NBR.

Nota-se que a influência da altura da peça na resistência ao cisalhamento, para elementos armados ao cisalhamento, é linear e direta, contribuindo para o 
aumento da parcela da força resistente devido ao concreto e indiretamente à parcela da força resistente devido aos estribos. Quanto maior a seção transversal do elemento, maior a força cisalhante resistente devido à capacidade do concreto em resistir à tração. Além disso, como a taxa de armadura transversal é constante, o aumento da seção transversal resulta no aumento da quantidade de estribos, sendo assim, quanto maior a seção do elemento, maior a quantidade de estribos e maior a parcela resistente destes.

Já a Figura 6.3 ilustra que para as peças sem armadura de cisalhamento existe uma redução na tensão resistente devido ao concreto, exceto para o modelo de cálculo da $\mathrm{ACl}$ (2008), em que $\tau_{r k}$ é independente da altura. A redução da tensão cisalhante resistente no concreto, devido ao aumento da altura do elemento, é um fenômeno muito estudado e chamado de efeito de escala ou "size effect".

O efeito da altura na resistência ao cisalhamento em peças com e sem estribos são opostos em linhas gerais. A altura causa uma variação não linear nos resultados calculados para as normas CSA (2004) e Eurocode (2004). No caso da norma NBR 6118 (2007) a relação é inversa até uma altura próxima de 70 $\mathrm{cm}$ e independente da altura de aproximadamente $70 \mathrm{~cm}$ até $250 \mathrm{~cm}$. Neste último intervalo as Normas CSA e NBR são quase coincidentes.

Diversos autores como, Collins et al (1996), Kuntia e Stojadinovic (2001) e Bazant e Sun (1987) detectaram este fenômeno em seus ensaios. Deve-se notar que peças com alturas maiores que $65 \mathrm{~cm}$ o comportamento dos modelos divergem significativamente. $O$ efeito de escala mostra que a redução na tensão cisalhante resistente, com o aumento da altura do elemento, ocorre por causa do surgimento de fissuras de flexão maiores. $\mathrm{O}$ aumento da abertura da fissura devido a flexão diminui o efeito de imbricamento dos agregados na fissura, reduzindo a força cisalhante transmitida pela fissura.

\subsubsection{Influência da resistência do concreto, fck}

Conforme a Figura 6.3 expressa, o Eurocode (2004), por não considerar a contribuição do concreto na resistência ao cisalhamento de peças com estribos, não apresenta ganho de resistência com o aumento da resistência do concreto para peças em que os estado limite de compressão da biela não condiciona o dimensionamento. Além disso, verifica-se a maior proximidade entre os valores resultantes das normas CSA (2004) e ACI (2008). A distinção dos valores previstos para elementos com concreto de alta resistência é notória e digna de uma análise mais completa.

A influência da resistência do concreto, na resistência ao cisalhamento para elementos não armados, é clara, porém a taxa de aumento da resistência ao cisalhamento devido ao acréscimo da resistência do concreto é divergente entre as normas apresentadas. Verifica-se na Figura 6.4, que para elementos com concreto de resistência superior a $50 \mathrm{MPa}$ a formulação derivada do MCFT, norma CSA (2004), indica uma taxa negativa, fenômeno esse oriundo da constatação de que, as fissuras de flexão em peças de concreto com resistência elevada, não se propagam contornando os agregados, mas progridem passando por eles. Sendo assim, a resistência ao cisalhamento fica 
mais influenciada pelas características da matriz composta pela argamassa e agregado.

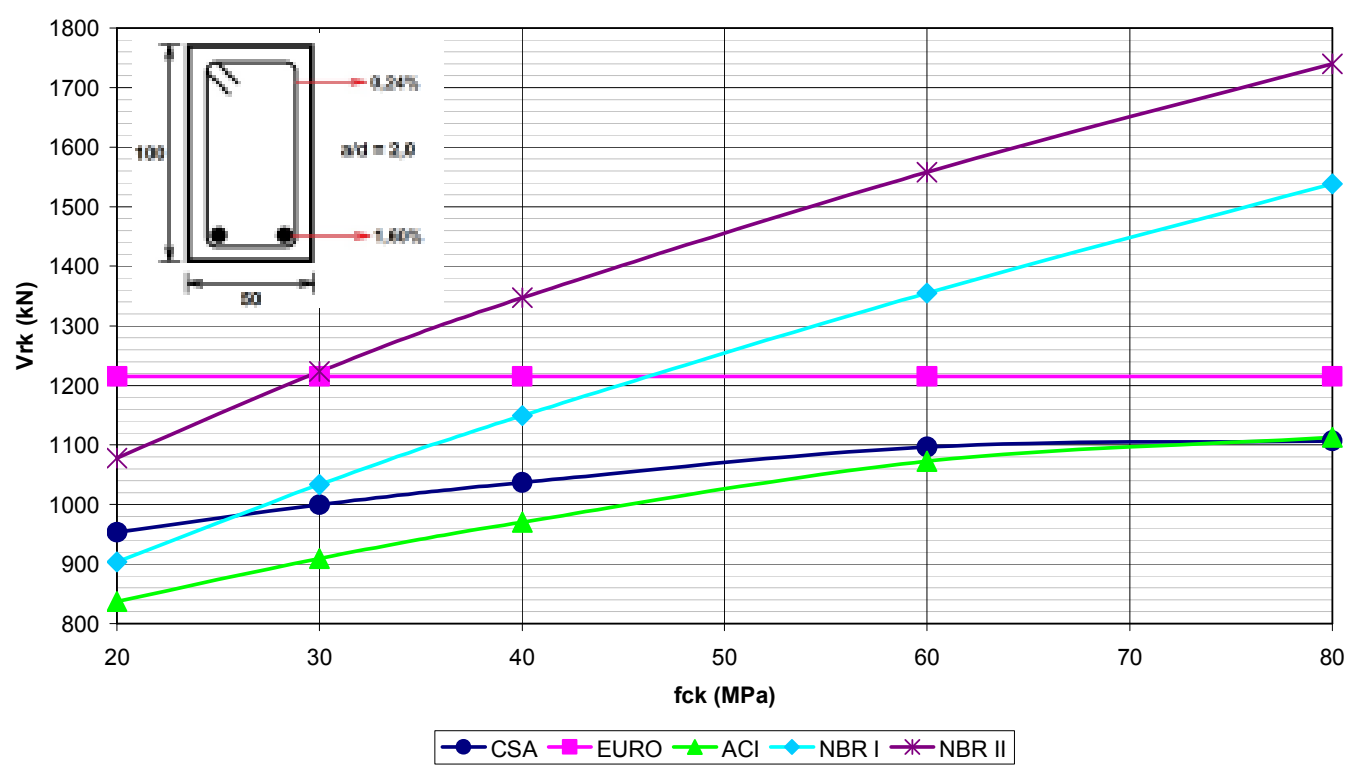

Figura 6.3: Influência da resistência do concreto,fck, em Vrk (força cisalhante resistente) em peças com estribos, calculada para as normas CSA, EURO, ACI, NBR I e NBR II.

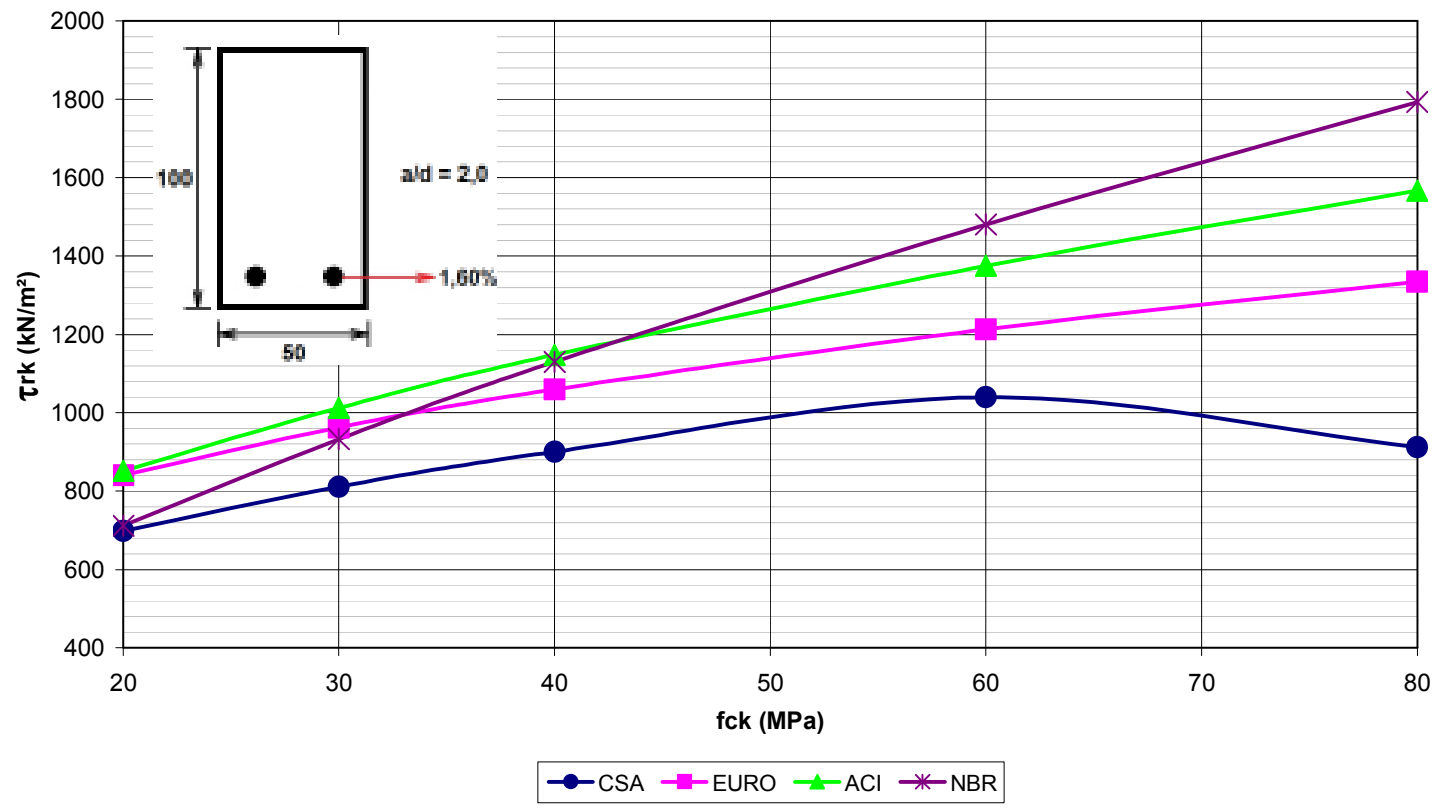

Figura 6.4: Influência da resistência do concreto,fck, em $\tau$ rk (tensão cisalhante resistente) em peças sem estribo, calculada para as normas CSA, EURO, $\mathrm{ACl}, \mathrm{NBR}$.

A influência da resistência do concreto é não linear para as normas $\mathrm{ACl}$, CSA e NBR I e II, e independente para a norma Eurocode, quando se trata de elementos de concreto armado (Figura 6.3). Para elementos não armado notase que o comportamento a influência da resistência do concreto é não linear para todas as normas. 
Por fim nota-se que tanto para elementos armados com estribos como para elementos não armados, quando utilizado concreto de resistência superior à $50 \mathrm{MPa}$ os modelos de predição de norma apresentam resultados distantes, dignos de um análise pontual.

\subsubsection{Influência da taxa de armadura transversal de cisalhamento}

O gráfico da Figura 6.5 expressa o aumento da resistência ao cisalhamento devido ao aumento da taxa geométrica da armação transversal (estribos) em elementos de concreto armado.

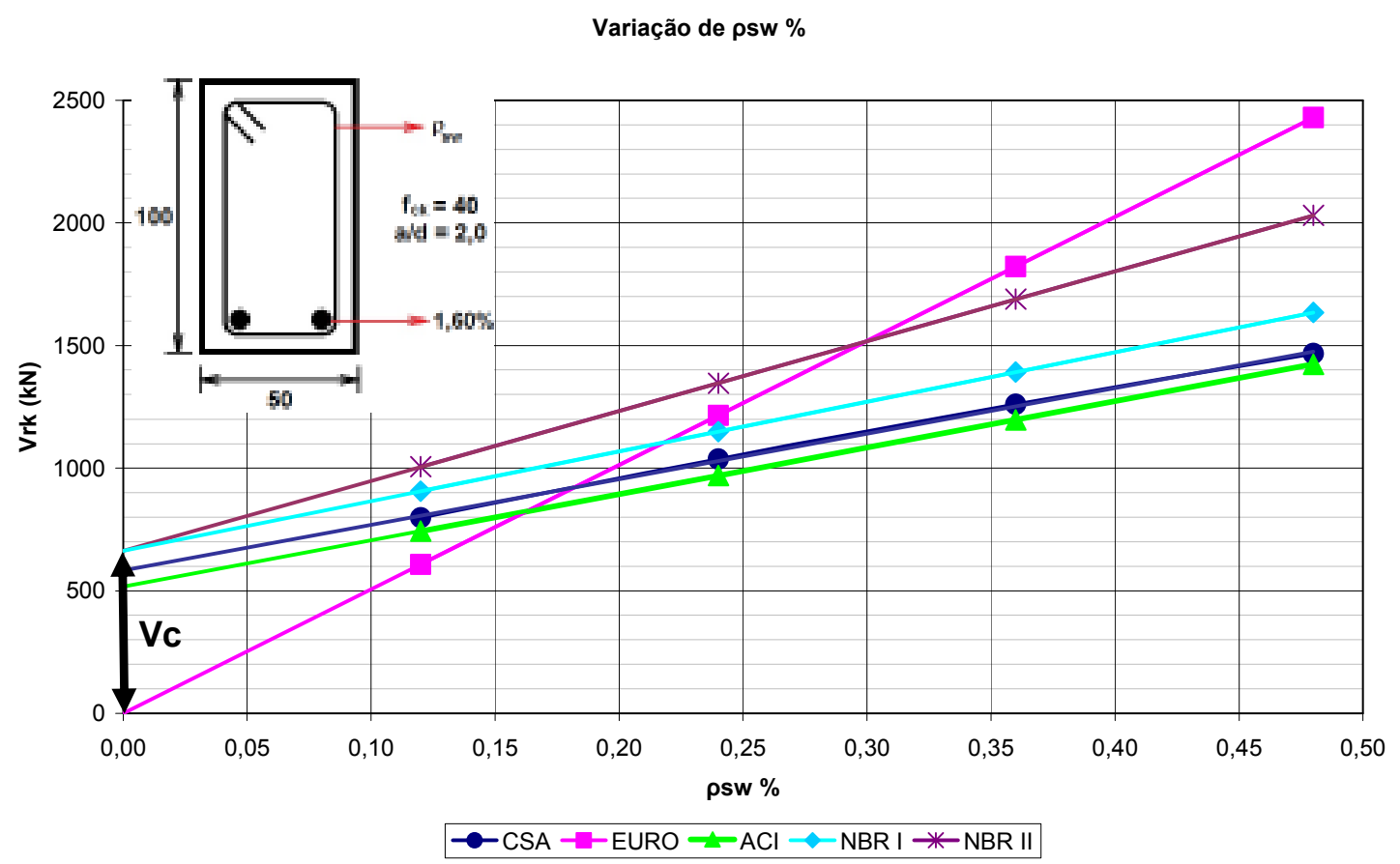

Figura 6.5: Influência da taxa geométrica de armação transversal, $\rho_{s w}$, em Vrk (força cisalhante resistente) em peças com estribos, calculada para as normas CSA, EURO, ACI, NBR I e NBR II.

As formulações de norma utilizam a mesma equação de equilíbrio para a determinação da força resistente ao cisalhamento devido aos estribos, obtida na formulação da treliça generalizada, o fator que difere entre as normas é a determinação do ângulo de inclinação da biela, $\theta$. A equação (4.2) indica o aumento linear da força resistente devido ao acréscimo de armadura transversal de cisalhamento, indicado pelas retas apresentadas na Figura 6.5. Neste caso, verifica-se um comportamento semelhante entre as normas, exceto pelo Eurocode (2004), pois este não considera a contribuição do concreto, $V_{c}$, na resistência ao cisalhamento de peças armadas com estribos. Verifica-se ainda que para uma faixa de $\rho_{\text {sw }}$ estreita entre $0,125 \%$ a 0,25 \% as normas apresentam resultados próximos. 


\subsubsection{Influência da taxa de armadura longitudinal de flexão}

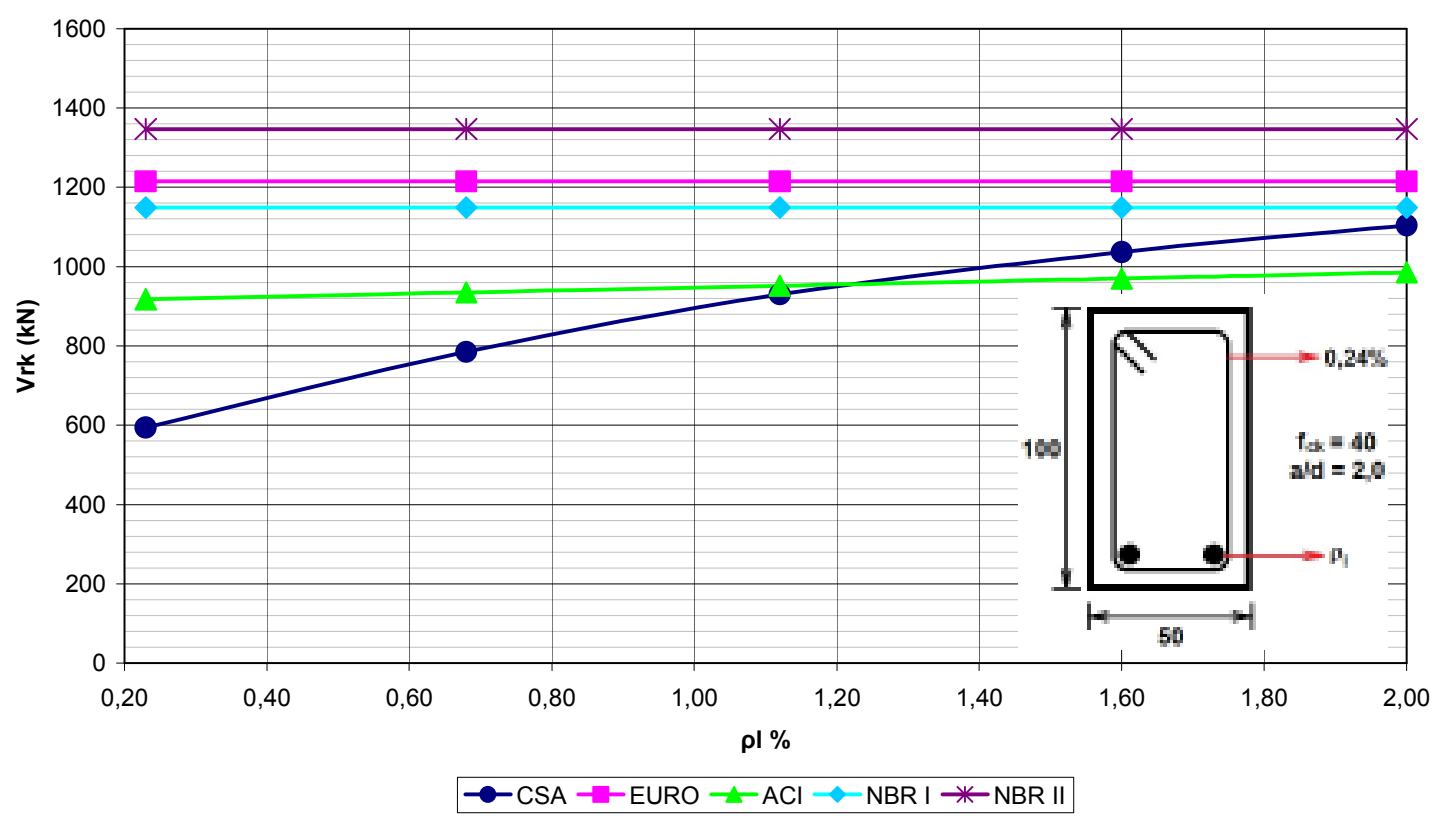

Figura 6.6: Influência da taxa de armadura longitudinal de peças com estribos, $\rho_{l}$, em Vrk (força cisalhante resistente) em peças com estribos, calculada para as normas CSA, EURO, ACI, NBR I e NBR II.

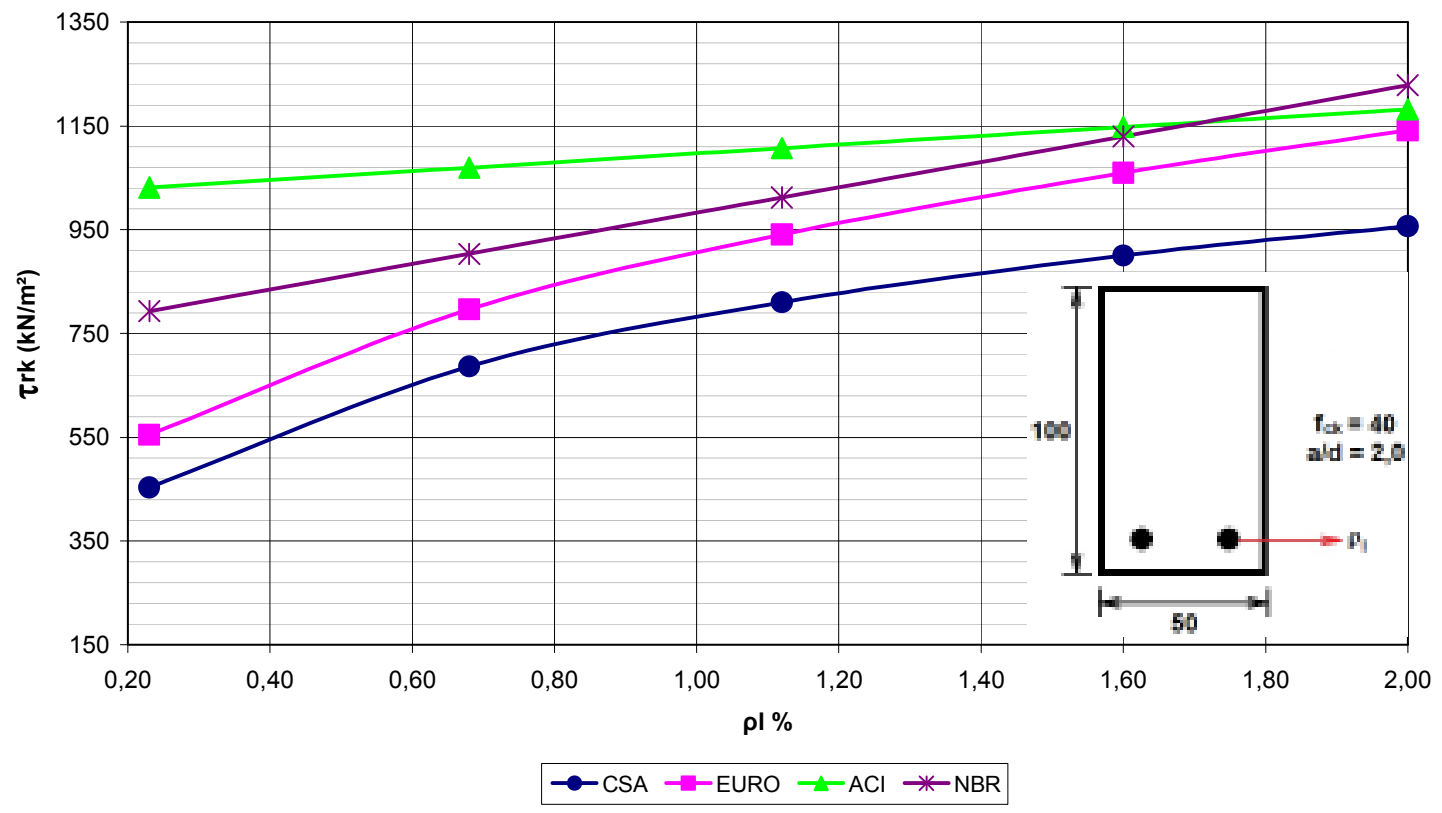

Figura 6.7: Influência da taxa de armadura longitudinal, $\rho_{l}$, em $\tau$ rk (tensão cisalhante resistente) em peças sem estribos, calculada para as normas CSA, EURO, $\mathrm{ACl}, \mathrm{NBR}$.

A influência da taxa de armadura longitudinal de flexão na resistência ao cisalhamento de elementos armados com estribo, ver Figura 6.6, não é significante para os modelos de norma, exceto para a CSA (2004), que prevê redução da força cisalhante resiste para peças com baixa densidade de armadura longitudinal de flexão. 
Para os casos de baixa densidade e armadura longitudinal de flexão, optou-se por não verificar a possibilidade de ocorrer uma ruptura por flexão antes da ruptura por cisalhamento, pois isto envolveria analisar também os modelos de dimensionamento a flexão das normas, e não seria o foco deste estudo paramétrico, que apresenta um caráter acadêmico e orientativo para as próximas etapas.

Nota-se na Figura 6.7 o ganho de resistência ao cisalhamento com o aumento da taxa geométrica de armação longitudinal de flexão para elementos sem estribos, e que confere características semelhantes entre as taxas de aumento das normas, exceto para a ACl 318M-08 (2008), que apresentou uma baixa taxa de ganho de resistência com o aumento da taxa de armadura longitudinal. O foco a ser estudado será o intervalo de baixa taxa de armadura, ou seja, menor que $1,0 \%$.

\subsubsection{Influência da tensão normal solicitante}

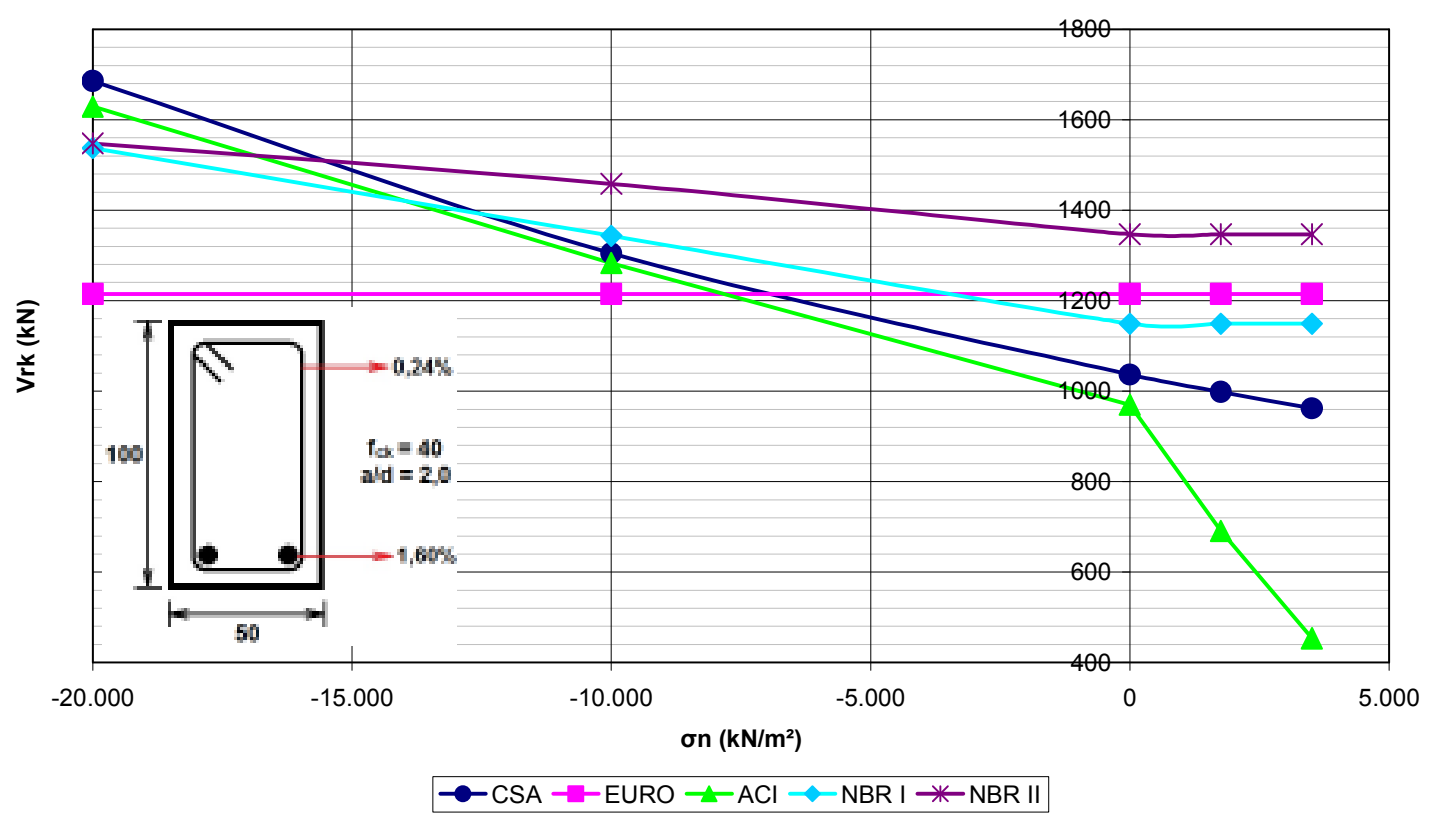

Figura 6.8: Influência da tensão axial normal solicitante, $\sigma_{n}$, em $V_{r k}$ (força cisalhante resistente) em peças com estribos, calculada para as normas CSA, EURO, ACI, NBR I e NBR II.

Os valores de tensões normais negativas indicam compressão e os valores positivos tração. 


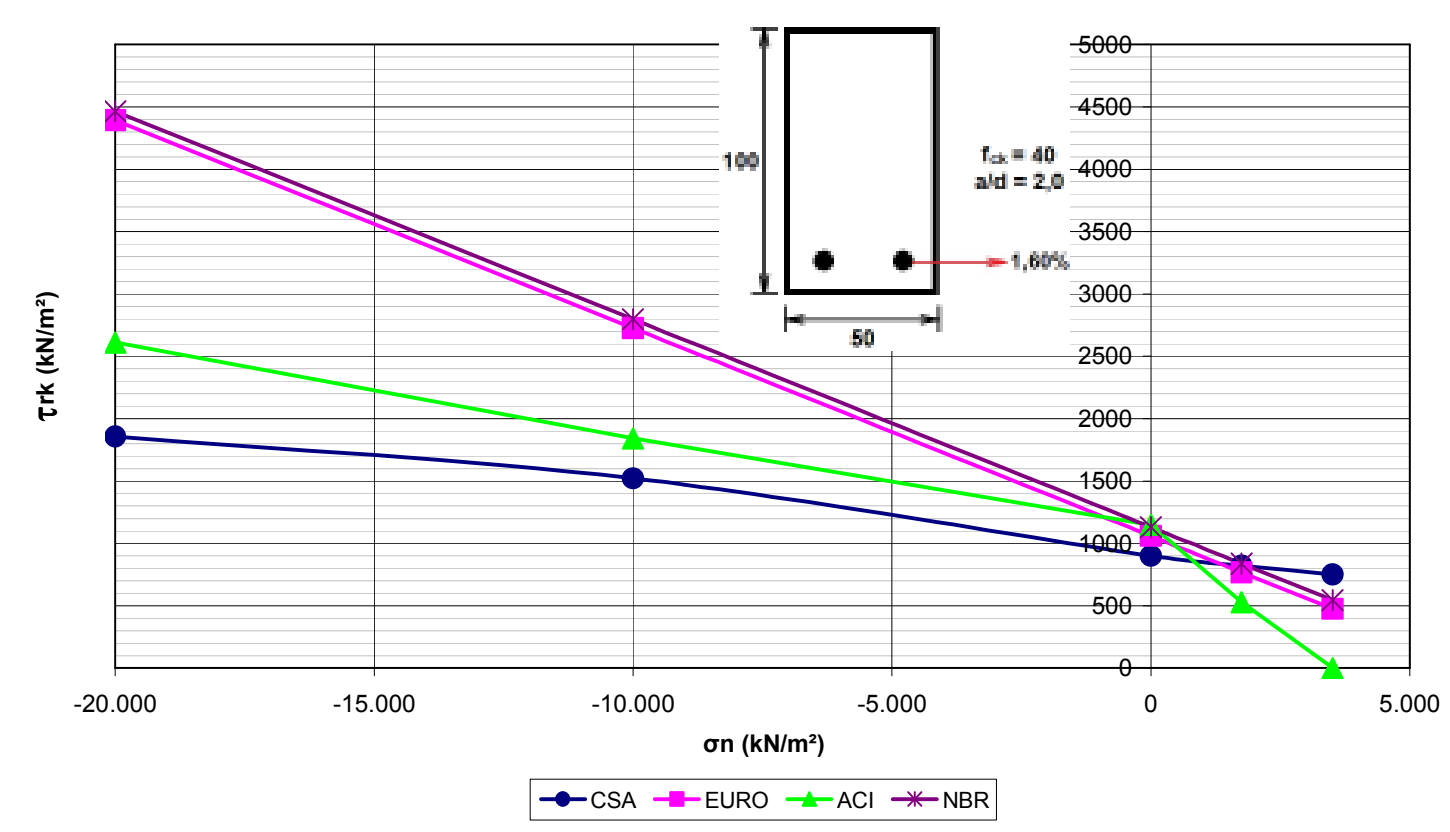

Figura 6.9: Influência da tensão normal solicitante, $\sigma_{n}$, em $\tau$ rk (tensão cisalhante resistente) em peças sem estribos, calculada para as normas CSA, EURO, $\mathrm{ACl}, \mathrm{NBR}$.

Os gráficos apresentados (Figura 6.8 e Figura 6.9) indicam que a contribuição de tensões normais de compressão ou a influência negativa das tensões normais de tração são abordadas diferentemente entre as normas estudadas. Para os elementos com estribos, verifica-se que inicialmente todas as formulações de norma responder semelhantemente para elementos sujeitos a esforços de compressão, exceto para a norma Eurocode, que não apresenta influência positiva entre as tensões de compressão e a tensão cisalhante resistente.

A Figura 6.9 indica que para elementos sem estribos as normas CSA e ACl apresentaram resultados semelhantes, assim como as normas EURO e NBR. O ganho de resistência com o aumento da tensão de compressão, em módulo, é mais pronunciado para os modelos de predição das normas EURO E NBR.

Para os elementos com e sem estribos, nota-se que a influência negativa da tensão axial de tração na resistência ao cisalhamento é abordada diferentemente entre as normas, sendo a $\mathrm{ACl}$ a norma que mais penaliza a resistência devido ao aumento da tração.

Com a análise paramétrica torna-se evidente que alguns modelos de norma preveem razoavelmente a influência de forças normais em certos intervalos, enquanto outras expressam resultados distantes dos previstos em ensaios. Este assunto está sendo estudado ao longo de décadas por diversos autores, como por exemplo: Mattock e Wang (1984), Shrinivas e Collins (1989), Zararis e Zararis (2008) e Xie et al (2011). Com isso, mostrou-se indispensável analisar os efeitos de forças normais na determinação dos esforços cisalhantes resistentes. 


\subsubsection{Influência do índice de esbeltez}

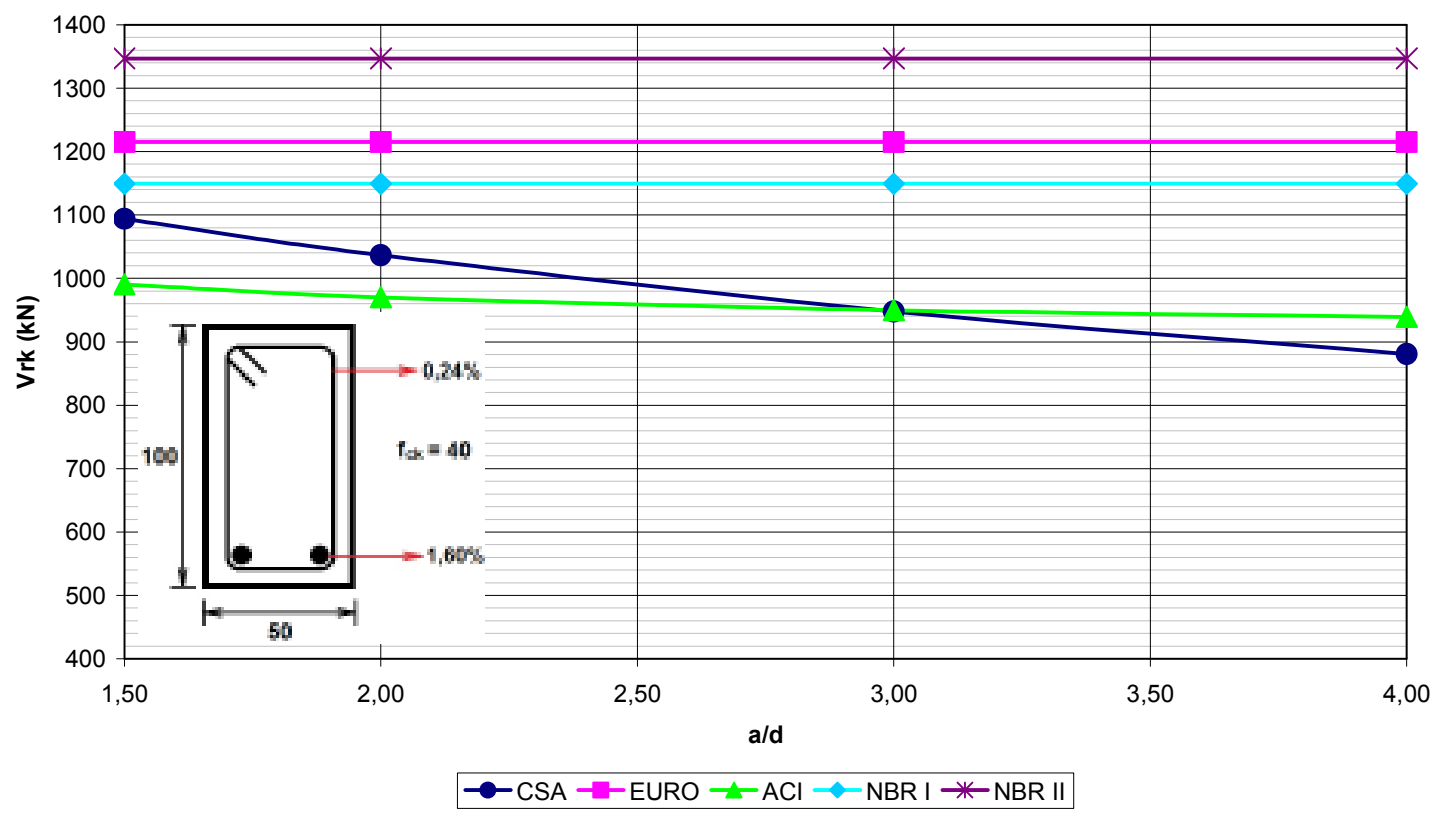

Figura 6.10: Influência do índice de esbeltez, a/d, em Vrk (força cisalhante resistente) em peças com estribos, calculada para as normas CSA, EURO, ACI, NBR I e NBR II.

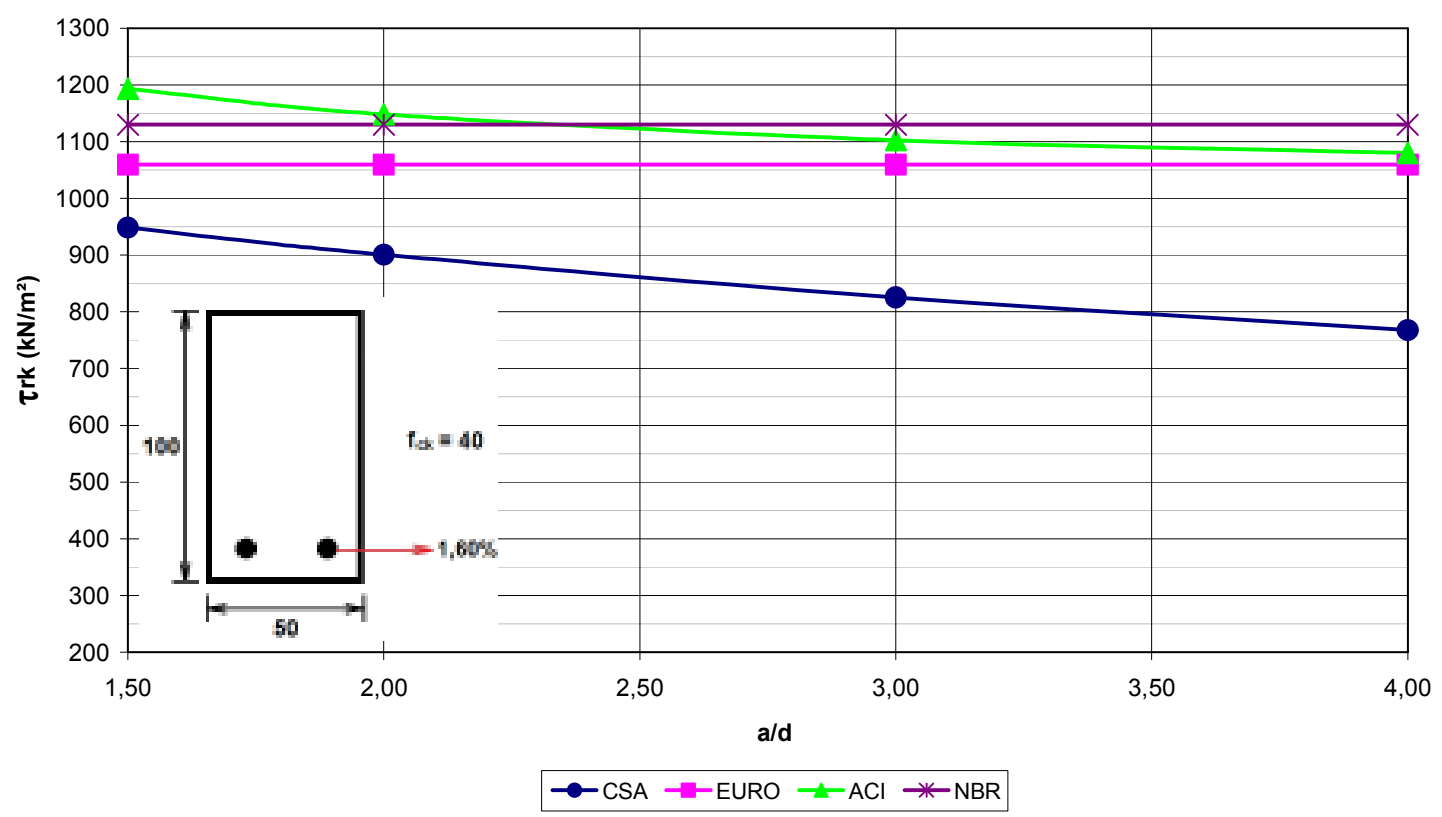

Figura 6.11: Influência do índice de esbeltez, a/d, em $\tau$ rk (tensão cisalhante resistente) em peças sem estribos, calculada para as normas CSA, EURO, ACI, NBR.

A influência da flexão na resistência ao cisalhamento em elementos ao cisalhamento com estribos mostra que as normas CSA e $\mathrm{ACl}$ indicam uma redução significativa da força cisalhante resistente, com o aumento do índice de esbeltez. A CSA (2004) considera a deformação axial da peça na determinação dos parâmetros de resistência, e quanto maior a solicitação de flexão, maior a deformação axial de alongamento e menor a eficiência da peça 
quando solicitada por esforços cisalhantes. A ACl reduz a eficiência da armadura longitudinal devido ao aumento dos esforços solicitantes de flexão.

Para ambos os casos, as normas EURO e NBR não indicaram um influência considerável do índice de esbeltez na resistência ao cisalhamento.

Sendo assim, a análise paramétrica confirma a importância de se analisar tal fenômeno e ressalta-se que baseado nas constatações de Kani (1964) separaram-se os elementos com relações a/d menores que 2,5, pois estes, não apresentam comportamento de vigas de Bernoulli, estando sujeitos a estados de tensões peculiares. A determinação dos esforços resistentes de cisalhamento para estes elementos $(a / d<2,5)$ se dá por outros modelos, por exemplo, o modelo de biela e tirante, que não serão contemplados neste estudo. Desta forma, o intervalo de interesse será para relações maiores que 2,5 .

\subsubsection{Influência dos fatores de segurança das normas}

Os coeficientes de segurança das normas podem ser separados em dois tipos: os majoradores dos esforços solicitantes e os redutores das resistências. Os coeficientes de segurança majoradores dos esforços solicitantes contemplam a incerteza e probabilidade de ocorrência do esforço solicitante, assim como a incerteza dos modelos físicos ou matemáticos que determinam os esforços solicitantes, e por fim a importância da solicitação. Para este estudo, definiu-se a premissa de que não será contemplada a análise da segurança relativa aos esforços solicitantes, devendo assim, considerar os coeficientes de majoração das cargas unitários, pois a análise de confiabilidade destes fatores de segurança seria fruto de outro estudo, com um viés nos esforços solicitantes.

Segundo item R9.3.1 da norma $\mathrm{ACl}$ (2008) o propósito do fator de redução das resistência é:

1. Permitir uma provável redução da resistência do elemento devida as variações nas dimensões e resistência do material;

2. Permitir a inexatidão das equações de norma;

3. Refletir o grau de ductilidade e confiabilidade necessário para o elemento carregado, e

4. Refletir a importância do elemento na estrutura.

Sendo assim, considerando que os ensaios foram executados em laboratórios, com o maior rigor possível para redução de variabilidades de geometria e materiais, definiu-se como premissa, que os coeficientes de redução das resistências possuem basicamente dois elementos principais, que são: a inexatidão das equações do modelo da norma e provável redução da resistência dos materiais.

A consideração de que a variabilidade geométrica do elemento é pequena se torna compreensível, ao considerar que os ensaios de laboratório foram executados minuciosamente. A pequena variabilidade na confeç̧ão dos 
materiais compreende para o concreto e para o aço, que a resistência do material, ao longo de toda a peça moldada, não possui variações em relação ao valor médio, com isso, o valor característico de projeto, que representa um quantil seguro, está relativamente próximo do valor médio. Portanto, não implicará em uma influencia negativa considerável, utilizar o valor médio medido através dos corpos de prova como o valor característico de projeto, $f_{c k}$ ou $f_{c}$.

A questão mais importante é que durante a fase de elaboração de um projeto, - projetista deve considerar os fatores de segurança de redução das resistências e este deve contemplar os quatro itens mencionados acima pela $\mathrm{ACl}$ (2008) para garantir uma segurança mínima. Assumindo a premissa que as condições de ensaios em laboratório são quase ideais e que a segurança do modelo resistente é representada por duas parcelas principais, ao se analisar a segurança da norma através da probabilidade de ruína, se torna evidente que se deve considerar o coeficiente de redução da resistência, pois este possui uma parcela responsável pela correção do valor esperado devido a inexatidão dos modelos e equações de norma. Sem conhecer profundamente a elaboração e as parcelas que compõe cada coeficiente de segurança, não é possível separar a parcela responsável pela segurança devido à redução da resistência do material, da parcela responsável pela inexatidão do modelo. Deve-se salientar que a utilização do conceito de probabilidade de ruína, neste trabalho, refere-se apenas aos esforços resistentes. A real probabilidade de ruína ocorre da concomitância da probabilidade dos esforços solicitantes serem maiores que um valor adotado e da probabilidade dos esforços resistentes serem menores que um valor mínimo esperado.

Procurando exemplificar tais argumentações, seguem dois exemplos simples de comparação entre resultados em valores características (coeficientes de segurança unitários) e valores de cálculo (coeficientes de segurança de norma).

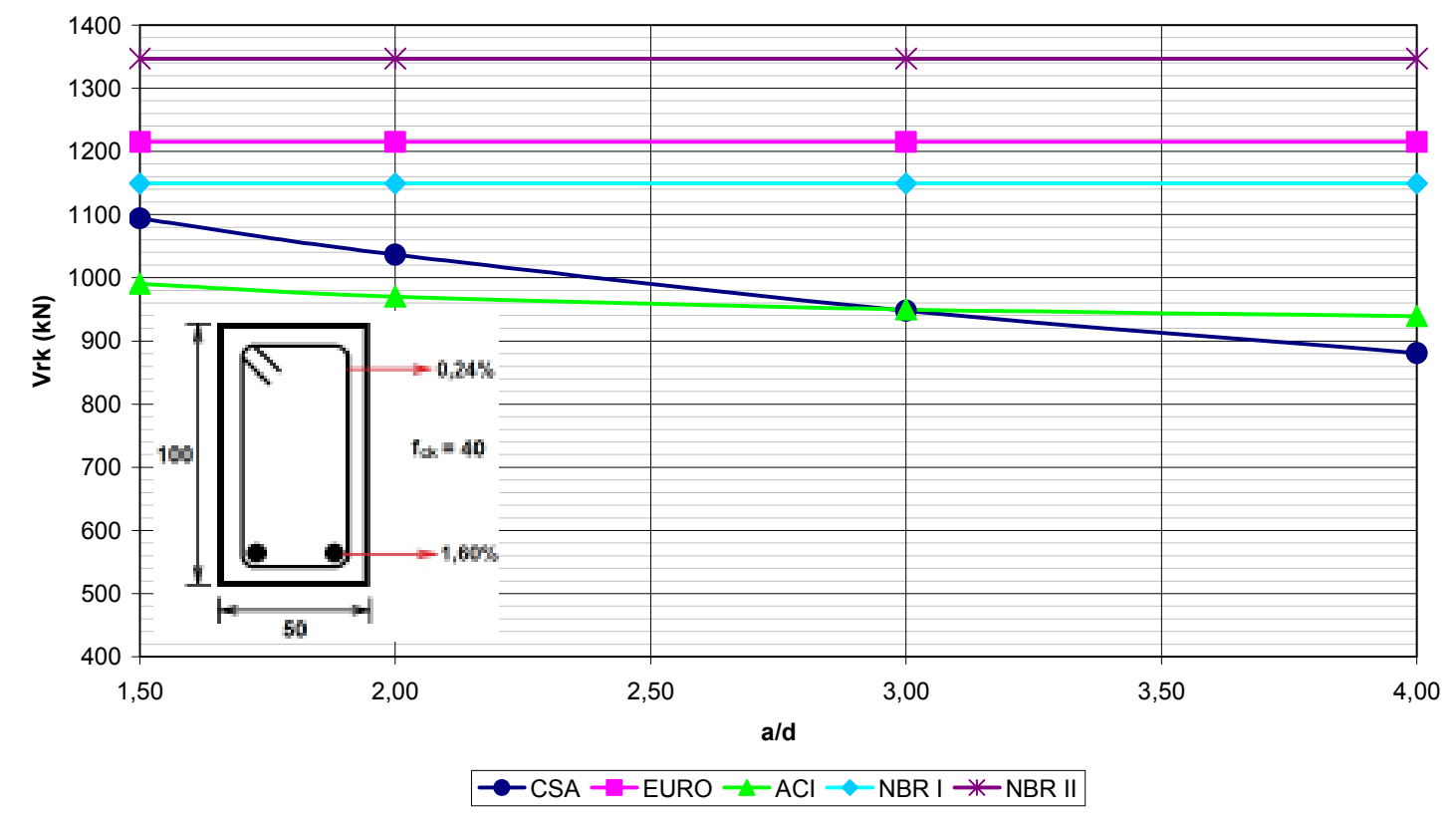

Figura 6.12: Elementos com estribos e fatores de segurança unitários 
O Primeiro exemplo mostra através da comparação entre resultados de predição de norma com e sem a utilização dos coeficientes de segurança para elementos armados com estribos, a importância da segurança implícita tanto no modelo como no coeficiente de segurança.

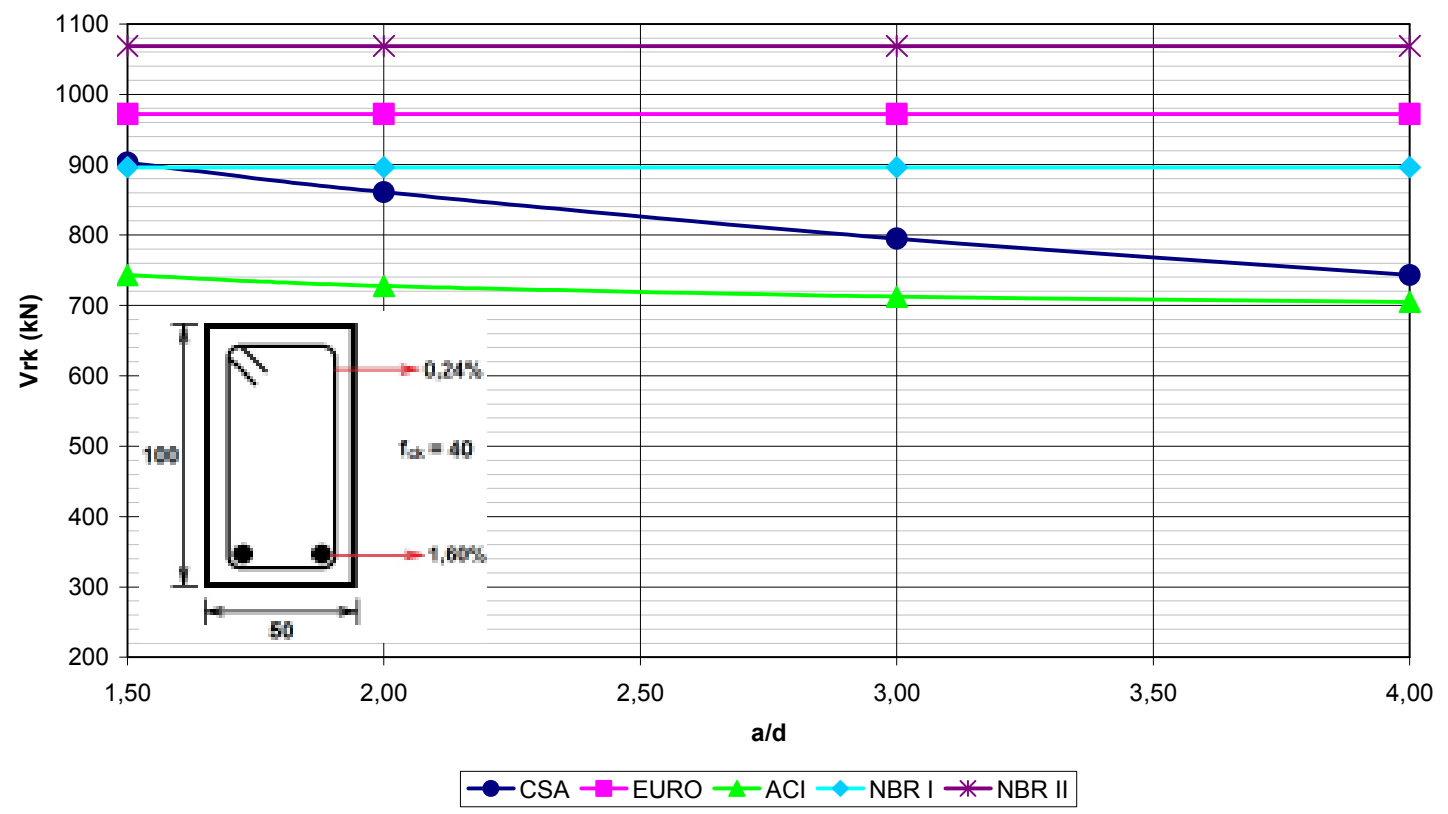

Figura 6.13: Elementos com estribos e fatores de segurança de norma

Analisando a Figura 6.12, que não considera a redução das resistências, podese perceber que, para grande relação de $a / d$, a análise puramente da força cortante resistente indica a norma CSA (2004) como mais conservadora, relativamente. Por outro lado, na Figura 6.2, a consideração dos coeficientes de segurança de norma, permite notar que a norma $\mathrm{ACl}$ (2008) se torna, neste intervalo, a mais conservadora.

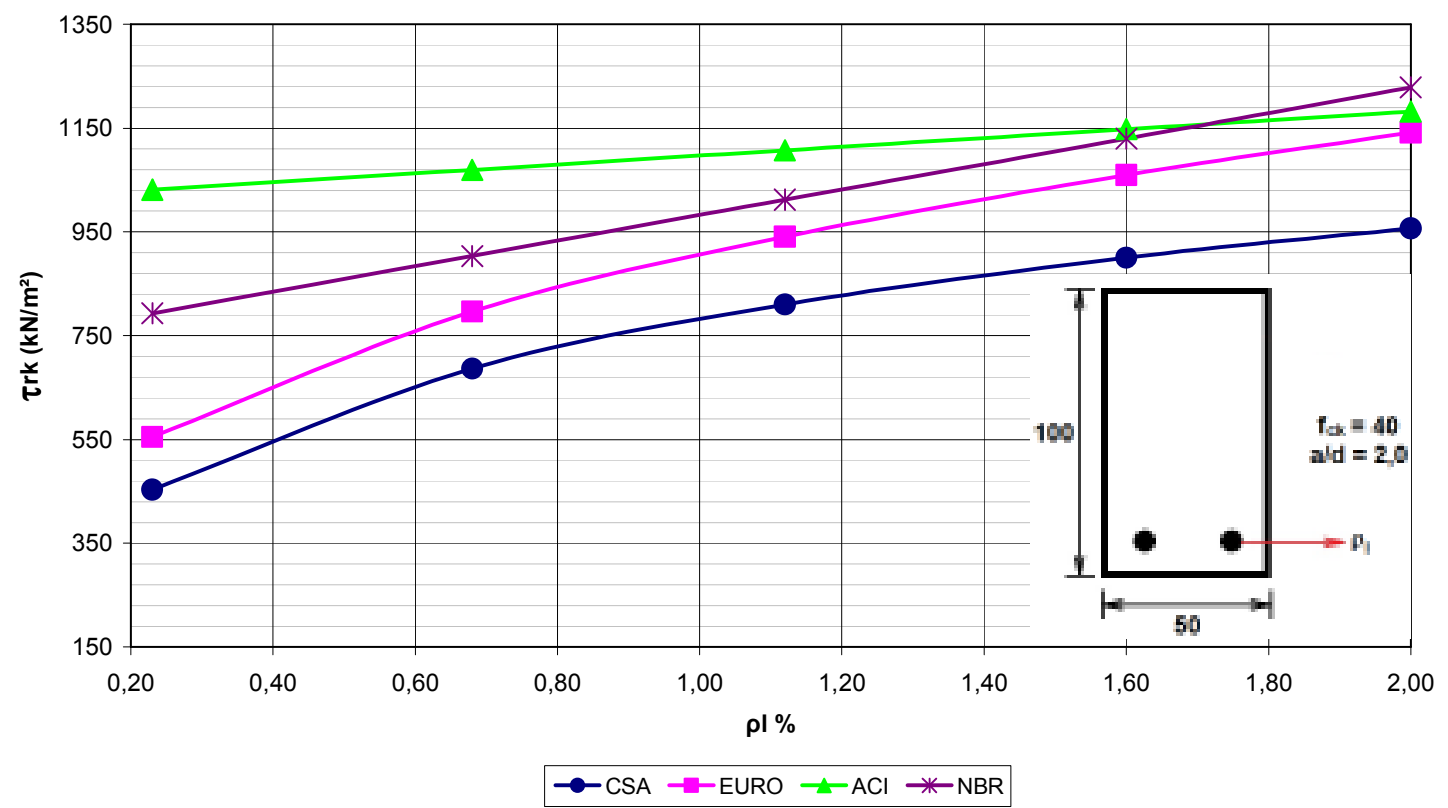

Figura 6.14: Elementos sem estribos e fatores de segurança unitários 


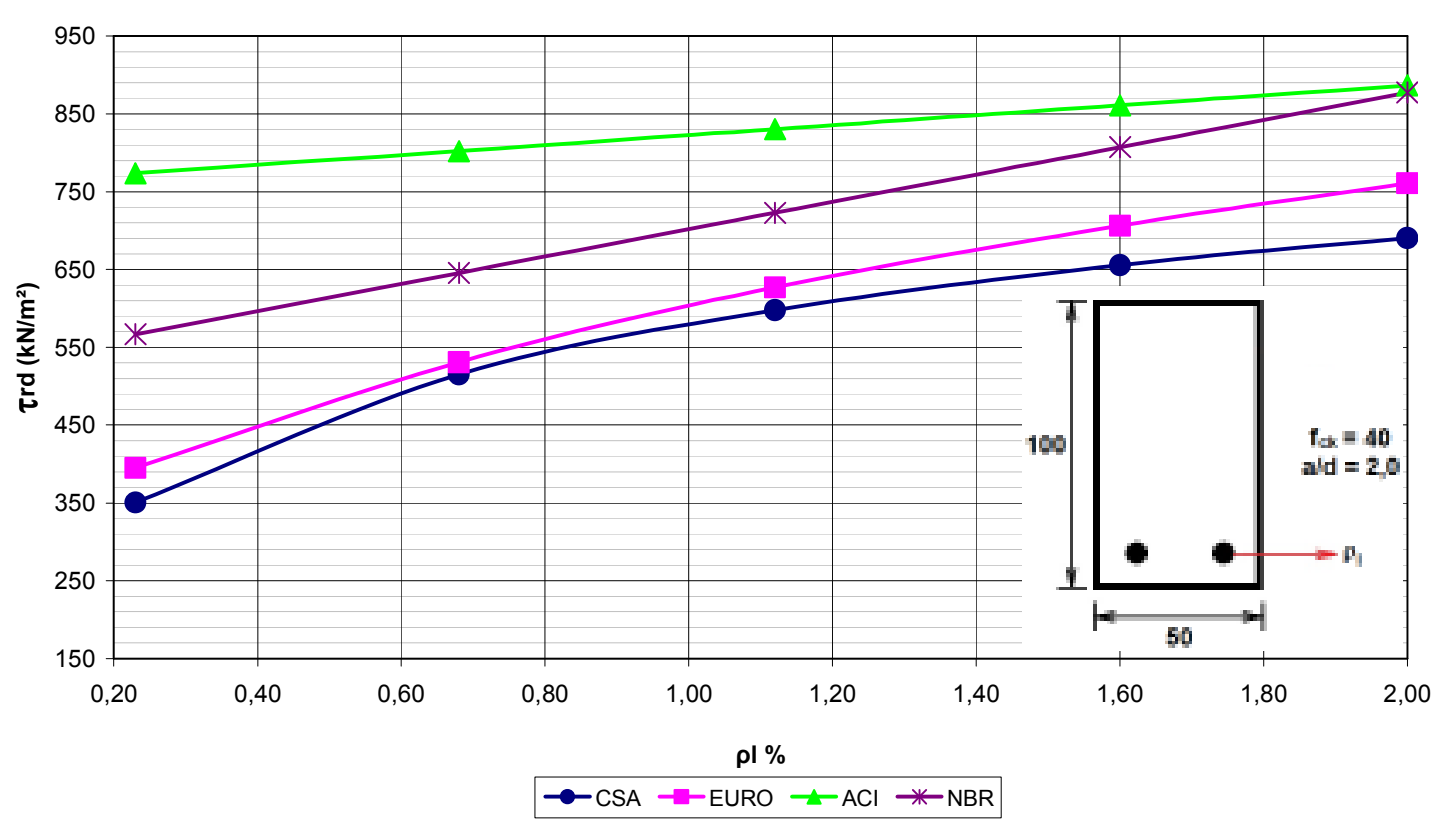

Figura 6.15: Elementos sem estribos e fatores de segurança de norma

Para elementos sem estribos, a Figura 6.15 ilustra que com a utilização dos coeficientes de segurança de norma os valores de predição das normas Eurocode (2004) e CSA (2004) apresentam-se equivalentes, algo que não existe na Figura 6.14. Isto ocorre porque os fatores de segurança de cada norma são diferentes. O estudo destes fatores e sua análise seria necessária outra dissertação ou de uma tese, apresentando os estudos de confiabilidade e analisando a segurança das normas.

\subsection{Análise dos Valores de Previsão das Normas}

Baseado nos resultados da análise paramétrica notou-se que cada norma possui uma sensibilidade quanto a variação de certo parâmetro de resistência, com isso tornou-se evidente que seria necessário verificar a aproximação entres os resultados dos modelos de predição de norma e os resultados de ensaios de laboratório. Para isso elaborou-se os bancos de dados para elementos com e sem estribos, que indicaram ruptura com força cortantetração, conforme descrito no item 5.2. e apresentados na Tabela 6.1, para elementos com estribos e na Tabela 6.2, para elementos sem estribos.

A análise e comparação entre os resultados de ensaios de laboratório e os resultados dos modelos de predição de norma para elementos de concreto armado com estribos que apresentaram ruptura com esmagamento do concreto, está apresentado no item 6.7. Para esta análise elaborou-se um banco de dados, cujos parâmetros e resultado de ensaio estão expressos na Tabela 6.32.

O item 6.8 apresenta a análise comparativa entre os resultados de ensaios e valores de predição de norma para elementos de concreto armado, com e sem estribos, solicitados por esforços axiais normais, de compressão e tração. 0 
banco de dados utilizado encontra-se indicado na Tabela 6.36 (sem estribos) e Tabela 6.41 (com estribos).

Ressalta-se que a análise dos valores de predição de norma para elementos que apresentam ruptura por força cortante-tração, possui caráter qualitativo e quantitativo, devido ao grande número de resultados de ensaios. Já as analises de elementos que apresentaram ruptura por esmagamento do concreto ou por influência de esforços axiais normais, devido ao menor número de ensaios, a análise possui um caráter qualitativo.

Desta forma, procede-se com apresentação dos bancos de dados utilizados para análise dos ensaios que apresentaram ruptura por força-cortante tração sem a influência de esforços axiais normais. A Tabela 6.1 apresenta os dados de ensaios de elementos com estribos e a Tabela 6.2 sem estribos. 
Tabela 6.1: Banco de dados compilado a partir de resultados experimentais de literatura, para elementos com estribos.

\begin{tabular}{|c|c|c|c|c|c|c|c|}
\hline Autor & \begin{tabular}{|c|}
$\begin{array}{c}\text { Número } \\
\text { de } \\
\text { Ensaios }\end{array}$ \\
\end{tabular} & d (cm) & fc (MPa) & pl \% & $\rho s w \%$ & $a / d$ & $\begin{array}{l}\text { psw.fyk } \\
\text { (MPa) }\end{array}$ \\
\hline $\begin{array}{l}\text { Anderson, N. S. Ramirez, J. A. } \\
(1989)\end{array}$ & 13 & $34,5-42,53$ & $28,69-42,76$ & $2,31-2,65$ & $0,39-0,53$ & $2,15-2,65$ & $2,14-2,83$ \\
\hline $\begin{array}{l}\text { Angelakos, D.; Bentz, E. C.; Collins } \\
\text { M. P. (2001) }\end{array}$ & 6 & 92,50 & $21-80$ & $0,5-1,01$ & 0,08 & 2,92 & 0,40 \\
\hline Bahl (1968) ${ }^{\mathrm{a}}$ & 4 & $30-120$ & $25,1-26,8$ & 1,26 & 0,15 & 3,00 & 0,66 \\
\hline Bresler ; Scordelis (1963) & 10 & $39-46,61$ & $23,17-38,75$ & $1,8-3,66$ & $0,1-0,38$ & $2,35-6,98$ & $0,33-1,26$ \\
\hline Bresler ; Scordelis (1966) ${ }^{a}$ & 22 & $45,67-46,25$ & $23,17-26,75$ & $1,67-2,34$ & $0,1-0,21$ & $3,95-4,01$ & $0,35-0,7$ \\
\hline Cho, S. H. (2003) & 24 & 21,50 & $52-73$ & 3,77 & $0,2-1,8$ & $1,5-2,5$ & $0,78-6,98$ \\
\hline Cladera, A.; Marí, A. R. (2005) & 11 & $35,1-35,3$ & $49,9-87$ & $2,28-2,99$ & $0,11-0,24$ & $3,06-3,08$ & $0,58-1,29$ \\
\hline Clark, A. P. (1951) & 51 & $31,37-39,4$ & $13,79-87$ & $1,63-3,42$ & $0,24-1,22$ & $1,16-3,08$ & $1,13-4,04$ \\
\hline Collins e Kuchma (1999) & 4 & $45,9-92$ & $71-75$ & $1,03-1,36$ & $0,13-0,16$ & $2,5-2,72$ & $0,65-0,8$ \\
\hline Debaiky, S. Y.; Elniema, E. I. (1982) & 9 & 26,00 & $17,23-31,4$ & $1,93-3,02$ & $0,2-0,42$ & $1,92-3,46$ & $0,63-1,33$ \\
\hline $\begin{array}{l}\text { Elstner, Moody, Viest, Hognestad } \\
(1955)^{\text {b }}\end{array}$ & 2 & 30,50 & $23-24$ & 4,76 & $0,95-1,47$ & 2,00 & $2,98-4,81$ \\
\hline Elzanaty, Nilson e Slate (1986) & 3 & 26,60 & $20,7-62,8$ & $2,5-3,3$ & 0,17 & 4,00 & 0,65 \\
\hline Fernandes, G. B. (1999) & 5 & 28,00 & $61,1-78,5$ & $4,1-6,18$ & $0,25-0,38$ & $3,57-5,36$ & $2,14-3,21$ \\
\hline Fukuhara, Kokusho (1982) & 19 & $34-36$ & $20-32$ & $0,61-3,21$ & $0,12-1,13$ & $1,76-2,35$ & $0,63-5,01$ \\
\hline Guralnick (1960)c & 9 & $30,6-31$ & $17-38$ & $1,41-4,38$ & 0,24 & $2,95-2,99$ & 1,26 \\
\hline Haddadin, Hong, Mattock (1971) & 22 & 38,10 & $13-44,9$ & $3,79-7,58$ & $0,19-1,26$ & $2,5-6$ & $0,68-4,77$ \\
\hline Hsiung, W.; Frantz, G. C.(1985) & 4 & 41,91 & 43,00 & 1,82 & $0,21-0,22$ & 3,00 & 0,62 \\
\hline Karayiannis e Chalioris (1999) $^{a}$ & 8 & 26,00 & 26,00 & $1,47-1,96$ & $0,04-0,25$ & $2,77-3,46$ & $0,11-0,64$ \\
\hline $\begin{array}{l}\text { Kokusho, Kobayashe, Mitsugi, } \\
\text { Kumagai }(1987)^{a}\end{array}$ & 9 & 34,00 & $20-38$ & 3,16 & $0,15-1$ & 1,76 & $2,09-14,31$ \\
\hline $\begin{array}{l}\text { Kong, P. Y. L.; Rangan, B. V. } \\
(1998)^{\text {d }}\end{array}$ & 43 & $19,8-54,2$ & $63,6-89,4$ & $\mid 1,66-4,47$ & $0,1-0,26$ & $1,75-3,3$ & $0,6-1,49$ \\
\hline $\begin{array}{l}\text { Krefeld, W. J.; Thurston, C. W. } \\
(1966)\end{array}$ & 20 & 45,57 & $15,73-48,49$ & 2,22 & $0,06-0,16$ & 4,02 & $0,21-0,64$ \\
\hline Lee, Kim; Mansour (2002) & 4 & $24,4-26,4$ & 42,00 & $2,67-3,6$ & $0,22-0,32$ & $2-4$ & $0,79-1,15$ \\
\hline Leonhardt; Walther (1962) $^{\mathrm{b}}$ & 4 & 27,00 & $28,2-30,4$ & 2,47 & $0,41-0,59$ & 2,78 & $1,52-1,63$ \\
\hline Leonhardt; Walther (1961) ${ }^{\mathrm{b}}$ & 1 & 82,50 & 23,84 & 9,44 & 2,83 & 3,03 & 11,71 \\
\hline Leonhardt; Walther (1963) $^{\mathrm{b}}$ & 1 & 27,00 & 28,16 & 2,02 & 2,02 & 0,58 & 9,39 \\
\hline Levi, F.; Marro, P. (1988) ${ }^{d}$ & 7 & 94,00 & $25-60$ & $3,5-5,3$ & $0,84-1,25$ & 4,20 & $4,03-6$ \\
\hline Lyngberg, B. S. $(1976)^{\mathrm{e}}$ & 2 & 54,00 & $25,7-26,6$ & 3,88 & 0,53 & 2,78 & $3,43-3,57$ \\
\hline $\begin{array}{l}\text { Matsuzaki, Nakano, Watanabe } \\
(1990)^{f}\end{array}$ & 8 & 33,60 & $23-37$ & 2,88 & $0,19-1,18$ & 1,79 & $1,29-8,59$ \\
\hline Mattock, A. H.;Wang, Z. (1984) & 8 & $31,5-34$ & $20-34,1$ & $2,07-3,16$ & $0,24-0,47$ & $1,76-3$ & $0,84-4,13$ \\
\hline $\begin{array}{l}\text { McGormley; Creary e Ramirez } \\
(1996)^{a}\end{array}$ & 12 & 41,90 & $35,3-56,7$ & 3,03 & 0,34 & 3,27 & 1,45 \\
\hline $\begin{array}{l}\text { Moody, K. G.; Viest, I. M.; Elstner, } \\
\text { R. C.; Hognestad, E.(1954) }\end{array}$ & 2 & 53,34 & $22,42-25,38$ & 4,25 & $0,52-0,95$ & 1,52 & $1,7-2,88$ \\
\hline Moretto, O. (1945) & 5 & $46,4-49,5$ & $23-33$ & 3,99 & 0,27 & $1,64-1,75$ & $0,85-1,02$ \\
\hline Mphonde; Frantz (1985) & 12 & 29,80 & $22,1-83$ & 3,36 & $0,12-0,38$ & 3,60 & $0,35-1,03$ \\
\hline Nishiura, Makitani, Shindou (1993) ${ }^{f}$ & 6 & 33,60 & $20-33$ & 2,88 & $0,4-0,89$ & 2,38 & $3,32-7,39$ \\
\hline $\begin{array}{l}\text { Ozcebe, G; Ersoy, U.; Tankut, T. } \\
(1999)\end{array}$ & 13 & $31-32,5$ & $58-82$ & $1,93-4,43$ & $0,14-0,28$ & $3-5$ & $0,35-0,71$ \\
\hline Peng (1999) & 8 & 27,40 & $29,3-33,7$ & 2,70 & $0,05-0,37$ & 3,10 & $0,3-1,68$ \\
\hline Piyamahant Songkram (2002) & 4 & 35,90 & $41,5-46,15$ & 1,06 & $0,04-0,08$ & 3,00 & $0,12-0,28$ \\
\hline Placas, A.; Regan, P. E. (1971) & 44 & $25,4-26,4$ & $12-57$ & $0,98-4,16$ & $0,14-0,84$ & $3,36-7,2$ & $0,38-2,25$ \\
\hline $\begin{array}{l}\text { Rajagopalan, K. S.; Ferguson, P. M. } \\
(1968)\end{array}$ & 3 & $26,42-26,59$ & $27,04-33,93$ & $1,71-1,74$ & $0,21-0,23$ & $4,16-4,23$ & $0,71-0,72$ \\
\hline Rangan, B. V. (1991) & 4 & 56,30 & $30,2-36,5$ & $8,35-9,81$ & $1,53-3,19$ & 2,49 & $7,42-15,47$ \\
\hline $\begin{array}{l}\text { Rodriguez, Bianchini, Viest, Kesler } \\
\text { (1959) }\end{array}$ & 12 & $30,9-32,6$ & $19-25$ & $2,6-2,74$ & $0,37-1,11$ & $1,99-2,29$ & $1,28-3,51$ \\
\hline Roller, J. J.; Russell, H. G. (1990) & 10 & $5,88-76,2$ & $2,42-125,32$ & $1,73-7,29$ & $0,08-1,76$ & $2,5-3$ & $, 34-8,05$ \\
\hline $\begin{array}{l}\text { Sarsam, K. F.; Al-Musawi, J. M. S. } \\
\text { (1992) }\end{array}$ & 14 & $23,2-23,5$ & $39-80,1$ & $2,23-3,51$ & $0,09-0,19$ & $2,5-4$ & $0,76-1,53$ \\
\hline Simplício (1999) & 5 & $27-35,4$ & $69,3-73,5$ & $2,33-2,96$ & $0,1-0,22$ & $3,3-3,8$ & $0,75-1,54$ \\
\hline Swamy e Andriopoulos (1970) ${ }^{\mathrm{C}}$ & 10 & $9,5-13,2$ & $25,9-29,4$ & $1,97-3,95$ & $0,06-0,6$ & $3-5$ & $0,17-1,33$ \\
\hline Takagi, Okudeh, Nitta (1989) $^{f}$ & 19 & 35,20 & $32-36$ & 3,09 & $0,19-1,21$ & 2,27 & $1,48-12,9$ \\
\hline Tompos, E. J.; Frosch, R. J. (2002) & 4 & $42,55-85,09$ & $35,8-42,7$ & 1,00 & $0,08-0,15$ & 3,00 & $0,41-0,72$ \\
\hline Xie, Y. et. al. (1994) & 9 & $19,81-20,32$ & $42,4-108,7$ & $3,2-4,54$ & $0,49-0,78$ & $1-4$ & $1,59-2,53$ \\
\hline $\begin{array}{l}\text { Yoon, Y. S.; Cook W. D.; Mitchell D. } \\
(1996)\end{array}$ & 9 & 65,50 & $36-87$ & 2,80 & $0,08-0,24$ & 3,05 & $0,35-1,02$ \\
\hline Zararis e Papadakis (1999) & 9 & 23,50 & $20,8-23,9$ & $0,68-1,37$ & $\mid 0,06-0,27$ & 3,60 & $0,16-0,73$ \\
\hline TOTAL & 547 & $9,5-120$ & $12-125,32$ & $0,5-9,81$ & $0,04-3,19$ & $0,58-7,2$ & $0,11-15,47$ \\
\hline \multicolumn{8}{|l|}{ a dados obtidos em Zararis (2003) } \\
\hline \multicolumn{3}{|l|}{ b dados obtidos em Reineck (2010) } & \multicolumn{5}{|c|}{ e dados obtidos em Cladera (2002) } \\
\hline${ }^{\mathrm{c}}$ dados obtidos em Collins (2008) & & & ${ }^{f}$ dados obtidos & Bette (2007) & & & \\
\hline
\end{tabular}


Tabela 6.2: Banco de dados compilado a partir de resultados experimentais de literatura, para elementos sem estribos.

\begin{tabular}{|c|c|c|c|c|c|c|}
\hline Autor & $\begin{array}{c}\text { Número } \\
\text { de } \\
\text { Ensaios }\end{array}$ & d (cm) & fc (MPa) & pl \% & $a / d$ & pl.fyk (MPa) \\
\hline Acharya, D. N.; Kemp, K. O. (1965) & 13 & $6,86-12,07$ & $36,83-57,25$ & $2,06-7,57$ & $1,32-5,56$ & $2-22,21$ \\
\hline Ahmad et al. (1995) ${ }^{\mathrm{e}}$ & 2 & 17,80 & $76,6-79,3$ & 1,39 & 3,70 & 5,75 \\
\hline $\begin{array}{l}\text { Ahmad, S. H.; Khaloo, A. R.; Poveda, } \\
\text { A. (1986) }\end{array}$ & 35 & $18,4-20,8$ & $60,8-67$ & $1,77-6,64$ & $1-4$ & $7,32-27,48$ \\
\hline $\begin{array}{l}\text { Angelakos, D.; Bentz, E. C.; Collins } \\
\text { M. P. (2001) }\end{array}$ & 15 & 92,50 & $21-99$ & $0,5-2,09$ & 2,92 & $2,75-11,5$ \\
\hline Bazant, Kazemi (1991) & 18 & $4,06-16,51$ & $46,1-46,8$ & $1,62-1,65$ & 3,00 & $11,18-11,39$ \\
\hline Bentz, E. C.; Buckley, S. (2005) & 9 & $8,4-33,3$ & $34,3-36,1$ & $1,55-1,63$ & $2,9-3$ & $6,2-6,52$ \\
\hline Bhal (1968) & 8 & $29,7-120$ & $22,8-29,1$ & $0,59-1,29$ & $2,94-3,03$ & $2,51-5,49$ \\
\hline Bresler, B; Scordelis, A. C. (1963) & 3 & $46,1-46,61$ & $22,54-37,57$ & $1,81-2,74$ & $3,97-6,94$ & $10,05-15,12$ \\
\hline Chana (1981) ${ }^{a}$ & 27 & $10,6-35,6$ & $24,7-41,7$ & $1,73-1,84$ & 3,00 & $7,45-9,27$ \\
\hline Cho, S. H. (2003) & 6 & 21,50 & $52-73$ & 3,77 & $1,5-2,5$ & 15,72 \\
\hline Cladera, A.; Marí, A. R. (2005) & 6 & 35,90 & $49,9-87$ & 2,24 & 3,01 & 11,20 \\
\hline Clark, A. P. (1951) & 10 & 38,80 & $21,52-26,21$ & 0,98 & $1,16-2,35$ & 3,63 \\
\hline Colins, M. P.; Kuchma D. (1999) & 36 & $11-92,5$ & $36-98,8$ & $0,5-1,03$ & $2,5-3,07$ & $2,75-5,5$ \\
\hline Ghannoum (1998) & 24 & $6,5-88,9$ & $34,2-58,6$ & $1,2-2$ & 2,50 & $5,2-14$ \\
\hline Haddadin, Hong, Mattock (1971) & 4 & 38,10 & $13,9-29,5$ & 3,79 & $2,5-4,25$ & 13,59 \\
\hline Kani (1967) & 35 & $13,2-109,7$ & $20,9-30,8$ & $2,59-2,89$ & $2,62-9,05$ & $9,29-11,32$ \\
\hline Kani, Huggins, Wiltkopp (1979) ${ }^{\mathrm{C}}$ & 75 & $13,7-109$ & $17-35$ & $0,5-2,86$ & $1,96-7$ & $1,75-10,22$ \\
\hline Kim, Park $(1994)^{c}$ & 16 & $14,2-91,5$ & 53,70 & $1,01-4,68$ & $3-4,5$ & $4,82-22,32$ \\
\hline Kim, W.; White, R. N. (1999) & 5 & 19,10 & $30,1-37,7$ & 1,65 & $1,5-4$ & 7,61 \\
\hline $\begin{array}{l}\text { Krefeld, W. J.; Thurston, C. W. } \\
(1966)\end{array}$ & 66 & $23,77-48,26$ & $12,21-39,04$ & $0,8-5,01$ & $2,35-7,3$ & $2,92-18,31$ \\
\hline Leonhardt; Walther (1962) ${ }^{\mathrm{b}}$ & 40 & $7-60$ & $11,2-37,7$ & $0,91-2,07$ & $1-8$ & $3,76-9,63$ \\
\hline Mathey, R. G.; Watstein, D. (1963) & 25 & 40,28 & $21,86-30,55$ & $0,47-3,05$ & $1,51-3,78$ & $3,27-12,82$ \\
\hline Mattock (1969) ${ }^{\mathrm{c}}$ & 7 & 25,40 & $16,2-46,9$ & $1,03-3,1$ & $3-5,4$ & $4,12-12,4$ \\
\hline $\begin{array}{l}\text { Moody, K. G.; Viest, I. M.; Elstner, R. } \\
\text { C.; Hognestad, E.(1954) }\end{array}$ & 40 & $26,16-53,34$ & $6,07-41,18$ & $0,8-4,25$ & $1,52-3,41$ & $2,48-13,18$ \\
\hline Morrow, Viest (1957) & 12 & $35,6-37,5$ & $14,7-45,7$ & $1,24-3,83$ & $2,76-7,86$ & $5,32-16,67$ \\
\hline Mphonde, A. G.; Frantz, G. C. (1985) & 19 & 29,80 & $20,6-93,71$ & $2,32-3,36$ & $1,5-3,6$ & $9,6-13,9$ \\
\hline Placas, A.; Regan, P. E. (1971) & 7 & 25,40 & $24,8-30,3$ & $0,98-4,16$ & $3,36-3,6$ & $6,05-25,83$ \\
\hline Podgorniak-Stanik, Bogdan A. (1998) & 15 & $22,5-92,5$ & $37-99$ & $0,51-1,31$ & $2,7-3$ & $2,81-6,55$ \\
\hline $\begin{array}{l}\text { Rajagopalan, K. S.; Ferguson, P. M. } \\
\text { (1968) }\end{array}$ & 10 & $25,86-26,85$ & $23,73-36,55$ & $0,25-1,73$ & $3,86-4,28$ & $3,3-11,33$ \\
\hline $\begin{array}{l}\text { Shioya, Iguro, Nojin, Akiyama, Okada } \\
(1989)^{f}\end{array}$ & 5 & $20-300$ & $19,7-28,5$ & 0,40 & 6,00 & $1,48-3,52$ \\
\hline Simplício (1999) & 2 & 27,00 & $72-76,4$ & 2,33 & 3,80 & 13,35 \\
\hline Taylor, H. P. J. (1972) & 15 & $14-93$ & $20,8-32$ & 1,35 & 3,00 & 5,67 \\
\hline Thorentfeldt, Drangsholt (1990) & 16 & $20,7-44,2$ & $54-97,7$ & $1,82-3,23$ & $3-4$ & $9,1-16,15$ \\
\hline Tompos, E. J.; Frosch, R. J. (2002) & 1 & 42,55 & 35,80 & 1,00 & 3,00 & 5,52 \\
\hline Van Den Berg, F. J. (1962) & 44 & $35,9-44,74$ & $17,73-77,38$ & $1,72-4,31$ & $2,12-4,88$ & $4,74-11,89$ \\
\hline Walraven $(1978)^{b}$ & 3 & $12,5-72$ & $27,4-27,8$ & $0,74-0,83$ & 3,00 & $3,26-3,65$ \\
\hline Walraven, J.; Lehwalter, N. (1994) ${ }^{\mathrm{C}}$ & 5 & $16-93$ & $18,1-20$ & $1,08-1,52$ & 1,00 & $4,53-6,36$ \\
\hline Xie, Y. et. al. (1994) & 6 & 21,59 & $39,7-104,2$ & 2,07 & $1-3$ & 8,71 \\
\hline $\begin{array}{l}\text { Yoon, Y. S.; Cook W. D.; Mitchell D. } \\
(1996)\end{array}$ & 3 & 65,50 & $36-87$ & 2,80 & 3,05 & 11,20 \\
\hline
\end{tabular}

\footnotetext{
a dados obtidos em Zararis (2003)

${ }^{\mathrm{b}}$ dados obtidos em Reineck (2010)

${ }^{c}$ dados obtidos em Collins (2008)

e dados obtidos em Cladera (2002)

f dados obtidos em Bette (2007)
} 


\subsection{Homogeneização do banco de dados}

A utilização de um banco de dados extenso para as análises estatísticas, sempre é desejável, pois, geralmente, se consegue uma melhor representação do fenômeno estudado, melhor representatividade do universo amostral. Porém a utilização de um banco de dados extenso, mas incoerente, implica em grandes dispersões, dificultando, ou até impossibilitando, a análise objetiva dos resultados.

Naturalmente o banco de dados coletado é heterogêneo, de forma que os resultados e correlações apresentaram grandes dispersões. A heterogeneidade é devida ao fato do banco de dados ser composto por resultados de diversos autores, efetuados em laboratórios diferentes e muitas vezes, seguindo procedimentos e critérios diferentes. Desta forma verificou-se a necessidade de homogeneizar o banco de dados, tentando assim eliminar os resultados que apresentavam incoerência com os demais.

A primeira preocupação ao se efetuar o tratamento no banco de dados é de se definir critérios coerentes e válidos para exclusão dos resultados discrepantes, sem excluir informações preciosas. Para isto utilizou-se de critérios práticos e estatísticos para se verificar a significância dos dados.

\subsubsection{Definição do critério de seleção desenvolvido}

O critério de seleção dos dados potencialmente representativos foi definido, neste trabalho, pela seguinte sequência:

1. Separação dos dados de ensaio de vigas armadas e não armadas ao cisalhamento com estribos.

2. Eliminação dos ensaios efetuados com um vão de cisalhamento menor que duas vezes e meia da altura efetiva da viga, ou seja, a/d menor que 2,5 .

3. Desconsideração de toda a campanha de ensaios do autor que obteve mais de $20 \%$ de seus ensaios muito discrepantes com os resultados calculados pelas normas. Nesta etapa calcularam-se os valores de predição das normas, contabilizou-se para cada autor qual a porcentagem de ensaios que estavam fora de um intervalo predefinido para todas as normas ao mesmo tempo, e quando a porcentagem ultrapassou $20 \%$, a campanha de ensaio do autor foi desconsiderada. Os intervalos utilizados foram diferentes para os dados de elementos armados dos não armados ao cisalhamento. Para elementos armados ao cisalhamento consideraram-se válidos os resultados de ensaios maiores que $67 \%$ e menores que $150 \%$ dos valores de norma, para todas as normas concomitantemente. Para os elementos não armados ao cisalhamento o limite inferior do intervalo foi $50 \%$ e o superior $200 \%$.

A Figura 6.16 mostra o caso de análise de apenas uma viga de um autor que foi considerado incompatível pelo fato da razão $V_{\text {exp }} / V_{u}$ ficar fora do intervalo considerado válido $(0,65$ à 1,50$)$ pelo critério definido. 


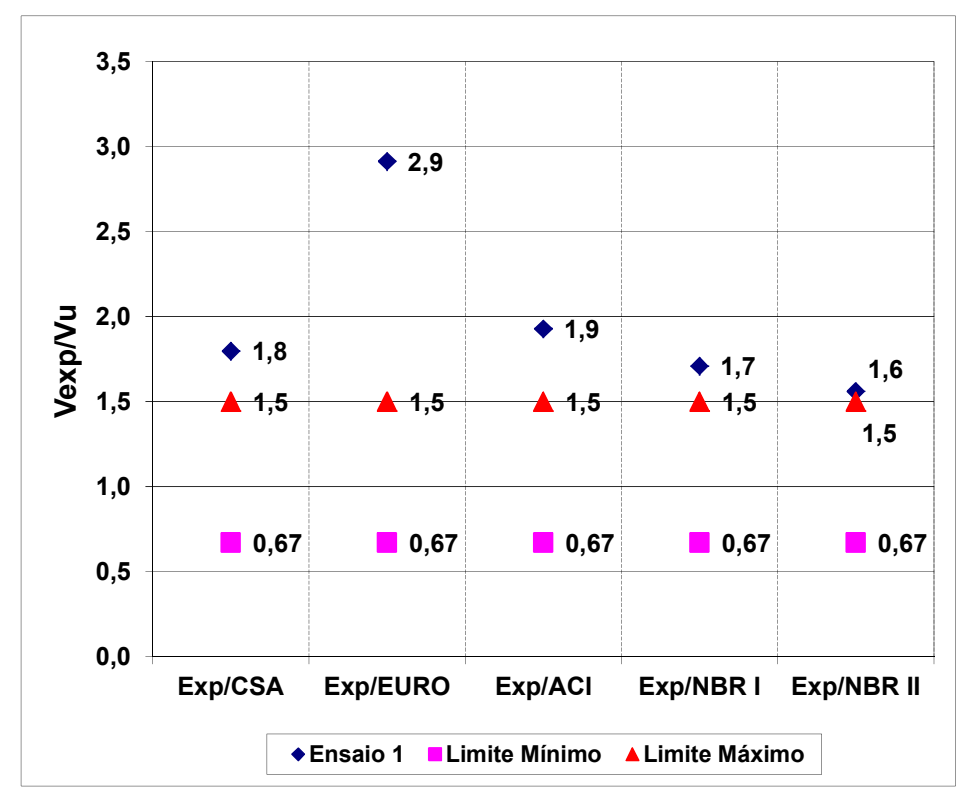

Figura 6.16: Resultados de uma viga com estribos reprovada pelo critério definido

Como se pode observar o resultado de ensaio desta viga ultrapassou os limites aceitáveis para todas as normas concomitantemente. $\mathrm{O}$ autor que obteve resultado não aceitável, pelo critério definido, em mais de $20 \%$ das vigas ensaiadas, teve todos os seus experimentos excluídos do banco de dados.

A Figura 6.17 indica o caso de uma viga ensaiada de um autor que obteve resultado aceitável pelo critério definido. Para os autores que tiveram mais que $80 \%$ de seus ensaios nesta situação (aprovada), tiveram todos os resultados de ensaios incorporados ao banco de dados final. Nesta figura, é possível perceber que na comparação com as normas CSA (2004) e NBR 6118 (2007) o valor de $V_{\text {exp }} / V_{\mathrm{u}}$ estavam dentro do intervalo composto pelos valores mínimo e máximo, e apenas duas comparações apresentaram resultados fora do permitido. Considerou-se reprovado o ensaio que obteve valores que extrapolaram os limites em todas as normas, concomitantemente.

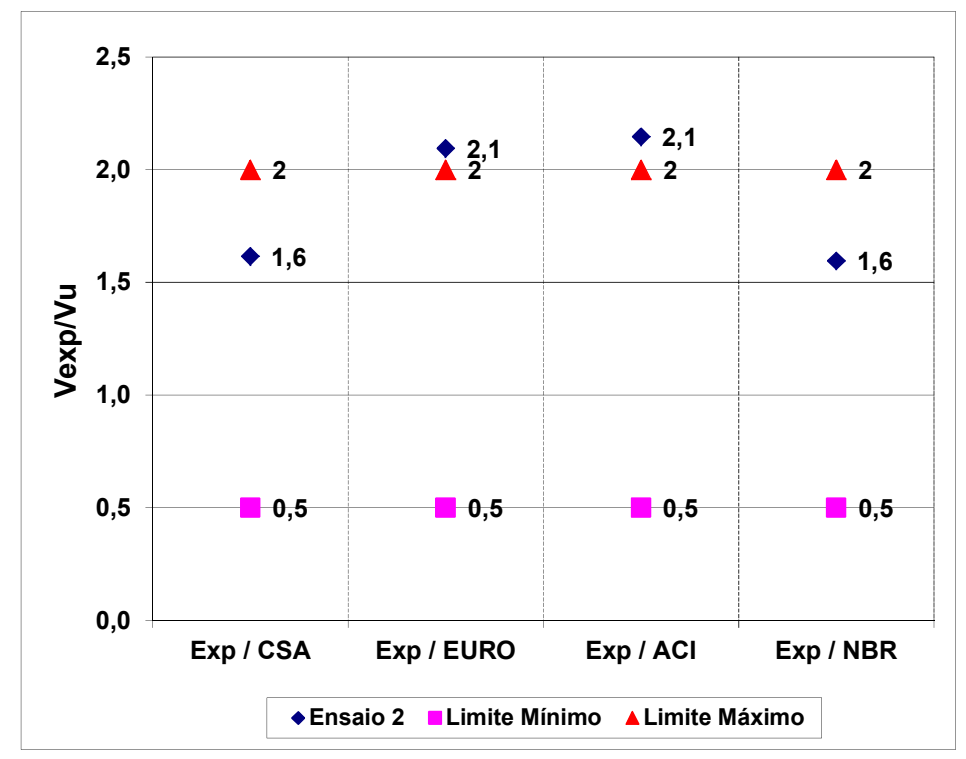

Figura 6.17: Resultados de uma viga sem estribos aprovada pelo critério definido 


\subsection{Critérios de análise desenvolvidos}

Após os valores dos ensaios do banco de dados criteriosamente selecionado, foi possível efetuar as análises e comparações entre os resultados experimentais e os valores de predição dos modelos de cálculo das normas.

O critério de análise, definido neste trabalho, pode ser divido em quatro grupos, aplicáveis para elementos armados e não armados ao cisalhamento com estribos, sendo eles:

1. Critério de análise da exatidão e precisão para intervalos válidos.

2. Critério de análise da segurança dos modelos das normas, para intervalos válidos.

3. Critério de análise da exatidão e precisão para intervalos não válidos.

4. Critério de análise da segurança dos modelos das normas, para intervalos não válidos.

O conceito de intervalo válido e não válido está associado ao fato que, todas as formulações de norma são válidas para um intervalo de parâmetros determinado, ou seja, provavelmente os dados de ensaios utilizados para elaboração e validação dos modelos são compostos por um conjunto de parâmetros que resultam em intervalos, sendo estes intervalos considerados válidos para aquele modelo. Desta forma, utilizar parâmetros fora do intervalo válido seria, por exemplo, calcular um valor de predição de uma norma utilizando um valor de resistência do concreto acima da máxima permitida. Portanto, dados de predição de norma válidos, são aqueles cujos parâmetros de entrada estão dentro dos intervalos permitidos para norma, e não válidos, exatamente o oposto.

Antes de descrever os critérios de análise, é necessário exprimir as premissas adotadas.

A segurança imposta por norma está, principalmente, representada pelos fatores de segurança, e também chamados de coeficientes de ponderação, que atuam nos esforços solicitantes (carregamentos ou ações) ou nos esforços resistentes. Esta análise, contempla o estudo da segurança representada pelos fatores de segurança de redução dos esforços resistentes, para aplicação em projetos de engenharia.

Segundo a norma ACl (2008), os propósitos dos fatores de segurança que atuam na redução das resistências são:

1. Admitir a probabilidade de uma redução na resistência do elemento devido a variação na resistência intrínseca do material e dimensões do elemento;

2. Admitir uma inexatidão das equações de projeto; 
3. Refletir um grau de ductilidade e de confiabilidade do elemento sobre os efeitos das cargas consideradas, e

4. Refletir a importância do elemento estrutural.

A norma NBR 6118 (2007) define que os fatores de segurança de redução das resistências são compostos essencialmente por 3 fatores:

1. A variabilidade da resistência dos materiais envolvidos;

2. A diferença entre a resistência do material no corpo de prova e na estrutura, e;

3. Os desvios gerados na construção e as aproximações feitas em projeto do ponto de vista das resistências.

A premissa adotada para o coeficiente de ponderação das resistências, $\gamma$, consiste em considerar que este coeficiente é formado principalmente por dois fatores. Um fator refere-se a uma provável redução das resistências dos materiais utilizados, $\gamma_{\text {mat }}$, e, o outro fator devido à inexatidão do modelo de predição da norma, $\gamma_{\text {mod, }}$, sendo assim:

$$
\gamma \cong \gamma_{\operatorname{mat}} \cdot \gamma_{\bmod }
$$

Os valores resistentes de cálculo são obtidos a partir dos valores teóricos utlimos correspondentes, pela sua multiplicação ou divisão pelo coeficiente de ponderação.

Se o coeficiente de ponderação for maior que o valor unitário tem-se:

$$
V d=\frac{V_{u}}{\gamma}
$$

Se o coeficiente de ponderação for menor que o valor unitário usa-se:

$$
V d=\phi \cdot V_{u}
$$

Sendo assim, o coeficiente de ponderação, $\Phi$, é o valor inverso do $\gamma$.

Cabe observar a dificuldade de se encontrar documentos válidos, que expressem exatamente os valores dos coeficientes parciais. Os principais documentos normativos não apresentam esta informação.

\subsubsection{Critério de análise da exatidão e precisão para intervalos válidos.}

Os valores resultantes dos modelos de predição de norma, quando comparados em sua forma característica com os resultados de ensaios de laboratórios, fornecem informações importantes em relação à exatidão e precisão. Ao utilizar dados de ensaios válidos, as comparações permitem 
identificar quais normas possuem seu modelo de predição mais ajustado e em qual intervalo isto ocorre.

Uma premissa importante para esta análise é considerar que os valores de resistência medidos nos ensaios, referem-se, com absoluta certeza, ao valor de resistência última da peça. Dados incoerentes, ou que foram obtidos seguindo critérios diferentes, muito provavelmente foram expurgados do banco de dados após a etapa de homogeneização.

A razão entre o valor último do experimento, $V_{\text {exp }}$, pelo valor de teórico ultimo, $V u$, será representado pela nomenclatura $V_{\text {exp }} / V_{\mathrm{u}}$.

Desta forma, a análise da exatidão dos modelos de predição das normas se dará através do cálculo das médias dos valores de $V_{\text {exp }} / V_{\mathrm{u}}$. $O$ modelo de predição de norma será considerado exato quando o valor médio de $V_{\text {exp }} / V_{\mathrm{u}}$ for igual ao valor unitário para um grupo de ensaios, ou seja, quando $V_{\text {exp }}$ for igual a $V_{\mathrm{u}}$.

Os modelos e equações de norma são baseados em correlações estatísticas, obtidas por experimentos realizados por diversos autores e em diversas condições. De forma geral, uma grande porção destes ensaios foi realizada utilizando intervalos de parâmetros diferentes, e consequentemente, cada modelo de norma foi concebido com resultados de ensaios em intervalos de ensaios restritos e diferentes. Sendo assim, os resultados das correlações obtidos por cada norma abordam diferentemente cada faixa de utilização dos parâmetros que influenciam a resistência ao cisalhamento. Com isto, definiu-se neste trabalho, um critério que analisa o afastamento entre os resultados calculados de predição de norma e os resultados individuais dos ensaios coletados. Esta medida de afastamento procura indicar a dispersão entre os resultados calculados e os resultados experimentais (lembrando que os valores individuais não contemplam a dispersão causada pelos erros experimentais). Baseado em uma analogia com a estatística descritiva, utilizou-se os princípios de cálculo do desvio padrão e do coeficiente de variação para determinação do afastamento e de um coeficiente de afastamento, admitindo que o valor individual de cada ensaio fosse o valor mais provável.

$O$ afastamento entre os valores calculados e os valores experimentais foi medido utilizando os resultados da razão $V_{\text {exp }} / V_{\mathrm{u}}$ para os diversos ensaios em determinados intervalos de parâmetros. $\mathrm{O}$ afastamento, definido neste trabalho, possui formulação semelhante ao desvio padrão da amostra e é expresso pela seguinte fórmula:

$$
s=\sqrt{\frac{1}{n-1} \sum_{i=1}^{n}\left(x_{i}-\bar{x}\right)^{2}}
$$


Sendo:

$$
\begin{aligned}
& X_{i}=\left(\frac{V_{\text {exp }}}{V_{u}}\right)_{i} \\
& \bar{X}=\frac{1}{n} \sum_{i=1}^{n} X_{i}
\end{aligned}
$$

Temos:

n - número total de ensaios utilizados na análise em certo intervalo de estudo;

A análise do afastamento dos resultados do modelo foi feita através do cálculo do coeficiente de afastamento dos diversos valores de $V_{\text {exp }} / V_{\mathrm{u}}$, obtendo-se assim, a dispersão dos resultados em relação ao valor médio, e foi considerado o modelo mais preciso aquele que obteve o menor valor do coeficiente de afastamento. A comparação entre o valor da média e mediana corrobora no entendimento da dispersão dos resultados em relação ao valor médio.

O coeficiente de afastamento segue a analogia do coeficiente de variação e é expresso da seguinte forma:

$$
c_{a}=\frac{s}{\bar{X}}
$$

Neste contexto, o autor intencionalmente substituirá o termo coeficiente de afastamento por coeficiente de variação, e implicitamente o termo afastamento por precisão. Sendo assim, ao analisar a precisão dos resultados de predição de um modelo de norma, na verdade está se analisando o afastamento entre os resultados das razões $V_{\text {exp }} / V_{\mathrm{u}}$, em relação ao valor médio, para diversos ensaios dentro de um intervalo de estudo.

Neste contexto, é possível comparar os diversos modelos de predição de norma elegendo o melhor modelo e o pior modelo para diversos cenários de verificação, ou seja, em diversos intervalos de parâmetros.

Cabe ressaltar como será definido o valor de predição ultimo teórico de norma, $V_{\mathrm{u}}$. De forma generalizada, para elementos com estribos a força cortante resistente é composta por duas parcelas, sendo uma derivada da resistência do concreto, $V_{\mathrm{c}}$ e outra da resistência dos estribos, $V_{\mathrm{s}}$. Para elementos sem estribos, existe apenas a parcela derivada do concreto. Sendo assim, genericamente define-se $V_{u}$ da seguinte forma:

$$
V_{u}=V_{c}+V_{s}
$$




\subsubsection{Critério de análise da segurança dos modelos das normas, para intervalos válidos.}

Ao se analisar um grupo de resultados de predição de norma para dados considerados válidos, verificou-se a importância de estimar a segurança intrínseca de cada modelo de predição de norma. O modelo de predição de norma deve prever de forma exata os valores resistentes últimos e diversos critérios de norma devem garantir a segurança dos elementos construídos. São diversos os critérios de norma que garantem a segurança, desde especificações de detalhes construtivos, folgas e tolerâncias construtivas, como determinação de valores seguros de esforços resistentes, através, por exemplo, da especificação de valores mínimos e máximos da resistência dos materiais, taxas de armações mínimas e máximas e intervalos de variação dos outros parâmetros, também, definidos. Esta segurança da norma como um todo é muito ampla e difere da segurança do modelo de predição. A segurança do modelo de previsão de norma reflete simplesmente o fato que as previsões não podem ser demasiadamente distantes do valor de ruptura medida no ensaio. Esta dissertação apresenta uma metodologia para analisar, apenas, a segurança dos modelos de predição de norma.

Sendo assim, algumas simplificações e considerações devem ser feitas, possibilitando, analisar apenas a segurança dos esforços resistentes dos modelos de predição:

1. A variabilidade das resistências dos materiais, utilizados em laboratório para a moldagem dos elementos de ensaio, é extremamente baixa, de forma que a resistência média do material é aproximadamente igual à resistência característica de projeto, responsável esta, por garantir, com certa confiança, uma resistência mínima do material para todo o elemento.

2. O esforço solicitante medido na ruptura do elemento equivale ao esforço solicitante de cálculo que determina o estado limite último do elemento.

3. Os coeficientes de segurança da resistência das normas são, basicamente, divididos em dois fatores principais, um deles responsável pela correção da inexatidão do modelo de cálculo, e o outro, referente à uma resistência inferior a especificada, devido a uma possível variabilidade da resistência dos materiais utilizados no elemento.

4. Os resultados de predição de norma são significativos quando respeitados os intervalos de validade de seus parâmetros, por exemplo, resistência do concreto máximo ou taxa mínima de armadura.

A primeira simplificação é aceitável, pois estamos trabalhando com resultados de laboratório, no qual as condições e parâmetros são controlados, resultando em menores variabilidades em relação ao campo prático. No campo prático a distinção entre valor característico de resistência dos materiais, principalmente do concreto e o valor médio é importante, determinar o valor característico (p.e. fck) a partir dos valores individuais resulta em permitir que no máximo $5 \%$ dos casos reais analisados sejam menores que o valor característico, resultando em uma segurança maior, considerada esta, uma segurança da norma e não 
do modelo de predição. Por este motivo, consideram-se nas análises os valores individuais medidos no experimento para os valores das resistências dos materiais.

Complementando as explicações e equações apresentadas no item 6.4.1, define-se, para elementos com estribos, o valor de cálculo, $V_{d}$, como:

$$
V d=\frac{V_{c}}{\gamma_{c}}+\frac{V_{s}}{\gamma_{s}}
$$

Ou também na forma:

$$
V d=\phi_{c} \cdot V_{c}+\phi_{s} \cdot V_{s}
$$

Após a determinação da força resistente de cálculo, $V_{d}$, utilizando os coeficientes de ponderação, $\Phi_{\mathrm{C}}$ e $\Phi_{\mathrm{S}}$, define-se o fator de segurança final, designado apenas como $\Phi$. Para elementos sem estribos, o fator de segurança final, $\Phi$, iguala-se ao valor de $\Phi_{c}$. . Para elementos com estribos, o fator de segurança final, $\Phi$, depende da ponderação entre as grandezas $V_{c}$ e $V_{s}$, por exemplo, em peças muito armadas $\Phi$ se aproxima do valor de $\Phi_{\mathrm{s}}$. No caso mais geral, obtém-se $\Phi$ da seguinte forma:

$$
\phi=\frac{V d}{V_{u}}=\frac{\phi_{c} \cdot V_{c}+\phi_{s} \cdot V_{s}}{V_{c}+V_{s}}
$$

Utilizando a premissa de que os coeficientes de ponderação das resistências são compostos por dois fatores, tem-se:

$$
\phi=\phi_{\text {mat }} \cdot \phi_{\mathrm{mod}}
$$

Sendo:

$\Phi$ : coeficiente de ponderação final;

$\Phi_{\text {mat: }}$ : coeficiente de ponderação parcial devido a variabilidade e possibilidade de uma baixa resistência dos materiais utilizados;

$\Phi_{\text {mod }}$ : coeficiente de ponderação parcial devido a inexatidão dos modelos de cálculo.

Definidos os conceitos iniciais, podem-se definir critérios congruentes de qualificação das normas quanto sua segurança, baseados na análise relativa entre o valor da força última medida do ensaio, $V_{\mathrm{Exp}}$, o valor de predição teórico ultimo, $V_{\mathrm{u}}$ e o valor de predição de cálculo, $V_{\mathrm{d}}$.

Para formação do critério de análise foi necessário expor um raciocínio intermediário, definindo-se 3 intervalos de análise. 
$O$ primeiro indica que se $o$ valor obtido no experimento, $V_{\text {exp }}$, for menor que $o$ valor de predição de norma de cálculo, $V_{d}$ (considerando os coeficientes redutores de norma), provavelmente, a predição da norma será perigosa, podendo resultar em valores não seguros e com chances maiores de ruína.

O segundo intervalo define que, se $V_{\text {exp }}$, estiver compreendido entre $V_{d}$ e $V_{u}$, o valor de predição de norma é seguro, porém quanto mais próximo $V_{\text {exp }}$ estiver de $V_{\mathrm{d}}$, menor será a "folga" disponível para garantir a segurança mediante uma redução das resistências dos materiais, ou seja, se o valor de $V_{\text {exp }}$ for próximo do valor de $V_{\mathrm{d}}$, menor será a disponibilidade real do coeficiente de segurança final, $\Phi$. Por outro lado, se o valor de $V_{\text {exp }}$ estiver próximo de $V_{\mathrm{u}}$, significa que se utilizou pouco do fator parcial do coeficiente de ponderação responsável por assegurar a inexatidão das equações, e quase toda a segurança disponível será disponibilizada para garantir a variabilidade da resistência do material.

$O$ terceiro intervalo define que se $V_{\exp }$ for maior que $V_{\mathrm{u}}$, a segurança obtida pela norma está superior àquela prevista apenas pelo coeficiente de ponderação final, $\Phi$, e se os valores de $V_{\exp }$ e $V_{u}$ forem demasiadamente distantes, as previsões se tornam onerosas, resultando em um consumo exagerado de materiais, para obtenção de uma resistência aquém da realmente necessária.

A Tabela 6.3, apresenta o resumo destes intervalos preliminares, pertencentes a um raciocínio intermediário.

Tabela 6.3: Intervalos preliminares para a avaliação das normas quanto à segurança ao dimensionamento.

\begin{tabular}{|c|l|}
\hline Critérios de Comparação & \multicolumn{1}{|c|}{ Situações } \\
\hline$V_{E x p}<\phi^{\prime} . V_{u}$ & PERIGOSA, INSEGURA \\
\hline$\phi^{\prime} . V_{u} \leq V_{E x p}<V_{u}$ & $\begin{array}{l}\text { POUCO SEGURA A MUITO } \\
\text { SEGURA }\end{array}$ \\
\hline$V_{E x p}>V_{u}$ & MUITO SEGURA A ONEROSA \\
\hline
\end{tabular}

Para definir um critério único de análise para todas as formulações concomitantemente, é necessário estimar uma valor médio para o coeficiente de segurança final, denominado como $\Phi$ '. Este coeficiente de segurança final médio, $\Phi^{\prime}$, foi obtido através da média dos coeficientes de segurança dos valores de previsão de cálculo de todas as normas.

A utilização do critério apresentado na Tabela 6.3, não permite qualificar objetivamente as normas quanto a segurança imposta, pois os intervalos descritos não apresentam critérios objetivos de quanto seguro é certa predição de norma, ou quando se pode considerar oneroso um baixo valor de predição. Desta forma será necessário criar um intervalo intermediário que permita avaliar a segurança, e defini-la como adequada. 
Sabendo que o coeficiente de ponderação final, $\Phi$, é composto principalmente por dois fatores, conforme equação (6.12), estimando que ambos os fatores sejam idênticos, consegue-se estimar duas faixas, uma responsável por garantir segurança mesmo com a obtenção de valores de resistência dos materiais inferiores aos estipulados e outra pela segurança devido à inexatidão do modelo. Sendo assim, obtêm-se os valores dos fatores dos coeficientes parciais.

$$
\phi_{\text {mat }} \cong \phi_{\mathrm{mod}} \cong \sqrt{\phi^{\prime}}
$$

O próximo refinamento será baseado na ideia de valor de predição de norma oneroso. Valor de predição de norma teórico ultimo igual ao valor observado no experimento ainda representa uma condição segura de dimensionamento, porém se o valor do experimento se mostrar muito superior ao valor previsto, a predição torna-se onerosa, e para definir qual seria o limite aceitável. Adotouse uma variação aceitável de $10 \%$ de acréscimo no valor de $V_{u}$, como sendo uma faixa aceitável, ou seja, se o valor observado for maior que $110 \%$ do valor de $V_{u}$, será considerada uma situação de custo elevado.

Após estes dois conceitos podem-se definir dois valores de referência, sendo um, $V_{\text {seg, }}$ responsável por delimitar a faixa aceitável de segurança, limite no qual o coeficiente de ponderação parcial $\Phi_{\text {mat }}$ não é consumido, e o outro, $V_{\text {one, }}$ valor que delimita a faixa aceitável para um sobre custo sem considerá-lo oneroso, conforme descrito a seguir:

$$
\begin{aligned}
& V_{\text {seg }}=\sqrt{\phi^{\prime}} \cdot V_{u} \\
& V_{\text {one }}=1,1 \cdot V_{u}
\end{aligned}
$$

A Figura 6.18 representa o conjunto de critérios e considerações, para análise da segurança de cada norma ao analisar em qual faixa estará o valor coletado no experimento de laboratório.

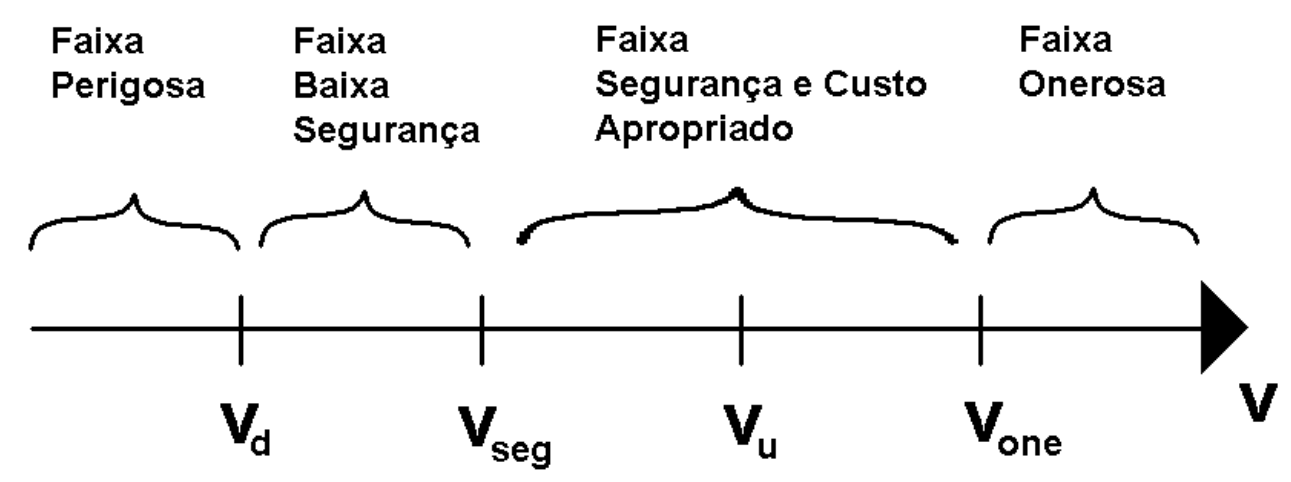

Figura 6.18: Definição das faixas de análise da força cisalhante resistente experimental ,Vexp. Sendo Vd - Valor de cálculo, Vseg - Valor limite seguro, Vu - Valor teórico ultimo e Vone - Valor limite oneroso 
Com isso, considerando os coeficientes de segurança das resistências de norma, pode-se analisar a porcentagem dos ensaios que representem situações: perigosa, baixa segurança, segurança e custo apropriados e situação onerosa. Os critérios de comparação dos resultados de predição de norma, $V_{u}$ e resultados de ensaios, $V_{\text {Exp }}$, definidos neste trabalho, estão apresentado na Tabela 6.4.

Tabela 6.4: Critério elaborado para avaliar a segurança dos resultados de predição das normas, situações e números dos grupos correspondentes

\begin{tabular}{|c|l|c|}
\hline Critérios de Comparação & \multicolumn{1}{|c|}{ Situações } & $\begin{array}{c}\mathbf{N}^{\circ} \text { do } \\
\text { Grupo }\end{array}$ \\
\hline$V_{\text {Exp }}<\phi^{\prime} . V_{u}$ & PERIGOSA & 1 \\
\hline$\phi^{\prime} \cdot V_{u} \leq V_{\text {Exp }}<\sqrt{\phi^{\prime}} \cdot V_{u}$ & BAIXA SEGURANÇA & 2 \\
\hline$\sqrt{\phi^{\prime}} \cdot V_{u} \leq V_{\text {Exp }} \leq 1,1 . V_{u}$ & $\begin{array}{l}\text { SEGURANÇA E CUSTO } \\
\text { APROPRIADOS }\end{array}$ & 3 \\
\hline$V_{\text {Exp }}>1,1 . V_{u}$ & ONEROSA & 4 \\
\hline
\end{tabular}

OBS: O símbolo Ф representa o coeficiente de redução final de norma.

A situação perigosa ocorre quando o valor observado no ensaio é menor que o valor de predição da norma minorado pelos coeficientes de redução das resistências, $\Phi$. Estes casos serão representados pelo grupo 1 .

O grupo 2, é composto pelo caso em que o valor observado está compreendido entre o valor de predição de norma de cálculo (minorado pelos coeficientes de redução) e o valor de predição seguro, ver equação (6.14). Neste intervalo, parte do coeficiente de segurança foi consumido pela inexatidão do modelo, restando apenas uma pequena segurança devido a incerteza na resistência dos materiais.

A situação apropriada, representada pelo grupo 3 , ocorrer quando o valor experimental estiver entre $o$ valor seguro, $V_{\text {seg }}$ e $o$ valor limite para custo aceitável, $V_{\text {one, }}$, ver equação (6.15).

Por fim, o grupo 4 representa os valores de predição de norma com grande segurança, que em muitos casos resultariam em projetos onerosos e pouco otimizados. Ressalta-se ainda que a sensibilidade para segurança ou valores onerosos é intrínseca da cultura de cada país, região, empresa ou pessoa. Neste trabalho, os valores estipulados são considerados satisfatórios, mas poderiam existir outros, dependendo do ponto de vista e aceitabilidade de cada um.

Os resumos dos coeficientes de ponderação ou redução das resistências, ou ainda, fatores de segurança, $\Phi$, estão apresentados na Tabela 6.5. 
Tabela 6.5: Coeficientes de redução das resistências, $\Phi$, para as normas utilizadas

\begin{tabular}{|c|c|c|}
\hline \multirow{2}{*}{ Norma } & \multicolumn{2}{|c|}{ Coeficientes de Segurança, $\boldsymbol{\Phi}$} \\
\cline { 2 - 3 } & Concreto, $\boldsymbol{\Phi c}$ & Armadura, $\boldsymbol{\Phi s}$ \\
\hline \multirow{2}{*}{ CSA (2004) } & 0,65 & 0,85 \\
\hline EUROCODE (2004) & $1 / 1,5=0,67$ & $1 / 1,25=0,8$ \\
\hline ACI (2008) & \multicolumn{2}{|c|}{0,75} \\
\hline NBR 6118 (2007) & $1 / 1,4=0,7$ & $1 / 1,15=0,87$ \\
\hline
\end{tabular}

Para auxiliar a análise final da segurança dos modelos de predição das normas na determinação da força cisalhante resistente, baseado no método de análise de Collins apud Cladera (2002), ver item 4.9, desenvolveu-se uma metodologia de análise da qualidade da formulação da norma, através da análise dos valores de $V_{\text {exp }} / V_{\mathrm{u}}$.

Neste trabalho, adaptou-se o processo idealizado por Collins, resumido na

Tabela 4.3, e desenvolveu-se através de critérios lógicos e explícitos, uma metodologia própria de qualificação e análise de segurança dos modelos de predição das normas, conforme expressa na Tabela 6.6.

Tabela 6.6: Critério elaborado para avaliar a confiabilidade e desempenho de normas, através da atribuição de pontos de demérito

\begin{tabular}{|l|c|c|}
\hline \multicolumn{1}{|c|}{ Classificação } & $\mathbf{V}_{\mathbf{e x p}} \mathbf{V}_{\mathbf{u}}$ & $\begin{array}{c}\text { Ponto de } \\
\text { Demérito }\end{array}$ \\
\hline PERIGOSA & $<\phi^{\prime}$ & 10 \\
\hline BAIXA SEGURANÇA & $\phi^{\prime} \vdash \sqrt{\phi^{\prime}}$ & 2 \\
\hline $\begin{array}{l}\text { SEGURANÇA E CUSTO } \\
\text { APROPRIADOS }\end{array}$ & $\sqrt{\phi^{\prime}} \vdash \mathbf{1 , 1}$ & 0 \\
\hline ONEROSA & $\geq \mathbf{1 , 1}$ & 2 \\
\hline
\end{tabular}

\subsubsection{Critério de análise da exatidão e precisão para intervalos não válidos.}

O critério de análise da exatidão e precisão das normas para dados não válidos segue a mesma definição do critério para dados válidos, apresentada no item 6.4.1. Porém, ao analisar dados considerados não válidos, os objetivos finais, em sua essência, mudam. Neste caso, o objetivo maior é verificar como os 
modelos de predição de norma se comportam fora dos intervalos válidos, identificando assim, se existe uma boa correlação, ou não, entre os valores experimentais e os valores de predição de norma. A boa correlação será analisada através da análise da exatidão e precisão (afastamento), cujos conceitos foram introduzidos no começo deste capítulo (6.4.1). Com isso, podem-se analisar quais formulações de norma estão mais bem ajustadas em intervalos específicos de parâmetros.

\subsubsection{Critério de análise da segurança dos modelos das normas, para intervalos não válidos.}

O nome deste item, numa primeira leitura parece que apresenta certa incoerência em querer analisar a segurança de uma norma, utilizando dados com parâmetros fora dos intervalos aceitáveis, ditos válidos, para cada norma. Porém pode-se interpretar o nível de segurança obtido, como um nível de prudência em se utilizar as formulações de uma norma fora de seus intervalos válidos. Isto poderia ocorrer em duas situações diferentes, a primeira seria um caso de retroanálise de uma estrutura existente em que, por qualquer motivo, algum parâmetro tenha sido extrapolado em relação aos limites aceitáveis, por exemplo, por uma falha, moldou-se uma viga com menos estribos que o mínimo permitido. Neste momento, é necessário decidir se a solução é a demolição e reconstrução do elemento ou, mediante verificação, manter o elemento e talvez restringir o uso, mas também, talvez retroanalisar o elemento e verificar que não há risco nenhum envolvido. Outra forma de utilizar este estudo, seria, por exemplo, no caso de uma readequação de uma estrutura existente a uma nova utilização. Por exemplo, existe um galpão industrial feito de elementos pré-moldados, com especificação de projeto para a resistência característica do concreto igual a $45 \mathrm{MPa}$, porém pretende-se aumentar a sobrecarga sobre estes elementos. Para isso, durante o processo de retroanálise, detecta-se que os elementos foram moldados com concreto que, seguramente, possuem $f c \geq 55 \mathrm{MPa}$, neste caso, verificando a nova capacidade estrutural dos elementos com a utilização na norma brasileira NBR 6118 (2007), os resultados obtidos serão válidos? Será prudente considerar a resistência característica do concreto igual a $55 \mathrm{MPa}$, ou deve-se obedecer ao limite de $50 \mathrm{MPa}$ ? As análises da segurança de utilização da norma fora do intervalo válido responderiam estas questões.

\subsection{Análise de vigas armadas ao cisalhamento com estribos e ruptura por força cortante-tração}

\subsubsection{Definição de grupos e categorias}

Após a homogeneização do banco de dados, os 339 ensaios de elementos armados ao cisalhamento com estribos, foram separados em grupos por semelhança de parâmetros, de forma a facilitar a interpretação dos resultados.

O agrupamento dos parâmetros seguiu critérios lógicos, desenvolvidos neste trabalho, e que representassem intervalos nos quais, possivelmente, houvesse divergências entre as normas, como explicado a seguir. 
Os principais parâmetros de análise foram agrupados conforme resumido na Tabela 6.7.

Tabela 6.7: Grupos de parâmetros para elementos com estribos

\begin{tabular}{|c|c|c|c|c|c|c|}
\hline & \multicolumn{5}{|c|}{ Grupos } \\
\hline & & G fc & G d & G rol & G psw.fyk & $\mathbf{G}$ a/d \\
\hline & & $(\mathrm{MPa})$ & $(\mathrm{cm})$ & $(\%)$ & $(\mathrm{MPa})$ & \\
\hline \multirow{3}{*}{ 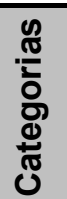 } & 1 & $\mathrm{fc} \leq 50$ & $d \leq 60$ & $\mathrm{rol} \leq 1,5$ & $\rho s w . f y k \leq 1$ & $a / d \leq 3$ \\
\hline & 2 & $50<$ fc $\leq 70$ & $d>60$ & $1,5<\mathrm{rol} \leq 3,0$ & $1<$ psw.fyk $\leq 2$ & $3<a / d \leq 4$ \\
\hline & 3 & fc $>70$ & & $\mathrm{rol}>3,0$ & psw.fyk $>2$ & $a / d>4$ \\
\hline
\end{tabular}

Para a definição do grupo "G fc", utilizou-se como valores limítrofes da resistência do concreto a compressão até $50 \mathrm{MPa}$, que é o limite máximo para utilização da norma brasileira NBR 6118 (2007). O outro extremo de $70 \mathrm{MPa}$ foi definido segundo o critério que valores acima deste podem ser considerados concretos de alta resistência, formando a categoria " 3 ". Desta forma, os ensaios cujos valores da resistência à compressão do concreto apresentaram valores maiores que $50 \mathrm{MPa}$ e menores ou iguais a $70 \mathrm{MPa}$, foram agrupados na categoria "2". Apesar da utilização do termo $f c$ para a denominação do grupo, deve-se compreender que os resultados são apresentados em termos de valores médios experimentais.

O Grupo "G d" foi definido, separando os elementos de altura efetiva, $d$, em duas categorias, sendo a primeira determinada pelos elementos com altura efetiva menor ou igual a $60 \mathrm{~cm}$, pois se considera este valor como um valor de referência, em que o efeito de escala ou "size effect" não é significativo. Para valores maiores que $60 \mathrm{~cm}$ designou-se como categoria " 2 ".

As categorias do grupo "G rol" se referem a discretização dos ensaios, conforme a taxa de aço longitudinal de flexão, $\rho_{\text {I. }}$ Consideraram-se taxas de armação baixas para valores menores que $1,5 \%$, e altas taxas, para valores maiores que $3 \%$, definindo-se assim, as categorias " 1 " e " 3 ", respectivamente. Para os ensaios cujos valores das taxas foram maiores que $1,5 \%$ e menores ou iguais a $3 \%$, se denominou a categoria "2".

O grupo "G psw.fyk" separa os ensaios conforme a taxa mecânica de armadura transversal de cisalhamento, sendo esta taxa definida pelo produto entre a taxa geométrica de armadura transversal de cisalhamento, $\rho_{s w}$, e a tensão resistente de escoamento da armadura transversal, $f_{y k}$. A categoria "1" foi definida com valores de taxa mecânica menores ou iguais a $1 \mathrm{MPa}$. Para a categoria "3" atribuíram-se os dados de taxa mecânica maiores que $2 \mathrm{MPa}$, considerando nesta categoria os elementos com alta taxa de armadura transversal.

Para o grupo "G a/d", responsável pela discretização do parâmetro a/d, que indica a relação entre o vão de cisalhamento e a altura efetiva da peça, definiram-se três categorias. A primeira, categoria "1", é composta pelos valores menores e iguais a 3 , a categoria "2" pelos valores maiores que $3 \mathrm{e}$ menores ou iguais a 4, e por fim, a categoria "3" para valores maiores que 4. Definiram-se assim três subgrupos que representam uma escala crescente da solicitação de flexão em relação à solicitação de cisalhamento. 
A Figura 6.19, indica a distribuição dos parâmetros dentro dos grupos definidos e a porcentagem de cada categoria em relação ao número total de ensaios (339).

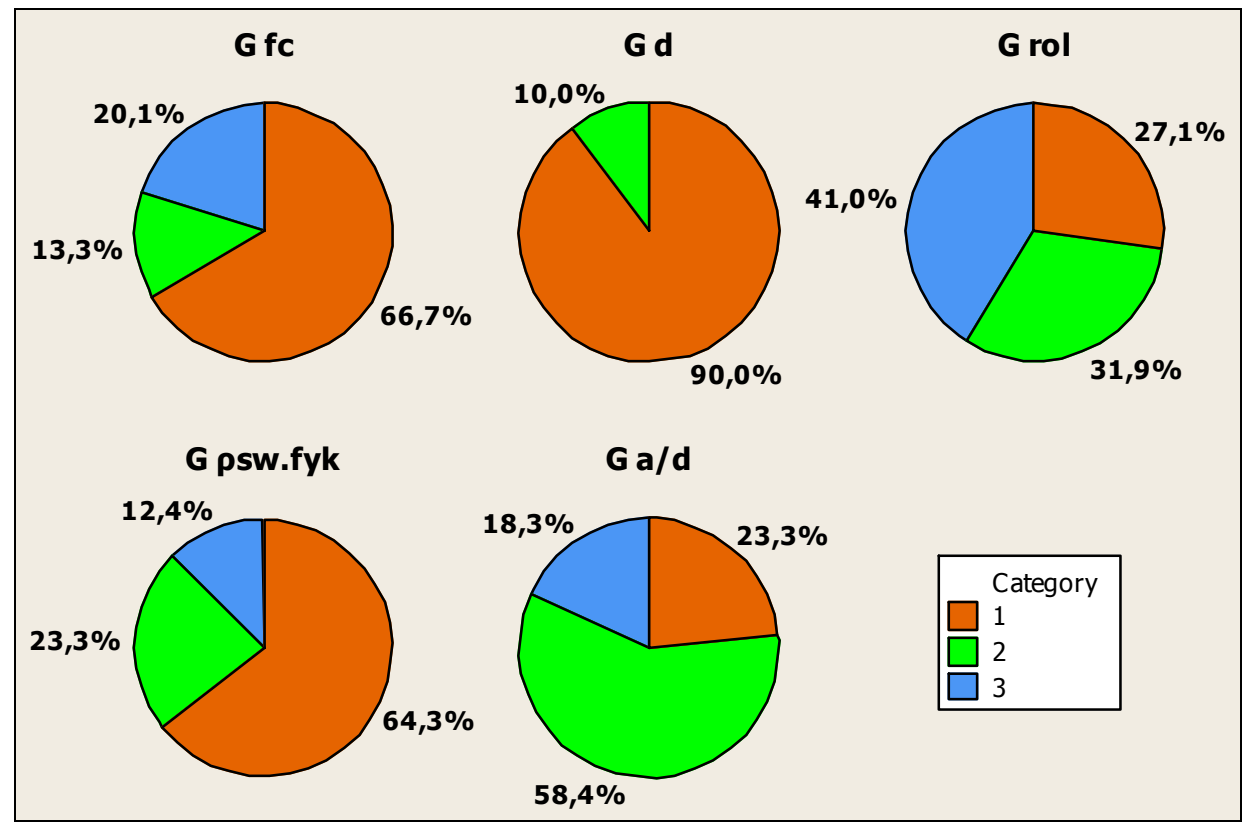

Figura 6.19: Distribuição dos parâmetros do banco de dados em categorias definidas na Tabela 6.7, para elementos com estribos

Resumidamente o banco de dados se caracteriza pela porcentagem maior de elementos de vigas de concreto armado com estribos de características usuais em termos de resistência do concreto, altura efetiva, taxas de armadura e vãos de cisalhamento, porém com quantidades de ensaios significantes estatisticamente de elementos "não usuais", ou seja, que possua algum parâmetro fora dos intervalos usuais da maioria das aplicações.

\subsubsection{Análise dos resultados de ensaios do banco de dados homogeneizado}

Os resultados das 339 vigas de concreto armados com armadura de cisalhamento (estribos) estão ilustrados na Figura 6.20. Utilizou-se o eixo da ordenadas para exprimir os valores das tensões cisalhantes resistentes dos experimentos, $\tau_{\text {exp }}$, ou seja, a divisão da força resistente última de ensaio $V_{\text {Exp }}$, pela área útil da seção $b_{w} \cdot d$. 


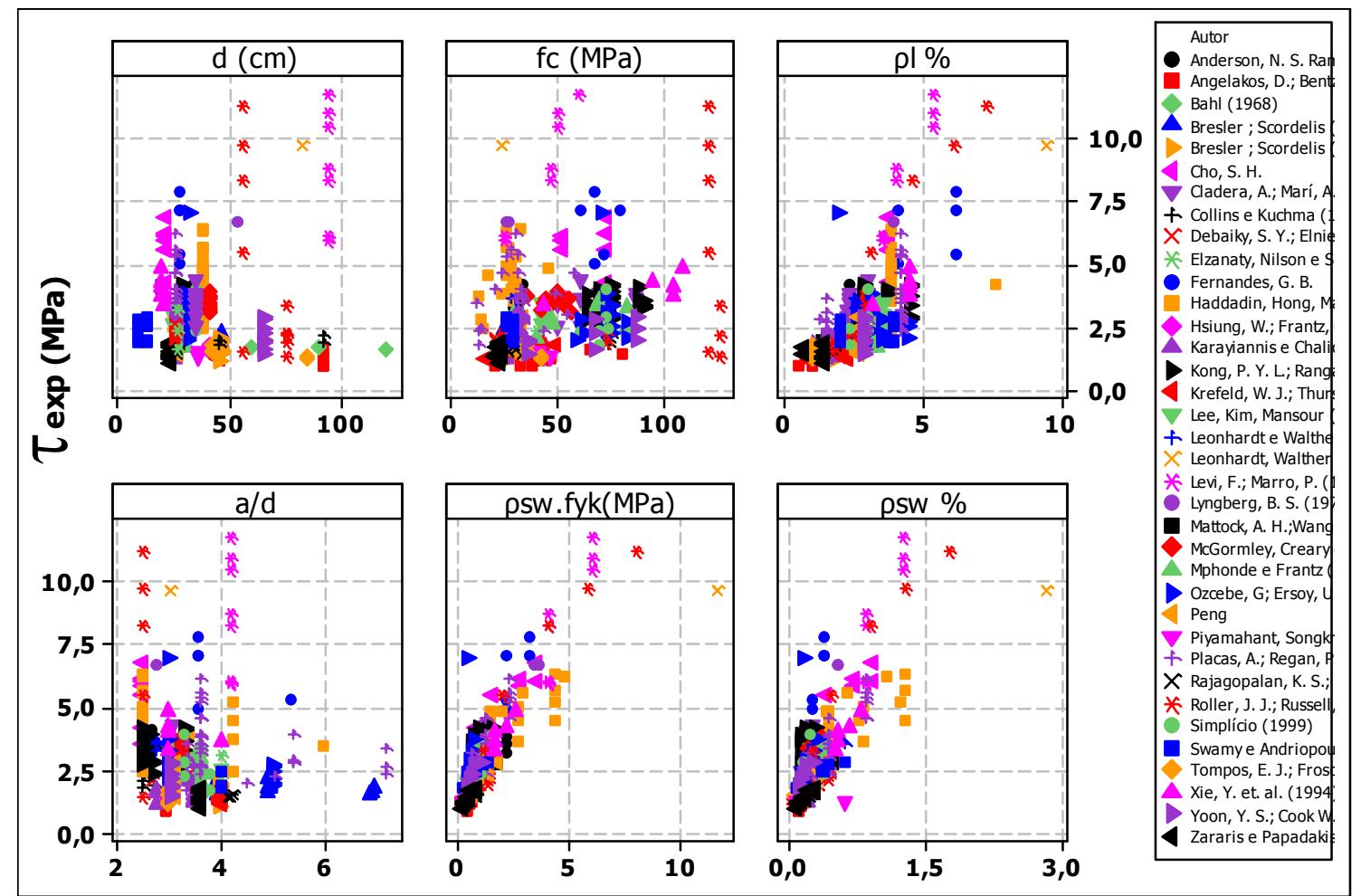

Figura 6.20: Correlação entre parâmetros de ensaios e tensão cisalhante resistente experimental, $\tau_{\text {exp }}$, para elementos com estribos, para cada autor, sendo: d - Altura do elemento; fc - Resistência do concreto; pl - Taxa geométrica de armadura de flexão; a/d - Índice de esbeltez; psw.fyk - Taxa mecânica de estribos e psw - Taxa geométrica de estribos

Os seis gráficos apresentados na Figura 6.20, representam visualmente as correlações entre os pares apresentados. Além disto, a diferenciação das cores dos símbolos dos ensaios representa os diferentes autores que forneceram experimentos válidos para a construção do banco de dados.

Analisando a Figura 6.20, é possível notar que existem correlações claras entre os pares: taxa mecânica da armadura de cisalhamento, $\rho s w . f y k$, e os resultados de ensaios, taxa geométrica, $\rho s w$, e a resistências observadas nos ensaios, e entre $\rho /$ e a resistências observadas nos ensaios. Nota-se que a correlação entre a taxa mecânica da armadura de cisalhamento e as resistências de ensaios é a mais pronunciada.

Para os elementos armados com estribos, verifica-se que não existe uma relação explícita entre a resistência ao cisalhamento e a resistência do concreto, conforme observado no segundo gráfico da Figura 6.20, cujo do título é fc (MPa). Como os resultados de ensaios apresentados referem-se apenas à rupturas por tração, torna-se evidente que a resistência ao concreto não deve influenciar significativamente os resultados, ao contrário de ensaios que tiveram ruptura por exceder o estado limite último de compressão da biela. Para a comprovação desta constatação elaborou-se a Figura 6.21, para ilustrar a influência da resistência do concreto na determinação da tensão cisalhante resistente. 
Nota-se também, que há uma relação entre a taxa geométrica de armadura longitudinal de flexão e a taxa transversal, pois com o aumento dos estribos é necessário aumentar a armadura longitudinal de flexão para que não ocorra ruptura por esgotamento da capacidade resistente a flexão. Neste banco de dados esta correlação foi expressa por meio do teste de Pearson, fornecendo um coeficiente de correlação de 0,616 e p igual 0,000 . Portanto, a correlação entre estas duas variáveis é significativa.

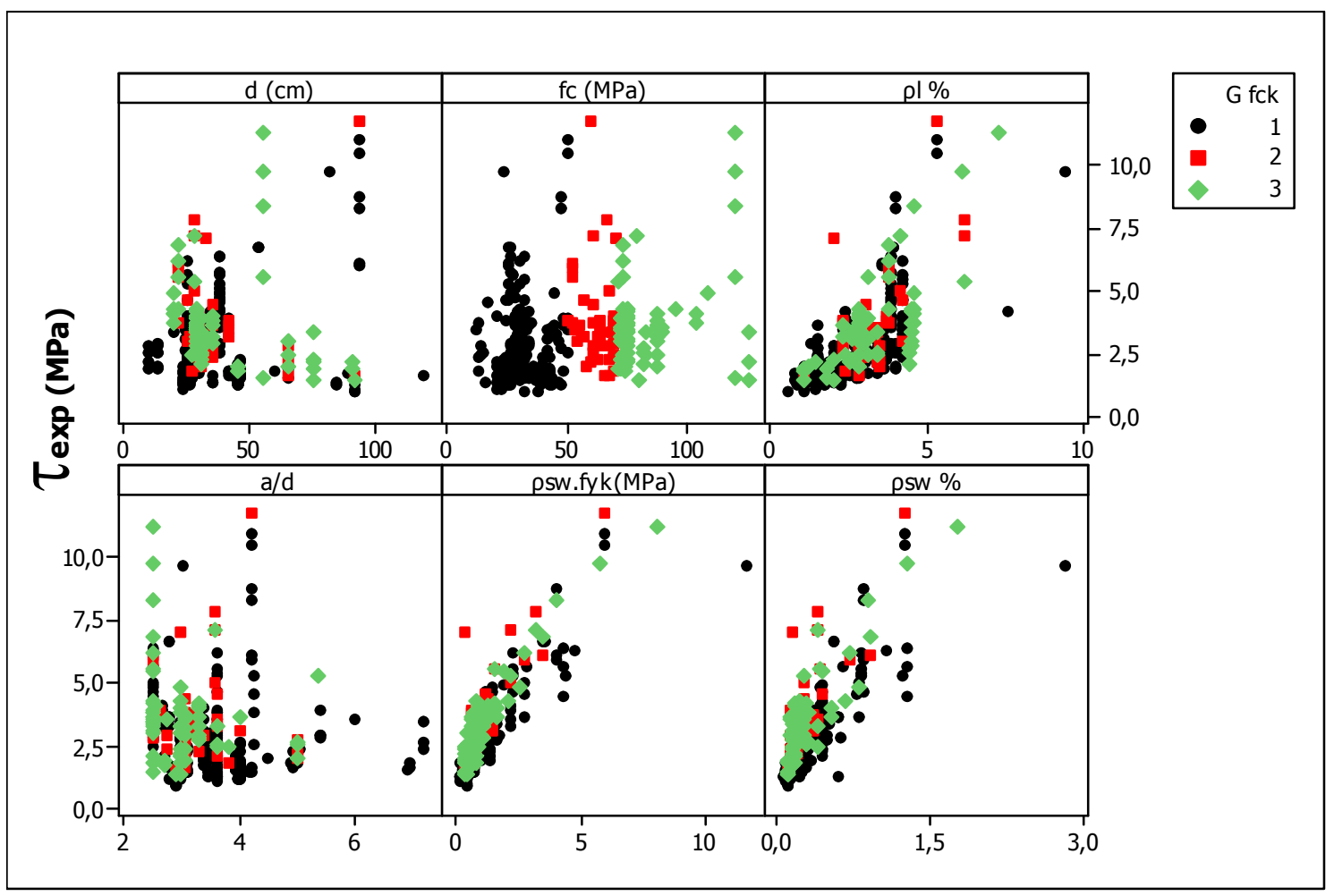

Figura 6.21: Correlação entre parâmetros de ensaios e tensão cisalhante resistente experimental, $\tau_{\text {exp }}$, para elementos com estribos, conforme o grupo $\mathbf{G}$ fc, sendo: d - Altura do elemento; fc - Resistência do concreto; pl - Taxa geométrica de armadura de flexão; a/d - Índice de esbeltez; psw.fyk Taxa mecânica de estribos e psw - Taxa geométrica de estribos

A Figura 6.21 representa as correlações entre os diversos parâmetros estudados, agrupados de acordo com as categorias da resistência a compressão do concreto, fc, como mostrado na legenda da figura.

Nas diversas correlações apresentadas na Figura 6.21, nota-se que não há evidencia de diferenciação das categorias nos gráficos de correlação. Todas as categorias têm o mesmo comportamento. Desta forma, na análise dos elementos armados com estribos não será abordado o aumento de resistência ao cisalhamento devido ao aumento da resistência do concreto, pois esta parcela não é o principal parâmetro que guia a resistência ao cisalhamento de elementos armados ao cisalhamento.

A Figura 6.22 apresenta a correlação entre os diversos parâmetros analisados, com discretização do grupo "G psw.fyk". Verifica-se que há uma distinção clara das categorias definidas pela taxa mecânica de armadura de cisalhamento nas diversas correlações apresentadas. 


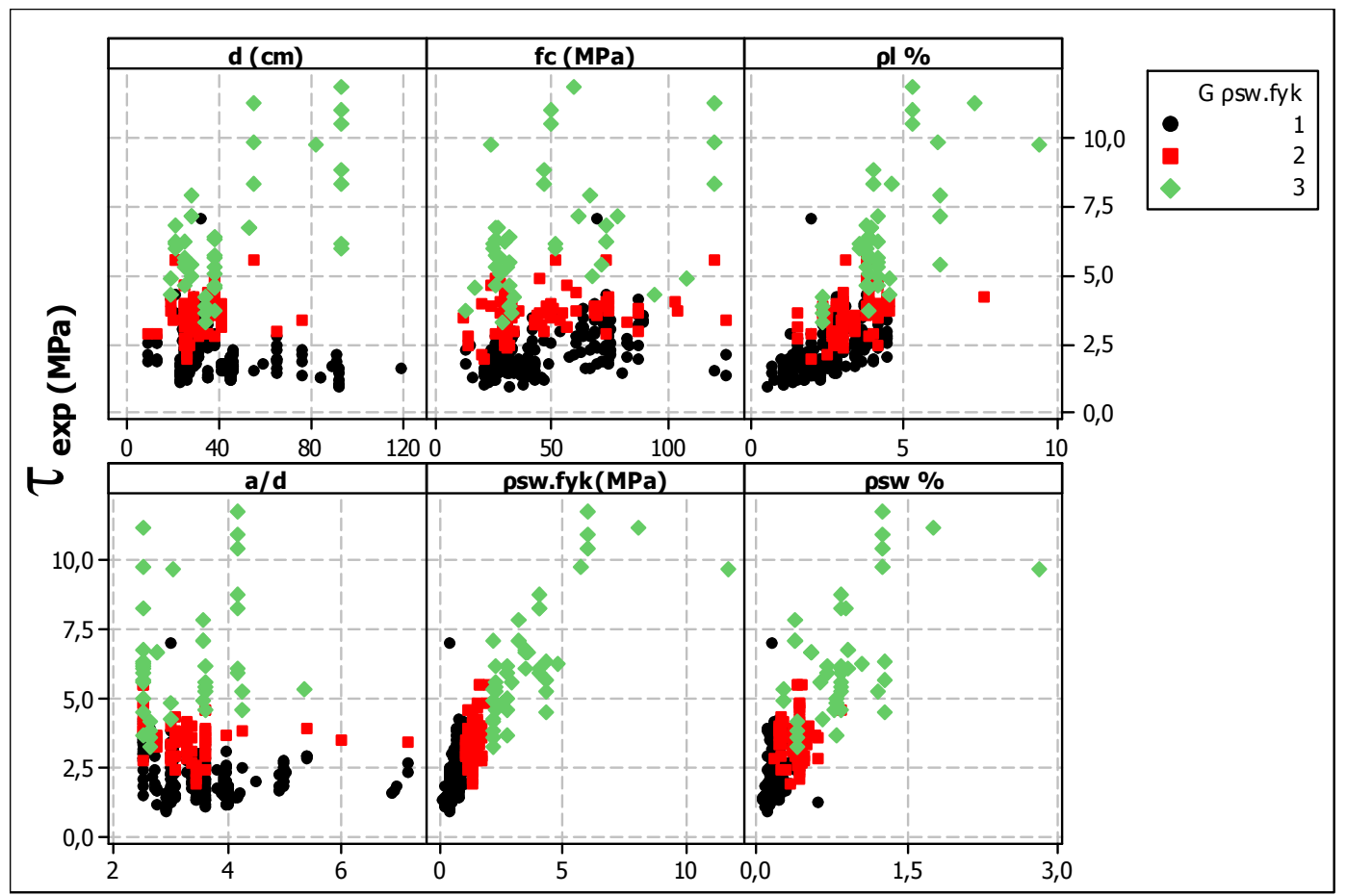

Figura 6.22: Correlação entre parâmetros de ensaios e tensão cisalhante resistente experimental, $\tau_{\text {exp }}$, para elementos com estribos, segundo o grupo $G$ psw.fyk, sendo: $d$ - Altura do elemento; fc - Resistência do concreto; $\rho$ l Taxa geométrica de armadura de flexão; a/d - Índice de esbeltez; psw.fyk - Taxa mecânica de estribos e psw - Taxa geométrica de estribos

Conclui-se que o fator principal a ser analisado é a taxa mecânica de estribos, e, portanto, este será o principal parâmetro a ser analisado, pois a resistência ao cisalhamento ficou bem caracterizada pelas categorias do grupo " $G$ psw.fyk". A categoria 1 correspondeu a baixas resistências ao cisalhamento, a categoria 2, resistências intermediárias e para a categoria 3 , resistências elevadas ao cisalhamento.

\subsubsection{Vigas com resistência do concreto e taxa de armadura transversal dentro dos intervalos válidos da norma}

Neste item foram verificados apenas os dados de ensaios que apresentaram seus parâmetros válidos, ou seja, resistência do concreto menor que a máxima permitida e taxa de estribo maior que a mínima. Como cada norma possui intervalos de validade diferentes, a quantidade de dados analisados foi diferente para cada norma.

\subsubsection{Análise da exatidão e precisão dos modelos das normas com o uso dos resultados de ensaios do banco de dados homogeneizado}

Conforme mencionado no subitem 6.5.2, a análise dos dados de ensaios e predição de norma para elementos armados ao cisalhamento com estribos, se torna simples, quando se utiliza a taxa mecânica da armadura transversal de cisalhamento como parâmetro de comparação, devido ao fato que na maioria dos casos este se mostra como parâmetro principal para determinação da resistência ao cisalhamento. 
Cabe ressaltar que as rotinas para determinação dos valores de predição de norma foram ajustadas de forma a otimizar os valores de resistência, reduzindo o ângulo de inclinação da biela, sem desrespeitar os limites e a condição do estado limite último de compressão. Isto também foi possível, pois todos os ensaios utilizados, não apresentaram indícios de escorregamento da armadura de flexão, ruína por flexão e também, pelo fato, que todas as vigas possuíam densidade de armadura longitudinal de tração constante ao longo de toda a peça.

Na Figura 6.23 utilizou-se o eixo das ordenadas para expressar a razão entre a força resistente do ensaio, $V_{\text {exp }}$, e a força resistente teórica ultima de norma, $V_{\mathrm{u}}$, resultando em um índice que mostra a distância relativa entre o valor medido no ensaio e o valor de predição de norma. Caso este índice seja próximo do unitário, mostra a exatidão da norma na sua predição do valor de ruptura, caso seja maior que maior que 1 indica que o valor de predição de norma é menor que o valor do ensaios, mostrando, a priori um resultado conservador e para índices menores que 1 , pouco conservador ou não seguros. A quantidade de dados comparados variou conforme cada norma, pois cada norma possui um valor limite de aceitabilidade para o valor da resistência do concreto do ensaio, e fizeram parte da análise apenas os dados de ensaios que respeitaram os limites de norma (fc, máx e Asw,min), considerando separadamente cada norma.

O eixo das abscissas foi composto pelos valores dos parâmetros psw.fyk (MPa).

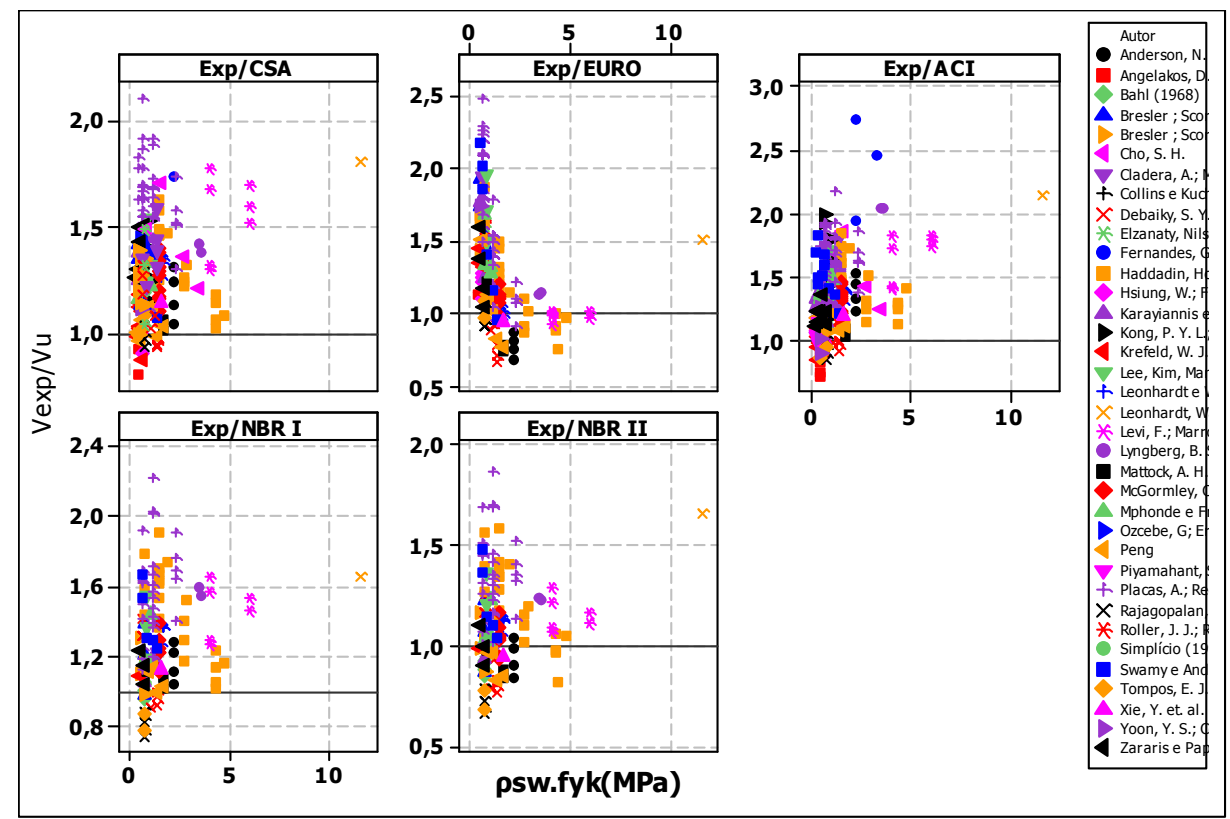

Figura 6.23: Correlação entre as razões Vexp/Vu e os valores do parâmetro psw.fyk, para as normas CSA, EURO, ACl, modelo I na NBR e modelo II da NBR, para elementos com estribos

Obs: Exp/CSA indica a razão entre o valor do resultado de ensaio e os valores de predição da norma CSA (2004), e de forma similar para Exp/EURO, Exp/ACI, Exp/NBR I e Exp/NBR II. 


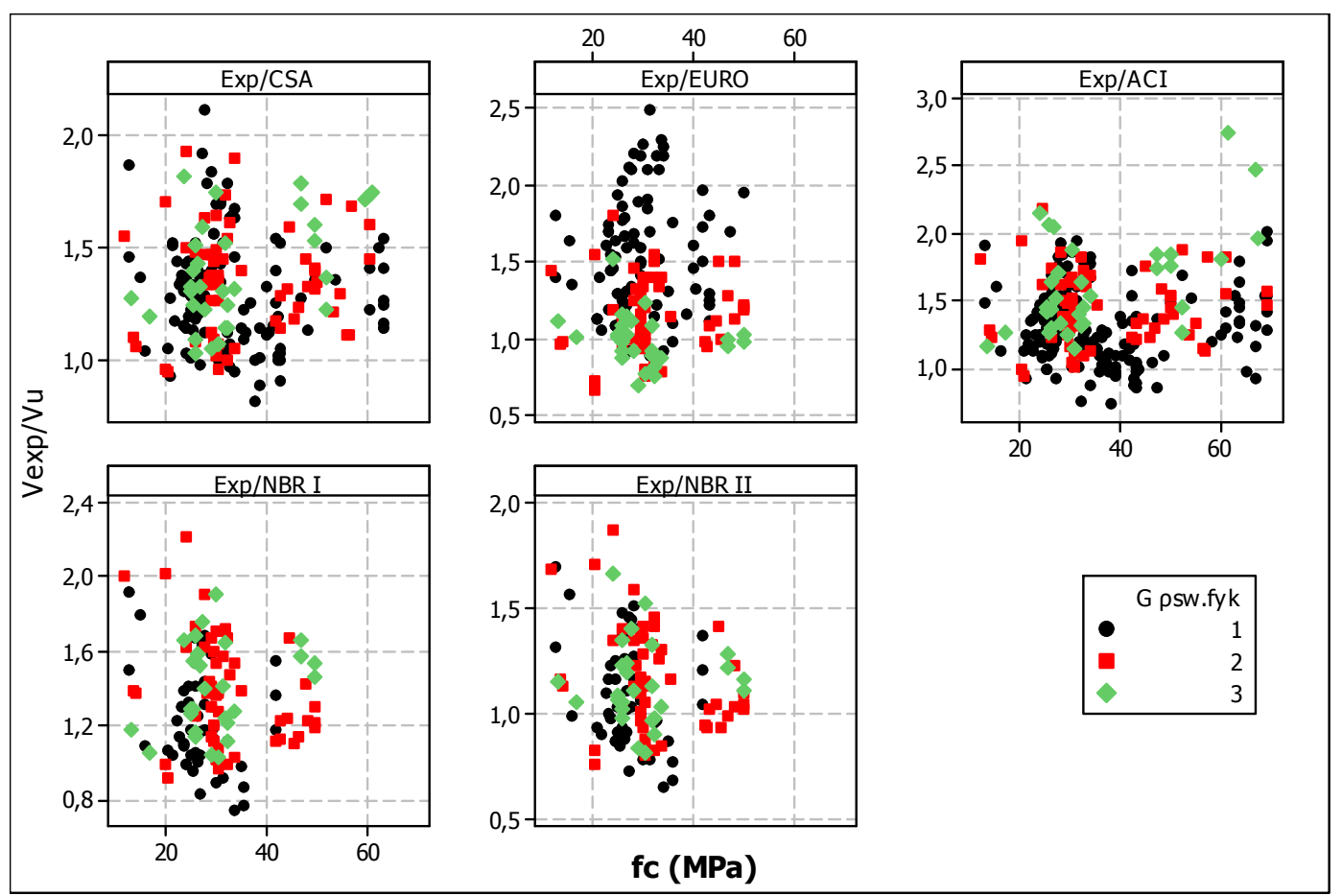

Figura 6.24: Correlação entre as razões Vexp/Vu e os valores do parâmetro psw.fyk, para as normas CSA, EURO, ACl, modelo I na NBR e modelo II da NBR, conforme a variação da resistência do concreto, para elementos com estribos

A Figura 6.24 apresenta a mesma correlação $V_{\text {exp }} / V_{\mathrm{u}}$ para as diversas normas, porém expressando a resistência a compressão do concreto nos eixos das abscissas. Nota-se que a resistência do concreto não possui relevância maior que a taxa mecânica de estribos e de forma geral não há nenhuma tendência de comportamento com a variação da resistência do concreto, não sendo assim, necessário subdividir o estudo em faixas de resistência do concreto.

As normas CSA (2004), Eurocode (2004) e ACl (2008) indicam maior concentração de valores acima de 1,0, indicando assim, que os valores de predição das normas estão seguros, porém cabe observar, na Figura 6.23, que - Eurocode (2004) apresentou boa exatidão para os casos com taxas mecânicas maiores que $2 \mathrm{MPa}$. O modelo I e II de predição da norma NBR 6118 (2007) apresentaram resultados espalhados em torno do valor unitário, indicando que na média os resultados apresentados estão próximos dos valores obtidos nos ensaios sendo necessário ainda analisar sua dispersão.

A Figura 6.25 indica algumas medidas estatísticas para todos os ensaios válidos agrupados por norma, em uma única análise. A priori, os resultados apresentados indicam comportamentos semelhantes para todas as normas. Apenas o modelo II indica um pequeno afastamento em relação ao comportamento médio das demais normas, sem contudo, caracterizar-se como diferente estatisticamente, pois os intervalos estão acoplados em mais de $5 \%$. 


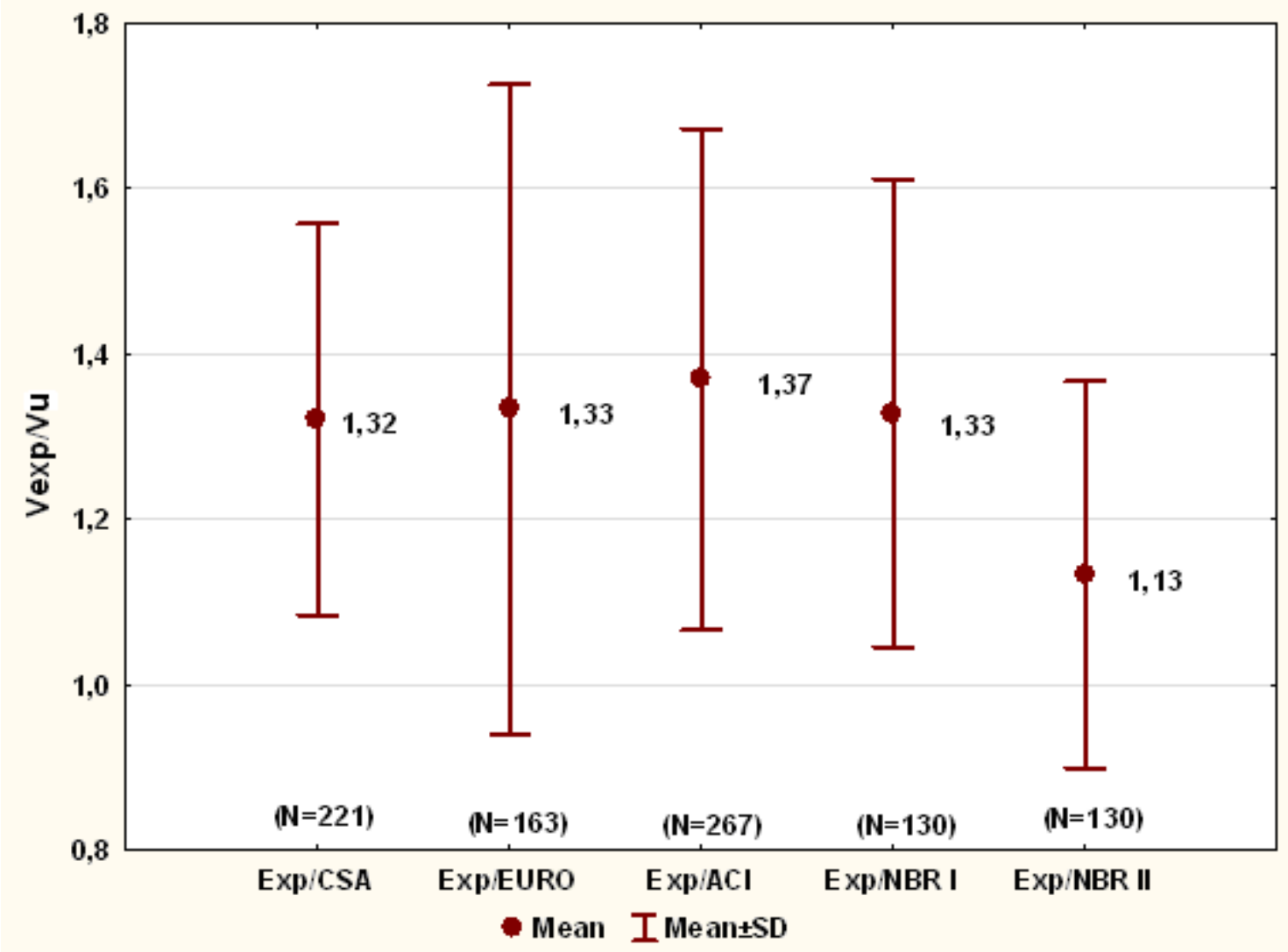

Figura 6.25: Análise dos valores médios e desvio padrão entre as razões Vexp/Vu para as normas CSA, EURO, ACI, modelo I na NBR e modelo II da NBR, para elementos com estribos e dados válidos

OBS: Os valores entre parênteses indicam a quantidades de ensaios utilizados na análise.

Realizando o teste de melhor ajuste da distribuição com o programa MINITAB 16 (Minitab Inc.), verificou-se que as distribuições dos índices não apresentaram bons resultados quando comparados com as distribuições normais simples, desta forma rigorosamente falando, o valor do afastamento não é o desvio padrão.

Com a finalidade de analisar melhor os comportamentos dos modelos de predição de norma, analisaram-se cada categoria do grupo " $G$ psw.fyk" separadamente, e os resultados foram mostrados na Figura 6.26 e Tabela 6.8. 


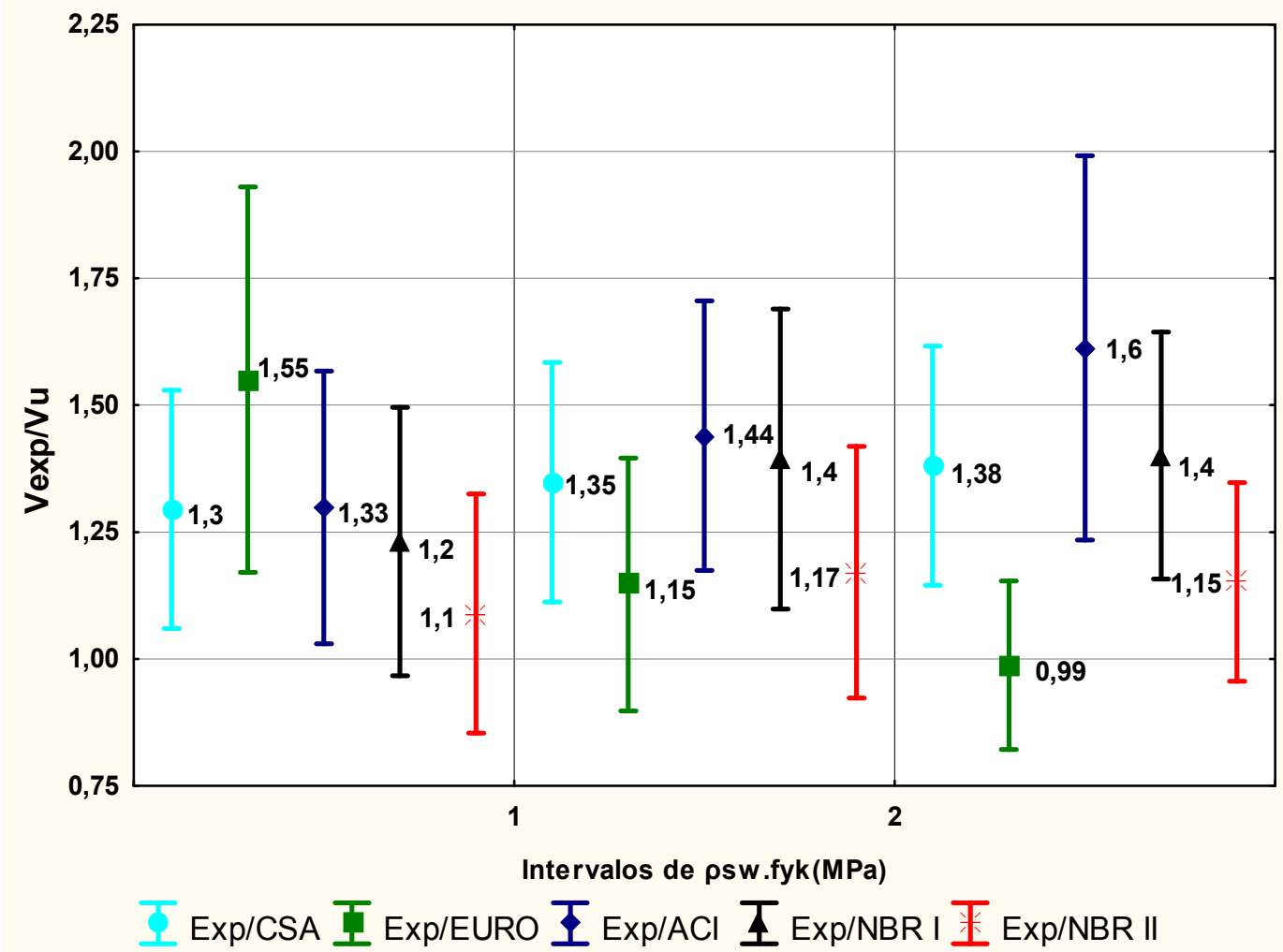

Figura 6.26: Análise dos valores médios e desvio padrão entre as razões Vexp/Vu para as normas CSA, EURO, ACI, modelo I na NBR e modelo II da NBR, para elementos com estribos e dados válidos, separados em três intervalos de psw.fyk

Tabela 6.8: Medidas estatísticas dos valores de predição de norma, agrupados e não agrupados (com estribos)

\begin{tabular}{|c|c|c|c|c|c|}
\cline { 3 - 6 } \multicolumn{2}{c|}{} & \multicolumn{4}{c|}{ Grupos para rosw.fyk } \\
\hline \multirow{3}{*}{ CSA } & Norma & $\mathbf{1 + 2 + 3}$ & $\mathbf{1}$ & $\mathbf{2}$ & $\mathbf{3}$ \\
\cline { 2 - 6 } & MEDIA & 1,321 & 1,295 & 1,348 & 1,381 \\
\cline { 2 - 6 } & COEF. VARIAÇÃO & 0,179 & 0,181 & 0,175 & 0,171 \\
\cline { 2 - 6 } EURO & MEDIANA & 1,316 & 1,276 & 1,355 & 1,323 \\
\cline { 2 - 6 } & MEDIA & 1,333 & 1,550 & 1,147 & 0,988 \\
\cline { 2 - 6 } & COEF. VARIAÇÃO & 0,295 & 0,245 & 0,217 & 0,168 \\
\cline { 2 - 6 } & MEDIANA & 1,242 & 1,519 & 1,141 & 0,988 \\
\hline \multirow{3}{*}{ ACI } & MEDIA & 1,370 & 1,298 & 1,440 & 1,613 \\
\cline { 2 - 6 } & COEF. VARIAÇÃO & 0,221 & 0,207 & 0,185 & 0,235 \\
\cline { 2 - 6 } & MEDIANA & 1,329 & 1,272 & 1,444 & 1,515 \\
\hline \multirow{3}{*}{ NBR I } & MEDIA & 1,329 & 1,231 & 1,394 & 1,401 \\
\cline { 2 - 6 } & COEF. VARIAÇÃO & 0,213 & 0,215 & 0,212 & 0,174 \\
\cline { 2 - 6 } & MEDIANA & 1,291 & 1,180 & 1,376 & 1,404 \\
\hline \multirow{3}{*}{ NBR II } & MEDIA & 1,133 & 1,089 & 1,171 & 1,152 \\
\cline { 2 - 6 } & COEF. VARIAÇÃO & 0,207 & 0,216 & 0,212 & 0,170 \\
\cline { 2 - 6 } & MEDIANA & 1,105 & 1,036 & 1,139 & 1,119 \\
\hline
\end{tabular}

Com o uso da Figura 6.26 e Tabela 6.8, pôde-se concluir que o modelo de predição da norma CSA (2004) é o mais preciso, para todas as categorias de $\rho s w . f y k$, ou seja baixa, média e alta densidade de estribos, pois apresenta os 
menores valores de coeficientes de variação, e com isso menor dispersão dos dados em relação a média, e também apresenta médias em torno de 1,3 o que representa uma maior segurança. Para baixas taxas de estribos norma Eurocode (2004) apresentou um coeficiente de variação de $24,5 \%$, além disso, para taxas altas de estribos, apresentou o valor de $17 \%$. A norma ACl (2008) apresentou coeficientes de variação de $21 \%$ e $23,5 \%$, para baixas e altas taxas de estribos, respectivamente.

Interpretando os resultados dos modelos de predição da norma NBR 6118 (2007), o modelo II indicou para baixa e média taxa mecânica de armadura, ou seja, $\rho s w . f y k \leq 2 \mathrm{MPa}$ resultados médios considerados exatos, em relação ao valores medidos nos ensaios, pois as médias para estes intervalos foram as menores dentre as outras, e próximo do valor unitário. A melhor exatidão para o intervalo intermediário foi obtido pela norma Eurocode (2004).

Por fim, para o intervalo $\rho s w . f y k>2$, a norma Eurocode (2004) apresentou a melhor exatidão e a melhor precisão.

As conclusões apresentadas estão resumidas no quadro da Tabela 6.9

Tabela 6.9: Resumo da análise de exatidão e precisão (com estribos)

\begin{tabular}{|c|c|c|c|}
\cline { 2 - 4 } \multicolumn{1}{c|}{} & \multicolumn{3}{c|}{ Categoria de $\rho s w . f y k$ (Mpa) } \\
\cline { 2 - 4 } \multicolumn{1}{c|}{} & $\rho$ sw.fyk $\leq 1$ & $1<\rho s w . f y k \leq 2$ & $\rho s w . f y k>2$ \\
\hline Melhor Exatidão & NBR II & EURO/NBR II & EURO \\
\hline Melhor Precisão & CSA & CSA & EURO \\
\hline
\end{tabular}

* Valores semelhantes

Inteira-se o fato de que exatidão e precisão não estão relacionados com os conceitos de segurança, apenas com a análise descritiva dos resultados dos modelos de predição de norma.

\subsubsection{Análise da parcela resistente devido ao concreto}

Com a análise do subitem anterior, 6.5.3.1, tornou-se clara a importância da parcela resistente ao cisalhamento devido ao concreto, para baixas taxas mecânicas de armadura de cisalhamento ( $\rho s w . f y k \leq 1)$. Normas que consideram esta parcela resistente, p. ex. NBR 6118 (2007) apresentaram valores de predição mais próximos dos valores reais de ensaios, por outro lado, a norma Eurocode (2004), que não considera esta parcela resistente apresentou valores médios de predição muito abaixo dos valores de ensaios, indicando assim baixa otimização de recursos.

Com isso, como a influência dos estribos é menos significativa para baixas taxas mecânicas de estribos, analisou-se como os modelos de predição das normas consideram a parcela resistente devido apenas ao concreto, frente a comparação com os dados de ensaios. 


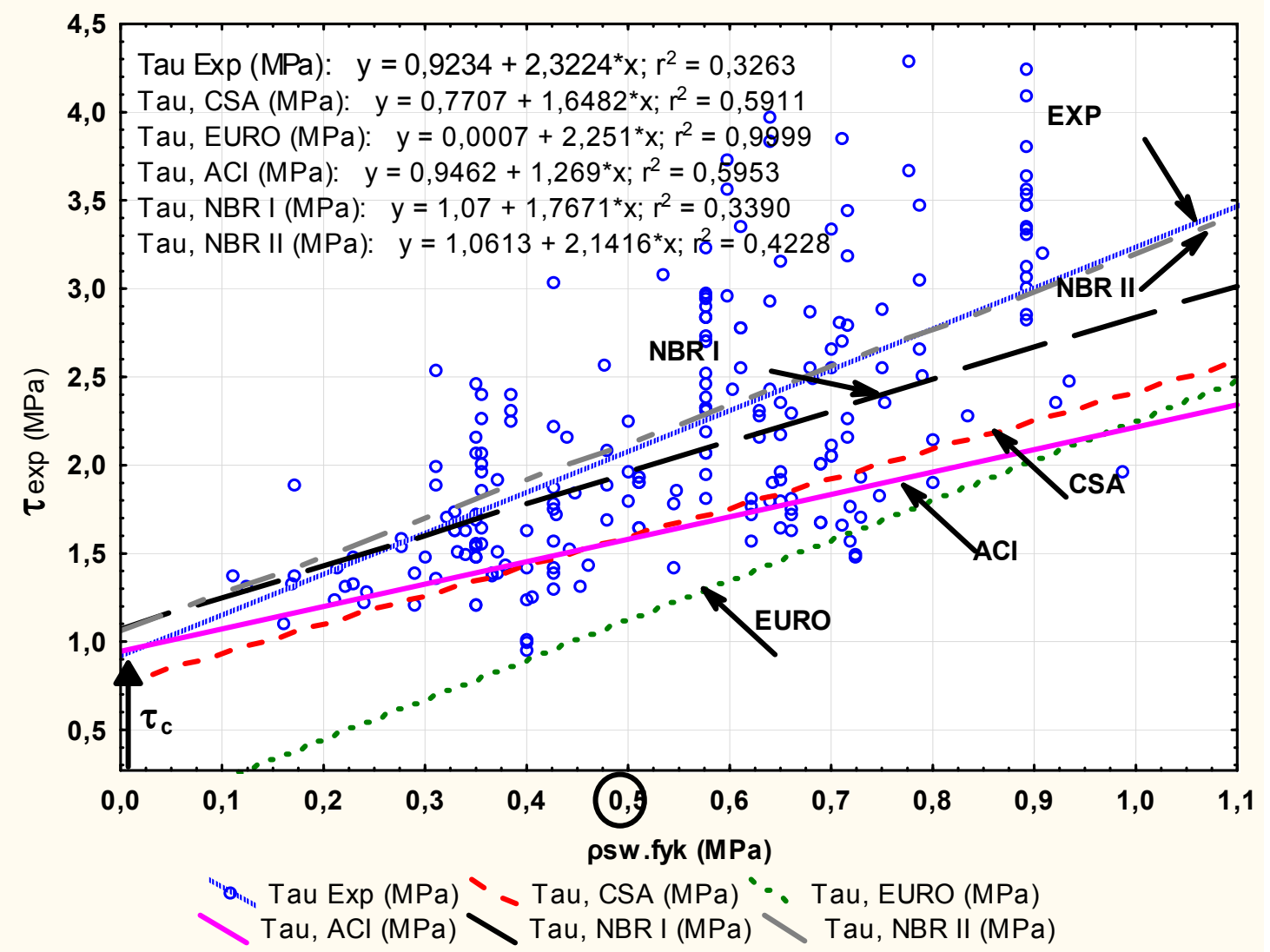

Figura 6.27: Análise dos modelos de predição de norma na determinação da parcela resistente devido ao concreto, $\tau_{c}$, baseados em resultados de ensaios de elementos armados com estribos, sendo EXP - reta de média dos ensaios; CSA - reta média dos valores de predição da norma CSA e analogamente para ACI, EURO, NBR I e NBR II

O gráfico da Figura 6.27 foi elaborado considerando apenas os dados de ensaios e predição de norma com a taxa mecânica de estribos menor que 1 $\mathrm{MPa}$, diminuindo assim a influência do acréscimo de resistência e domínio no fenômeno causado pelos estribos. No eixo das ordenadas são impressos os valores das tensões cisalhantes resistentes em MPa e no eixo das abscissas as taxas mecânicas $\rho s w . f y k$.

Concluiu-se que o modelo da norma ACl (2008) apresentou a melhor estimativa para a parcela resistente devido apenas ao concreto quando a taxa mecânica aproxima-se de zero. Porém, para elementos armados ao cisalhamento com uma taxa mecânica mínima definida nas normas, como por exemplo, para um elemento de concreto com uma resistência $20 \mathrm{MPa}$ a taxa seria aproximadamente $0,5 \mathrm{MPa}$, e sendo assim, na faixa de intervalo próximo deste valor, o modelo II da norma NBR 6118 apresentou a melhor estimativa média.

\subsubsection{Análise da segurança dos modelos das normas com o uso dos resultados de ensaios do banco de dados homogeneizado}

A precisão e exatidão dos modelos foram analisadas utilizando os valores teóricos ultimos, ou seja, considerando os fatores de segurança unitários, 
extinguindo a possibilidade de análise da segurança do modelo de predição de norma. Conforme amplamente discutido no item 6.4, para se analisar a segurança dos modelos resistentes, deve-se pesquisar a influência dos fatores de segurança, confrontados com os resultados de ensaios, aceitando como válida a premissa que estes são resultados exatos da resistência última dos elementos.

Neste item, é necessário determinar o valor médio de $\Phi_{\text {mod }}$, que será estimado aproximadamente como $\sqrt{\phi}_{\text {med }}$, sendo $\Phi_{\text {med }}$ a média dos coeficientes de redução das resistências de todas as previsões de normas. Analisando todos os valores de predição de normas, das normas CSA (2004), Eurocode (2004), ACl (2008) e NBR 6118 (2007), obteve-se um fator de segurança final médio igual a 0,78 , portanto o $\Phi_{\text {mod }}$ adotado foi 0,90 . Como o critério de análise deve ser o mesmo para todas as normas, uma forma de padronizar qual é o coeficiente de ponderação final que deverá ser utilizado para definir o intervalo de dados apropriados.

Sendo assim o Grupo 3 da Tabela 6.4 ficou definido como:

\begin{tabular}{|l|l|}
\hline $0,9 . V_{u} \leq V_{E x p} \leq 1,1 . V_{u}$ & $\begin{array}{l}\text { SEGURANÇA E CUSTO } \\
\text { APROPRIADOS }\end{array}$ \\
\hline
\end{tabular}

Nas figuras seguintes, sobre cada barra indica-se a porcentagem de dados que uma dada norma possui em certo grupo de situações.

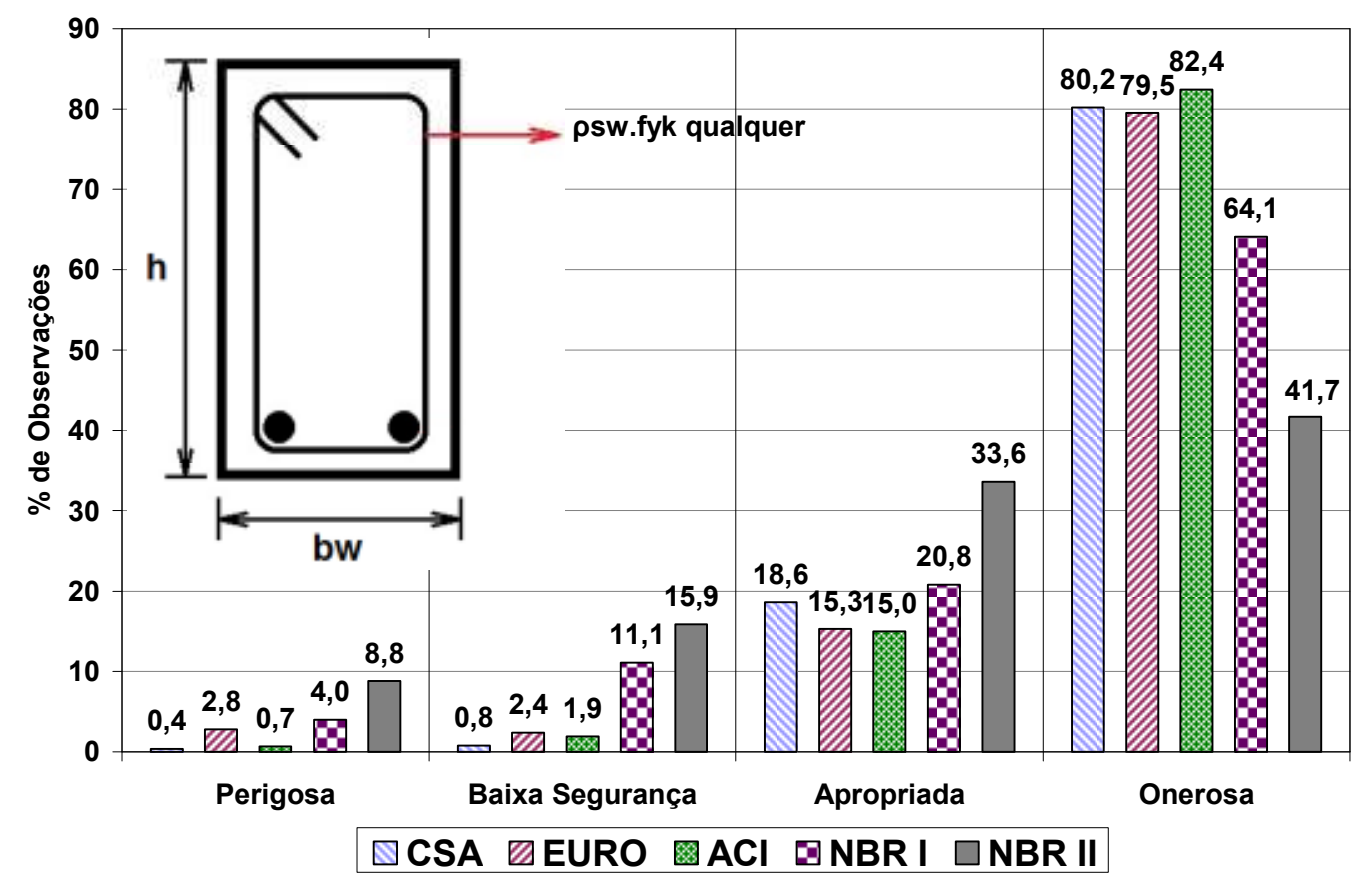

Figura 6.28: Distribuição das normas, segundo o critério de comparação, dados válidos e elementos com estribos, definido neste trabalho

Obs: Cód. CSA representa a porcentagem de previsões da norma CSA (2004), Cód. EURO representa a porcentagem de previsões da norma Eurocode 
(2004), Cód. ACl representa a porcentagem de previsões da norma $\mathrm{ACl}$ (2008), Cód. NBR I representa a porcentagem de previsões do modelo I da norma NBR 6118 (2007), e Cód. NBR II representa a porcentagem de previsões do modelo II da norma NBR 6118 (2007)

A Figura 6.29 foi elaborada considerando todas as vigas com estribos, desde que o valor da resistência do concreto e a taxa de estribos estivessem dentro dos intervalos aceitos para cada norma. Com isto objetiva-se analisar a segurança dos modelos de predição das normas através da porcentagem de resultados em cada grupo definido na Tabela 6.4.

É de extrema importância lembrar o conceito de armadura mínima, que, visando um comportamento seguro em elementos com baixa solicitação, e por consequência baixa taxa de armadura transversal, as normas em geral, definem uma quantidade mínima de armadura de cisalhamento. Para efetuar a análise de segurança, removeram-se os dados referentes aos elementos moldados com taxa de armadura menor que a mínima, estipulada por norma, pois estes elementos, em um caso real de construção, nunca poderiam ter sido feitos. Estes elementos deveriam ter um acréscimo de armadura de cisalhamento até atingir o valor mínimo, e com isso os resultados obtidos nos ensaios de laboratório seriam diferentes.

Em todos os casos analisados, em que a taxa da armadura de cisalhamento dos elementos ensaiados estava abaixo da taxa de armadura mínima de norma, constatou-se que a condição mais restritiva se deu pela armadura mínima da norma NBR 6118 (2007). Portanto, removeu-se do banco de dados estes ensaios e elaboraram-se os seguintes gráficos.

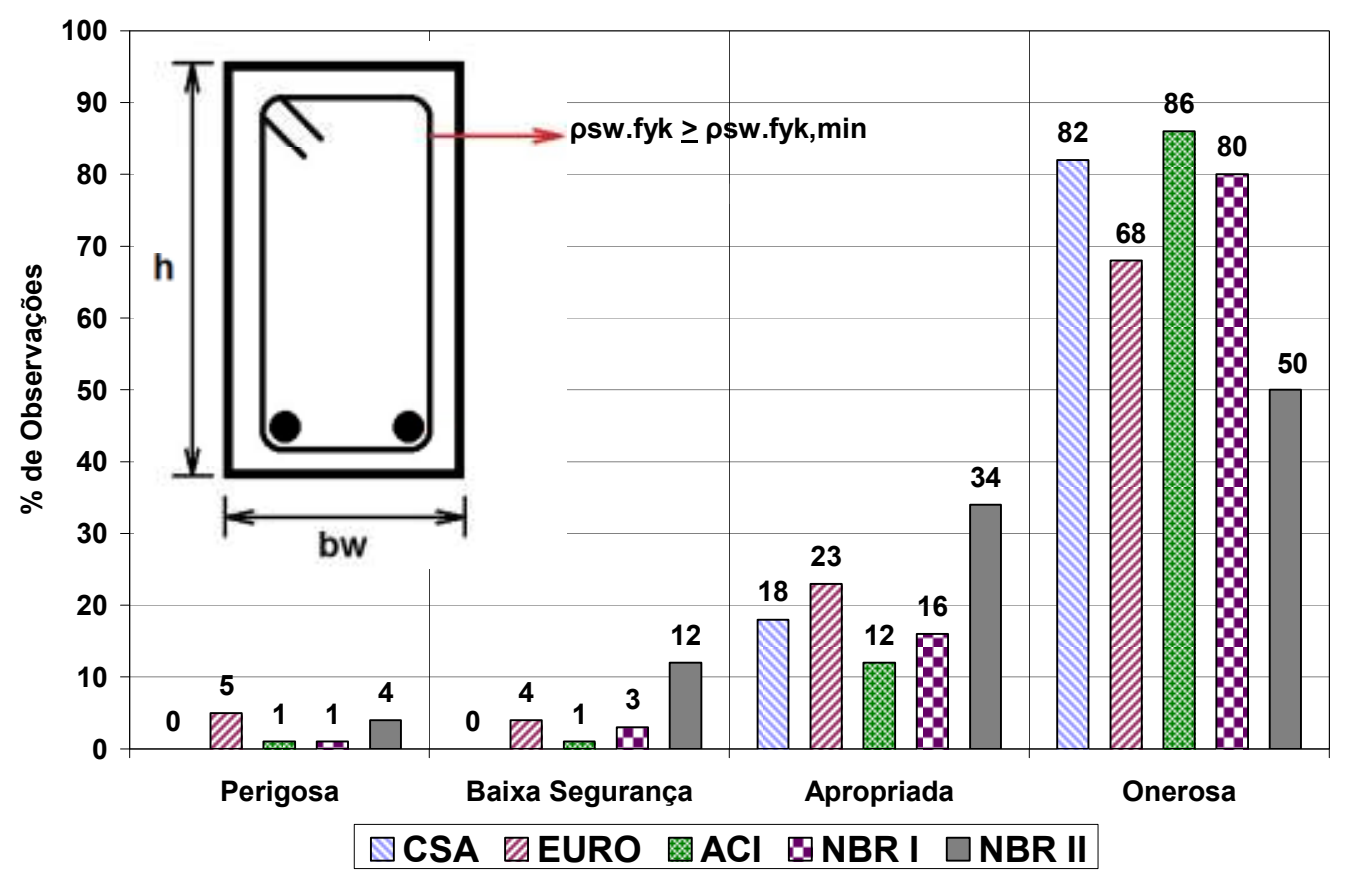

Figura 6.29: Distribuição das normas, segundo o critério de comparação, dados válidos ( $\rho s w . f y k \geq \rho s w$.fyk,min e fc $\leq$ fc,máx), definidos neste trabalho 
Analisando a Figura 6.28 e a Figura 6.29 , pode-se confirmar que a norma NBR 6118 (2007), para o modelo II, apresenta a melhor exatidão, devido a porcentagem de $34 \%$ das previsões dentro do grupo 3 (previsões de segurança e custo apropriados), reforçando as conclusões apresentadas na Figura 6.25 .

Para a análise da segurança, observa-se na Figura 6.29, que as normas CSA (2004), ACl (2008) e Modelo I da NBR 6118 (2007), apresentaram resultados com segurança adequada, ou seja, poucas ou nenhuma das previsões perigosas (Grupo 1). Destas, destaca-se o modelo I da NBR 6118 (2007), pois apresentou a maior porcentagem no grupo 3 (Apropriado) e menor porcentagem no grupo 4 (Oneroso).

Para melhor compreender o comportamento dos modelos de predição nos campos da segurança e custo, dividiram-se os ensaios em grupos conforme os valores de taxa mecânica de estribos dos ensaios, ou seja, o grupo $G$ rosw.fyk.

O gráfico da Figura 6.30, apresenta os dados de vigas que possuem osw.fyk $\leq 1 \mathrm{MPa}$ e que apresentavam uma taxa mecânica de estribos maior ou igual a mínima necessária. Confirma-se que as normas CSA (2004), Eurocode (2004) e ACl (2008) apresentam resultados conservadores e onerosos, porém com porcentagem desprezível de casos perigosos. A norma NBR 6118 (2007) apresentou para o modelo II, a maior porcentagem de casos perigosos, sendo um caso perigoso a cada 7 ensaios. O modelo I da NBR 6118 (2007) apresentou 1 caso dentre os 53 ensaios considerados, e $21 \%$ dos casos considerados apropriados.

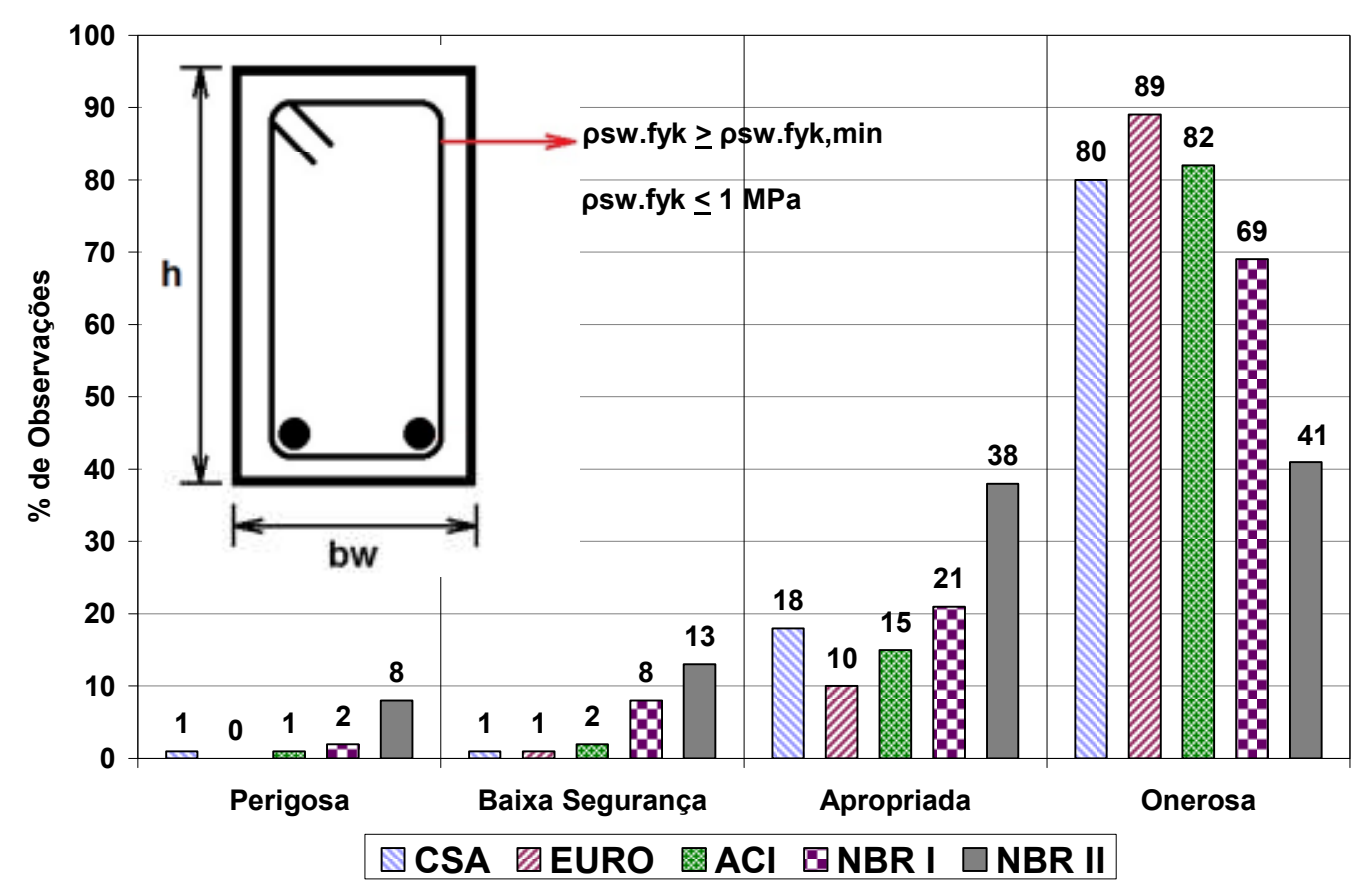

Figura 6.30: Aplicação do critério de comparação para psw.fyk $\leq 1 \mathrm{MPa}$, definido neste trabalho 
As comparações para elementos com $\rho s w$.fyk entre 1 e $2 \mathrm{MPa}$, apresentam-se na Figura 6.31. Para este intervalo apenas as normas Eurocode (2004) e o modelo II da NBR 6118 (2007) apresentaram casos de predição que representariam uma situação perigosa de segurança para peças executadas, que seriam referentes a uma possível ruína a cada 8 e 50 ensaios, respectivamente. Nota-se o bom desempenho do modelo I da norma NBR 6118 (2007) e da norma CSA (2004) com $14 \%$ e $19 \%$ dos valores previstos considerados apropriados, respectivamente, e nenhuma predição perigosa. A $\mathrm{ACl}$ (2008) apresentou mais de $90 \%$ dos resultados na faixa considerada onerosa ou com muita segurança, enquanto o modelo I apresentou $86 \%$.

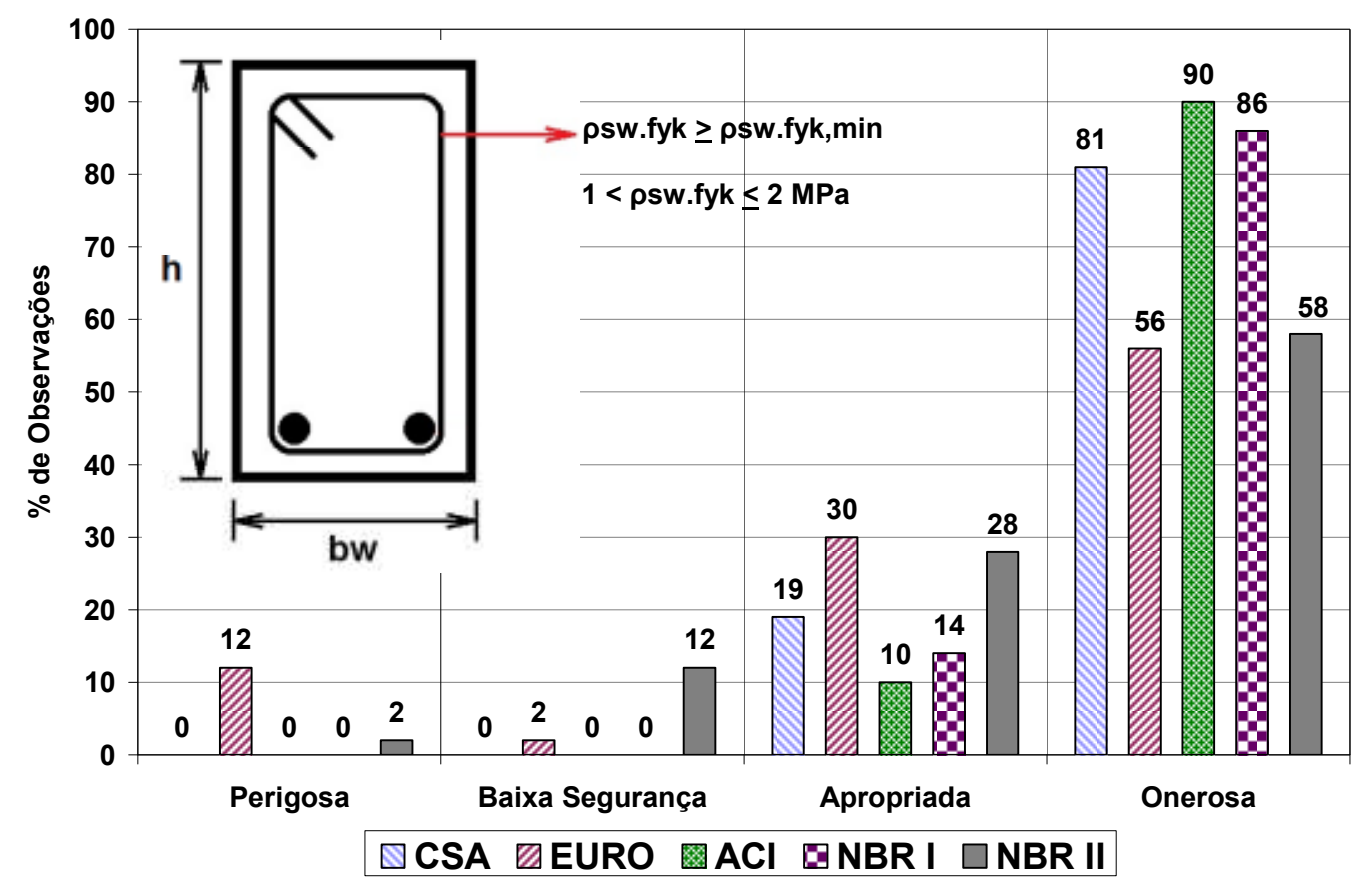

Figura 6.31: Aplicação do critério de comparação para psw.fyk entre 1 e $2 \mathrm{MPa}$, definido neste trabalho 


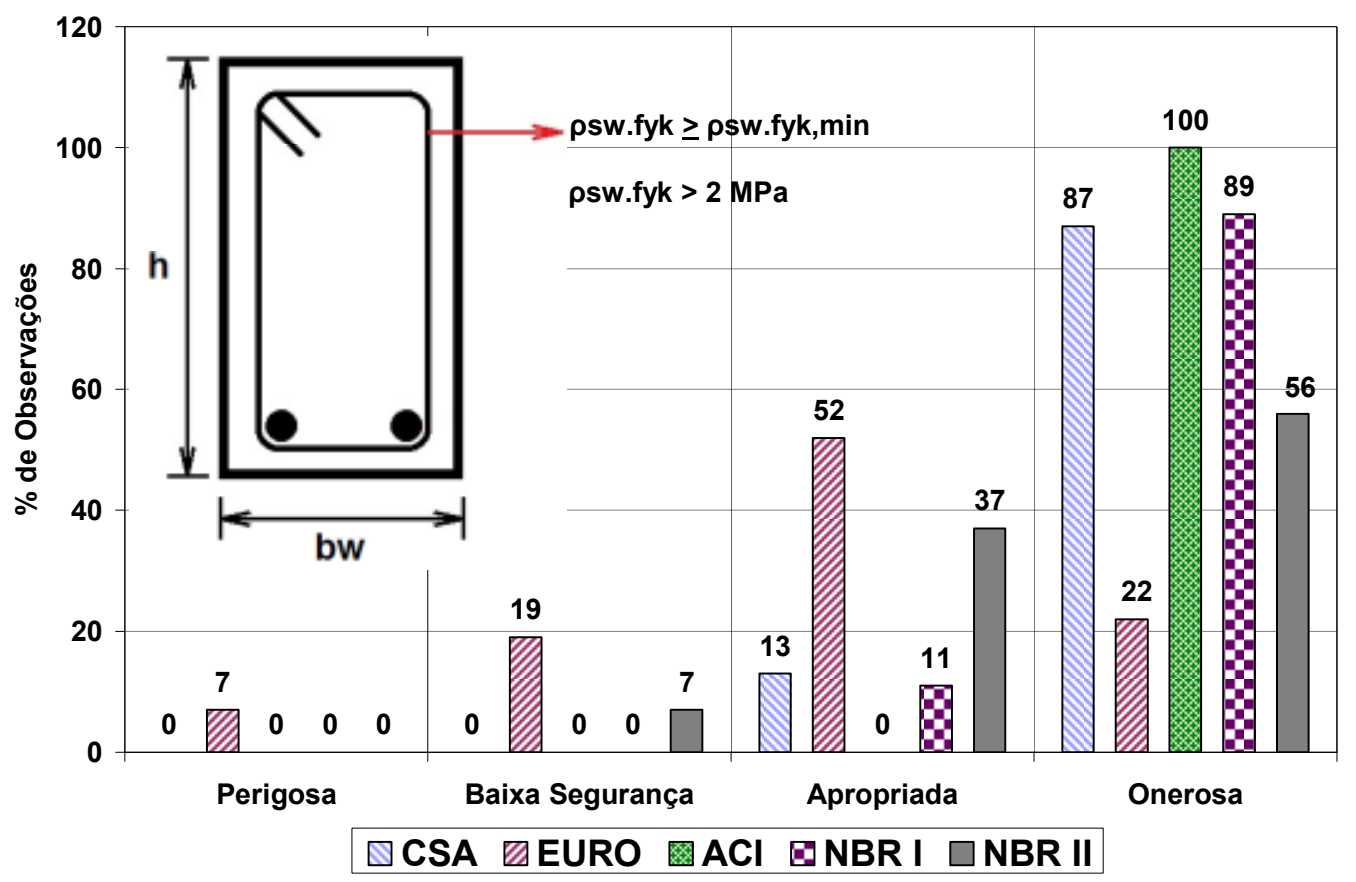

Figura 6.32: Aplicação do critério de comparação para psw.fyk $>2 \mathrm{MPa}$, definido neste trabalho

Para os elementos com maiores taxas de armadura transversal de cisalhamento, os resultados das comparações expressos na Figura 6.32, indicam que o modelo II da NBR 6118 (2007) apresentou bons resultados, não havendo previsões perigosas, e com $37 \%$ das previsões consideradas apropriadas. Para as normas ACl (2008) e CSA (2004) os resultados apresentados indicaram porcentagens dos valores de predição onerosos, com $100 \%$ e $87 \%$, respectivamente. O modelo da norma Eurocode (2004) apresentou uma porcentagem de $7 \%$ no grupo 1 (Perigoso) indicando um caráter inseguro das previsões.

Os comentários efetuados estão resumidos na Tabela 6.10, destacando em vermelho os valores considerados não aceitáveis, seja em termos de porcentagem perigosa ou de predição onerosa. Para a porcentagem perigosa, determinou-se como aceitável porcentagem menor ou igual a $1 \%$ e para predição onerosa, $75 \%$.

Tabela 6.10: Quadro resumo das porcentagens de previsões não seguras e onerosas (vigas com estribos)

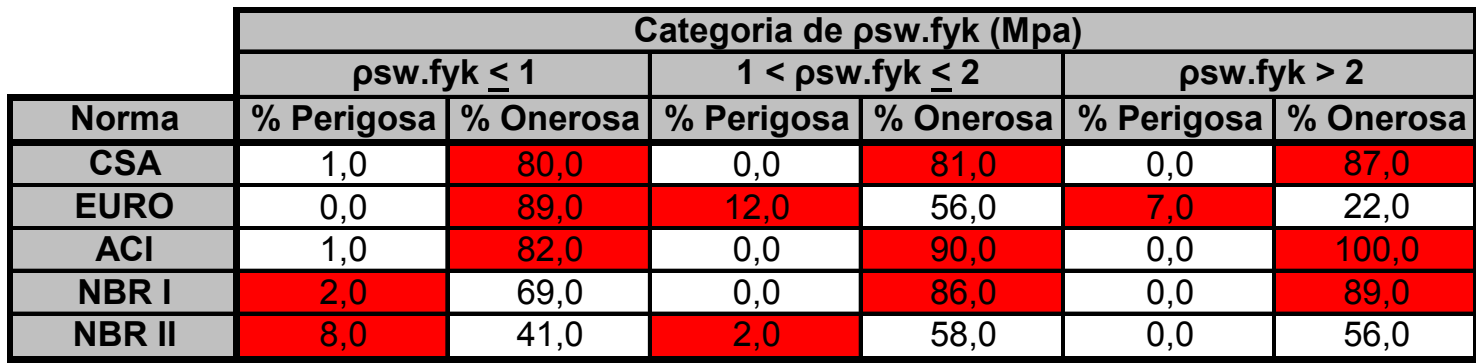


Tabela 6.11: Resultados do método dos pontos de deméritos

\begin{tabular}{|c|c|c|c|c|c|c|c|c|c|}
\hline & \multicolumn{9}{|c|}{ Categoria de psw.fyk (Mpa) } \\
\hline & \multicolumn{3}{|c|}{ psw.fyk $\leq 1$} & \multicolumn{3}{|c|}{$1<\rho$ sw.fyk $<2$} & \multicolumn{3}{|c|}{ psw.fyk > 2} \\
\hline Norma & $\mathrm{N}^{\circ}$ ensaios & Ptos & Média & $\mathrm{N}^{\circ}$ ensaios & Ptos & Média & $\mathrm{N}^{\circ}$ ensaios & Ptos & Média \\
\hline CSA & $\overline{131}$ & 222 & 1,7 & $\overline{59}$ & 96 & 1,6 & 31 & 54 & 1,7 \\
\hline EURO & 86 & 154 & 1,8 & 50 & 118 & 2,4 & 27 & 42 & 1,6 \\
\hline$\overline{\mathrm{ACl}}$ & 136 & 246 & 1,8 & 61 & 110 & 1,8 & 33 & 66 & 2,0 \\
\hline$\overline{\text { NBR I }}$ & 53 & 92 & 1,7 & 50 & 86 & 1,7 & 27 & 48 & 1,8 \\
\hline NBR II & 53 & 98 & 1,8 & 50 & 80 & $\overline{1,6}$ & 27 & 34 & $\overline{1,3}$ \\
\hline
\end{tabular}

Aplicando o método de atribuição dos pontos de demérito (ver Tabela 6.6) obteve-se a Tabela 6.11, que indica em negrito os menores valores de pontos de deméritos médios. A diferença entre os números de ensaios de cada norma era esperada, pois os critérios e limites de intervalos válidos são diferentes para cada norma. Para o primeiro intervalo, $\rho s w . f y k$ menor que $1 \mathrm{MPa}$, as normas CSA (2004) e modelo I NBR 6118 (2007) obtiveram a menor média de pontos de demérito, indicando que ambas as normas, a priori, são adequadas para o intervalo em questão. Para o segundo intervalo, $\rho s w$.fyk entre 1 e 2 MPa, as normas CSA (2004) e modelo II da NBR 6118 (2007), apresentaram resultados satisfatórios segundo este critério de pontos de demérito, e por fim para o último intervalo o modelo II apresentou-se adequado.

Por fim, a Tabela 6.12 apresenta o quadro resumo das análises dos casos de vigas armadas com estribos, com uma taxa de armadura transversal maior ou igual ou mínimo estipulado por cada norma, e com resistência do concreto dentro do intervalo de validade de cada norma. Lembrando que o critério de segurança aqui estabelecido não contempla a análise probabilística, apenas determinística dos dados de comparação entre a predição da norma e o resultado obtido no ensaio.

Tabela 6.12: Quadro resumo para elementos com estribos

\begin{tabular}{|c|c|c|c|}
\hline & \multicolumn{3}{|c|}{ Categoria de psw.fyk (Mpa) } \\
\hline & $\rho s w . f y k \leq 1$ & $1<\rho s w . f y k \leq 2$ & psw.fyk $>2$ \\
\hline Maior Insegurança & NBR II & EURO & EURO \\
\hline Maior Custo & EURO & $\mathrm{ACl}$ & $\mathrm{ACl}$ \\
\hline $\begin{array}{l}\text { Menos Pontos de } \\
\text { Deméritos }\end{array}$ & CSA/NBR I & NBR II/CSA & NBR II \\
\hline Norma Mais Adequada & $\overline{\mathrm{CSA} /{ }^{*}}$ & $\mathrm{CSA} / \mathrm{NBR} \mathrm{I}^{* *}$ & NBR II \\
\hline
\end{tabular}

O critério de escolha da norma mais apropriada para cada intervalo, inicialmente elimina o modelo de predição de norma que apresentaram porcentagens de casos perigosos maiores que $1 \%$. Depois disto analisa-se a porcentagem de casos onerosos auxiliado pelos resultados da análise por pontos de deméritos.

Desta forma, para psw.fyk $\leq 1 \mathrm{MPa}$, os modelos I e II da norma NBR 6118 (2007) foram desclassificados por apresentarem $2 \%$ e $8 \%$ de casos perigosos, respectivamente, apesar de apresentar ótimos resultados para os casos apropriados e onerosos. Uma análise probabilística destes resultados 
poderia concluir se esta quantidade de resultados de predição perigosos são significativos estatisticamente. O modelo de predição da norma CSA (2004) apresentou-se como o mais adequado, apesar das altas porcentagens de casos onerosos.

Para 1 < psw.fyk $\leq 2 \mathrm{MPa}$, o modelo II da norma NBR 6118 (2007) foi desclassificado por apresentar $2 \%$ de casos perigosos. O modelo I da mesma norma foi considerada adequada, pois apresentou a segunda melhor pontuação no critério de demérito. A norma CSA (2004) apresentou a melhor pontuação no critério de demérito e porcentagem nula de casos perigosos, porém apresentou uma porcentagem de $81 \%$ de casos onerosos.

Para psw.fyk > $2 \mathrm{MPa}$, o modelo II da norma NBR 6118 (2007) mostrou-se bastante adequado, com a melhor pontuação no critério de demérito, porcentagem nula de casos perigosos e porcentagem desejável de casos onerosos $(\leq 75 \%)$.

Cabe ressaltar que os resultados de ensaios apresentados foram selecionados de forma a não contemplar nenhum caso de ruptura com compressão excessiva da biela do concreto, ou seja, exceder o estado limite último de compressão. Portanto, as previsões do modelo II da NBR 6118 (2007) possibilitaram considerar uma inclinação da biela de compressão, $\theta$, igual a $30^{\circ}$ na maioria dos casos, o que resultou em valores de predição maiores que os do modelo I. Constatou-se que fixando os valores de $\theta$ iguais a aproximadamente $39^{\circ}$, os resultados de predição dos modelos I e II se equivalem. Sendo assim, o modelo II se torna o mais indicado para prever a força resistente para elementos de concreto armado munidos de estribos, desde que se utilize como limite inferior para o ângulo da biela o valor de $39^{\circ}$ no intervalo de $1<\rho s w$.fyk $\leq 2$, e sempre utilizar uma taxa de estribos maior ou igual a mínima de norma.

\subsubsection{Vigas com resistência do concreto e taxa de armadura transversal fora dos intervalos válidos da norma}

Neste item foram verificados apenas os dados de ensaios que apresentaram seus parâmetros não válidos, ou seja, resistência do concreto maior que a máxima permitida e taxa de estribo menor que a mínima. Como cada norma possui intervalos de validade diferentes, a quantidade de dados analisados foi diferente para cada norma.

A quantidade de dados para análise neste item foi composta principalmente pelos dados de ensaios que tiveram parâmetro de taxa de armadura transversal menor que a mínima permitida para cada norma. Sendo assim, as análises de exatidão, precisão e segurança se restringirão apenas ao intervalo de psw.fyk $\leq 1 \mathrm{MPa}$, pois apenas neste intervalo a quantidade de dados foi significativa.

\subsubsection{Análise da exatidão e precisão dos modelos das normas com o uso dos resultados de ensaios}

Seguindo os mesmos conceitos aplicados para a análise dos dados válidos, se deu a análise dos dados não válidos. 


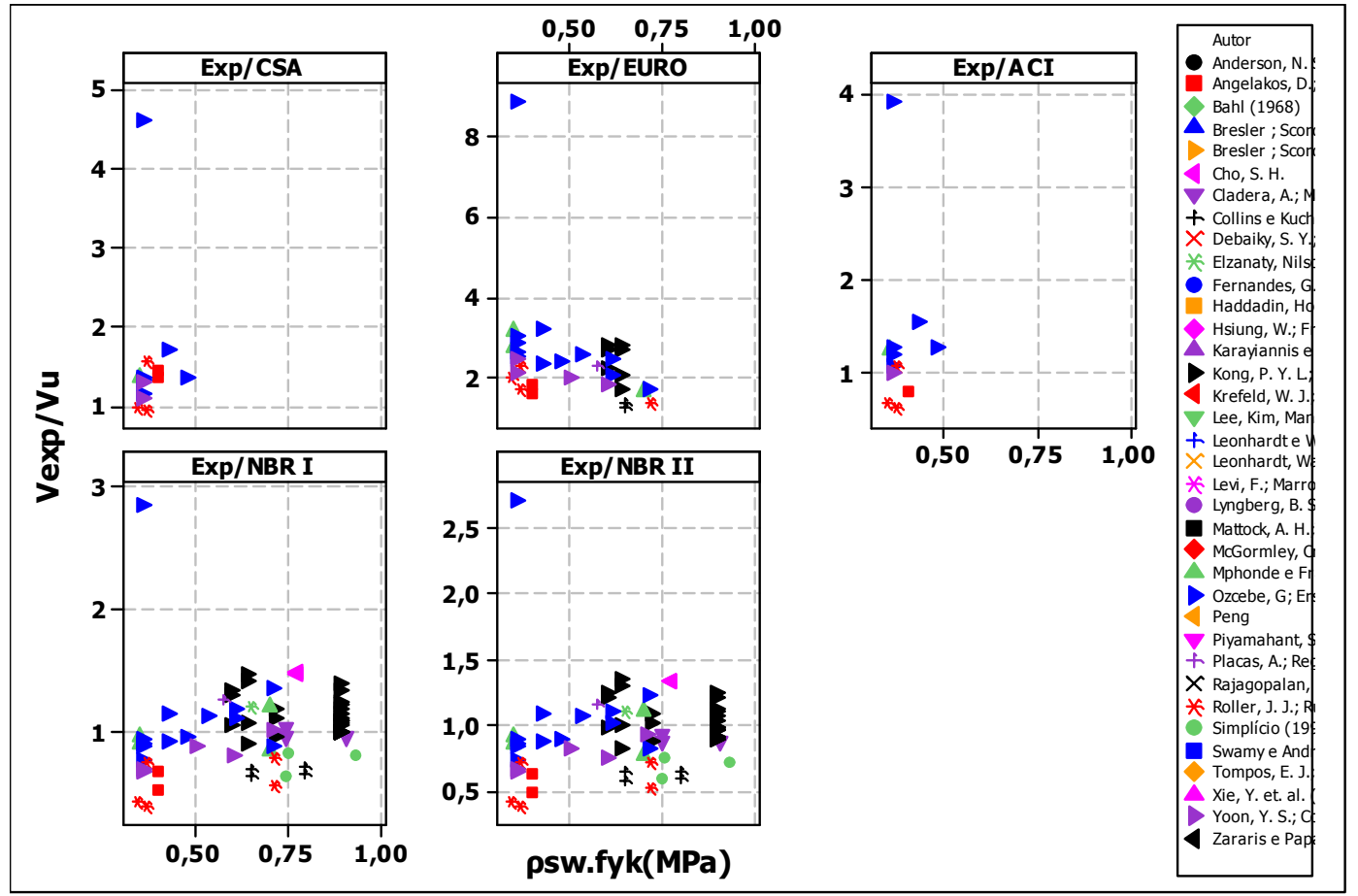

Figura 6.33: Correlação entre as razões Vexp/Vu e os valores do parâmetro psw.fyk, para as normas CSA, EURO, ACI, modelo I na NBR e modelo II da NBR, para elementos com estribos e dados fora do intervalo válido

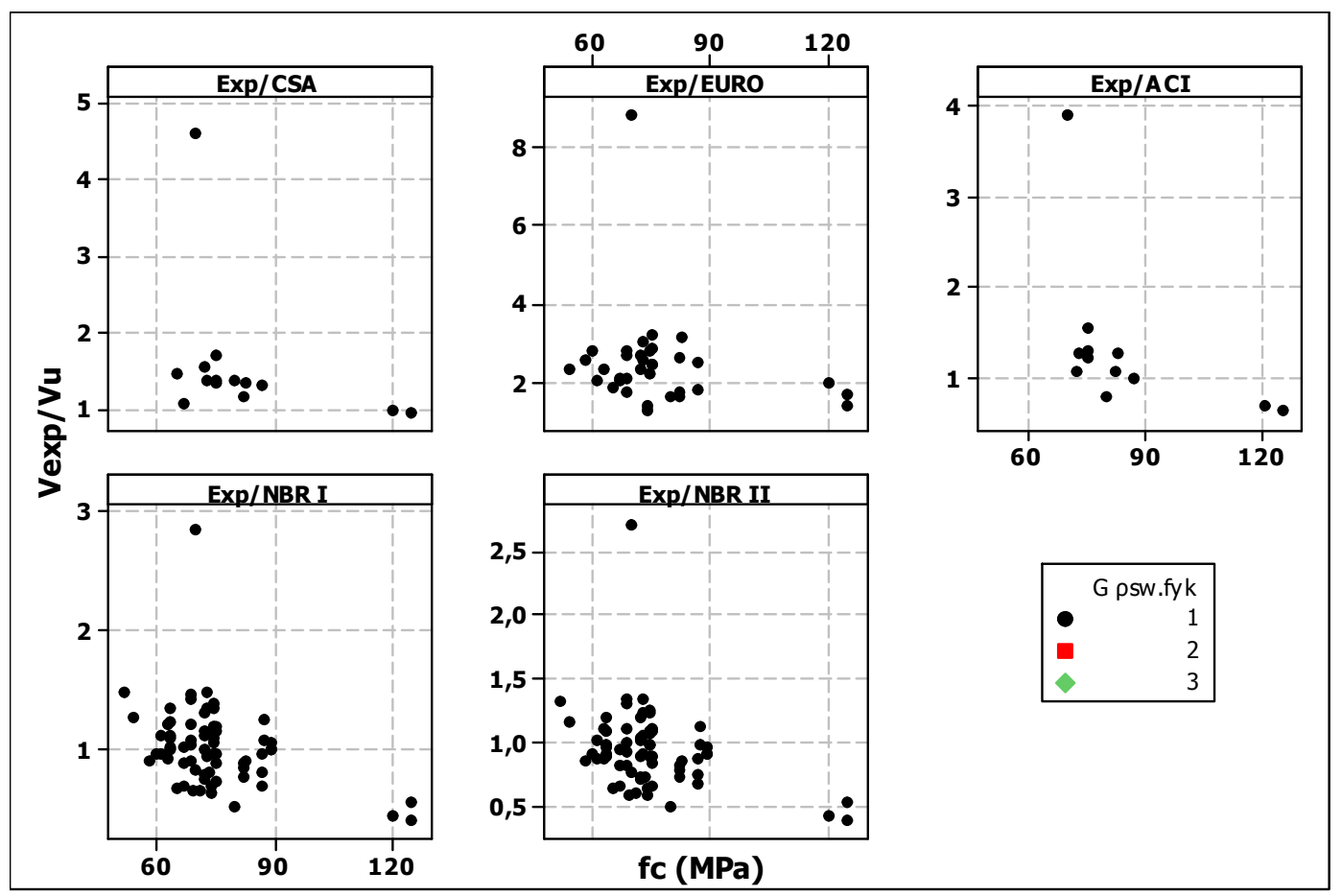

Figura 6.34: Correlação entre as razões $\mathrm{Vexp} / \mathrm{Vu}$ e os valores da resistência do concreto, fc, para as normas CSA, EURO, ACl, modelo I na NBR e modelo II da NBR, para elementos com estribos e dados fora do intervalo válido, para as três categorias do grupo G psw.fyk 
A Figura 6.34 apresenta a mesma correlação $V_{\text {exp }} / V_{u}$ para as diversas normas, porém expressando a resistência a compressão do concreto nos eixos das abscissas. Nota-se que a resistência do concreto não possui relevância maior que a taxa mecânica de estribos, apesar de se verificar que uma pequena tendência dos modelos de predição das normas se tornarem não seguros com o aumento da resistência do concreto, ou seja, para elementos com pequena quantidade de estribos o aumento da resistência do concreto não aumenta significativamente a resistência ao cisalhamento. Esta é uma das observações que levam a estipular uma taxa mecânica mínima de estribos.

A Figura 6.35 e a Tabela 6.13 indicam que para dados de ensaios considerados não válidos, os modelos I e II da norma NBR 6118 (2007) apresentaram uma boa exatidão, com valores de média próximos do valor unitário, 1,02 e 0,94, respectivamente. Os menores coeficientes de variação também pertencem aos modelos I e II, com $33 \%$ aproximadamente, indicando assim uma melhor precisão e menor dispersão em relação ao valor médio das outras normas.

Com isto pode-se concluir que os modelos I e II da norma NBR 6118 (2007) são os que melhor preveem o comportamento de elementos de concreto armado com estribos, em um taxa bastante baixa, sendo inferior a mínima definida por norma.

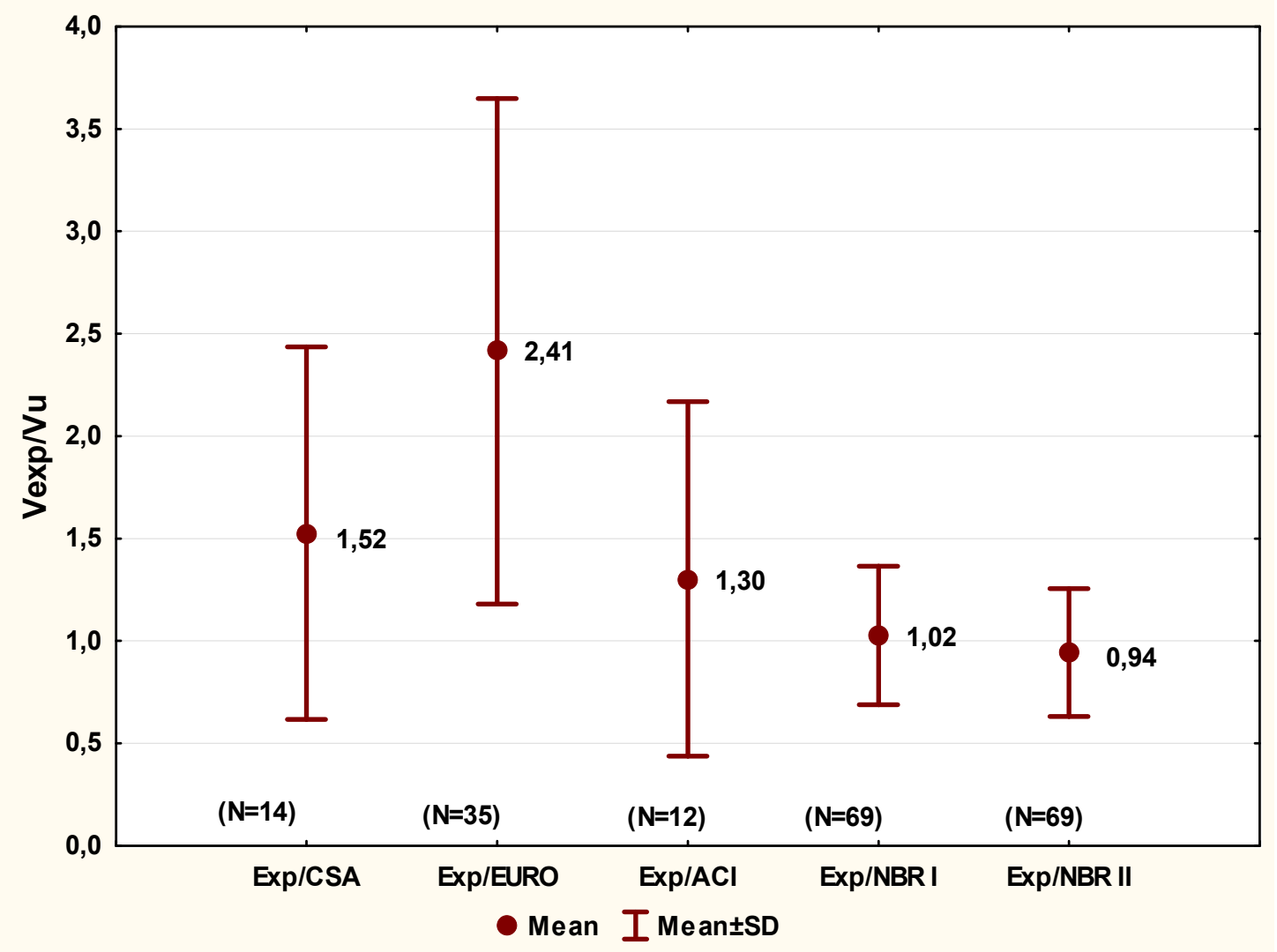

Figura 6.35: Análise dos valores médios e desvio padrão entre as razões Vexp/Vu para as normas CSA, EURO, ACI, modelo I na NBR e modelo II da NBR, para elementos com estribos e dados não válidos 
OBS: Os valores entre parênteses indicam a quantidades de ensaios utilizados na análise.

Tabela 6.13: Medidas estatísticas dos valores de predição de norma (dados não válidos)

\begin{tabular}{|c|c|c|}
\hline \multicolumn{2}{|c|}{ Norma } & rosw.fyk $\leq 1 \mathrm{MPa}$ \\
\hline \multirow{3}{*}{ CSA } & MEDIA & 1,526 \\
\cline { 2 - 3 } & COEF. VARIAÇÃO & 0,596 \\
\cline { 2 - 3 } & MEDIANA & 1,341 \\
\hline \multirow{3}{*}{ EURO } & MEDIA & 2,415 \\
\cline { 2 - 3 } & COEF. VARIAÇÃO & 0,511 \\
\cline { 2 - 3 } & MEDIANA & 2,295 \\
\hline \multirow{3}{*}{ ACI } & MEDIA & 1,303 \\
\cline { 2 - 3 } & COEF. VARIAÇÃO & 0,665 \\
\cline { 2 - 3 } & MEDIANA & 1,131 \\
\hline \multirow{3}{*}{ NBR I } & MEDIA & 1,026 \\
\cline { 2 - 3 } & COEF. VARIAÇÃO & 0,329 \\
\cline { 2 - 3 } & MEDIANA & 1,004 \\
\hline \multirow{3}{*}{ NBR II } & MEDIA & 0,943 \\
\cline { 2 - 3 } & COEF. VARIAÇÃO & 0,331 \\
\cline { 2 - 3 } & MEDIANA & 0,907 \\
\hline
\end{tabular}

\subsubsection{Análise da segurança dos modelos das normas com o uso dos resultados de ensaios}

A precisão e exatidão dos modelos foram analisadas seguindo os critérios definidos em 6.4.

$\mathrm{Na}$ figura seguinte, sobre cada barra indica-se a porcentagem de dados, que cada norma possui em dado grupo de situações.

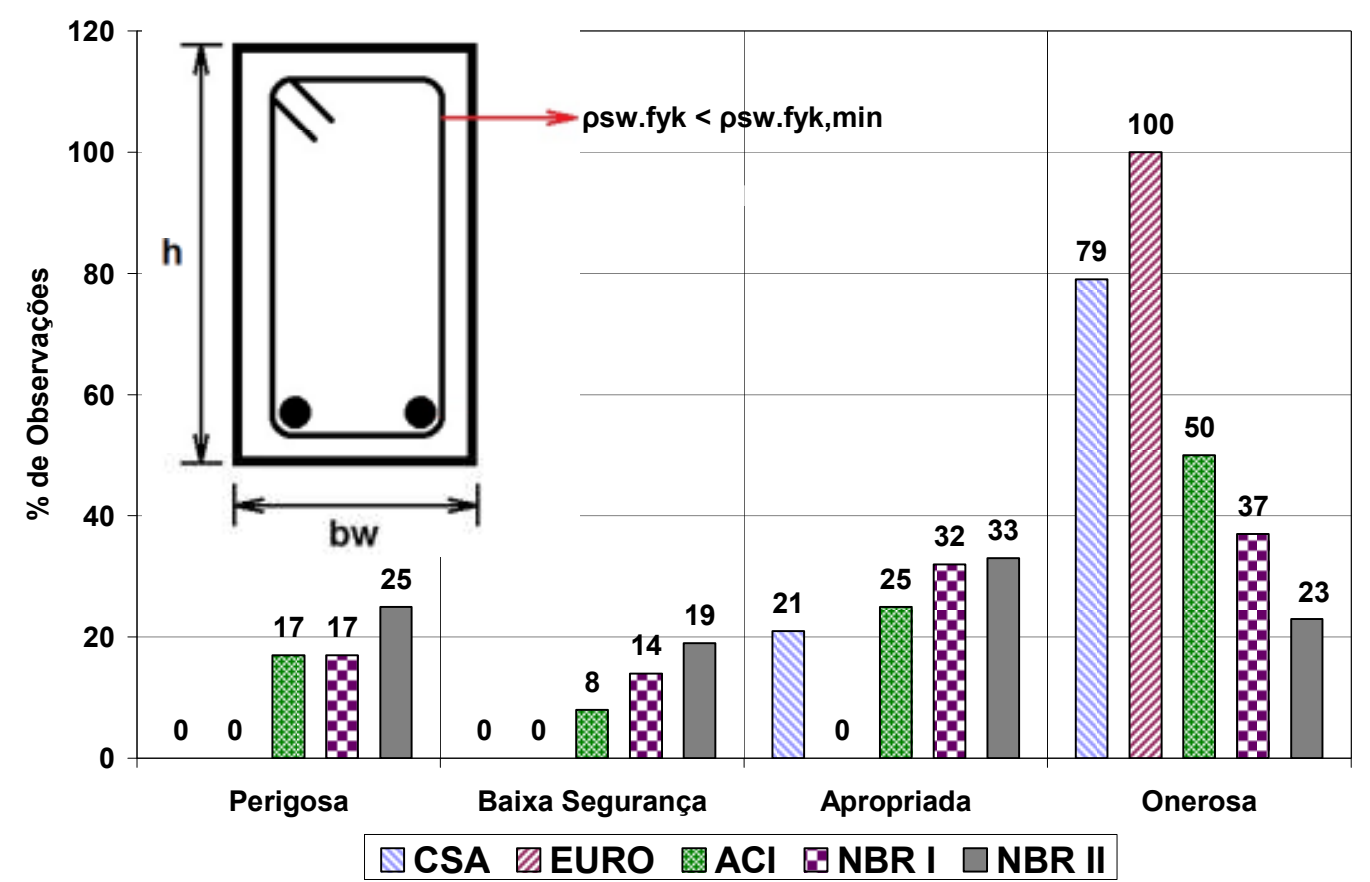

Figura 6.36: Distribuição das normas, segundo o critério de comparação (com estribos) 
Obs: Cód. CSA representa a porcentagem de previsões da norma CSA (2004), Cód. EURO representa a porcentagem de previsões da norma Eurocode (2004), Cód. ACl representa a porcentagem de previsões da norma $\mathrm{ACl}$ (2008), Cód. NBR I representa a porcentagem de previsões do modelo I da norma NBR 6118 (2007), e Cód. NBR II representa a porcentagem de previsões do modelo II da norma NBR 6118 (2007)

Analisando a segurança das formulações das normas através da interpretação dos resultados apresentados na Figura 6.36, na Tabela 6.14 e Tabela 6.15, pode-se concluir que a norma CSA (2004) mostrou-se mais adequada para utilização na predição de valores de resistência ao cisalhamento para elementos com pouca armadura transversal, em quantia menor que a mínima. A norma Eurocode (2004) apresentou em $100 \%$ dos casos resultados conservadores. As normas ACl (2008) e NBR 6118 (2007) apresentaram resultados não aceitáveis para a situação perigosa, o que poderia resultar em estruturas com maior insegurança.

Tabela 6.14: Quadro resumo das porcentagens de previsões não seguras e onerosas (vigas com estribos)

\begin{tabular}{|c|c|c|}
\cline { 2 - 3 } \multicolumn{1}{c|}{} & \multicolumn{2}{c|}{ $s w . f y k<\rho s w . f y k, m i n$} \\
\hline Norma & $\%$ Perigosa & $\%$ Onerosa \\
\hline CSA & 0,0 & 79,0 \\
\hline EURO & 0,0 & 100,0 \\
\hline ACI & 17,0 & 50,0 \\
\hline NBR I & 17,0 & 37,0 \\
\hline NBR II & 25,0 & 23,0 \\
\hline
\end{tabular}

Considerou-se uma porcentagem aceitável para casos perigosos, valores menores ou iguais a $1 \%$, e porcentagem aceitável para casos onerosos, valores menores que $75 \%$.

Tabela 6.15: Resultados do método dos pontos de deméritos

\begin{tabular}{|c|c|c|c|}
\cline { 2 - 4 } \multicolumn{1}{c|}{} & \multicolumn{3}{c|}{ $s w . f y k \leq \rho s w . f y k, m i n$} \\
\hline Norma & $\mathbf{N}^{\circ}$ ensaios & Ptos & Média \\
\hline CSA & 14 & 22 & $\mathbf{1 , 6}$ \\
\hline EURO & 35 & 70 & 2,0 \\
\hline ACI & 12 & 34 & 2,8 \\
\hline NBR I & 69 & 190 & 2,8 \\
\hline NBR II & 69 & 228 & 3,3 \\
\hline
\end{tabular}

\subsection{Análise de vigas não armadas ao cisalhamento e ruptura por força cortante-tração}

\subsubsection{Definição de grupos e categorias}

O banco de dados referente aos elementos não armados com estribos, originalmente possuíam 688 ensaios. Após a homogeneização citada no 
subitem 6.3, os 580 ensaios resultantes foram separados em grupos, seguindo um critério de semelhança de parâmetros, de forma a facilitar a interpretação dos resultados.

O agrupamento dos parâmetros seguiu critérios lógicos e que representasse intervalos nos quais, possivelmente, houvessem divergências entre as normas, como explicado a seguir.

Os principais parâmetros de análise foram a grupados conforme resumido na Tabela 6.16.

Tabela 6.16: Grupos de parâmetros para elementos sem estribos

\begin{tabular}{|c|c|c|c|c|}
\hline & \multicolumn{3}{|c|}{ Grupos } \\
\hline & & G fc & G d & G rol \\
\hline & & (MPa) & $(\mathrm{cm})$ & $(\%)$ \\
\hline \multirow{3}{*}{ 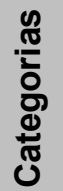 } & 1 & fc $\leq 50$ & $d \leq 25$ & $\mathrm{rol} \leq 1,5$ \\
\hline & 2 & $50<$ fc $\leq 70$ & $25<d \leq 60$ & $1,5<\mathrm{rol} \leq 3,0$ \\
\hline & 3 & fc $>70$ & $d>60$ & $\mathrm{rol}>3,0$ \\
\hline
\end{tabular}

Para a definição do grupo "G fc", utilizou-se como valores limítrofes da resistência do concreto a compressão até $50 \mathrm{MPa}$, que é o limite máximo para utilização da norma brasileira NBR 6118 (2007). O outro extremo de $70 \mathrm{MPa}$ foi definido segundo o critério que valores acima deste podem ser considerados concretos de alta resistência, formando a categoria " 3 ". Desta forma, os ensaios cujos valores da resistência à compressão do concreto apresentaram valores maiores que $50 \mathrm{MPa}$ e menores ou iguais a $70 \mathrm{MPa}$, foram agrupados na categoria "2". Apesar da utilização do termo $f c$ para a denominação do grupo, deve-se compreender que os resultados são apresentados em termos de valores médios experimentais.

O Grupo "G d" foi definido, separando os elementos de altura efetiva, $d$, em três categorias, sendo a primeira determinada pelos elementos com altura efetiva menor ou igual a $25 \mathrm{~cm}$, considerando que a maioria das lajes não armada comporiam esta categoria. A segunda categoria refere-se aos elementos com altura efetiva entre 25 e $60 \mathrm{~cm}$, inclusive, pois se considera um intervalo que representaria lajes não usuais ou vigas não armadas e que, possivelmente, o efeito de escala ou "size effect" não é muito pronunciado. Para valores maiores que $60 \mathrm{~cm}$ designou-se a categoria " 3 ".

As categorias do grupo "G rol" se referem a discretização dos ensaios, conforme a taxa de aço longitudinal de flexão, $\rho_{\text {I. }}$ Considerou-se taxas de armação baixas para valores menores que 1,5\%, e altas, para valores maiores que $3 \%$, definindo-se assim as categorias " 1 " e " 3 ", respectivamente. Para os ensaios cujos valores da taxa foram maiores que $1,5 \%$ e menores ou iguais a $3 \%$, se destinou a categoria " 2 ". 
A Figura 6.37, indica a distribuição dos parâmetros dentro dos grupos definidos e a porcentagem de cada categoria em relação ao número total de ensaios (536).

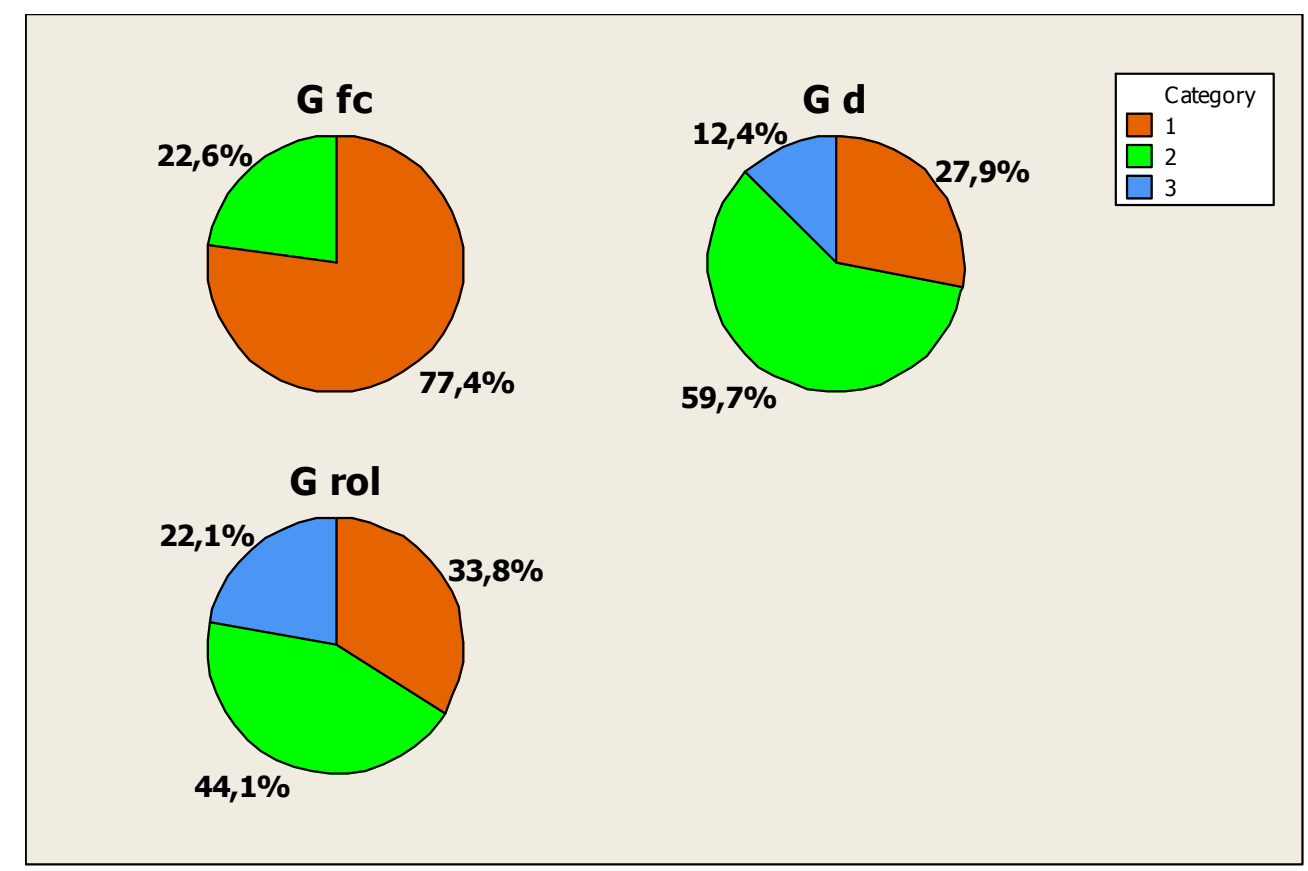

Figura 6.37: Distribuição dos parâmetros do banco de dados em categorias definidas na Tabela 6.7, para elementos sem estribos

Resumidamente o banco de dados se caracteriza pela porcentagem maior de elementos de vigas de concreto armado sem estribos de características usuais em termos de resistência do concreto, altura efetiva, taxas de armadura e vãos de cisalhamento, porém com quantidades de ensaios significantes estatisticamente de elementos "não usuais", ou seja, que possua algum parâmetro fora dos intervalos usuais da maioria das obras.

\subsubsection{Análise dos resultados de ensaios do banco de dados homogeneizado}

Os resultados das 580 vigas de concreto armados sem armadura de cisalhamento (estribos) estão ilustrados na Figura 6.38. Utilizou-se o eixo da ordenadas para exprimir os valores das tensões cisalhantes resistentes dos experimentos, $\tau_{\text {exp }}$, ou seja, a divisão da força resistente última de ensaio $V_{\text {Exp }}$, pela área útil da seção $b_{w} \cdot d$. 


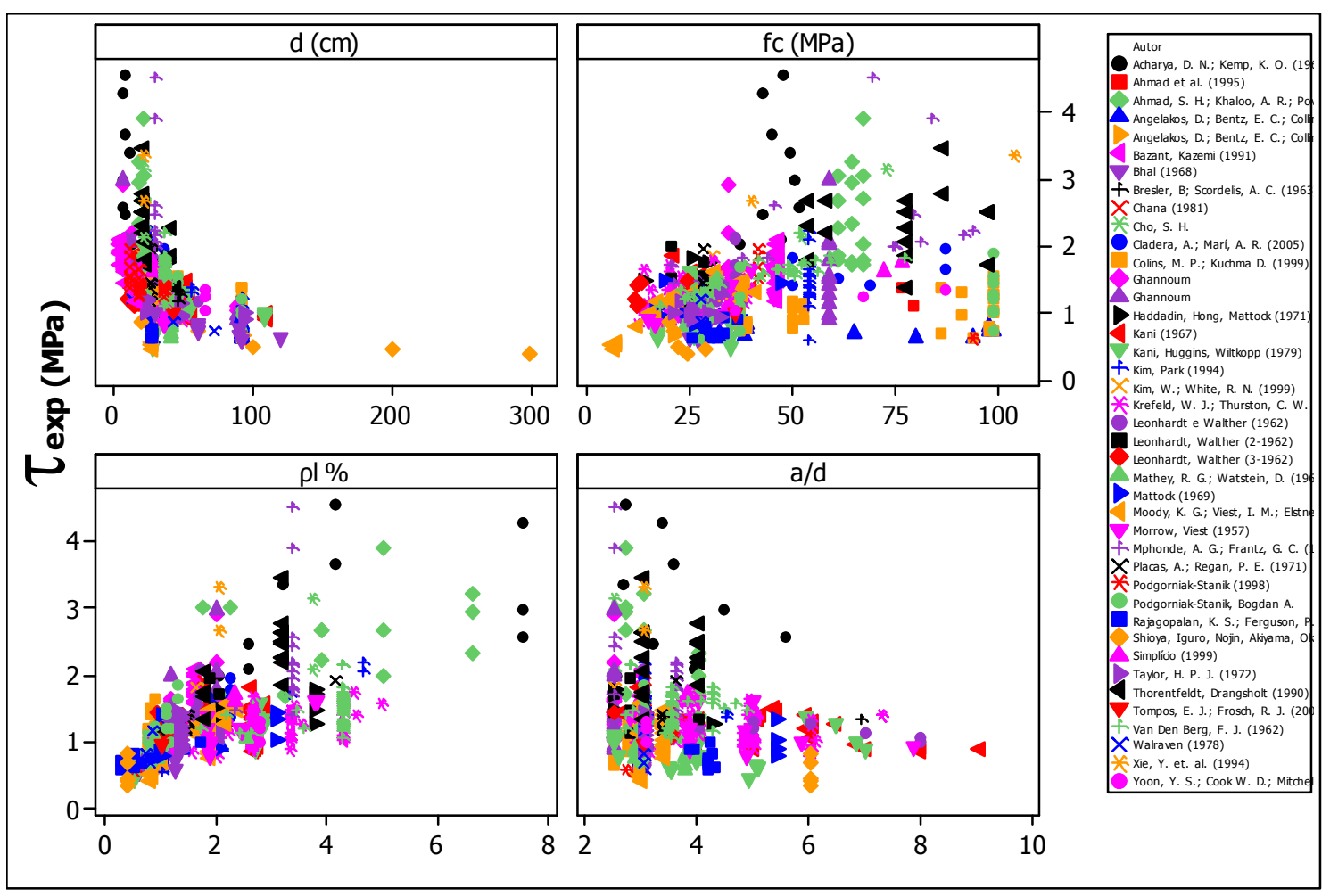

Figura 6.38: Correlação entre parâmetros de ensaios e tensão cisalhante resistente experimental, $\tau_{\text {exp }}$, para elementos sem estribos, para cada autor, sendo: d - Altura do elemento; fc - Resistência do concreto; pl - Taxa geométrica de armadura de flexão e a/d - Índice de esbeltez

Analisando a Figura 6.38, é possível notar que com o aumento da altura da peça, $d$, e do vão de cisalhamento, a/d, as tensões de cisalhamento resistentes decrescem, caracterizando uma correlação inversa. Observa-se uma correlação forte entre a taxa geométrica de armadura longitudinal de flexão, $\rho$, e os resultados de ensaios, sendo que o aumento da taxa resulta no aumento da tensão cisalhante resistente.

A influência da resistência do concreto na força cortante resistente de elementos não armados com estribo é muito importante, porém esta deve ser analisada juntamente com outros fatores que influenciam a resistência. A Figura 6.39, apresenta a aumento da tensão cisalhante resistente juntamente com o aumento da resistência a compressão do concreto, subdividido conforme as categorias de $d$ e $\rho$, ou seja, a altura útil da peça e a taxa geométrica de armadura de flexão. 


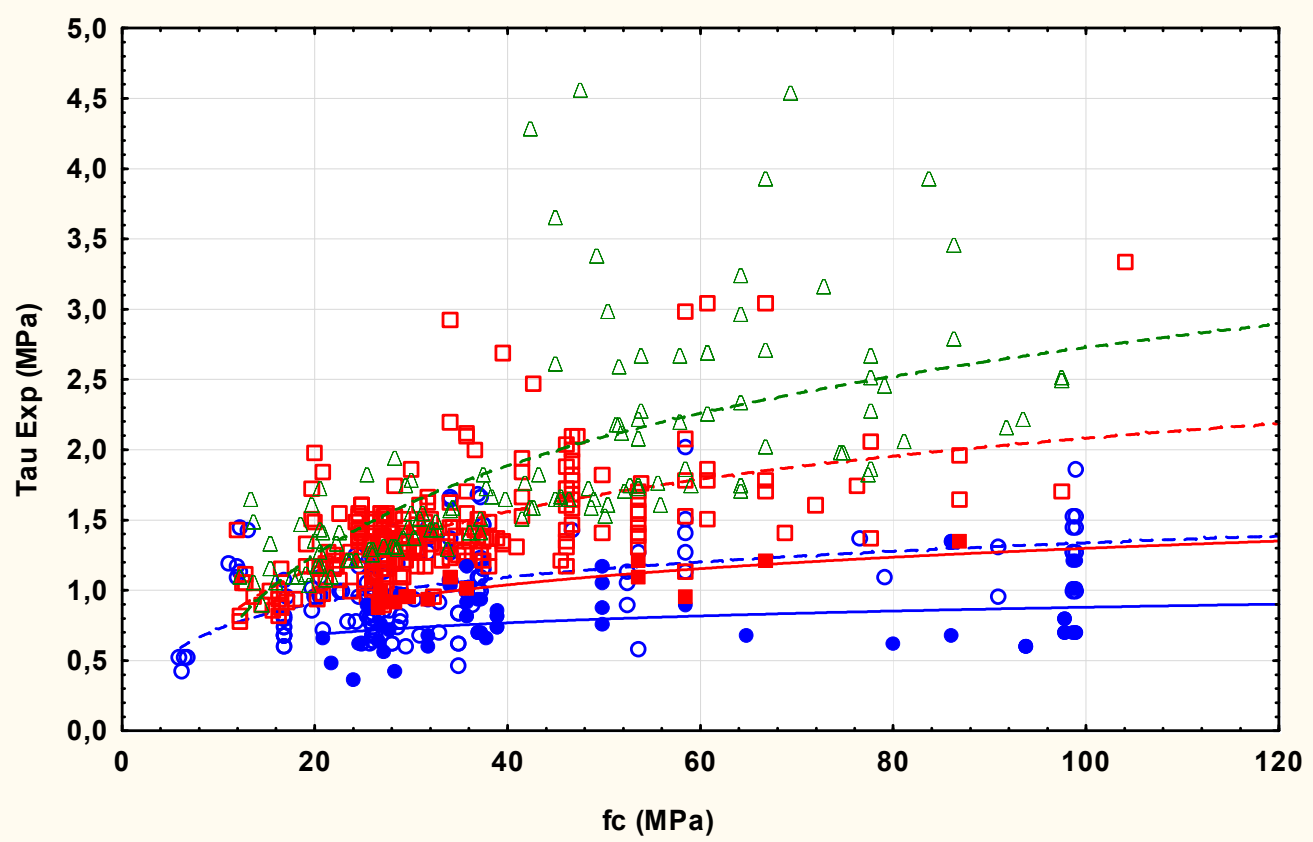

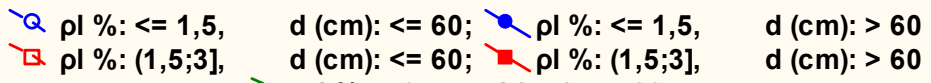
pl \%: > 3, d (cm): <= 60;

Figura 6.39: Influência da taxa geométrica de armadura de flexão, pl, para diversas resistências de concreto, fc, na tensão cisalhante resistente dos resultados experimentais de elementos sem estribos

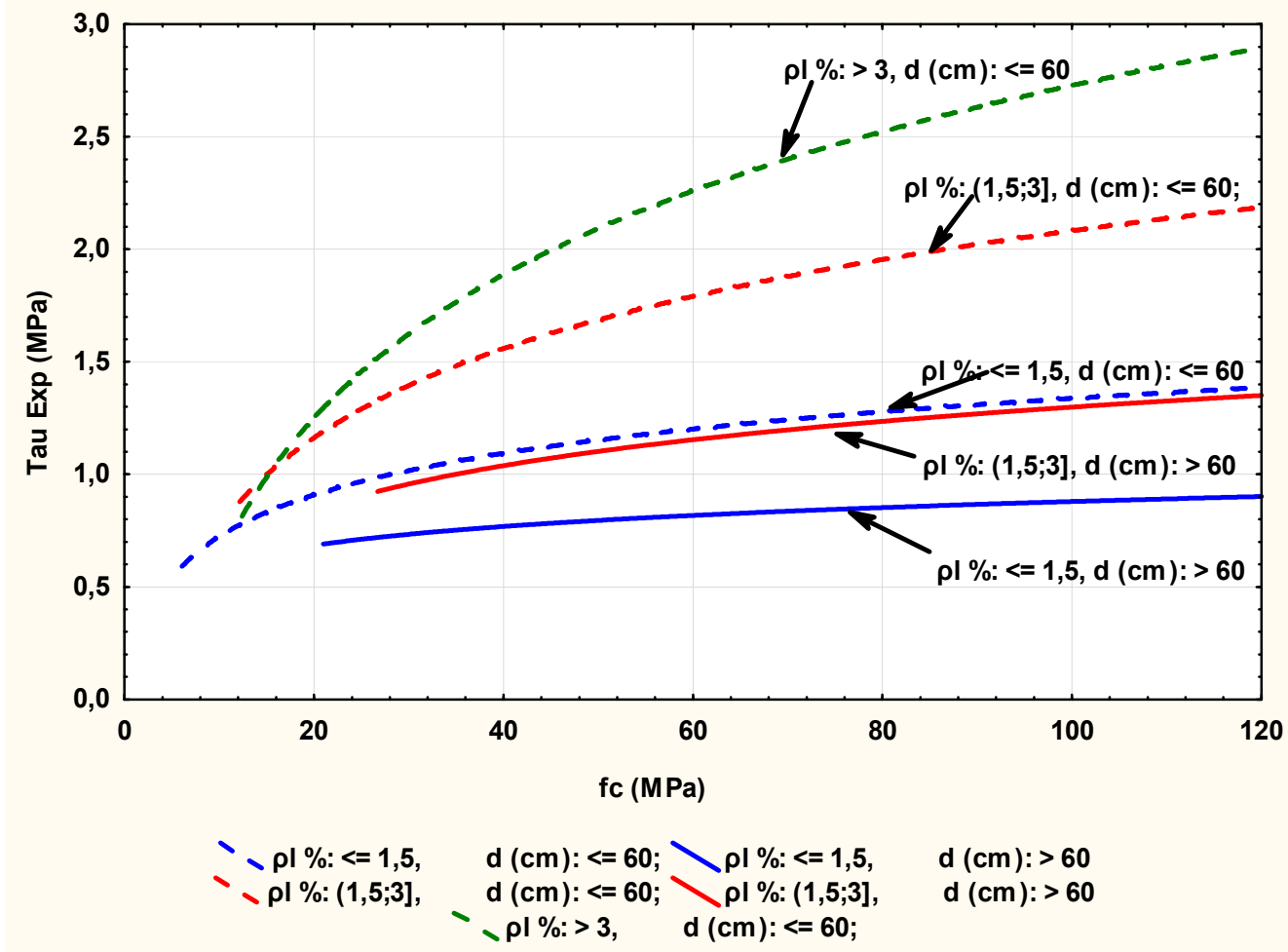

Figura 6.40: Curvas de aproximação da correlação entre a taxa geométrica de armadura de flexão, $\rho l$, para diversas resistências de concreto, fc, na tensão cisalhante resistente e os resultados experimentais de elementos sem estribos 
A Figura 6.40, apresenta apenas as curvas logarítmicas utilizadas para representar os dados de ensaios, facilitando a compreensão do comportamento médio. Pode-se observar que existe o aumento da tensão cisalhante resistente devido ao aumento da resistência a compressão do concreto, porém o aumento da altura efetiva do elemento apresenta reduções na eficiência do mecanismo resistente, assim como a redução da taxa de armadura longitudinal de flexão. Desta forma, fica evidente que é necessário analisar os resultados de predição de norma considerando os intervalos de variação da altura efetiva da peça, taxa de armadura longitudinal e resistência do concreto.

Serão agrupados os resultados de comparação entre os valores de predição de norma com o uso dos ensaios, conforme a Tabela 6.16, e apresentados em dois subitens, 6.6 .3 e 6.6.4, conforme a resistência do concreto. A comparação entre o valor da força resistente última obtida no ensaio e a força dos modelos de norma serão novamente expressos pela razão entre estas duas forças, objetivando o valor unitário para a melhor exatidão do valor previsto pela norma.

\subsubsection{Vigas com resistência do concreto dentro do intervalo válido da norma}

A utilização dos dados de ensaios que tiveram a resistência do concreto com valor menor ou igual ao máximo permitido por norma permite avaliar o comportamento dos modelos de predição das normas para concretos com valores de resistência considerados usuais, para os padrões atuais. Após a utilização do critério de seleção indicado no item 6.3.1, para cada norma foram filtrados os ensaios com estas características (fc $\leq \mathrm{fc}$,máx). Com isto manipulou-se os dados de predição de norma de forma a possibilitar a análise da exatidão, precisão e segurança dos modelos, considerando as faixas de variações dos parâmetros: $d$ e $\rho$ l.

Apenas como ilustração do comportamento de vigas não armadas ao cisalhamento com resistência do concreto considerada usual, elaborou-se a Figura 6.41, com o uso de 449 dados de vigas sem estribos e com resistência do concreto menor que $50 \mathrm{MPa}$, ressaltando a importância destes dois parâmetros na determinação da resistência da peça. Os valores da tensão cisalhante dos ensaios, $\tau_{\text {exp }}$, foram divididos pela raiz quadrada do valor da resistência do concreto, expressando assim a porção mobilizada, efetivamente, da resistência do concreto à tração.

Verifica-se que para elementos com altura efetiva maior que $60 \mathrm{~cm}$, não armados ao cisalhamento e com taxas geométrica de armadura de flexão abaixo de $2 \%$, a tensão cisalhante resistente última é menor que $0,2 \sqrt{f c}(\mathrm{MPa})$ 


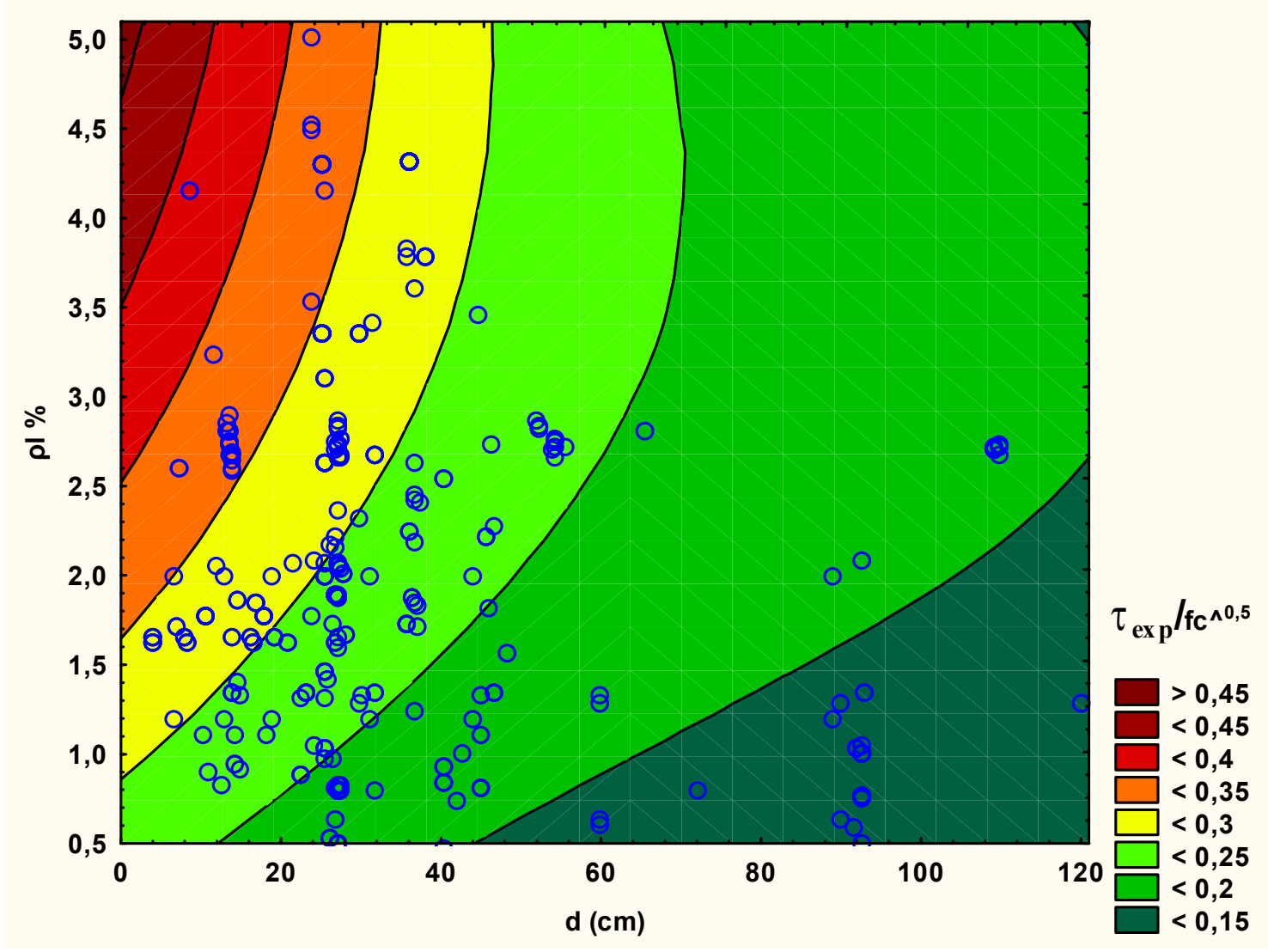

Figura 6.41: Curvas de contorno de $\tau \exp (\mathrm{MPa})$, em função da taxa de armadura longitudinal, $\rho$, e altura efetiva do elemento, d, para 449 ensaios.

A Figura 6.41 indica que na medida em que se aumenta a altura útil, é necessário aumentar a taxa geométrica de armadura longitudinal, para conseguir um melhor aproveitamento da resistência do concreto ao cisalhamento. Por exemplo, para se manter o mesmo grau de aproveitamento da resistência do concreto, indicado por $\tau_{\text {exp }} / \mathrm{fc}^{\wedge}{ }^{\wedge, 5}$ igual a aproximadamente 0,22 , os elementos com $d=14 \mathrm{~cm}$ e $\rho \mathrm{l}=1,0 \%$, equivaleriam a elementos com maiores alturas e taxas geométricas de armadura longitudinal, ou seja, $d=50$ $\mathrm{cm} \mathrm{e} \rho \mathrm{l}=2,5 \%$.

\subsubsection{Análise da exatidão e precisão dos modelos das normas com o uso dos resultados de ensaios do banco de dados homogeneizado}

A análise da exatidão e precisão dos modelos de norma foi efetuada seguindo as premissas definidas no item 6.4. Os resultados das razões entre as forças últimas dos ensaios e as forças previstas pelas normas, estão expressas na Figura 6.42, ressaltando que para cada norma utilizou-se apenas os dados de ensaios que não apresentaram valor da resistência do concreto incompatível com os limites estabelecidos por cada norma. 


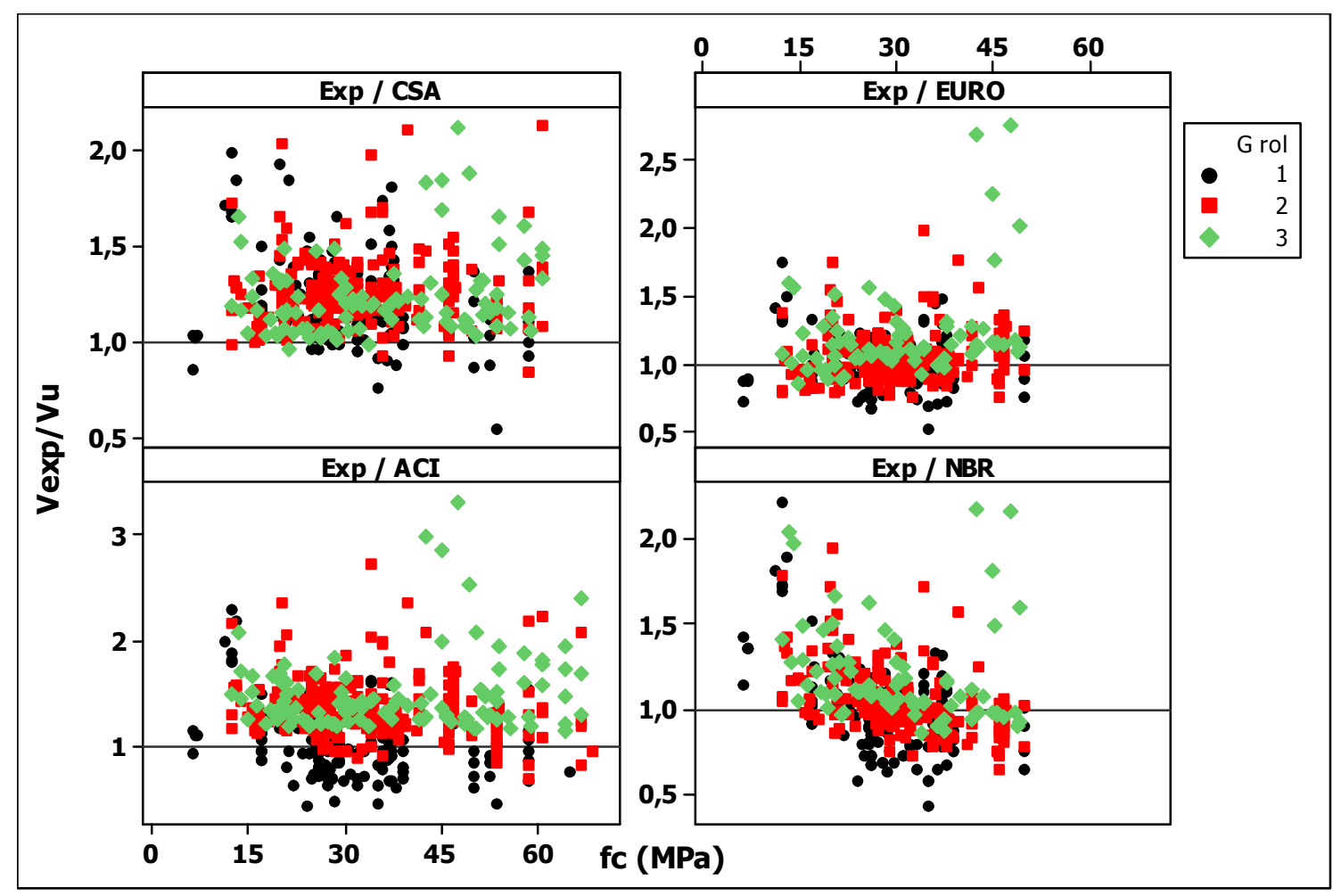

Figura 6.42: Correlação entre as razões $V \exp / \mathrm{Vu}$ e os valores da resistência do concreto, fc, para as normas CSA, EURO, ACl e NBR, para elementos sem estribos e dados dentro do intervalo válido, para as três categorias do grupo $\mathbf{G}$ rol

Na Figura 6.42, pode-se observar que as normas Eurocode (2004), ACI (2008) e NBR 6118 (2007) apresentaram uma leve distinção dos resultados de predição, para as três diferentes categorias de taxa de armadura longitudinal. Por outro lado, a norma CSA (2004) apresentou a maioria dos resultados acima do valor unitário, indicando, a priori, um caráter conservador. Verifica-se que o aumento da taxa geométrica de armadura longitudinal, representada pelas três categorias da legenda, resultam em valores de predição maiores que os valores dos ensaios, exceto para a norma CSA (2004), pois não se observa distinção entre as categorias, indicando que $o$ aumento de armadura longitudinal não condiciona significativamente os valores da razão $V_{\text {exp }} / V_{u}$.

Para melhor compreender os comportamentos dos modelos de predição das normas, serão analisadas separadamente as três categorias do grupo "G rol", e depois as três categorias do grupo " $\mathrm{G}$ d".

Idem ao subitem 6.5.3.1, a análise de exatidão e precisão dos modelos de norma será feita utilizando os valores ultimos dos resultados de predição de norma, ou seja, considerando unitários os coeficientes de segurança. Desta forma a exatidão será analisada pela média, e a precisão pelo coeficiente de variação (afastamento). 


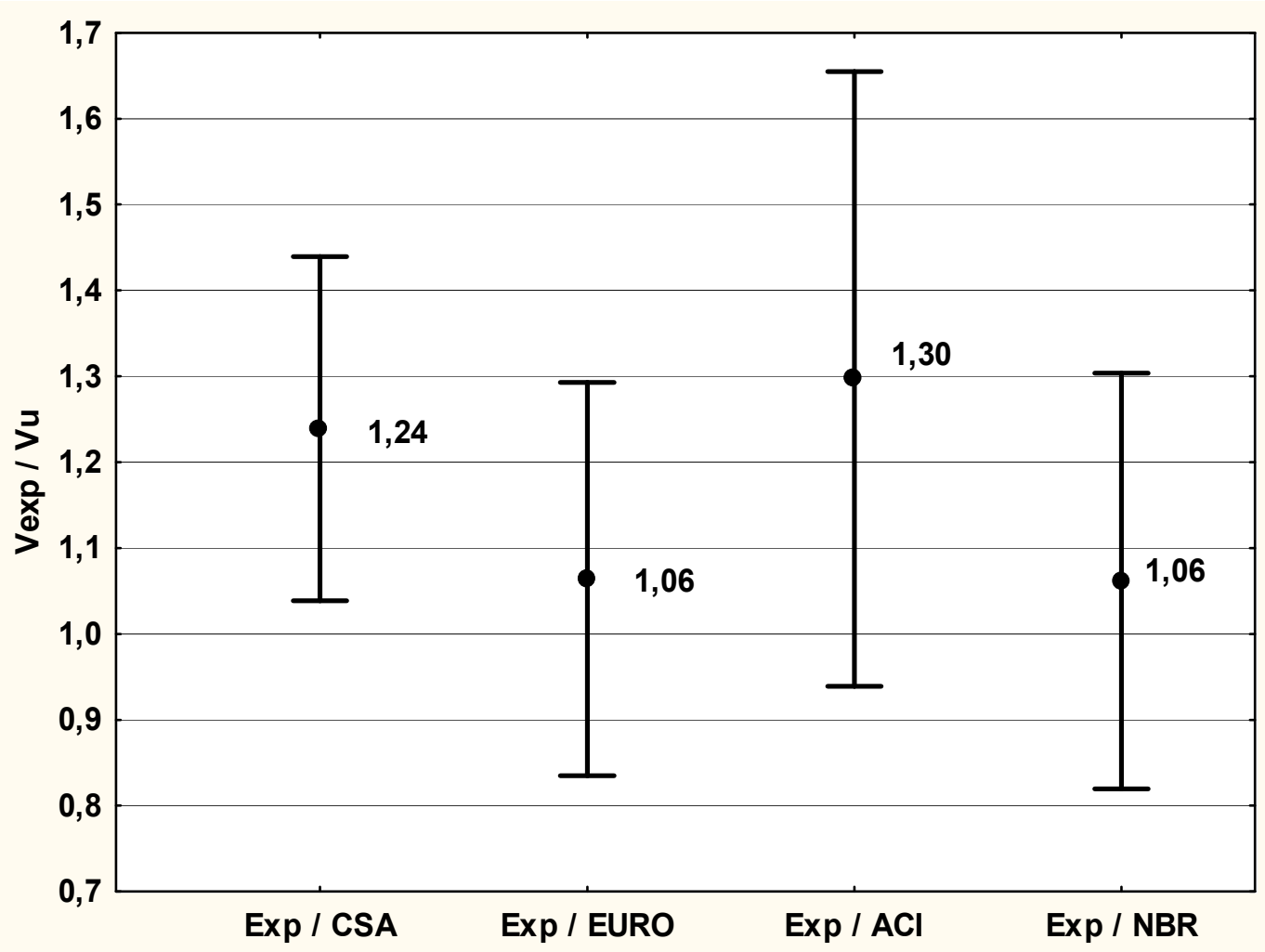

Figura 6.43: Análise dos valores médios e desvio padrão entre as razões Vexp/Vu para as normas CSA, EURO, ACl e NBR, para elementos sem estribos e dados válidos

A Figura 6.43 apresenta os valores das médias de $V_{\text {Exp }} / V_{\text {norma, }}$, para cada norma e o intervalo compreendido pela médias mais ou menos o desvio padrão da média. Para cada norma, foram analisados os ensaios que tiveram os valores das resistências dos concretos considerados válidos, ou seja, dentro do intervalo especificado. Nota-se um comportamento médio semelhante entre as normas Eurocode (2004) e a NBR 6118 (2007), porém, estatisticamente todas as normas apresentaram resultados semelhantes, pois os intervalos são sobrepostos em mais de $5 \%$. A exatidão destas normas será confrontada com a segurança no item de análise 6.6.3.2.

A Figura 6.44 representa a precisão e exatidão dos modelos de norma, discretizadas nas três categorias do grupo "G rol".

Para valores de taxa de armadura longitudinal de flexão menores que 1,5\% os modelos das normas do Eurocode (2004) e NBR 6118 (2007) apresentaram as melhores exatidões médias, com valores aproximadamente iguais a 1 , além disso, os coeficientes de variação foram próximos de 0,20 e as medianas com valores próximos das médias, indicando modelos, relativamente, precisos e com valores bem distribuídos ao redor das médias.

Os resultados obtidos para a categoria 2, 1,5 \% $<\mathrm{\rho} \leq 3,0 \%$, as norma NBR 6118 (2007) e Eurocode (2004) apresentaram novamente a melhor exatidão média e comportamento semelhante ao citado na categoria 1.

$\mathrm{Na}$ categoria 3, representada pelas altas taxas de armadura longitudinais, verifica-se uma exatidão bastante semelhante entre as normas CSA (2004) 
Eurocode (2004) e NBR 6118 (2007). Sendo esta última a responsável pela melhor exatidão por apresentar a menor média $(1,20)$.

O modelo da norma CSA (2004) apresentou, para as três categorias, a melhor precisão, com os menores coeficientes de variação, $0,18,0,14$ e 0,17 , respectivamente, indicando assim que esta norma apresenta um pequeno desvio em relação à média.

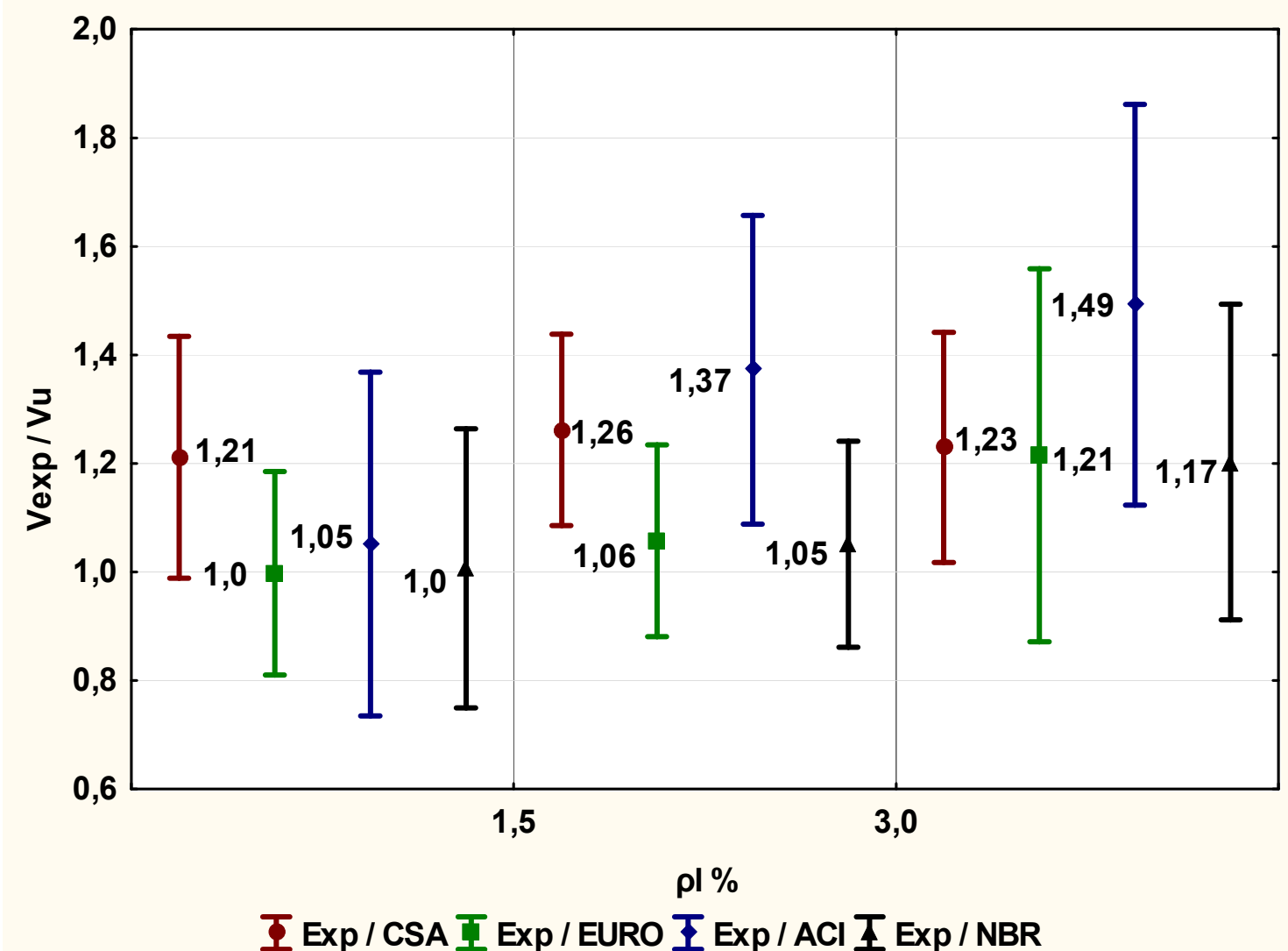

Figura 6.44: Análise dos valores médios e desvio padrão entre as razões Vexp/Vu para as normas CSA, EURO, ACl e NBR, para elementos sem estribos e dados válidos, separados em três intervalos de $\mathrm{\rho l}$

A Tabela 6.17 representa o resumo das medidas estatísticas obtidas pelo agrupamento de todas as categorias $(1+2+3)$ e também pelas categorias isoladas $(1,2$ ou 3$)$. 
Tabela 6.17: Medidas estatísticas dos valores de predição de norma, agrupados e não agrupados por pl, dados válidos e elementos sem estribos

\begin{tabular}{|c|c|c|c|c|c|}
\cline { 3 - 6 } & \multicolumn{4}{c|}{ Grupos para pl } \\
\hline \multirow{3}{*}{ CSA } & Norma & $\mathbf{1 + 2 + 3}$ & $\mathbf{1}$ & $\mathbf{2}$ & $\mathbf{3}$ \\
\cline { 2 - 6 } & MEDIA & 1,239 & 1,211 & 1,262 & 1,229 \\
\cline { 2 - 6 } & COEF. VARIAÇÃO & 0,162 & 0,184 & 0,140 & 0,173 \\
\hline \multirow{3}{*}{ EURO } & MEDIANA & 1,208 & 1,178 & 1,241 & 1,164 \\
\cline { 2 - 6 } & MEDIA & 1,064 & 0,998 & 1,058 & 1,215 \\
\cline { 2 - 6 } & COEF. VARIAÇÃO & 0,215 & 0,188 & 0,167 & 0,283 \\
\hline \multirow{3}{*}{ ACI } & MEDIANA & 1,031 & 0,981 & 1,027 & 1,128 \\
\cline { 2 - 6 } & MEDIA & 1,297 & 1,052 & 1,373 & 1,492 \\
\cline { 2 - 6 } & COEF. VARIAÇÃO & 0,276 & 0,301 & 0,207 & 0,248 \\
\hline \multirow{3}{*}{ NBR } & MEDIANA & 1,279 & 1,002 & 1,353 & 1,379 \\
\cline { 2 - 6 } & MEDIA & 1,062 & 1,007 & 1,051 & 1,202 \\
\cline { 2 - 6 } & COEF. VARIAÇÃO & 0,228 & 0,256 & 0,180 & 0,242 \\
\cline { 2 - 6 } & MEDIANA & 1,025 & 0,989 & 1,017 & 1,103 \\
\hline
\end{tabular}

Tabela 6.18: Resumo da análise de exatidão e precisão por intervalo de $\rho$, dados válidos e elementos sem estribos

\begin{tabular}{|c|c|c|c|}
\cline { 2 - 4 } \multicolumn{1}{c|}{} & \multicolumn{3}{c|}{ Categoria de $\rho \mathrm{l}(\%)$} \\
\cline { 2 - 4 } \multicolumn{1}{c|}{} & $\mathrm{\rho l} \leq 1,5$ & $\mathbf{1 , 5}<\boldsymbol{\mathrm { l }} \leq \mathbf{3}$ & $\mathrm{\rho l}>\mathbf{3}$ \\
\hline Melhor Exatidão & $\mathrm{NBR} /$ EURO $^{*}$ & $\mathrm{NBR} /$ EURO & NBR \\
\hline Melhor Precisão & $\mathrm{CSA}$ & $\mathrm{CSA}$ & $\mathrm{CSA}$ \\
\hline
\end{tabular}

* Valores médios semelhantes

Ressalta-se o fato de que exatidão e precisão não estão relacionadas com conceitos de segurança, apenas com a análise descritiva dos resultados dos modelos de predição de norma.

De uma forma mais reduzida, fez-se o estudo comparativo entre o comportamento dos modelos de predição de norma e os resultados de ensaios, mediante a variação da altura da seção, procurando assim, analisar a exatidão e a precisão das normas nas categorias definidas no grupo " $G$ d", cujos intervalos estão na Tabela 6.16 .

A Figura 6.45 representa a precisão e exatidão dos modelos de norma, separadas nas três categorias do grupo " $\mathrm{G}$ d". 


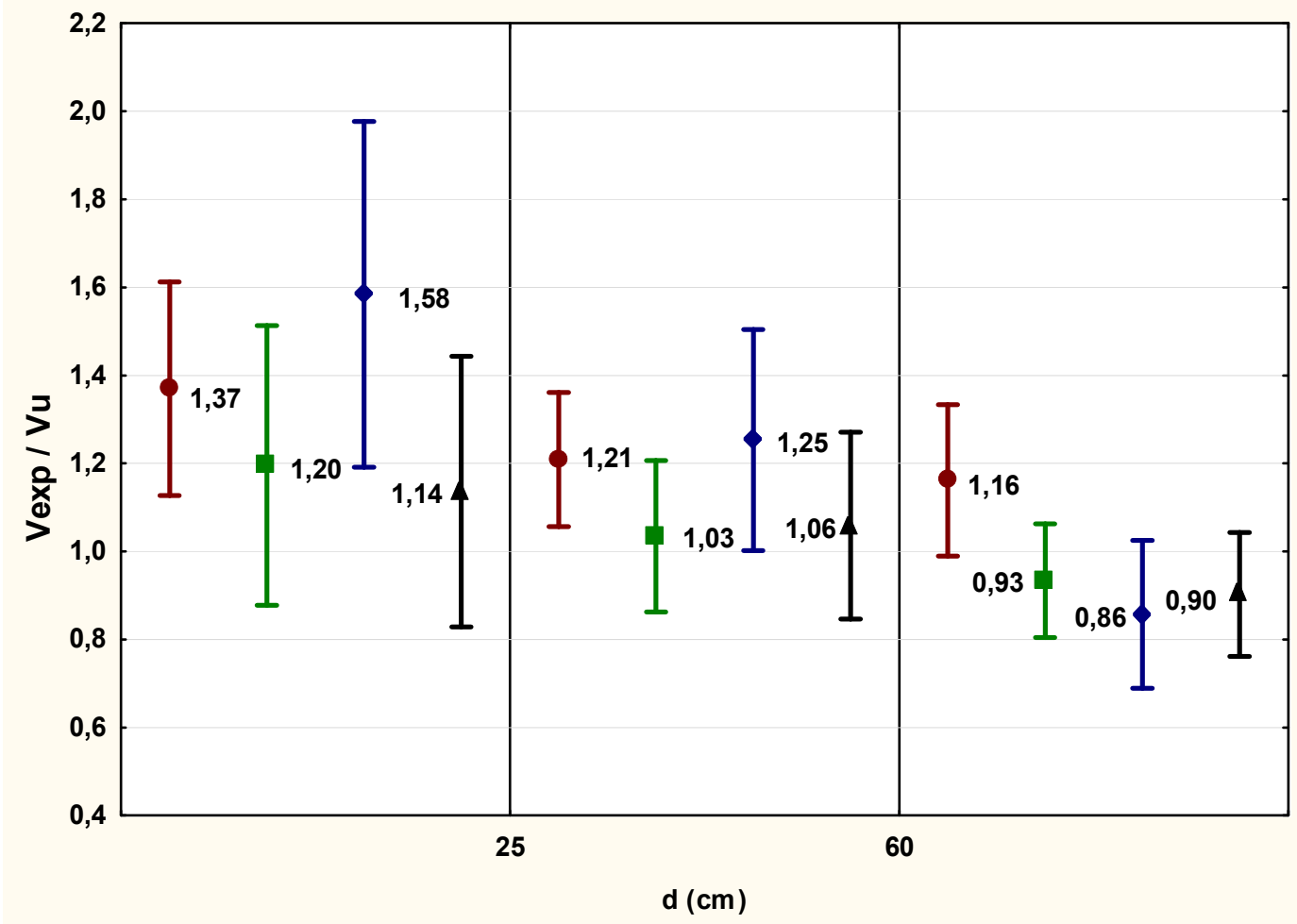

I Exp / CSA I Exp / EURO 互 Exp / ACI I I Exp / NBR

Figura 6.45: Análise dos valores médios e desvio padrão entre as razões Vexp/Vu para as normas CSA, EURO, ACI e NBR, para elementos sem estribos e dados válidos, separados em três intervalos de d

Tabela 6.19: Medidas estatísticas dos valores de predição de norma, agrupados por d, dados válidos e elementos sem estribos

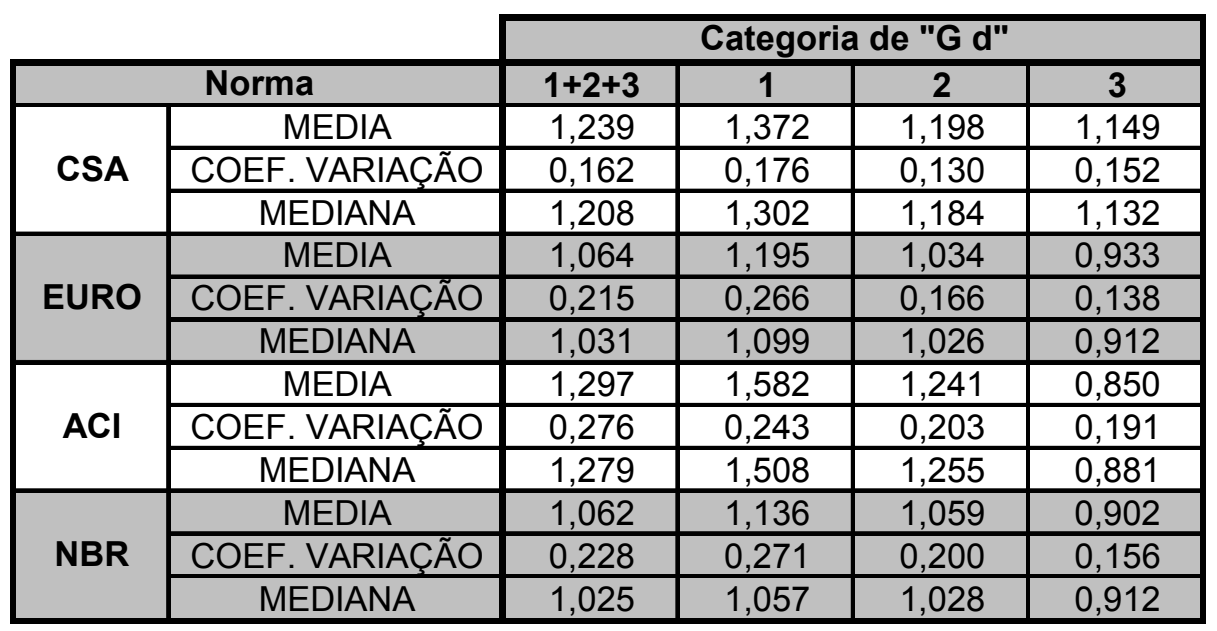

Aplicando os mesmos critérios de análise utilizados para os dados separados pelas diferentes categorias de taxas de armadura longitudinal de flexão, descritos anteriormente, resumiu-se as análises na Tabela 6.20. 
Tabela 6.20: Resumo da análise de exatidão e precisão por intervalo de $d$, dados válidos e elementos sem estribos

\begin{tabular}{|c|c|c|c|}
\cline { 2 - 4 } \multicolumn{1}{c|}{} & \multicolumn{3}{c|}{ Categoria de $\mathrm{d}(\mathrm{cm})$} \\
\cline { 2 - 4 } \multicolumn{1}{c|}{} & $\mathrm{d} \leq \mathbf{2 5}$ & $\mathbf{2 5 < \mathrm { d } \leq 6 0}$ & $\mathrm{d}>\mathbf{6 0}$ \\
\hline Melhor Exatidão & $\mathrm{NBR}$ & $\mathrm{NBR} /$ EURO & EURO/NBR* \\
\hline Melhor Precisão & $\mathrm{CSA}$ & $\mathrm{CSA}$ & $\mathrm{CSA}^{*} \mathrm{NBR}^{*}$ \\
\hline
\end{tabular}

Unindo as informações da Tabela $6.18 \mathrm{com}$ a da Tabela 6.20, gerou-se a Tabela 6.21, na qual se pode concluir que o modelo de predição da norma CSA (2004) é o mais preciso, ou seja, os valores estão relativamente próximos da média, porém a média está aproximadamente $20 \%$ acima do ideal, ou seja, na média, os valores de predição da norma canadense estão $20 \%$ menores que os valores medidos nos ensaios.

O modelo de predição da norma NBR 6118 (2007) apresentou a melhor exatidão dentre as demais normas, e em seguida a norma Eurocode (2004), sendo ainda necessário analisar a segurança destes modelos, pois apresentam dispersões significativas em relação ao valor médio, o que pode resultar em previsões onerosas ou não seguras.

Tabela 6.21: Resumo da análise de exatidão e precisão, intervalo válido e dados sem estribos

\begin{tabular}{|c|c|c|c|c|c|c|}
\hline & \multicolumn{3}{|c|}{ Categoria de $\mathrm{pl}(\%)$} & \multicolumn{3}{|c|}{ Categoria de d $(\mathrm{cm})$} \\
\hline & $\rho \leq 1,5$ & $1,5<\rho \mid \leq 3$ & $\rho \mathrm{\rho l}>3$ & $d \leq 25$ & $25<d \leq 60$ & $d>60$ \\
\hline Melhor Exatidão & NBR/EURO* & NBR/EURO* & NBR & $\overline{\mathrm{NBR}}$ & NBR/EURO* & EURO/NBR* \\
\hline Melhor Precisão & CSA & CSA & CSA & CSA & CSA & CSA/NBR* ${ }^{*}$ \\
\hline
\end{tabular}

* Valores médios semelhantes

\subsubsection{Análise da segurança dos modelos das normas com o uso dos resultados de ensaios do banco de dados homogeneizado}

Para analisar a segurança dos modelos de predição das normas para elementos não armados ao cisalhamento, considerou-se para cada norma os dados de ensaios válidos, ou seja, que apresentavam resistência do concreto a compressão dentro do limite estipulado por cada norma. Foram utilizadas as premissas de análise definidas nos itens 6.4.

Neste item precisa determinar o valor médio de $\Phi_{\text {mod, }}$ cujo valor será estimado

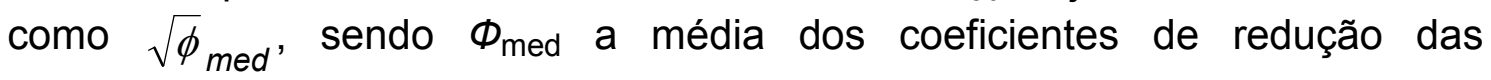
resistências de todas as previsões de normas. Analisando todos os valores de predição de normas [CSA (2004), Eurocode (2004), ACI (2008) e NBR 6118 (2007)], obteve um fator de segurança final médio igual a 0,71 , portanto o $\Phi_{\bmod }$ adotado foi 0,85 , que é aproximadamente a raiz quadrada de 0,71 . Sendo assim o Grupo 3 da Tabela 6.4 ficou definido:

$$
0,85 \cdot V_{u} \leq V_{E x p} \leq 1,1 . V_{u} \quad \begin{aligned}
& \text { SEGURANCCA E CUSTO } \\
& \text { APROPRIADOS }
\end{aligned}
$$


Os grupos de análises seguiram as mesmas divisões relatadas no item 6.6.3.1, sendo os dois principais fatores, $\rho /$ e $d$, explorados em três categorias cada um.

Os gráficos elaborados apresentam a porcentagem dos dados que se enquadram dentro dos critérios de quatro grupos: perigoso, baixa segurança, segurança e custo apropriados, e onerosos.

Para taxa de armadura longitudinal menor $(\rho / \leq 1,5 \%)$ e considerando apenas os dados com resistência de concreto menor que a máxima permitida por cada norma, elaborou-se o gráfico da Figura 6.46. Neste, pode-se notar que para $\rho l \leq 1,5 \%$, as normas ACl (2008) e NBR 6118 (2007) apresentaram porcentagens de previsões perigosas não aceitáveis. Todas as normas, exceto a CSA (2004), apresentaram baixas porcentagens de resultados de previsões consideradas apropriadas e onerosas. A norma Eurocode (2004) apresentou uma porcentagem de previsões perigosas desprezível (1 para 152), a maior porcentagem de casos apropriados, e uma pequena porcentagem de casos onerosos, porém apresentou $16 \%$ dos casos considerados de baixa segurança.

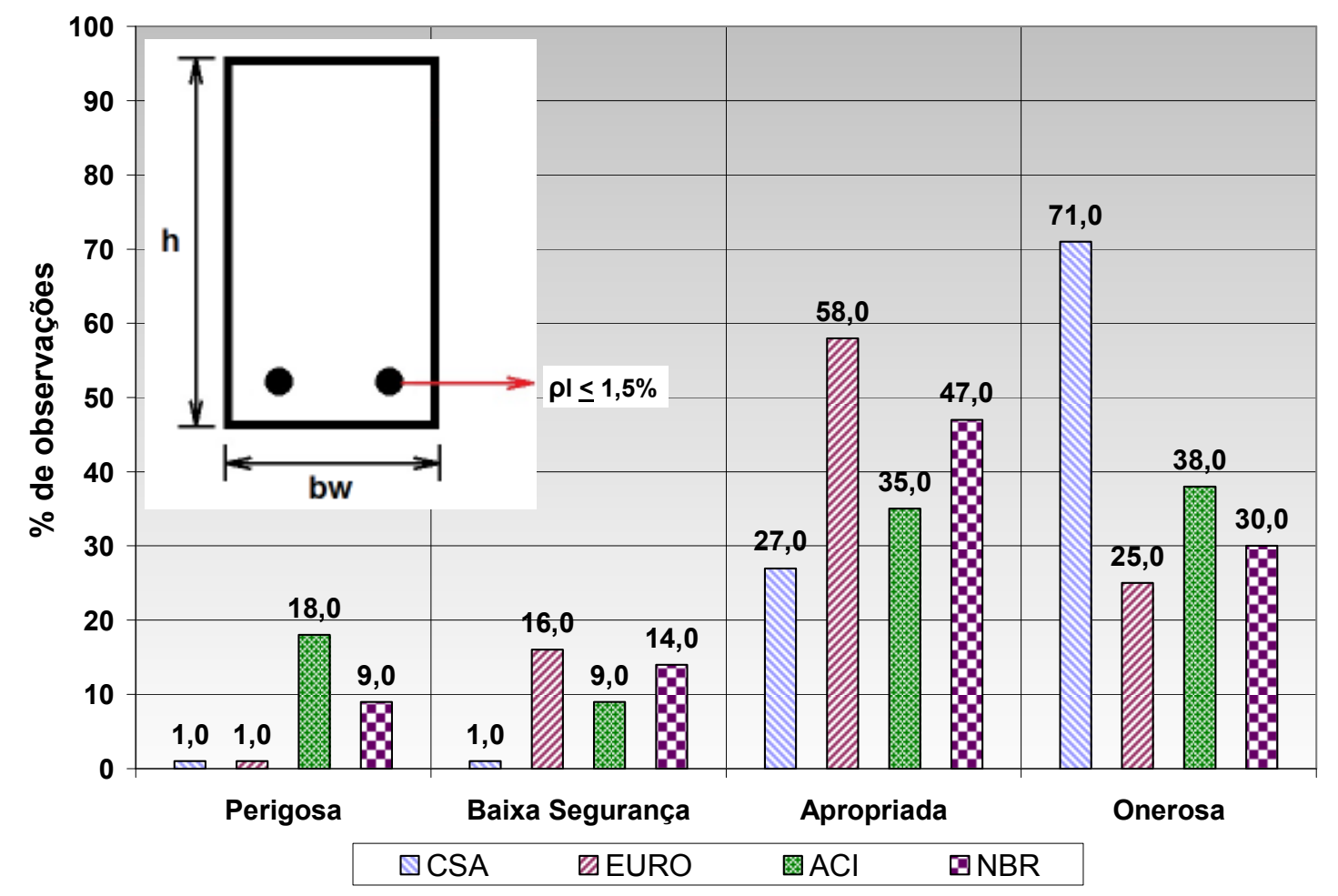

Figura 6.46: Análise da segurança para $\rho \mathrm{I} \leq 1,5 \%$, para dados válidos e elementos sem estribos

Para a segunda categoria da taxa de armadura longitudinal $(1,5<\rho /<3)$, elaborou-se a Figura 6.47. 


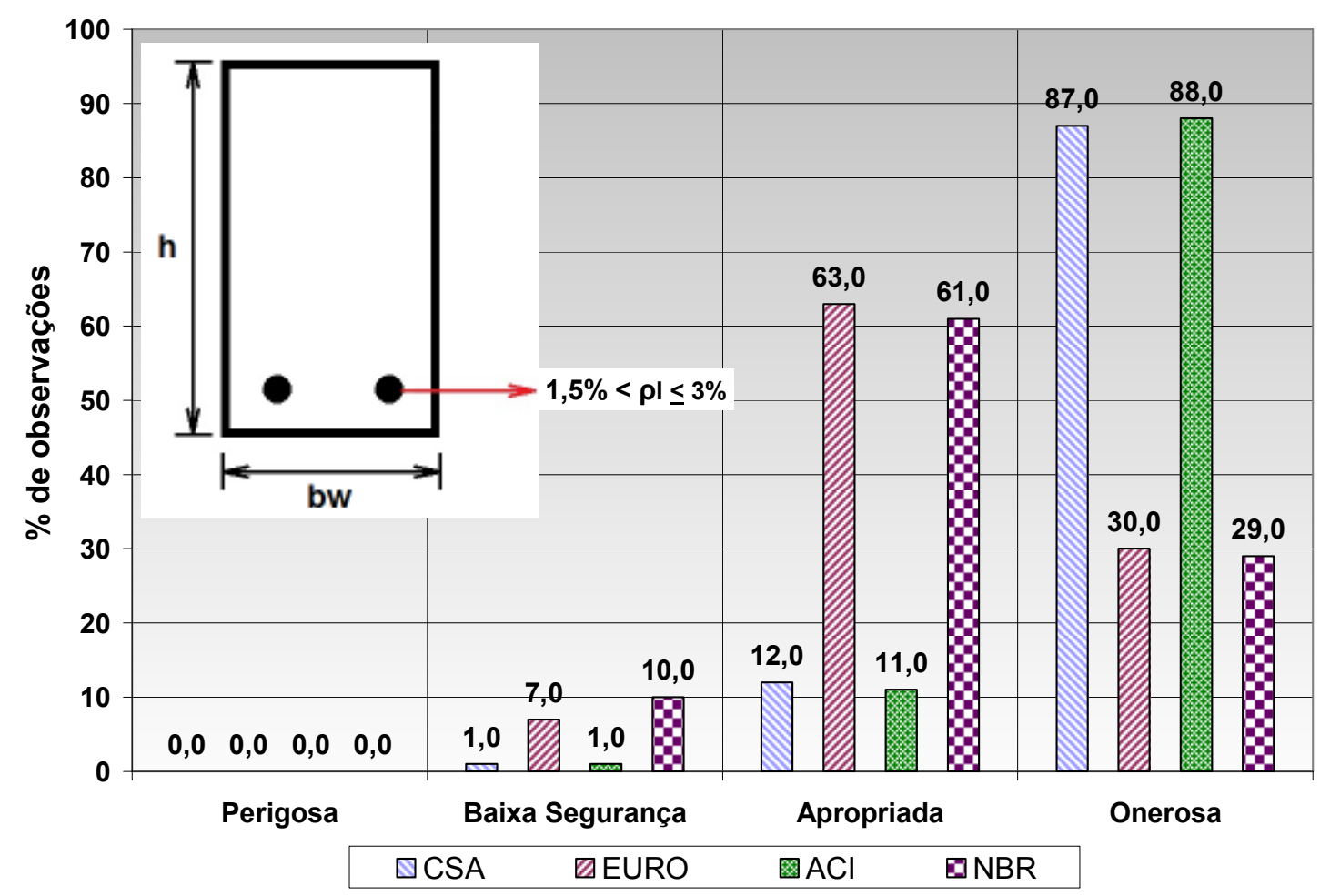

Figura 6.47: Análise da segurança para $1,5 \leq \rho \mid<3 \%$, para dados válidos e elementos sem estribos

A Figura 6.47 indica comportamentos semelhantes para as normas CSA (2004) e ACl (2008), com elevadas porcentagens de previsões consideradas onerosas, em contra partida, porcentagens nulas de casos perigosos. Por fim, o Eurocode (2004) e a NBR 6118 (2007) apresentaram os melhores resultados, com porcentagens nulas de casos de ruína, menores porcentagens de casos onerosos e porcentagens boas de casos considerados adequados.

A última categoria da taxa de armadura longitudinal refere-se ao intervalo $\mathrm{\rho l} \geq 3 \%$, neste contexto elaborou-se a Figura 6.48, na qual verifica-se que as normas CSA (2004) e Eurocode (2004) apresentaram previsões satisfatórias, com tendências mais conservadoras e sem porcentagens de previsões perigosas. A norma $\mathrm{ACl}$ (2008) apresentou $100 \%$ das previsões onerosas, o que resultaria em altos custos nos processos de fabricação, quando utilizada. A norma NBR 6118 (2007) apresentou o melhor resultado, com porcentagem nula de previsões perigosas, e com $50 \%$ das previsões apropriadas e $50 \%$, de previsões onerosas. 


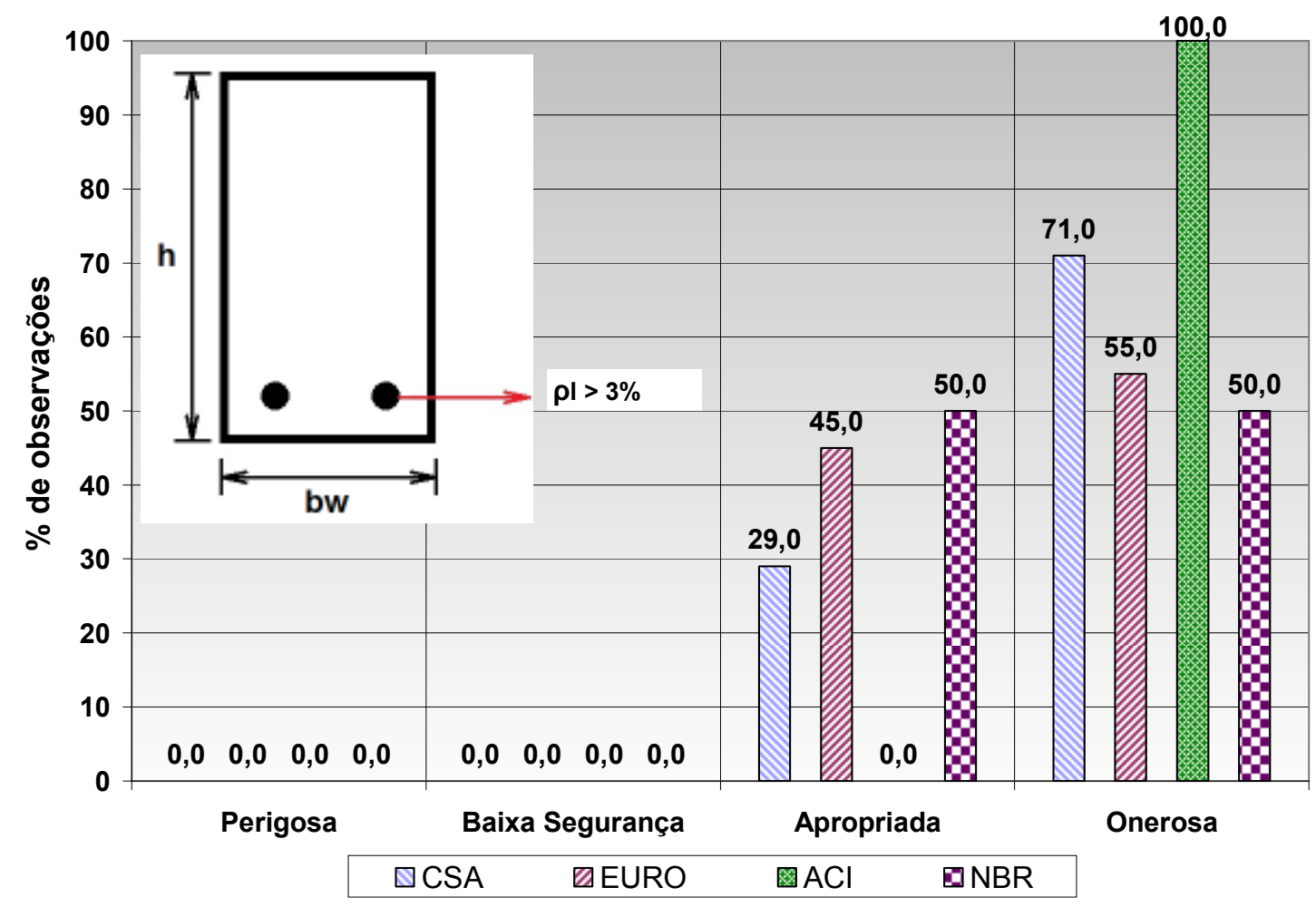

Figura 6.48: Análise da segurança para $\rho \mathrm{l} \geq 3 \%$, para dados válidos e elementos sem estribos

Para a análise das previsões das normas nas diversas categorias do grupo "G d", foram elaborados gráficos considerando as três categorias separadamente, considerando os dados que não extrapolaram os limites válidos de norma.

A Figura 6.49 , representa a categoria $d \leq 25 \mathrm{~cm}$, na qual os resultados de predição das normas apresentaram de forma geral boas aproximações, apenas a norma NBR 6118 (2007) que apresentou uma porcentagem insignificante de $1 \%$ para os casos perigosos. A norma NBR 6118 (2007) e o Eurocode (2004) apresentaram os melhores resultados, devida as maiores porcentagens de previsões apropriadas, $54 \%$ e $47 \%$, respectivamente, e baixas porcentagens de valores de previsões onerosas, $37 \%$ e $50 \%$, respectivamente. 


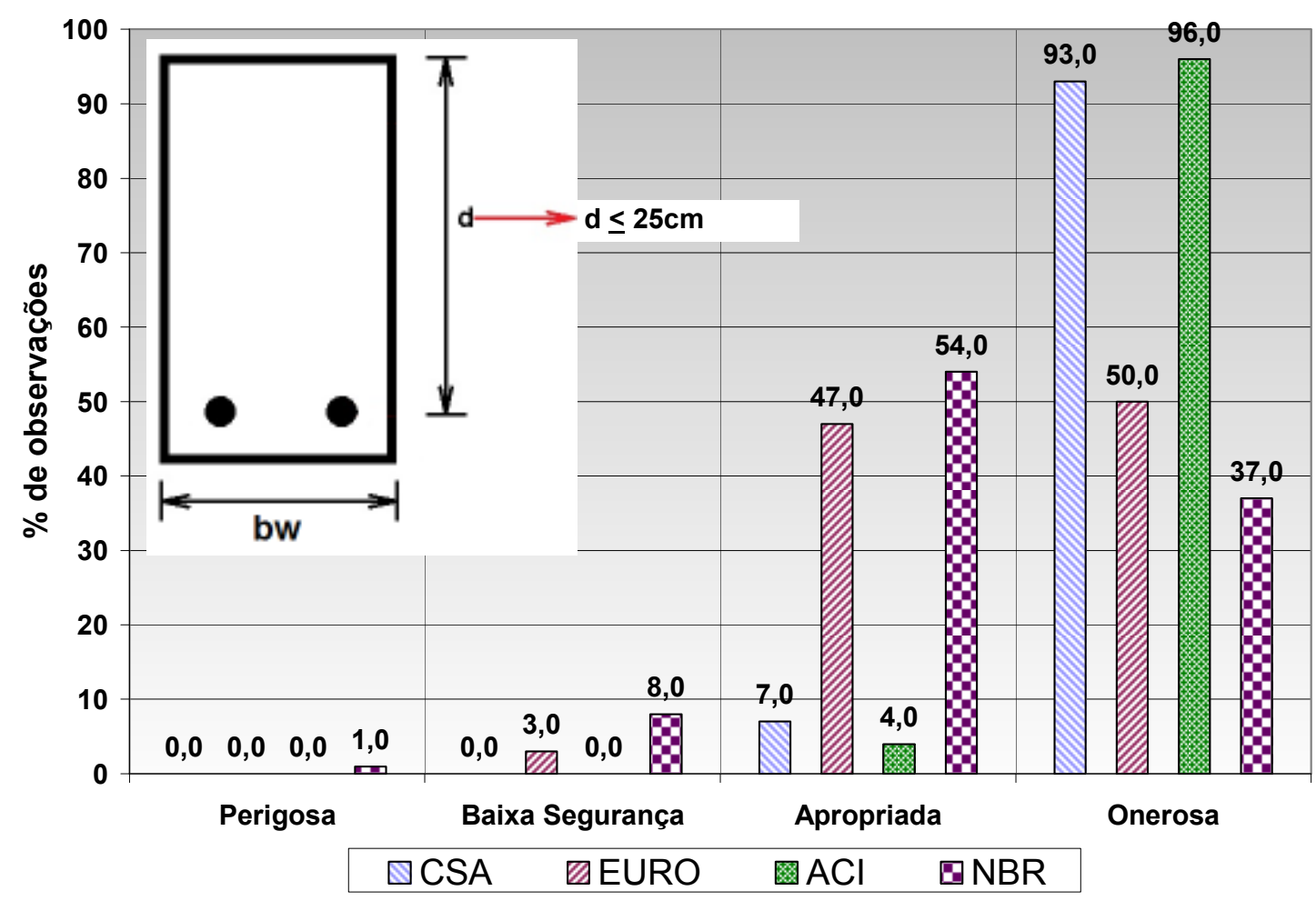

Figura 6.49: Análise da segurança para $\mathrm{d} \leq 25 \mathrm{~cm}$, para dados válidos e elementos sem estribos

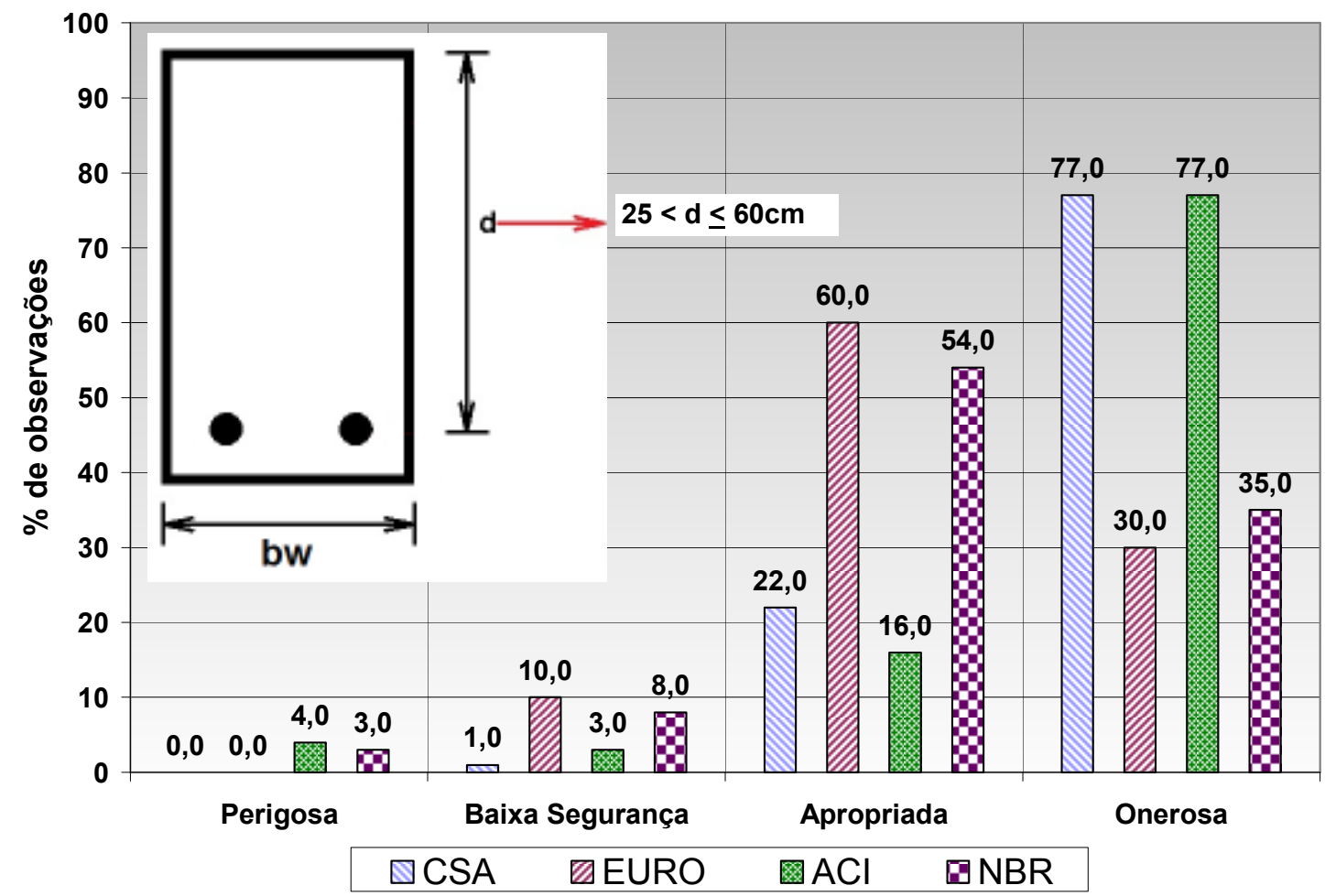

Figura 6.50: Análise da segurança para $25<\mathrm{d} \leq 60 \mathrm{~cm}$, para dados válidos e elementos sem estribos 
Para $25<d \leq 60 \mathrm{~cm}$ (Figura 6.50) as previsões das normas NBR 6118 (2007) e $\mathrm{ACl}$ (2008) mostraram resultados perigosos, $3 \%$ e $4 \%$, respectivamente, o que não é aceitável. Por outro lado, as normas CSA (2004) e Eurocode (2004) apresentaram porcentagens nulas de previsões perigosas e porcentagens consideráveis de previsões apropriadas. $\mathrm{Na}$ faixa de previsões de baixa segurança a norma Eurocode (2004) apresentou $10 \%$ de previsões, que exige cautela na utilização da mesma neste intervalo.

Por fim, para a análise de segurança da categoria de elementos de grandes alturas, $d>60 \mathrm{~cm}$ (Figura 6.51), mostra que apenas as normas CSA (2004) e Eurocode (2004) apresentaram resultados satisfatórios, pois as porcentagens obtidas para os casos perigosos foram nulas. A norma Eurocode (2004) apesar da porcentagem nula de ruínas, e baixa porcentagem de resultados onerosos, apresentou uma porcentagem alta de dados com coeficientes de segurança reduzidos (19 \%), o que gera uma preocupação em relação a segurança. As normas ACl (2008) e NBR 6118 (2007) apresentaram porcentagens de casos perigosos considerados inadmissíveis. Por fim a norma CSA (2004) apresentou porcentagens satisfatórias para todos os grupos de análises.

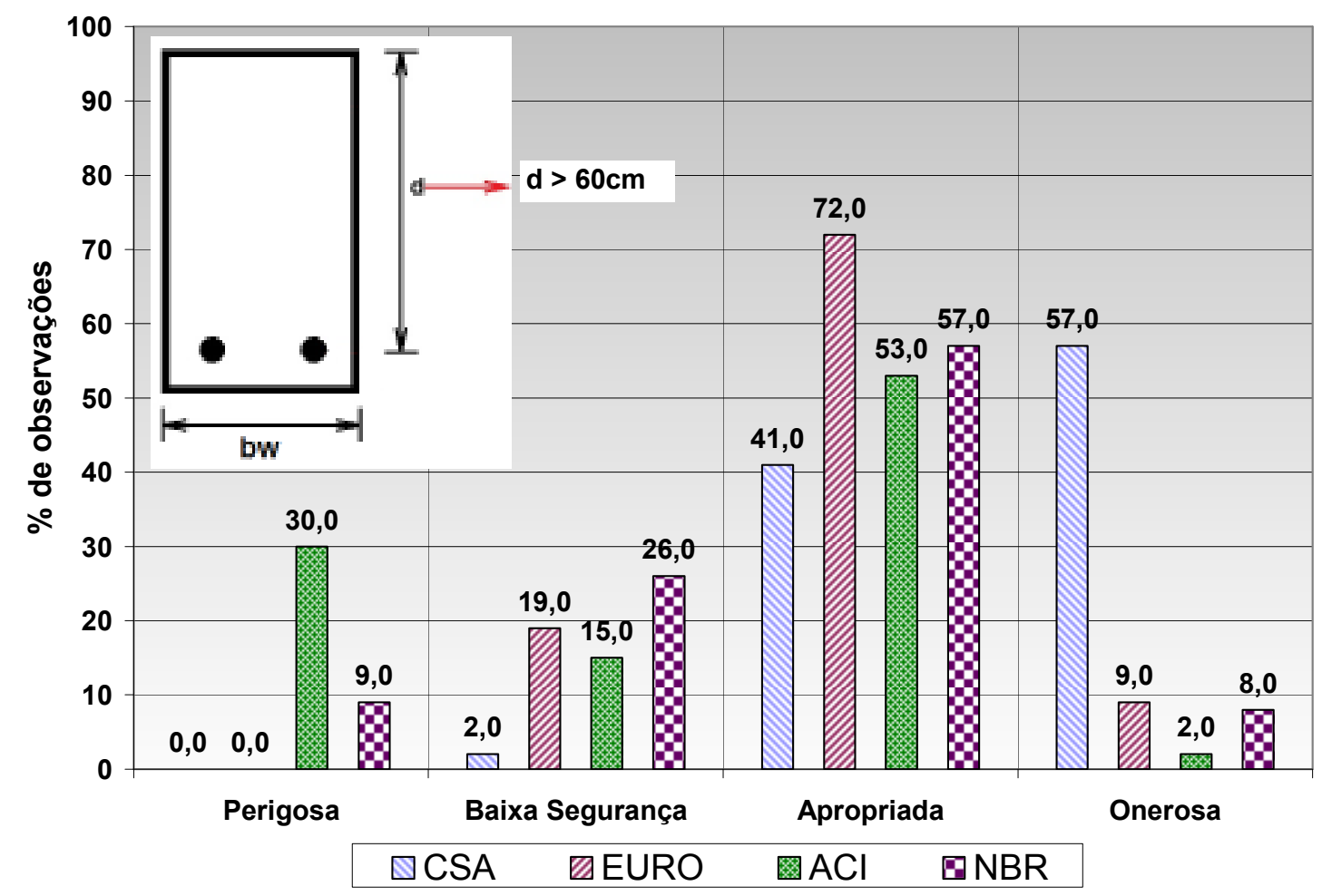

Figura 6.51: Análise da segurança para $d \geq 60 \mathrm{~cm}$, para dados válidos e elementos sem estribos

As porcentagens referentes aos casos perigosos e outro extremo de casos onerosos, para as seis categorias estudadas, foram reunidas e apresentadas na Tabela 6.22. 
Tabela 6.22: Resumo das porcentagens de resultados perigosos e onerosos, dados válidos e elementos sem estribos

\begin{tabular}{|c|c|c|c|c|c|c|c|c|c|c|c|c|}
\hline & \multicolumn{6}{|c|}{ Categoria de pl (\%) } & \multicolumn{6}{|c|}{ Categoria de $\mathrm{d}(\mathrm{cm})$} \\
\hline & \multicolumn{2}{|c|}{$\rho \mid<1,5$} & \multicolumn{2}{|c|}{$1,5<\rho \mid<3$} & \multicolumn{2}{|c|}{$\rho \mathrm{\rho l}>3$} & \multicolumn{2}{|c|}{$d<25$} & \multicolumn{2}{|c|}{$25<d<60$} & \multicolumn{2}{|c|}{$d>60$} \\
\hline Norma & \% Perigosa & $\%$ Onerosa & \% Perigosa & $\%$ Onerosa & \% Perigosa & $\%$ Onerosa & \% Perigosa & $\%$ Onerosa & \% Perigosa & $\%$ Onerosa & $\%$ Perigosa & $\%$ Onerosa \\
\hline CSA & 1,0 & 71,0 & 0,0 & 87,0 & 0,0 & 71,0 & 0,0 & 93,0 & 0,0 & 77,0 & 0,0 & 57,0 \\
\hline EURO & 1,0 & 25,0 & 0,0 & 30,0 & 0,0 & 55,0 & 0,0 & 50,0 & 0,0 & 30,0 & 0,0 & 9,0 \\
\hline $\mathrm{ACl}$ & 18.0 & 38,0 & 0,0 & 88.0 & 0,0 & 100.0 & 0,0 & 96.0 & 4.0 & 77.0 & 30.0 & 2,0 \\
\hline NBR & 9,0 & 30,0 & 0,0 & 29,0 & 0,0 & 50,0 & 1,0 & 37,0 & 3,0 & 35,0 & 9,0 & 8,0 \\
\hline
\end{tabular}

$\square$ Valores não aceitáveis

Aplicando o critério de classificação por análise dos pontos de deméritos, conforme indicado na Tabela 6.23 , verificou-se que para as duas faixas compreendidas por $\rho \mathrm{l} \leq 3 \%$ a norma Eurocode (2004) apresentou as menores médias de pontos de méritos, tornando-a recomendada para o uso segundo este critério. Para a faixa $\mathrm{\rho l}>3 \%$ a candidata foi a norma NBR 6118 (2007)

Tabela 6.23: Classificação pelo critério de pontos de deméritos (sem estribos)

\begin{tabular}{|c|c|c|c|c|c|c|c|c|c|}
\hline \multirow[b]{3}{*}{ Norma } & \multicolumn{9}{|c|}{ Categoria de pl (\%) } \\
\hline & \multicolumn{3}{|c|}{$\rho \mid<1,5$} & \multicolumn{3}{|c|}{$1,5<\rho \mid<3$} & \multicolumn{3}{|c|}{$\rho \mid>3$} \\
\hline & $\mathbf{N}^{\circ}$ ensaios & Ptos & Média & $\mathbf{N}^{\circ}$ ensaios & Ptos & Média & $\mathbf{N}^{\circ}$ ensaios & Ptos & Média \\
\hline CSA & 163 & 246 & 1,5 & 242 & 428 & 1,8 & 101 & 144 & 1,4 \\
\hline EURO & 152 & 136 & 0,9 & 221 & 164 & 0,7 & 76 & 84 & 1,1 \\
\hline$\overline{\mathrm{ACl}}$ & 164 & 444 & 2,7 & 247 & 446 & 1,8 & 110 & 220 & 2,0 \\
\hline NBR & 152 & 272 & 1,8 & 221 & 180 & 0,8 & 76 & 76 & 1,0 \\
\hline
\end{tabular}

\begin{tabular}{|c|c|c|c|c|c|c|c|c|c|}
\cline { 2 - 11 } \multicolumn{1}{c|}{} & \multicolumn{9}{c|}{ Categoria de d (cm) } \\
\cline { 2 - 11 } \multicolumn{1}{c|}{ Norma } & \multirow{2}{*}{ N $^{\circ}$ ensaios } & Ptos & Média & No ensaios & Ptos & Média & No ensaios & Ptos & Média \\
\hline CSA & 134 & 250 & 1,9 & 321 & 508 & 1,6 & 51 & 60 & 1,2 \\
\hline EURO & 112 & 118 & 1,1 & 290 & 240 & $\mathbf{0 , 8}$ & 47 & 26 & $\mathbf{0 , 6}$ \\
\hline ACI & 146 & 280 & 1,9 & 322 & 652 & 2,0 & 53 & 178 & 3,4 \\
\hline NBR & 112 & 112 & $\mathbf{1 , 0}$ & 290 & 344 & 1,2 & 47 & 72 & 1,5 \\
\hline
\end{tabular}

Por fim, resumidamente as conclusões sobre os modelos das normas e suas seguranças, quando analisadas as variações dos parâmetros $\rho l$ e $d$, foram condensadas na Tabela 6.24.

Tabela 6.24: Tabela resumo da análise de segurança, dados válidos e elementos sem estribos

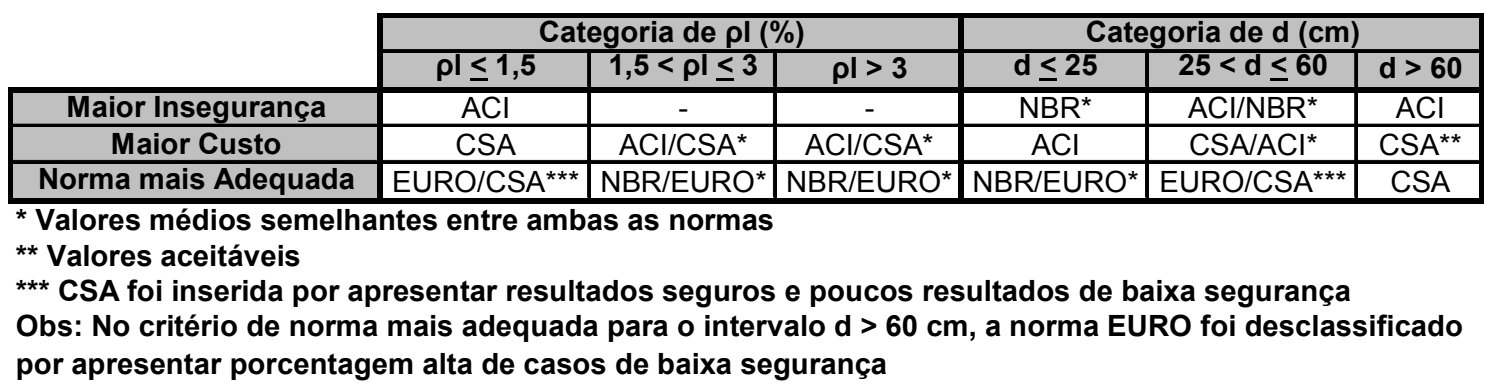

$\mathrm{Na}$ última linha da Tabela 6.24, pode-se verificar a indicação da norma que apresenta uma segurança adequada e ao mesmo tempo, resultados que não são demasiadamente onerosos. Nota-se que prevalecem as indicações da normas Eurocode (2004) e que a norma CSA (2004) é indicada para os casos 
extremos de baixa taxa de armadura longitudinal e peças de grandes dimensões.

\subsubsection{Vigas com resistência do concreto fora dos intervalos válidos da norma}

A utilização dos dados de ensaios que tiveram a resistência do concreto com valor fora do intervalo válido das normas permite avaliar o comportamento dos modelos de predição das normas para concretos com valores de resistência considerados de alta resistência, e, além disso, analisar a validade de extrapolar os modelos de predição para intervalos não válidos. Este estudo também é valido para casos de retroanálise de estruturas existentes, para a definição de novas cargas e capacidades.

Em cada estudo, após a utilização do critério de seleção indicado no item 6.3.1, foram filtrados os ensaios com características de parâmetros que extrapolaram os intervalos válidos. Com isto, manipularam-se os dados de predição de norma de forma a possibilitar a análise da exatidão, precisão e segurança dos modelos, considerando as faixas de variações dos parâmetros: $d$ e $\rho$ l.

Apenas como ilustração do comportamento de vigas não armadas ao cisalhamento com alta resistência do concreto, elaborou-se a Figura 6.52, que ilustra uma superfície de aproximação para os 131 dados de vigas sem estribos e com resistência do concreto maior que $50 \mathrm{MPa}$, para a análise da importância destes dois parâmetros na determinação da resistência da peça. Deve-se notar que o aumento da altura efetiva da peça associada com a baixa taxa de armadura de flexão resulta em tensões cisalhantes resistentes reduzidas, indicando a existência do efeito de escala ("Size Effect").

A Figura 6.52 indica que na medida em que se aumenta a altura útil, é necessário aumentar a taxa geométrica de armadura longitudinal, para conseguir um melhor aproveitamento da resistência do concreto ao cisalhamento. Por exemplo, para se manter o mesmo grau de aproveitamento da resistência do concreto, indicado por $\tau_{\mathrm{exp}} / \mathrm{fc}^{\wedge} \mathrm{c}^{\wedge, 5}$ igual a aproximadamente 0,22 , os elementos com $d=10 \mathrm{~cm} \mathrm{e} \rho \mathrm{l}=1,2 \%$, equivaleriam a elementos com maiores alturas e taxas geométricas de armadura longitudinal, ou seja, $d=40$ $\mathrm{cm} \mathrm{e} \rho \mathrm{l}=3,2 \%$. 


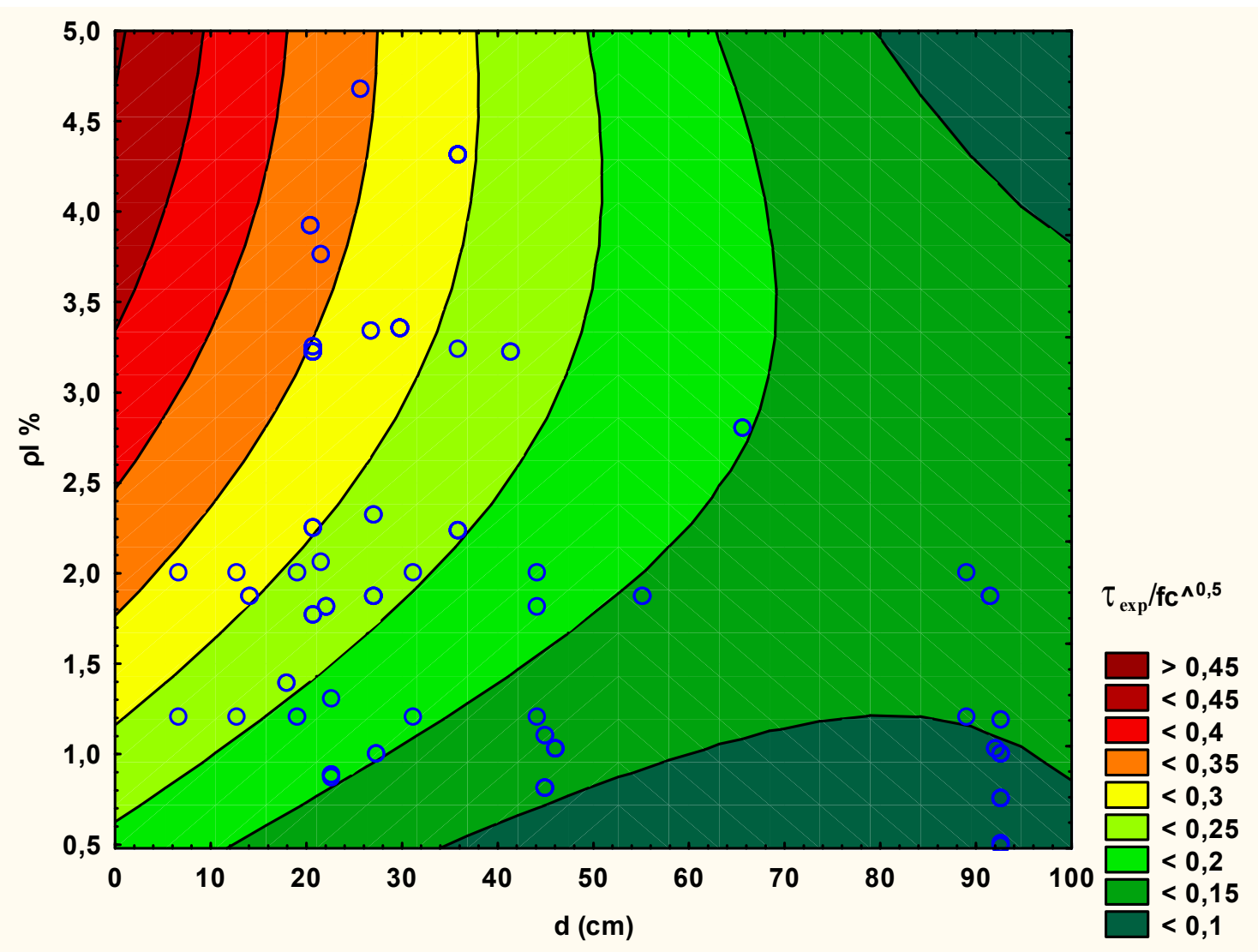

Figura 6.52: Curvas de contorno de $\tau_{\exp } / \sqrt{f C}$, em função da taxa de armadura longitudinal, $\rho$ l, e altura efetiva do elemento, d, para 131 ensaios de vigas sem estribos.

6.6.4.1. Análise da exatidão e precisão dos modelos das normas com o uso dos resultados de ensaios do banco de dados homogeneizado

A análise da exatidão e precisão dos modelos de norma foi efetuada seguindo as mesmas premissas definidas no item 6.5.3.1. Os resultados das razões, entre as forças últimas dos ensaios e as forças previstas pelas normas, estão expressas na Figura 6.53. 


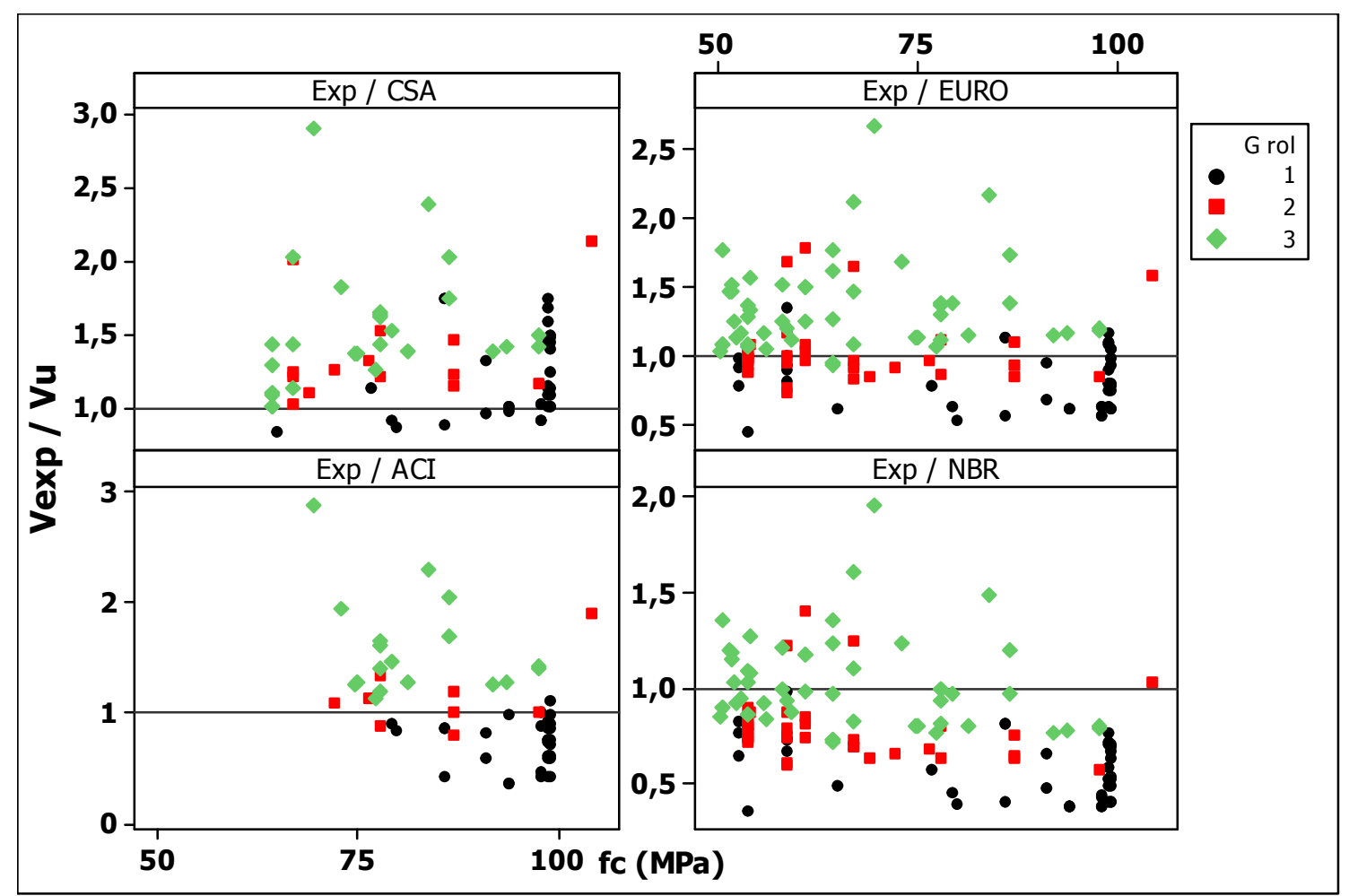

Figura 6.53: Correlação entre as razões $\mathrm{Vexp} / \mathrm{Vu}$ e os valores da resistência do concreto, fc, para as normas CSA, EURO, ACI e NBR, para elementos sem estribos e dados fora do intervalo válido, para as três categorias do grupo G rol

$\mathrm{Na}$ Figura 6.53, observa-se que mesmo extrapolando o intervalo válido da resistência do concreto, a norma CSA (2004) apresentou resultados de predição de norma adequados, enquanto as normas Eurocode (2004), ACl (2008) e NBR 6118 (2007) apresentaram uma quantidade maior de resultados distante do valor de ensaio, principalmente para baixas taxas de armadura longitudinal. Para melhor compreender os comportamentos dos modelos de predição das normas, serão analisadas separadamente as três categorias do grupo "G rol", e depois as três categorias do grupo "G d".

Idem ao subitem 6.5.3.1, a análise de exatidão e precisão dos modelos de norma será feita utilizando os valores ultimos dos resultados de predição de norma, ou seja, considerando unitários os coeficientes de segurança. Desta forma a exatidão será analisada pela média, e a precisão pelo coeficiente de variação (afastamento). 


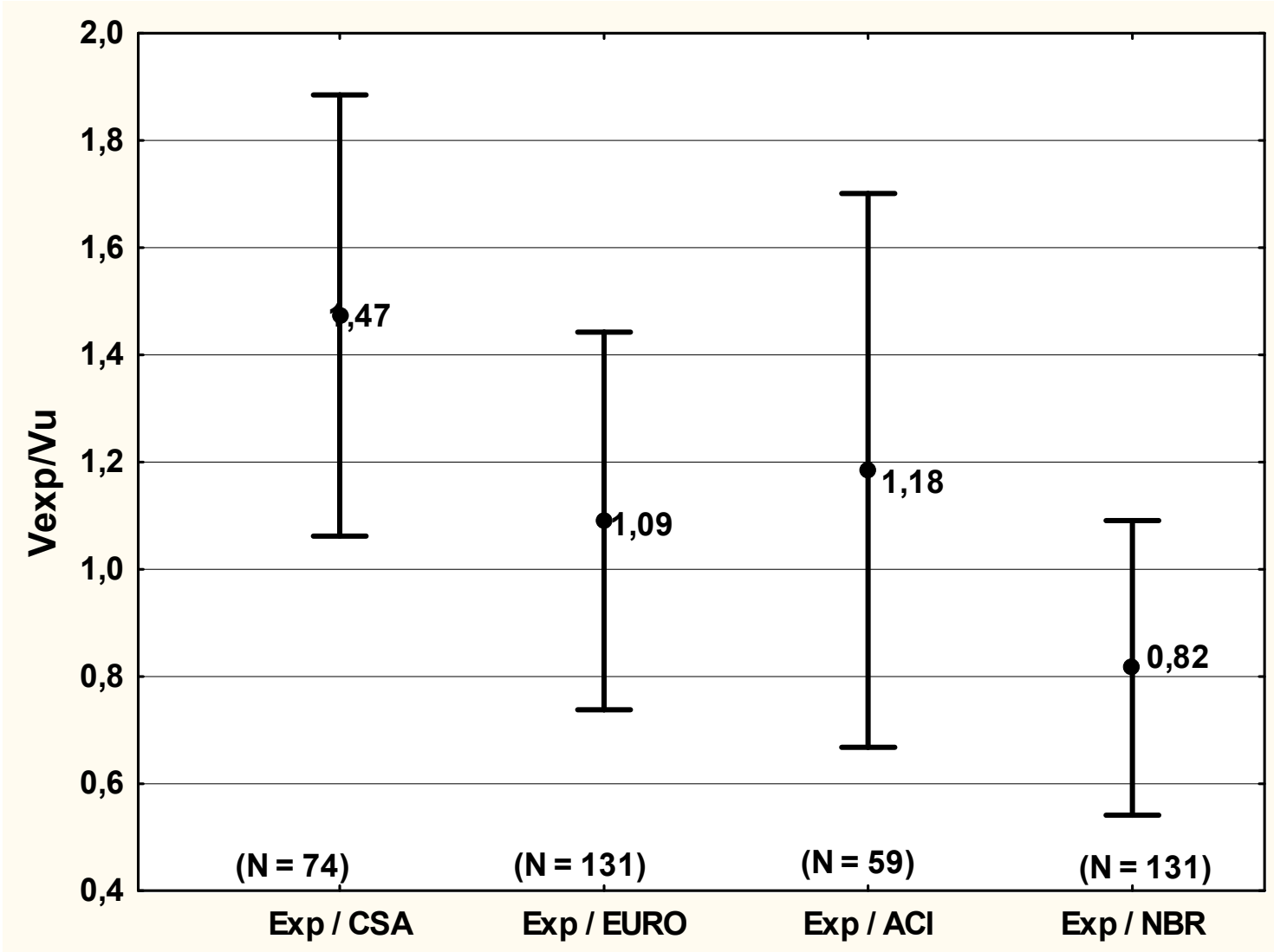

Figura 6.54: Análise dos valores médios e desvio padrão entre as razões Vexp/Vu para as normas CSA, EURO, ACI e NBR, para elementos sem estribos e dados não válidos, sendo $\mathbf{N}$ - quantidade de ensaios

A Figura 6.54 apresenta os valores das médias de $V_{\text {Exp }} / V_{\text {norma, }}$ para cada norma e o intervalo compreendido pela médias mais ou menos o desvio padrão da média. Destaca-se a norma NBR 6118 (2007), com uma média consideravelmente inferior ao valor unitário.

A Figura 6.55 representa a precisão e exatidão dos modelos de norma, discretizadas nas três categorias do grupo "G rol".

Para valores de taxa de armadura longitudinal de flexão menores que $1,5 \%$ o modelo de predição de norma do $\mathrm{ACl}$ (2008) apresentou a melhor exatidão média, pois apresentou um índice médio igual a 0,86 , porém distante do valor unitário, além disso, o coeficiente de variação foi o menor $(0,253)$. A norma CSA (2004) apresentou resultados bastante seguros $(1,35)$ e do outro lado a norma NBR 6118 (2007) apresentou resultados não seguros $(0,59)$.

Os resultados obtidos para a categoria 2, 1,5\%< $1 \leq 3,0 \%$, mostram que a norma Eurocode (2004) apresenta a melhor exatidão média, devido a média no valor de 1,04 e com o valor da mediana semelhante ao da média. Ainda neste mesmo quesito, as normas ACl (2008) e NBR 6118 (2007) apresentaram índices médios 1,285 e 0,800, respectivamente.

A categoria 3 , representada pelas altas taxas de armadura longitudinais, verifica-se que a norma NBR 6118 (2007) apresentou uma boa exatidão, com média igual a 1,02 e coeficiente de variação igual a 23,8 \%. Em segundo lugar 
o Eurocode (2004) a segunda melhor média, 1,35 e um coeficiente de variação igual a $24,4 \%$. As demais normas apresentaram médias acima de 1,6, o que mostra baixa exatidão dos modelos.

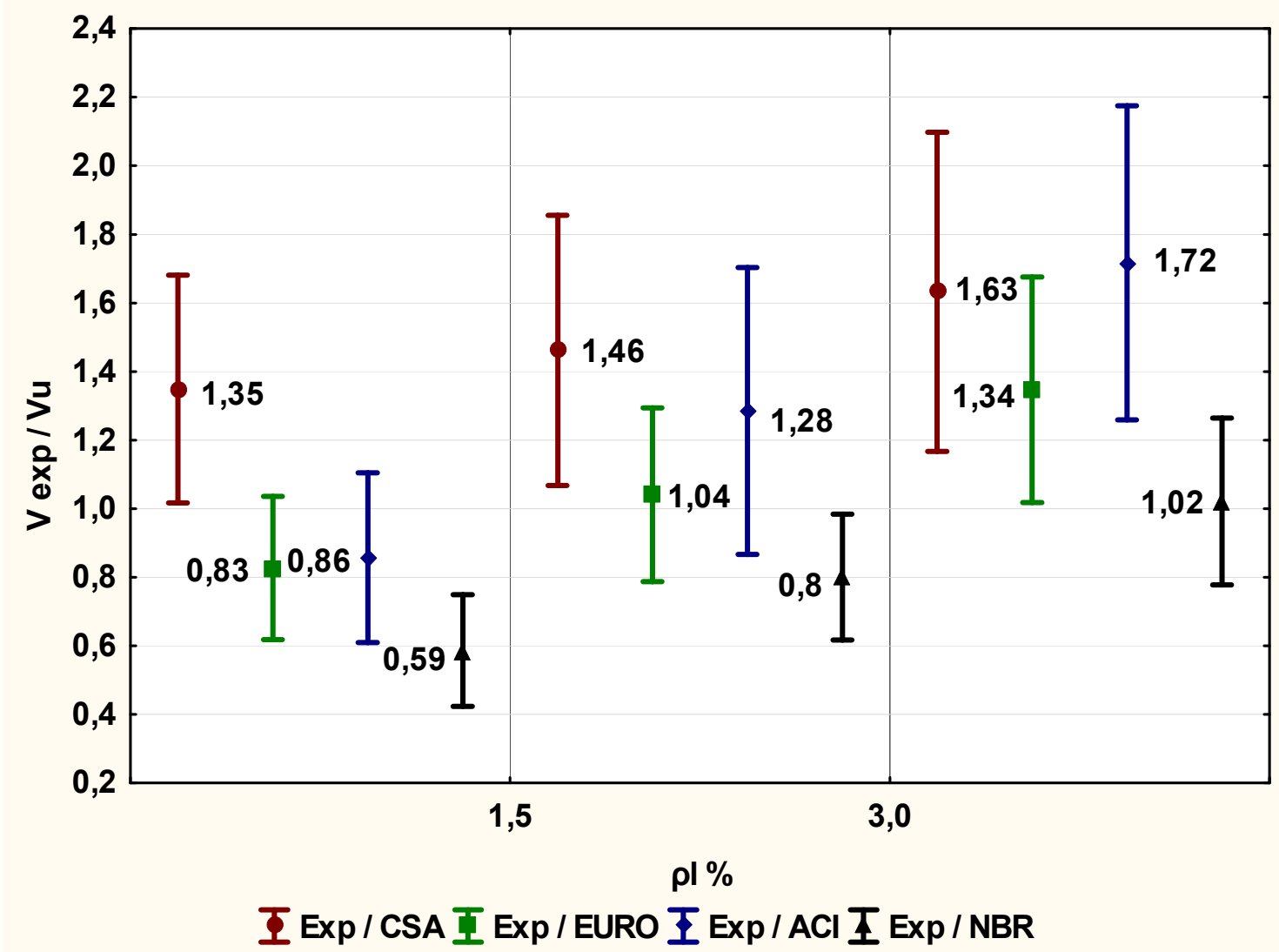

Figura 6.55: Análise dos valores médios e desvio padrão entre as razões Vexp/Vu para as normas CSA, EURO, ACI e NBR, para elementos sem estribos e dados não válidos, separados em três intervalos de $\rho \mathrm{I}$

A Tabela 6.25 representa o resumo das medidas estatísticas obtidas pelo agrupamento de todas as categorias $(1+2+3)$ e também pelas categorias isoladas $(1,2$ ou 3$)$.

Tabela 6.25: Medidas estatísticas dos valores de predição de norma, agrupados e não agrupados por pl, para dados de ensaios não válidos e elementos sem estribos

\begin{tabular}{|c|c|c|c|c|c|}
\cline { 3 - 6 } \multicolumn{2}{c|}{} & \multicolumn{4}{c|}{ Grupos para pl } \\
\hline \multirow{3}{*}{ CSA } & Norma & $\mathbf{1 + 2 + 3}$ & $\mathbf{1}$ & $\mathbf{2}$ & $\mathbf{3}$ \\
\cline { 2 - 6 } & MEDIA & 1,473 & 1,349 & 1,461 & 1,632 \\
\cline { 2 - 6 } & COEF. VARIAÇÃO & 0,279 & 0,246 & 0,270 & 0,285 \\
\cline { 2 - 6 } & MEDIANA & 1,386 & 1,233 & 1,323 & 1,573 \\
\hline \multirow{3}{*}{ EURO } & MEDIA & 1,090 & 0,827 & 1,041 & 1,346 \\
\cline { 2 - 6 } & COEF. VARIAÇÃO & 0,323 & 0,253 & 0,243 & 0,244 \\
\cline { 2 - 6 } & MEDIANA & 1,043 & 0,809 & 0,969 & 1,262 \\
\hline \multirow{3}{*}{ ACI } & MEDIA & 1,185 & 0,857 & 1,285 & 1,717 \\
\cline { 2 - 6 } & COEF. VARIAÇÃO & 0,436 & 0,289 & 0,325 & 0,267 \\
\cline { 2 - 6 } & MEDIANA & 1,118 & 0,913 & 1,184 & 1,615 \\
\hline \multirow{3}{*}{ NBR } & MEDIA & 0,816 & 0,586 & 0,800 & 1,021 \\
\cline { 2 - 6 } & COEF. VARIAÇÃO & 0,337 & 0,278 & 0,230 & 0,238 \\
\cline { 2 - 6 } & MEDIANA & 0,795 & 0,554 & 0,763 & 0,971 \\
\hline
\end{tabular}


Tabela 6.26: Resumo da análise de exatidão e precisão por intervalo de $\rho l$, para dados de ensaios não válidos e elementos sem estribos

\begin{tabular}{|l|c|c|c|}
\cline { 2 - 4 } \multicolumn{1}{c|}{} & \multicolumn{3}{c|}{ Categoria de $\rho \mathrm{l}(\%)$} \\
\cline { 2 - 4 } \multicolumn{1}{c|}{} & $\mathrm{\rho l} \leq 1,5$ & $\mathbf{1 , 5}<\mathrm{\rho l} \leq \mathbf{3}$ & $\mathrm{\rho l}>\mathbf{3}$ \\
\hline Melhor Exatidão & $\mathrm{ACl}$ & EURO & NBR \\
\hline Melhor Precisão & $\mathrm{CSA}$ & NBR & NBR \\
\hline
\end{tabular}

Fez-se o estudo comparativo entre o comportamento dos modelos de predição de norma e os resultados de ensaios, mediante a variação da altura da seção, procurando assim, analisar a exatidão e a precisão das normas nas categorias definidas no grupo "G d", cujos intervalos estão na Tabela 6.16.

A Figura 6.56 representa a precisão e exatidão dos modelos de norma, separadas nas três categorias do grupo " $G$ d".

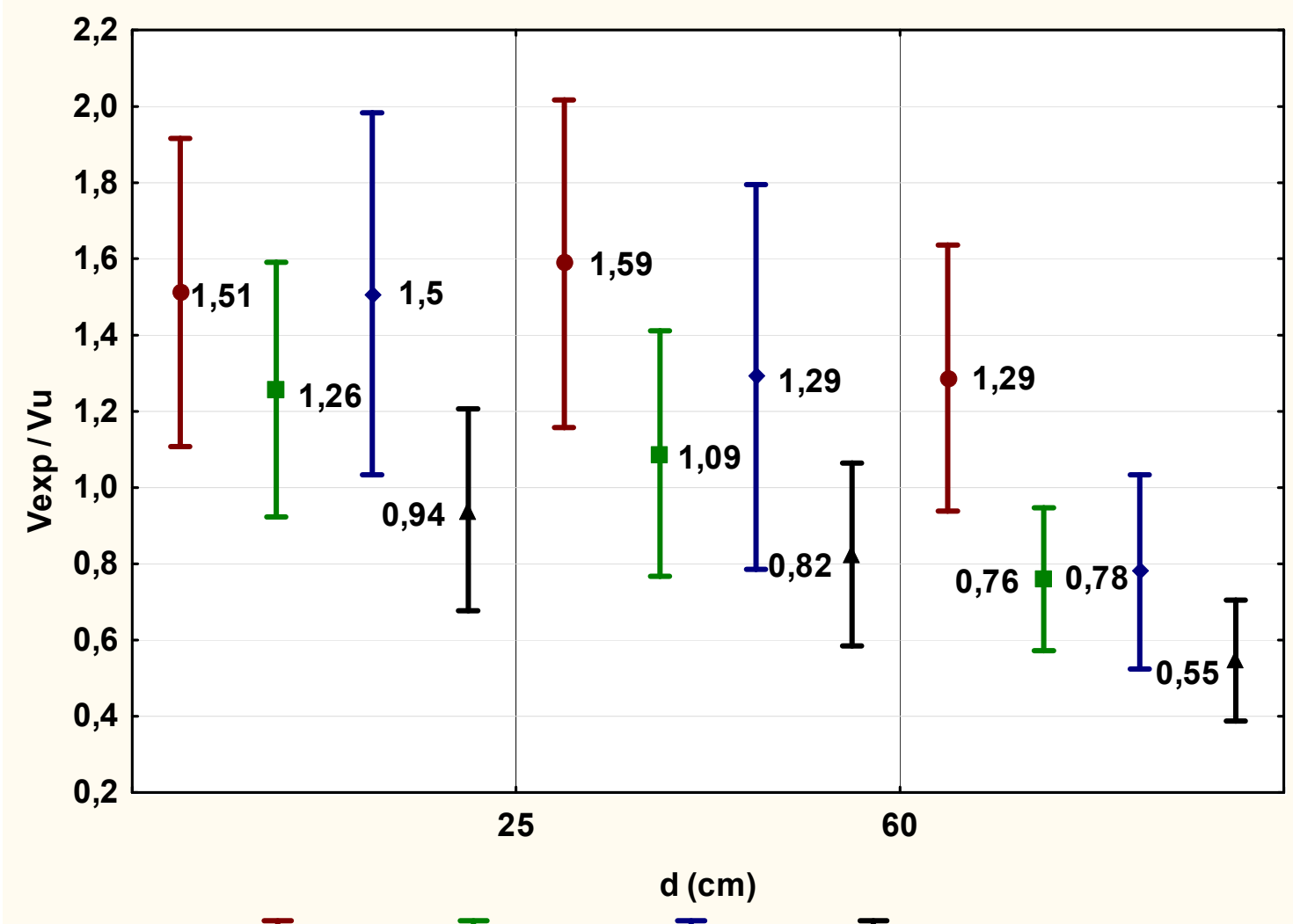

平 Exp / CSA 互 Exp / EURO 王 Exp / ACI 巫 Exp / NBR

Figura 6.56: Análise dos valores médios e desvio padrão entre as razões Vexp/Vu para as normas CSA, EURO, ACI e NBR, para elementos sem estribos e dados não válidos, separados em três intervalos de d

Para a primeira categoria, $d \leq 25 \mathrm{~cm}$, a norma NBR 6118 (2007) apresentou a melhor exatidão com média igual a 0,94 e em segundo lugar o Eurocode (2004) com 1,26, além disso o Eurocode (2004) também apresentou a melhor precisão, devido ao coeficiente de variação igual a $26,6 \%$. As normas CSA (2004) e ACl (2008) apresentar médias elevadas próximas de 1,5.

Para os dados da categoria 2, $25<d \leq 60 \mathrm{~cm}$, o Eurocode (2004) apresentou a melhor média, 1,09, e depois a NBR 6118 (2007), com média 0,82. Referente a 
precisão, as normas CSA (2004), Eurocode (2004) e NBR 6118 (2007) apresentaram coeficientes de variação semelhantes e próximos de $28 \%$.

$\mathrm{Na}$ terceira categoria, $d>60 \mathrm{~cm}$, a norma $\mathrm{ACl}$ (2008) apresentou a melhor exatidão, com média igual a 0,78 , porém consideravelmente distante do valor unitário. Em relação a precisão, nenhuma das normas apresentou resultado satisfatório, sendo o menor coeficiente de variação igual a $24,7 \%$ pertencente a norma Eurocode (2004).

Tabela 6.27: Medidas estatísticas dos valores de predição de norma, agrupados por d, dados não válidos e elementos sem estribos

\begin{tabular}{|c|c|c|c|c|c|}
\cline { 3 - 6 } \multicolumn{2}{c|}{} & \multicolumn{4}{c|}{ Categoria de "G d" } \\
\hline \multirow{3}{*}{ CSA } & Norma & $\mathbf{1 + 2 + 3}$ & $\mathbf{1}$ & $\mathbf{2}$ & $\mathbf{3}$ \\
\cline { 2 - 6 } & MEDIA & 1,473 & 1,511 & 1,587 & 1,287 \\
\cline { 2 - 6 } & COEF. VARIAÇÃO & 0,279 & 0,268 & 0,271 & 0,271 \\
\cline { 2 - 6 } & MEDIANA & 1,386 & 1,392 & 1,503 & 1,154 \\
\hline \multirow{3}{*}{ EURO } & MEDIA & 1,090 & 1,257 & 1,089 & 0,760 \\
\cline { 2 - 6 } & COEF. VARIAÇÃO & 0,323 & 0,266 & 0,296 & 0,247 \\
\cline { 2 - 6 } & MEDIANA & 1,043 & 1,233 & 1,056 & 0,643 \\
\hline \multirow{3}{*}{ ACI } & MEDIA & 1,185 & 1,508 & 1,290 & 0,779 \\
\cline { 2 - 6 } & COEF. VARIAÇÃO & 0,436 & 0,315 & 0,392 & 0,327 \\
\cline { 2 - 6 } & MEDIANA & 1,118 & 1,544 & 1,208 & 0,860 \\
\hline \multirow{3}{*}{ NBR } & MEDIA & 0,816 & 0,941 & 0,825 & 0,546 \\
\cline { 2 - 6 } & COEF. VARIAÇÃO & 0,337 & 0,281 & 0,291 & 0,290 \\
\cline { 2 - 6 } & MEDIANA & 0,795 & 0,911 & 0,793 & 0,490 \\
\hline
\end{tabular}

Aplicando os mesmos critérios de análise utilizados para os dados separados pelas diferentes categorias de taxas de armadura longitudinal de flexão, descritos anteriormente, resumiu-se as análises na Tabela 6.28.

Tabela 6.28: Resumo da análise de exatidão e precisão por intervalo de d, agrupados por d, dados não válidos e elementos sem estribos

\begin{tabular}{|l|c|c|c|}
\cline { 2 - 4 } \multicolumn{1}{c|}{} & \multicolumn{3}{c|}{ Categoria de $\mathrm{d}(\mathrm{cm})$} \\
\cline { 2 - 4 } \multicolumn{1}{c|}{} & $\mathrm{d} \leq \mathbf{2 5}$ & $\mathbf{2 5}<\mathrm{d} \leq \mathbf{6 0}$ & $\mathrm{d}>\mathbf{6 0}$ \\
\hline Melhor Exatidão & NBR & EURO & ACl/EURO \\
\hline Melhor Precisão & EURO/CSA & CSA & EURO \\
\hline
\end{tabular}

* Valores médios semelhantes

Unindo as informações da Tabela $6.26 \mathrm{com}$ a da Tabela 6.28, gerou-se a Tabela 6.29, que juntamente com as outras informações pode-se concluir que ao desrespeitar os intervalos válidos das normas para a máxima resistência a compressão do concreto, algumas normas apresentaram comportamentos preocupantes.

Tabela 6.29: Resumo da análise de exatidão e precisão, dados não válidos e elementos sem estribos

\begin{tabular}{|c|c|c|c|c|c|c|}
\hline & \multicolumn{3}{|c|}{ Categoria de pl (\%) } & \multicolumn{3}{|c|}{ Categoria de $\mathrm{d}(\mathrm{cm})$} \\
\hline & $\rho l \leq 1,5$ & $1,5<\rho \mid<3$ & $\rho l>3$ & $d \leq 25$ & $25<d \leq 60$ & $d>60$ \\
\hline Melhor Exatidão & $\overline{\mathrm{ACl}}$ & EURO & NBR & NBR & EURO & $\mathrm{ACl} / \mathrm{EURO}^{*}$ \\
\hline Melhor Precisão & $\overline{C S A}$ & $\overline{N B R}$ & NBR & EURO/CSA* & $\overline{C S A}$ & EURO \\
\hline
\end{tabular}

*Valores médios semelhantes 


\subsubsection{Análise da segurança das previsões dos modelos das normas com o uso dos resultados de ensaios e dados não válidos (fc > fc,máx)}

As comparações dos valores de predição de norma, com os resultados de ensaios que apresentaram o parâmetro de resistência do concreto fora das faixas consideradas válidas pelas normas, foram analisadas neste item. Esta parte de estudo não contempla a análise profunda nas diversas categorias de outros parâmetros como $\rho /$ ou $d$, como feito no item 6.6.3.2. De outra forma, uma análise simples destes dados permite ilustrar a importância de respeitar os limites de utilização das normas. Neste caso, os dados analisados extrapolaram a restrição de resistência máxima do concreto permitida. Ainda assim, esta análise é importante ao se imaginar uma retroanálise de uma estrutura existente que teria outra utilização, diferente da originalmente projetada, mas ao medir a resistência do concreto, verifica-se um elevado valor, em relação a resistência de projeto.

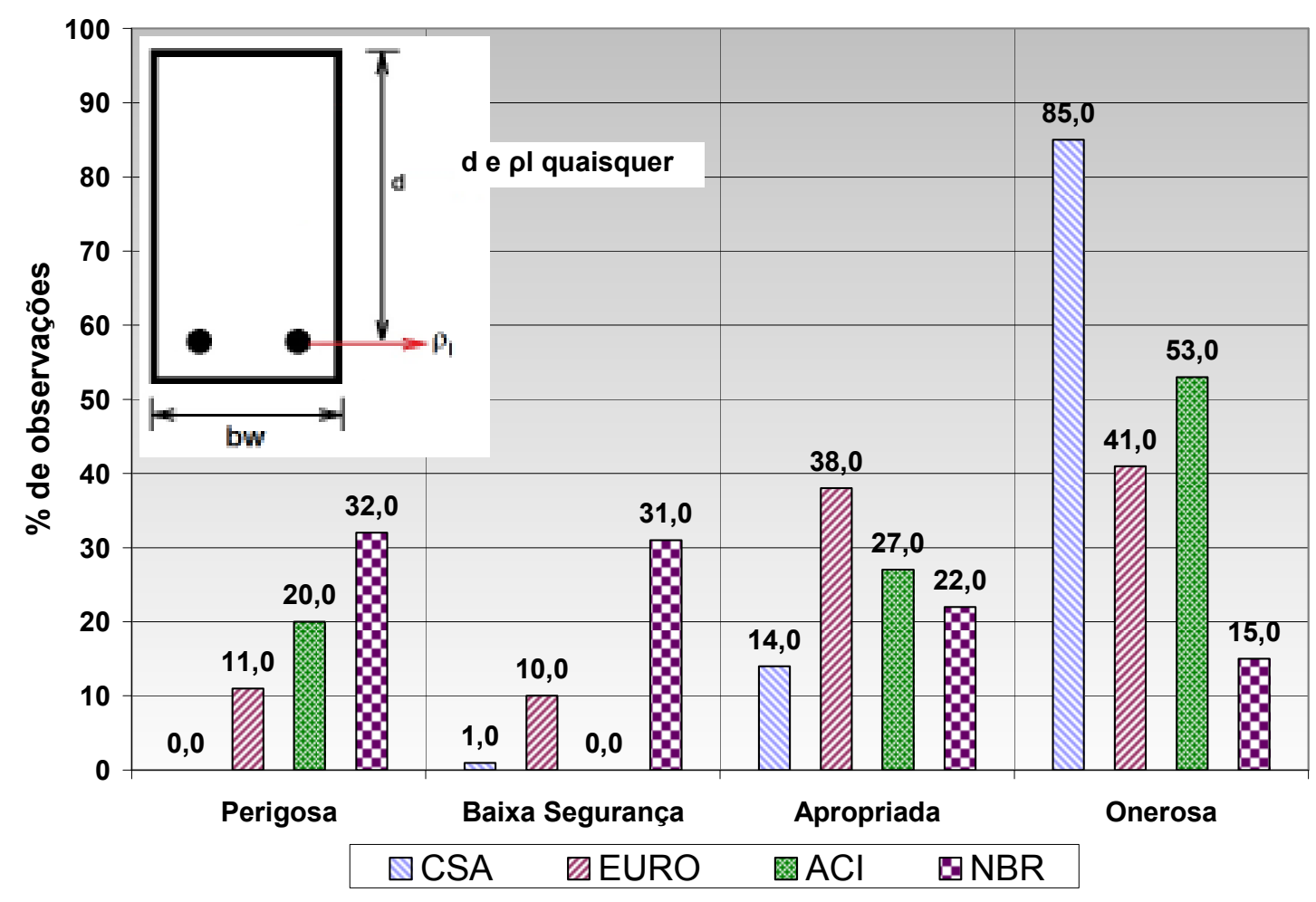

Figura 6.57: Análise dos dados considerados não validos, para valores de resistência do concreto acima da máxima permitida, para elementos sem estribos

A Figura 6.57 ilustra que todas as normas, exceto a CSA (2004) apresentaram elevadas porcentagens de casos perigosos, o que indica certa preocupação ao utilizar as formulações de norma fora de suas faixas de validade. Particularmente a norma CSA (2004) apresentou porcentagem nula de ruína, apenas um caso de baixa segurança e $85 \%$ dos casos considerados com segurança elevada, ou onerosos. Neste caso confirma-se também o caráter conservador da norma, porém mostra que o uso dela, em condições que extrapolem os limites estabelecidos, apresentará valores de predição seguros. Para melhor compreender a segurança dos modelos de predição das normas 
nas 6 categorias de $\rho /$ e $d$, foram elaborados os gráficos de barras para cada caso.

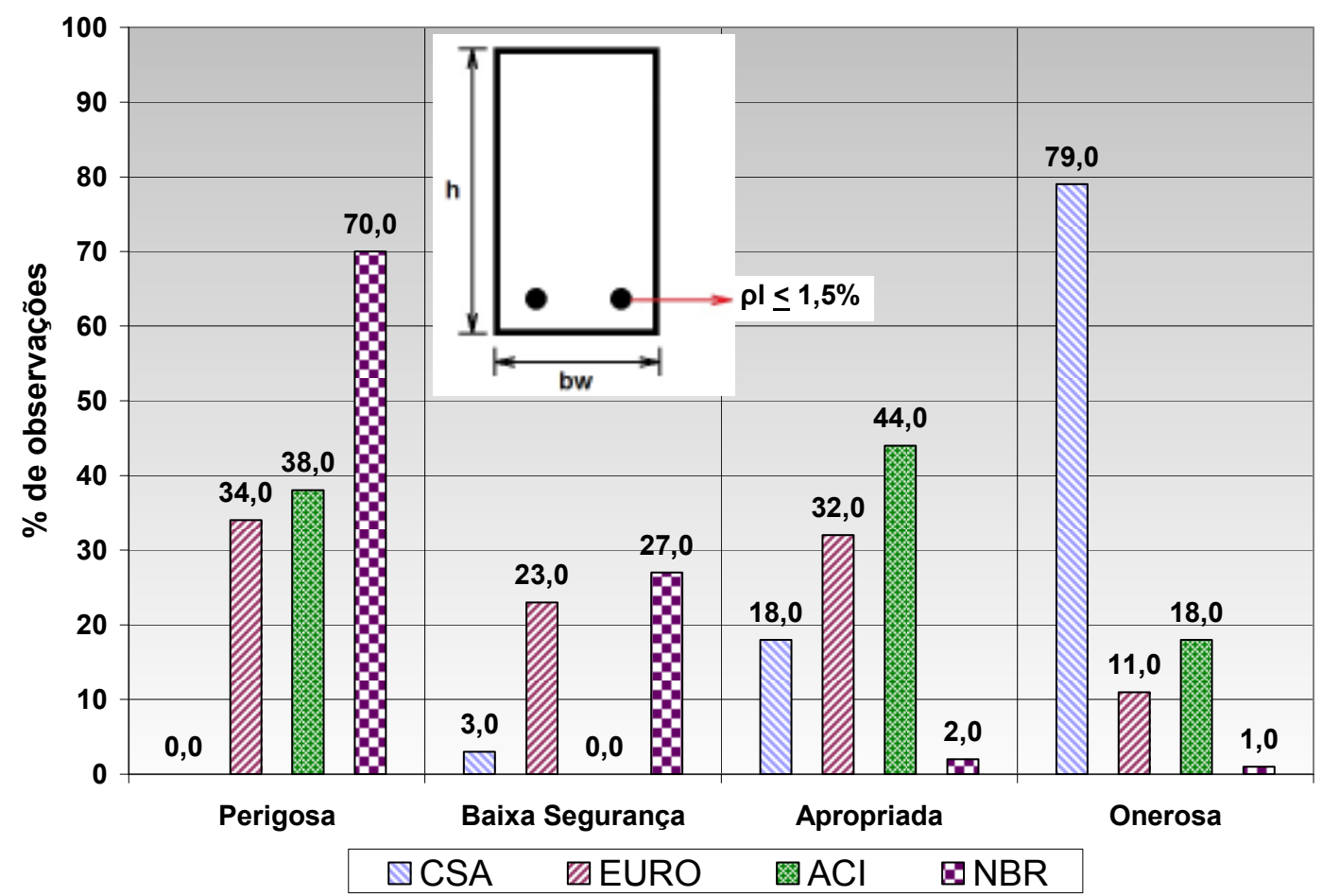

Figura 6.58: Análise da segurança para $\mathrm{\rho l}<1,5 \%$, dados não válidos e elementos sem estribos

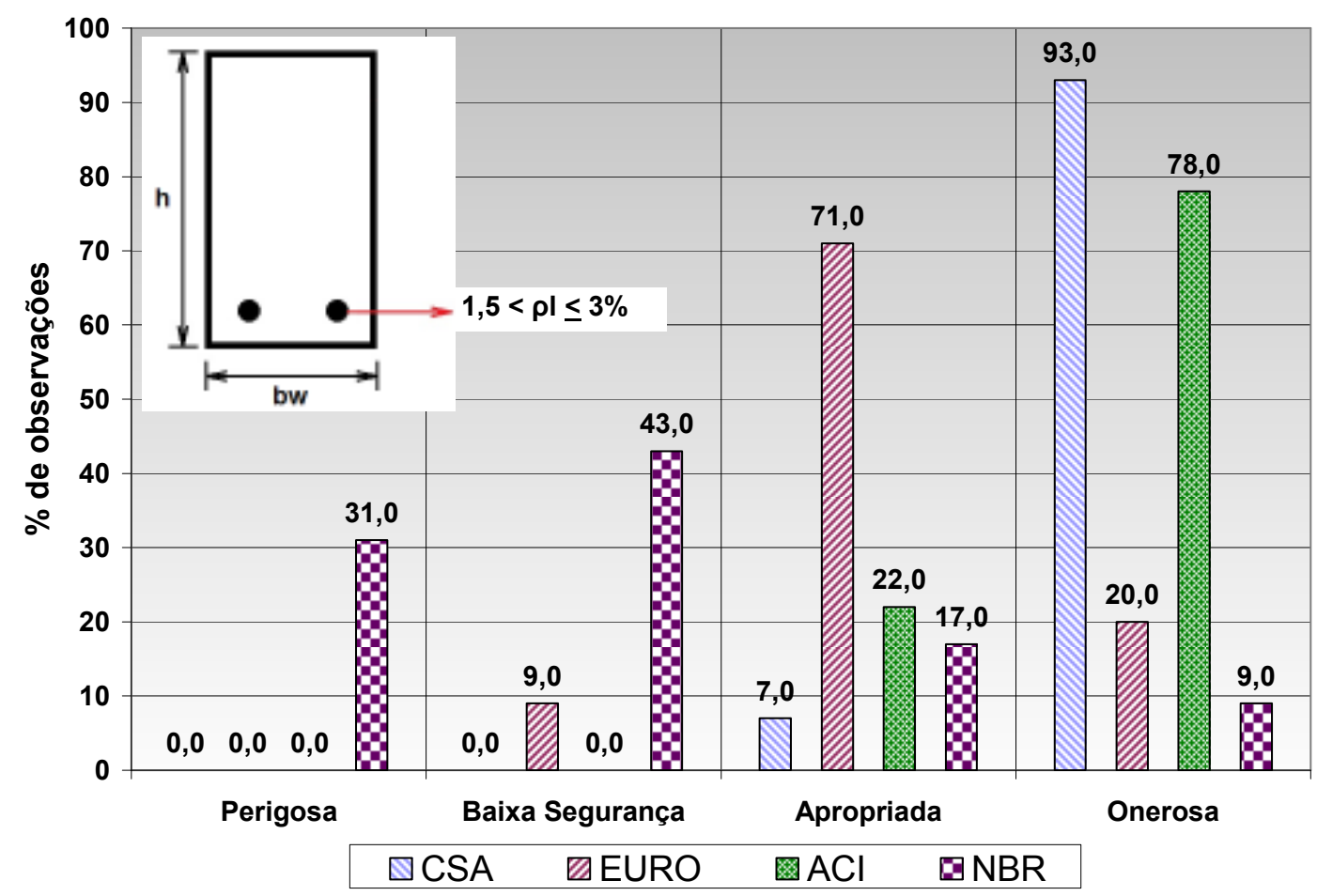

Figura 6.59: Análise da segurança para $1,5<\rho \mathrm{\rho} \leq 3 \%$, dados não válidos e elementos sem estribos 
Para a categoria de $\rho l \leq 1,5 \%$ nota-se que todas as normas mostram-se inadequadas, por apresentarem porcentagem significativa de previsões consideradas perigosas, exceto a norma CSA (2004), que apesar de apresentar $79 \%$ das previsões consideradas onerosas, não apresentou nenhum caso de predição perigosa.

Analisando a categoria de $1,5 \rho l \leq 3,0 \%$, todas as normas, exceto a NBR 6118 (2007) apresentaram porcentagens nulas de previsões perigosas, e destaca-se a norma Eurocode (2004) com grande porcentagem de valores considerados adequados e baixa porcentagem de previsões com baixa segurança, $9 \%$, sendo necessário cautela para o seu uso. A norma CSA (2004) apresentou 93 $\%$ dos casos de predição considerados onerosos, desta forma, em relação a critérios de custos, será necessário cautela para a sua utilização.

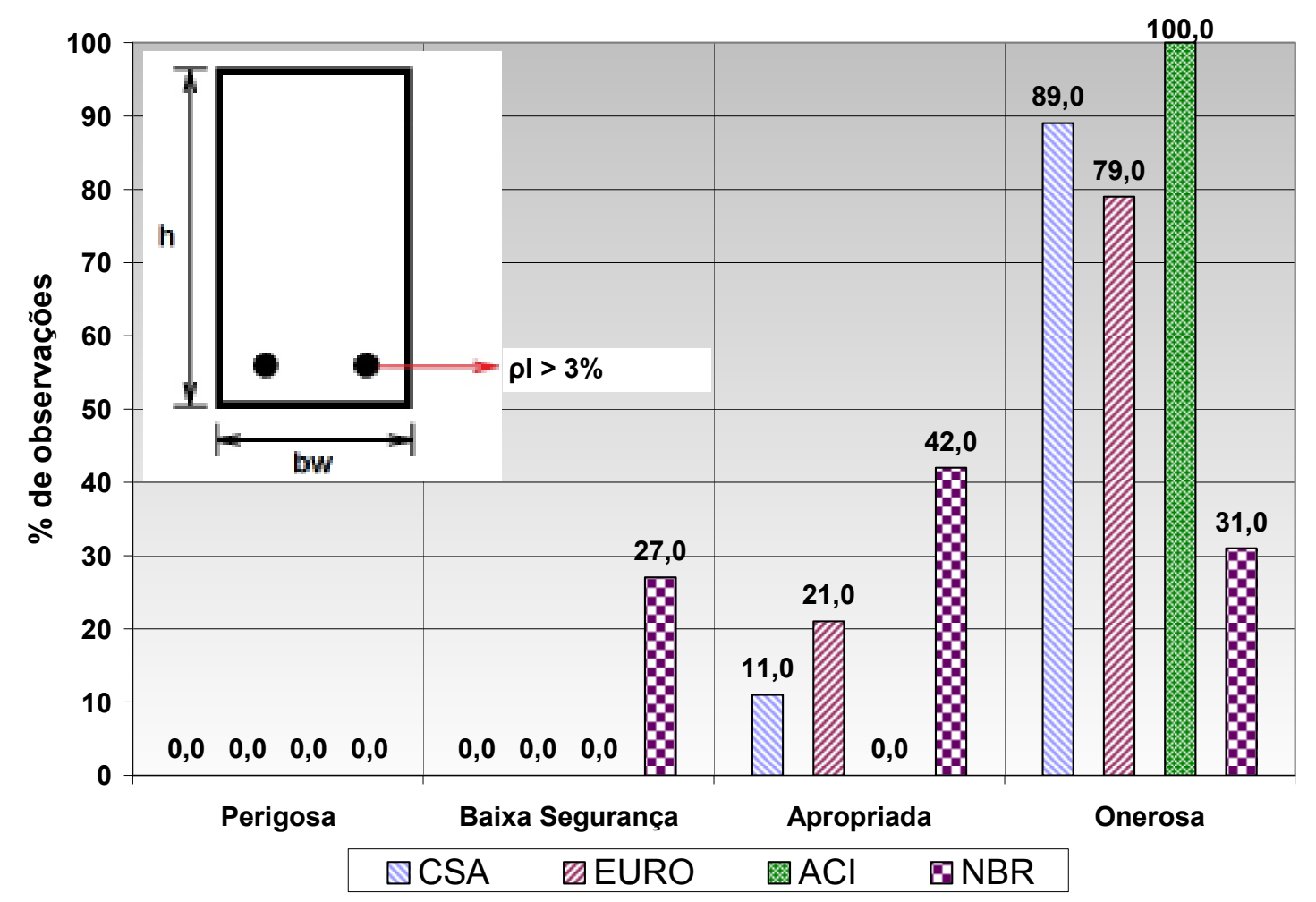

Figura 6.60: Análise da segurança para $\rho \mathrm{l}>3 \%$, dados não válidos e elementos sem estribos

A Figura 6.60 , ilustra a categoria $3, \rho l>3 \%$, e nota-se os comportamentos seguros e onerosos das diversas normas, com porcentagens elevadas de dados onerosos e nulas para os casos perigosos, exceto para a norma NBR 6118 (2007) que apresentou apenas $31 \%$ dos casos considerados onerosos, e $27 \%$ dos casos com coeficientes de segurança reduzidos. Analisando apenas os dados referentes aos $27 \%$ de casos de baixa segurança, verifica-se que o uso desta norma deve ocorrer com cautela.

A Análise da primeira categoria do grupo " $G \mathrm{~d}$ ", $d \leq 25 \mathrm{~cm}$ (Figura 6.61), permite avaliar que apenas a norma NBR 6118 (2007) apresentou uma porcentagem significativa de previsões perigosas. As normas CSA (2004) e $\mathrm{ACl}$ (2008) apresentaram mais de $75 \%$ das previsões onerosas. A Norma 
Eurocode (2004) apresentou $32 \%$ das previsões consideradas apropriadas, mas apresentou $2 \%$ das previsões perigosas, não sendo assim, recomendada. A norma $\mathrm{ACl}(2008)$ apresentou porcentagens de $25 \%$ para casos adequados e $75 \%$ para casos onerosos, podendo esta ser a mais recomendada, apesar da porcentagem elevada para casos onerosos.

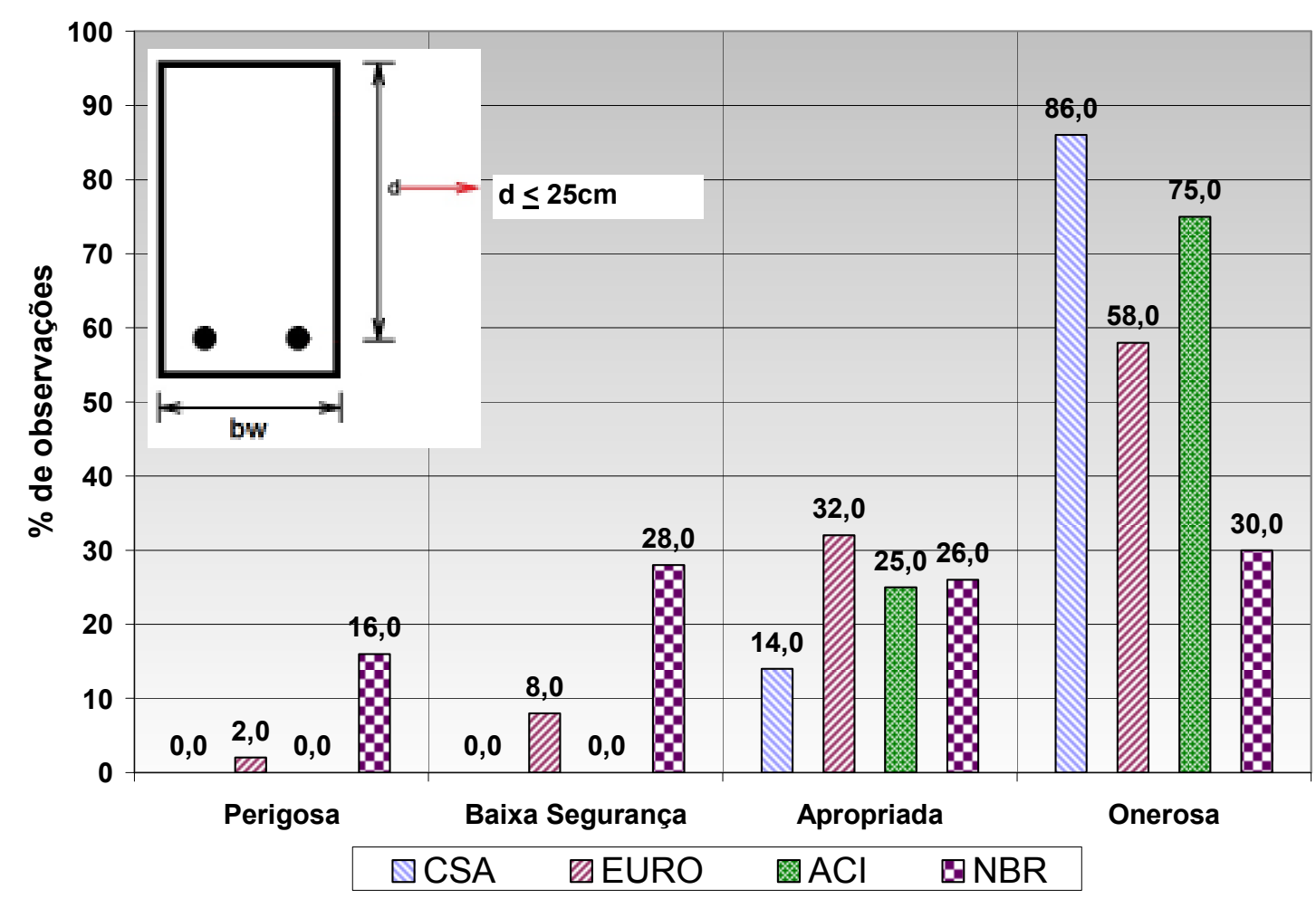

Figura 6.61: Análise da segurança para $\mathrm{d} \leq 25 \mathrm{~cm}$, dados não válidos e elementos sem estribos

Para $25<d \leq 60 \mathrm{~cm}$, as normas Eurocode (2004), ACl (2008) e NBR 6118 (2007) apresentaram porcentagens não aceitáveis de prováveis ruínas, tornando inapropriadas. A norma CSA (2008) apresentou $96 \%$ das provisões onerosas e porcentagens nulas para os casos de baixa segurança e perigoso. A norma Eurocode (2004) apresentou um valor não aceitável de $2 \%$ para as previsões não seguras, apesar de bons resultados para os casos de segurança apropriada e onerosa, $45 \%$ e $39 \%$ respectivamente. 


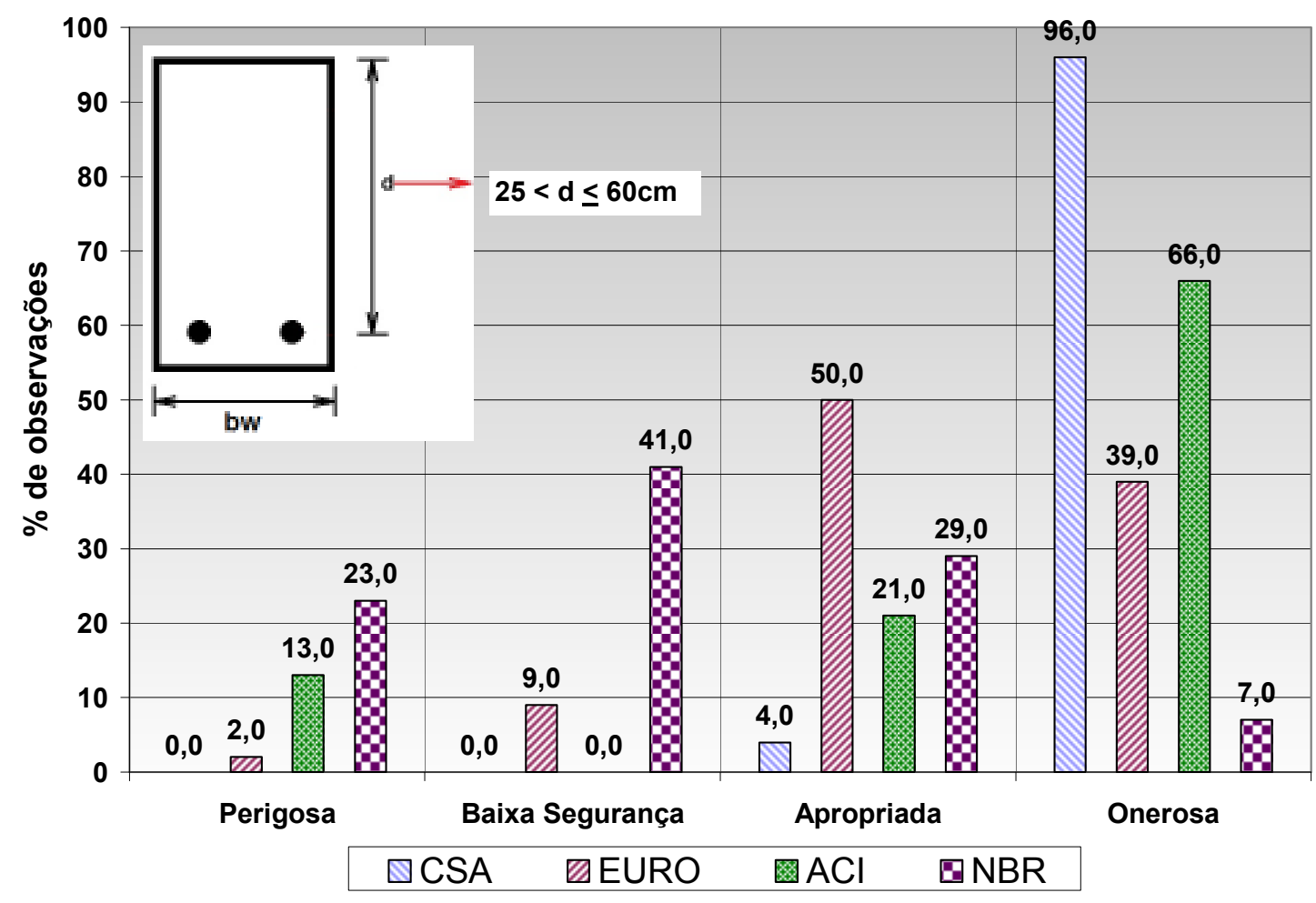

Figura 6.62: Análise da segurança para $25<\mathrm{d} \leq 60 \mathrm{~cm}$, dados não válidos e elementos sem estribos

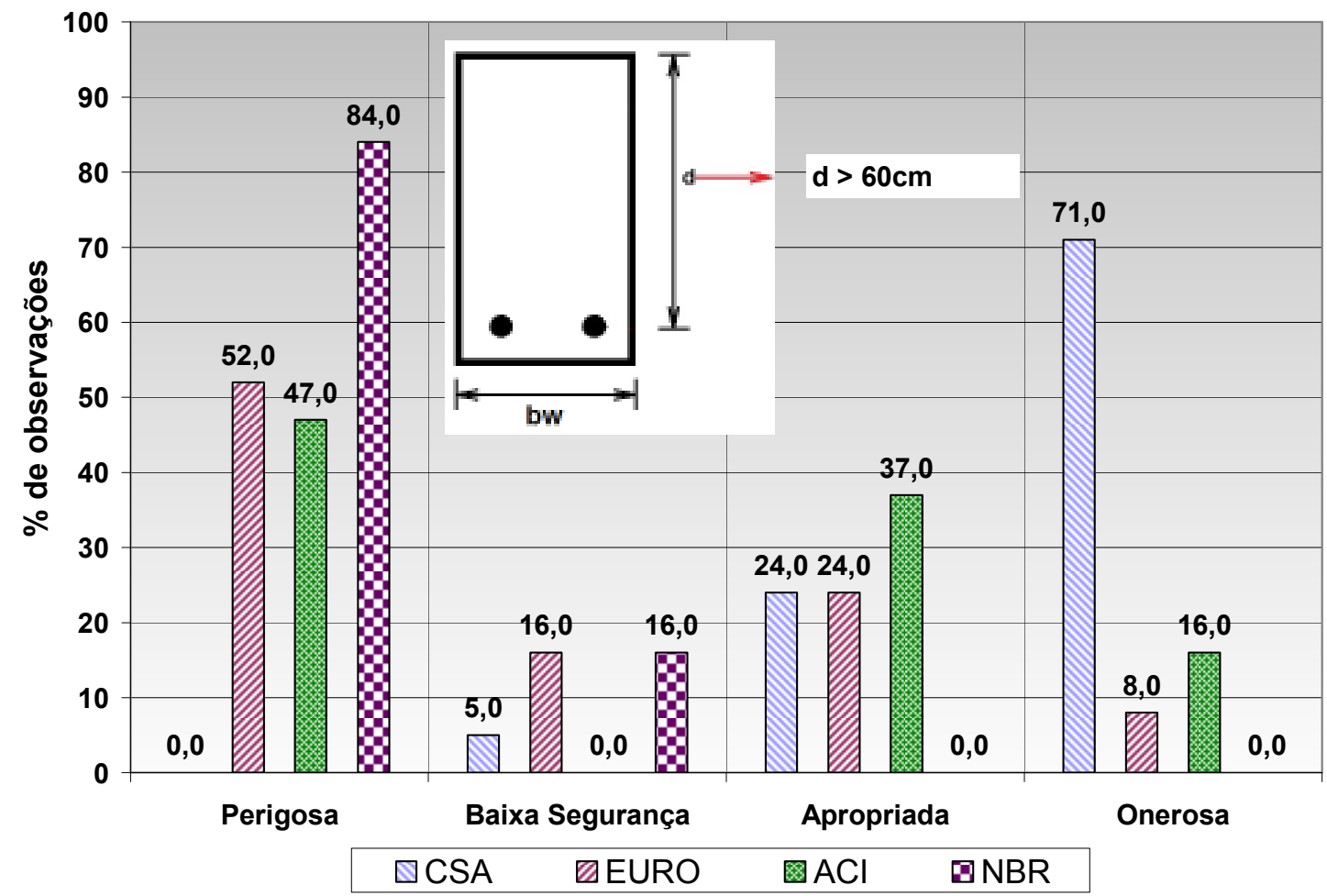

Figura 6.63: Análise da segurança para $d>60 \mathrm{~cm}$, dados não válidos e elementos sem estribos 
A análise relacionada com a utilização de peças de grandes dimensões $(d>60$ $\mathrm{cm}$ ) está ilustrada na Figura 6.63, na qual se analisou uma pequena quantidade de ensaios (14 a 25 ensaios por norma), porém pode-se concluir que todas as normas, exceto a CSA (2004), não são adequadas neste intervalo, pois apresentam porcentagens de prováveis ruínas elevadas.

Para ajudar na análise e determinação das normas mais adequadas para cada categoria, aplicou-se o critério de classificação segundo a atribuição dos pontos de deméritos e elaborou-se a Tabela 6.30 .

Tabela 6.30: Classificação pelo critério de pontos de deméritos (sem estribos e dados não válidos)

\begin{tabular}{|c|c|c|c|c|c|c|c|c|c|}
\hline & \multicolumn{9}{|c|}{ Categoria de $\mathrm{pl}(\%)$} \\
\hline & \multicolumn{3}{|c|}{$\rho \mid<1,5$} & \multicolumn{3}{|c|}{$1,5<\rho \mid<3$} & \multicolumn{3}{|c|}{$\rho \mathrm{\rho l}>3$} \\
\hline Norma & $\begin{array}{c}\begin{array}{c}\mathbf{N}^{\circ} \\
\text { ensaios }\end{array} \\
\text { s. }\end{array}$ & Ptos & Média & $\mathbf{N}^{\circ}$ ensaios & Ptos & Média & $\mathbf{N}^{\circ}$ ensaios & Ptos & Média \\
\hline CSA & 33 & 54 & 1,6 & 14 & 26 & 1,9 & 27 & 48 & 1,8 \\
\hline EURO & 44 & 180 & 4,1 & 35 & 20 & 0,6 & 52 & 82 & 1,6 \\
\hline$\overline{\mathrm{ACl}}$ & 32 & 132 & 4,1 & 9 & 14 & 1,6 & 18 & 36 & 2,0 \\
\hline NBR & 44 & 334 & $\overline{7,6}$ & 35 & 146 & 4,2 & 52 & 60 & 1,2 \\
\hline
\end{tabular}

\begin{tabular}{|c|c|c|c|c|c|c|c|c|c|}
\hline \multirow[b]{3}{*}{ Norma } & \multicolumn{9}{|c|}{ Categoria de $\mathrm{d}(\mathrm{cm})$} \\
\hline & \multicolumn{3}{|c|}{$d<25$} & \multicolumn{3}{|c|}{$25<d<60$} & \multicolumn{3}{|c|}{$d>60$} \\
\hline & $\begin{array}{c}\mathrm{N}^{\circ} \\
\text { ensaios }\end{array}$ & Ptos & Média & $N^{\circ}$ ensaios & Ptos & Média & $N^{0}$ ensaios & Ptos & Média \\
\hline CSA & 28 & 48 & 1,7 & 25 & 48 & 1,9 & 21 & 32 & 1,5 \\
\hline EURO & 50 & 76 & 1,5 & 56 & 64 & 1,1 & 25 & 142 & 5,7 \\
\hline $\mathrm{ACI}$ & 16 & 24 & 1,5 & 24 & 62 & 2,6 & 19 & 96 & 5,1 \\
\hline NBR & 50 & 138 & 2,8 & 56 & 184 & 3,3 & 25 & 218 & 8,7 \\
\hline
\end{tabular}

Tabela 6.31: Resumo da análise de segurança, dados não válidos e elementos sem estribos

\begin{tabular}{|c|c|c|c|c|c|c|}
\hline & \multicolumn{3}{|c|}{ Categoria de pl (\%) } & \multicolumn{3}{|c|}{ Categoria de $\mathrm{d}(\mathrm{cm})$} \\
\hline & $\rho \mid \leq 1,5$ & $1,5<\rho \mid \leq 3$ & $\rho \mid>3$ & $d \leq 25$ & $25<d \leq 60$ & $d>60$ \\
\hline Maior Insegurança & NBR & NBR & - & NBR & NBR & NBR \\
\hline Maior Custo & $\overline{C S A}$ & $\overline{C S A} / \mathrm{ACl}^{*}$ & $\mathrm{ACl}$ & CSA & $\overline{C S A}$ & CSA \\
\hline Norma mais Adequada & $\overline{C S A}$ & EURO ${ }^{\mathrm{a}} / \mathrm{ACl}$ & NBRª/EURO & $\overline{\mathrm{ACl}}$ & $\overline{C S A}$ & $\mathrm{CSA}^{a}$ \\
\hline
\end{tabular}

* Valores médios semelhantes entre ambas as normas

a Segurança reduzido, é necessário cautela

Por fim, a Tabela 6.31 resume a análise de segurança de uso das normas para valores de resistência do concreto fora dos intervalos válidos por cada norma. A norma NBR 6118 (2007) apresentou-se inadequada para prever a força cisalhante resistente em diversas categorias dos parâmetros $\rho /$ e $d$, exceto para $\rho />3 \%$, que mostrou ser apropriada, desde que utilizada com cautela. De forma geral, a norma CSA (2004) indicou resultados de predição onerosos ou com maior segurança, podendo se tornar apropriada para uso, dependendo das condições de utilização e finalidade. Em alguns casos, conforme indicado na última linha da Tabela 6.31, as normas Eurocode (2004) e ACl (2008) 
apresentaram resultados satisfatórios, podendo ser utilizado na maioria dos casos.

\subsection{Análise de vigas armadas ao cisalhamento com estribos e ruptura por esmagamento do concreto}

Elementos de concreto armado, reforçados com estribos podem ter seu estado limite último de compressão excedido, principalmente para elementos com altas taxas mecânicas de armadura de cisalhamento.

Desta forma coletaram-se dados de ensaios que claramente indicavam a ruptura dos elementos por esgotamento do concreto da biela de compressão, de forma a possibilitar a análise do comportamento dos modelos de predição das normas quando à verificação do estado limite último de compressão.

\subsubsection{Banco de dados utilizado}

O banco de dados utilizado está apresentado na Tabela 6.32. Pode-se notar que as peças tiveram altas taxas mecânicas de estribos, de forma a proporcionar a ruptura por esmagamento do concreto. Os ensaios foram executados em elementos com estribos, carregados perpendicularmente ao eixo principal, armados a flexão e apresentaram ruptura por esmagamento do concreto.

Devido ao número de ensaios serem apenas 20 , a análise feita teve um caráter mais qualitativo, indicando apenas o comportamento das normas frente a variação da resistência do concreto, pois este é o parâmetros principal para a determinação da resistência última da peça, quando solicitada por esforços cortantes. 
Tabela 6.32: Banco de dados para ruptura por esmagamento do concreto

\begin{tabular}{|c|c|c|c|c|c|c|c|c|}
\hline Autor & $\mathrm{d}(\mathrm{cm})$ & fc (MPa) & pl \% & $a / d$ & $\begin{array}{c}\text { Tau Exp } \\
\text { (MPa) }\end{array}$ & psw \% & $\begin{array}{l}\text { psw.fyk } \\
\text { (MPa) }\end{array}$ & $V k(k N) \operatorname{Exp}$ \\
\hline $\begin{array}{l}\text { Placas e Regan } \\
\text { (1971) }\end{array}$ & 25,40 & 29,86 & 1,25 & 3,40 & 9,93 & 2,16 & 13,404 & 160,1 \\
\hline $\begin{array}{l}\text { Placas e Regan } \\
\text { (1971) }\end{array}$ & 25,40 & 12,62 & 1,46 & 3,40 & 5,57 & 2,16 & 13,404 & 89,9 \\
\hline $\begin{array}{l}\text { Placas e Regan } \\
(1971)\end{array}$ & 25,40 & 45,54 & 1,46 & 3,40 & 12,36 & 2,16 & 13,404 & 199,3 \\
\hline $\begin{array}{l}\text { Placas e Regan } \\
(1971)\end{array}$ & 25,40 & 34,27 & 1,46 & 3,40 & 11,75 & 3,25 & 20,168 & 189,5 \\
\hline $\begin{array}{l}\text { Placas e Regan } \\
(1971)\end{array}$ & 25,40 & 33,92 & 4,16 & 3,40 & 9,60 & 2,16 & 13,404 & 154,8 \\
\hline $\begin{array}{l}\text { Placas e Regan } \\
(1971)\end{array}$ & 25,40 & 34,34 & 3,00 & 3,40 & 10,04 & 2,09 & 12,969 & 161,9 \\
\hline $\begin{array}{l}\text { Haddadin, Hong e } \\
\text { Mattock (1971) }\end{array}$ & 38,10 & 13,41 & 3,81 & 2,50 & 3,71 & 0,76 & 3,909 & 251,3 \\
\hline $\begin{array}{l}\text { Haddadin, Hong e } \\
\text { Mattock (1971) }\end{array}$ & 38,10 & 17,07 & 3,81 & 2,50 & 4,54 & 1,21 & 6,260 & 307,3 \\
\hline $\begin{array}{l}\text { Haddadin, Hong e } \\
\text { Mattock (1971) }\end{array}$ & 38,10 & 25,65 & 3,81 & 2,50 & 5,75 & 1,73 & 8,957 & 389,5 \\
\hline $\begin{array}{l}\text { Haddadin, Hong e } \\
\text { Mattock (1971) } \\
\end{array}$ & 38,10 & 25,72 & 3,81 & 4,25 & 4,59 & 0,76 & 3,909 & 310,6 \\
\hline \begin{tabular}{|l|} 
Haddadin, Hong e \\
Mattock (1971) \\
\end{tabular} & 38,10 & 26,13 & 3,81 & 2,50 & 6,32 & 1,05 & 5,432 & 427,8 \\
\hline \begin{tabular}{|l|} 
Haddadin, Hong e \\
Mattock (1971) \\
\end{tabular} & 38,10 & 26,30 & 3,81 & 2,50 & 5,72 & 1,21 & 6,260 & 387,2 \\
\hline $\begin{array}{l}\text { Haddadin, Hong e } \\
\text { Mattock (1971) }\end{array}$ & 38,10 & 26,75 & 3,81 & 2,50 & 5,66 & 0,63 & 3,261 & 383,5 \\
\hline $\begin{array}{l}\text { Haddadin, Hong e } \\
\text { Mattock (1971) }\end{array}$ & 38,10 & 28,58 & 3,81 & 2,50 & 5,05 & 0,76 & 3,909 & 342,4 \\
\hline $\begin{array}{l}\text { Haddadin, Hong e } \\
\text { Mattock (1971) }\end{array}$ & 38,10 & 30,44 & 3,81 & 4,25 & 5,29 & 1,21 & 6,260 & 358,3 \\
\hline $\begin{array}{l}\text { Haddadin, Hong e } \\
\text { Mattock (1971) }\end{array}$ & 38,10 & 32,54 & 3,81 & 2,50 & 6,40 & 1,21 & 6,260 & 433,4 \\
\hline Rangan (1991) & 56,30 & 36,50 & 8,35 & 2,49 & 10,88 & 2,72 & 12,376 & 453,1 \\
\hline Rangan (1991) & 56,30 & 30,20 & 8,35 & 2,49 & 8,90 & 1,53 & 6,962 & 371,0 \\
\hline Rangan (1991) & 56,30 & 31,20 & 9,81 & 2,49 & 10,41 & 3,19 & 14,515 & 369,1 \\
\hline Rangan (1991) & 56,30 & 35,70 & 9,66 & 2,49 & 11,55 & 1,77 & 8,054 & 416,0 \\
\hline Total $=20$ ensaios & $25,4-56,3$ & $12,6-45,5$ & $1,3-9,8$ & $2,5-4,3$ & $3,7-12,4$ & $0,6-3,3$ & $3,3-20,2$ & $89,9-453,1$ \\
\hline
\end{tabular}

\subsubsection{Análise dos valores de predição de norma}

A Figura 6.64 apresenta a correlação entre os resultados de ensaios e os parâmetros principais mensurados por cada autor. No eixo da ordenadas está indicada a tensão de cisalhamento do experimento, $\tau_{\text {exp }}$, sendo definida pela divisão entre a força resistente última, $V_{\text {exp }}$, pela área útil da peça, $b_{w}$.d. Podese verificar que o aumento da resistência do concreto está intimamente relacionada com o aumento da tensão cisalhante resistente. Para os outros parâmetros não é possível verificar nenhuma correlação, exceto para o caso da taxa mecânica de estribos, pois obviamente, deve-se aumentá-la para possibilitar que o esgotamento da capacidade suporte da peça se dê pelo esgotamento da resistência a compressão do concreto. 


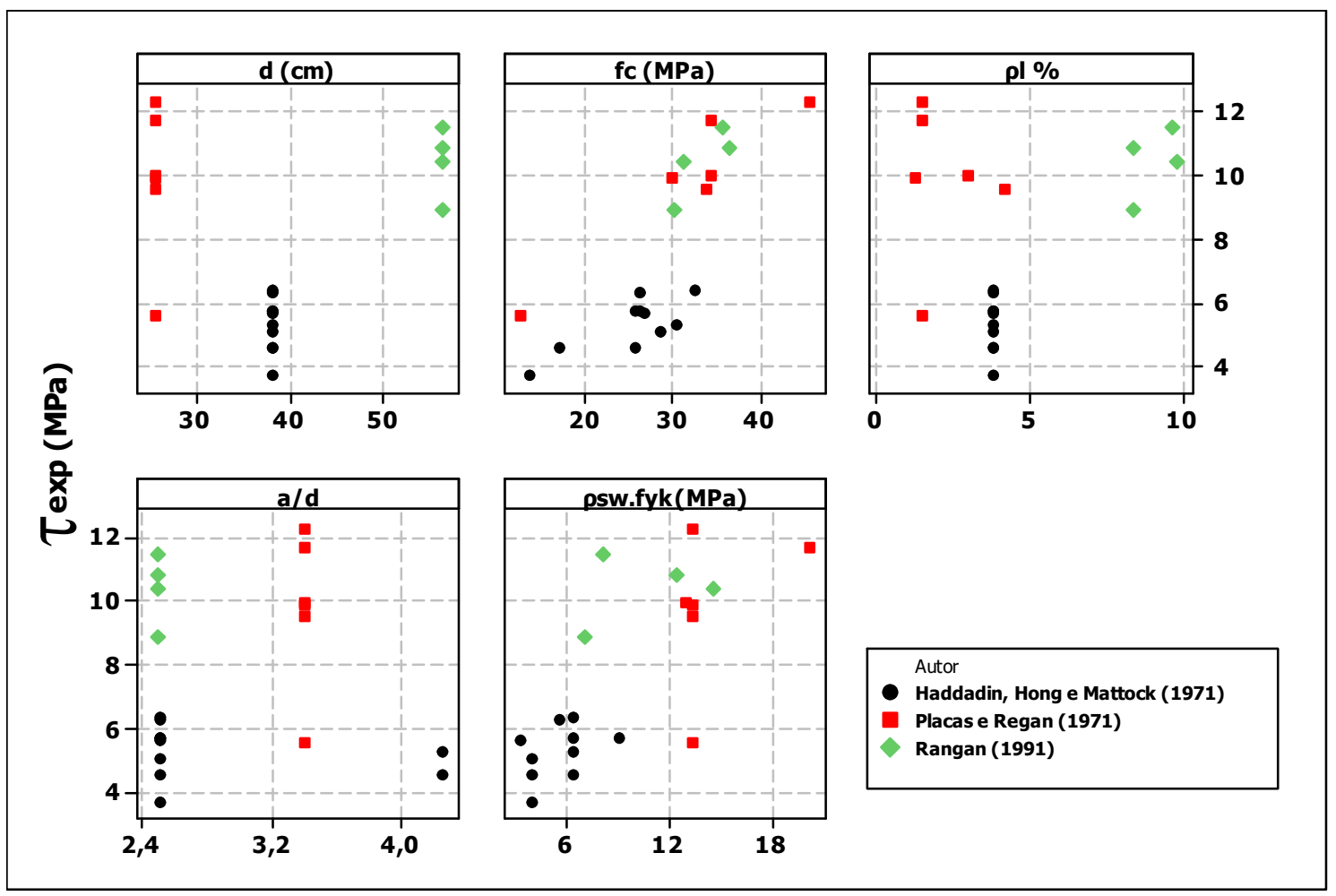

Figura 6.64: Correlação entre parâmetros de ensaios e tensão cisalhante resistente experimental, para elementos com estribos e ruptura por esmagamento, segundo os autores, sendo: d - Altura do elemento; fc - Resistência do concreto; $\rho$ - Taxa geométrica de armadura de flexão; a/d - Índice de esbeltez e psw.fyk - Taxa mecânica de estribos

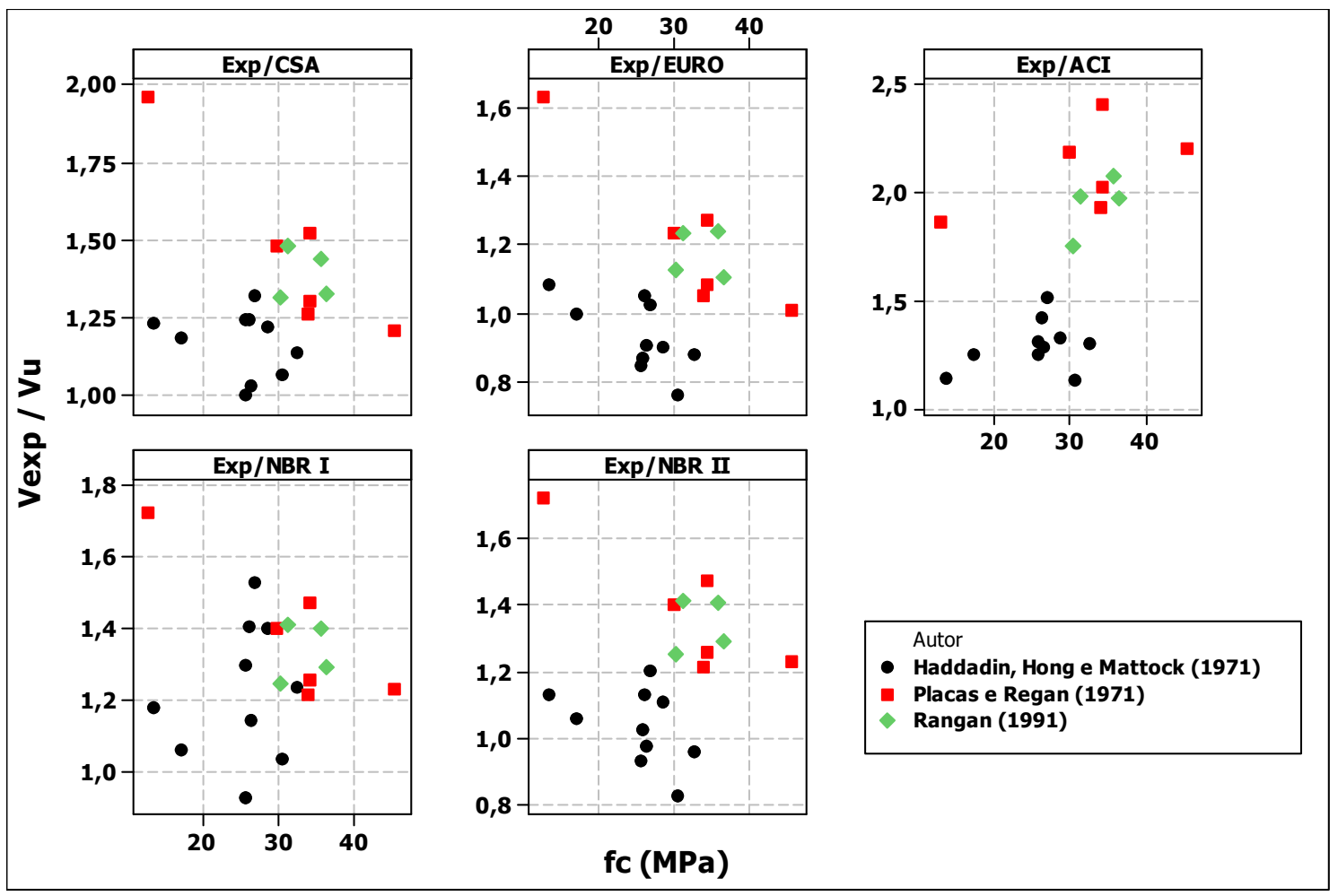

Figura 6.65: Correlação entre as razões $\operatorname{Vexp} / \mathrm{Vu}$, para as normas CSA, EURO, ACI, modelo I na NBR e modelo II da NBR, conforme a variação da resistência do concreto, para elementos com estribos e com ruptura por esmagamento do concreto 
Baseado nas figuras apresentadas verifica-se que todas as normas apresentaram valores de predição menos seguros para os ensaios de Haddadin, Hong e Mattock (1971), que são caracterizados por uma menor taxa mecânica de armadura transversal (estribos). Este fato deverá ser analisado em pesquisas futuras com a elaboração de ensaios específicos, de forma a ter uma melhor representação estatística do fenômeno.

Os resultados de ensaios foram comparados com os resultados de predição de norma, e as medidas estatísticas obtidas estão contempladas na Tabela 6.33.

$\mathrm{Na}$ Tabela 6.33, verifica-se que a norma Eurocode (2004) apresentou a melhor exatidão nos valores de predição, com uma média igual a 1,063. O modelo I da norma NBR 6118 (2007) apresentou o menor coeficiente de variação $(0,143)$, indicando uma boa precisão. A norma ACl (2004) apresentou valores relativamente altos para exatidão e precisão, ou seja, média e coeficiente de variação.

Tabela 6.33: Medidas estatísticas dos valores de predição de norma, para elementos com ruptura por esmagamento do concreto

\begin{tabular}{|c|c|c|}
\hline Norma & \multicolumn{2}{|c|}{ Medidas Estatísticas } \\
\hline \multirow{3}{*}{ CSA } & MEDIA & 1,297 \\
\cline { 2 - 3 } & COEF. VARIAÇÃO & 0,165 \\
\cline { 2 - 3 } & MEDIANA & 1,250 \\
\hline \multirow{3}{*}{ EURO } & MEDIA & 1,063 \\
\cline { 2 - 3 } & COEF. VARIAÇÃO & 0,186 \\
\cline { 2 - 3 } & MEDIANA & 1,048 \\
\hline \multirow{3}{*}{ ACI } & MEDIA & 1,665 \\
\cline { 2 - 3 } & COEF. VARIAÇÃO & 0,249 \\
\cline { 2 - 3 } & MEDIANA & 1,635 \\
\hline \multirow{3}{*}{ NBR I } & MEDIA & 1,291 \\
\cline { 2 - 3 } & COEF. VARIAÇÃO & 0,143 \\
\cline { 2 - 3 } & MEDIANA & 1,274 \\
\hline \multirow{3}{*}{ NBR II } & MEDIA & 1,200 \\
\cline { 2 - 3 } & COEF. VARIAÇÃO & 0,179 \\
\cline { 2 - 3 } & MEDIANA & 1,208 \\
\hline
\end{tabular}




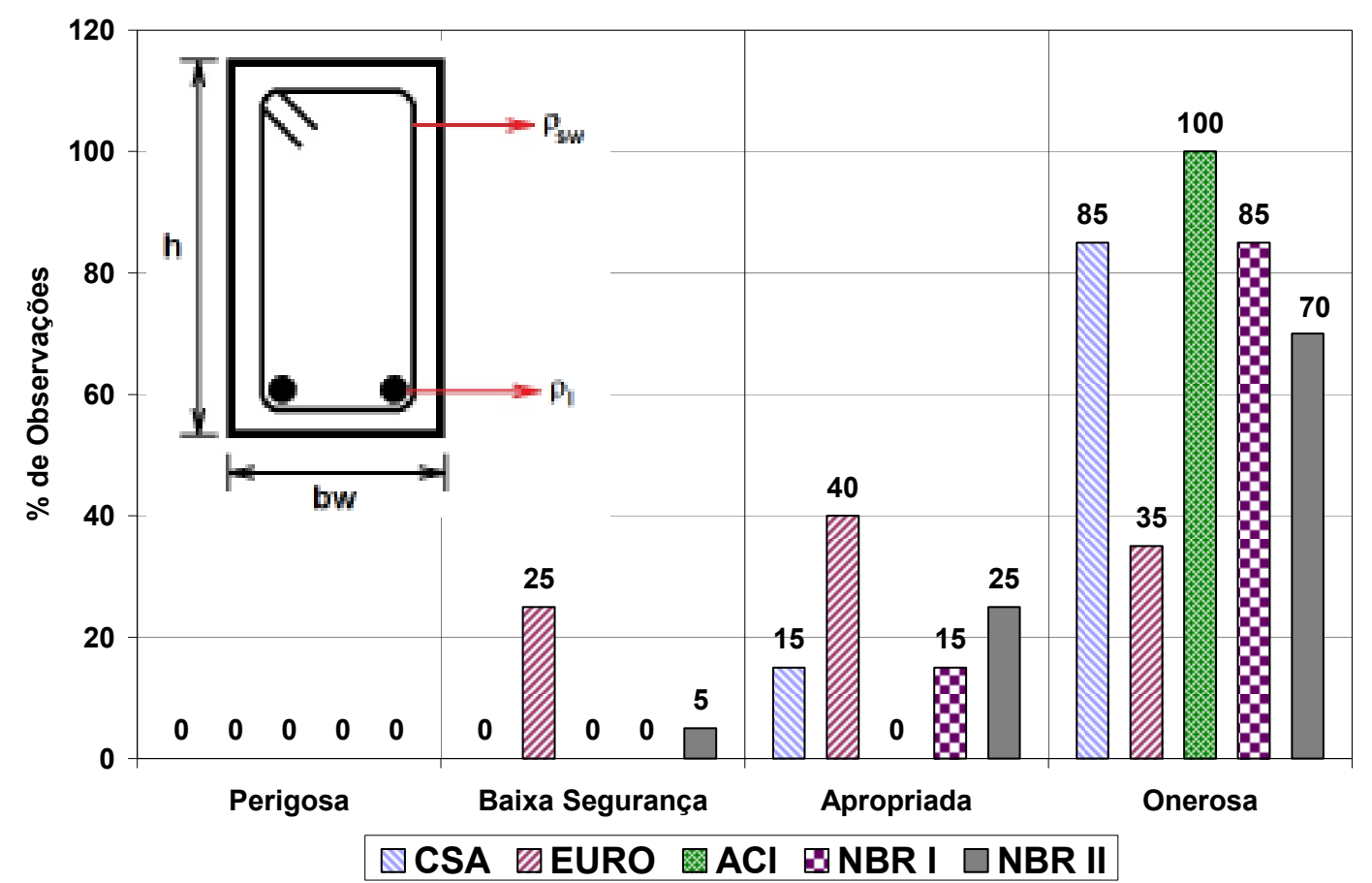

Figura 6.66: Análise da segurança para casos de ruptura por esmagamento do concreto

Orientando-se pelos critérios de análise (item 6.4), definidos neste trabalho, estudou-se a segurança dos modelos de predição das normas em suas previsões, cujos resultados estão expressos na Figura 6.66. Nota-se que nenhuma norma apresentou resultados de predição dos valores de resistência considerados perigosos, porém a norma Eurocode (2004) e o modelo II da norma NBR 6118 (2007) apresentaram alguma porcentagem de previsões dentro do intervalo considerado de baixa segurança. Neste caso, como o mecanismo resistente está relacionado, praticamente, com a resistência a compressão do concreto, seria necessário prudência no uso destas duas normas que resultaria na construção de um elemento com baixa segurança. Por fim, nota-se que a norma $\mathrm{ACl}$ (2008) apresentou como onerosos todos os valores de predição.

Analisando a Tabela 6.34 e a Tabela 6.35, além dos comentários efetuados, qualificou-se o modelo II da norma NBR 6118 (2007) como o mais apropriado para a verificação do estado limite último de compressão da biela, pois apresentou segurança e precisão adequadas. A norma Eurocode (2004) foi penalizada por apresentar alta porcentagem de previsões com baixa segurança. 
Tabela 6.34: Resumo das porcentagens de resultados perigosos e onerosos, para casos de ruptura por esmagamento do concreto

\begin{tabular}{|c|c|c|}
\hline Norma & \% Perigosa & \% Onerosa \\
\hline CSA & 0,0 & 85,0 \\
\hline EURO & 0,0 & 35,0 \\
\hline ACI & 0,0 & 100,0 \\
\hline NBR I & 0,0 & 85,0 \\
\hline NBR II & 0,0 & 70,0 \\
\hline
\end{tabular}

Valores inaceitáveis

Tabela 6.35: Classificação pelo critério de pontos de deméritos, para casos de ruptura por esmagamento do concreto

\begin{tabular}{|c|c|c|c|}
\hline Norma & $\mathbf{N}^{\circ}$ ensaios & Ptos & Média \\
\hline CSA & 20 & 34 & 1,7 \\
\hline EURO & 20 & 24 & $\mathbf{1 , 2}$ \\
\hline ACI & 20 & 40 & 2,0 \\
\hline NBR I & 20 & 34 & 1,7 \\
\hline NBR II & 20 & 30 & 1,5 \\
\hline
\end{tabular}

\subsection{Análise de vigas solicitadas por esforços axiais}

O efeito dos esforços axiais sobre a resistência ao cisalhamento das peças de concreto armado foi bastante estudado para a utilização de elementos protendidos, ou seja, atuação de normal de compressão, porém, os estudos de elementos sujeitos a esforços de tração concomitantemente aos esforços tangenciais são mais escassos.

Neste item foram analisados os casos de vigas carregadas axialmente por esforços de tração e compressão, para elementos com e sem estribos.

\subsubsection{Análise de vigas sem estribos solicitadas por esforços axiais}

Esta análise contempla os dados de ensaios de elementos de concreto armado sem armadura de cisalhamento (estribos) e a comparação destes resultados com os resultados de predição de norma.

\subsubsection{Banco de dados utilizado}

A Tabela 6.36 apresenta o banco de dados utilizados para efetuar a análise comparativa entre os valores dos resultados de ensaios e os valores de predição das normas, para elementos sem estribos solicitados por esforços axiais normais. 
Tabela 6.36: Banco de dados elementos sem estribos solicitados por forças axiais

\begin{tabular}{|c|c|c|c|c|c|c|c|}
\hline Autor & Viga & bw $(\mathrm{cm})$ & $\mathrm{d}(\mathrm{cm})$ & $\mathrm{f}^{\prime} \mathrm{c}(\mathrm{MPa})$ & $\sigma n\left(k N / m^{2}\right)$ & pl \% & $a / d$ \\
\hline Mattock (1969) & 1 & 15,20 & 25,40 & $\overline{17,1}$ & 0 & 1,03 & 2,74 \\
\hline Mattock (1969) & 2 & 15,20 & 25,40 & 15,5 & -1.316 & 1,03 & 2,74 \\
\hline Mattock (1969) & 3 & 15,20 & 25,40 & 46,9 & 0 & 1,03 & 2,74 \\
\hline Mattock (1969) & 4 & 15,20 & 25,40 & 46,2 & 626 & 1,03 & 2,74 \\
\hline Mattock (1969) & 5 & 15,20 & 25,40 & 16,1 & 626 & 1,03 & 2,74 \\
\hline Mattock (1969) & 6 & 15,20 & 25,40 & 18,4 & -1.316 & 2,07 & 2,74 \\
\hline Mattock (1969) & 7 & 15,20 & 25,40 & 17,5 & -2.761 & 2,07 & 2,74 \\
\hline Mattock (1969) & 8 & 15,20 & 25,40 & 43,7 & -1.316 & 2,07 & 2,74 \\
\hline Mattock (1969) & 9 & 15,20 & 25,40 & 48,0 & -2.761 & 2,07 & 2,74 \\
\hline Mattock (1969) & 10 & 15,20 & 25,40 & 18,6 & 0 & 3,10 & 2,74 \\
\hline Mattock (1969) & 11 & 15,20 & 25,40 & 15,3 & 1.316 & 3,10 & 2,74 \\
\hline Mattock (1969) & 12 & 15,20 & 25,40 & 16,2 & -1.316 & 3,10 & 2,74 \\
\hline Mattock (1969) & 13 & 15,20 & 25,40 & 49,8 & -1.316 & 3,10 & 2,74 \\
\hline Mattock (1969) & 14 & 15,20 & 25,40 & 49,0 & -2.761 & 3,10 & 2,74 \\
\hline Mattock (1969) & 18 & 15,20 & 25,40 & 18,1 & 0 & 2,07 & 5,14 \\
\hline Mattock (1969) & 19 & 15,20 & 25,40 & 18,5 & 626 & 2,07 & 5,14 \\
\hline Mattock (1969) & 20 & 15,20 & 25,40 & 48,3 & 626 & 2,07 & 5,14 \\
\hline Mattock (1969) & 21 & 15,20 & 25,40 & 50,6 & 1.316 & 2,07 & 5,14 \\
\hline Mattock (1969) & 22 & 15,20 & 25,40 & 16,2 & 0 & 3,10 & 5,14 \\
\hline Mattock (1969) & 23 & 15,20 & 25,40 & 18,5 & 626 & 3,10 & 5,14 \\
\hline Mattock (1969) & 24 & 15,20 & 25,40 & 29,2 & 0 & 3,10 & 5,14 \\
\hline Mattock (1969) & 25 & 15,20 & 25,40 & 27,6 & 1.035 & 3,10 & 5,14 \\
\hline Mattock (1969) & 26 & 15,20 & 25,40 & 28,8 & 1.726 & 3,10 & 5,14 \\
\hline Mattock (1969) & 27 & 15,20 & 25,40 & 30,6 & -1.381 & 3,10 & 5,14 \\
\hline Mattock (1969) & 28 & 15,20 & 25,40 & 24,3 & -2.761 & 3,10 & 5,14 \\
\hline Mattock (1969) & 29 & 15,20 & 25,40 & 53,3 & 626 & 3,10 & 5,14 \\
\hline Mattock (1969) & 30 & 15,20 & 25,40 & 55,2 & -1.316 & 3,10 & 5,14 \\
\hline Mattock (1969) & 31 & 15,20 & 25,40 & 52,7 & -2.761 & 3,10 & 5,14 \\
\hline $\begin{array}{l}\text { Cossio, Siess } \\
(1960)\end{array}$ & B-2 & 15,20 & 25,40 & 28,6 & -1.920 & 1,00 & 3,00 \\
\hline $\begin{array}{l}\text { Cossio, Siess } \\
(1960)\end{array}$ & B-3 & 15,20 & 25,40 & 26,4 & -1.920 & 1,00 & 4,00 \\
\hline $\begin{array}{l}\text { Cossio, Siess } \\
(1960)\end{array}$ & B-4 & 15,20 & 25,40 & 28,3 & -1.920 & 1,00 & 5,00 \\
\hline $\begin{array}{l}\text { Cossio, Siess } \\
(1960)\end{array}$ & B-12 & 15,20 & 25,40 & 27,1 & -1.920 & 3,33 & 3,00 \\
\hline $\begin{array}{l}\text { Cossio, Siess } \\
(1960)\end{array}$ & B-13 & 15,20 & 25,40 & 27,9 & -1.920 & 3,33 & 4,00 \\
\hline $\begin{array}{l}\text { Cossio, Siess } \\
(1960)\end{array}$ & B-14 & 15,20 & 25,40 & 29,3 & -1.920 & 3,33 & 5,00 \\
\hline $\begin{array}{l}\text { Cossio, Siess } \\
(1960)\end{array}$ & B-15 & 15,20 & 25,40 & 25,1 & -1.920 & 3,33 & 6,00 \\
\hline $\begin{array}{l}\text { Haddadin, Hong e } \\
\text { Mattock (1971) }\end{array}$ & A1C & 17,80 & 38,00 & 25,9 & -5.190 & 3,81 & 2,50 \\
\hline $\begin{array}{l}\text { Haddadin, Hong e } \\
\text { Mattock (1971) }\end{array}$ & A1 & 17,80 & 38,00 & 29,5 & 0 & 3,81 & 2,50 \\
\hline $\begin{array}{l}\text { Haddadin, Hong e } \\
\text { Mattock (1971) }\end{array}$ & A1T & 17,80 & 38,00 & 27,9 & 3.244 & 3,81 & 2,50 \\
\hline $\begin{array}{l}\text { Haddadin, Hong e } \\
\text { Mattock (1971) }\end{array}$ & $\mathrm{C} 1 \mathrm{C}$ & 17,80 & 38,00 & 27,5 & -5.190 & 3,81 & 4,25 \\
\hline $\begin{array}{l}\text { Haddadin, Hong e } \\
\text { Mattock (1971) }\end{array}$ & C1 & 17,80 & 38,00 & 25,9 & 0 & 3,81 & 4,25 \\
\hline $\begin{array}{l}\text { Haddadin, Hong e } \\
\text { Mattock (1971) }\end{array}$ & $\mathrm{C} 1 \mathrm{~T}$ & 17,80 & 38,00 & 29,2 & 3.244 & 3,81 & 4,25 \\
\hline
\end{tabular}

\begin{tabular}{|l|c|c|c|c|c|c|c|}
\hline \multicolumn{1}{|c|}{ Autor } & $\begin{array}{c}\text { Número } \\
\text { de } \\
\text { Ensaios }\end{array}$ & bw (cm) & d (cm) & fck (MPa) & on $\mathbf{( k N / \mathbf { m } ^ { 2 } ) ^ { * }}$ & pl \% & a/d \\
\hline Mattock (1969) & 28 & 15,20 & 25,40 & $15,3-55,2$ & -2761 a 1725 & $1,03-3,1$ & $2,74-5,14$ \\
\hline $\begin{array}{l}\text { Cossio, Siess } \\
\text { (1960) }\end{array}$ & 7 & 15,20 & 25,40 & $25,05-29,32$ & -1919 & $1-3,33$ & $3-6$ \\
\hline $\begin{array}{l}\text { Haddadin, Hong e } \\
\text { Mattock (1971) }\end{array}$ & 6 & 17,80 & 38,00 & $25,85-29,5$ & -5190 a 3243 & 3,81 & $2,5-4,25$ \\
\hline
\end{tabular}




\subsubsection{Análise dos valores de predição de norma}

As correlações entre os resultados de ensaios e os parâmetros de ensaios estão ilustrados na Figura 6.67, sendo tensões axiais de compressão negativas e tensões de tração positivas.

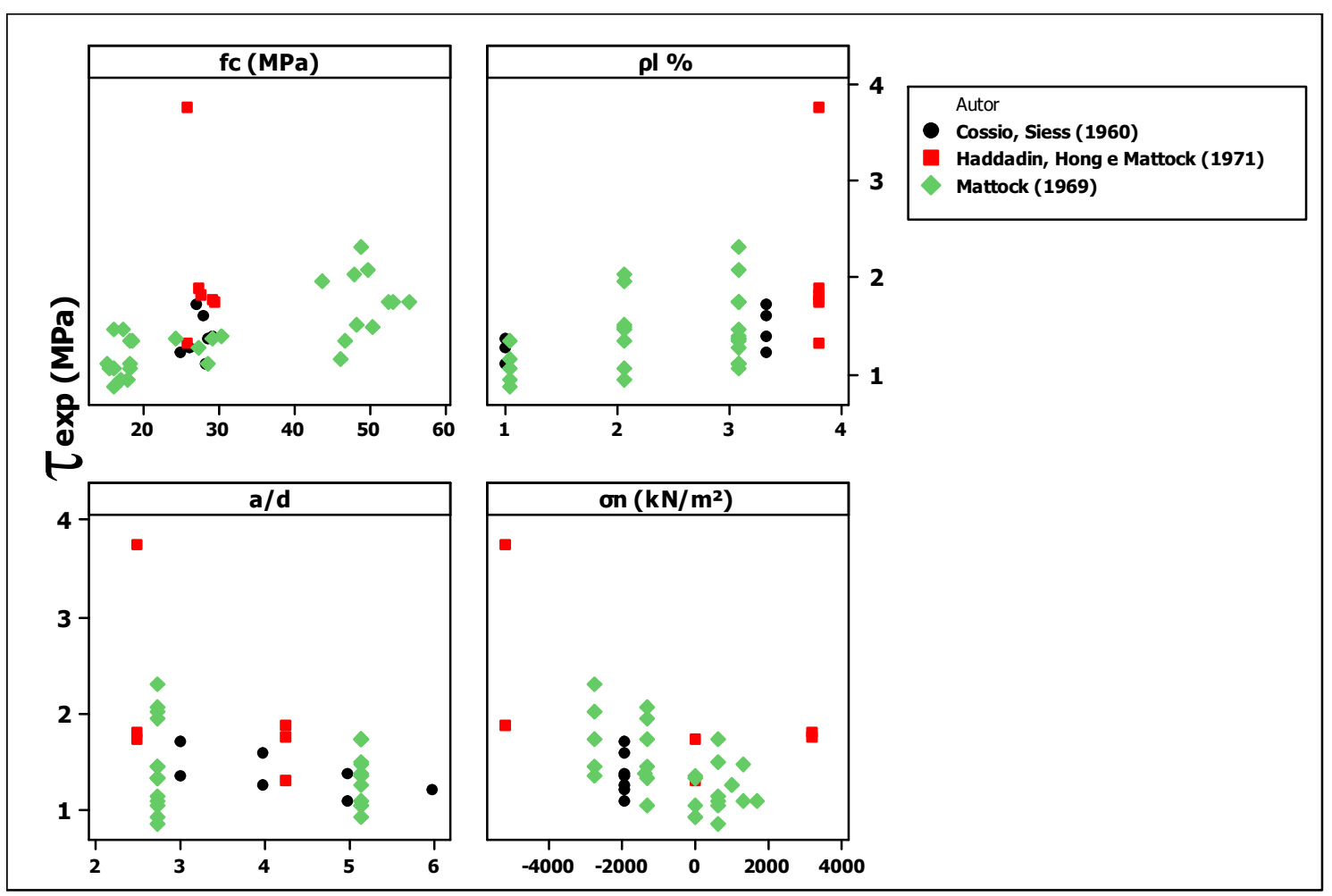

Figura 6.67: Correlação entre parâmetros de ensaios e tensão cisalhante resistente experimental, para elementos sem estribos e carregados axialmente, segundo os autores, sendo: fc - Resistência do concreto; pl - Taxa geométrica de armadura de flexão; a/d - Índice de esbeltez e on - Tensão axial

Na Figura 6.67, pode-se observar uma forte correlação entre a força cortante última dos elementos não armados ao cisalhamento e os parâmetros referentes a taxa de armadura longitudinal de flexão e a tensão axial. O aumento da taxa de armadura longitudinal resulta no aumento do efeito pino destas armaduras, e também, segunda teoria do MCFT, diminui a deformação axial longitudinal dos elementos, aumentando assim a capacidade de transferir esforços pelas fissuras de tração. A diminuição da força de compressão e o aumento da força de tração provocam a redução da resistência ao cisalhamento.

A Figura 6.68 e a Figura 6.69 apresentam as razões entre as forças últimas dos experimentos e as forças de predição de norma. Em ambas as figuras, para a norma ACl (2008) foram suprimidos dois dados de comparação referentes aos ensaios de Haddadin et al. (1971), mais especificadamente os ensaios A1T e C1T, pois apresentaram razões iguais a 34 e 35, o que levaria a uma distorção de escala nos gráficos. Essas baixas previsões da $\mathrm{ACl}$ ocorrem, devido a componente resistente do concreto ser bastante reduzida, para elementos não 
armados ao cisalhamento, quando as tensões de tração são elevadas, resultando em previsões conservadoras.

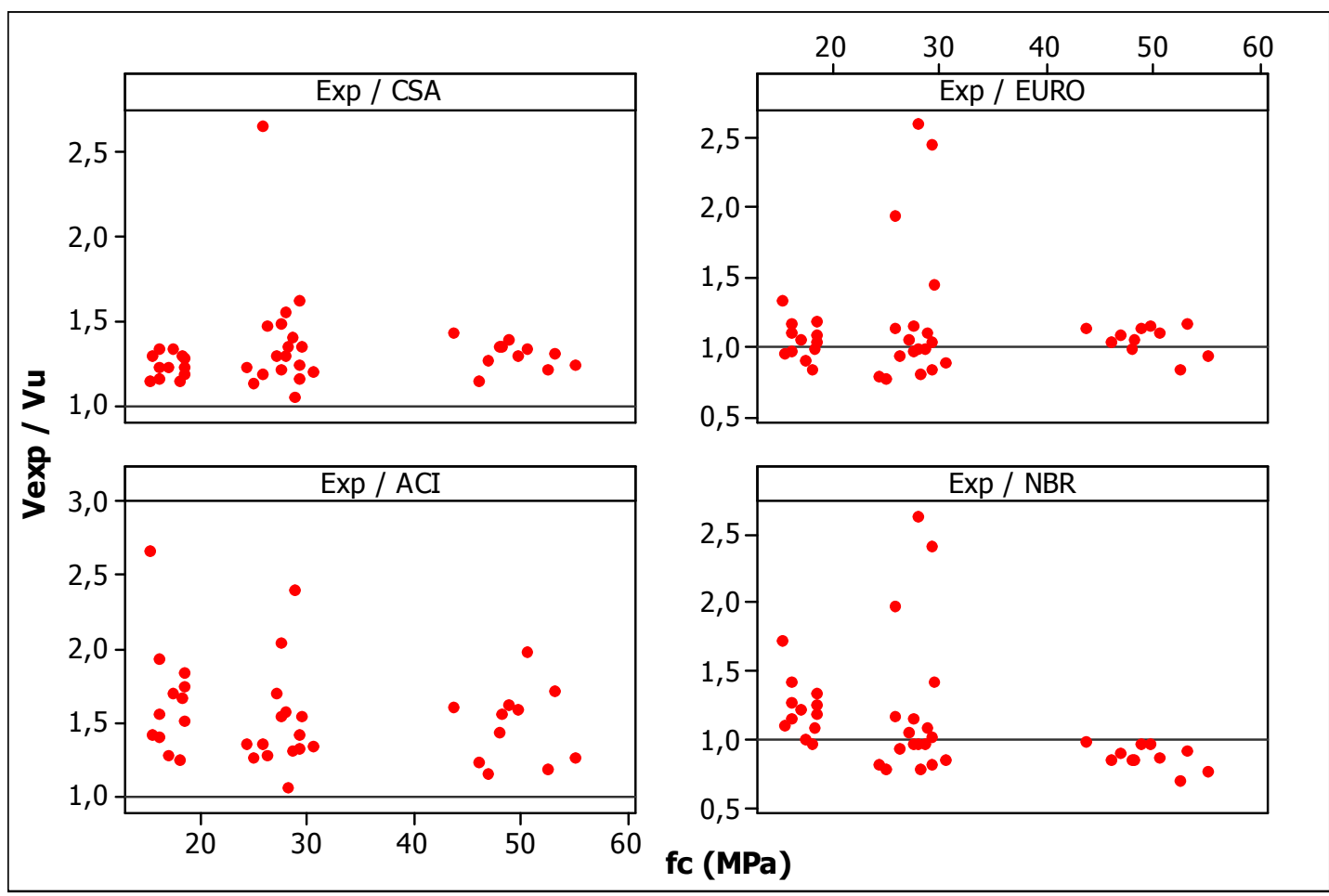

Figura 6.68: Correlação entre as razões Vexp/Vu, para as normas CSA, EURO, ACI e NBR, conforme a variação da resistência do concreto, fc, para elementos sem estribos e solicitados por esforços axiais

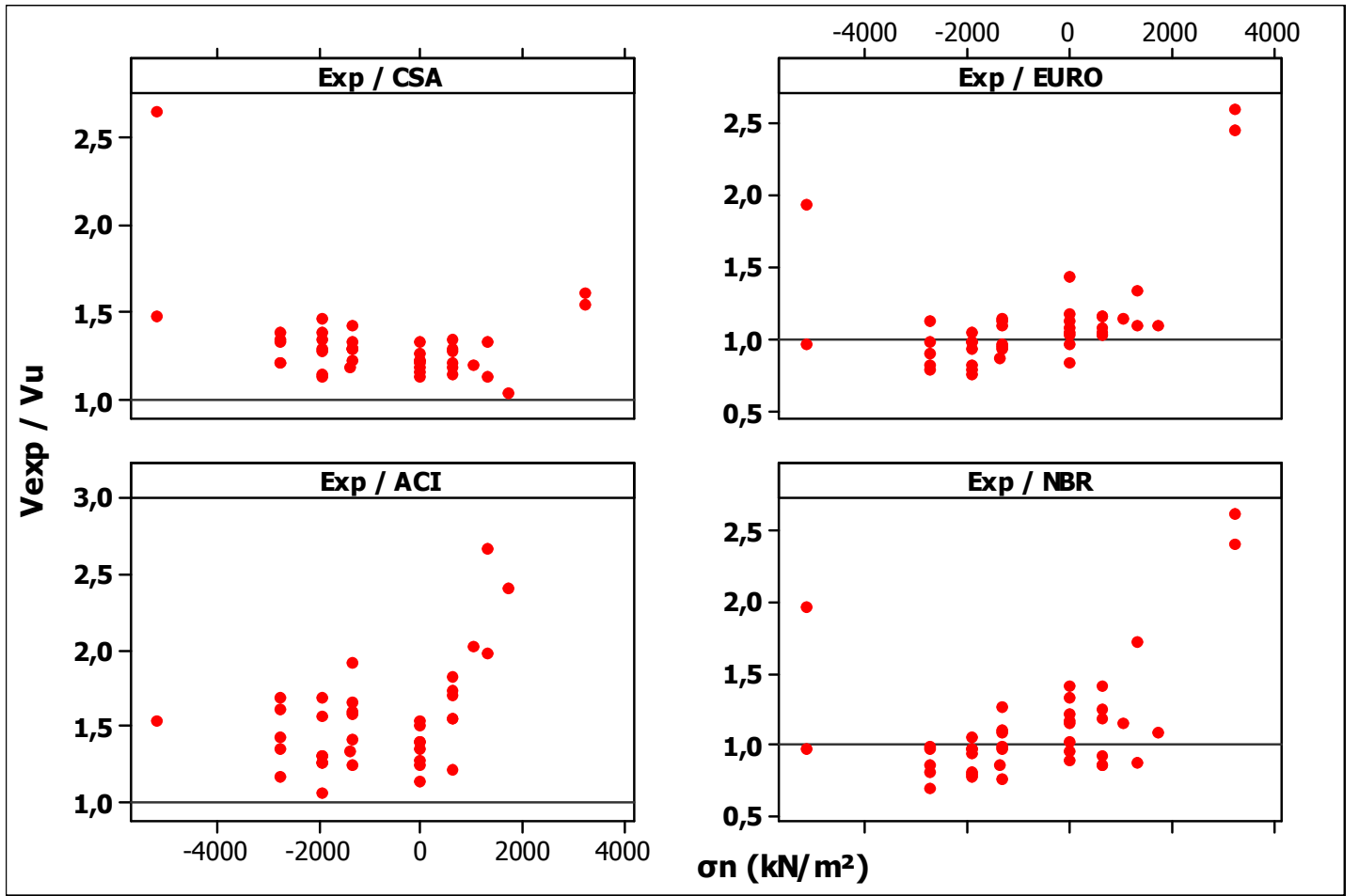

Figura 6.69: Correlação entre as razões Vexp/Vu, para as normas CSA, EURO, ACI e NBR, conforme a variação da tensão axial, $\sigma n$, para elementos sem estribos e solicitados por esforços axiais 
Pela análise das medidas estatísticas apresentadas na Tabela 6.37, considerando todos os dados juntos, nota-se que a norma CSA (2004) apresentou a melhor precisão, ou seja, o menor coeficiente de variação (afastamento), indicando comportamento bastante homogêneo em todo o intervalo dos parâmetros dos ensaios. Para todos os dados analisados, a norma Eurocode (2004) e a NBR 6118 (2007) apresentaram valores médios de predição considerados precisos com valores da média aritmética próximos do unitário.

Tabela 6.37: Medidas estatísticas dos valores de predição de norma, para elementos sem estribos, quanto a solicitação axial

\begin{tabular}{|c|c|c|c|c|c|}
\cline { 3 - 6 } \multicolumn{2}{c|}{} & \multicolumn{4}{c|}{ Esforço normal } \\
\hline \multirow{3}{*}{ CSA } & Norma & Tudo & $\mathbf{N}<\mathbf{0}$ & $\mathbf{N}=\mathbf{0}$ & $\mathbf{N}>\mathbf{0}$ \\
\cline { 2 - 6 } & MEDIA & 1,307 & 1,363 & 1,212 & 1,272 \\
\cline { 2 - 6 } & COEF. VARIAÇÃO & 0,188 & 0,228 & 0,054 & 0,131 \\
\cline { 2 - 6 } & MEDIANA & 1,279 & 1,285 & 1,214 & 1,241 \\
\hline \multirow{3}{*}{ EURO } & MEDIA & 1,114 & 0,993 & 1,083 & 1,347 \\
\cline { 2 - 6 } & COEF. VARIAÇÃO & 0,340 & 0,245 & 0,162 & 0,411 \\
\cline { 2 - 6 } & MEDIANA & 1,035 & 0,959 & 1,058 & 1,121 \\
\hline \multirow{3}{*}{ ACI } & MEDIA & 3,120 & 1,533 & 1,356 & 7,074 \\
\cline { 2 - 6 } & COEF. VARIAÇÃO & 2,209 & 0,279 & 0,097 & 1,721 \\
\cline { 2 - 6 } & MEDIANA & 1,540 & 1,429 & 1,372 & 1,901 \\
\hline \multirow{3}{*}{ NBR } & MEDIA & 1,122 & 0,978 & 1,144 & 1,360 \\
\cline { 2 - 6 } & COEF. VARIAÇÃO & 0,365 & 0,270 & 0,158 & 0,441 \\
\cline { 2 - 6 } & MEDIANA & 0,984 & 0,965 & 1,157 & 1,168 \\
\hline
\end{tabular}

Tudo (Todos os dados)

$\mathrm{N}<0$ (Todos os dados com compressão)

$\mathrm{N}=0$ (Todos os dados sem força axial)

$\mathrm{N}>0$ (Todos os dados com tração)

A Tabela 6.38 representa a análise de exatidão e precisão para os casos com compressão $(\mathrm{N}<0)$, força axial nula $(\mathrm{N}=0)$ e tração $(\mathrm{N}>0)$. Nota-se que para os três cenários a norma CSA (2004) obteve os menores coeficientes de variação, porém com valores médios acima de 1,2, além disto, para elementos solicitados por esforços axiais de tração, esta norma apresentou a melhor exatidão, ou seja, o valor de média, mais próximo do valor unitário. Para elementos solicitados por compressão as normas NBR 6118 (2007) e Eurocode (2004) apresentaram as menores médias.

Tabela 6.38: Resumo da análise de exatidão e precisão, para elementos sem estribos, quanto a solicitação axial

\begin{tabular}{|l|c|c|c|}
\cline { 2 - 4 } \multicolumn{1}{c|}{} & \multicolumn{3}{c|}{ Esforço normal } \\
\cline { 2 - 4 } \multicolumn{1}{c|}{} & $\mathbf{N}<\mathbf{0}$ & $\mathbf{N}=\mathbf{0}$ & $\mathbf{N}>\mathbf{0}$ \\
\hline Melhor Exatidão & NBR/EURO* & EURO & CSA \\
\hline Melhor Precisão & CSA & CSA & CSA \\
\hline
\end{tabular}

Efetuou-se a análise da segurança através da interpretação apenas dos gráficos de ensaios com esforços de compressão (Figura 6.70) e de tração (Figura 6.71), pois a análise dos elementos sem esforços axiais já foi amplamente explorado no item 6.6. 
Para os ensaios com esforços axiais de compressão, nota-se que apenas a norma brasileira NBR 6118 (2007) apresentou dados na faixa considerada perigosa, com porcentagem de $5 \%$. Ambas as normas, Eurocode (2004) e NBR 6118 (2007), apresentaram porcentagens consideráveis de previsões de baixa segurança, $24 \%$ e $29 \%$, respectivamente, que por se tratar de previsões para elementos não armados com estribos, podem ser consideradas inapropriadas para o uso. Por fim, apenas as normas CSA (2004) e ACl (2008) apresentaram resultados confiáveis, com porcentagens consideradas seguras, porém onerosas de $100 \%$ e $95 \%$, respectivamente.

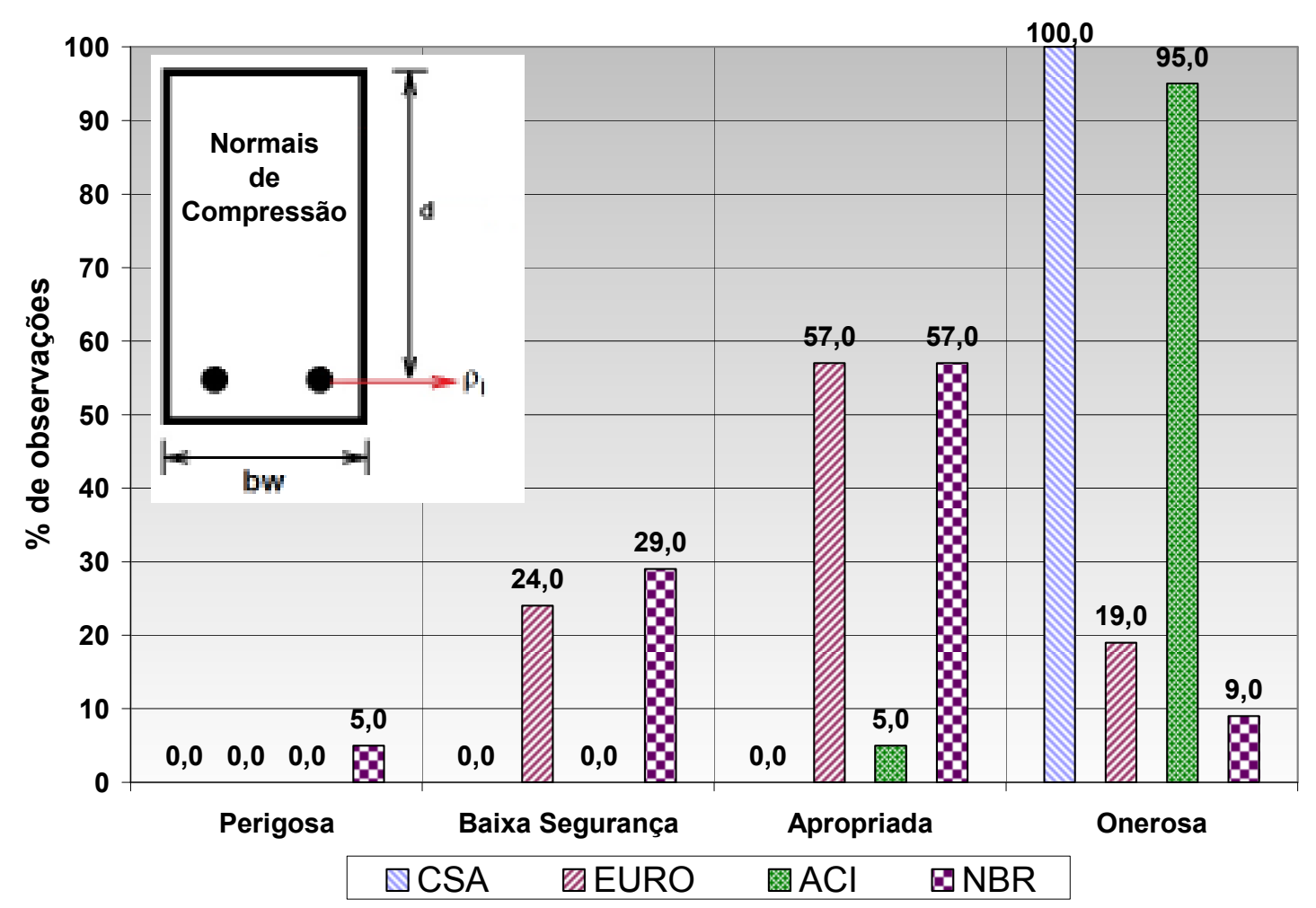

Figura 6.70: Análise da segurança para casos de ruptura elementos sem estribos solicitados por esforços axiais de compressão.

Para os ensaios de elementos solicitados por esforços axiais de tração, Figura 6.71, nenhuma norma apresentou previsões perigosas e apenas as NBR 6118 (2007) apresentou $8 \%$ das previsões com baixa segurança. Ressalta-se o bom desempenho da norma Eurocode (2004) com $50 \%$ das previsões consideradas apropriadas. As previsões das normas CSA (2004) e ACl (2008) apresentaram resultados elevados para as porcentagens de previsões onerosas, o que resultou em classificá-las como menos recomendadas devido aos elevados custos, porém ressalta-se que a utilização desta é segura. 


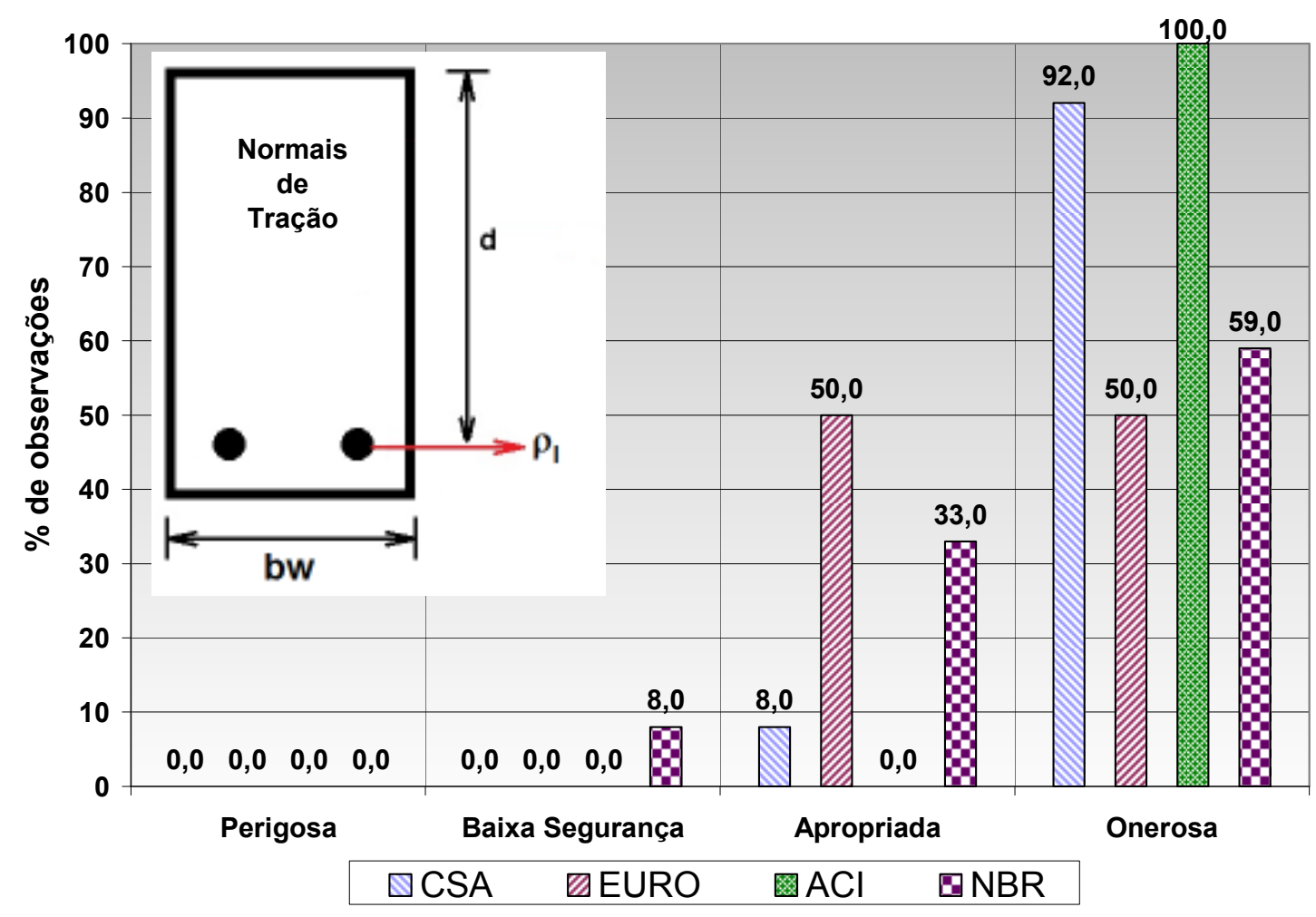

Figura 6.71: Análise da segurança para casos de ruptura elementos sem estribos solicitados por esforços axiais de tração.

Tabela 6.39: Resumo das porcentagens de resultados perigosos e onerosos (sem estribos)

\begin{tabular}{|c|c|c|c|c|}
\cline { 2 - 5 } \multicolumn{1}{c|}{} & \multicolumn{4}{c|}{ Esforço normal } \\
\cline { 2 - 5 } \multicolumn{1}{c|}{} & \multicolumn{2}{c|}{$\mathbf{N}<\mathbf{0}$} & \multicolumn{2}{c|}{$\mathbf{N}>\mathbf{0}$} \\
\hline Norma & $\%$ Perigosa & \% Onerosa & \% Ruina & \% Onerosa \\
\hline CSA & 0,0 & 100,0 & 0,0 & 92,0 \\
\hline EURO & 0,0 & 19,0 & 0,0 & 50,0 \\
\hline ACI & 0,0 & 95,0 & 0,0 & 100,0 \\
\hline NBR & 5,0 & 9,0 & 0,0 & 59,0 \\
\hline
\end{tabular}

प Valores não aceitáveis

Tabela 6.40: Classificação pelo critério de pontos de deméritos (sem estribos)

\begin{tabular}{|c|c|c|c|c|c|c|}
\cline { 2 - 7 } \multicolumn{1}{c|}{} & \multicolumn{3}{c|}{$\mathbf{N}<\mathbf{0}$} & \multicolumn{3}{c|}{$\mathbf{N}>\mathbf{0}$} \\
\hline Norma & $\begin{array}{c}\mathbf{N}^{\mathbf{0}} \\
\text { ensaios }\end{array}$ & Ptos & Média & $\begin{array}{c}\mathbf{N}^{\circ} \\
\text { ensaios }\end{array}$ & Ptos & Média \\
\hline CSA & 21 & 42 & 2,0 & 8 & 16 & 2,0 \\
\hline EURO & 21 & 18 & $\mathbf{0 , 9}$ & 8 & 8 & $\mathbf{1 , 0}$ \\
\hline ACI & 21 & 40 & 1,9 & 8 & 16 & 2,0 \\
\hline NBR & 21 & 26 & 1,2 & 8 & 10 & 1,3 \\
\hline
\end{tabular}

Para os elementos comprimidos, verificou-se que apesar do modelo de predição da norma Eurocode (2004) apresentar a menor pontuação de demérito, esta não foi considerada adequada por apresentar uma porcentagem de $24 \%$ dos dados considerados de baixa segurança. Neste caso, verificou-se que a $\mathrm{ACl}$ (2004) se mostrou mais indicada, pois não apresentou previsões de 
baixa segurança e apresentou menor porcentagem de resultados onerosos em relação a CSA (2004).

Para os elementos tracionados, verificou-se que as previsões da norma Eurocode (2004) apresentaram melhores resultados, contendo a maior porcentagem de previsões apropriadas, porcentagens nulas de previsões perigosas e de baixa segurança, além do menor somatório de pontos de demérito, sendo esta a mais indicada.

A norma CSA (2004) apresentou resultados seguros para as previsões de forças resistentes, porém ressalta-se que os resultados são conservadores. Neste caso como a dispersão dos resultados medida através do coeficiente de variação (afastamento) apresentou resultado adequado, pode-se concluir que as formulações apresentadas resultam em previsões coerentes em relação aos valores observados, porém com uma segurança elevada.

\subsubsection{Análise de vigas com estribos solicitadas por esforços axiais}

Neste item apresentam-se as análises de resultados de ensaios e valores de predição das normas para elementos de vigas armados com estribos e que possuíram ruptura caracterizada por exceder o estado limite de tração no cisalhamento.

\subsubsection{Banco de dados utilizado}

O banco de dados utilizado para efetuar a análise comparativa entre os valores dos resultados de ensaios e os valores resistentes dos modelos de predição de norma, de elementos com estribos solicitados por esforços axiais, estão expressos na Tabela 6.41.

Tabela 6.41: Banco de dados elementos com estribos solicitados por forças axiais

\begin{tabular}{|c|c|c|c|c|c|c|c|c|c|}
\hline Autor & Viga & $\begin{array}{c}\text { bw } \\
\text { (cm) }\end{array}$ & d (cm) & $\begin{array}{c}\mathbf{f}^{\prime} \mathbf{c} \\
(\mathrm{MPa})\end{array}$ & $\rho_{s w} \%$ & pl \% & $a / d$ & $\underset{ }{\sigma n}$ & $\rho_{s w} \cdot f_{y k}$ \\
\hline \begin{tabular}{|l} 
Mattock and Wang \\
$(1984)$
\end{tabular} & $\begin{array}{l}\text { C305- } \\
\text { D0 }\end{array}$ & 15,0 & 31,5 & 26,0 & 0,23 & 2,61 & 2,87 & 0 & 0,830 \\
\hline $\begin{array}{l}\text { Mattock and Wang } \\
(1984)\end{array}$ & $\begin{array}{l}\text { C305- } \\
\text { D1 }\end{array}$ & 15,0 & 31,5 & 26,0 & 0,23 & 2,61 & 2,87 & -2.034 & 0,830 \\
\hline $\begin{array}{l}\text { Mattock and Wang } \\
(1984)\end{array}$ & $\begin{array}{l}\text { C305- } \\
\text { D2 }\end{array}$ & 15,0 & 31,5 & 26,0 & 0,23 & 2,61 & 2,87 & -4.076 & 0,830 \\
\hline $\begin{array}{l}\text { Mattock and Wang } \\
(1984)\end{array}$ & $\begin{array}{l}\text { C305- } \\
\text { D4 }\end{array}$ & 15,0 & 31,5 & 26,0 & 0,23 & 2,61 & 2,87 & -8.145 & 0,830 \\
\hline $\begin{array}{l}\text { Mattock and Wang } \\
(1984)\end{array}$ & $\begin{array}{l}\text { C305- } \\
\text { D6 }\end{array}$ & 15,0 & 31,5 & 26,0 & 0,23 & 2,61 & 2,87 & -12.223 & 0,830 \\
\hline $\begin{array}{l}\text { Mattock and Wang } \\
(1984)\end{array}$ & $\begin{array}{l}\text { C310- } \\
\text { D10 }\end{array}$ & 15,0 & 31,5 & 26,0 & 0,46 & 2,61 & 2,87 & 0 & 1,660 \\
\hline \begin{tabular}{|l}
$\begin{array}{l}\text { Mattock and Wang } \\
(1984)\end{array}$ \\
\end{tabular} & $\begin{array}{l}\text { C310- } \\
\text { D11 }\end{array}$ & 15,0 & 31,5 & 26,0 & 0,46 & 2,61 & 2,87 & -2.076 & 1,660 \\
\hline \begin{tabular}{|l}
$\begin{array}{l}\text { Mattock and Wang } \\
(1984)\end{array}$ \\
\end{tabular} & $\begin{array}{l}\text { C310- } \\
\text { D13 }\end{array}$ & 15,0 & 31,5 & 26,0 & 0,46 & 2,61 & 2,87 & -6.221 & 1,660 \\
\hline \begin{tabular}{|l} 
Mattock and Wang \\
$(1984)$
\end{tabular} & $\begin{array}{l}\text { C310- } \\
\text { D20 }\end{array}$ & 15,0 & 31,5 & 24,5 & 0,46 & 2,61 & 2,87 & 0 & 1,660 \\
\hline \begin{tabular}{|l}
$\begin{array}{l}\text { Mattock and Wang } \\
(1984)\end{array}$ \\
\end{tabular} & $\begin{array}{l}\text { C310- } \\
\text { D21 }\end{array}$ & 15,0 & 31,5 & 24,5 & 0,46 & 2,61 & 2,87 & -2.128 & 1,660 \\
\hline
\end{tabular}


Tabela 6.41 (cont.): $\quad$ Banco de dados elementos com estribos solicitados por forças axiais

\begin{tabular}{|c|c|c|c|c|c|c|c|c|c|}
\hline Autor & Viga & $\begin{array}{l}\text { bw } \\
\text { (cm) }\end{array}$ & $d(\mathrm{~cm})$ & $\begin{array}{c}\mathrm{f}^{\prime c} \\
(\mathrm{MPa})\end{array}$ & $\rho_{\text {sw }} \%$ & pl \% & $a / d$ & $\begin{array}{c}\sigma n \\
\left(\mathrm{kN} / \mathrm{m}^{2}\right)\end{array}$ & $\begin{array}{l}\rho_{\text {sw. }} \cdot f_{\text {yk }} \\
(\mathrm{MPa})\end{array}$ \\
\hline $\begin{array}{l}\text { Mattock and Wang } \\
\text { (1984) }\end{array}$ & $\begin{array}{l}\text { C310- } \\
\text { D23 }\end{array}$ & 15,0 & 31,5 & 24,5 & 0,46 & 2,61 & 2,87 & -6.358 & 1,660 \\
\hline $\begin{array}{l}\text { Haddadin, Hong e } \\
\text { Mattock (1971) }\end{array}$ & A2 & 17,8 & 38,1 & 29,2 & 0,19 & 3,81 & 2,50 & 0 & 0,680 \\
\hline $\begin{array}{l}\text { Haddadin, Hong e } \\
\text { Mattock (1971) }\end{array}$ & A3 & 17,8 & 38,1 & 30,1 & 0,41 & 3,81 & 2,50 & 0 & 1,450 \\
\hline $\begin{array}{l}\text { Haddadin, Hong e } \\
\text { Mattock (1971) }\end{array}$ & АЗ & 17,8 & 38,1 & 29,2 & 0,41 & 3,81 & 2,50 & 3.244 & 1,450 \\
\hline $\begin{array}{l}\text { Haddadin, Hong e } \\
\text { Mattock (1971) }\end{array}$ & A4C & 17,8 & 38,1 & 28,4 & 0,76 & 3,81 & 2,50 & -5.190 & 2,710 \\
\hline $\begin{array}{l}\text { Haddadin, Hong e } \\
\text { Mattock (1971) }\end{array}$ & A4 & 17,8 & 38,1 & 28,6 & 0,76 & 3,81 & 2,50 & 0 & 2,710 \\
\hline $\begin{array}{l}\text { Haddadin, Hong e } \\
\text { Mattock (1971) }\end{array}$ & A4T & 17,8 & 38,1 & 29,6 & 0,76 & 3,81 & 2,50 & 3.244 & 2,710 \\
\hline $\begin{array}{l}\text { Haddadin, Hong e } \\
\text { Mattock (1971) }\end{array}$ & A5C & 17,8 & 38,1 & 27,1 & 1,22 & 3,81 & 2,50 & -5.190 & 4,350 \\
\hline $\begin{array}{l}\text { Haddadin, Hong e } \\
\text { Mattock (1971) }\end{array}$ & A5 & 17,8 & 38,0 & 26,3 & 1,22 & 3,81 & 2,50 & 0 & 4,350 \\
\hline $\begin{array}{l}\text { Haddadin, Hong e } \\
\text { Mattock (1971) }\end{array}$ & A5T & 17,8 & 38,0 & 27,6 & 1,22 & 3,81 & 2,50 & 3.244 & 4,350 \\
\hline $\begin{array}{l}\text { Haddadin, Hong e } \\
\text { Mattock (1971) }\end{array}$ & B3C & 17,8 & 38,0 & 27,7 & 0,41 & 3,81 & 3,37 & -5.190 & 1,450 \\
\hline $\begin{array}{ll}\text { Haddadin, Hong e } \\
\text { Mattock (1971) }\end{array}$ & B3 & 17,8 & 38,0 & 27,7 & 0,41 & 3,81 & 3,37 & 0 & 1,450 \\
\hline $\begin{array}{l}\text { Haddadin, Hong e } \\
\text { Mattock (1971) }\end{array}$ & B3T & 17,8 & 38,0 & 24,1 & 0,41 & 3,81 & 3,37 & 3.244 & 1,450 \\
\hline $\begin{array}{l}\text { Haddadin, Hong e } \\
\text { Mattock (1971) }\end{array}$ & $\mathrm{C} 2 \mathrm{C}$ & 17,8 & 38,0 & 27,9 & 0,19 & 3,81 & 4,25 & -5.190 & 0,680 \\
\hline $\begin{array}{l}\text { Haddadin, Hong e } \\
\text { Mattock (1971) }\end{array}$ & $\mathrm{C} 2$ & 17,8 & 38,0 & 27,8 & 0,19 & 3,81 & 4,25 & 0 & 0,680 \\
\hline $\begin{array}{ll}\text { Haddadin, Hong e } \\
\text { Mattock (1971) }\end{array}$ & $\mathrm{C} 2 \mathrm{~T}$ & 17,8 & 38,0 & 30,2 & 0,19 & 3,81 & 4,25 & 3.244 & 0,680 \\
\hline $\begin{array}{l}\text { Haddadin, Hong e } \\
\text { Mattock (1971) }\end{array}$ & C3C & 17,8 & 38,0 & 26,7 & 0,41 & 3,81 & 4,25 & -5.190 & 1,450 \\
\hline $\begin{array}{l}\text { Haddadin, Hong e } \\
\text { Mattock (1971) }\end{array}$ & C3C & 17,8 & 38,0 & 27,3 & 0,41 & 3,81 & 4,25 & -2.595 & 1,450 \\
\hline $\begin{array}{l}\text { Haddadin, Hong e } \\
\text { Mattock (1971) }\end{array}$ & C3 & 17,8 & 38,0 & 24,2 & 0,41 & 3,81 & 4,25 & 0 & 1,450 \\
\hline $\begin{array}{ll}\text { Haddadin, Hong e } \\
\text { Mattock (1971) }\end{array}$ & C3T & 17,8 & 38,0 & 29,3 & 0,41 & 3,81 & 4,25 & 3.244 & 1,450 \\
\hline $\begin{array}{ll}\text { Haddadin, Hong e } \\
\text { Mattock (1971) }\end{array}$ & E3C & 17,8 & 38,0 & 15,5 & 0,41 & 3,81 & 2,50 & -5.190 & 1,450 \\
\hline $\begin{array}{l}\text { Haddadin, Hong e } \\
\text { Mattock (1971) }\end{array}$ & G5T & 17,8 & 38,0 & 26,7 & 1,05 & 3,81 & 2,50 & 3.244 & 4,780 \\
\hline
\end{tabular}

\begin{tabular}{|c|c|c|c|c|c|c|c|c|c|}
\hline Autor & $\begin{array}{l}\text { Número } \\
\text { de } \\
\text { Ensaios }\end{array}$ & $\begin{array}{l}\text { bw } \\
(\mathrm{cm})\end{array}$ & $\mathrm{d}(\mathrm{cm})$ & $\begin{array}{c}\mathrm{fc} \\
(\mathrm{MPa})\end{array}$ & pl \% & $\rho_{s w} \%$ & $a / d$ & $\underset{\left(k N / m^{2}\right)}{\sigma n}$ & $\begin{array}{l}\rho_{\text {sw. }} \text { fyk } \\
\text { (MPa) }\end{array}$ \\
\hline $\begin{array}{l}\text { Mattock and Wang } \\
\text { (1984) }\end{array}$ & 11 & 15,00 & 31,50 & $\begin{array}{c}24,5- \\
26\end{array}$ & 2,61 & $\begin{array}{c}0,23- \\
0,46\end{array}$ & 2,87 & $\begin{array}{c}-12.222 a \\
0 \\
\end{array}$ & $\begin{array}{c}0,83- \\
1,66 \\
\end{array}$ \\
\hline $\begin{array}{l}\text { Haddadin, Hong e } \\
\text { Mattock (1971) }\end{array}$ & 21 & 17,80 & $\begin{array}{l}38- \\
38,1 \\
\end{array}$ & $\begin{array}{c}15,5- \\
30,2 \\
\end{array}$ & 3,81 & $\begin{array}{c}0,19- \\
1,22 \\
\end{array}$ & $\begin{array}{l}2,5- \\
4,25 \\
\end{array}$ & $\begin{array}{c}-5.190 \mathrm{a} \\
3.243 \\
\end{array}$ & $\begin{array}{c}0,68- \\
4,78 \\
\end{array}$ \\
\hline TOTAL & 32 & $\begin{array}{l}15- \\
17,8 \\
\end{array}$ & $\begin{array}{c}31,5- \\
38,1 \\
\end{array}$ & $\begin{array}{c}15,5- \\
30,2\end{array}$ & $\begin{array}{r}2,61- \\
3,81 \\
\end{array}$ & $\begin{array}{c}0,19- \\
1,22 \\
\end{array}$ & $\begin{array}{l}2,5-25 \\
4,25 \\
\end{array}$ & $\begin{array}{c}-12.222 \mathrm{a} \\
3.243 \\
\end{array}$ & $\begin{array}{c}0,68- \\
4,78 \\
\end{array}$ \\
\hline
\end{tabular}




\subsubsection{Análise dos valores de predição de norma}

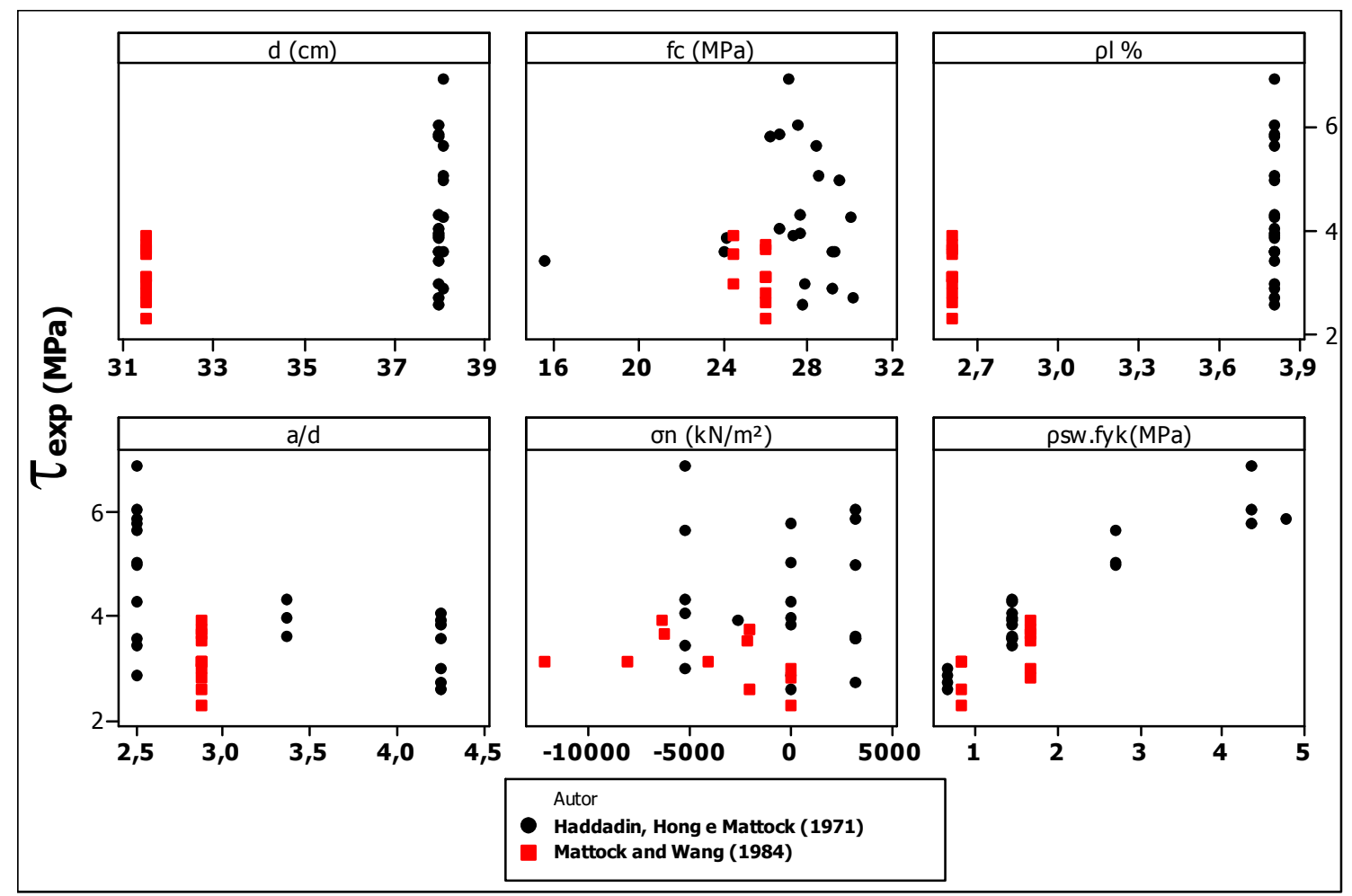

Figura 6.72: Correlação entre parâmetros de ensaios e tensão cisalhante resistente experimental, para elementos com estribos solicitados por esforços axiais, segundo os autores, sendo: d - Altura do elemento; fc Resistência do concreto; pl - Taxa geométrica de armadura de flexão; a/d - Índice de esbeltez; on - Tensão axial solicitante e psw.fyk - Taxa mecânica de estribos

A Figura 6.72 mostra os resultados de correlação entre os parâmetros de ensaios e os resultados de ensaio. Deve-se notar que, devido ao fato dos elementos serem armados ao cisalhamento com estribos, não há uma correlação clara entre a resistência do concreto, $f_{\mathrm{c}}$, e a tensão cisalhante resistente, $\tau_{\text {exp }}$. Existem fortes evidencias que o aumento da solicitação de flexão acarreta na redução da resistência ao cisalhamento, além disso, existe uma forte correlação entre as taxa mecânica de estribos, $\rho_{\mathrm{sw}} \cdot f_{\mathrm{yk}}$, e a tensão cisalhante resistente. Conforme também constatado por Haddadin et al. (1971), nos dados apresentados, não se verificou a correlação entre a tensões axiais, $\rho_{\mathrm{n}}$, com a tensão cisalhante resistente para elemento armados ao cisalhamento.

A Figura 6.73 representa as comparações entre os resultados de ensaios e as previsões de norma, analisando como parâmetro principal a tensão axial em que as peças foram submetidas. Observa-se que as previsões de norma mostram resultados coerentes para todo o intervalo de variação de $\rho_{\mathrm{n}}$. Apenas a norma $\mathrm{ACl}$ (2008), apresentou uma grande redução dos valores de predição para elementos submetidos a esforços de tração. 


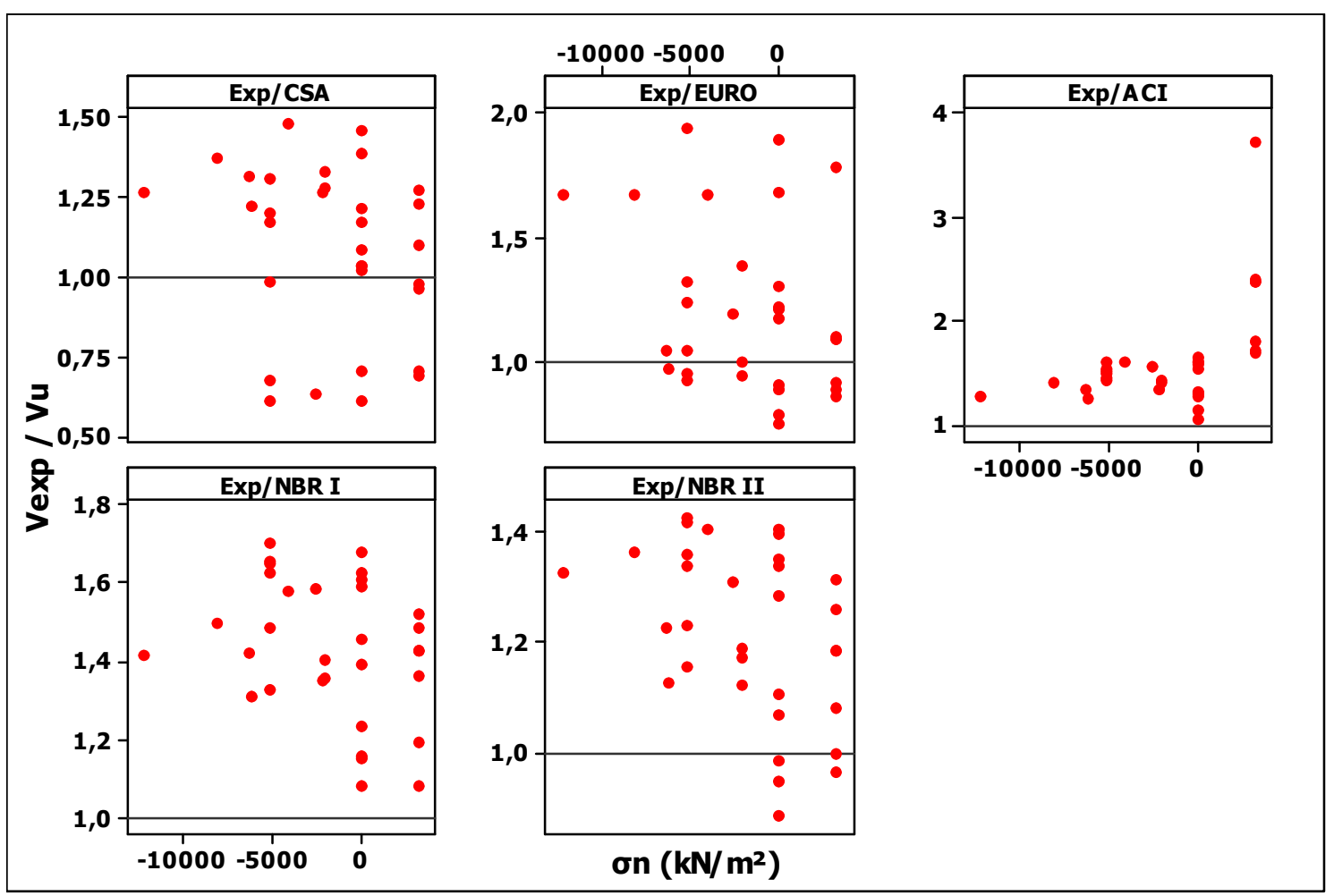

Figura 6.73: Correlação entre as razões Vexp/ $\mathrm{Vu}$, para as normas CSA, EURO, ACI e NBR, conforme a variação da tensão axial, $\sigma \mathrm{n}$, para elementos com estribos e solicitados por esforços axiais

A Figura 6.74 apresenta resultados de correlações bastante ricos em termos qualitativos. De forma geral as normas apresentam resultados mais precisos quanto maior for a taxa mecânica de estribos, exceto para o norma CSA (2004). Pode-se perceber que os modelos de predição das normas também indicam que não há uma forte correlação entre a resistência ao cisalhamento e as tensões axiais de compressão ou de tração, e de modo geral, os modelos de predição resultam em valores resistentes seguros.

As medidas estatísticas deste estudo apresentam-se na Tabela 6.42, e verificase que a norma CSA (2004) apresentou a melhor exatidão em termos de resultados médios e os modelos de predição das normas NBR 6118 (2007) apresentaram as melhores precisões médias, devido aos menores coeficientes de variação, considerando todos os dados.

Analisando apenas os dados com esforços axiais de compressão $(N<0)$, notase que a norma Eurocode (2004) apresentou a melhor exatidão e a norma CSA (2004) a melhor precisão. 


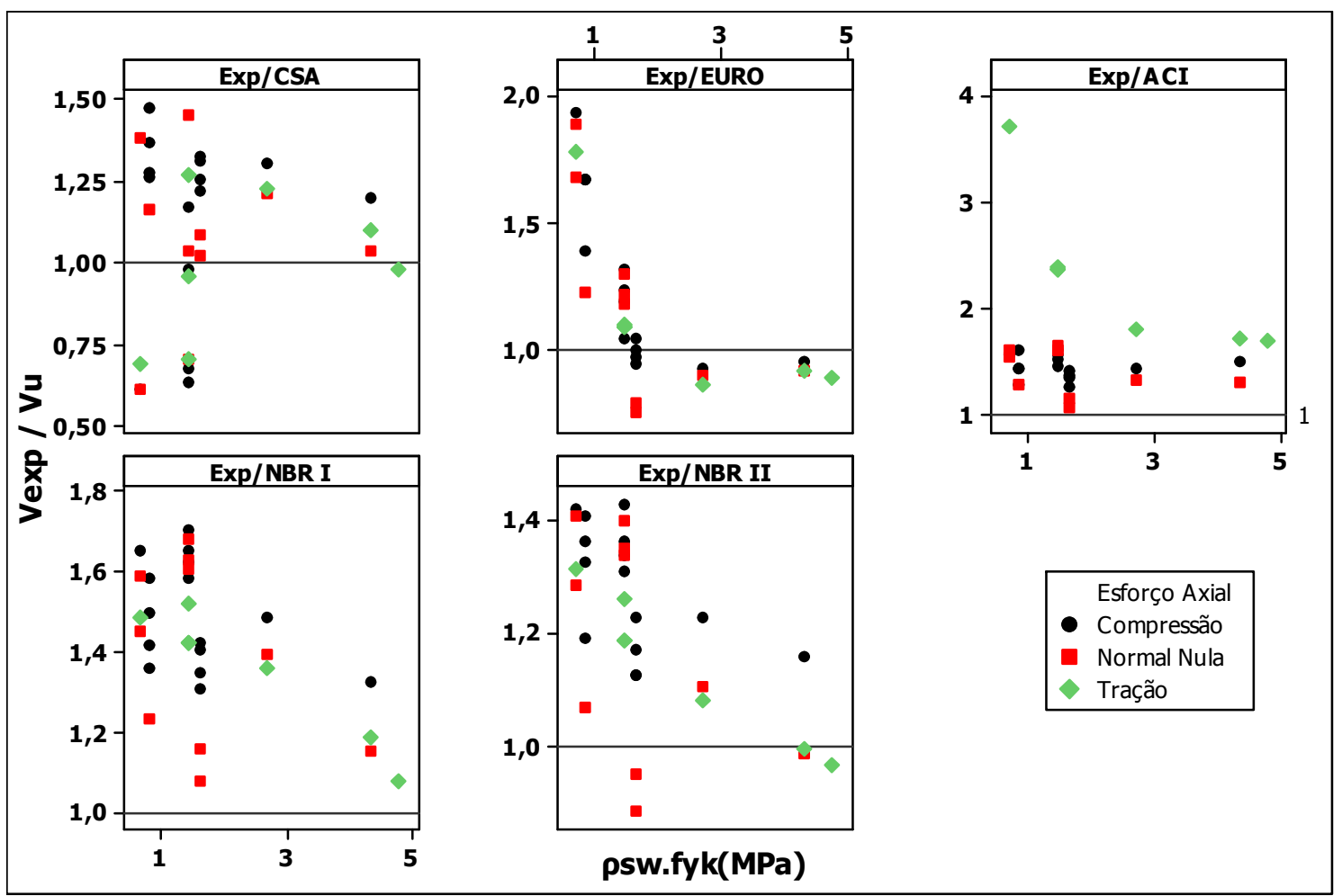

Figura 6.74: Correlação entre as razões Vexp/Vu, para as normas CSA, EURO, ACI e NBR, conforme a variação da tensão axial, $\sigma n$, para elementos com estribos e solicitados por esforços axiais, separados conforme o tipo de solicitação axial

Tabela 6.42: Medidas estatísticas dos valores de predição de norma para, elementos com estribos e solicitados por esforços axiais, separados conforme o tipo de solicitação axial

\begin{tabular}{|c|c|c|c|c|c|}
\hline & & \multicolumn{4}{|c|}{ Esforço normal } \\
\hline \multicolumn{2}{|r|}{ Norma } & Todos & $\mathrm{N}<0$ & $\mathrm{~N}=0$ & $N>0$ \\
\hline \multirow{3}{*}{ CSA } & MEDIA & 1,070 & 1,129 & 1,059 & 0,959 \\
\hline & COEF. VARIAÇÃO & 0,270 & 0,266 & 0,271 & 0,286 \\
\hline & MEDIANA & 1,167 & 1,259 & 1,061 & 0,976 \\
\hline \multirow{3}{*}{ EURO } & MEDIA & 1,205 & 1,264 & 1,185 & 1,106 \\
\hline & COEF. VARIAÇÃO & 0,280 & 0,262 & 0,317 & 0,285 \\
\hline & MEDIANA & 1,097 & 1,193 & 1,196 & 1,093 \\
\hline \multirow{3}{*}{$\mathrm{ACl}$} & MEDIA & 1,617 & 1,443 & 1,406 & 2,292 \\
\hline & COEF. VARIAÇÃO & 0,307 & 0,077 & 0,152 & 0,306 \\
\hline & MEDIANA & 1,530 & 1,425 & 1,427 & 2,371 \\
\hline \multirow{3}{*}{ NBR I } & MEDIA & 1,434 & 1,494 & 1,399 & 1,357 \\
\hline & COEF. VARIAÇÃO & 0,124 & 0,090 & 0,163 & 0,120 \\
\hline & MEDIANA & 1,426 & 1,489 & 1,424 & 1,426 \\
\hline \multirow{3}{*}{ NBR II } & MEDIA & 1,217 & 1,279 & 1,178 & 1,142 \\
\hline & COEF. VARIAÇÃO & 0,127 & 0,085 & 0,170 & 0,115 \\
\hline & MEDIANA & 1,229 & 1,310 & 1,194 & 1,186 \\
\hline
\end{tabular}

Todos (Todos os ensaios)

$\mathrm{N}<0$ (Todos os ensaios com compressão)

$\mathrm{N}=0$ (Todos os ensaios sem força axial)

$\mathrm{N}>0$ (Todos os ensios com tração) 
Analisando apenas os dados com esforços axiais de tração $(N>0)$, nota-se que a norma CSA (2004) apresentou a melhor exatidão e o modelo II da NBR 6118 (2007) a melhor precisão.

A análise de segurança dos modelos de predição das normas será feita considerando apenas os casos de elementos solicitados por compressão e por tração, pois os elementos não solicitados por forças axiais foram minuciosamente analisados no item 6.5.

A Figura 6.75 ilustra a análise da segurança para elementos armados com estribos solicitados por esforços axiais de compressão. Nota-se que apenas a norma CSA (2004) apresentou resultados insatisfatórios, devido as porcentagens de $13 \%$ para os casos perigosos e $7 \%$ para os casos de baixa segurança. O Eurocode (2004) apresentou os melhores resultados, contemplando $47 \%$ das análises dentro do intervalo de previsões apropriadas. As normas ACl (2004) e NBR 6118 (2007) apresentaram $100 \%$ das previsões como onerosas, resultando assim em previsões seguras, porém com custos executivos maiores.

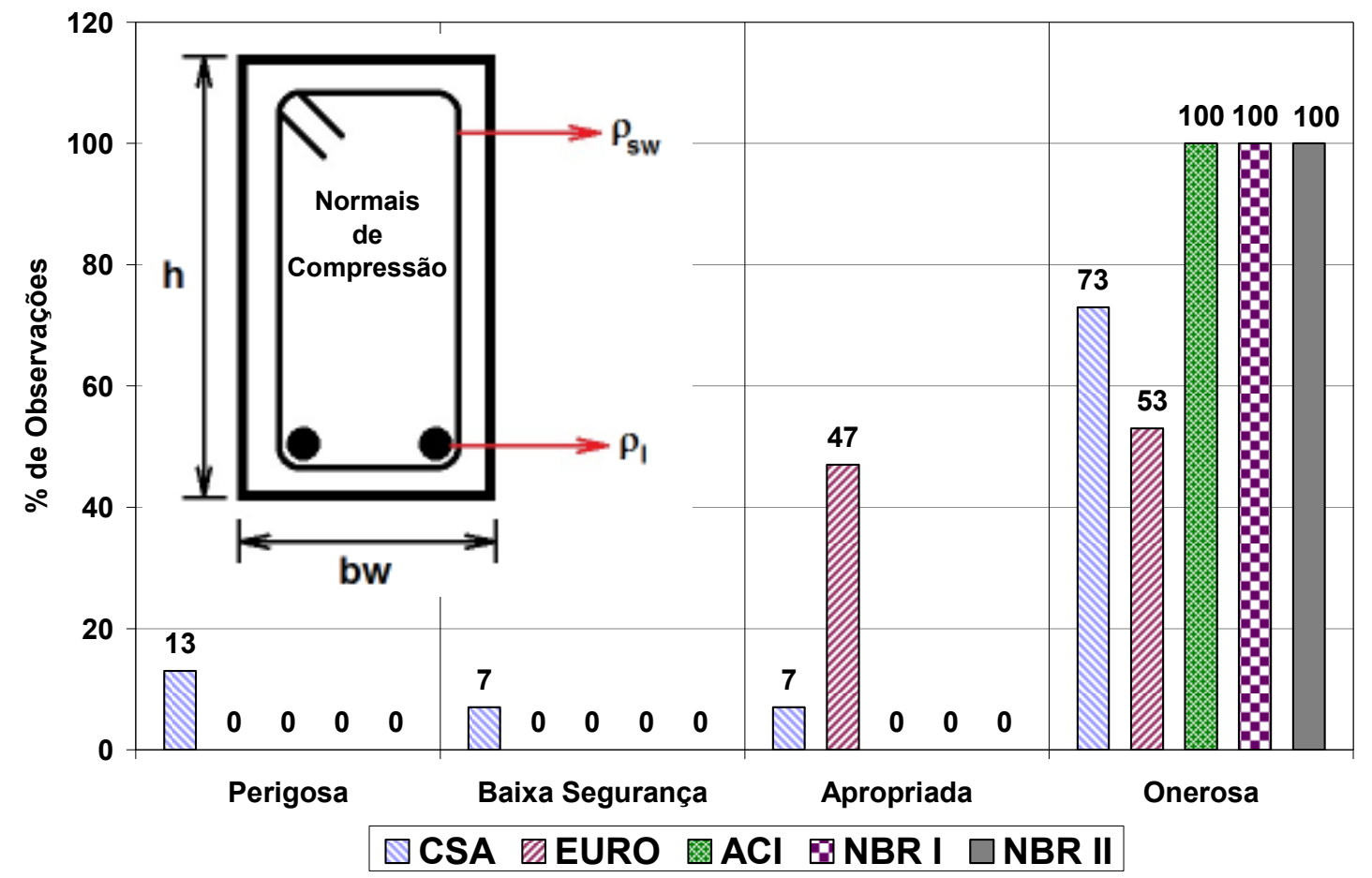

Figura 6.75: Análise da segurança para casos com compressão, para elementos com estribos

Para a análise da segurança dos elementos submetidos aos esforços axiais de tração, elaborou-se a Figura 6.76, na qual se observa que a norma CSA (2004) apresenta $29 \%$ das previsões consideradas perigosas. A norma Eurocode (2004) apresentou $29 \%$ das previsões consideradas com baixa segurança. 


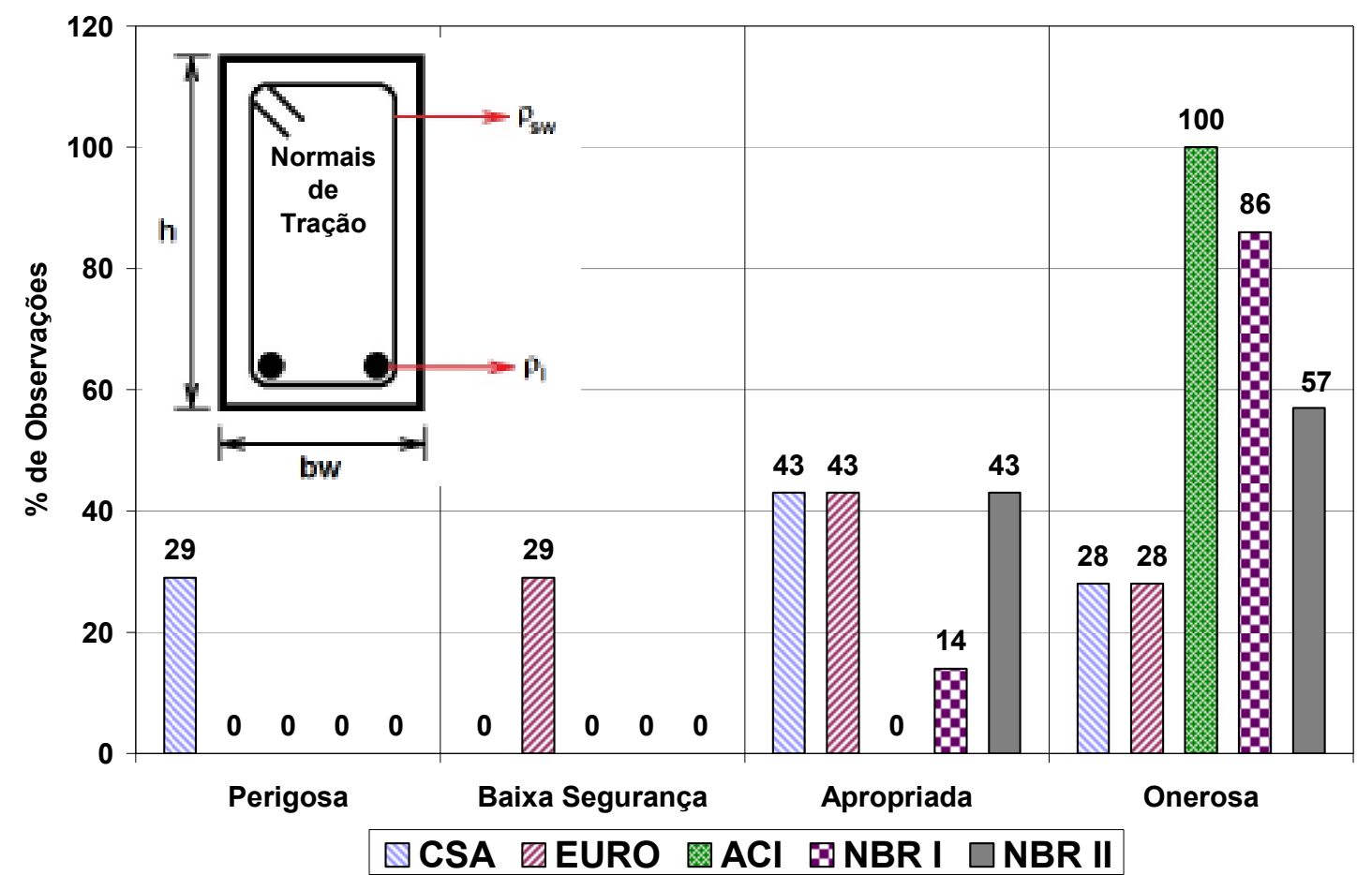

Figura 6.76: Análise da segurança para casos com esforços tração, para elementos com estribos

A norma Eurocode (2004) apesar de não apresentar previsões perigosas, apresentou 29 \% das previsões com baixa segurança. A porcentagem de baixa segurança, para elementos armados com estribos não é menos preocupante, porém como a segurança está comprometida e a porcentagem de casos é elevada, esta norma foi considerada imprópria para o uso. Os dois modelos de cálculo da norma NBR 6118 (2007) apresentaram resultados satisfatórios, ressaltando o modelo II, que apresentou uma porcentagem de $43 \%$ para os casos apropriados, e 57 \% para os casos onerosos. A norma ACl (2004) apresentou $100 \%$ das previsões como onerosas, não sendo, por este motivo, recomendada para o uso, porém suas previsões são seguras.

Tabela 6.43: Resumo das porcentagens de resultados perigosos e onerosos (com estribos)

\begin{tabular}{|c|c|c|c|c|}
\cline { 2 - 5 } \multicolumn{1}{c|}{} & \multicolumn{3}{c|}{ Categoria de psw.fyk (Mpa) } \\
\cline { 2 - 5 } \multicolumn{1}{c|}{} & \multicolumn{2}{c|}{$\mathbf{N}<\mathbf{0}$} & \multicolumn{2}{c|}{$\mathbf{N}>\mathbf{0}$} \\
\hline Norma & $\%$ Perigosa & \% Onerosa & \% Perigosa & $\%$ Onerosa \\
\hline CSA & 13,0 & 73,0 & 29 & 28 \\
\hline EURO & 0,0 & 53,0 & 0 & 28 \\
\hline ACI & 0,0 & 100,0 & 0 & 100 \\
\hline NBR I & 0,0 & 100,0 & 0 & 86 \\
\hline NBR II & 0,0 & 100,0 & 0 & 57 \\
\hline
\end{tabular}

Valores não aceitáveis 
Tabela 6.44: Classificação pelo critério de pontos de deméritos (com estribos)

\begin{tabular}{|c|c|c|c|c|c|c|}
\cline { 2 - 7 } \multicolumn{1}{c|}{} & \multicolumn{6}{c|}{ Categoria de psw.fyk (Mpa) } \\
\cline { 2 - 8 } \multicolumn{1}{c|}{} & \multicolumn{3}{c|}{ N < 0 } & \multicolumn{3}{c|}{ N > 0 } \\
\hline Norma & $\mathbf{N}^{\circ}$ ensaios & Ptos & Média & $\mathbf{N}^{\circ}$ ensaios & Ptos & Média \\
\hline CSA & 15 & 44 & 2,9 & 7 & 24 & 3,4 \\
\hline EURO & 15 & 16 & $\mathbf{1 , 1}$ & 7 & 8 & $\mathbf{1 , 1}$ \\
\hline ACI & 15 & 30 & 2,0 & 7 & 14 & 2,0 \\
\hline NBR I & 15 & 30 & 2,0 & 7 & 12 & 1,7 \\
\hline NBR II & 15 & 30 & 2,0 & 7 & 8 & $\mathbf{1 , 1}$ \\
\hline
\end{tabular}

Por fim, segundo as mesmas premissas de análise e qualificação das normas utilizadas ao longo desta dissertação, e analisando a Tabela 6.43 e Tabela 6.44 , pode-se concluir que o modelo de norma recomendado para efetuar a predição de elementos armados com estribos sujeitos a esforços axiais de compressão é o Eurocode (2004) e para elementos tracionados o modelo II da NBR 6118 (2007). As normas CSA (2004) e Eurocode (2004) não são as mais indicadas para as tais previsões, e a norma ACl (2008) apresenta resultados extremamente conservadores.

\section{Resumo dos resultados e discussões}

A Tabela 7.3 e a Tabela 7.4 apresentam a síntese de todas as análises efetuadas neste trabalho, baseadas em critérios de análise, elaborados nesta dissertação, fundamentados em critérios lógicos e explícitos. Na Tabela 7.3 foram condensadas as conclusões referentes às análises de exatidão, precisão e segurança do modelo de predição para os elementos armados com estribos, cujos critérios e metodologias estão apresentados nos itens 6.4. e 5, respectivamente. Analogamente, a Tabela 7.4 apresenta as conclusões referentes às análises dos elementos não armados ao cisalhamento.

De forma a racionalizar as conclusões, elaborou-se uma nomenclatura para indicar, de forma clara, a qualificação de cada modelo de predição de norma em relação à aplicabilidade, nos intervalos estudados. Além disso, mesmo utilizando estas nomenclaturas houve intervenções pontuais, nas análises, de forma que se tivesse, pelo menos, uma norma recomendada ao uso, em cada intervalo de estudado.

Para as análises da exatidão e precisão dos modelos de predição das normas, se indicou como exata, "EX", a norma que apresentou o valor de média geométrica das razões $V_{\text {exp }} / V_{\mathrm{u}}$ entre 0,9 e 1,1, e se indicou como precisa. "PR", a norma que apresentou valor de coeficiente de variação (afastamento) menor ou igual a $20 \%$, conforme resumido na Tabela 7.1. 
Tabela 7.1: Siglas utilizadas para classificar os modelos de predição das normas quanto à exatidão e precisão

\begin{tabular}{|c|c|}
\hline $\begin{array}{c}\text { Classificação quanto a } \\
\text { exatidão e precisão }\end{array}$ & Sigla \\
\hline EXATO & EX \\
\hline PRECISO & PR \\
\hline EXATO E PRECISO & EX PR \\
\hline
\end{tabular}

Para as análises de segurança dos modelos de predição das normas quanto a sua utilização, definiram-se algumas siglas que permitem identificar as normas, cujo resumo se encontra na Tabela 7.2.

Utilizou-se a nomenclatura Menos recomendado por questões de segurança, "MS" aos modelos de predição de normas que apresentaram mais de $1 \%$ das previsões de resistência teórica ultima consideradas perigosas, num certo intervalo de estudo. Nesta classe de qualificação, entende-se que o modelo que apresentasse mais do que $1 \%$ de casos considerados perigosos seria um modelo possivelmente inseguro, para aquele intervalo.

Definiu-se a classe de qualificação Cautela/Custo, "CC", aos casos em que a porcentagem de previsões consideradas onerosas ultrapassasse o limite de $85 \%$, determinando assim, que o modelo da norma resultou numa segurança adequada para o uso, porém deve-se ter cautela, pois os resultados podem ser onerosos quando aplicados a um intervalo de estudo específico.

A classe de qualificação Cautela/Segurança, "CS", indica que os modelos de predição das normas que apresentaram porcentagem de previsões com baixa segurança maiores que $10 \%$, representam uma menor segurança quanto sua utilização, e deve-se ter cautela ao utilizá-las, pois os resultados podem implicar em menores coeficientes de segurança, como por exemplo, redução da segurança destinada a cobrir uma baixa resistência dos materiais empregados. Em casos de retroanálise, por exemplo, que se tem grande parte das informações das resistências dos materiais empregados, mediante a execução de ensaios, é possível ser mais permissivo e utilizar estes modelos, mediante o fato que não se detectou baixas resistências nos materiais empregados.

Sendo assim, apresentada a nomenclatura utilizada e baseando-se nas discussões e resultados apresentados no desenvolvimento desta dissertação, pode-se tecer as conclusões, conforme apresentadas em seguida.

Ressalta-se que, na utilização de todas as formulações de norma, para se obter o valor da força de cisalhamento resistente ultima do elemento de concreto armado, otimizaram-se as rotinas de cálculo de forma a se resultar no maior esforços resistente possível, desde que todas as verificações e condições de norma não fossem desrespeitadas. Por exemplo, utilizando o modelo II da norma NBR 6118 (2007) para o cálculo da força resistente ultima, definiu-se o ângulo de inclinação da biela mínimo que resulta-se na máxima força resistente, sem que a verificação do esmagamento do concreto fosse desrespeitada e escoamento das armaduras de flexão. 
O termo segurança empregado refere-se ao modelo de predição de norma, que por sua vez não é responsável por toda a segurança da norma. Ao indicar um modelo de predição de normaca como menos recomendado por questão de segurança, não significa que a norma não seja segura, apenas que o modelo prevê valores da resistência teórica última otimistas e que podem resultar em situações inseguras. Existem diversas exigências, que complementam a segurança do modelo de predição e compõe a segurança da norma, garantido assim a segurança da norma.

Tabela 7.2: Siglas utilizadas para qualificar os modelos de predição das normas quanto ao uso

\begin{tabular}{|c|c|c|}
\hline Qualificação quanto ao uso & Sigla & Critério* \\
\hline Recomendado & $\mathrm{R}$ & \\
\hline $\begin{array}{c}\text { Menos recomendado por questão de } \\
\text { segurança }\end{array}$ & $\mathrm{MS}$ & $\%$ Perigosa $>1 \%$ \\
\hline Cautela/Custo & $\mathrm{CC}$ & $\%$ Onerosa $\geq 85 \%$ \\
\hline Cautela/Segurança & CS & $\%$ Baixa segurança $\geq 10 \%$ \\
\hline * Critério orientativo
\end{tabular}

\subsection{Resumo das análises dos elementos armados ao cisalhamento com estribos}

De forma a organizar as conclusões, serão apresentados em subitens os resultados obtidos nas análises dos valores de predição de norma e valores experimentais para elementos em concreto armado com estribos.

A Tabela 7.3 expressa os resultados da aplicação dos critérios de análise das normas frente sua aplicabilidade em intervalos definidos de parâmetros. Cada conclusão, referente a um intervalo de análise apresenta-se nos itens a seguir.

\subsubsection{Elementos com estribos, parâmetros dentro dos intervalos válidos e ruptura por força cortante-tração}

Os resultados apresentados se referem aos casos de elementos com estribos, que tiveram suas rupturas, nos ensaios, do tipo força cortante-tração e com os parâmetros considerados válidos, ou seja, dentro dos intervalos permitidos.

Taxa mecânica de armadura transversal, $\rho s w . f y k$, menor que $1 \mathrm{MPa}$

Para predições dos valores de resistência ao cisalhamento para elementos com estribos e taxa mecânica menor que $1 \mathrm{MPa}$, constatou-se que:

A utilização do modelo I da norma NBR 6118 (2007), no intervalo psw.fyk $\leq 1$ $\mathrm{MPa}$, é menos recomendada, pois apresentou $2 \%$ dos casos de predição considerados perigosos.

O modelo II da norma NBR 6118 (2007), também, teve sua utilização considerada menos recomendada, pois apresentou $8 \%$ dos casos de predição considerados perigosos, apesar de apresentar da boa exatidão dos valores previsto, devido à média de $V_{\text {exp }} / V_{u}$, ser igual a 1,09 . Sendo assim, neste caso, fica evidente que o modelo apresentou, na média, valores de $V_{\text {exp }} / V_{u}$ próximos 
do valor unitário, porém com um afastamento grande entre valores individuais de $V_{\text {exp }} / V_{\mathrm{u}}$ e valor médio de $V_{\text {exp }} / V_{\mathrm{u}}$, gerando uma dispersão. Esta dispersão resultou no caráter pouco seguro da norma.

O modelo de predição da norma Eurocode (2004) apresentou-se como aplicável ao uso, porém com cautela em relação a custos maiores, pois apresentou $89 \%$ dos valores de predição onerosos.

O modelo de predição da norma $\mathrm{ACl}$ (2008) apresentou bons resultados de valores de predição de norma, podendo, considerá-la recomendada ao uso, neste intervalo de aplicação, devido à constatação de $15 \%$ dos valores de predição considerados apropriados, porcentagens pouco relevantes de previsões perigosas e de baixa segurança, $1 \%$ e $2 \%$, respectivamente.

Por último, o modelo de predição da norma CSA (2004) foi qualificado como recomendada ao uso, devido ao ótimo desempenho em termos de precisão e segurança. $O$ afastamento entre os valores de predição e o valor médio das previsões foi baixo, caracterizado pelo coeficiente de variação (afastamento) de $18,1 \%$. Além disso, em questões de segurança, apesar da porcentagem de $80 \%$ de previsões onerosas, apresentou $18,6 \%$ de previsões apropriadas e porcentagens pouco significativas de previsões perigosas e de baixa segurança, $0,4 \%$ e $0,8 \%$, respectivamente.

Taxa mecânica de armadura transversal, $\rho s w . f y k$, maior que $1 \mathrm{MPa}$ e menor ou igual a $2 \mathrm{MPa}$

As previsões feitas utilizando o modelo de predição da norma Eurocode (2004) apresentaram resultados insatisfatórios, em relação à segurança, devido à porcentagem de $12 \%$ de casos perigosos.

A utilização do modelo II da norma NBR 6118 (2007) resultou numa porcentagem de $2 \%$ de casos perigosos, não podendo assim, ser a mais recomendada ao uso.

O modelo de predição da norma $\mathrm{ACl}$ (2008) apresentou resultados de valores individuais de $V_{\text {exp }} / V_{\mathrm{u}}$ com pequenas dispersões em relação ao valor médio de $V_{\text {exp }} / V_{\mathrm{u}}$, caracterizando uma pequena dispersão dos valores, representado assim, pelo coeficiente de variação (afastamento) igual a 18,5\%. Além disso, o modelo de predição da norma se mostrou recomendado ao uso, porém devendo ter cautela em relação a custos maiores, devido à porcentagem de 90 $\%$ dos casos de predição considerados onerosos e apenas $10 \%$ dos casos, considerados, apropriados.

O modelo de cálculo I da norma NBR 6118 (2007) apresentou 86\% das previsões, consideradas, onerosas, indicando um caráter oneroso, porém seguro, sendo assim, o seu uso é recomendado mediante cautela.

O modelo de predição da norma CSA (2004) apresentou bons resultados em relação à dispersão, com coeficiente de variação (afastamento) dos valores de $V_{\text {exp }} / V_{\mathrm{u}}$, igual a $17,5 \%$. Devido às porcentagens nulas de casos perigosos e de 
baixa segurança, $19 \%$ de casos apropriados e $81 \%$ de casos onerosos, classificou-se o modelo de predição da norma como recomendado ao uso.

Taxa mecânica de armadura transversal, $\rho$ sw.fyk, maior que $2 \mathrm{MPa}$

As previsões feitas utilizando o modelo de predição da norma Eurocode (2004) apresentaram resultados insatisfatórios, em relação à segurança, devido à porcentagem de $7 \%$ de casos perigosos, apesar de apresentar uma média dos valores de $V_{\text {exp }} / V_{u}$ igual 0,988 e coeficiente de variação (afastamento) igual a $16,8 \%$.

A utilização do modelo de predição da norma $\mathrm{ACl}$ (2008) resultou numa porcentagem de $100 \%$ dos valores previstos, definidos como onerosos, tendo assim, sua utilização recomendada mediante cautela em relação aos custos.

O modelo de cálculo I da norma NBR 6118 (2007) apresentou $89 \%$ das previsões, consideradas, onerosas, indicando um caráter custoso, porém seguro, sendo assim, o seu uso é recomendado mediante cautela. Este modelo apresentou uma menor dispersão entre os valores individuais de $V_{\text {exp }} / V_{\mathrm{u}}$, e o valor médio, contabilizando assim, um valor de coeficiente de variação (afastamento) igual a $17,4 \%$.

O modelo de predição da norma CSA (2004) apresentou bons resultados em relação à dispersão, com coeficiente de variação (afastamento) dos valores de $V_{\text {exp }} / V_{\mathrm{u}}$, em relação ao valor médio, igual a $17,1 \%$. Devido às porcentagens nulas de casos perigosos e de baixa segurança, $19 \%$ de casos apropriados e $87 \%$ de casos onerosos, classificou-se o modelo de predição da norma como recomendado ao uso mediante a cautela em relação a custos.

A utilização do modelo II da norma NBR 6118 (2007) resultou numa porcentagem satisfatória dos valores de predição, considerados apropriados, $37 \%$, e baixa porcentagem de casos onerosos, $56 \%$, podendo-se assim ser recomendada ao uso. Verificou-se também, que a dispersão dos valores de $V_{\text {exp }} / V_{\mathrm{u}}$, em relação ao valor médio, medido pelo coeficiente de variação (afastamento) igual a 17\%, conferindo a esta norma uma precisão.

\subsubsection{Elementos com estribos, parâmetros fora dos intervalos válidos e ruptura por força cortante-tração}

Os resultados apresentados se referem aos casos de elementos com estribos, que tiveram suas rupturas, nos ensaios, do tipo força cortante-tração e com os parâmetros considerados não válidos, ou seja, algum parâmetro de ensaios ficou fora dos intervalos permitidos.

Destaca-se que não é recomendado desobedecer aos critérios e limites das normas na elaboração de projetos, por questões de segurança. Este tópico revela a aderência dos modelos de predição de norma quando utilizados fora dos intervalos considerados válidos, subsidiando assim estudos e decisões futuras para aumentar ou diminuir os intervalos de validade dos modelos, ou ainda melhorar a exatidão dos modelos. 
Taxa mecânica de armadura transversal, $\rho s w . f y k$, menor que a taxa mínima recomendada por norma, $\rho s w . f y k$, min

A utilização do modelo I da norma NBR 6118 (2007), é menos recomendada, pois apresentou $25 \%$ dos casos de predição considerados perigosos, apesar o modelo de cálculo apresentar um ajuste em relação aos valores médios de $V_{\text {exp }} / V_{\mathrm{u}}$, devido à obtenção de uma média igual a 0,943.

O modelo II da norma NBR 6118 (2007), também, teve sua utilização considerada menos recomendada, pois apresentou $17 \%$ dos casos de predição considerados perigosos, apesar de apresentar da boa exatidão dos valores previsto, devido à média de $V_{\text {exp }} / V_{\mathrm{u}}$, ser igual a 1,026.

Para ambos os modelos de cálculo da norma NBR 6118 (2007) fica evidente que os modelos apresentaram, na média, valores de $V_{\text {exp }} / V_{\mathrm{u}}$ próximos do valor unitário, porém com um afastamento grande entre valores individuais de $V_{\text {exp }} / V_{\mathrm{u}}$ e valor médio de $V_{\text {exp }} / V_{\mathrm{u}}$, gerando uma dispersão. Esta dispersão resultou no caráter menos seguro do modelo de predição da norma.

O modelo de predição da norma $\mathrm{ACl}$ (2008) foi considerado menos recomendado ao uso neste intervalo, pois apresentou $17 \%$ dos casos de predição, considerados, perigosos.

O modelo de predição da norma Eurocode (2004) apresentou $100 \%$ dos valores de predição, considerados, onerosos, tendo o seu uso recomendado mediante cautela em relação a custos.

Em fim, o modelo de predição da norma CSA (2004) foi qualificado como recomendado ao uso, devido ao ótimo desempenho em questões de segurança, com uma porcentagem de $79 \%$ de previsões onerosas, $21 \%$ de previsões apropriadas e porcentagens nulas de previsões perigosas e de baixa segurança.

\subsubsection{Elementos com estribos, solicitados por esforços axiais e ruptura por força cortante-tração}

Os resultados apresentados se referem aos casos de elementos com estribos, que tiveram suas rupturas, nos ensaios, do tipo força cortante-tração quando solicitados concomitantemente por esforços normais axiais de compressão ou tração, conforme indicado nos itens seguintes.

\section{Elementos solicitados por esforço axial de compressão}

O modelo de predição da norma CSA (2004) foi qualificado como menos recomendado por questão de segurança, pois apresentou $13 \%$ dos valores de predição, considerados, perigosos.

Os modelos I e II da norma NBR 6118 (2007) e o modelo de predição da norma $\mathrm{ACl}$ (2008) apresentaram 100\% dos valores de predição considerados onerosos, caracterizando assim dimensionamentos seguros, apesar de maiores custos de execução. Desta forma, estes modelos foram qualificados como recomendados ao uso mediante cautela devido a maiores custos. Além 
disso, estas normas apresentaram menores dispersões entre os valores individuais de $V_{\text {exp }} / V_{\mathrm{u}}$, em relação aos valores médios, caracterizadas pelos valores de coeficiente de variação (afastamento) iguais a $9 \%, 8,5 \%$ e 7,7 \%, respectivamente.

O modelo de predição da norma Eurocode (2004) apresentou 53\% dos valores de predição, considerados, onerosos, e $47 \%$, apropriados. Desta forma, foi considerado recomendado ao uso nestas condições.

\section{Elementos solicitados por esforço axial de tração}

O modelo de predição da norma CSA (2004) foi qualificado como menos recomendada por questão de segurança, pois apresentou $29 \%$ dos valores de predição, considerados, perigosos.

O modelo de predição da norma Eurocode (2004), devido à porcentagem de 29 $\%$ dos valores de predição, considerados, de baixa segurança, optou-se por considerá-lo menos recomendado ao uso, por questões de segurança. Como os elementos sujeitos a esforços axiais de tração caracterizam, atualmente, situações de possível insegurança para a maioria dos calculistas de estruturas, uma porcentagem de $29 \%$ não foi permitida.

O modelo de predição da norma $\mathrm{ACl}$ (2008) apresentou $100 \%$ dos valores de predição, considerados, onerosos, indicando assim um comportamento seguro, porem relacionado a maiores custos. Desta forma, este modelo foi considerado recomendado ao uso mediante cautela em relação a custo.

Os modelos I e II da norma NBR 6118 (2007) apresentaram os melhores resultados de predição de norma, com $86 \%$ e $57 \%$, dos valores de predição, considerados onerosos, respectivamente. Apresentaram porcentagens nulas de casos perigosos e de baixa segurança, e $14 \%$ e $43 \%$ de porcentagem de casos, considerados, apropriados, respectivamente. Além disto, ambos os modelos apresentaram baixas dispersões de resultados, representadas pelos valores de coeficiente de variação (afastamento) iguais a 12\% e 11,5\%, respectivamente. Por fim, ambos os modelos são recomendados ao uso nestas condições de aplicação.

\subsubsection{Elementos com estribos e ruptura por esmagamento do concreto}

Os resultados apresentados se referem aos casos de elementos com estribos, que tiveram suas rupturas, nos ensaios, caracterizadas pelo tipo força cortantecompressão, ou seja, esgotamento da capacidade resistente do concreto das bielas.

O modelo II da norma NBR 6118 (2007) foi qualificado como recomendada ao uso, porém mediante cautela em relação à segurança, pois a obtenção de $5 \%$ dos casos, considerados, de baixa segurança. Ressalta-se a importância de um bom controle na confecção do concreto e moldagem das peças, pois estes elementos, nestas condições, dependem essencialmente à resistência do concreto a compressão, para garantir a resistência ao cisalhamento. 
O modelo de predição da norma Eurocode (2004) apresentou $100 \%$ dos valores de predição, considerados, onerosos, indicando assim valores seguros de respostas, porém com possibilidade de maiores custos de execução. Por outro lado, notou-se que o comportamento da norma, segundo os critérios de exatidão e predição foram considerados adequados, devido aos valores de média igual a 1,063 e coeficiente de variação (afastamento), 18,6\%. Sendo assim, esta norma teve seu uso qualificado como recomendado mediante cautela em relação a custos. $\mathrm{Na}$ análise desta norma, verificou-se a porcentagem de $25 \%$ dos valores de predição de norma dentro do intervalo de baixa segurança, e sabendo que o estado limite ultimo de compressão das bielas depende praticamente da resistência a compressão, neste caso, se faz uma ressalva de que as condições de confecção e aplicação do concreto devem ser bem controladas.

O modelo de predição da norma $\mathrm{ACl}$ (2008) apresentou $100 \%$ dos valores de predição, considerados, onerosos, resultando numa qualificação de recomendado ao uso mediante cautela em relação a custos. Como atualmente o custo do aço de armação é mais significativo que o custo do concreto, possivelmente a utilização desta norma no dimensionamento de elementos de concreto armado não resulte em custos tão elevados.

O modelo de predição da norma CSA (2004) e o modelo I da norma NBR 6118 (2007) apresentaram comportamentos semelhantes, com $85 \%$ dos casos de predição qualificados como onerosos e $15 \%$ dos casos, apropriados, recebendo assim a recomendação ao uso. Nota-se também que ambos os modelos se destacaram em relação aos critérios de precisão, devido à obtenção dos valores de coeficiente de variação (afastamento) iguais a 16,3\% e $14,3 \%$ respectivamente.

\subsection{Resumo das análises dos elementos não armados ao cisalhamento}

Os subitens seguintes fazem referencia os resultados obtidos nas análises dos valores de predição de norma e valores experimentais para elementos em concreto armado sem estribos.

A Tabela 7.4 expressa os resultados da aplicação dos critérios de análise dos modelos das normas frente sua aplicabilidade em intervalos definidos de parâmetros. Cada conclusão, referente a um intervalo de análise apresenta-se nos itens a seguir.

\subsubsection{Elementos sem estribos, parâmetros dentro dos intervalos válidos e ruptura por força cortante-tração}

Os resultados apresentados se referem aos casos de elementos sem estribos, que tiveram suas rupturas, nos ensaios, do tipo força cortante-tração e com os parâmetros considerados válidos, ou seja, dentro dos intervalos permitidos.

Taxa geométrica de armadura longitudinal, $\rho$ l, menor ou igual a 1,5\%

O modelo de predição da norma $\mathrm{ACl}$ (2008), para a predição dos valores de resistência ao cisalhamento para elementos cujas taxas geométricas de 
armadura longitudinal, $\rho l$, eram menores ou iguais a 1,5\%, apresentou $18 \%$ dos valores, considerados, perigosos, o que permitiu atribuir a qualificação de menos recomendado ao uso nestas condições e intervalos de utilização, por questões de segurança. De forma semelhante, o modelo da norma NBR 6118 (2007), com uma porcentagem de $9 \%$ de possíveis casos perigosos, foi qualificado como menos recomendado ao uso. Ambas os modelos de norma apresentaram como média dos valores individuais de $V_{\text {exp }} / V_{\mathrm{u}}$, próximos do valor unitário.

Os valores de predição do modelo da norma Eurocode (2004) tiveram uma porcentagem de $16 \%$ enquadrada na faixa de baixa segurança, $58 \%$ adequadas, $25 \%$ onerosa e apenas $1 \%$, na faixa perigosa. Sendo assim, a utilização deste modelo de norma, nestas condições, foi qualificado como recomendado mediante atenção e cautela em relação à segurança. O modelo da norma apresentou valor da média dos valores individuais de $V_{\text {exp }} / V_{\mathrm{u}}$, próximo do valor unitário e coeficiente de variação (afastamento) de 18,8 \% conferindo assim, um modelo exato e preciso.

O modelo de predição da norma CSA (2004) teve seu uso recomendado, mediante a apresentação de porcentagens pouco expressivas de valores de predição perigosos e de baixa segurança, $1 \%$ para ambos. Ainda assim, apresentou $27 \%$ dos valores dentro da faixa apropriada e $71 \%$ da faixa onerosa. A dispersão dos valores individuais de $V_{\text {exp }} / V_{u}$, em relação ao valor médio foi representada pelo coeficiente de correlação (afastamento) igual a $18,4 \%$, indicando assim uma precisão razoável.

Taxa geométrica de armadura longitudinal, $\rho$, maior do que $1,5 \%$ e menor ou igual a 3,0\%

Os valores de predição dos modelos das normas ACl (2008) e CSA (2004) apresentaram conclusões semelhantes. Os modelos apresentaram $87 \%$ e $88 \%$ destes valores, respectivamente, dentro da faixa onerosa, e porcentagens nulas na faixa perigosa, conferindo a eles a qualificação de recomendados mediante cautela em relação aos possíveis custos elevados. Apenas o modelo da norma CSA (2004), devido ao coeficiente de variação (afastamento) reduzido, $14 \%$, recebeu destaque quanto a precisão.

Os modelos de predição das normas Eurocode (2004) e NBR 6118 (2007) apresentaram $63 \%$ e $61 \%$ das previsões, consideradas apropriadas, porcentagens nulas de casos perigosos e porcentagens desprezíveis de valores com baixa segurança, podendo assim, indicá-los como modelos recomendados ao uso nesta faixa de parâmetros.

Taxa geométrica de armadura longitudinal, $\rho$, maior do que 3,0\%

Os valores de predição dos modelos das normas CSA (2004), Eurocode (2004) e NBR 6118 (2007) apresentaram resultados considerados bons, sendo os três recomendados ao uso. Os modelos das normas apresentaram $71 \%, 55 \%$ e 50 $\%$ dos valores de predição, considerados, onerosos, respectivamente, e porcentagens nulas de previsões perigosas ou de baixa segurança. Destas 
normas, apenas a CSA (2004) apresentou um menor coeficiente de variação (afastamento), igual a 17,3\%, conferindo Ihe uma precisão adequada.

Por fim o modelo da norma $\mathrm{ACl}$ (2008) foi qualificado como recomendado, porém, deve-se ter cautela ao utilizá-la, pois apresentou $100 \%$ dos valores de predição, considerados, onerosos.

Altura útil do elemento, $d$, menor ou igual a $25 \mathrm{~cm}$

Para este intervalo de estudo, os valores de predição dos modelos das normas ACl (2008) e CSA (2004) apresentaram conclusões semelhantes. Os modelos de norma apresentaram $96 \%$ e $93 \%$ destes valores, respectivamente, dentro da faixa onerosa, e porcentagens nulas na faixa perigosa, conferindo a eles a classificação de recomendados mediante cautela em relação aos possíveis custos elevados. Apenas a norma CSA (2004), devido ao coeficiente de variação (afastamento) reduzido, 17,6 \%, recebeu destaque quanto à precisão.

Os modelos de predição das normas Eurocode (2004) e NBR 6118 (2007) apresentaram $50 \%$ e $37 \%$ das previsões, consideradas apropriadas, porcentagens desprezíveis de casos perigosos e porcentagens não significativas de valores com baixa segurança, podendo assim, indicá-los como modelos recomendados ao uso nesta faixa de parâmetros.

Altura útil do elemento, d, maior do que $25 \mathrm{~cm}$ e menor ou igual a $60 \mathrm{~cm}$

O modelo de predição da norma $\mathrm{ACl}$ (2008), para a predição dos valores de resistência ao cisalhamento para elementos, neste intervalo de estudo, apresentou $4 \%$ dos valores, considerados, perigosos, o que permitiu atribuir a classificação de menos recomendado ao uso nestas condições e intervalos de utilização, por questões de segurança. De forma semelhante, o modelo da norma NBR 6118 (2007), com uma porcentagem de $3 \%$ de possíveis casos perigosos, foi classificado como menos recomendado ao uso, também. Apenas o modelo da norma NBR 6118 (2007) apresentou como média dos valores individuais de $V_{\text {exp }} / V_{\mathrm{u}}$, valor próximo ao valor unitário.

Os valores de predição do modelo da norma Eurocode (2004) tiveram uma porcentagem de $10 \%$ enquadrada na faixa de baixa segurança, $60 \%$ adequadas e $30 \%$ onerosa. Sendo assim, a utilização deste modelo de norma, nestas condições, foi qualificado como recomendado mediante atenção e cautela em relação à segurança. $\mathrm{O}$ modelo apresentou valor da média dos valores individuais de $V_{\text {exp }} / V_{\mathrm{u}}$, próximo do valor unitário e coeficiente de variação (afastamento) de 16,6 \% conferindo assim, um modelo exato e preciso.

O modelo de predição da norma CSA (2004) teve seu uso recomendado, mediante a apresentação de porcentagens pouco expressivas de valores de predição perigosos e de baixa segurança, menores do que $1 \%$ para ambos. Ainda assim, apresentou $22 \%$ dos valores dentro da faixa apropriada e $77 \%$ da faixa onerosa. A dispersão dos valores individuais de $V_{\text {exp }} / V_{u}$, em relação ao valor médio foi representada pelo coeficiente de correlação (afastamento) igual a 13,0 \%, indicando assim uma precisão razoável. 
Altura útil do elemento, d, maior do que $60 \mathrm{~cm}$

O modelo de predição da norma $\mathrm{ACl}$ (2008), para a predição dos valores de resistência ao cisalhamento para elementos, neste intervalo de estudo, apresentou $30 \%$ dos valores, considerados, perigosos, o que permitiu atribuir a qualificação de menos recomendado ao uso nestas condições e intervalos de utilização, por questões de segurança. De forma semelhante, o modelo da norma NBR 6118 (2007), com uma porcentagem de $9 \%$ de possíveis casos perigosos, foi qualificado como não recomendado ao uso, também. Ambos os modelos apresentaram valores de coeficiente de variação (afastamento) iguais a $19,1 \%$ e $15,6 \%$, respectivamente.

Os valores de predição do modelo da norma Eurocode (2004) tiveram uma porcentagem de $19 \%$ enquadrada na faixa de baixa segurança, $72 \%$ adequadas e $9 \%$ onerosa. Sendo assim, a utilização deste modelo de norma, nestas condições, foi qualificado como menos recomendado ao uso, pois considerou a porcentagem de valores com baixa segurança preocupantes, para elementos sem estribos, cuja resistência depende praticamente da resistência do concreto utilizado. A norma apresentou valor da média dos valores individuais, de $V_{\text {exp }} / V_{u}$, próximo do valor unitário, 0,933 , e coeficiente de variação (afastamento) de 13,8 \% conferindo assim, um modelo exato e preciso.

O modelo de predição da norma CSA (2004) teve seu uso recomendado, mediante a apresentação de porcentagens pouco expressivas de valores de predição perigosos e de baixa segurança, $0 \%$ e $2 \%$ respectivamente. Ainda assim, apresentou $41 \%$ dos valores dentro da faixa apropriada e $57 \%$ da faixa onerosa. A dispersão dos valores individuais de $V_{\text {exp }} / V_{u}$, em relação ao valor médio foi representada pelo coeficiente de correlação (afastamento) igual a $15,2 \%$, indicando assim uma precisão razoável.

\subsubsection{Elementos sem estribos, parâmetros fora dos intervalos válidos e ruptura por força cortante-tração}

Os resultados apresentados se referem aos casos de elementos sem estribos, que tiveram suas rupturas, nos ensaios, do tipo força cortante-tração e com os parâmetros considerados não válidos, ou seja, fora dos intervalos permitidos.

Taxa geométrica de armadura longitudinal, $\rho$, menor ou igual a 1,5\%

Os modelos de predição das normas NBR 6118 (2007), ACI (2008) e Eurocode (2004) apresentaram porcentagens dos valores de predição considerados perigosos, iguais a $70 \%, 38 \%$ e $34 \%$, respectivamente, o que permitiu atribuir a eles, a qualificação de menos recomendados ao uso, nestas condições e intervalos de utilização, por questões de segurança.

O modelo da norma CSA (2004) teve seu uso recomendado, mediante a apresentação de porcentagens pouco expressivas de valores de predição perigosos e de baixa segurança, $0 \%$ e $3 \%$ respectivamente. Ainda assim, apresentou $18 \%$ dos valores dentro da faixa apropriada e $79 \%$, da faixa onerosa. 
Taxa geométrica de armadura longitudinal, $\rho$, maior do que $1,5 \%$ e menor ou igual a 3,0\%

Para este intervalo de utilização, o modelo de predição da norma NBR 6118 (2007) foi qualificado como menos recomendado ao uso devido a questões de baixa segurança, pois apresentou porcentagem de valores de predição perigos igual a $31 \%$.

O modelo de predição da norma Eurocode (2004) apresentou uma porcentagem de $9 \%$ dos valores de predição, referente ao intervalo de baixa segurança, $71 \%$ no intervalo apropriado e $20 \%$, no intervalo oneroso, sendo assim, este pôde ser qualificado como recomendado ao uso, mediante cautela, em relação à segurança.

O modelo de predição da norma CSA (2004) foi qualificado como recomendada ao uso, porém com cautela em relação a possíveis custos elevados, devido à porcentagem de $93 \%$ dos valores de predição de norma, contemplados no intervalo de dados onerosos, e também, por obter porcentagens nulas de dados perigosos ou de baixa segurança.

O modelo de predição da norma $\mathrm{ACl}$ (2008) foi qualificado como recomendado ao uso, por apresentar porcentagens nulas de valores de predição, considerados, de baixa segurança ou perigosos, e porcentagens de $22 \%$ e 78 $\%$ para os casos de segurança apropriada e onerosos, respectivamente.

Taxa geométrica de armadura longitudinal, $\rho$, maior do que 3,0\%

O modelo de predição da norma NBR 6118 (2007) apresentou uma porcentagem de $27 \%$ dos valores de predição, referente ao intervalo de baixa segurança e porcentagem nula de previsões perigosas, conferindo-lhe assim, a qualificação de apropriado ao uso mediante cautela em relação à segurança.

Para este intervalo de estudo, os valores de predição das normas ACl (2008) e CSA (2004) apresentaram conclusões semelhantes. As normas apresentaram $100 \%$ e $89 \%$ destes valores, respectivamente, dentro da faixa onerosa, e porcentagens nulas na faixa perigosa, conferindo a elas a classificação de recomendada mediante cautela em relação aos possíveis custos elevados.

O modelo de predição da norma Eurocode (2004) foi qualificado como recomendado ao uso, por apresentar porcentagens nulas de valores de predição, considerados, de baixa segurança ou perigosos, e porcentagens de $21 \%$ e $79 \%$ para os casos de segurança apropriada e onerosos, respectivamente.

Altura útil do elemento, d, menor ou igual a $25 \mathrm{~cm}$

Os modelos de predição das normas NBR 6118 (2007) e Eurocode (2004) apresentaram porcentagens dos valores de predição considerados perigosos, iguais a $16 \%$ e $2 \%$, respectivamente, o que permitiu atribuir a eles, a qualificação de menos recomendados ao uso, nestas condições e intervalos de utilização, por questões de segurança. 
O modelo de predição da norma CSA (2004) foi qualificado como recomendado ao uso, porém, deve-se ter cautela ao utilizá-la, pois apresentou $86 \%$ dos valores de predição, considerados, onerosos, e apenas $14 \%$, apropriados, indicando um caráter conservador, mas também, oneroso.

O modelo de predição da norma $\mathrm{ACl}$ (2008) teve seu uso recomendado, mediante a apresentação de porcentagens nulas de valores de predição perigosos e de baixa segurança. Ainda assim, apresentou $25 \%$ dos valores dentro da faixa apropriada, e $75 \%$, da faixa onerosa.

Altura útil do elemento, d, maior do que $25 \mathrm{~cm}$ e menor ou igual a $60 \mathrm{~cm}$

Os modelos de predição das normas NBR 6118 (2007), ACl (2008) e Eurocode (2004) apresentaram porcentagens dos valores de predição, considerados, perigosos, iguais a $23 \%, 13 \%$ e $2 \%$, respectivamente, o que permitiu atribuir a eles, a qualificação de não recomendados ao uso, nestas condições e intervalos de utilização, por questões de segurança.

O modelo de predição da norma CSA (2004) teve seu uso recomendado, mediante a apresentação de porcentagens nulas de valores de predição perigosos e de baixa segurança. Ainda assim, apresentou $4 \%$ dos valores dentro da faixa apropriada e $96 \%$, da faixa onerosa. A priori, este modelo de norma deveria ser qualificado como recomendado ao uso mediante cautela em questões relacionadas aos custos, porém, como neste intervalo, não foi possível considerar nenhum outro modelo de norma, recomendado, a CSA (2004) foi eleita recomendada.

Altura útil do elemento, $d$, maior do que $60 \mathrm{~cm}$

Os modelos de predição das normas NBR 6118 (2007), ACl (2008) e Eurocode (2004) apresentaram porcentagens dos valores de predição, considerados, perigosos, iguais a $84 \%, 47 \%$ e $52 \%$, respectivamente, o que permitiu atribuir a eles, a qualificação de menos recomendados ao uso, nestas condições e intervalos de utilização, por questões de segurança.

O modelo de predição da norma CSA (2004) teve seu uso recomendado, mediante a apresentação de porcentagem nula de valores de predição perigosos, e $5 \%$ de baixa segurança. Ainda assim, apresentou $24 \%$ dos valores dentro da faixa apropriada e $71 \%$, da faixa onerosa, conferindo assim a qualificação indicada.

\subsubsection{Elementos com estribos, solicitados por esforços axiais e ruptura por força cortante-tração}

Os resultados apresentados se referem aos casos de elementos sem estribos, que tiveram suas rupturas, nos ensaios, do tipo força cortante-tração quando solicitados concomitantemente por esforços normais axiais de compressão ou tração, conforme indicado nos itens seguintes. 


\section{Elementos solicitados por esforço axial de compressão}

O modelo de predição da norma NBR 6118 (2007) apresentou $5 \%$ dos casos de predição considerados perigosos, qualificando-o, como menos recomendado ao uso. O modelo da norma Eurocode (2004) apresentou uma porcentagem de $24 \%$ dos valores de predição, dentro da faixa de baixa segurança, conferindo-lhe o caráter de recomendado ao uso, porém com muita cautela em relação à segurança.

Os modelos de predição das normas CSA (2004) e ACl (2008) deveriam, a priori, ser qualificados como recomendados ao uso, mediante cautela em sua utilização, devido a possíveis custos elevados. Porém de forma a qualificar, pelo menos um modelo de norma como recomendado ao uso, definiu-se que apesar dos modelos apresentarem, $100 \%$ e $95 \%$ dos valores de predição, considerados, onerosos, indicou-se como recomendados ao uso.

\section{Elementos solicitados por esforço axial de tração}

Para este intervalo de estudo, os valores de predição dos modelos das normas ACl (2008) e CSA (2004) apresentaram conclusões semelhantes. Os modelos das normas apresentaram $92 \%$ e $100 \%$ destes valores, respectivamente, dentro da faixa onerosa, e porcentagens nulas na faixa perigosa, conferindo a elas a qualificação de recomendado ao uso, mediante cautela em relação aos possíveis custos elevados. Apenas o modelo da norma CSA (2004), devido ao coeficiente de variação (afastamento) reduzido, 13,1\%, recebeu destaque quanto à precisão.

Os modelos de predição das normas Eurocode (2004) e NBR 6118 (2007) apresentaram $50 \%$ e $59 \%$ das previsões, consideradas apropriadas, porcentagens nulas de casos perigosos e porcentagens não significativas de valores com baixa segurança, podendo assim, indicá-los como modelos recomendados ao uso nesta faixa de parâmetros. 
Tabela 7.3: Qualificação dos modelos de predição das normas, quanto à exatidão, precisão e segurança ao uso, para elementos com estribos

\begin{tabular}{|c|c|c|c|c|c|c|c|}
\hline & \multicolumn{7}{|c|}{ Elementos com Estribos } \\
\hline & \multicolumn{3}{|c|}{ Intervalos Válidos } & \multirow{2}{*}{\begin{tabular}{|l|} 
Intervalos não Válidos \\
psw.fyk < $\rho s w . f y k, m i n$ \\
\end{tabular}} & \multicolumn{2}{|c|}{ Esforços Axiais $^{a}$} & \multirow{2}{*}{$\frac{\text { Esmagamento }^{\mathrm{a}}}{-}$} \\
\hline & psw.fyk $\leq 1$ & $1<$ psw.fyk $\leq 2$ & $\rho s w . f y k>2$ & & Compressão & Tração & \\
\hline CSA & PR & PR & PR & & & EX & PR \\
\hline EURO & & & EX PR & & & & EX PR \\
\hline $\mathrm{ACl}$ & & PR & & & PR & & \\
\hline NBR I & & & PR & EX & PR & PR & PR \\
\hline \multirow[t]{4}{*}{ NBR II } & EX & & PR & EX & PR & PR & PR \\
\hline & \multicolumn{7}{|c|}{ Elementos com Estribos } \\
\hline & \multicolumn{3}{|c|}{ Intervalos Válidos } & Intervalos não Válidos & \multicolumn{2}{|c|}{ Esforços Axiais $^{a}$} & Esmagamento $^{\mathrm{a}}$ \\
\hline & psw.fyk $\leq 1$ & $1<\rho s w . f y k \leq 2$ & psw.fyk > 2 & psw.fyk $\leq \rho s w . f y k$,min & Compressão & Tração & - \\
\hline CSA & $\mathbf{R}$ & $\mathbf{R}$ & $\mathrm{CC}$ & $\mathbf{R}$ & MS & MS & $\mathbf{R}$ \\
\hline EURO & $\mathrm{CC}$ & MS & MS & $\mathrm{CC}$ & $\mathbf{R}$ & MS & $\mathrm{CC}$ \\
\hline $\mathrm{ACl}$ & $\mathbf{R}$ & $\mathrm{CC}$ & $\mathrm{CC}$ & MS & $\mathrm{CC}$ & $\mathrm{CC}$ & $\mathrm{CC}$ \\
\hline NBR I & MS & CC & CC & MS & CC & $\mathbf{R}$ & $\mathbf{R}$ \\
\hline NBR II & MS & MS & $\mathbf{R}$ & MS & CC & $\mathbf{R}$ & CS \\
\hline & ${ }^{a}$ Conclusõe & ualitativas $d$ & vido ao nú & ero reduzido de dado & & & \\
\hline & Obs: Os valore & das taxas mecâni & ica de estribo: & s,psw.fyk, estão expresso & em MPa & & \\
\hline
\end{tabular}


Tabela 7.4: Qualificação dos modelos de predição das normas, quanto à exatidão, precisão e segurança ao uso, para elementos sem armadura ao cisalhamento

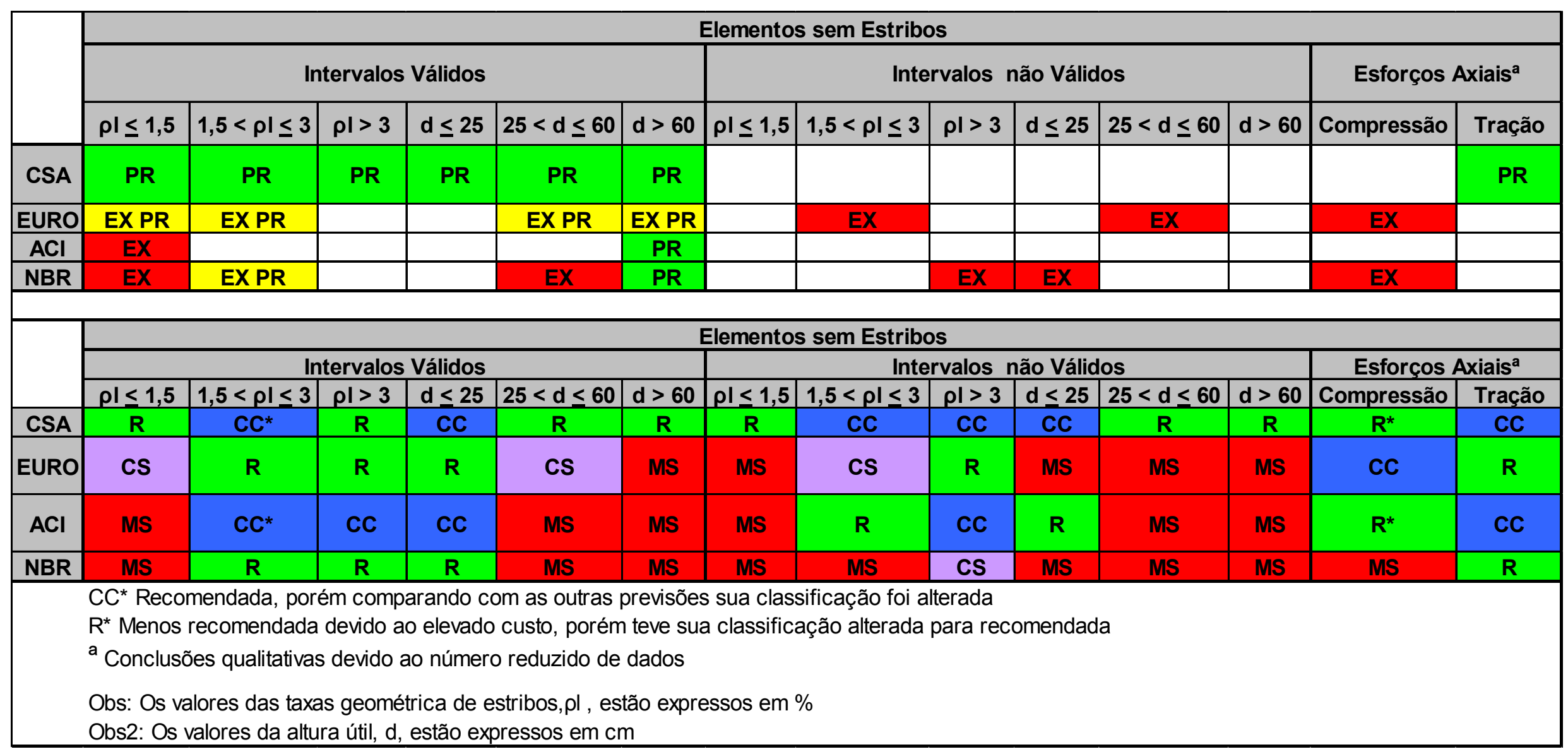




\section{Conclusões Finais}

A análise paramétrica apresentada no item 6.1 , mostrou que os modelos de predição das normas apresentam comportamentos distintos em alguns intervalos de parâmetros. Tanto para elementos armados transversalmente com estribos, quanto para elementos não armados, os resultados obtidos na comparação entre os valores de predição dos modelos das normas CSA (2004), Eurocode (2004), ACl (2008) e NBR 6118 (2007), motivaram a análise comparativa entre os valores de predição e valores dos resultados de ensaios de laboratório.

Verificou-se que os critérios de homogeneização do banco de dados, dentro das suas limitações, apresentaram resultados satisfatórios, conseguindo assim, eliminar dados de ensaios que não apresentavam coerência com os demais resultados experimentais.

Pode-se concluir que a aplicação dos critérios de análise definidos neste trabalho, nos valores de ensaios dos bancos de dados e nos valores de predição teóricos ultimos, permitiu qualificar de forma objetiva e clara os diversos modelos de predição de norma, quanto à utilização para dimensionamento e verificação de elementos de concreto armado, submetidos a esforços de cisalhamento. É evidente que as conclusões deste trabalho estão intimamente relacionadas com o critério de análise e homogeneização desenvolvido.

O resumo de todas as análises efetuadas foi apresentado no item 7 , desta forma, com a finalidade de indicar sucintamente, quais são os modelos de norma recomendados e os menos recomendados ao uso, segundo a metodologia, elaboraram-se duas tabelas, Tabela 8.1 e Tabela 8.2. Os modelos de predição das normas recomendadas ao uso são aquelas que apresentaram valores de predição seguros e, possivelmente, econômicos, resultando na otimização dos materiais empregados. O fato de qualificar alguns modelos como menos recomendados, não significa que a utilização da norma não seja recomendada por questões de segurança. O objeto da análise é o modelo de predição, e os resultados apresentado permitem localizar os intervalos em que os modelos são menos recomendados e carecem de maiores estudos de forma a melhorar a exatidão e diminuir a imprecisão. A segurança da norma, que é diferente da segurança do modelo de predição, em seu sentido mais amplo, contempla diversos outros requisitos de detalhamento, sendo alguns, a determinação de valores característicos seguros para a resistência dos matériais, cálculo dos esforços solicitantes majorados, taxas de armação mínima, valores máximos e mínimos para certos parâmetros, o que garante utilizar as normas com segurança para dimensionamento e detalhamento dos elementos. 
A Tabela 8.1, apresenta as conclusões para as análises de elementos armados com estribos.

Tabela 8.1: Modelos de predição de norma recomendados e menos recomendados para análise de elementos com estribos, sendo: CSA - CSA (2004), EURO Eurocode (2004), ACI - ACI (2008), NBR I - modelo I da NBR 6118 (2007) e NBR II - modelo II da NBR 6118 (2007)

\begin{tabular}{|c|c|c|c|c|c|c|}
\hline \multirow{3}{*}{$\begin{array}{l}\text { Qualificação do } \\
\text { modelo de } \\
\text { predição }\end{array}$} & \multicolumn{6}{|c|}{ Elementos com Estribos } \\
\hline & \multicolumn{3}{|c|}{ Intervalos Válidos } & \multicolumn{2}{|c|}{ Esforços Axiais* } & \multirow{2}{*}{$\begin{array}{c}\text { Esmagamento* } \\
-\end{array}$} \\
\hline & $\begin{array}{c}\rho s w . f y k \\
M P a\end{array}$ & $\begin{array}{c}1<\rho s w . f y k \\
\mathrm{MPa}\end{array}$ & $\begin{array}{c}\text { psw.fyk }>2 \\
M P a\end{array}$ & Compressão & Tração & \\
\hline $\begin{array}{c}\text { Mais } \\
\text { Recomendado }\end{array}$ & $\mathrm{CSA} / \mathrm{ACl}$ & CSA & NBR II & EURO & NBR I e NBR II & CSA / NBR I \\
\hline $\begin{array}{c}\text { Menos } \\
\text { Recomendado } \\
\end{array}$ & NBR I / NBR II & EURO / NBR II & EURO & CSA & CSA / EURO & - \\
\hline
\end{tabular}

O modelo da norma CSA (2004), é o mais recomendado em 3 dos 6 casos estudados, e os modelos I e II da norma NBR 6118 (2007), juntos, são os mais recomendados em 2 casos. Por fim os modelos das normas ACl (2008) e Eurocode (2004), são recomendados apenas em um caso cada.

Os modelos de predição da norma NBR 6118 (2007) mostraram-se menos recomendados ao uso, no intervalo de taxa mecânica de armaduras menor ou igual que $1 \mathrm{MPa}$. Apenas o modelo II foi menos recomendado para taxa mecânica menor ou igual a $2 \mathrm{MPa}$.

A Tabela 8.2, apresenta as conclusões para as análises de elementos armados sem estribos.

O modelo da norma CSA (2004) é mais recomendado em 5 dos 8 casos de estudo, da norma Eurocode (2004) em 4, da norma NBR 6118 (2007) em 4 e por último, da $\mathrm{ACl}$ (2008) em 1 caso.

A aplicação do modelo da norma NBR 6118 (2007) não se mostrou a mais adequada na determinação exata e precisa da resistência ao cisalhamento para elementos sem estribos, nos casos de baixa taxa geométrica de armadura longitudinal $(\rho \mathrm{l} \leq 1,5 \%$ ), ou altura útil do elemento, $d$, maior que $25 \mathrm{~cm}$. Novamente, ressalta-se que, utilizando a metodologia de análise e critério de homogeneização definidas neste trabalho, pôde-se concluir que o modelo da NBR 6118 (2007) carece de maiores ajustes, porém deve-se notar que a norma brasileira não permite que elementos de vigas não sejam armados ao cisalhamento com pelo menos a taxa mínima de estribos, conferindo assim a segurança necessária para a utilização da norma. 
Tabela 8.2: Modelos de predição norma recomendados e menos recomendados para análise de elementos sem estribos, sendo: CSA - CSA (2004), EURO Eurocode (2004), ACI - ACI (2008) e NBR - NBR 6118 (2007)

\begin{tabular}{|c|c|c|c|c|c|c|}
\hline \multirow{3}{*}{$\begin{array}{c}\text { Qualificação do } \\
\text { modelo de } \\
\text { predição }\end{array}$} & \multicolumn{6}{|c|}{ Elementos sem Estribos } \\
\hline & \multicolumn{6}{|c|}{ Intervalos Válidos } \\
\hline & $\rho \mathrm{\rho}<1,5 \%$ & $1,5 \%<\rho \mid<3$ & pl > $3 \%$ & $d<25$ & $25<\mathrm{d}<60$ & $d>60$ \\
\hline $\begin{array}{c}\text { Mais } \\
\text { Recomendado }\end{array}$ & CSA & EURO / NBR & $\begin{array}{c}\text { CSA / EURO / } \\
\text { NBR }\end{array}$ & EURO / NBR & CSA & CSA \\
\hline $\begin{array}{c}\text { Menos } \\
\text { Recomendado } \\
\end{array}$ & $\mathrm{ACl} / \mathrm{NBR}$ & - & - & - & $\mathrm{ACl} / \mathrm{NBR}$ & $\begin{array}{c}\text { EURO / ACl / } \\
\text { NBR } \\
\end{array}$ \\
\hline \multirow{3}{*}{ Classificação } & \multicolumn{2}{|c|}{ Elementos sem Estribos } & & & & \\
\hline & \multicolumn{2}{|c|}{ Esforços Axiais* } & & & & \\
\hline & Compressão & Tração & & & & \\
\hline $\begin{array}{c}\text { Mais } \\
\text { Recomendado }\end{array}$ & $\mathrm{CSA} / \mathrm{ACl}$ & EURO / NBR & & & & \\
\hline $\begin{array}{c}\text { Menos } \\
\text { Recomendado }\end{array}$ & NBR & - & & & & \\
\hline
\end{tabular}

* Conclusões qualitativas devido ao número reduzido de dados

Por fim, conclui-se que o modelo da norma canadense CSA (2004), baseada na teoria do MCFT, apresentou a maior frequência de casos qualificados como recomendados para uso, e também, por conseguencia, os modelos das normas ASHTO-LRFD (2007) e o Código Modelo - FIB (2010), que apresentam valores de resistência ao cisalhamento semelhantes aos valores obtidos pelo modelo da norma CSA (2004).

Ressalta-se ainda, conforme já discutido, que o modelo II da NBR 6118 (2007), quando utilizado com o ângulo de inclinação da biela, $\theta$, aproximadamente igual a $39^{\circ}$, fornece resultados semelhantes aos do modelo I, da própria norma. Sendo assim, quando o modelo I da NBR 6118 (2007) apresenta resultados considerados recomendados, resultados semelhantes poderiam ser obtidos, utilizando o modelo II, utilizando um limite inferior do ângulo da biela de $39^{\circ}$. 


\section{Propostas para Pesquisas Futuras}

Propõem-se para novas pesquisas:

1. Aprimorar o modelo II da NBR 6118 (2007) com a implementação de correlações que permitam definir intervalos dinâmicos para o ângulo de inclinação da biela, ou seja, os valores limítrofes seriam obtidos em função dos valores dos diversos parâmetros a serem considerados;

2. Desenvolver um ou mais modelos de predição de comportamento, através da correlação com os resultados dos bancos de dados, podendo assim, diminuir a dispersão e melhorando a exatidão;

3. Efetuar uma análise estatística com caráter probabilístico dos modelos de predição, frente à comparação com os dados de ensaios, permitindo assim, a aplicação de métodos para a análise de confiabilidade;

4. Efetuar ensaios cujos parâmetros estejam fora do intervalo válido das normas, possibilitando correlacionar de forma segura, dados e valores de resposta dos modelos;

5. Verificar se não há relação entre os valores de resistência ultima ao cisalhamento e a taxa mecânica de armadura transversal (estribos), para elementos cuja ruptura se dê pelo esmagamento do concreto das bielas de compressão. Caso seja verificada tal relação, desenvolver modelo de predição ajustado para este fenômeno. 


\section{Referências Bibliográficas:}

ACHARYA DN, KEMP K.O. Significance of dowel forces on the shear failure of rectangular reinforced concrete beams without web reinforcement. ACl Journal, 62-69, 1965, p.1265-1278.

ACI-ASCE COMMITTEE 445. Recent Approaches to Shear Design of Strucutal Concrete (445R-99). ACl Journal, Proceedings, 1999.

ADEBAR, P.; COLLINS, M.P. Shear Strength of Members without Transverse Reinforcement. Canadian Journal of Civil Engineering, V.23, N.2, 1996. p.297-305.

AHMAD, S.H. ; KHALOO, A.R. ; POVEDA, A. Shear capacity of reinforced high-strength concrete beams. ACl Journal, March-April 1986, p.297-305.

AMERICAN ASSOCIATION OF STATE HIGHWAY AND TRANSPORTATION OFFICIALS. AASHTO LRFD Bridge Design Specifications, $4^{a}$ edição, Washington DC, Distrito de Colúmbia, Estados Unidos, 2007, 1512 p.

AMERICAN CONCRETE INSTITUTE (ACI), Committee 318: Building Code Requirements for Structural Concrete and Commentary (ACl 318-08), Detroit, 2008, 479 p.

ANDERSON, N.S.; RAMIREZ, J.A. Detailing of stirrup reinforcement. ACI Structural Journal, V.86, N.5, 1989. p.507-515.

ANGELAKOS, D. The influence of the concrete strength and longitudinal reinforcement ratio on the shear strength of large-size reinforced concrete beams with and without transverse reinforcement. M.A.Sc. thesis, Department of Civil Engineering University of Toronto, 1999.

ANGELAKOS, D.; BENTZ, E.C.; COLLINS, M.P. Effect of concrete strength and minimum stirrups on shear strength of large members. ACI Structural Journal, V.98, N.3, 2001. p.290-300.

ANGELAKOS, D.; BENTZ. E.C.; COLLINS, M.P. Effect of concrete strength and minimum stirrups on shear strength of large members. ACI Structural Journal, V.98, N.3, 2001. p. 290.

ASSOCIAÇÃO BRASILEIRA DE NORMAS TÉCNICAS. NBR 6118: Projeto de estruturas de concreto - Procedimento. Rio de Janeiro, Brasil, 2007. 221 p.

BAZANT, Z. P.; KAZEMI, M.T. Size Effect on Diagonal Shear Failure of Beams without Stirrups. ACI Structural Journal, V.88, N. 3, 1991. p.268-276.

BAZANT, Z. P.; SUN, H. H. Size Effect in Diagonal Shear Failure Influence of Aggregate Size and Stirrups. ACI Material Journal, V.84, N.4, 1987. p. 259.

BAZANT, Z.P.; KIM, J.K. Size Effect on Diagonal Shear Failure of Beams Without Stirrups. ACI Structural Journal, V.88, V.3, 1991, p.268-276. 
BELARBI, A.; HSU, T.T.C. Stirrup Stresses in Reinforced Concrete Beams. ACl Structural Journal, V.87, N.5, 1990. p.530-538.

BENTZ, E. C.; VECCHIO, F. J.; COLLINS, M. P. Simplified modified compression field theory for calculating shear strength of reinforced concrete elementes. ACI Structural Journal, V.103, N.4, 2006. p. 614.

BENTZ, E.C. ; BUCHLEY, S. Repeating a classic set of experiments on size effect in shear of members without stirrup. ACI Structural Journal, V.102, N.6, 2005, p.832-838.

BENTZ, E.C. Sectional Analysis of Reinforced Concrete Members. Tese (Doutorado), University of Toronto, 2000, 316p.

BETTE,S.C. Avaliação da precisão dos modelos de cálculo da NBR 6118/03 para o dimensionamento de vigas de concreto armado ao esforço cortante. FAPESP, Relatório final de bolsa de iniciação científica, Bauru/SP, 2007.

BHIDE, S. B.; COLLINS, M. P. Influence of Axial Tension on the Shear Capacity of Reinforced Concrete Members. ACl Structural Journal, V.86, N.5, 1989. p. 570.

BRESLER, B.; SCORDELIS, A.C. Shear strength of reinforced concrete beams. ACl Journal Proceedings., V.60, N.1, 1963. p.51-74.

BRITISH STANDARDS INSTITUTION, BS EN 1992-1-1:2004 - Eurocode 2. Reino Unido, 2004. 230 p.

CANADIAN STANDARDS ASSOCIATION. CSA A23.3-04 standard - Design of concrete structures. Ontario, Canadá, 2004. 240 p.

$\mathrm{CHO}, \mathrm{S} . \mathrm{H}$. Shear strength prediction by modified plasticity theory for short beams. ACI Structural Journal, V.100, N.1, 2003, p.105-112.

CLADERA, A. ; MARI, A.R. Experimental study on high-strength concrete beams failing in shear. Engineering Structures, V.27, 2005, p.1519-1527.

CLADERA, A. ; MARI, A.R. Shear design procedure for reinforced normal and high- strength concrete beams using artificial neural networks. Part I: beams without stirrups. Engineering Structures, V.26, 2004, p.917-926.

CLADERA, A. ; MARI, A.R. Shear design procedure for reinforced normal and high- strength concrete beams using artificial neural networks. Part II: beams with stirrups. Engineering Structures, V.26, 2004, p.927-936.

CLADERA, A. Shear Design of Reinforced High-Strength Concrete Beams. Tese de doutorado, Universitat Politècnica de Catalunya, Barcelona, Espanha, 2002. 284p.

CLADERA, A.; MARÍ A. R. Experimental Study on High-Strength Concrete Beams Failing in Shear. Elsevier Engineering Structures, V.27, N.10, 2005. p.1529-2005. 
CLADERA, A.; MARÍ A. R. Shear Strength in The New Eurocode 2. A Step Forward? FIB Structural Concrete, V.8, N.2, 2007. p. 57.

COLLINS, M. P.; MITCHELL, D.; ADEBAR, P.; VECCHIO, F. J. A General Shear Design Method. ACI Structural Journal, V.93, N.1, 1996. p. 361996.

COLLINS, M.P., VECCHIO, F.J.; SELBY, R.G. The Failure of An Offshore Platform. Concrete International, V.19, N.8, 1997. p. 28-35.

COLLINS, M.P.; KUCHMA, D. How Safe Are Our Large, Lightly Reinforced Concrete Beams, Slabs and Footings? ACl Structural Journal, V.96, N.4, 1999. p.482-490.

COLLINS, M.P; BENTZ, E.C.; SHERWOOD, E.G. Where is Shear Reinforcement Required? Review of Research Results and Design Procedures. ACI Structural Journal, V.105, N.5, 2008. p. 590.

COSSIO, R.D.; SIESS, C. P. Behavior and Strength in Shear of Beams and Frames without Web Reinforcement. ACl Journal, Proceedings, V.57, N.2, 1906. p.695-735.

CUI, Q.; NIE H. Analytical model for the ultimate shear strength of reinforced concrete beams. College of Architecture \& Civil Engineering, 2011.

DAEJOONG, K.; WOO, K.; WHITE, R.N. Arch Action in Reinforced Concrete Beams-A Rational Prediction of Shear Strength. ACI Structural Journal, Proceedings, V.96, N.4, 1999. p. 586.

DEBAIKY, S.Y. ; ELNIEMA, E.I. Behavior and Strength of Reinforced Concrete Haunched Beams in Shear. ACl Journal, 1982, p.184-194.

ELSTNER, R. C.; HOGNESTAD, E. Laboratory Investigation of Rigid Frame Failure. ACI Journal, Proceedings, V.53, N.1, 1957. p. 637.

ELZANATY, A.H. ; NILSON, H. ; SLATE, F.O. Shear capacity of reinforced concrete beams using high-strength concrete. ACI Structural Journal, V.83, N.2, 1986, p.290-96.

ELZANATY, A.H.; NILSON, A.H.; SLATE, F.O. Shear Capacity of Reinforced Concrete Beams Using High-Strength Concrete. ACl Journal, Proceedings, V.83, N.2, 1986. p.290-296.

FERNANDES, G. B. Behavior of Reinforced High-Strength Concrete Corbels - Experimental Investigation and Design Model. ACl Structural Journal, V.186, 1999. p. 445-462.

FUKUHARA M, KOKUSHO S. Effectiveness of high tension shear reinforcement in reinforced concrete members. Journal of the Structural Construction Engineering, AIJ 320, 1982, p.12-20.

FUSCO, P. B. Estruturas de Concreto: Solicitações Tangenciais. 1. ed. São Paulo: Editora PINI Ltda., 2008. V.1. 328 p. 
GHANNOUM, W.M. Size effect on shear strength of reinforced concrete beams. M.E. thesis, Department of Civil Engineering and Applied Mechanics, McGill University, Montreal, 1998.

HADADDIN, M.J.; HONG, S.; MATTOCK, A.H. Stirrup Effectiveness in Reinforced Concrete Beams with Axial Force. Journal of Structural Division Proceedings of the ASCE, V.97, N.9, 1971. p.2277-2297.

HSIUNG, W. ; FRANTZ, G.C. Transverse Stirrup Spacing in R/C Beams. American Society of Civil Engineers, ASCE, V.111, N.2, 1985, p.353-363.

INTERNATIONAL FEDERATION FOR STRUCTURAL CONCRETE (FIB). Código modelo - FIB. Lausanne, Suíça, 2010. Volumes 1 e 2.

JOHNSON, M.K.; RAMIREZ, J.A. Minimum Shear Reinforcement in Beams with Higher Strength Concrete. ACl Structural Journal, V.86, N.4, 1989. p.376-382.

KANI, G.N. How Safe are Our Large Concrete Beams?. ACl Journal, Proceedings, V.64, N.3, 1967. p.128-141.

KANI, G.N.J. The Riddle of shear Failure and Its Solution. ACl Journal, Proceedings, V.61, N.4, 1964. p.441-467.

KHUNTIA M.; STOJADINOVIC, B. Shear Strength of Reinforced Concrete Beams without Transverse Reinforcement. ACI Structural Journal, V.98, N.5, 2001. p. 648-656.

KIM, D.; KIM, W.; WHITE, R.N. Arch Action in Reinforced Concrete Beams A Rational Prediction of Shear Strength. ACI Structural Journal, V.96, N.4, 1999. p. 586-593.

KREFELD W.J.; THURSTON C.W. Studies of the shear and diagonal tension strength of simply supported reinforced concrete beams. $\mathrm{ACl}$ Journal Proceedings, V.63, N.4, 1966, p.451-476.

KREFELD, W. J.;THURSTON, C. W.; Contribution of Longitudinal Steel to Shear Resistance of Reinforced Concrete Beams. ACl Journal Proceedings, V.63, N.3, 1966. p. 325-342.

KULKARNI, S.M.; SHAH, S.P. Response of Reinforced Concrete Beams at High Strain Rates. ACI Structural Journal, V. 95, N.6, 1998. p.705-715.

KUNTIA, M.; STOJADINOVIC, B. Shear strength of reinforced concrete beams without transverse reinforcement. ACI Structural Journal, V.98, N.5, 2001. $648 \mathrm{p}$.

KUO, W. W.; CHENG, T. J.; HWANG, S. J. Force transfer mechanism and shear strength of reinforced concrete beams. Engineering Structures, V. 32, N. 6, p. $1537,2010$. 
LEE, J.; WATANABE, F. Shear Design of Reinforced Concrete Beams with Shear Reinforcement Considering Failure Modes. ACl Structural Journal, V.97, N.3, 2000. p. 477-484.

LEE, J.Y. ; KIM, S.W. ; MANSOUR, M.Y. Predicting the shear response of reinforced concrete beams using a new compatibility aided truss model. ACI Structural Journal, 2002.

LEONHARDT, F.; MÖNNIG, E. Construções de concreto - Princípios básicos do dimensionamento de estruturas de concreto armado. v.1, Rio de Janeiro, Ed. Interciência, 1982, 305p.

LUBELL, A. S.; BENTZ, E. C.; COLLINS, M. P. Influence of longitudinal reinforcement on one-way shear in slabs and wide beams. Journal os structural engineering, 2009.

MATHEY, R.G. ; WATSTEIN, D. Shear strength of beams without web reinforcement containing deformed bars of di.erent yield strengths. $\mathrm{ACl}$ Journal Proceedings, V.63, 1963, p.183-206.

MATTOCK, A. H.; WANG, Z. Shear Strength of Reinforced Concrete Members Subject to High Axial Compressive Stress. ACI Structural Journal, V.81, N.3, 1984. p. 287.

MATTOCK, A.H. Diagonal Tension Cracking in Concrete Beams with Axial Forces. Journal of the Structural Division, ASCE, V. 95, N. ST9, p. 1887-190, 1969.

MATTOCK, A.H.; WANG, Z. Shear strength of reinforced concrete members subject to high axial compressive stress. ACI Structural Journal, V.81, N.3, 1984 , p.287-98.

MORETTO, O. An investigation of the strength of welded stirrups in reinforced concrete beams. ACl Journal, Proceedings, V.42, N.2, 1945, p.141-162.

MORROW, J.; VIEST, I.M. Shear Strength of Reinforced Concrete Frame without Web Reinforcement. ACl Journal, Proceedings, V.28, N.9, 1957. p.833-869.

MPHONDE, A.G.; FRANTZ, G.C. Shear Tests of High and Low-Strength Concrete Beams without Stirrups. ACl Journal, Proceedings, V.81, N.4, 1984. p.350-357.

MPHONDE, A.G. Use of stirrup effectiveness in shear design of concrete beams. ACI Structural Journal, 86 (5), 1989, p.541-545.

NATIONAL COOPERATIVE HIGHWAY RESERCH PROGRAM. Simplified shear design of structural concrete members. Washington, D.C., 2005.

OZCEBE, G. ; ERSOY, U. ; TANKUT, T. Evaluation of minimum shear reinforcement requirements for higher strength concrete. $\mathrm{ACl}$ Structural Journal, V.96, N.3, 1999, p.361-368. 
PENG L. Shear strength of beams by shear friction. M.A.Sc. thesis, the University of Calgary, Calgary, Alberta, 1999.

PLACAS, A.; REGAN, P. E. Shear Failure of Reinforced Concrete Beams. ACl Journal, Proceedings, V.68, N.10, 1971. p.763-773.

PODGORNIAK-STANIK, B. The influence of concrete strength, distribution of longitudinal reinforcement, amount of transverse reinforcement, and member size on shear strength of reinforced concrete members. M.A.Sc. thesis, Department of Civil Engineering, The University of Toronto, 1998.

RAJAGOPALAN, K.S. ; FERGUSON, P.M. Exploratory shear tests emphasizing percentage of longitudinal steel. ACl Journal, V.65, N.8, 1968, p.634-38.

RAMIREZ, J.A.; BREEN, J.E. Evaluation of Modified Truss-Model Approach for Beams in Shear. ACl Structural Journal, V.88, N.5, 1991. p.562-571.

RANGAN, B.V. Web Crushing Strength of Reinforced and Prestressed Concrete Beams. ACI Structural Journal, V.88, N.1, 1991. p.12-16.

REINECK, K.H.; KUCHMA, D.A; FITIK, B. Extended databases with shear tests on structural concrete beams without and with stirrups for the assessment of shear design procedures. University of Stuttgart, University of Illinois, 2010.

RODRIGUEZ JJ, BIANCHINI AC, VIEST IM, KESLER CE. Shear strength of two-span continuous reinforced concrete beams. ACl Journal, Proceedings, V.55, N.10, 1959, p.1089-1130.

ROLLER, J.J. ; RUSSELL, H.G. Shear strength of high-strength concrete beams with web reinforcement. ACl Structural Journal, V.87, N.2, 1990, p.191-198.

SANTOS NETO, P- Resistência do Concreto à Força Cortante em Peças Fletidas. São Carlos, EESC-USP, 1977

SARSAM, K.F.; AL-MUSAWI, J.M.S. Shear Design of High- and Normal Strength Concrete Beams with Web Reinforcement. ACl Structural Journal, V.89, N. 6, 1992. p. 658-664.

SHRINIVAS, B. B.; COLLINS, M. P. Influence of axial tension on the shear capacity of reinforced concrete members. ACl Structural Journal, Proceedings, V. 86, N. 5, 1989. p. 570.

SILVA, R.; GIONGO, J. S. Modelos de bielas e tirantes aplicados a estruturas de concreto armado. São Carlos, EESC-USP, 2002.

SIMPLICIO, M.A.S. ; ÁVILA, J.I.S.L. Avaliação da capacidade resistente a força cortante em vigas segundo a NBR 6118:2003. IN: Anais $47^{\circ}$ Congresso Brasileiro do Concreto, IBRACON, CBC2005, ISBN 85-98576-07-7, V. XII - Projetos de Estruturas de Concreto, Trabalho 47CBC0142, Set/2005, $8 \mathrm{p}$. 
SONGKRAM PIYAMHANT. Shear Behavior of Reinforced Concrete Beams with a Small amount of Web Reinforcement. Departmente of infrastructure system engineering, Kocki University of Technology, Kocki, Japan, 2002.

TALBOT, A. N. Test of Reinforced Concrete Beams: Resistence to Web Stress of 1907 and 1908. Bulletin 29, University of Illinois Engineering Experiment Station, Urbana, III, 1909.

TAYLOR, H.P.J. Shear Strength of Large Beams. ASCE Journal of the Structural Division, V.98, 1972, p.2473-2490.

THORENFELDT, E.; DRANGSHOLD, G. Shear Capacity of Reinforced HighStrength Concrete Beams. ACl Special Publication, SP-121, Nov. 1990, p. 129-154.

TOMPOS, E.J.; FROSH, R.J. Influence of Beam Size, Longitudinal Reinforcement, and Stirrup Effectiveness on Concrete Shear Strength. ACl Structural Journal, V.99, N. 5, 2002. p.559-567.

TUREYEN, A. K.; FROSCH, R. J. Concrete Shear Strength: Another Perspective. ACI Structural Journal, V.100, N.5, 2003. p. 609.

UZEL, A.; PODGORNIAK, B.; BENTZ, E. C.; COLLINS, M.P. Design of large footings for one-way shear. ACI Structural Journal, Proceedings, V.108, N.2, 2011. p. 131.

VAN DEN BERG F.J. Shear strength of reinforced concrete beams without web reinforcement Part 2 - factors a.ecting load at diagona cracking. $\mathrm{ACl}$ Journal Proceedings 1962.

VECCHIO, F. J., COLLINS, M. P. The Modified Compression-Field Theory for Reinforced Concrete Elements Subjected to Shear. ACl Structural Journal, V.83, N.2, 1986. p. 219.

WALRAVEN, J.C. Shear in Prestressed Concrete Members. Bulletin d'information, N.180, 1987.

XIE, L.; BENTZ, E. C.; COLLINS, M. P.Influence of Axial Stress on Shear Response of Reinforced Concrete Elements. ACl Structural Journal,V.108, N.6, 2011. p. 745.

XIE, Y.; AHMAD, S.H.; YU, T.; HINO, S.; CHUNG, W. Shear Ductility of Reinforced Concrete Beams of Normal and High-Strength Concrete. ACl Structural Journal, V.91, N.2, 1994. p.140-149.

YOON, Y.S.; COOK, W.D.; MITCHELL, D. Minimum Shear Reinforcement in Normal, Medium and High-Strength Concrete Beams. ACl Structural Journal, V.93, N.5, 1996., p.576-584.

YU, Q.; BAZANT, Z. P. Can stirrups suppress size effect on shear strength of RC beams? Journal of structural engineering, V.137, N.5, 2011. p. 607. 
YU, Q.; BAZANT, Z. P. Shear Strength of Reinforced Concrete Members Subject to High Axial Compressive Stress. ACl Journal, Proceedings, V.81, N.3, 1982. p. 287.

ZARARIS, P. D.; ZARARIS, I. P. Shear Strength of Reinforced Concrete Beams under Uniformly Distributed Loads. ACl Structural Journal, V.105, N.6, 2006. p. 711.

ZARARIS, P. D.; ZARARIS, I. P. Shear Strength of Reinforced Concrete Slender Beams with or without Axial Forces-A Generalized Theory. ACl Structural Journal, V.106, N.6, 2009. p. 782.

ZARARIS, P.D. ; PAPADAKIS, G.C. Diagonal shear failure and size effect in RC beams without web reinforcement. Journal Structural Engineering, ASCE, 127(7), 2001, p.733-742.

ZARARIS, P.D. Shear strength and minimum shear reinforcement of reinforced concrete slender beams. ACI Structural Journal, V.100, N.2, 2003. p.203-214. 